
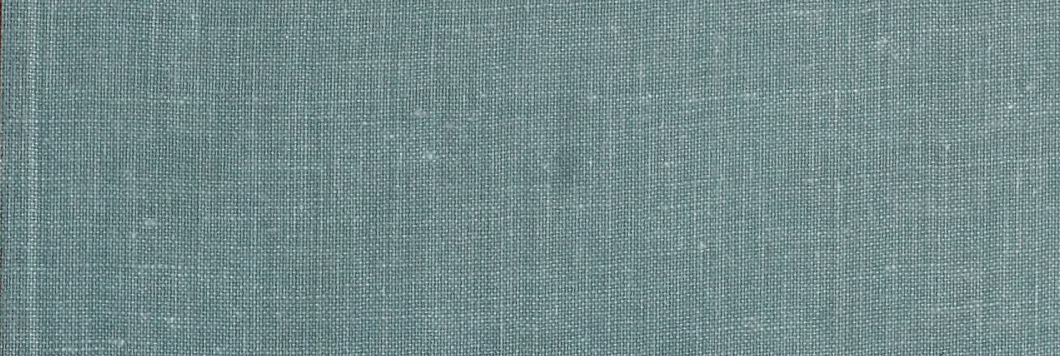

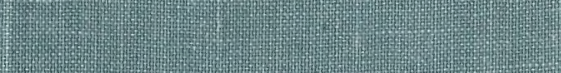
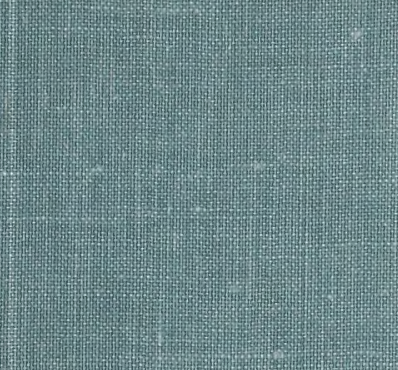

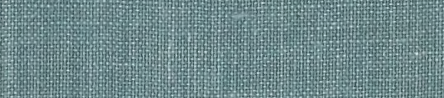









\section{MEMOIRS}

OF THE

\section{MUSEUM OF COMPARATIVE ZOÖLOGY}

$$
\text { AT }
$$

\section{HARVARD COLLEGE.}

VOL. XXVIII.

CAMBRIDGE, U.S.A. PRINTED FOR THE MUSEUM.

1903. 



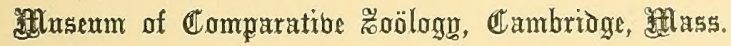

With the compliments of

ALEXANDER AGASSIZ. 


\section{MEMOIRS}

OF THE

\section{MUSEUM OF COMPARATIVE ZOÖLOGY}

\section{HARVARD COLLEGE.}

VOL. XXVIII.

CAMBRIDGE, U.S.A.

PRINTED FOR THE MUSEUM.

1903. 



\section{O N T E N T S.}

REPORTS ON THE SCIENTIFIC RESULTS OF THE EXPEDITION TO THE TropiCal PACIfiC, in charge of Alexander Agassiz, by the U. S. Fish Commission Steamer "Albatross," from August, 1899, to March, 1900, Commander Jefferson F. Moser, U. S. N., Commanding. IV. The Coral Reefs of the Tropical Paclfic. By Alexander Agassiz. pp. xxxiii., 410. 238 Plates. February, 1903.

One Volume Text. Three Volumes Plates. 



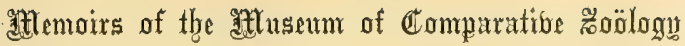 \\ AT HARVARD COLLEGE.
}

Vol. XXVIII.

\begin{abstract}
REPORTS ON THE SCIENTIFIC RESULTS OF THE EXPEDITION TO THE TROPICAL PACIFIC, IN CHARGE OF ALEXANDER AGASSIZ, BY THE U. S. FISH COMMISSION STEAMER "ALBATROSS," FROM AUGUST, 1899, TO MARCH, 1900, COMMANDER JEFFERSON F. MOSER, U. S. N., COMMANDING.
\end{abstract}

IV.

\section{THE CORAL REE F \\ OF THE}

\section{TROPICAL PACIFIC.}

BT ALEXANDER AGASSIZ.

WITH TWO HUNDRED AND THIRTX-EIGHT PLATES.

TEXT.

[Published by permission of GEorge M. Bowers, U. S. Commissioner of Fish and Fisheries.]

CAMBRIDGE, U.S.A. :

韭rinted far the ftthent

February, 1903. 



\section{TABLE OF CONTENTS.}

INTRODUCTION

xi

The Marquesas, Plates 2, 3, 200, and Fig. 1 ,

The Paumotus, Plates 4-83, 201-207.

The Paumotu Plateau, Plates 201, 234, and Figs. 1-12

Rangiroa, Plates 4-19, 201, 202; 204, figs. 3,4 ; 205, fig. 3 ; and Figs. 2, 3,5 .

Tikahau, Plates 20, figs. 2-4; 201, $202 ; 204, \mathrm{fig} .4$. . . . .

Matahiva, Plates, 20, fig. 1; 201, $202 ; 204$, fig. 4 . . . . . .

Makatea, Plates 21-32; 201, 202 ; 205, fig. 1 ; and Figs. 7, 8 . .. .

Niau, Plates 33-36, 201, 202 . . .

Apataki, Plates 37,$39 ; 40$, fig. 1 ;

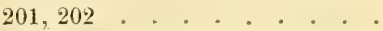

Tikeî, Plates 40, figs. $2-4$; 41-44, 201, 203

Katuehi, Plates 45, 201, 203

Fakarava, Plates $46-50$; 51 , fig. 2 ; 58, fig. 1 ; 201, 203; 204, figs. 1,7

Anaa, Plates 51, fig. 1; 52, 53, 201, 203

Tahanea, Plates 54, 55, 201, 203

The Raveskoi Islands

Tepoto

Tuanake, Plates 201, 203

Takume, Plates 56, 57 ; 58, fig. 2; 201, 203, 205

Raroia, Plates 201, 203.

Taenga, Plates 201, 203

Makemo, Plates 59-65; 75, fig. 4; 201, 203, 204

Tekokota, Plates 66, 201, 203

Hikueru, Plates 201, 203

PAge

1
Marokau and Ravahere, Plates 70, figs. 1, 2; 201, 203; 204, fig. 5 . 111

Hao, Plates 67, 201, 203 ; 205, fig. 2113

Aki-Aki, Plates 68, 69, 201, 203 . 116

Nukutavake, Plates 70 , figs. 3, 4 ; 71, 201, 203

118

Pinaki, Plates 72-75, 201, 203; 206, fig. 3

The Duke of Gloucester Islands . . 125

Nukutipipi, Plates 76, 77, 201, 203 ; 206 , fig. 4 . . . . . . 125

Anu-Anurunga, Plates 78, 202, 203; 206, fig. 1 . . : . . . . . 128

Anu-Anuraro, Plates 201, 203 ; 206, fig. 2 . . . . . . . . . 130

Hereheretue, Plates 79-83, 201, 203131

The Societr Islands, Plates 84-105, $201,202,208-210$. . . . . 135

Mehetia, Plates 90, fig. 2 ; 95 , fig. 1 ; 202 .

Tahiti, Plates 84 80, $202,208-210$

Murea, Plates 90, fig. $1 ; 91 ; 208$, fig. 6 . . . . . . . . 156

Huaheine, Plates 92; 94, fig. 4; 202 ; 210, fig. 1 .

Raiatea and Tahaa, Plates 93; 94, figs. $1-3$; 96, fig. 2; 210, fig. 2 . 159

Bora Bora, Plates 96, fig. 3 ; $97-$ 103,$202 ; 210$, fig. $3 . . . .161$

Maupiti, Plates 104, figs. 3, 4 ; 105 , $202 ; 210$, fig. 4 . . . . . . . 164

Motu Iti, Plates 104, figs. 1, 2; 202165

Tetiaroa, Plates 95, figs. 2, $3 ; 96$, fig. $1 ; 202$. . . . . . . 166

The Cook Islaxds, Plates 106, fig. 1 ; $211 ; 212$, figs. 2,5 
Aitutaki, Plates 106, fig. 1; 211 ; 212, fig. 2 .

Niue, Plates 106, figs. 2, 3; 107-110; $211 ; 212$, fig. $1 ; 213$.

The Tonga Archipelago, Plates 111$125,213-219$

Eua Island, Plates 111-114; 122, fig. $3 ; 212$, fig. $4 ; 213,214$. .

Tongatábu, Plates 115-118; 213-215

The Nomuka Group, Plates 119, 214, 216

The Haapai Group, Plates 217, 218

Vavau, Plates 120-125, 219 .

The Fiju Islands, Plates 126-128, 220

Kambara, Plates 126, 127, 220 .

The Ellice Islands, Plates 129-137; 212 , figs. $6-8$; 221,$222 ; 224$, fig. 1

Nurakita, Plates 129, fig. 1; 212, fig. $8 ; 221$

Funafuti, Plates 129, fig. 4; 130 $137,221,222$; 224, fig. 1 . .

Nukufetau, Plates 129, figs. 2, 3 ; 212 , fig, $6 ; 221$. . . . . .

The Gilbert Islands, Plates 138-160, 223 ; 224, figs. $2-6$; 226, figs. 1-3

Arorai, Plate 223

Onoatoa, Plate 223 . . . . .

Tapetenea, Plates 138, figs. 1-3; 223 ; 226, fig. 1 . . . . . .

Apamama, Plates 138, fig. 4 ; 139, figs. $1-3 ; 223 ; 226$, fig. 2 . .

Maiana, Plates 139, fig. $4 ; 140$, fig. 1 ; $223 ; 224$, fig. 6 .

Tarawa, Plates 140 , figs. $2-4$; $141-$ $144 ; 145$, fig. 4 ; 223 ; 224, fig. 5 .

Apaiang, Plates 145 , figs. $1-3 ; 223$; 224 , fig. 2 . . . . . .

Maraki, Plates 146-150, 223; 224, fig. 3

Taritari, Plates 151-160, 223; 224, fig. 4

The Marsitall Islands, Plates 161182 , figs. 1,$2 ; 225 ; 226$, figs. $4-10 ; 227,228$

Jaluit, Plates 161-166; 167, fig. 2 ; 225 ; 226 , figs. $4-10 ; 227$, figs. $1-3 ; 228$, fig. 2 .
PAgE

169

171

175

180

188

192

195

197

204

206
Ailinglap, Plates 168; 171, fig. 1; 225 ; 226, fig. 5 .

PAgE

Namu, Plates 167, fig. 1 ; 225; 227, fig. 1

Kwajalong, Plates 169, 170, 225; 227, fig. 2 .

Rongelab, Plates 171, figs. 2, 3 ; $172,173,225 ; 226$, fig. 8 . .

Likieb, Plates 174-177, 225; 228, fig. 3 . . . . . . . . 307

Wotje, Plates 178-180, figs, 1, 2; 225 ; 227, fig. 4 ; 228, fig. 1

Arhno, Plates 180 , figs. 3,$4 ; 181$; 182 , figs. 1,$2 ; 225 ; 228$, fig. 4 .

Namorik, Plates 225 ; 226, fig. 10 .

The Caroline Islands, Plates 182, figs. 3,$4 ;$ 183-193, 225, 229232 ; 233, figs. $1-3$. . . . .

Kusaie, Plates 182, fig. 3 ; 184-187, 225,229

Pingelap, Plates 183, figs. 2-4; 225 ; 227, fig. 5 ... . . . . . . 340

The Seniavina Islands . . . . . 342

Ponapi, Plates 188-190, figs. 1-3; 225,230 . . . . . . 342

Andema Islands, Plates 182, fig. 4 ; 183 , fig. $1 ; 225,230$. . . . 350

Losap, Plates 232; 233, fig. 3 . . 351

Nama, Plate 232 . . . . . . . 351

The Royalist Islands, Plates 190, fig, $4 ; 231,232 \quad$. . . . . . 352

Truk, Plates 191-193, 231, 232 . . 353

Namonuito, Plates 232; 233, fig. 1363

The Ladrones, Plates 194-199; 232 ; 233 , figs. 4,5

365

Guam, Plates 194-198; 232; 233, fig. 4 . . . . . . . . . . 366

Rota, Plates 199, 232 ; 233, fig. 5 . 376

List of the Stations occupied by the "Albatross" . . . . . . . 379

San Francisco, Cal., to Nukuhiva, Marquesas Islands . . . . . . . 379

Marquesas Islands to Tahiti, Society Islands, via Northwestern Paumotus

Stations in vicinity of the Marquesas Islands

Stations from the Marquesas to Rangiroa 
Rangiroa to Tikahau and to Matahiva. . . . . . . .

Matahiva to Makatea and to Papieté, Tahiti Island . . . . . . . . 382

Through the Paumotu Archipelago . 383

Tahiti to Makatea, via Tetiaroa . . 383

Makatea to Apataki, via Niau . . 383

Apataki to Tikeï . . . . . . . 383

Ngarue Pass, Fakarava, to Takume, via Ana and Tahanea . . . . . 383

Takume to Makemo, via Raroia and

Taenga . . . . . . 385

Makemo to Hikueru, via Tekokota . 385

Hikueru to Hao, via Marokau and

Ravahere . . . . . . . . 385

Hao to Aki-Aki . . . . . . 386

Aki-Aki to Pinaki, via Nukutavake . 386

Pinapi to Nukutipipi . . . . . 386

Nukutipipi to Hereberetue, via AnuAnurunga and Anu-Anuraro . . 387
Hereheretne to Tahiti, via Mehetia . 387

Society Islands to Tongatábu, Tonga Archipelago, via Leeward Society Islands, the Cook Group, and Niue Island . . . . . . . 388

From Tahiti to the Leeward Society Islands . . . . . . . . . . 388

From Aitutaki to Niue . . . . 388

From Niue to Eua (Tonga) . . . 388

Vavau to Fiji . . . . . . . . 388

In Fiji Archipelago . . . . . . 389

Fiji through Ellice and Gilbert Islands to Jaluit, Marshall Archipelago . 389

From Taritari to Jaluit . . . . . 390

Through the Marshall Arcbipelago . 390

Marshall Islands through the Carolines to Guam, Ladrones, and to Yokohama, Japan . . . . . . 391

Through the Carolines . . . . 391

Namonuito to Guam . . . . . 392 



\section{N T R O D U C T I O N.}

While in charge of the expedition of the United States Fish Commission Steamer "Albatross" during the winter of 1899-1900 we visited the coral reef districts of the tropical Pacific, with the exception of the Sandwich, the Samoan Islands, and the Galapagos. The Hawaiian Islands I had explored on former occasions, and had also obtained a bird's-eye view of the reefs of Samoa on my way to examine the Great Barrier Reef of Australia.

It has thus been my good fortune to observe the structure of the great majority of the coral reefs, atolls, and coral islands of the tropical Pacific, and to have the benefit of the excellent charts published since the days of Darwin and Dana. One cannot overestimate the great advantages to be derived from recent surveys in studying groups of coral islands like the Fiji or the Society Islands. The charts and "Sailing Directions" contain an amount of information which no one individual could hope to bring together, and their publication has made it possible for an observer to cover an immense area and obtain within a reasonable time an insight into the structure of the coral reefs of an oceanic realm like the Pacific.

In this, as in preceding Reports, I have limited myself to an exposition and explanation of the observations made in each of the coral reef districts examined, and have only made such comparisons between the various groups as seemed essential to the proper understanding of the Report.

These investigations on coral reefs date back to 1877; they have now covered the principal coral reefs and islands of the Pacific, the West Indies, and the Indian Ocean. The earlier reports were mainly descriptive, and limited to statements that the facts observed did not seem to confirm Darwin's theory of the structure and formation of coral reefs. As the work 
was extended the subject proved far more complicated than had been suspected by previous investigators. The explorations were not continued for the sake of proving Darwin to be wrong, as seems to be the impression of some of my critics. Year after year the subject of coral reefs became more engrossing, and it was studied for its own sake. I had no theory of my own as a guiding star, nor did I attempt to uphold any one of the theories on coral reefs advanced since the publication of Darwin's "Structure and Distribution of Coral Reefs."

An immense amount of information regarding the coral reefs and islands of the Pacific may be found in the journals of missionaries, who have often spent years at certain localities. Some of the descriptions by Williams, Whitmee, Gill, and Turner are remarkably accurate, and many of their illustrations most interesting; especially instructive are the reports of the voyages of English, French, and Russian navigators in the last part of the eighteenth and beginning of the nineteenth century, containing the first accurate charts of atolls, barrier and fringing reefs published.

A number of independent travellers have also published sketches of their journeys. The voyage of the "Blossom " under Beechey, ${ }^{1}$ of the "Beagle," and the United States Exploring Expedition under Wilkes, are memorable for Darwin's and Dana's reports on coral reefs and the geology of the islands of the Pacific.

These expeditions have been supplemented by the surveys of the British Admiralty and the French Hydrographic Bureau, as well as by several minor expeditions sent out by the United States Government. Their results include the publication of a series of excellent charts covering nearly all the oceanic island groups of the tropical Pacific, like those of Fiji, of Tonga, of the Society Islands, and of many of the Line Islands; they far surpass in accuracy the earlier publications and give us a very different idea of the structure of atolls, of coral reefs, both fringing and barrier, from that obtained from data available fifty years ago.

Since the "Challenger" expedition, dating with the appearance of Murray's "Structure and Origin of Coral Reefs" in 1880, ${ }^{2}$ Darwin's theory of

1 An excellent analysis of the results of Beechey's voyages by Ainsworth will be found in the Journal of the Royal Geographical Society of London, Vol. I., 1831, p. 193.

${ }^{2}$ Proceedings of the Royal Society of Edinburgh, X., p. 508. 
the formation of barrier reefs and atolls has been subjected to prolonged criticism. Following Rein and Semper, recent investigators have, with few exceptions, regarded it as untenable. Semper's investigations in the Pelew Archipelago have hardly received the recognition they deserve. As far back as 1861 he spent nearly ten months in the Pelews, ${ }^{1}$ and called attention to the fact that all kinds of reefs (atolls, barrier and fringing reefs) are found in the Pelews, within a comparatively short distance, in a region considered by Darwin as one of subsidence, and that at the southern extremity of the group an elevated coralliferous limestone island (Ngaur) rose to a height of over 300 feet, containing, according to Wichman, fossils of late tertiary age. Semper lays great stress on the effects of currents between the land rim and the barrier reef in widening barrier reef lagoons; reef platform lagoons such as I have described illustrate this well. He further suggests that marine animals may build up a foundation for the growth of reef corals, from far greater depths than those at which corals can thrive.

Semper furst called attention to the effect of solution in removing material from an atoll, but it is to Sir John Murray ${ }^{2}$ that we owe careful experiments to determine the amount of lime removed by solution and the suggestion of its importance as a factor in the formation of lagoons. Semper considers the effect of solution in removing lime from the lagoon of an atoll as balancing the constructive agencies proved by the growth of corals in it.

To Professor Dana was undoubtedly due the general acceptance of Darwin's theory of the formation of coral reefs. Dana's views on coral reefs were based upon the study of the coral reefs of Samoa, the Hawaiian Islands, Tahiti, the larger Fiji Islands, seven of the islands in the Paumotus, of Tongatábu, of 'Tapeteuea and Apaiang in the Gilbert Islands, of Gente Hermosa, Fakaofu, Oatafu, Hull, and Enderbury among the Line Islands. The publication of his results in $1849^{3}$ supporting in the main Darwin's theory could not fail to supply a mass of evidence wanting in the Report of Darwin's researches, based as they were upon the survey of the

1 Die Natürlichen Existenzbedingungen d. Thiere, I,eipzig, II., 1880, p. 39.

2 Proceedings of the Royal Society of Edinburgh, XVII., 1889-90, p. 79.

${ }^{3}$ Geology of the United States Exploring Expedition under Commodore Wilkes. 
comparatively limited field of Keeling, Tahiti, and Mauritius. Darwin's theory was also adopted by Jukes, who had just completed a survey of the Great Barrier Reef of Australia. The field covered by Dana and Jukes thus seemed to include all that was essential to satisfy the demands of Darwin's theory.

The problems which have arisen from a more extended study of the coral reefs since that time have greatly modified the views so generally held regarding their origin. A number of explorers in recent years have attacked limited areas, and their conclusions have in nearly all instances been opposed to Darwin's theory. It is unfortunate that so much has been written on the subject of coral reefs by persons who have never studied them in the field, and who have added to the bibliography of coral reefs a mass of material which has done little or nothing towards the solution of the questions at issue.

It may not be out of place to sketch rapidly the characteristics of the coral reef groups of the Pacific.

The Galapagos ${ }^{1}$ and Marquesas are not of special interest as far as coral reefs are concerned. In both groups corals are limited to restricted shore areas; they do not even form fringing reefs; they are mere patches in the shallow bays cut into volcanic bluffs.

In the Sandwich and Samoan Islands occur fringing reefs limited to certain parts of the larger volcanic islands; on the shores of other islands they are either absent or reduced to mere patches.

In the Sandwich Islands, Lysan, Lisianski, French Frigate Shoal, Maro, Hermes, Cure, and Midway Islands are atolls and coral reefs scattered along the chain of volcanic islets extending to the westward of Kauai. Elevated coralliferous limestones occur along the southern face of Oahu. On the northern side æolian rocks attain a height of twenty to twenty-five feet and the fringing reefs are underlaid by a base of elevated tertiary limestone from which a reef flat platform has been eroded.

In Samoa extensive fringing reefs and barrier reefs occur on Upolu. In Savaii the east face is flanked by barrier reefs. In Tutuila, as in the islands

\footnotetext{
1 At the Galapagos, during a deep sea expedition off the Panamic distriet, we found nothing of importance regarding coral reefs. See also Darwin, Coral Reefs, p. 197.
} 
named above, stretches of disconnected fringing reefs occur along the southern shores. Rose Island is the only atoll of the Samoan Islands; it is described as such by Wilkes; he states that outliers of volcanic rock are found upon the encircling reef. An excellent sketch of the atoll is given in Graeffe's Samoa, "Journ. d. Museum Godeffroy," Heft I., 1873, p. 32, Pl. 1.

The Paumotu Archipelago consists of more than seventy atolls, many of great size and of elevated islands composed of coralliferous limestone. The low atolls have been cut down from the denudation and submarine erosion of higher islands, forming sounds or sinks surrounded at first by high rims subsequently cut into islands or islets with passes leading into the sounds, until the land rims were reduced to the level they now occupy. The successive stages of denudation and submarine erosion are represented by such islands as Makatea, Niau, Rangiroa, Hao, and others. Some of the easternmost of the Paumotu atolls are diminutive, and such atolls as Pinaki, Nukutipipi, Anu-Anurunga, Anu-Anuraro are admirable epitomes of the structure of the larger ones.

Some of the smaller of the Paumotu Islands have a central sink or apparent depression formed by the closing in of a part of the summit of a reef flat by beaches thrown up on the sea faces of the islands. If the island flat is somewhat below low-water mark a shallow lagoon is formed, and according to the height of the reef flat a dry sink may be enclosed, to be filled only during the rainy season.

The Paumotus are flanked on the east by Manga Reva, a cluster of volcanic islands encircled by a barrier reef, and on the west by the Society Islands. This group is, with the exception of Tetiaroa, composed of volcanic islands surrounded by barrier reefs, edging often a very wide barrier reef flat, enclosing a lagoon of moderate depth. The fringing reefs of the Society Islands are also noted for their great breadth; on Tahiti the reefs of the northwest and western coast show admirably how a wide fringing reef may gradually become gouged out into a barrier reef edging a shallow lagoon, and ultimately a wide and deep barrier reef lagoon. On some of the Society Islands the islands on the barrier reef form a nearly continuous belt, covered with a luxuriant growth of cocoanut trees and 
of low bushes, separating the barrier reef lagoon from the sea. Erosion and denudation have been great factors in shaping the volcanic slopes of the islands of the group, and the wide platform on which the encircling reefs have obtained a foothold has been cut by submarine erosion.

In the Paumotus there is a great development of buttresses of tertiary coralliferous limestone; they run across the beaches of the sea face and of the reef flat platforms, and are the last remnants of the former elevated land once covering a large area of the atolls.

In the Ellice and the Marshall Islands, and some of the Gilbert Islands, we find similar buttresses of modern reef rock and conglomerate indicating an elevation of a few feet. In the Gilbert Islands we find buttresses of both modern and tertiary limestone, as we also do in the Paumotus and Fiji.

We should remember the existence of many reefs, elevated to a few feet only, where the elevated mass consists of recent reef rock material or of recent conglomerate or breccia. These reefs are not to be confounded with elevated coralliferous limestones of tertiary age, though they may have been lifted to a moderate height only and may also constitute the underlying base of the elevated modern reef rock.

In the Paumotus, as in other groups like the Marshall, Ellice, and Gilbert, the width of the land rim varies greatly. We may state in general that a part of the land rim is built up on the sea face, a part may similarly be built up from the lagoon side where the atolls are large enough to be swept by the trades, or the land rim may be increased simultaneously both on the lagoon side and the sea face. Finally the land rim may be widened by the material blown or swept over it from the sea face towards the lagoon side, the latter process rapidly filling small lagoons, or in larger atolls shoaling the lagoons and restricting their area by the formation of extensive flats on the lagoon side of the land rim; or, as in some of the Marshall Islands, the sand dunes of the lagoon face are blown over the land rim and encroach upon the outer reef flat platform. Add to this the changes due to the solvent action of the sea, both on the sea face and lagoon side of the land rim, and we get an idea of the complicated factors at work in maintaining an equilibrium between the destructive or constructive agencies acting on the land rim of an atoll. Any one of these factors may obtain 
the preponderance; thus in adjoining atolls different results may take place, according to the conditions which obtain the mastery. The above factors are at work in the Paumotus upon plateaus of elevated coralliferous limestone cut down towards the level of the sea, while in other groups where the nature of the underlying plateau is not known, they are at work upon a land rim of modern reef rock, or modern conglomerate or breccia.

The bottom deposits on the deep parts of the ocean separating the atolls or groups of atolls in the Paumotus are truly oceanic in character. The many and wide passages dividing the islands are extensions of the great red clay belt, covering the trough lying to the southeast of the northern and central Paumotus between the main belt of the Paumotus and the Gloucester Islands line, and a similar trough separating the Paumotus and Marquesas. There is, however, a marked difference in the extension of this red clay into the volcanic bottom which surrounds the Marquesas and its passage into the globigerina-ooze; Pteropod and finally coral sand ooze is developed round the Paumoti Islands in shallower water.

The Cook Archipelago consists of volcanic islands with encircling reefs, of elevated coralliferous limestone islands and of low atolls, the underlying base of which is not known. The elevated islands have narrow reef flat platforms formed by subinarine erosion; some of the elevated islands are partly volcanic and partly limestone.

On a small independent plateau between the Cook Islands and Tonga rises the island of Niue, also composed of elevated coralliferous limestone.

The elevated limestone islands of Tonga and Fiji are flanked by narrow reef platforms; these are not continuous and occur only on parts of the islands where the sloughing off of the terraces has formed a shore platform which in its turn has been subject to submarine erosion. On this platform corals have established themselves, usually as fringing reefs.

The Tonga Archipelago consists of an extensive area of elevated coralliferous limestone, greatly denuded and eroded. At the two extremes of the plateau land masses of considerable extent have been elevated; the southern mass, Tongatábu, is greatly indented at its northern face and forms the southern face of an ill-defined lagoon. The northern land mass, Vavau, is cut 
into numerous islands and sounds. Both the northern and southern islands are terraced. The Haapai group to the north of Tongatábu is flanked with low islands on the east face, while in the Nomuka group we find elevated coralliferous limestone islands as well as volcanic or limestone islands where volcanic outbursts have pushed through the limestone mass.

The bank of which Eua Island is the summit has been elevated to a height of over 1000 feet and is separated from Tongatábu by a channel of a greatest depth of not more than 108 fathoms; a part of the submarine plateau to the south of Tongatábu extends as far as Pylstaart. The banks forming the greater Tonga Plateau are separated by water of a considerable depth, from 200 to 300 fathoms.

A line of voleanic islands runs parallel with the Tonga Plateau. Two of its summits, Falcon Island and Metis Shoal, are of great interest, as they both perhaps indicate the depths to which the action of the sea may extend in shaping platforms of submarine erosion. ${ }^{1}$ Falcon Island at one time attained a height of 250 feet; it now forms a breaking shoal; Metis Shoal, with a depth of fifteen fathoms, was once an island, reputed at first, in 1875 , to be twenty-nine feet high, subsequently raised to 150 feet.

Admiral Wharton ${ }^{2}$ has suggested that the depth to which the action of the waves reaches may be indicated by the change of slope generally taking place off shore, below a depth of eighty to one hundred fathoms, and further that the existence of banks in the open sea at a depth of thirty to forty fathoms may be the limit of depth to which oceanic waves cut down a mass upon which they act. $^{3}$ He also suggests that we may have in the future an opportunity of testing this by sounding the banks now forming on the former site of Falcon and of Metis Islands in Tonga since their disappearance.

That such extensive submarine denunation takes place seems to me

1 Wharton, Sir J. W., "Nature," VI, p. 611.

2 Address to the Geographical Section of the British Association, Oxford, 1896 ; "Nature," February $25,1897$.

3 It is known that the effect of great oceanic eurrents like the Gulf Stream is felt at considerable depth. At the straits of Bemini in 439 fathoms the bottom is swept clean, as it also is to the north of Jupiter. Inlet along the east coast of the United States as far north as Cape Hatteras, and along this stretch the Gulf Stream carries a certain amount of silt; this must act like a hydraulic flume and wear the bottom very perceptibly. This is seeu in the sections across the Gulf Stream given in "Three Cruises of the Blake," Vol. I. p. 258. 
abundantly proved from the great variety of submarine platforms formed at the base of volcanic islands and of elevated limestone masses throughout the Pacific, the depth of these platforms being fairly indicated by that of the lagoons enclosed by the encircling reefs or by that of the barrier reef lagoons.

The formation of huge masses of limestone in which occur at intervals layers of corals or beds of reef-building corals must have taken place in areas of subsidence, - the subsidence taking place at a comparatively slow rate while the coralliferous belts were deposited, and while the non-coralliferous limestones were laid down at a more rapid rate at a depth greater than that at which corals could grow. This process has nothing in common with the formation of atolls. But when these coralliferous masses of limestone of great thickness were elevated either suddenly or intermittently to heights of more than 1000 feet, the resulting islands in the first case must have represented either a bed deposited near the surface - if coralliferous - enclosing perhaps a lagoon, or a sound, or a basin of solution and erosion, formed in comparatively modern times, with recent corals forming a capping of moderate thickness. In the second case, during each stage of rest the elevated beds were subject to denudation and erosion by the action of the sea. If each stage was an elevation greater than the depth at. which corals can grow, the denudation and erosion may have continued long enough to cut the elevated limestone down, or nearly down to, the terrace which marks the uprising of the mass. Or the denudation and erosion may merely have gone far enough to open the circumscribed area to the action of the sea at some points only, and thus connect what was the lagoon or basin at the first sea-level with the lagoon or basin or sound of the second stage of rest.

One can readily see how complicated the resultant action may become when we take into account the varying height of the different stages of elevation, the condition of the limestone mass and of the coralliferous limestones after the elevation, and the action of denudation and of erosion upon such an elevated mass, as well as the solvent action taking place on the summit and sides, and finally the eroding action of the sea upon the interior basin, should it once break through the outer rim of the elevated basin or 
sink, when its lowest point has reached the level of the sea. This break would thus form an entrance to the lagoon, much as is formed the entrance to any lagoon or sound. Should this mass be elevated a second, a third, or a fourth time, we may find one, or two, or more entrances to the old lagoons and sounds according to the rate of denudation and of erosion of the elevated mass during the periods of rest.

The coralliferous limestone rings would be fairly continuous in case of a slow rate of denudation and erosion; if broken through by the action of the sea and with a rapid rate of denudation, only disconnected patches, more or less numerous, according to the rate of erosion, would indicate the former ring; and finally, with a very rapid denudation and erosion, both of the exterior and interior face of the lagoon, or sound, nothing would be left of the elevated mass except the submerged reef-ring. This becomes still more complicated when the limestone mass, while elevated, has been broken through by the underlying volcanic rocks, and they have displaced portions of the coralliferous limestone beds and left them nore exposed to the effects of denudation and of erosion, especially when this action has taken place on the outer face of the elevated mass, and left cuts and openings connecting the outer sea and the interior basins, which would thus soon be transformed into great sounds or lagoons. The erosive as well as the solvent action of the sea would soon level the outer rim to the plane of the sea, the further disintegration being stopped by the growth of recent corals or of coralline Algx upon the surface of the coralliferous or massive limestone eroded to the level of the sea or below it. ${ }^{1}$ With the more rapid erosion and denudation, both atmospheric and marine, the limestones would rapidly disappear, and there would be left only the volcanic mass which had uplifted them, with here and there a remnant of the limestones to indicate the probable course of events. Of course, when the volcanic masses come up without elevating any limestone beds the conditions are much simpler, and it becomes only a question of the

1 According to Dana's views the existence of such foundations "only prove that, in coral seas, corals will grow over any basis of rock that may offer where the water is right in depth, and do not nullify any of the evidence of subsidence" (Am. Jour. Scien., XXX., September, 1885, p. 181); yet these very instances are advanced as supporting the theory of subsidence, and we may justly reply that they have great interest as they are opposed to the application of the theory of subsidence as explanatory of the formation of coral reefs in the areas where these rock bases occur. 
mode of formation of the recent corals around the base of the elevated volcanic mass.

The want of continuity of the atolls of the eastern Paumotus, of the Ellice, Gilbert, and Marshall Islands, their separation by considerable distances and great depths, would seem to preclude the idea of the formation of tertiary limestones over great areas. The existence of these disconnected and isolated limestone islands would suggest their formation upon mounds or ridges elevated to very different heights below the surface of the ocean, - the mounds and ridges consisting of volcanic or other rocks elevated by the volcanic agencies we know to have been active over very extensive areas of the Pacific from tertiary times to the present day. In some of the Pacific archipelagoes the areas covered by the tertiary limestones are of considerable extent, as, for instance, the plateau of the northwestern Paumotus, of the Tonga Islands, and that upon which the eastern islands of the Fiji Archipelago rise: the so-called Lau or Windward group of Fiji. Conditions similar to those under which the central Pacific tertiary limestones were deposited must have been of wide geographical range; they appear in the Philippines, the Loyalty, the New Hebrides, and Solomon Islands, in New Caledonia, in the China Sea, the East Indian Archipelago, at Christmas Island in the Indian Ocean, the Red Sea, and the West Indian area.

Dana very justly remarks: "It is important to have in mind that the coral-reef era probably covered the whole of the Quaternary and perhaps the Pleiocene Tertiary also, and hence the local elevations that have taken place in the ocean were not crowded events of a short period." 1

The boring at Funafuti will show us the character and age of the rocks underlying the mass of recent material of which the land rim, not only of that atoll, but probably also that of the other atolls of the Ellice and of neighboring groups, is composed; though of course we can only judge by analogy the probable character of the underlying base from that of the nearest islands where it has been ascertained: The bore at Funafuti reached 1114 feet; it passed at first through the modern reef rock

1 Dana, J. D., Origin of Coral Reefs and Islands. Am. Jour. Scien., XXX., September, 1885, p. 173. 
material, and below that must have, judging by analogy, penetrated either an underlying mass of tertiary limestone similar to that of the raised tertiary limestones of Tonga, Fiji, Niue, Nauru, and Paanopa, or have passed through the mass of recent reef rock forming the outer talus of the atoll of Funafuti. Groups like the Ellice, Gilbert, and Marshall Islands give us the means of studying the many modes of formation of the land rims in a most satisfactory manner. Nowhere have we been able to follow as clearly the results of the various agencies at work in shaping the endless variations produced in the islands and islets of the land rims of the different atolls of these groups; changes due either to slight elevation or to the incessant handling and rehandling of the older material in place, or of the fresh material added from the disintegration of the sea or lagoon faces of the land rim, or of the corals on the outer and inner slopes. It has been most interesting to trace the ever-changing conditions which have produced so many variations in the appearance and structure of the islands, islets, and of the land rims of the different groups.

It is of course most difficult to form an opinion regarding the original dimensions of an atoll before it spreads laterally after having reached the surface; its summit naturally becomes wider as it approaches the surface and its talus may be spread as a thin sheet or disappear entirely in the deep waters adjoining an atoll.

The Fiji group consists of volcanic islands of elevated coralliferous limestone islands and of islands partly volcanic and partly of limestone. Two of the volcanic islands are of great size and flanked by wide barrier and fringing reefs, as well as by belts of older elevated coralliferous limestone of tertiary age and by stratified beds of the so-called soapstone of Fiji. A number of the volcanic islands are surrounded by encircling reefs enclosing lagoons of considerable depths.

In the Lau group some of the elevated limestone islands attain a height of over 1000 feet; they have a wide reef platform and are more or less hatshaped. In others the original limestone mass has disappeared; nothing is left, as in Argo for instance, to show its existence except a diminutive limestone island on the outer belt of the encircling reef.

We find all the intermediate stages between a solid mass of corallifer- 
ous limestone to one cut into separate columns or wedges surrounding a central sound or basin, or a basin more or less filled with islands and islets of limestone to one where the outer limestone masses or the islands are reduced to a minimum forming either an elevated central area encircled by a barrier reef or by a belt of low islands.

The volcanic islands surrounded by encircling reefs show a similar gradation from islands with a flanking belt of fringing or barrier reefs enclosing a narrow lagoon, to islands with an extensive lagoon enclosed by a barrier reef belt, or even to an atoll with a volcanic island on the outer reef flat.

In the Fiji as in the Society Islands, the wider fringing reef flats often pass gradually into barrier reefs with a narrow lagoon between the outer edge of the reef platform and the shore line. The rotten condition of the inner part of a wide fringing reef is most favorable to its removal by solution or mechanically, and leads to the formation of narrow lagoons, which may, as is the case in Tahiti, become wide and deep barrier reef lagoons. The small number of islands and islets of the outer barrier reef in Fiji atolls contrast strongly with the well-wooded islands and islets on the encircling belt of the Society Islands.

The disintegration of the masses of corals growing upon a reef is due to the boring Echini, Mollusks, Annelids, Crustacea, and sponges which infect the larger masses; as these become weakened they are torn off by the waves, and rapidly reduced to shingle. The smaller fragments are then still further disintegrated by boring sponges and Algæ, and by attrition on the wide reef platforms both of the sea face and lagoon side reduced first to coarser, then to fine sand and impalpable silt which may be carried off in suspension.

In addition to the mechanical destruction constantly going on, chemical action takes place and sea water carries off in solution large quantities of lime from the sea face, where we can trace the extent of its action from the undercut faces of cliffs, of masses of corals, and the rotten condition of smaller fragments of corals. The same action takes place in the lagoon even to a greater extent; in every direction we can trace the effect of solution on the beach rock beaches, the conglomerate or breccia ledges, the 
patches of corals, the samples of the bottom, the slopes of the shoals or ledges within the lagoon, all showing that solution is a prominent factor in removing carbonate of lime from the interior of a lagoon.

The Ellice, Gilbert, and Marshall Islands represent atolls in which the movement of the material forming the land rim is the characteristic feature. With the exception of a few atolls in the Gilberts where the old tertiary ledge cropped out on the land rim we did not observe the structure of the foundation upon which the material composing the land rim of the Ellice or of the Marshall Islands rested. While there is every indication that the modern reef rock conglomerate or breccia which crops out on the islands in every direction has been elevated a few feet, yet it has not been sufficiently raised to expose the underlying rocks.

The formation of the extensive Millepore and Porites flats described from Taritari represents a stage of land growth somewhat more advanced than we find it on some of the faros of the Maldives where the faces of the slopes and surface of the flats are covered with thriving corals (generally Pocillipores and Madrepores). The formation of the flats at the Maldives I shall shortly have occasion to describe. I need here only call attention to the existence at the Maldives of an earlier stage in the formation of such flats as the Millepore and Porites flats of the Gilbert and Marshall Islands.

The atolls of the Ellice, Gilbert, and Marshall Islands are noted for their extensive lagoon flats, for the formation of gaps, of bays, and of secondary lagoons, where they take a greater development than in any other group of coral reefs in the Pacific. There are only a few small coral islands among these groups which have no lagoons; they are more numerous among the Marshall Islands. The shape of the atolls varies greatly in the Ellice, Gilbert, and Marshall Islands, and in no groups is the outline less like the mythical typical circular atoll; this is especially marked in the Gilbert and Marshall atolls.

The land rims of these groups are narrow, but nowhere is the land rim reduced to such an insignificant width as in the Marshall Islands. There are no important islands in any of the lagoons; they contain shoals, ledges, and sand keys, but no well-wooded islands, as in the Paumotus and Fiji, except 
close to the lagoon edge of the land rim where they form secondary lagoons. Nauru and Paanopa to the west of the Gilbert Islands are elevated coralliferous limestone islands, rising to over 250 feet, similar to the elevated islands of the Paumotus and Fiji.

We noted in the Marshall Islands the large amount of sand blown into the lagoons from the sea face through gaps. Much of this sand is held in suspension and carried out through the passes on the lee side, while a part of it forms spits and flats near the gaps and passes of the weather side. A part of the sand goes to fill the lagoon; a part is carried off and reduces the width of the land rim on the sea face.

The Carolines are divided into high volcanic islands surrounded by fringing, barrier, and encircling reefs, low atolls with groups of islands reduced to narrow encircling reef flats on which a few islands have been thrown up on the weather face, the underlying foundation of which is not exposed and atolls where the islands and islets of the surrounding reef flat platform consist of elevated coralliferous limestone. In Ponapi the barrier reef flats are wider than round any other volcanic island in the Pacific.

The southern islands of the Ladrones, the last group of islands we examined, are partly volcanic and partly composed of elevated coralliferous limestone, while the northern islands are volcanic and have no coral reefs. Coral reefs take but a slight development either in Guam or Rota; the reef flat platforms are narrow, irregularly scattered; at Guam they take their greatest development at San Luis d'Apra and along parts of the western coast. At San Luis d'Apra a deep reef harbor has been eroded from the elevated coralliferous limestone flat which once jutted out to the north of Oroté Point to Cabras Island. Guam is one of the largest of the islands composed in part of coralliferous limestone and in part of volcanic material.

We may approximately classify the atolls, elevated islands, and volcanic islands where reefs are found into the following categories:

Large volcanic islands with barrier and fringing reefs, like Tahiti, Viti, and Vanua Levu, the larger Samoan Islands, New Caledonia, the Solomon, New Hebrides, and Sandwich Islands; in these the land mass occupies a large area as compared with that of the reefs. Viti Levu and Vanua Levu, 
as well as the Solomon, ${ }^{1}$ New Hebrides, and Oahn in the Sandwich Islands, are partly flanked by elevated coralliferous limestone.

Next may come smaller volcanic islands with barrier and fringing reefs, like the Pelew Islands, Yap, 'Truk, Ponapi, Kusaie; the smaller New Hebrides and Fiji Islands, like Nairai, Makongai, Mbengha; the volcanic islands of the Cook group, as Aitutaki, Rarotonga; the Horne Islands, Rotumah, the Marquesas, and such islands as Maupiti, Bora Bora, Raiatea, Huaheine, Eimeo, in which the area of encircling reefs is as large, if not larger, than the enclosed volcanic mass.

Volcanoes like Totoya and Thombia in Fiji show the possibility of the formation of an atoll-like island by the growth of corals on the submerged or denuded rim of an extinct volcano, enclosing a central basin: the old crater of the volcano. In Totoya the extension of the volcanic reef rim forms a barrier reef surrounding the island and enclosing a barrier reef lagoon, with ship passes leading into it.

Niuafou and Tofua in T'onga are both islands with extinct craters filled with brackish water. Were the rim cut down to below the level of the sea, they would become reef flats enclosing a deep lagoon, as is the case with a part of the rim of Thombia and Totoya.

Elevated coralliferous limestone islands, probably of tertiary age, with limited areas of narrow reef flat platforms, like Makatea, Niue, Nauru, Paanopa, Naiau, Wangava, with ill-defined sinks or basins occupying part of the summit.

Elevated coralliferous limestone islands, like Mango, Kambara, Tuvuthá, in which the sink is better defined and where a volcanic outburst has broken through the rim or central part of the sink or both.

Elevated islands of coralliferous limestone, like Fulanga, Yangasá, Ongrea, where the sea has eaten through the limestone rim towards the inner sink cutting the rim into islands, and has formed a sound or lagoon dotted over with limestone outliers forming undercut and weathered islands and islets. The encircling land rim may disappear or be reduced to a few heads, as in Argo, Ongea, or Yangasá.

1 Dr. Guppy has given an excellent account of the geology of the Solomon Islands. He was the first to call attention to the great importance of the comparatively thin elevated coral reefs of those islands and to the existence in the Pacific of underlying calcareous rocks probably of tertiary age. "The Solomon Islands: their Geology . . by H. B. Guppy. London, 1887." 
Elevated coralliferous limestone islands, cut down nearly to the level of the sea by atmospheric agencies, like Niau in the Paumotus, with a shallow sink (lagoon) connecting with the sea only through the porous mass of the land rim, or Rangiroa, and the majority of the islands in the Paumotus and some of the Gilbert Islands (Apamama, Tapeteuea), with a lagoon enclosed by a land rim composed of disconnected islands and islets forming passes and gaps communicating with the sea; islands all noted for the great development of buttresses of modern reef rock and of tertiary age on the reef platforms, the remnants of a higher land mass now denuded to the level of the sea. Similar outliers in the lagoon form shoals, islands, and islets.

Extensive elevated limestone masses, like those of the Tonga Archipelago with volcanic outbursts of limited extent that have pushed through the limestone masses.

Atolls with disconnected limestone and volcanic islands, the remnants of islands partly volcanic and partly limestone, like Guam and Eua, only on a smaller scale. In these the voleanic outbursts as well as the limestone masses have been denuded and eroded, and formed the groups of Vanua Mbalavu, Lakemba, Naitimba, Mothe, and the like.

Low atolls, like those of the Ellice, Marshall, and the Gilbert Islands in part, where the land rim is reduced to a minimum and best developed on the weather side, and where the material composing it is subject to constant transport, the material being derived from the corals growing on the sea slope of the reef flat platforms and from the disintegration of the slightly elevated modern reef rock conglomerate or breccia. Atolls all characterized by the great changes taking place in the extent of the islands of the land rim, owing to the formation of sand bars, shoals, flats, bays, the closing of gaps, the filling of lagoons by sand blown in from the sea face, the throwing up of extensive dams on the lagoon flats to form secondary lagoons, the existence of reef platform lagoons; the islands on the land rims of these atolls being flanked with coral sand, shingle or boulder beaches on the sea face, with sand beaches or beach rock flats on the lagoon faces. The islets, shoals, and islands in the lagoons are either patches of elevated modern reef rock or knolls of growing corals, many of them with 
deep passes, usually most numerous on the lee side. The corals growing on the sea slope of the reef platforms are often overwhelmed by sand dunes blown over the land rim from the lagoon flats.

Atolls like Tarawa, Tapeteuea, and Nonuti in the Gilbert group, and Makemo, Fakarava, and others in the Paumotus, with a well-developed land rim on the weather face flanked on the lee by submerged reef flats.

Finally, such islands and islets as Tikeï, Nukutavake, and a number of small islands with central sinks or depressions formed by the beaches thrown up on the outer edge of the flat or summit of the island, leaving an open central space enclosed by the beach dams. Similar islands occur in the Gilbert group, as Arorai and Tamana; Mejit, Lib, and Jemo in the Marshall, and Nurakita and Nanomana in the Ellice groups.

The soundings taken by the "Albatross" in the Marquesas show that two of those volcanic islands are connected by a plateau with a depth of 800 fathoms (Pl. 200, Stations 24-28, p. 380). The soundings in the Paumotus (Pl. 201, Stations 34-60, 70-120, p. 380) developed the plateau from which the northwestern islands of the group rise, ${ }^{1}$ a plateau with a depth of about 800 fathoms. The soundings among the central and eastern Paumotus developed smaller plateaus or spurs uniting adjoining atolls, and also showed that the eastern atolls and islands are separated by channels of great depths (Pl. 201, Stations 122-172, p. 385).

The Society Islands are also separated by deep channels (Pl. 202, Stations 65-75, p. 382), and deep soundings separate the Cook Archipelago from Niue and Tonga (Pl. 211, Stations 181-187, p. 388).

In Tonga the general depth of the three component plateaus is about fifty fathoms; the plateaus themselves are separated by channels with not more than 250 fathoms (Pls. 213, 214); the land masses of Tongatábu, Haapai, and Vavau slope gradually into the general level of their respective plateaus, and the scattered islands of Nomuka rise very gradually from the main plateau at a depth of twenty-five to thirty fathoms.

Somewhat shallower water exists between Tonga and Fiji (Pl. 213, Station 188, p. 388) than between Niue and Tonga. The soundings in the channel between Yangasá, Mothe, and beyond indicate the shallower 1 See p. 25, Figs. 1-12. 
depths (324 fathoms) of the southern extension of the eastern plateau of Fiji, upon which are situated the Lau group of atolls and islands (Pl. 220, Stations 189-193, p. 389).

The Admiralty Charts of Fiji and north of that group contain numerous soundings ( $\mathrm{Pl}$. 221). As far as practicable we intercalated our soundings with those already published; we sounded usually within a half or a third of a mile off the different islands and atolls, as well as in the centre of the channels separating them. We showed that in the Ellice group, as had already been indicated by the "Penguin," the atolls are separated by deep channels (PI. 221, Stations 194, 195, p. 389). We found the same to be the case in the Gilbert Islands (Pl. 223, Stations 196-207, p. 389), though some of the atolls (Apaiang, Tarawa, and Maiana) are, as in the Paumotus, united by a comparatively shallow plateau. Over 2500 fathoms separates the Gilbert from the Marshall Islands (Stations 208-212, p. 390); the atolls of the Marshall Islands are, like those of the Ellice and Gilbert groups, separated by deep channels, a few of the atolls (Namu and Odia) being united by shallower plateaus (Pl. 225, Stations 213-238, p. 390).

The islands and atolls of the Carolines are separated by deep water (Pl. 232, Stations 239-244, p. 391), and between the Carolines and Guam the United States Steamer "Nero" obtained, about one hundred miles southeast of Guam, the greatest oceanic depth as yet recorded (5269 fathoms). Nothing is known of the submarine slope of the Carolines with the exception of the soundings taken by the "Albatross" a short distance off Port Lottin and Nama (Stations 239, 242); the depths correspond to those off similar islands in the Society and Gilbert Islands. The soundings of the "Challenger" and of the "Nero" indicate great depths between the voleanic islands of the line extending from Guam to Japan (Pls. 1, 234).

We took a number of soundings off the atolls of the Paumotus, Gilbert, and Marshall Islands at a distance varying from one mile to a quarter of a mile. These soundings, like those off the Paumotus, varied from 225 to over 400 fathoms, and only showed that at those distances from the shore we had already reached the oceanic slopes of the atolls. They all indicate, within those limits, steep slopes in the upper part of the reefs (see the List of Soundings for these groups, p. 379). 
There are as yet comparatively few soundings off the sea faces of atolls and reefs to give us more than very general ideas regarding the slope of the upper parts of a coral reef. A number of soundings are known taken a distance of half a mile or a mile from the edge of the reef, but within that distance comparatively few data exist. We must except the soundings of the "Challenger" on the outer slope of the barrier reef off Papieté and the soundings off Funafuti by the "Penguin;" they are more numerous than those taken off any other atoll and show great diversity in the slope on the different faces of the atoll.

All the soundings known indicate that coral reefs rise independently upon summits formed by tertiary limestones or volcanic rocks, summits which have been formed either by elevation or submarine denudation or upon summits of accretion forming submarine banks.

The nature of the underlying base is naturally an important factor in determining the pitch of the sea slope; we may assume that the steep slopes of the upper part of reefs is due to the sloughing off of the limestone cliffs down to thirty or forty fathoms, much as they are sloughed off from the faces of elevated islands above high-water mark. If composed of volcanic ash or harder volcanic material the slope in one case will be very slight, spreading rapidly laterally under the influence of the waves; in the other the slope of volcanic material will not differ materially under water from that above high-water mark. When the slope is a talus of reef material it may lie at a steep angle or may follow closely the slope of the underlying base below the depth at which corals or Nullipores grow.

In the Atlantic the slopes off the Florida barrier reef have been carefully sounded; they are not steep, but pass very gradually into deep water. The same is true of the slopes off the Bahamas sounded by the "Albatross" under Captain Tanner, and of those off the Bermudas as determined by the "Challenger." These all are in marked contrast to the steep sea faces off the Great Barrier Reef of Australia, off Tahiti, and Fiji. The slope of Masámarhu Island ${ }^{1}$ in the Red Sea has been carefully surveyed; it is quite abrupt to a depth of about eighty fathoms. Two excellent sections have

$$
\text { i “Nature," } 1887 \text {, p. } 413 .
$$


been published of Macclesfield Bank, ${ }^{1}$ the one showing a steep fall to a depth of about 100 fathoms, preceded by a very gradual slope to the fifty fathom line and a more gradual slope from the 100 to the 700 fathom line. The other, nearly at right angles, shows a longer upper slope to the fifty fathom line and a less steep slope to 400 fathoms than the corresponding depths of the first section.

The legend of the cliart (Pl. 234) which has been prepared to illustrate the distribution of the coral reefs in the Pacific requires some additional explanation.

Many of the volcanic islands represented as without belts of elevated limestones have unimportant patches of fringing reefs; these have not been noted, having no important bearing on the question of the theory of the coral reefs. They are such islands as the Bonin Islands and other volcanic islands north of the Ladrones extending toward Japan, and some of the Sandwich and Marquesas Islands.

Volcanic islands, like those of the Society, Cook, Fiji, or Caroline Islands, which are colored blue with a yellow ring, indiente the presence of barrier and of fringing reefs. Islands partly volcanic and partly elevated limestone, as in the Lau group of Fiji, or in Tonga, are also surrounded by fringing and barrier reefs, or reef flat platforms. Elevated coralliferous limestone islands are similarly surrounded in part by fringing reefs or by reef flat platforms and barrier reefs. This is the case in elevated islands with sinks, or in elevated islands which have been eroded to the level of the sea, the land rim of which surrounds a sound; the underlying base of barrier and fringing reefs of the elevated islands being tertiary limestones.

Islands and groups colored yellow indicate low atolls elevated perhaps a few feet, but of which the land rim consists of modern reef rock or conglomerate or breccia, the underlying base of which is not known.

The Great Barrier Reef of Australia and its extension along the coast of New Guinea to the Louisiade Archipelago, as well as the barrier reef of New Caledonia, is colored to indicate that these barrier reefs are probably underlaid by the submarine extension of the rocks of the adjacent shores.

1 Clina Sea. Report on the Results of Dredgings obtained on the Macclesfield Bank; Admiralty, 1894, 3 Charts. 
The track of the "Albatross" on Pl. 234 will indicate those islands which are colored from our observations, or from other reliable information, as well as those which have been colored by analogy.

A very convenient "Index to the Islands of the Pacific Ocean" with their synonymy has been published by Dr. William T. Brigham in No. 2, Vol. I., of the Memoirs of the B. P. Bishop Museum (1900). It will be noticed that the spelling of many of the atolls and islands often differs in the text, in the charts, and in the "Sailing Directions." This has been unavoidable, as the English, American, French, and German charts have not adopted the same nomenclature as that of the English "Sailing Directions." This I have generally followed. Even the nomenclature of successive editions of the same charts often varies.

An exploration like that made by the "Albatross" through the tropical Pacific suggests a number of interesting problems, such as the comparative study of the fauna and flora of oceanic islands, the geological examination of the volcanic, continental, or oceanic islands scattered throughout the Pacific; to say nothing of the study of the human races inhabiting them. Such studies become each year more difficult from the inroads of civilization, which affect the inhabitants as well as the fauna and flora.

It was our intention to investigate the marine fauna of each of the great oceanic groups of islands and trace the passage of the littoral into the abyssal fauna, and to obtain the material needed for a comparison of isolated oceanic faunæ to one another. Unfortunately we were not able to carry out this part of our programme.

After the publication of the results of my expedition to the Maldives during the winter of 1901 to 1902, I hope to present in a connected form a résumé of the observations recorded during the fifteen seasons I have devoted to the study of coral reefs.

In spite of all that has been accomplished during the last twenty-five years towards settling the debatable points of the theory of coral reefs, much remains to be done. Most important is an extensive system of boring at well-selected points, to include barrier and fringing reefs and atolls in volcanic or other districts, as well as elevated coralliferous limestone islands or islands partly limestone and partly volcanic. The boring should be sup- 
plemented by lines of soundings and dredgings taken from low-water mark to the depths at which oceanic slopes are met.

The data thus obtained would give us the pitch of the slope of the strata underlying a barrier and a fringing reef, and of its continuation beyond the outer edge of the barrier reef. For an atoll the bore would indicate the width of the talus, the original dimensions of the summits upon which the recent reef rock material was deposited, and the extent of lateral growth, both seaward and lagoonward. This would give a degree of precision now wanting in the observations I have recorded.

Newport, Rhode Island, October 20, 1902.

ALEXANDER AGASSIZ. 



\section{THE MARQUESAS.}

Plates 2, 3, 200, and Fig. 1.

ON the 14th of September we obtained our first view of the Marquesas Islands, Hatutu, distant about ten miles. This island is quite barren, and seen from the north presents no such striking shores as those of Nukuhiva.

The appearance of the coast line of Nukuhiva and of its slopes clearly indicates the immense amount of erosion to which the Marquesas Islands have been subjected. Steaming along the southern coast from off Chickakoff Point past Tai oa Bay to Taï o-haé, one follows a huge, lofty, nearly vertical wall (Pl. 2, fig. 1), broken into by the deep valleys facing the bays and harbors of that part of the island. ${ }^{1}$ To the rear of these rises, to a height of over 3000 feet, the ridge which forms the backbone of Nukuhiva and separates the valleys fronting on the north from those facing the south and east.

On the northeast shore a number of needle-like peaks have been left at Adam and Eve Point, and peculiarly shaped rocks stand out prominently at the entrance of Comptroller Bay and to the north of Cape Martin. The southwest point is also marked by a prominent line of cliffs projecting beyond the general outline of the promontory. The western outline of Nukuhiva is quite unbroken, its face formed by a rather gentle uniform barren slope, stretching from the highest central summit to the shore. On the sonthwest point of Ua pu occur sharp pinnacles and cones of disintegration similar to those of the north shore of Nukuhiva.

\footnotetext{
1 The finest examples of erosion in Nukuhiva are found on the face of the eliffs forming the ridge on the west side of Tai oa Bay (Pl. 2, fig. 1).
} 
Looking into the narrow entrance of the deep Tai oa Bay, we can trace the bedded lines of lava, following the general slope of the island, and running across the numerous ridges, spurs, and diminutive peaks which cover the steep slopes of the western side of the bay (Pl. 2, fig. 1). ${ }^{1}$ The volcanic strata, as cut by the valley, are seen to dip at an angle of about $20^{\circ}$ towards the sea, and the steep western slope is gouged by deep channels forming secondary ridges or rather lamellæ, regular knife edges, along the whole western face of the valley. The crests of the ridges and their faces are cut into endless peaks and cones extending far up the continuation of the valley of Tai on Bay.

The high wall of stratified volcanic ash which extends between Tai oa Bay and Taï-o-haé Bay is full of deep holes and caverns and pits (Pl. 2, fig. 2), and through it is cut Taï-o-haé Bay, where we anchored during our stay at the Marquesas. The harbor is surrounded by the sharp ridge running in a southerly direction from a peak rising to over 2100 feet to the north of the valley, forming a huge amphitheatre at the back of the bay. The slopes of the ridge are bare; but the valleys leading to the peaks are more or less well wooded. The entrance of Taï-o-haé Bay is flanked on each side by two rocks called the Sentinels; they are remnants of the points which once extended farther out to sea on both sides of the entrance to that harbor.

The general account of Nukuhiva may serve for the other islands of the group. They show the same prominent features, - a central ridge with spurs extending towards the coast separating deep valleys; their shores either cut into deep bays or amphitheatres, or edged by high, steep volcanic cliffs formed by the disintegration of points once extending into the sea, or by uniform lava slopes reaching from the central backbone. The islands have their steepest faces on the eastern exposures attacked by the southeast trades and the prevailing easterly winds which blow from October to April.

The Marquesas Archipelago ${ }^{2}$ consists of three fairly well defined clusters, trending in a general direction from southeast to northwest

1 A similar cliff is figured on A. Chart 1640 to the rear of Resolution Bay on Tauata Island, one of the southern cluster of the group.

2 A. Chart 1640. 
(PI. 200). The northern cluster consists of three small islands, two of which are volcanic, and the others (Coral Islands ${ }^{1}$ ) are reported to be two small coral islands on a shoal. According to the statement of the latives, this is the only point in the Marquesas where corals grow in abundance, as elsewhere in the Marquesas corals are limited to a narrow fringe or patches of fringing reefs on the shores of the bays which indent the islands of the group. In from two to three fathoms in Taï-o-haé Bay coral patches form an irregular fringing reef, composed of a few species of coral. They have but little influence on the character of the beach sand thrown up at the head of the bay, the greater part of which is volcanic silt washed down from the hillside mixed with a little coral sand.

The central group, which we visited, consists of the islands of Nukuhiva, Ua Huka, and Ua pu. These as well as all the other islands of the group, with the exception of the Coral Islands, are volcanic and rise to a considerable height, the highest point of Nukuhiva being over 3800 feet, of $\mathrm{Ua}$ pu over 4000 , and of Hiva Oa, the largest island of the southern cluster, more than 3000 .

Nukuhiva is about 14 miles in length and about 10 broad; while its shores are very steep on the northeastern and southern faces, with numerous waterfalls dropping nearly vertically into the sea from 2000 feet, the western slope is comparatively gentle. The slope off the south coast of Nukuhiva is steep; within less than a mile there are depths of from 45 to 60 fathoms over a fine volcanic sand bottom.

What is very striking at the Marquesas is the absence of coral reefs. Here is a group of volcanic islands situated in latitude $9^{\circ}$ south, and in the region of the southenst trades, under the most favorable conditions of temperatire of the sea $\left(80^{\circ}\right)$, yet there are nowhere in the group the great barrier and fringing reefs so common in the Society Islands, the Fiji, and other volcanic island groups in the Pacific. Coral reefs exist in the Marquesas only as patches scattered here and there in protected bays. They are indicated on the Admiralty charts at Vaeio Bay, at Hakahe

1 We did not visit the Coral Islands, as, according to the sailing directions, they are exposed to heavy seas, making landing difficult. 
tau, in Ua pu Island, also at Hanaiapa, Hiva Oa Island, at Anaho Bay on the north side of Nukuhiva, and in Comptroller Bay on the south coast, besides at several points in Taï-o-haé Bay.

I can only attribute the absence of coral reefs in the group to the fact that there have been no great platforms of erosion formed at the base of the slopes of these islands. It is difficult to imagine why such platforms do not exist here, for the angle of the slopes and their character are not different from that of other volcanic groups where both fringing and barrier coral reefs occur. Owing to the greater depths near the coast line, corals find a depth suitable for their growth only in the closest proximity to land; there is no opportunity for lateral expansion, as in volcanic islands which are flanked by a wide platform of erosion, on which the soundings are comparatively shallow or far within the depth at which corals can grow. The absence of this platform of erosion does not mean that these volcanic islands are not eroded fully as fast as similar islands in Fiji and in the Society group in about the same latitude, and under similar conditions of exposure to the tradewinds. A glance at the charts ${ }^{1}$ will show how extensive this erosion has been. The steep bluffs or the sloping faces, which in one case flank the inner side of the reef platform, in the case of the Marquesas simply flank the edge of the shore, but if they slough off, they become disintegrated and worn into volcanic sand or small masses on which corals can find no footing, as is also the case in the Galapagos. This seems to me to be the probable explanation of the absence of corals in the Marquesas; it is confirmed by what exists in the Galapagos ${ }^{2}$ and in the island of Mehetia to the southeast of Tahiti, where the absence of a shore platform is most striking, the more so as Mehetia is in a region where corals are wonderfully developed upon the shore platforms of other volcanic islands in the Society Islands.

Round the base of the extinct crater of Mehetia there are neither barrier nor fringing reefs. Corals are limited to a small area at the

1 A. Chart 1640 .

2 In the Galapagos district the absence of corals is partly due to other causes. Bull. M. C. Z., XXIII., No. 1, p. 69. 
"Albatross"Tropical Pacific Ex

SECTIO

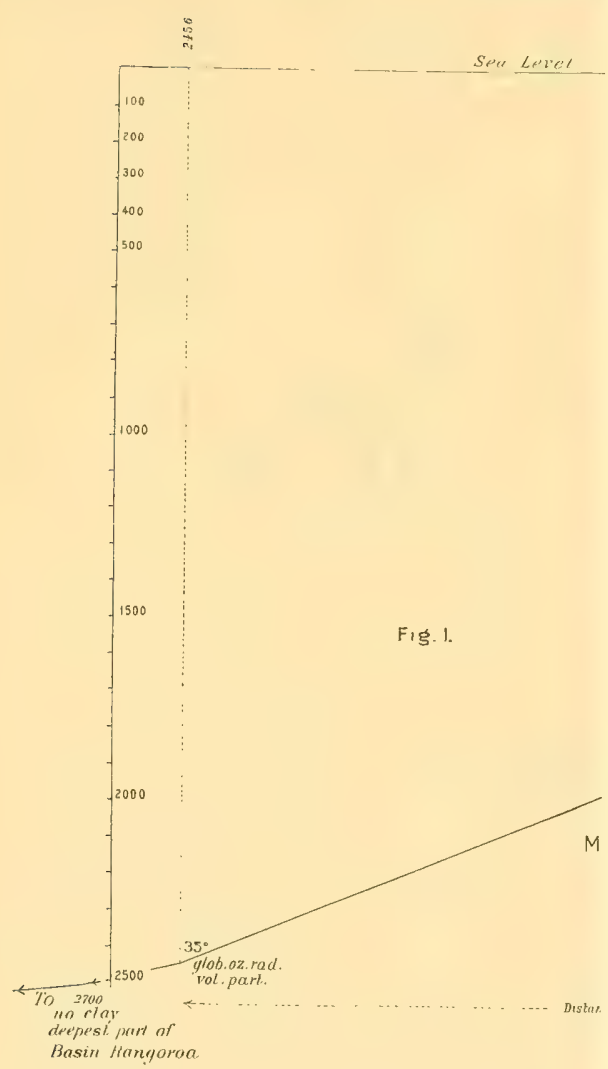

Despest pert of Moser Bnsin 3088 
"Albatross"Tropical Pacific Ex.

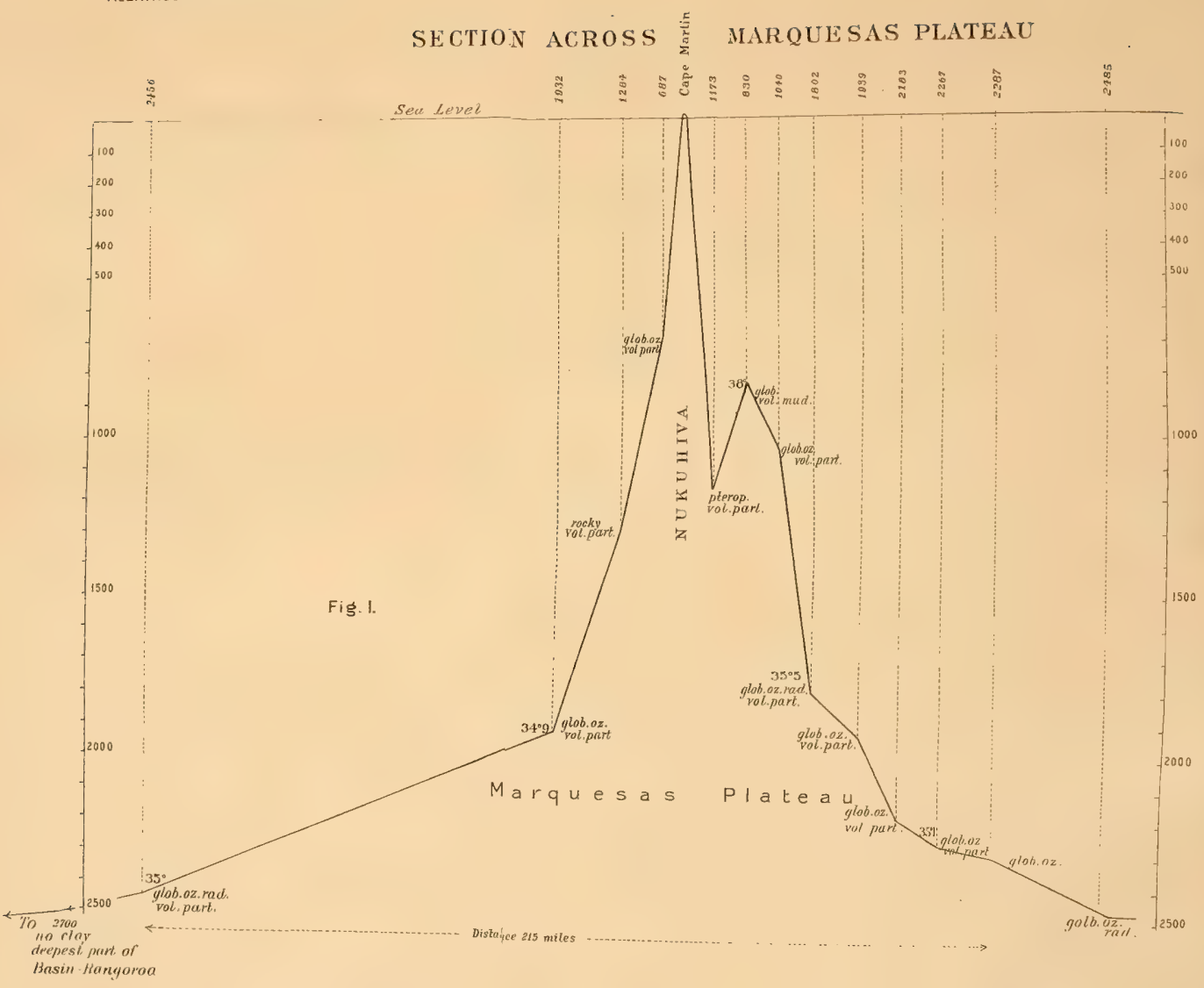

Deepest part of Moser Basin 3088

General Level of Enstern part of Woser Basiu. $\rightarrow$ SOUNDINGS IN FATHOMS. 


southeast and northwest spits, where the promontories of the islands extend seaward as shallow points, on which corals have established themselves. It is also possible that the successive flows of lava from Mehetia and the extinct craters of the Marquesas may have destroyed the corals or prevented their obtaining a foothold. Corals occur only in patches in the Galapagos Islands, in a still active volcanic district, where their development should be most favored, judging from the ocennic conditions existing there, and where there is no trace of any subsidence having occurred.

Dana and Darwin have supposed that the absence of corals on these islands was due to their having gradually subsided, yet subsided so fast that corals were not able to find a footing on their steep slopes. Dana ${ }^{1}$ also attributes the absence of corals in the Marquesas to the depth of water about the islands in addition to subsidence; he says in substance, if before the subsidence there was some extent of shallow water round an island, it might have had very bold shores after it had half sunk beneath the waves. The Marquesas may therefore have had barrier reefs which were sunk from too rapid subsidence; others again failed to form on account of deep water near the shore. There are, as I have stated, no indications that either the Marquesas or Mehetia has been subjected to the effect of subsidence, as Dana assumes.

The soundings which we took ( $\mathrm{Pl} .200$, stations 24, 25, 26, 27, 28) indicate that there is a ridge gradually rising from a depth of about 2100 to a depth of about 800 fathoms, which connects Ua Huka and Nukuhiva (Fig. 1), but existing soundings do not indicate what connection (if any exists) there may be between the other islands of the group.

It is not uncommon to find voleanic islands with insignificant fringing reefs, or with only patches of fringing reefs, in regions where other volcanic islands have well-developed barrier and fringing reefs due to the existence of more or less wide platforms of submarine erosion. I might mention the Horne Islands (A. Chart 987), not more than 90 miles distant from the Fiji group; both volcanic groups, the former

1 Dana, Corals and Coral Islands, 3d edition, 1890, pp. 340, 361. 
with very narrow fringing reefs, the latter with wide fringing or barrier reefs.

The east coast of Madagascar has only patches of coral reefs, while the northwest face is studded with them (A. Chart 758). Of the Comoro Islands, Mayotta alone is protected by a barrier reef (A. Charts 2762 and 2741). Bourbon has only coral patehes (A. Chart 1497), while both Mauritius (A. Chart 711) and Rodriguez (A. Chart 715) have barrier and fringing reefs, in the latter they are strikingly similar to the wide reef flats of Ponapi. Similarly the Amirante Islands all have barrier or fringing reefs, while in the Seychelles the principal islands - Mahé. Silhouette, and others - have only comparatively unimportant fringing reefs (A. Chart 721). I would also refer to similar conditions due to the absence of these platforms on several of the volcanic islands of the West Indian Windward group. ${ }^{1}$ Martinique ${ }^{2}$ is specially interesting, having a well-marked platform round the southern extremity, while the slopes of Pelée, forming the northern part of the island, pass into a steep submarine slopè.

1 Grenada, H. O. Chart 1316. Grenadines, H. O. Chart 357. Dominica, H. O. Chart 1318. St. Vincent, H. O. Chart 1279. Guadeloupe, H. O. Chart 363. See also A. Agassiz, Bull, M. C. Z., Vol. XXVI., No. 1, 1894, p. 145.

2 H. O. Chart 1009.

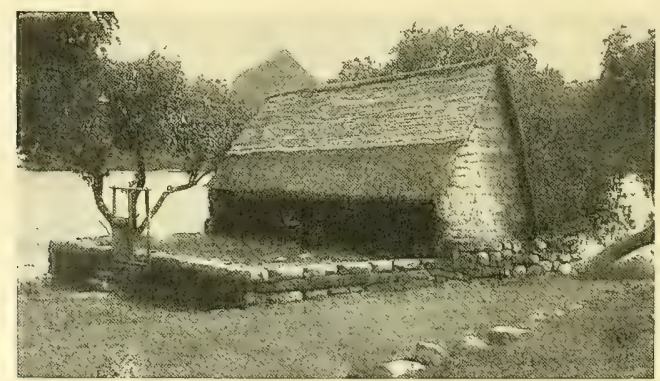

Native Hut, 'TAï-o-haé Bay, Marquesas. 


\title{
THE PAUMOTUS.
}

\author{
Plates 4-83, 201-207.
}

The Paumotus form a broad belt of atolls extending for nearly a thousand miles from the southeast to the northwest. Quiros, a Spanish navigator, first gave notice of their existence in 1606. A number of islands of the group were subsequently discovered by French and English explorers, but it was not until the beginning of the last century that we have any very exact information regarding the Paumotus. The most important notices are those of Beechey, Fitzroy, and Wilkes, and the later surveys of the French, under whose protectorate nearly all the islands of the group are placed. It may be interesting to repeat here the more important observations of Beechey and of Wilkes on the Paumotus.

Captain Beechey, ${ }^{1}$ in the "Blossom," made in 1826 a most accurate survey of the Gambier group, to which but little has been added by subsequent explorers. ${ }^{2}$ The Gambier Islands (Pl. 207) are interesting from a historical point of view, as they are stated by Darwin to have been the group which gave him the first hint for the theory of subsidence as explanatory of the formation of atolls and barrier reefs.

Beechey's remarks on coral islands and coral reefs are most instructive, and his views are far more accurate than those of many of his successors. It is interesting to read some of his remarks on the Gambier group. Beechey mentions the following shrubs and trees as found in the Paumotus: Saccharum, Achyranthus, Capparidia, Eugenia, Scævola, Tournefortia, Convolvulus, Pemphis, Thespesia, Poron, and Lipidium.

Beechey visited no less than twenty-nine coral islands, most of which he discovered. He noticed that the so-called central sink may be due merely to the piling up of the sand beaches on the sea faces above the central part of

1 Foster's observations on the formation of coral reefs are interesting historically, but have not the value of Beechey's later surveys. John Reinold Foster, Observations made during a Voyage round the World, London, 1778.

2 See Chart of the Gambier Group, p. 133, Vol. I., Narrative of a Voyage to the Pacific and Bering's Strait in H. M. Ship. "Blossom," London, 1831, and compare it with A. Chart 1112 (Pl. 207), published in 1885 . 
a flat island. He suggested that the lagoons of some atolls had probably been filled by the blowing in of sand over the summit of the encircling beaches, and he noticed the mode of formation of islets and islands on the land rim of many of the atolls he visited. Beechey suggests that openings in the reef are due to their being opposite some stream of fresh water. He quaintly says: "The aversion of the Lithophytes to fresl water is not singular, as, independent of its not being the natural element of these animals, it probably supplies no materials with which they can work."

He was the first to describe the outer reef platform of an atoll as well as the lagoon platform, and he sounded a number of lagoons. He observed, as is seen from his description of. Hao, the mode of formation of sinks parallel to the lagoon shore. He notes that some of the surveys of Cook do not differ from his, and that where he has instituted careful comparison he cannot see that any change has taken place in the coral reefs since the days of Cook, for more than sixty years. He further says that when any differences exist they are changes readily accounted for, and generally due to the superficial action of the wind and sea. Beechey speaks of the small number of islands he examined where no lagoon exists. Of the twentynine he visited only Aki-Aki, Nukutavake and Henderson had no lagoon.

Henderson Island is, according to Captain Beechey, who examined it in 1826, a mass of coralliferous limestone rising about 80 feet above the level of the sea. He speaks of it as "compact, having the fracture of secondary limestone." It must be in its structure very similar to Niue (Pl. 212), which we visited; only the elevation of Nine is somewhat greater, and it is a larger island. Henderson Island is about five miles long, and two and a half miles wide in its greatest width. It is rectangular towards the north, and triangular towards the south. ${ }^{1}$ Judging from the chart, there must be a well-defined terrace at the height of 50 feet above high-water mark, leading to a second terrace at a height of 80 feet, which forms the summit, the flat surface extending over the greater part of the island.

Beechey observed that in the Paumotus the passages into the lagoons were generally on the lee side of the atolls, and that the direction. of the 
trades had a great influence in shaping the land rim of one face, while the other was only a half-drowned reef flat, often wholly under water. He sounded lagoons from 20 to 38 fathoms, and from such information as he gathered inferred that there had been, according to the statements of the natives, very little change in the depth of the passages. He noticed the effect of the wide outer-reef platform in regulating the flow of the sea into the lagoons over submerged parts of the rim and between the gaps of low islands forming the land rim. He observed that the height of the water in the lagoons was subject to the strength of the trades, which influenced greatly the strength of the currents and their direction through the passages. While examining Bow Island (Hao), he observed the nature of the bottom of the lagoon and the growth of the coral knolls scattered throughout its area.

Beechey's ideas on the structure of coral reefs are interesting, and are well illustrated by a diagram and sketch of Pinaki (Whitsunday), ${ }^{1}$ which is accompanied by an excellent description of the island. That diagram and sketch have been very generally copied in all books on geography, so that Whitsunday has unfortunately obtained a wide recognition as a typical atoll.

There are scattered throughout Wilkes" "Narrative of the United States Exploring Expedition" many accurate observations and shrewd remarks on the formation of coral reefs. I may especially refer to Wilkes' disappointment on landing on a coral island. ${ }^{2}$ His account of its barremness is in marked contrast to the poetic descriptions which have been handed down by so many writers on coral reefs.

Wilkes ${ }^{3}$ gives also a sketch of Clermont-tonnerre, and the results of soundings made off the east side of the atoll. At 300 feet from the edge of the reef he obtained 90 fathoms; at 180 feet 85 fathoms; at 130 feet 7 fathoms. At three quarters of a mile from the southern point the "Peacock" sounded in 350 fathoms. He gives a short list of the principal trees and shrubs, and speaks of the number of birds on the islands as incredible. The lagoon of Raraka was sounded ; ${ }^{4} 30$ fathoms was found inside a short distance from the entrance, where the water is from five to eight fathoms.

1 Beechey, loc. cit., pp. 188-193.

${ }^{2}$ Loc. sit., p. 317, Vol. I. of the Narrative.
${ }^{8}$ Loc. cit., p. 311 of Vol. I.

+ Loc, cit., p. 331. 
The lagoon of $\mathrm{Ahe}^{1}$ is said to be quite shallow and much obstructed by growing corals.

A cut ${ }^{2}$ is given of what must probably be elevated old limestone rocks. Unfortunately no locality is named; it may be (Kauehi) Vincennes Island.

There is a grood cut of Metia (Makatea) reproduced in Dana's "Geology of the Exploring Expedition" and in his "Coral Islands." The ascent of the bluff on the western face of Metia ${ }^{4}$ is described; on reaching an open space on the top a clear view of the interior was obtained. The general shape, as far as it could be seen, was pan-like, or in the form of a dry lagoon. He also says: "The island ${ }^{5}$ has unequivocal marks of having been uplifted at different periods; the cliff at two different heights appears to have suffered abrasion by the sea." He gives a figure ${ }^{6}$ of a part of the great sea wall on the southern face of Rangiroa, with islands to the rear, taken from a drawing made by Mr. Agate while the "Peacock" ran along the south shore.

Lientenant Johnson ${ }^{7}$ was left on Aratika to make some borings; the greatest depth reached was 21 feet, the principal difficulties encountered being "the looseness of the sand and the falling in of the coral stones." 8

Wilkes also gives ${ }^{9}$ an account of the method used by the Expedition in surveying the coral islands. The basis of the method rested upon the measure of distances by sound. Guns being fired alternately from the different vessels, any three of them being stationary, the distances and positions of objects could be determined from them by direct angles, or by angles between them taken from the shore, or from boats. On page 431 a woodeut is given showing the method of surveying one of the islands. The survey of an island ${ }^{10}$ about seven miles in length was made in three hours and thirty-five minutes.

1 Loc. cit., p. 337.

${ }^{3}$ Loc. cil., p. 338.

5 Loc. cit., p. 341.

2 Loc. cit., p. 334.

4 Loc. cit., p. 340.

6 Loc. cit., p. 342.

7 Loc. cit, p. 267, Vol. IV.

8 At Bow Island Captain Belcher bored to a depth of 45 feet; near Blossom anchorage he passed through a fine coralline sand. A second attempt made on the outer belt of the island failed, as the borer got jammed at a depth of 9 feet. Narrative of a Voyage round the World in the "Sulphur," by Captain Sir Edward Belcher, R. N., 2 vols., 1843, Vol. I. p. 366.

9 Loc. cit., p. 429 , Vol. I.

10 Probably Puka-rulıa, H. O. Chart 78. The woodent differs greatly in details from the island as represented in the Hydrographic Chart, which is a bad copy of the original. 
Wilkes looked upon the coral islands of the Paumotus as showing unequivocal signs that they are undergoing dissolution. ${ }^{1}$ He based this opinion on the position and size of some of the coral blocks on the top of the reefs, which he considers - and justly, to my mind - as having formed an upper shelf of which they are the sole remains. He was greatly struck with the varying heights of the islands and coral reefs of the Paumotus.

I will refer to the more detailed observations of Dana in the description of the various islands of the Paumotus.

Next to the Maldives the Paumotu Archipelago contains the greatest number of known atolls; then come the Marshall and the Fiji Islands. The Paumotus extend for over 1000 miles in a southeast to northwest direction from Manga Reva to Matahiva, and the greatest width of the belt of islands from Anaa to Fakaina is over 300 miles in an easterly direction (Pls. 201, 202). There are in addition a number of detached islands on the eastern flank of the group which present no feature differing from those of the atolls we visited. The charts of this group are somewhat inaccurate, and, while most useful as sketches, cannot be used as are the admirable charts of the Fijis, of the great barrier reef of Australia, of the New Hebrides, Solomon, and Tonga groups, or those of the Society, Cook Islands, or Maldives, to determine the points of interest for a first examination of the islands. To obviate this difficulty we steamed around each atoll so as to obtain a general view of it, and when we entered the lagoon we limited our examination to the interesting points we had noticed on skirting the land rim close to the outer reef.

The general sketch charts published by the French Hydrographic Office are far more accurate than those which have been issued either by the British or the American Hydrographic Office. It is true that we have a large number of sketches of varions atolls of the Paumotus made by Wilkes in the early forties, as well as surveys by Beechey and Fitzroy and a few sketches by Kotzebue, Bellingshausen, and Duperrey in the beginning of the last century, but they do not compare in accuracy with later or more recent surveys. The islands which have been sketched by Wilkes are Ahe, ${ }^{2}$

1 Loc. cit., p. 269, Vol. IV.

2 I have adopted the spelling of the French Charts of the Paumotus. Dépôt des cartes et plans de la marine, 985 . 
Takaroa and Takapoto, Kauehi, Raraka, Puka-ruha, Taiaro, Marokau, Ravahere, Napuka, Reao (commonly known as Clermont-tonnerre), Aratika, Manihi, Takume, the Sea Gull Islands ('Tuanake, Hiti, and Tepoto), Tauere, Makatea, Hereheretue, Nukutipipi, Anu-Anuraro, and Anu-Anurunga.

Although I did not visit Fakaina, I have given a sketch plan of the island (Pl. 204), as there are, outside of Wilkes' sketches, so few of the Paumotns properly surveyed that we have to depend almost wholly upon the general chart of the group for illustrations of the shape and characteristics of most of the atolls. Fakaina, Hao, and Mururoa are the only islands of the principal mass of the Paumotus of which sketches are given in some detail.

The islands of Manga Reva (Pl. 207) were surveyed by Captain Beechey and d'Urville, Hao Island by Captain Cook, Bougainville, and Beechey, while the French have surveyed, since 1874, the southern extremity of the island of Apataki, the entrance of some of the harbors, as that of Amyot on Toau Island, and Avatoru and Tiputa entrances on the island of Rangiroa. The entrance to Takaroa, to Ahe, and to Manihi, a part of the atoll of Fakarava was surveyed in 1880 by the French, from the northern pass to Rotoava and to the east a distance of about three miles. The northern pass of Makemo was also surveyed by the French. The officers of the "Albatross" made a rumning sketch of the western shore of Fakarava (Pl. 204, fig. 1) as we steamed along its western edge, and also determined the position of Rotoava and the land to the eastward, as well as that of the western extremity of Rangiroa. They also determined the position of the southwestern end of Tikahau, and corrected the position of Matahiva as well as its outline. We also took a line of soundings from Rotoava directly south, and then across towards the southwestern shore of the atoll to a cluster of numerous islands situated near the central part of the atoll. A line of soundings was also run across Makemo from our anchorage to the southern shore.

We came upon the Paumotus from the northeast, striking the west coast of the island of Ahe at a distance of about ten miles. We did not examine either Ahe or Manihi, as, from their descriptions by Dana and the sketches given by him and by Wilkes, it was evident that they 
would not differ from other islands of the Paumotus which we intended to examine. On the south face of Ahe the islands of the low land rim are separated by a series of gaps and of cuts such as we found characteristic of Rangiroa; the entrance into Ahe differs in no way from those of a number of other islands of the Paumotus. The entrance to the lagoon of Manihi, although somewhat narrower than any we entered, is yet very similar to the entrances into Hao, Rangiroa, Tikahau, and other islands of the group. The sketches of Tikahau and of Rangiroa, as given by Wilkes, are somewhat incorrect; they give the idea that the land rim is continuous, while in reality it is composed of islands and islets separated by long stretches of reef, bare at low water. The gaps between them allow an immense amount of water to enter the lagoon from either face of the atoll. The description which has been given of many. of the Paumotu atolls would give one the impression that they are closed and have only a single well-marked passage. On the contrary, with the exception of a few atolls to which we shall return later, the water flows into the lagoon from either side of the atolls through numerous cuts.

It was only after an examination of the old ledges exposed in the gaps of the northern land rim of Rangiroa, and especially in the elevated wall of coralliferous limestone of the weather coast, that we obtained a satisfactory explanation of the formation of the atolls of the Paumotus, - an explanation further confirmed after we had visited the elevated islands of Niau, Makatea, and the other low Paumotu Islands. It is to the cutting down of the elevations of the old ledge to a general level, and the subsequent building up of the atolls by the material supplied from the reef flats and from the coral slopes, that is due the great uniformity of all these atolls.

Certainly subsidence could not have acted in such a uniform way, and have lowered the level of these numerous atolls, once raised to very different heights, to the same point. We can, of course, imagine subsidence to have lowered many of them, but not all, to the same level. The cutting down by erosion and denudation and the planing action of the sea are all factors which we still see going on at all points of the Paumotus, and which readily explain the phenomena as we 
meet them, not only in the Paumotus, but also as they are modified by the local conditions existing in the Marquesas, in the Society Islands, the Tonga group, and the many regions where atolls and coral reefs flourish. In not one of these can it be said that the explanation adapted for the structure of any one group can be applied to that of another without some modification, and often with very great changes. Nor can we say that a universal law such as that of subsidence can explain the conditions now existing in the formation of atolls and of barrier reefs in the coralliferous regions of the Atlantic and of the Pacific. We must seek in the many mechanical causes due to the trades, to the geological composition of the islands, to the general geodetic and orogenic conditions, to chemical action and to minute local conditions, the varied and numerous factors at work in building up an atoll or a barrier reef.

After striking Ahe we made for Rangiroa, the largest atoll of the Paumotus. As Rangiroa was the first typical atoll we visited characteristic of a supposed area of depression, it was of course with great interest that we examined the conditions of the land rim and became acquainted with a type of formation so common in the Paumotus, the Ellice, the Gilbert, and the Marshall Islands as to become monotonous at the end of a few months' sailing. Rangiroa is characterized by the extreme narrowness of the land rim, the width of the reef flats on the weather side of the atoll, and the nearly uniform depth of the lagoon.

At Rangiroa we obtained the first intimation of the immense amount of water which flows in and out through the main passes, and, according to the strength of the trades, continues sometimes to flow two or three days in one direction, and is forced by them over the narrow part of the reef flats, which is bare at low water, or between the gaps separating the islands and islets which have been thrown up on the weather or lee side of the atoll. During the strong trades both wind and seas follow the trend of the shores of the islands, and little or no lee is found under them.

It was fortunate that our first examination of the Paumotus was made among the northwestern atolls and islands of the group. Rangiroa, Tikahau, Matahiva, and Makatea readily gave us the key to the structure of the rest of the group. I doubt if an examination of the southern and eastern Pau- 
motus would have given us so good a basis for an explanation of the causes which have been at work to bring about the existing conditions of the islands and atolls of the group. These have so persistently been represented as low atolls, that with such a preconceived notion strengthened by an examination of the lower islands and atolls of the group, it would have been an easy matter to fail to see in the structure of Rangiroa, Niau, and Makatea the survival of a state of things the history of which can easily be read as demonstrated by what these islands teach, but which it would be difficult to trace from a study of the lower islands alone. It would have been comparatively simple to recognize in the outliers and remnants of the old ledge in the low islands the same tertiary elevated limestone with which we had become familiar in the Fiji, Tonga, and Sandwich Islands, yet we could have formed no conception of the great orographic changes the low islands and atolls of the group had undergone after their elevation and subsequent erosion. The old ledge crops out at various points in the narrow cuts which divide the land rim of the lagoon into a number of smaller islands; in these secondary passes the underlying ledge, full of fossil corals, is left exposed. In some of the secondary passes a clear channel extends across from the lagoon to the sea side, through which water flows at high or half tide. In other cases the cuts are silted up with coral sand blown in from the lagoon side. In others the cut is shut off by a high sand bank, or a bank composed of broken fragments of corals, leaving access to the water from the northern shore only; and finally the cuts are also shut off on the northern side by sand and broken coral banks, the extension of the north-shore outer beach, leaving a depression which at first is filled with salt water and gradually silted up both from the lagoon side and the sea face, and forms the typical north-shore land rim of the lagoon. This building up of the land rim of the Paumotu atolls by the accumulation of material both from the lagoon side and the sea face, is very characteristic of the atolls of that group. It is a feature which I have not seen so marked in any other coral reef district.

The land rim of the atolls in the Paumotus and Fiji is very stable. There is not much movement except in hurricanes; and there is no such regular migration of sand as occurs on some islands in Florida. I know nothing to 
sustain Dana's ${ }^{1}$ statement regarding the removal of material from the inside of lagoons; one need only look at all the islands and islet beaches on the inside of the lagoon at Rangiroa, Tikahau, and Matahiva. The sea face platform, Dana also says, is always greater than that on the lagoon side. Certainly this is not the case in a great number of the atolls in the Paumotus, Society, Fiji, and Marshall Islands, where the surface area of the lagoon flats far exceeds that of the sea face platform.

It became very evident, after we had examined a number of atolls, that the underlying ledge is the remnant of a bed of tertiary coralliferous limestone, which at one time covered the greater part of the area of the lagoon, portions of which may have been elevated to a considerable height. This limestone was gradually denuded and eroded to the level of the sea. Passages were formed on its outside edge, allowing the sea access to the inner parts of the lagoon limestone flat. This began to cut away the inner portions of the elevated limestone, forming large sounds, as in the case of Fiji atolls, and leaving finally on the weather side only a flat strip of great width, which has gradually been further eroded on the lagoon side and also on the sea face, to leave only a narrow strip of land varying in height; the material for this land has come from the disintegration of the ledge of tertiary limestone, both on the sea face and the lagoon side. There exist in the lagoons a number of small islets which also consist of outliers of this same tertiary limestone in process of disintegration and transformation to coral sand islets and bars.

The underlying ledge is not the remnant of a modern reef; its character is identical with that of the elevated limestones of Fiji, which are of Tertiary age, and the rock is in every respect the same as that I observed on many of the elevated islands of Fiji. The atoll of Rangiroa, for instance, is in a stage of denudation and erosion very similar to that of Ngele Levu, in Fiji, only in Ngele Levu the elevated limestone attains a height of about 60 feet, whereas at Rangiroa the coralliferous limestone ledge is from 12 to 14 feet high and about 40 to 50 feet wide at the top, forming on the sea face of the islands and islets of the land rim a great stone-wall more or less broken into distinct parts, a ledge consisting of elevated limestone as

1 Loc, cit., p. 300 , 
hard as calcite, full of corals, honeycombed and pitted, and undercut by the action of the waves both on the lagoon side and on the sea face, worn into countless spires and spurs and needles and blocks of all sizes and shapes, separated by deep crevasses or pot-holes, recalling a similar scene in Ngele Levu on the windward end of the lagoon. The reef flat or shore platform of many of the Paumotu atolls is strewn here and there with huge masses, outliers of the ledge of elevated reef rock, or torn from its outer edge. ${ }^{1}$ Similar rocks and boulders occur on the lagoon side of the islands, forming their outer land rim; they are either torn off from the lagoon face of the outcropping ledge, or are outlying parts of the ledge which have remained in place and have not been planed down to the base level of the reef.

The amount of water which is forced into the larger lagoons such as Rangiroa over the flats of the weather side is something colossal, and when we observe that there are often but a small number of passages through which it can find its way ont again on the leeward side, it is not surprising that we should meet with such powerful currents, seven to eight knots in several cases, sweeping out of the passages on the lee side.

The islands and islets of most of the Paumotus are fairly well covered with low trees and shrubs and large groves of cocoanut trees.

The land rims are formed by material piled up both from the lagoon side and the sea face, - material derived from the disintegration of the underlying tertiary limestone, which crops out here and there along the sea face and the inner shores of the lagoons. The islets and islands of the land rim are more or less connected by outliers of the elevated limestone ledge, attesting its greater extension in past times.

Some of the islands appear to have been formed by accretion of sand from the decomposing ledges of the lagoon. The outer land rim sometimes appears as if formed by sand banks driven in from the sea face and also driven out from the lagoon side by the action of the waves. It is evident that shallow lagoons could readily be closed by such a process and the sea no longer have access to it.

It was with great interest that we approached Makatea, as it is the only

1 I am informed that enormons outliers of elevated coralliferous limestone fully 30 feet in height occur on the south side of Kaukura. 
high elevated island of which Dana speaks as occurring in the western Paumotus. ${ }^{1}$ For though he mentions some others as possibly having been elevated five or six feet, yet he considered them all, as well as Makatea (Metia, or Aurora, of Dana), as modern elevated reefs. From the very description given by him of the character of the cliffs and of the surface of Makatea, I felt satisfied that it was composed of the same elevated coralliferous limestone so characteristic of the elevated reefs of Fiji, and which, from the evidence of the fossils and the character of the rock, both Mr. Dall and myself have been led to regard as of Tertiary age.

As we approached the island it soon became evident that it presented all the characteristics to which I had become so accustomed in Fiji, and upon landing this was found to be the case. The cliffs had the same appearance as those of Vatu Leile, Ongea, Mango, Kambara, Yangasá, and many other elevated islands of Fiji. There were fewer fossils, perhaps, but otherwise the petrographic character of the rock was identical with that of Fiji.

At Makatea we also first came upon well-defined terraces and lines of caverns at the base of the cliffs indicating the line of present action of the sea. The position of these terraces was usually more clearly seen along the face of the cliffs at prominent points, where they were undercut much as I have figured them for certain cliffs in Vatu Leile, Yangasá, Mango, Fulanga, and others in Fiji, in my report on the islands and coral reefs of that group. ${ }^{2}$

The evidence of elevation in the atolls of the western Paumotus is very definite. Makatea is an elevated mass of coralliferons limestone similar in all respects to masses like Vatu Vara, Thithia, and others in Fiji, having, like some of the Fiji elevated islands, a sink of considerable depth occupying a little more than one third the length of the island. So that it is not unnatural to look upon the area of the Paumotus, as I am inclined to do, as one of elevation, the raised and elevated land of which has been affected much in the same way, by denudation and by erosion, as have the masses of elevated coralliferous limestone of Fiji. Only there seems to have been, from the evidence thus far presented, a far greater uniformity in the height

1 Corals and Coral Islands, 3d ed., 1890, p. 193.

${ }^{2}$ Bull. M. C. Z., Vol. XXXIII, 1899; Pls. 80, 84, 92, 100. 
of the elevation of the Paumotus. This would render the explanation I have given less evident had. I not the experience of the Fiji group to guide me. Evidence of this elevation is found at the two extremities and at many intermediate points of the Paumotu plateau, at Makatea and at Niau, elevated islands consisting of tertiary coralliferous limestone, at the Gambier Islands, which are volcanic islands of considerable height (over 1300 feet), and at Henderson Island. Furthermore, as we shall see, there are other islands and atolls in the Paumotu group showing traces of this elevation, so that I am, at any rate, justified in denying that the Paumotus are situated in an area of subsidence, and that subsidence has been the great factor, as is maintained by Darwin and Dana, in the formation of the characteristic atolls of the group.

It may be well to point out also that the western part of the Paumotus, like the Marquesas on one side and the Society Islands on the other, are situated upon a plateau rising from an oceanic basin which surrounds them, with a depth of from 2300 to 2500 fathoms, the plateau itself having a dep:h of 1200 to 1500 fathoms. For the differences which distinguish the plateaus of these groups I refer to the accompanying diagrams (Figs. 1-12).

From Makatea, we visited Niau, Apataki, Tikeï, Fakarava, Anaa, Tahanea, Raroia, Takume, Taenga, Makemo, Tekokota, Hikueru, Marokau, Hao, Aki-Aki, Nukutavake, going as far east as Pinaki, when we turned westward again to Nukutipipi.

On arriving at Pinaki we decided to give up the exploration of the eastern extremity of the Paumotus, and not to make our contemplated visit to the Gambier Islands, our time having been greatly curtailed by delays at Fakarava and Makemo, from bad weather and the non-arrival of our coal supply. We therefore reluctantly turned westward again and made for the Gloucester Islands. These, as well as Hereheretue, proved most interesting; they formed, as it were, an epitome of what we had seen on a gigantic scale in the larger atolls of the western and central Paumotus. We could see at a glance in such small atolls as Nukutipipi and Anu-Anurunga the connection between structural features which, in an atoll of 40 miles in length and from 10 to 15 miles in width, it was often difficult to determine. We anchored in Fakarava and Makemo lagoons, spending a number of 
days in both these atolls. We usually timed our visits to the islands where we could not anchor so as to spend the day, or the greater part of the day, at these atolls, making our passages at night, and sounding whenever practicable on the way.

All the islands we examined are, without exception, formed of tertiary coralliferous limestone, which has been elevated to a greater or less extent above the level of the sea, and then planed down by atmospheric agencies and submarine erosion, the greatest elevation being at Makatea (about 230 feet), and at Niau, where the tertiary coralliferous limestone does not rise to a greater height than 20 feet. At Rangiroa it was 15 to 16 feet high. At other islands it could be traced only as forming the shore platform, from 50 to 250 feet wide, which forms the outer face of the Paumotus and is so characteristic a feature of the atolls of the group. In other parts the old ledge could be traced cropping up in the interior of the outer land rim, or in the open cuts connecting the lagoon with the outer sea face of the atolls. Everywhere the space between the outcroppings of the old ledge, as I will call the tertiary coralliferous limestone, was filled with beach rock, or a pudding-stone, or with a breccia or conglomerate of coralliferous material consisting in part of fragments of the old ledge, and of frigments of recent corals and shells cemented together. The appearance of the old ledge and of the modern reef rock is so strikingly different that it is very simple to distinguish the two, even where only comparatively small fragments are found.

We did not find in the Paumotus, as in Fiji, all possible stages of denudation and of submarine erosion between islands like Vatu Vara, Naiau, Kambara, Fulanga, Ongea, Oneata, Ngele Levu, Wailangilala, and atolls with a mere ring of surf to indicate their existence. In the Paumotus nearly all the islands have been elevated to a very moderate height and probably to about the same height, for the old ledge forming the base of the modern structure is found exposed nearly everywhere at about low water, when it cannot be traced at a slightly greater elevation. This would readily account for the uniform height of the islands throughout the group.

But there is another element which comes into play in this group, and has an important part in shaping the ultimate condition of these atolls. At 
the Fijis we have seen the submarine erosion continue until there is little left of many of the atolls beyond the merest islet or rock to indicate its structure. In the Paumotus, in the great atolls, which are perhaps only the exposed summits of parts of ridges or spurs of an extensive tertiary coralliferous limestone bed, the land rim of the atoll is, after having been denuded to the level of the sea, again built up from the material of its two faces, which is thrown up on the wide reef flats both from the sea face and from the lagoon side. We do not find in the Fijis, as in the Paumotus, the wide reef shelves which supply such masses of material from the breaking up of the outer and inner edges of the tertiary limestone platforms, in addition to the fragments of the recent corals growing upon the flats and their slopes, which, when dead, are thrown up on the top of the reef flats and formed into shingle and sand to form a pudding-stone, or a conglomerate, or breccia, with the fragments of the old ledge.

This pudding-stone, or beach rock, is found on all the reef flats of the islands of the group. It forms great bars, at right angles usually to the shore line, and upon the sea face of these bars is thrown up coral shingle, both old and recent, which builds up short reaches of beaches separated by wide flats through which the sea rushes at high water, or merely covers the flats at low tide; while on the lagoon side of the wide reef flats a similar process is going on, throwing up finer sand among the beach-rock bars and along their sides, and thus building up, little by little, at first small sand bars, then larger bars, or islets, at right angles to the shore line, and as they become larger by accretions from both sides, they finally form islands from 1000 to 1200 feet long, according to the width of the reef flat, extending from the lagoon edge of the flat to the ser face of the atoll. The sand bars, little by little, become covered with vegetation, and at some stages of tide appear like islands and islets situated a considerable distance within the lagoon. Whenever the material supplied both from the lagoon side and from the sea face is very abundant, the land rim becomes more or less solid, the islets become consolidated into islands, separated by narrow or wider cuts, until finally they form the larger islands which seem at first glance to form a continuous land rim along the edge of the lagoon, but which are often seen to be separated according to local conditions by narrow 
cuts, which gradually silting up finally close the gaps, and merely indicate the former separation of the various parts of the land rim.

In the lagoons of atolls of such great length as some of those of the Paumotus, like Rangiroa, Fakarava, Makemo, and Hao, which are between 30 and 40 miles long, and others of less dimensions, considerable sea rises under the prevailing trades. The sea and wind generally follow the trend of the shores, both in the lagoon and along the sea face, so that the bars of beach rock act like buttresses and collect material at their inner and outer extremities, forming the sand bars and islets which eventually become the land rim of the lagoon. When, from local causes, the material is not very abundant, or is washed out over the flats, there are fewer islands, and these are often but mere islets or bars for long reaches of the submerged land rim forming the weather faces of many of the lagoons.

Many of the lagoons are filled with shoals or ledges awash or a few feet above the sea level. These shoals are parts of the old ledge which have not as yet been eroded, and the disintegration of which has gone far to supply material from the lagoon side, for the land of the outer rims of the atolls. In the Fakarava lagoon there are no less than thirty-six islands and islets and ledges, parts of a former great flat, now broken up, once existing parallel to the outer reef flat. Similar reef flats exist in Tahanea, where they form a secondary lagoon with two to three fathoms of water, extending nearly the whole length of the western face of the atoll. There are several large islands on this flat, and at high water they would appear, as the islands and islets of Fakarava do, as disconnected and planted in the lagoon itself. A secondary lagoon also exists in Ravahere and one in Anaa; in both these atolls the reef flat extends across one extremity of the lagoon, and does not run parallel to the longer line of the land rim of the atoll.

The lagoons of these atolls have a general depth of 13 to 20 fathoms. In some cases they are somewhat deeper; some of the greater depths, to 30 fathoms or more, are probably due to orogenic conditions. Some of the lagoons are quite shallow, as at Matahiva, as well as Pinaki, where they are not more than two to three fathoms, and Takume, where it is 
from five to six fathoms deep. Some of the smaller islets we visited, among which are Tikeï, Aki-Aki, and Nukutavake, have no lagoons. The former has a small shallow sink in which fresh water collects, but the rim is only very slightly higher than the interior. The last two islands are apparently depressed in the centre, three to four feet below the outer bank of sand which forms the rim (about 10 to 12 feet high) of the basin of the island; I was at first inclined to look upon them as examples of islands which had been cut down to the level of the sea and subsequently been built up by beach rock and sand in the manner described above. The existence of extensive sand dunes on two sides of the island at Pinaki, and of lạge dunes (estimated to be 35 feet high) on the south shore of Nukutavake, seems to indicate the possibility of there having been a shallow lagoon occupying the centre of Aki-Aki and of Nukutavake, and that these lagoons were gradually filled by the sand dunes, much as Pinaki is filling now.

At Pinaki, as at other atolls and islets to the eastward, there are fewer large trees than on the western atolls, the vegetation consisting in great part of pandanus and putu trees and the usual coral-reef vegetation of the Paumotus ${ }^{1}$ and Fijis.

The only atoll we have seen in the Paumotus the lagoon of which is entirely shut off from the sea is Niau. In this case the old ledge forming the land rim which surrounds the nearly circular lagoon is about a third of a mile in width and sufficiently high, 15 to 20 feet, to prevent any sea from having access to it except in case of a cyclone, as that of 1878, when the sea washed into the lagroon. The lagoon is shallow, of an average depth of about three fathoms, the deeper parts perhaps five. The sea, however, undoubtedly finds its way into the lagoon through the cavernous rim.

Dana, and other writers on coral reefs, mention a great number of lagoons as being absolutely shut off from the sea. I take it these statements are due to their descriptions being taken from charts, many of which, as in the case of the Paumotus, are very defective. For nothing is easier than to pass unnoticed even at a short distance the wide or narrow cuts which allow in so many cases the freest access to the sea to 
the interior of the lagoon, and yet are described as closed because they have no boat passages. I could mention, as instances of such lagoons, those of the atolls of Takume, Hikueru, Anaa, etc., or the weather faces of many atolls which may be said to be closed, yet into which a huge volume of water is poured at every tide over low parts of the encircling reef flats.

When Dana speaks of there being no entrance to a lagoon, it merely means that no boats can pass the reef flats; it does not mean that the water in the lagoon is not constantly replaced from the outside sea rushing over the low sea reef flats or denuded parts of the reef platform. Dana ${ }^{1}$ says Margaret (Nukutipipi) has no entrance, but the reef flat is low and submerged on the east side, allowing full access of the sea to the lagoon. He also says ${ }^{2}$ Taiaro has no entrance; there is one. Having thus assumed the non-existence of openings to many atolls, - Anu-Anurunga, Honden (Puka-Puka), and others, - he bases upon their absence a number of theoretical considerations regarding the elosing of lagoons, ${ }^{3}$ which naturally fall to the ground now that the existence of passages has been proved.

The large number of flat-topped or slightly dished elevated islands of coralliferous limestone like Niue, Makatea, Henderson Island, Tongatábu, Vavau, Guam, Vatu Vara, and others in Fiji and elsewhere, seem to indicate a gradation between those which are nearly flat-topped, like Niue and Henderson and Guam, to others like Makatea and Eua, which are dished or gouged by valleys, and to such islands as are so deeply dished as to appear like elevated atolls, as Mango, Kambara, Naiau, and others.

As I have already called attention in my Report on the Fiji Reefs, ${ }^{4}$ we have in the Lau group all the gradations between the so-called elevated atolls and such atolls as Fulanga, Yangasa, and others, in which the uplifted limestones are reduced to diminutive islets which represent all that remains of an uplifted limestone plateau. Naiau (in Fiji) would soon pass into the condition of a ring composed of limestone islets were the sea to find access to its sink by breaking through the land rim. We might in that case have on a small scale an atoll like Rangiroa, in which what is left of the original elevated limestone plateau would be reduced to a low wall on the weather 

SECTION MARQLESAS CAPE MLARTIN TO RANGIROA PACMOTLS

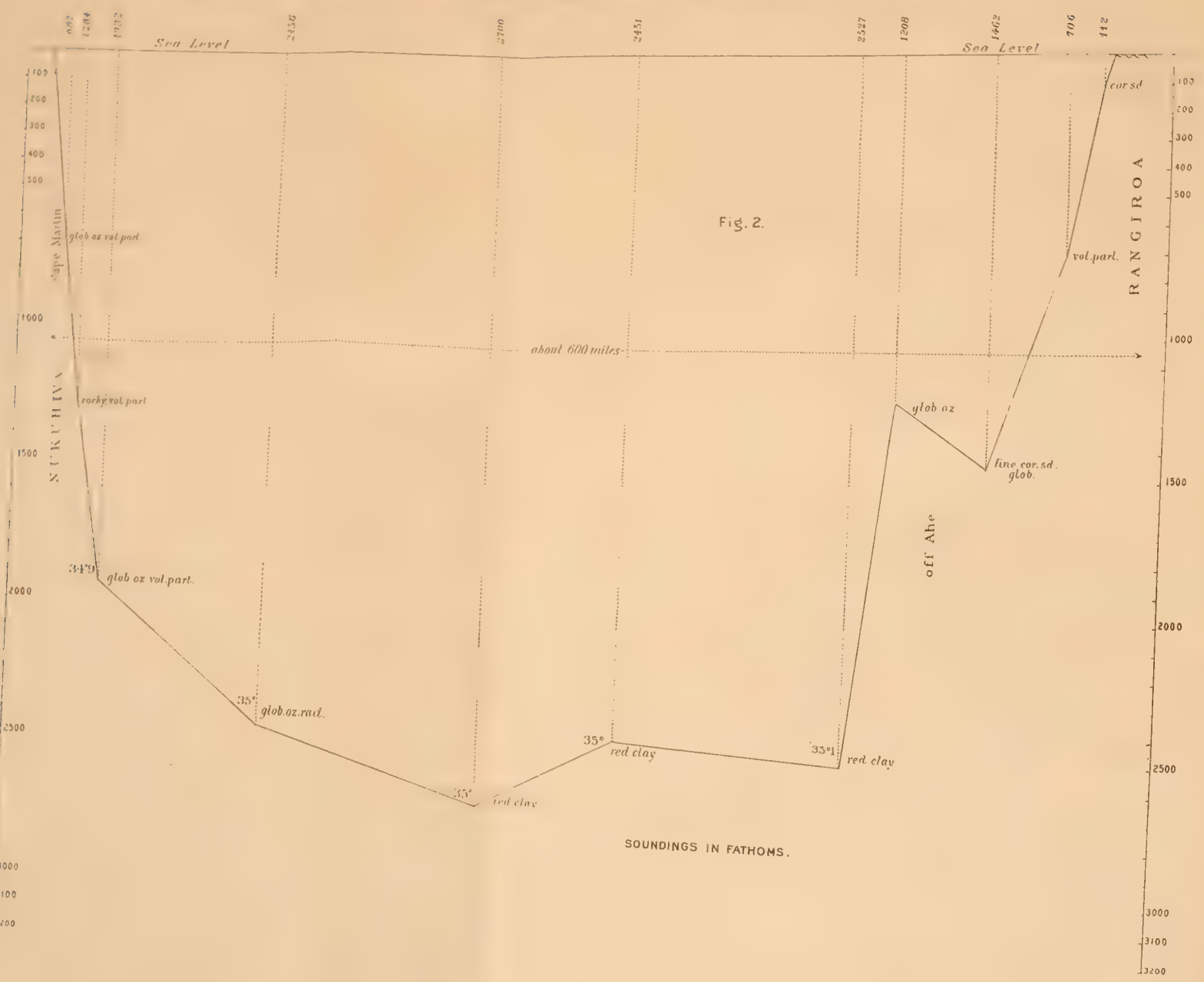




side, and to outliers of the elevated coralliferous limestone exposed in the gaps of the land rim on the lee face of the atoll. The lagoon of Rangiroa represents a huge sound, the marginal land rim of which has been denuded and eroded to attain its present condition.

In all elevated coralliferous limestone islands it is difficult to determine if their sink is the remnant of a former lagoon of the island, or of a sound formed during its elevation, or if it has been formed by the action of rain and atmospheric agencies. The amount of denudation and erosion to which some islands have been subjected is very great, as is clearly indicated by the small cañons, pinnacles, spires, and walls of limestone, as well as crevasses which occur in all directions over the surface of the basin or sink. The extent to which this action has penetrated into the mass of the island is plainly shown by the great number of caverns which crop out along the sea face of the cliffs of elevated islands. Some of the caverns are of great lengtl, and extend as long galleries far into the interior of the island. It is of course difficult, in the face of this extensive denudation and erosion, to state positively what may be part of the ancient lagoon, or sound, and what has been carried away by atmospheric and other agencies since the elevation of the island.

\section{The Paumotu Plateau.}

Plates 201, 234, and Figs. 1-12.

Between the Marquesas and the northwestern extremity of the Paumotus (Fig. 2) we occupied nine stations; close to the Marquesas the depth was over 1900 fathoins, the greatest depth on that line being 2700 fathoms at Station 31 , in lat. $12^{\circ} 20^{\prime} \mathrm{S}$., and long. $144^{\circ} 15^{\prime} \mathrm{W}$. The depths varied between 2451 and 2527 fathoms, and diminished to 1208 fathoms off the west end of Ahe, and then to 706 fathoms when about sixteen miles N. E. off Avatoru Pass in Rangiroa atoll.

We developed to a certain extent the width of the Paumotu plateau by a line of soundings in continuation of the direction of Avatoru Pass, extending a little less than nine miles seaward, where we obtained a depth of 819 fathoms. Subsequently we ran a similar line normal to the south shore 
of the lagoon of Rangiroa, a distance of nearly twelve miles, into 897 fathoms (Fig. 3); this seems to be the depth of the western part of the Paumotu plateau.

Between Rangiroa and Tikahau, the next atoll to the westward, we obtained a depth of 664 fathoms.

Between Tikahau and Matahiva six soundings were made, with a depth of 488 fathoms half a mile from shore, and a greatest depth of 850 fathoms six and a half miles from Tikahau. The slope approaching Matahiva is steeper than the Tikahau slope (Fig. 5).

From Matahiva to Makatea (Aurora) Island, we made six soundings: from 624 fathoms about two and a half miles off shore to 581 fathoms about one and one-eighth miles off the west side of the latter island, the depths passing to $860,1257,1762$, and the greatest depth being 2267 fathoms, then 2247, and rising more rapidly near Makatea to 581 fathoms (Pl. 201).

Between Makatea and Tahiti we made eight soundings, beginning with 1363 fathoms, two miles off the southern end of Makatea, passing to 2238, 2363 (the greatest depth on that line), to $2224,1930,1585,775$, and finally 867 fathons off Point Venus (Fig. 7).

The soundings from Makatea to Niau (PI. 201 and Fig. 8) indicate that Makatea is an isolated peak rising from great depths and separated from the Paumotu plateau, as we find 2238 fathoms in the direction of Tahiti, 2268 fathoms in the direction of the Niau plateau, and 2267 fathoms towards Matahiva.

A line from Niau to the north of Apataki gave us a greatest depth of 677 fathoms between Niau and the southern face of Apataki, while to the north of Apataki the Paumotu plateau drops off rapidly to over 1300 fathoms (Fig. 8).

Judgring from the soundings to the east of the line from Niau to Apataki, on the eastern extension of the Paumotu plateau are probably situated Fakarava, Kauehi (Fig. 4), Tahanea, Makemo, and Taenga (Fig. 6). Anaa stands upon an isolated ridge separated by over 1700 fathoms from 'Tahanea, and by 1531 from Fakarava (Figs. 4, 9); Raroia and Takume rise from the same plateau (Fig. 6), but are separated from the eastern part of the Paumotu plateau (Taenga) by more than 1500 fathoms. 
"albatross"Tropical pacific Ex.

ANAA TO ISAUEHI

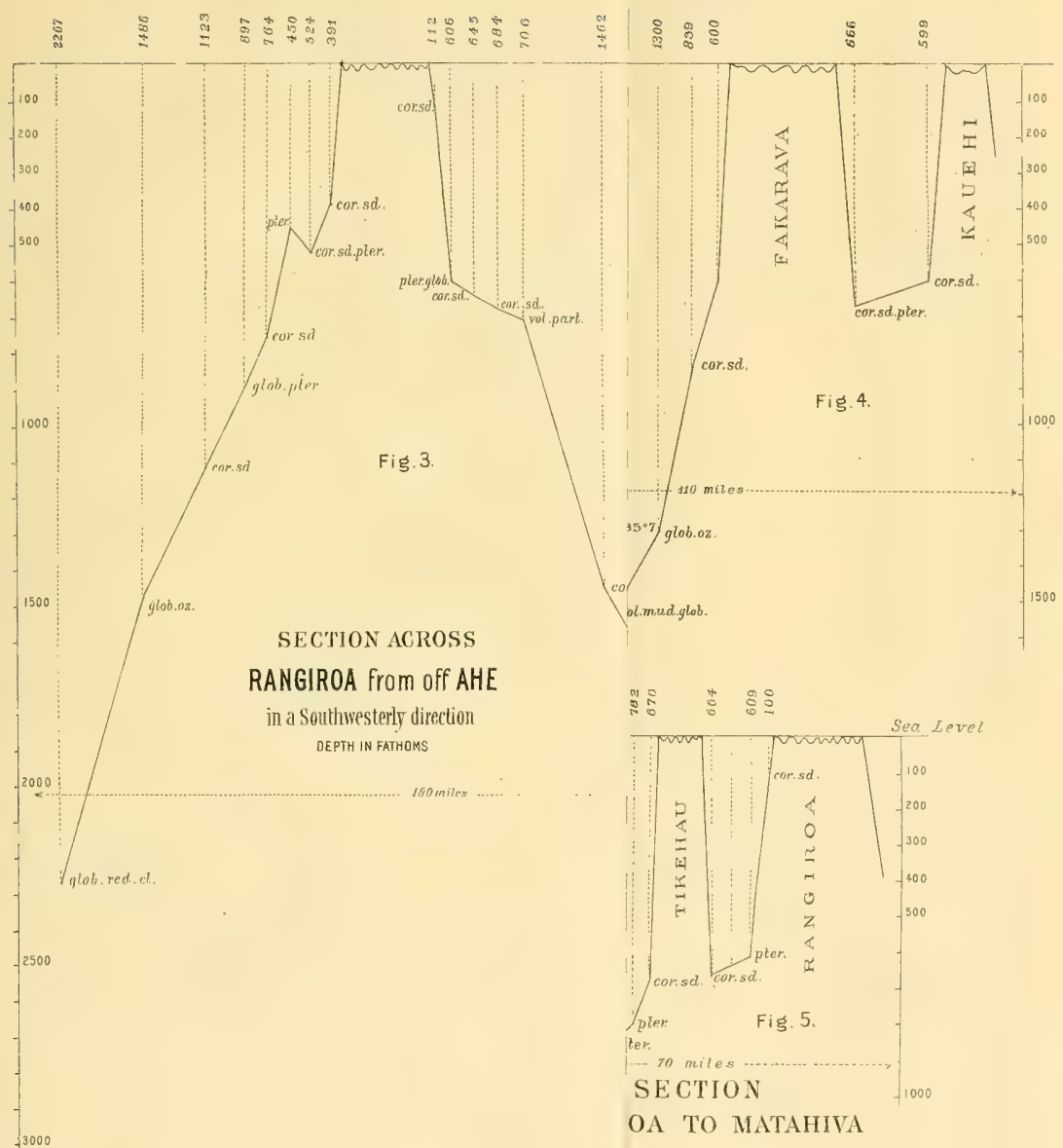



"Albatross"Tropical Pacific Ex.

SECTION ANAA TO IIAEHI

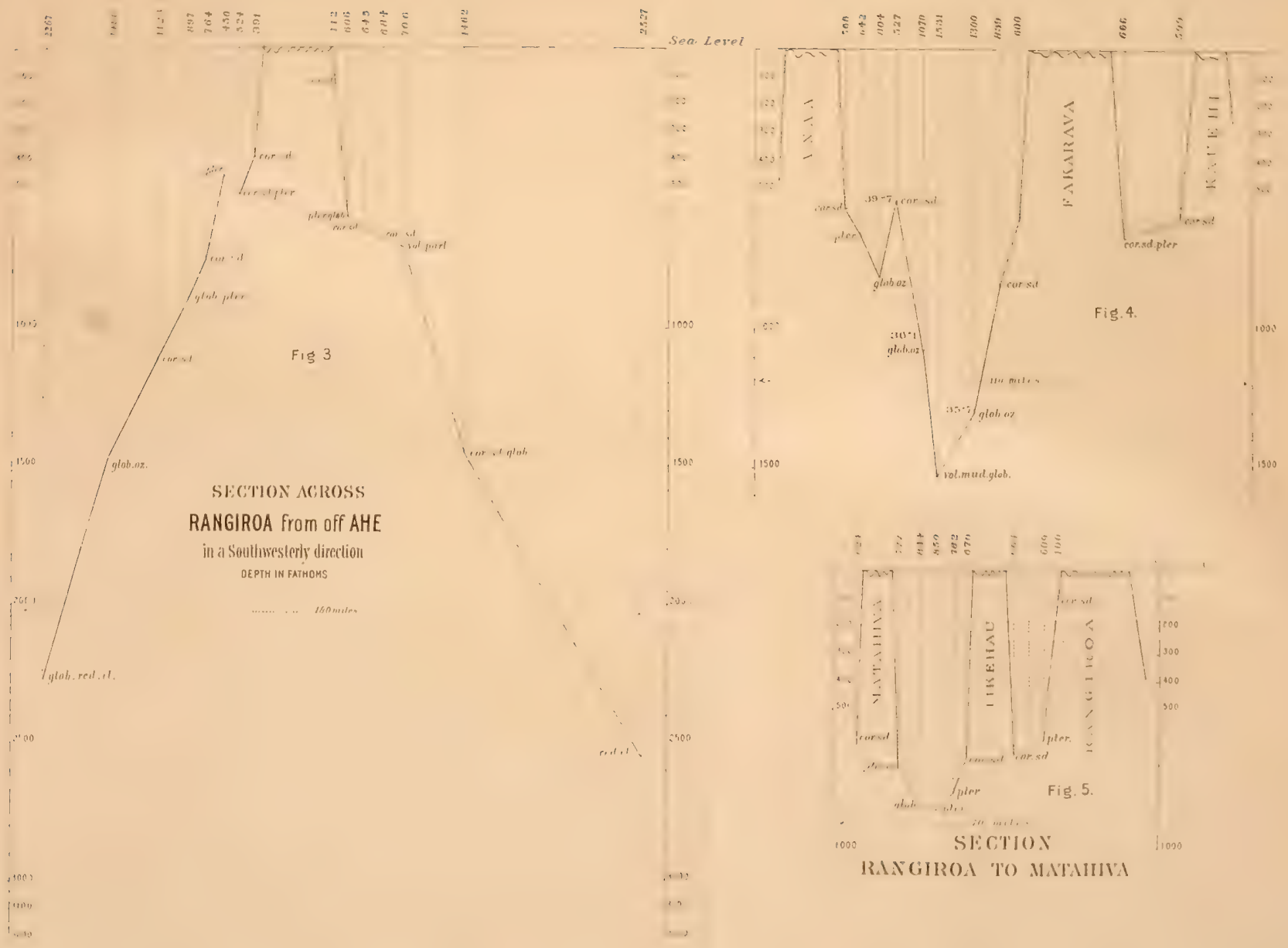




"Albatross"Tropical Pacific Ex.

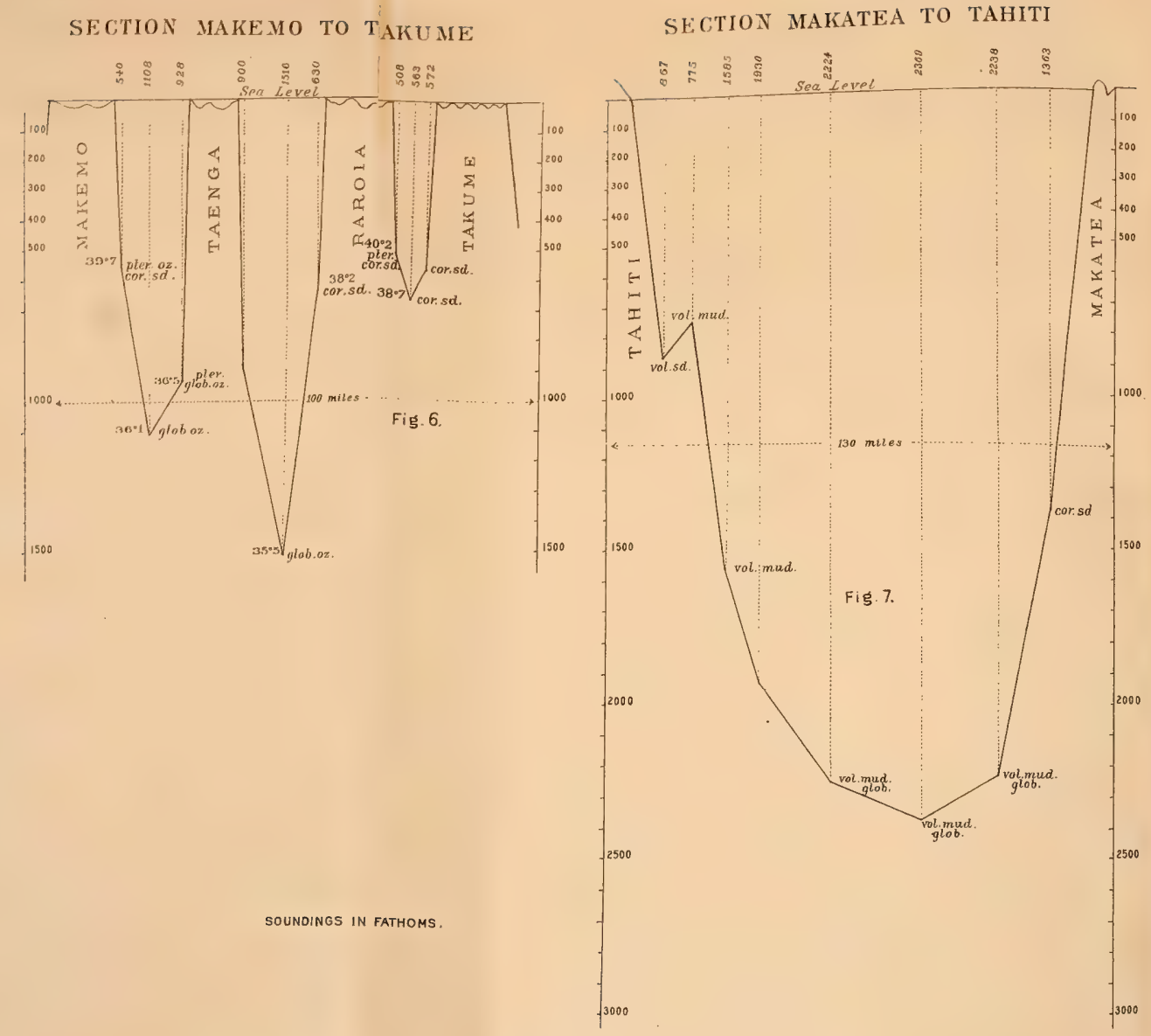




To the eastward of Makemo our soundings indicate (P1. 201 and Fig. 10) a gradual increase in depth. Makemo and Neérou are separated by a channel with a depth of 1221 fathoms. We find about the same depth between Neérou and Tekokota, which with Hikueru seem to be on a shallower ridge with not more than 1009 fathoms. Between Hikueru and Marokau the depth increases to 1620 fathoms; between the latter and Hao it has increased to nearly 2200 fathoms. It is again over 2100 fathoms between Hao and Aki-Aki, and over 2300 fathoms between Aki-Aki and Nukutavake. The latter, with Pinaki, are upon a distinct plateau with a depth of less than 900 fathoms. So that we may state that east of Hao the different atolls of the Paumotus rise independently, and are separated by channels of considerable depths which are gradually becoming greater as we go farther east (Pls. 201-203).

From Pinaki to Nukutipipi (Fig. 11), crossing the deep channel which runs parallel to the general trend of the Paumotus, we find a greatest depth of 2467 fathoms, and reach the area of red clay again.

Finally, on the line from Nukutipipi towards Mehetia (Pl. 201 and Fig. 12) we find steep slopes between the atolls, a depth of 1609 fathoms separates Nukutipipi and Anu-Anurunga, 1890 fathoms is found between the latter and Anu-Anuraro, and a stretch of red clay exists between it and Hereheretue in 2524 fathoms. The area of the red clay extends towards Mehetix, the deepest sounding towards that island being over 2400 fathoms.

In the Paumotus the islands from Hao to Matahiva trend in a general way from southeast to northwest. But the islands to the north of a line from Rangiroa to Makemo, except Apataki, run at right angles to that line. They are Takaroa, Takapoto, Manihi, Ahe, Raroia, Takume, Fakaina, and a number of the outlying islands to the eastwaird, as Amanu, Tatakoto. The islands of Nakutavake, Vahitahi, and Tatakoto run in a northeasterly direction, while others, like Reao, Puka-ruha, and Marutea, run again from southeast to northwest.

There thus seem to be traceable a number of lines of upheaval in the group. Off Rangiroa, at right angles to its trend, run Ahe and Manihi. A second line at right angles to Apataki consists of Takapoto and Takaroa. A third line off Makemo is formed by Raroia and Takume. While the out- 
lying islands of Tatakoto and Fakaina run in the same direction as Amanu off IIao, Nukutavake has the same northeasterly trend, as well as Marutea morth of the Manga Reva group, while the atolls of Hereheretue, AnuAnurunga, and Anu-Anuraro are on a lime parallel to the principal trend of the Paumotus from southeast to northwest. The soundings show Hereheretue to be an independent peak isolated from the Duke of Gloncester group, which may be said to rise from a connecting ridge of nearly 1900 fathoms surrounded by depths of more than 2500 fathoms.

We made more than one hundred and fifty soundings through the Paumotus and their approaches. These have shown in a general way that the western islands are probably all on a great plateau connected perhaps by the 800 fathom line; that such islands as Anaa may be on spurs or independent smaller plateaux, separated from the main plateau by somewhat deeper water; the same may be the condition of Raroia and Takume, and of Hao and Amanu, while such smaller and isolated islands as Tikei, Aki-Aki, Nukutavake and Pinaki, as well as the Gloucester Islands, rise from greater depths and are isolated peaks. At any rate, these soundings indicate, as do the soundings off the Fijis, that atolls do not necessarily rise from very great depths, and that in this characteristic atoll district, atolls are found, with steep slopes, it is true, but rising from moderate depths. The slopes of these atolls would probably resemble in every respect the slopes of the elevated coralliferous limestone islands characteristic of the Lau group in Fiji, where they have not been obliterated by erosion, denudation, and atmospheric agencies.

The deepest sounding among the Paumotus was on the line to the northward of Hereheretue in the direction of Mehetia, where we found a depth of 2524 fathoms, and a continuation of the red clay characterizing the soundings since we left Pinaki. In nearly all the soundings among the Paumotus, even at moderate depths not far from the atolls, we brought up manganese particles or small manganese nodules. The last haul, made in deep water on the way from Hereheretue to Mehetia in 2440 fathoms, brought at least half a ton of manganese nodules, the bottom being red clay.

We steamed about 2500 miles among the Paumotus, and although we had not the advantage of the accurate surveys of the English Hydrographic charts, which made the exploration of Fiji so easy, yet from the structure of 
"Albatross"tropical Pacifi

\section{TO APATAKI}

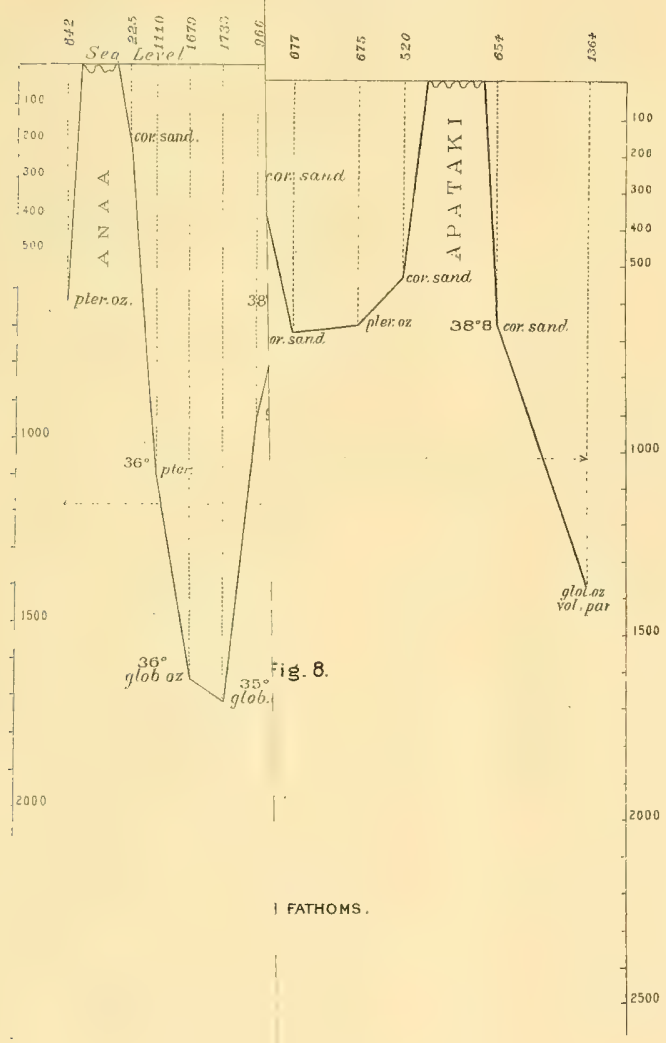



Albatross" Tropical PaCific EX.

SECTON AXAA TO TAKUNE

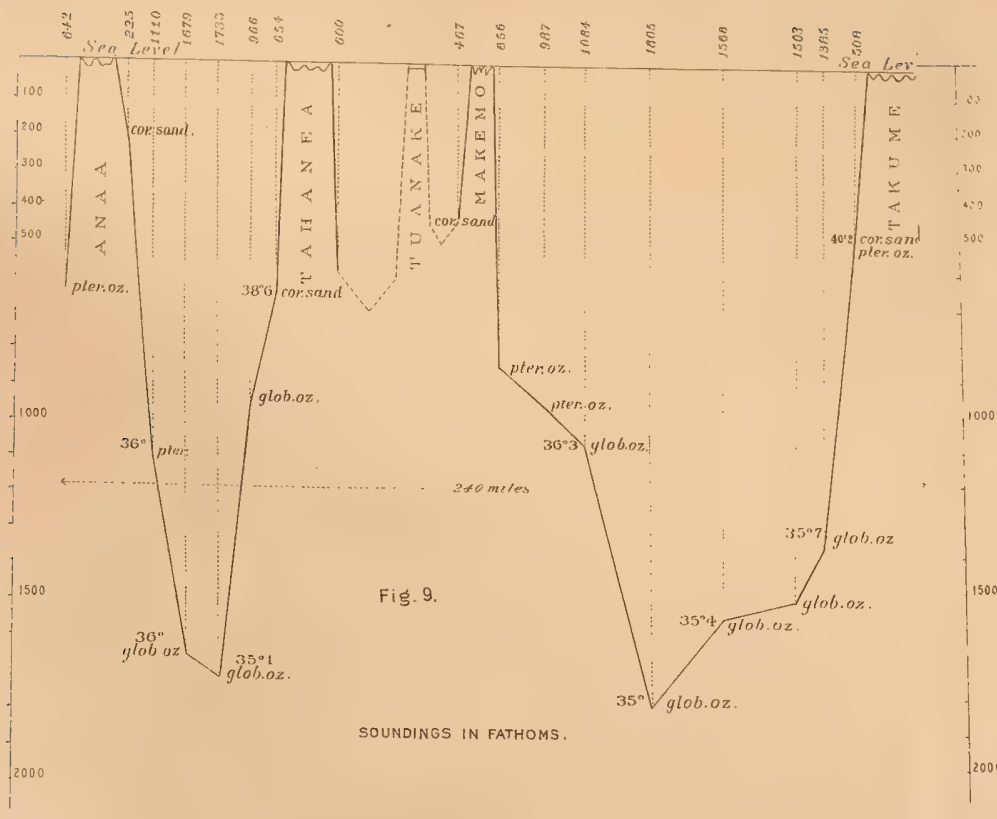

SI:CTOX MALATEA TO APATAKI

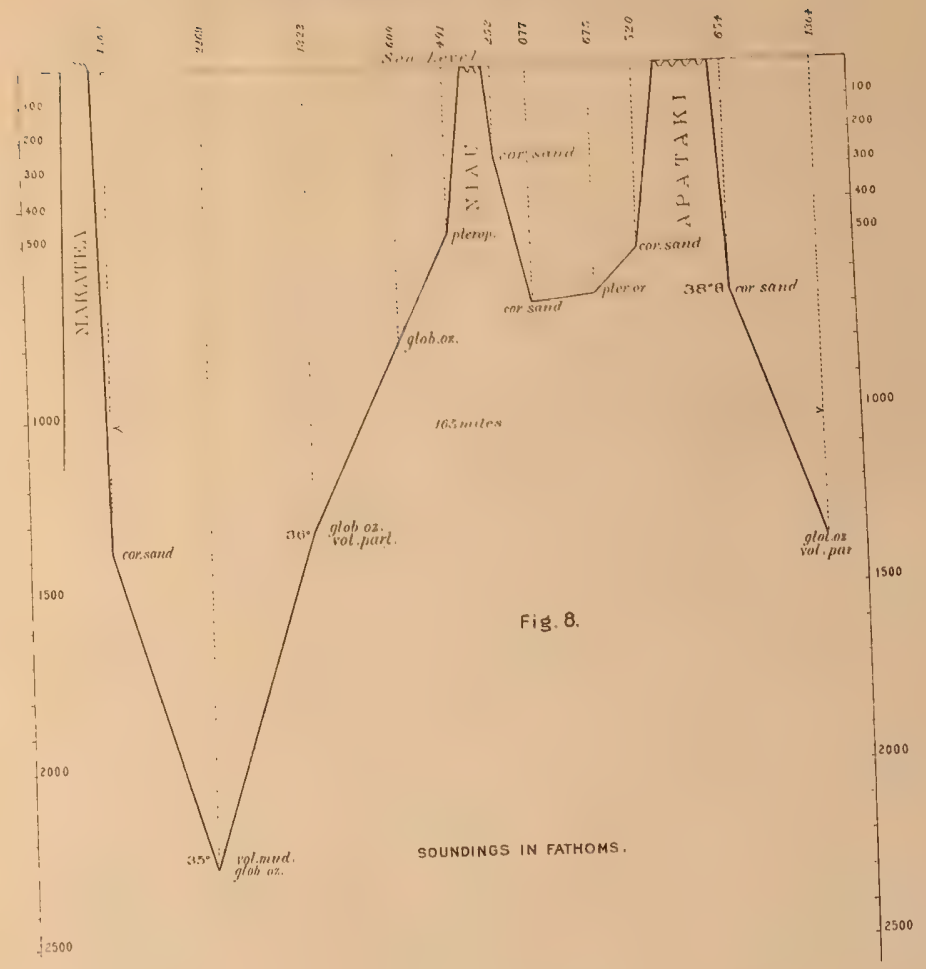




"Albatross" Tropical Pacific Ex.

SECTION MAIKENO TO PINATA

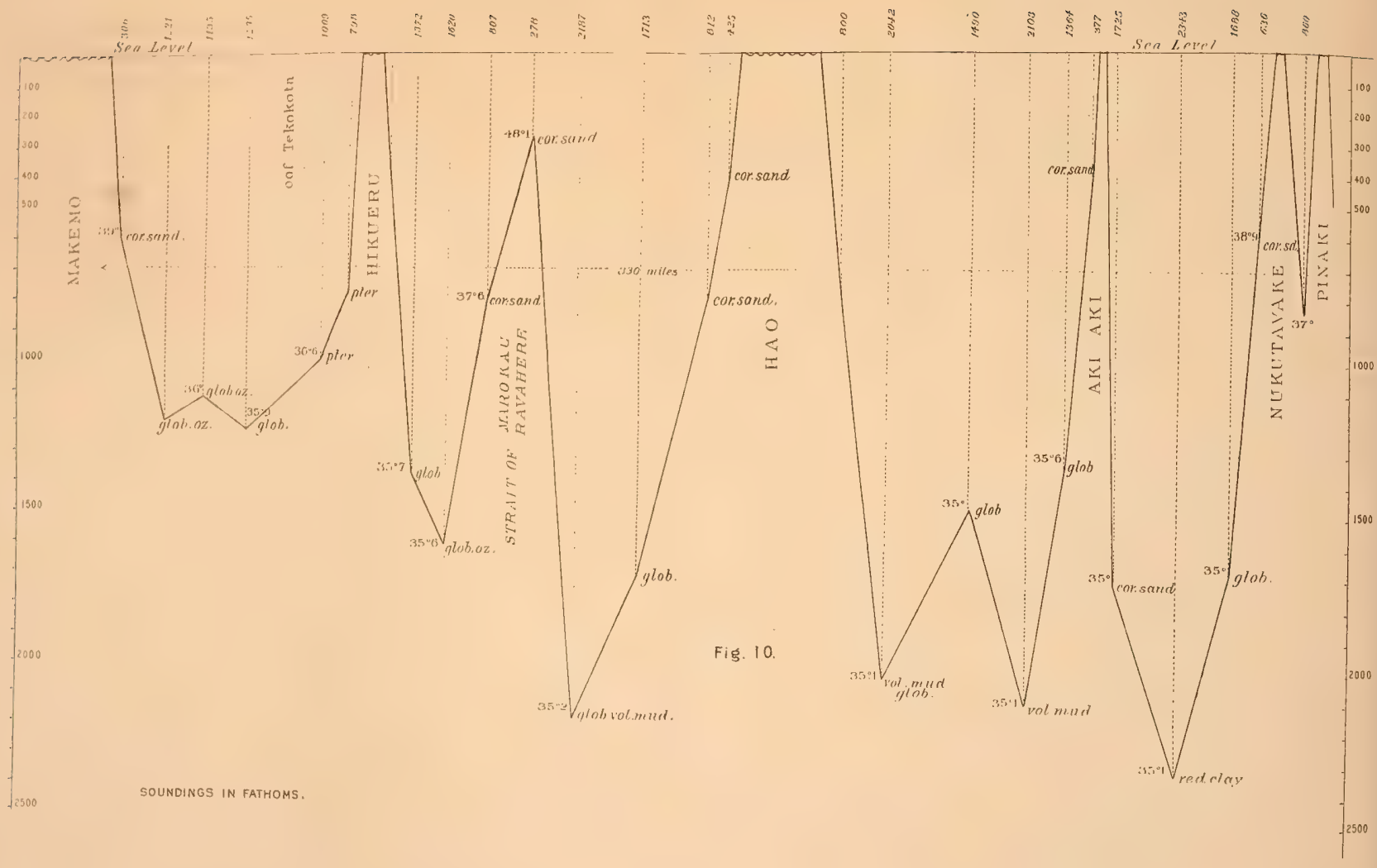




these atolls it was a comparatively simple task to get a fairly good idea of them. We have seen nothing in this more extended examination of the group tending to show that there has anywhere been subsidence. On the contrary, the existing condition of the atolls of the Paumotus cinnot, it seems to me, be explained on any other theory except that they have been formed in an area of elevation extending from Matahiva on the west to Pinaki in the east, and from the Gloucester Islands on the south to Tikei on the north, although the islands in the line of Manga Reva to Tahiti are separated from the other Paumotus by a deep channel, nearly 200 miles wide and more than 2400 fathoms in depth, with scattered islets and atolls extending from Manga Reva to Pinaki, and northward to Pukaruha and islands beyond, which are not connected with the extensive plateau upon which the greater number of the Paumotu Islands to the westward of Hao rise.

The character of the reef corals of the Paumotus is very different from that of other coral reef regions I have seen. Nowhere have I seen such a small number of genera, so many small species, and such stunted development of the corals. The outer reefs in from 3 to 15 fathoms of water are composed almost entirely of dense masses of Astræans, Pavonia, and of several species of Madrepora and of Pocillipora.

A yellowish green nodular species of Millepora is very common between the surface and three fathoms. On the shallow reef flats are found the following corals arranged in the order of the frequency of their occurrence,several species of Madrepora, Porites, Goniastræa, Astræa, Pocillipora, Alveopora, Fungia, Mussa ; no Mrandrinæ were found, and, what is specially noteworthy, no huge heads of any of the species of corals mentioned above are to be seen. This is in striking contrast to the colossal masses of so many species of corals which characterize the physiognomy of the Great Barrier Reef of Australia and of the West Indian region. The general absence of the large fleshy Alcyonaria of Australia is very marked in the Paumotus, so far as our experience shows, and there are but few Sponges to be found among the corals. Gorgonians and the like are also infrequent, coming up only in our trawl hauls. Plexaura was found on a shallow reef flat in the lagoon of Makemo, where Allopora is quite common in from 12 to 
13 fathoms. Tubipora was brought up from deep water (742 fathoms) off Marokau Island. The bathymetrical limit of the reef-building corals seems to be about 20 to 22 fathoms.

Nowhere have I seen such extraordinary development of incrusting Nullipores as on the sea edge of the shore platforms of some of the Paumotu atolls, where they build up to a height often of four feet to form the outer edge of what may be called a secondary barrier reef so frequently seen along the sea reef faces of the Paumotus. Incrustation by Nullipores gives the reef platform a decided peach or pinkish or orange red tint in addition to that of the patches of Pocillipora growing upon the very edge of the platforms. ${ }^{1}$ The whole platform thus has a very decided hue, but most marked and brilliant on the raised edge of the sea face.

The Tridacnas of the Paumotus are not more than six to eighteen inches in length, - dwarfs compared to the giant species of the Queensland coast. It is only when we come as far west as the Gilbert Islands that we again strike the giant Tridacna, which has a special value to the natives of the groups adjoining the Gilberts. They use the thick part of the shell near the hinge to make mat-beaters, and the harder and tougher parts of the curved part of the shells they shape into axes and knives.

But little seems to be known regarding the reproduction of the pearl oyster, and thus far all attempts at planting and artificial reproduction or regulation of fisheries have proved unsuccessful. Certain islands are after the lapse of a couple of years thrown open again to pearl-divers, and this close season has thus far proved successful in checking the destruction of the pearl by overfishing. But a single season like the present one at Hikueru, where the greater part of the fishing population of the Paumotus is assembled within such narrow limits as the Hikueru atoll to collect pearl shells, must be a great strain on its productive capacity.

On pearl shells said by the natives to be six years old we found growing stems of a species of Madrepora and one of Allopora, each fully eight inches in length.

The Echinoderms we collected in the Paumotus all belong to genera and species having a wide geographical range, the majority extending from the

1 See Dana's description of this on the Ahe platform, loc. cit., p. 201. 
"Albatross "Tropical Pacific Ex.

SECTION NUIIUTI

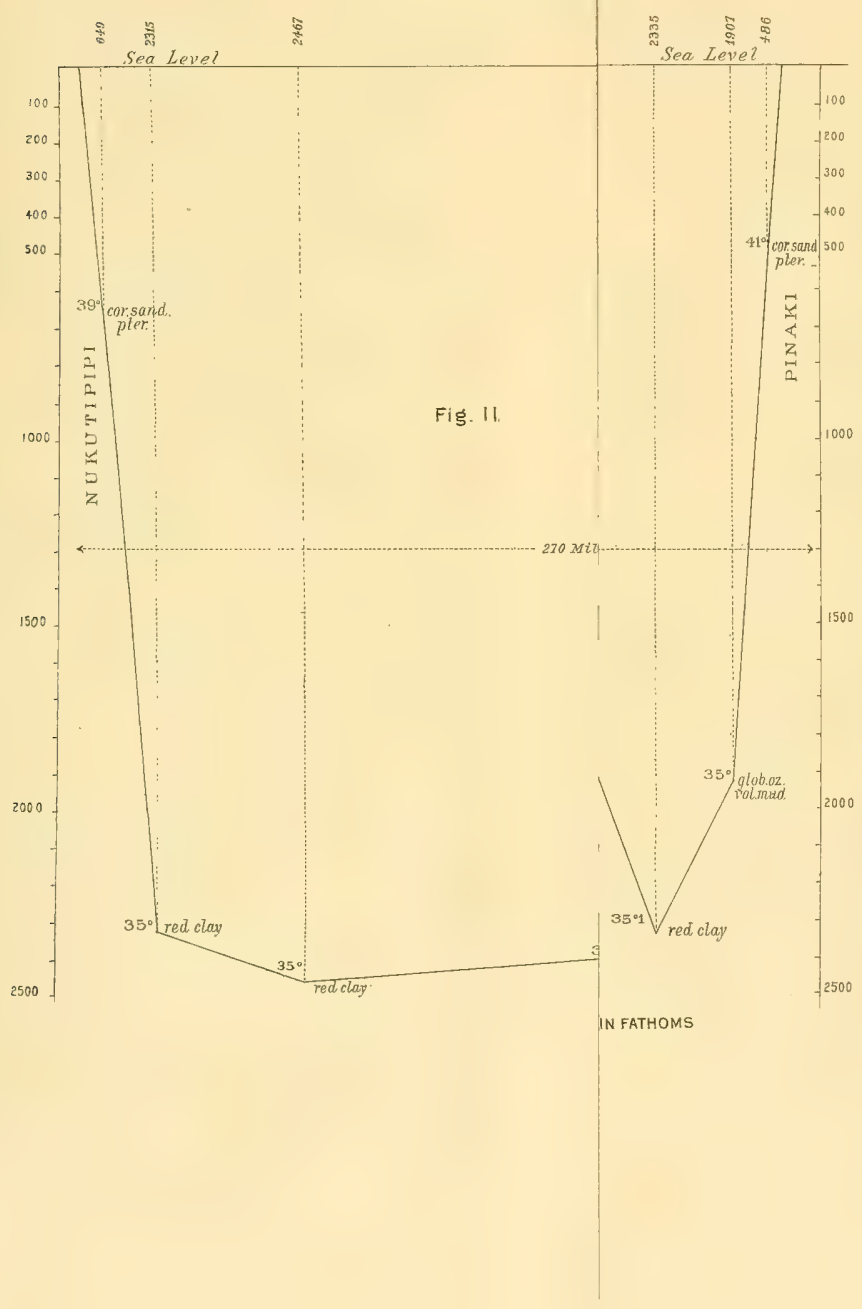



"Albatross"Tropical Pacific EX.

SECTIOA NUKUTIPIPI TO PINAKI

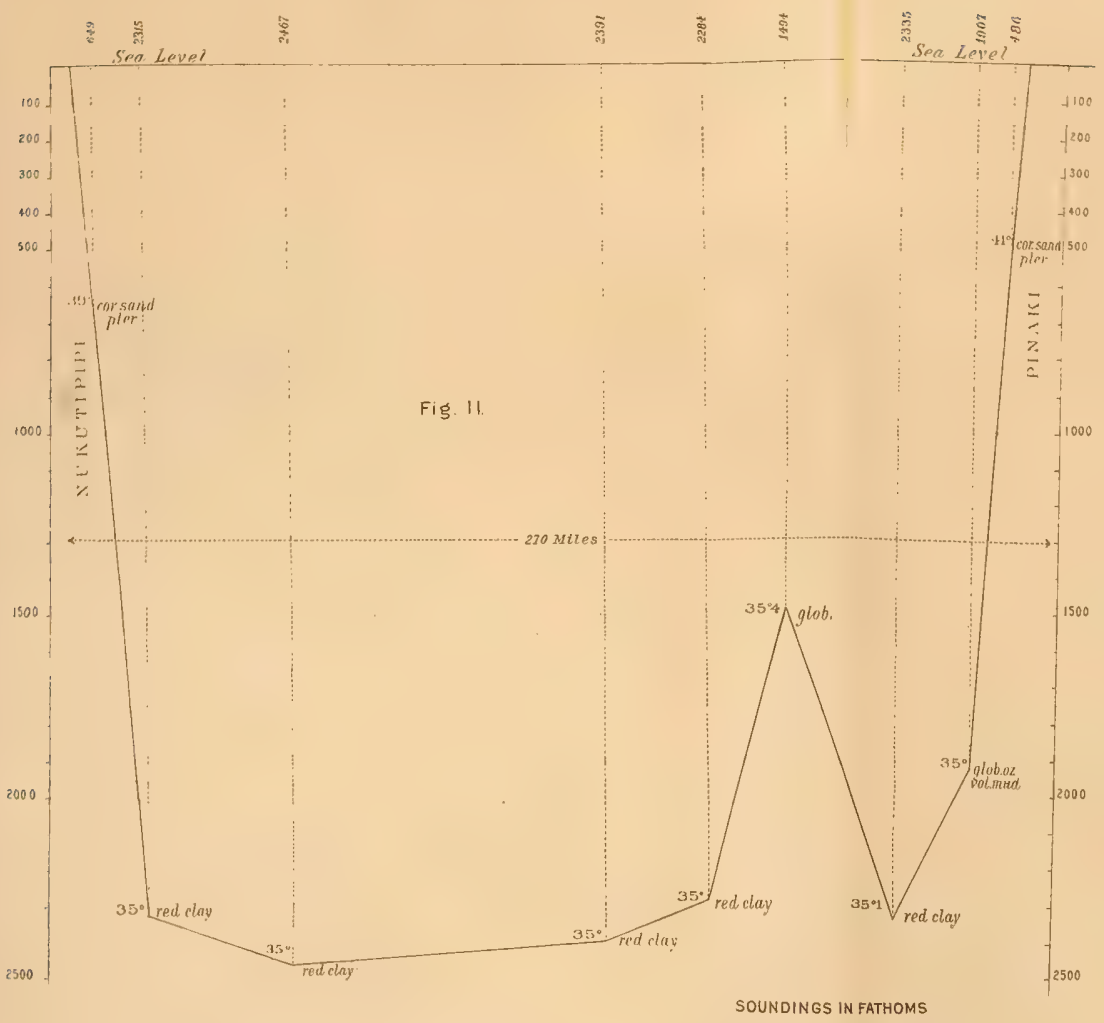






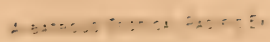

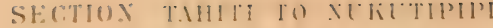

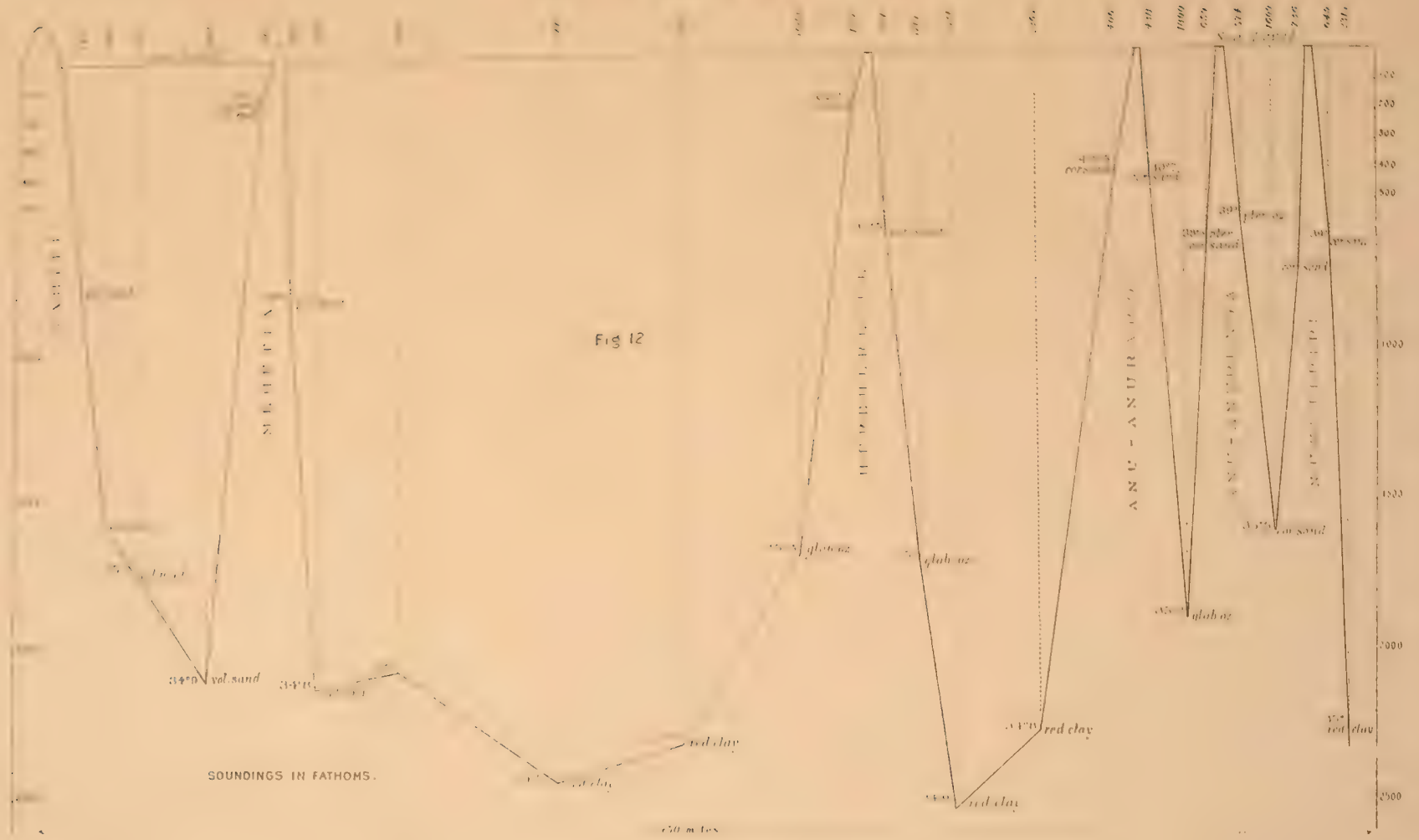




Paumotus to Australia, to the East Indies, and even farther to the west, to the east coast of Africa. Among the genera we collected were Parasalenia, Metalia, Heterocentrotus, Echinometra, Echinaster, Culcita, and other genera having a very general distribution in the tropical Pacific.

Of birds the number of species is also small; a babbler, a pigeon, a curlew, snipe, a small parroquet, a kingfisher, are the principal types, in addition to the terns, boobies, frigate birds, petrels, and tropic birds, all of which spread over the Pacific.

The Large Birgus (cocoanut-tree crab) is abundant on some of the islands of the Paumotus.

As far as we observed, the temperature of the lagoons at the surface is identical with that of the sea outside of the atolls, and at a depth of about 500 fathoms a temperature of $40^{\circ} \mathrm{F}$. was recorded.

We made a number of surface hauls, as well as intermediate hauls with the tow-nets, but obtained very little animal life in the Paumotus. The poverty of the surface pelagic life and down to 300 fathoms is remarkable. I do not think I have ever sailed over so extensive an area as that of the Paumotus and observed so little surface life; on calm days, under the most favorable conditions, nothing could be seen with the naked eye, and at night there was little or no phosphorescence. Inside of the lagoons our hauls were equally barren.

The same paucity of animal life seemed to extend to the deep-water fauna. All the hauls we made off the islands, in from 600 to 1000 fathoms, usually the most productive area of a sea slope, brought nothing, or so little that we came to grudge the time spent in trawling on the bottom, as well as towing on the surface or near it, - a great contrast to the conditions in the Atlantic in similar latitudes, and very different from our anticipations.

For these reasons we did not attempt to make a trial of the deep-sea pump while in such unproductive areas; and unfortunately while we were in the region of the equatorial currents the weather conditions were not suited for a trial of the apparatus.

The vegetation of the land rim is composed entirely of small trees and low bushes, and it is only on the larger islands that they lave been cleared and cocoanut trees have been planted in their place. 
An atoll like Rangiroa, and similar islands in the Paumotus, supplies an abundance of food for the few natives living upon it. In fact, there are not enough natives in the group to collect the copra and prepare it for export.

The occurrence of young cocoanut trees on the isolated islets and bars formed on the weather side of the reef flats of many of the atolls would seem to indicate that cocoanuts can be carried a great distance and take root. Though Dana, while acknowledging that the cocoanut is well adapted for marine transportation, ${ }^{1}$ is of the opinion that "there is no known evidence that an island never inhabited has been found supplied with cocoanut trees," yet it is also evident that some of the atolls of the Paumotus and Marshall Islands as well as other regions are sufficiently near and so placed with reference to the favorable transportation of cocoanuts by the trades, that it seems most probable that the cocoanuts have been successfully transported by the ocean from one atoll to another. So that cocoanuts probably do not form an exception to the extensive transportation by marine agencies of the many plants which characterize the scanty vegetation of the Paumotus and other Pacific islands, - vegetation which becomes more luxuriant in proportion as we go west.

Dana $^{2}$ has already called attention to the small number of plants which characterize the Paumotus; the two most characteristic trees and shrubs being a Pisonia and a Scævola, a fleshy plant with large leaves which grows well on the sea face of the atolls in the poorest coral soil and exposed to the full strength of the winds, and usually forms the outer belt of protective vegetation of the plantations. Mangroves do not play an important part in the vegetation of the Paumotus.

1 Loc. cit., p. 327.

${ }^{2}$ A list of the principal plants has been given by Dana (loc. cit., p. 326), " not more than twenty. eight to thirty species." 


\section{Rangiroa.}

Plates 4-19, 201, 202 ; 204, figs. 3, 4; 205, fig. 3; and Figs. 2, 3, 5.

After striking the we made for Rangiroa, skirting the northern shore. Rangiroa $^{1}$ is somewhat pear-shaped (Pls. 201, 202; 204, fig. 4). Its broadest part is towards the northwestern face. The northern land rim is thickly wooded. The irregular arc forming the southern face of the atoll is edged by the great wall of elevated reef rock; there are but few islets and islands on the sea face of the wide reef platform, which extends far into the lagoon.

About five miles east of Tiputa Entrance (Pl. 204, fig. 3) there are masses of large coral rocks and boulders ${ }^{2}$ at the foot of the high sand beach, which cover the shore platform for a considerable distance. Steaming parallel with the shore, we find these reaches of boulders alternate with clear flats of the shore platform. This is about 250 to 500 feet in width from the base of the steep coral sand beach, which varies in height from 8 to 15 feet. Occasionally the outer platform can be seen to extend in towards the lagoon and to form a shallow pass from it to the outer sea across the narrow land rim forming the northern side of the Rangiroa atoll. The northern land rim is well wooded with masses of shrubs and low trees, and with tall cocoanut trees rising to a height of from 25 to 40 feet.

At Tiputa Pass we obtained our first glance into one of the large Paumotu atolls. The entrance is a little over a cable length wide (Pl. 204, fig. 3), and a strong current flows out during ebb tide, running, it is said, from seven to eight knots per hour. 'The outward flow is regulated by the strength of the trades; if they force much water over the weather side of the reef, it continues sometimes to flow out for several days in succession. On the interior of the western side of the pass a couple of small islands ( $\mathrm{Pl}$. 204, fig. 3), Nui Nui, extend, of which the base is, as we shall see, made up of tertiary coralliferous limestone covered over in part with recent stratified beach rock or coral breccia and conglomerate.

I I give an account of each island and of the various groups we visited in the order in which we examined them.

2 Dana mentions such large boulders as occurring at Raraka, Kauehi, Manihi, and Aratika. 
Between Tiputa and Avatoru Pass (Pl. 4, fig. 1) the outer islands are flanked on the sea side with steep coral sand beaches alternating with reaches of large boulders (Pls. 4, fig. 2; 13, fig. 1) extending on the inner face of the shore platform to the foot of the sand beach or reaching across the low cuts into the lagoon (Pls. $8 ; 9$, fig. 1; 12, fig. 2; 13, fig. 2). When the coral sand beaches are high, the boulders on the platform are usually absent, having been ground up into fragments to form the sand beaches or the coral shingle beaches so characteristic, as we found later, of the onter beaches of the atolls in the Paumotus (Pl. 4, fig. 2), and which often run unbroken for miles on the lee side of the atolls.

The reaches of old reef rock on the outer beaches are mixed with recent stratified beach rock (Pl. 8, figs. 1, 11), or with a conglomerate or breccia of corals, consisting of recent coral fragments and of fragments or masses of the underlying tertiary coralliferous limestone, so that, unless one has had some experience with the coral rocks composing this heterogeneous mass, it is difficult to make out its composition, and it would be most natural to assume that the conglomerate or coral breccia was composed only of fragments of recent corals more or less weathered, cemented together, after having been piled up on the underlying tertiary coralliferous reef rock.

Avatoru Pass (Pl. 4, fig. 1) is nearly a quarter of a mile wide and more than half a mile long, with a depth ranging from 15 fathoms at the outer entrance to three or four fathoms at the bar (Pl. 205, fig. 3) on the inner side of the pass, which deepens rapidly to 9 or 10 fathoms towards the interior of the lagoon. The bar is more or less connected with the spit which extends from the southern point of Brander Island (Motoufara). On steaming in we found a strong current of from four and a half to five knots running out of the lagoon. In the pass itself are corals growing in profusion down to 9 or 10 fathoms, then thinning out gradually to 20 fathoms. They also grow abundantly on the inner lagoon faces of the islands forming the outer land rim of the atoll, and extend into 5 to 9 fathoms. On the islets which occur in the lagoon (Pl. 205, fig. 3), such as Brander (Pl. 12, fig. 1) and Mohican Island (Pl. 7), corals are found on all the slopes extending into the deeper water of the lagoon from two to three feet to 8 or 9 fathoms. The inner extremity of Avatoru Pass is cut in two by Brander 
Island; to the west of it is a narrow passage not more than a tenth of a mile in width, and with about six fathoms. The slopes of the sides of the pass are steep, and the current rushing through it is often so strong that it is impossible, at certain stages of the tide, to attempt to steam against it. About six miles to the east of Avatoru Pass is another deep passage much narrower and somewhat more shallow (Tiputa Pass, Pl. 204, fig. 3).

The first appearance of such an atoll as Rangiroa was very different from that of any atoll I had thus far visited. The long line of narrow low islands covered with cocoanut trees (Pls. 4, fig. 1 ; 6) forms the only visible land of the atoll; extending eastward and westward as far as the eye could reach was presented an aspect very different from that of the atolls of the Fijis, and I was scarcely prepared for this great difference, in spite of the description given of them by Beechey and Dana, though the account given by Lesson of the belt of low sand islets thrown up on the barrier reef, and covered with cocoanuts and low shrubs, surrounding the volcanic islands of the Society group, had prepared me for what I saw in the Society Islands.

At a first glance it would seem as if the outer land rim had been formed from the disintegration of the material thrown up on the reef platform, forming either a coral shingle or a coral sand beach. Upon the outside shore or in the reaches stretching across the narrow land rim to the lagoon, but few boulders or negro-heads are left to indicate the former position of the old land formed of tertiary coralliferous limestone, the greater part of which has been eroded to below low-water mark or thereabout, when the process of building up again commenced, - a process which has not been recognized by those who have attributed to subsidence the existing conditions in the Paumotu atolls.

In atolls of such a size as Rungiroa, nearly 45 miles long and from 12 to 14 miles wide, the conditions become very different from those which affect smaller atolls. The prevailing southeast trades sweep nearly parallel with the longer axis of the atoll, and naturally considerable sea is constantly washing the bars, knolls, and islets found in the large atolls, acting upon them in many instances, according to their position in the atoll, much as if they were exposed to the full force of the seas which break upon the outer sea-shores of the islands on the land rim of the lagoon. 
Brander and Mohican Islets (Pl. 205, fig. 3), which project partly across the western side of Avatoru Pass, and Nui Nui Islet, which holds the same position to Tiputa Pass (Pl. 204, fig. 3), show the whole process of disintegration and erosion of the old tertiary coralliferous limestone to below lowwater mark. During this erosion it has, not been planed off uniformly; some parts have been more easily washed away, leaving ledges and ridges of the old rock, and the spaces between them have been filled by the formation of the recent beach rock, breccias, and conglomerates (Pls. 8, fig. 2 ; 9, fig. 1; 11). The former greater extent of these islands and islets is indicated by the prolongation lagoonward of the inner platform, on which are still found here and there boulders of the old reef rock (Pls. 9, fig. 2; 13, fig. 2), resting upon it, associated with boulders of the modern beach rock gradually passing into the modern reef flat.

The vegetation on the lagoon side of the outer land rim is usually more luxuriant (Pl. 6, fig. 1) than on the sea face, and immediately behind the highest part of the beach slope ( $\mathrm{Pl} .5$ ), where the shrubs and bushes and trees are exposed to the more violent winds which sweep in from the sea. It is remarkable bow uniformly the winds and seas follow the outline of the lagoon, making it quite difficult, from the prevailing swell, to effect a landing, except under very favorable conditions, on the sea face of the lee islands of an atoll.

The bottom of the lagoon at our anchorage in $9 \frac{3}{4}$ fathoms consisted of incrusting Nullipores and coralline Alga, forming, as a general rule, a hard coating upon the bottom. Similar bottom was found everywhere in the lagoon on the line from Avatoru Pass to Tiputa Pass, and on the line carried across the lagoon by Lieutenant Rodman from our anchorage to the weather side of the atoll (Pl. 204, fig. 4). A few shoals were found, and an islet (PI. 19) similar in its structure to the islet west of Mohican Island. The soundings varied from 14 to 17 fathoms (Pl. 204). The bottom consisted entirely of hard Nullipore growth. Nothing came up in the boat dredge, and the depth was quite uniform. The same hard Nullipore bottom appears to cover the bottom of the lagoon wherever there are no coral patches. Corals occurred in the lagoon in extensive patches in from two and three to 10 fathoms of water, both along the 
lagoon fice of the reef platform on the weather and lee sides of the lagoon and on the slopes of the islets found in the lagoon.

On the lagoon side of the lee land the steep beach in places is made up of fragments of coral more or less weathered, and forming what I may call coral shingle (Pls. 6, fig. 2; 9, fig. 2). When examined, the shingle is found to be composed of fragments of recent species of corals, of fragments of beach rock, of pieces of coral breccia or conglomerate mixed with fragments of the old tertiary reef rock or corals disintegrated from it. The breccia and conglomerate on the lagoon and sea face (Pls. 5, 8, 11) also are made up in part of modern material and in part of fragments of the old reef rock torn by the waves from the edges and sea face of the old platform and thrown up on the beach in benches.

On crossing the island to the east of Avatoru Pass, we came upon the different stages of its growth as first formed by the disintegration and erosion of the old tertiary ledge, then of its fragments thrown up towards the interior, mixed with those of recent corals growing at that point. Near the gendarme's house we came upon a ledge of old reef rock (tertiary coralliferous limestone) in situ about seven feet above high-water mark. In the central part of the island, which varies in width from 800 to 1200 feet, are found large loose masses of recent beach rock, corals, and old reef rock, together with finer and coarser blocks of coral. In the depressions near the edge of Avatoru Pass and in some parts of the centre of the island we come upon the ancient reef rock in situ. At a point near the entrance to Avatoru Pass, on the east side, a projecting ledge consisted in part of recent conglomerate and in part of ancient reef rock, which had been eaten away to form the adjacent beach. On the sea face the slope of the outer beach was covered with fragments of old reef corals and coral rock which had been thrown up, mixed with the worn fragments of recent reef corals, forming, a gray shingle on the beach nearly 16 feet high. In fact, the same conditions which exist on the lagoon face exist on the sea face of the island.

Isolated Astræans are growing on the old reef rock plateau, which is planed off to a general level, and honeycombed and pitted and grooved and covered with sharp points projecting from the surface of this flat ledge. 
On the south shore (the lagoon shore) of the outer island this ledge projects in an irregular outline from the shore, and in many places is completely hidden by the overlying stratified recent beach rock or the recent breccia and conglomerate. I was informed that at Kaukura there were great outliers of old reef rock fully 17 feet above the general level of the lagoon plateau.

A section made across the land rim east of Avatoru Pass from the lagoon side to the sea is quite simple. Starting from our anchorage in $9 \frac{3}{4}$ fathoms at a distance of about half a mile from the shore, the water shoals very gradually to three or four fathoms, where we came across patches, some of considerable size, of Porites, of Madrepores, and of Pocillipores, growing either on the slopes of the outcropping reef flat or on its surface. We then came to the base of the steep coral sand beach or coral shingle beach from six to eight feet in height, at the base of which crops out here and there the recent stratified beach rock or conglomerate.

The lagoon beach to the east of Avatoru village is an excellent example of the character of an inside beach of one of the larger atolls ( Pl. 6, figs. 1,2). The beach is steep, with a bench at a height of from five to six feet; below it the slope is covered with moderately fine sand made up of coral and broken shells. The upper part of the shelf above the bench consists mainly of broken shells, large fragments of recent corals, more or less worn, and of fragments of old reef rock and old reef rock corals, the latter derived from the disintegration and erosion on the lagoon side of the edges of the same platform which crops out as the reef platform on the sea face, and forms the underlying base of the lee land of the atoll. This platform varies greatly in width; usually it is much narrower on the sea face of the land rim, being sometimes not more than 75 to 150 feet wide (Pl. 11), while on the lagoon side the old platform is at times more than a mile wide. The shingle of coral and shells is weathered and thrown up to the very top of the beach from seven to eight feet above low-water mark; it consists of pieces of coral shingle varying in size from a walnut to that of one's fist, and on the slope of the shelf of pieces varying from a half to two inches, intermixed with more or less coarse coral sand. At the foot of the beach slope, near low-water mark, both above and also below 
it, crop out bands of recent beach rock (Pl. 9), stratified and dipping at a slight angle towards the lagoon; between the patches of beach rock are heads of old reef rock, either as boulders which had been separated from the lagoon edge of the old reef rock ledge and thrown up on the beach slope, or still attached to the ledge, large pieces of which occasionally crop out inland, but usually so hidden and covered by the surrounding fragments of recent beach rock and fragments of corals that it is difficult to decide whether they are part of the ancient reef rock ledge or have been thrown up by the sea from the lagoon face of the old ledge of the island.

From its highest point the beach slopes inland, and forms the outer dam of a shallow sink in which fresh water collects. This lagoon sink (Pl. 205) is better developed in other islands, and will be described elsewhere. In the rear of the village, to the eastward, the sink becomes a small shallow pond which furnishes a large part of the fresh-water supply of the natives. On the northern side of the sink the ground rises again, is undulating, and is composed mainly of beach rock, the interstices being filled with coral shingle and sand, which extends to the southern face of the high coral sand and shingle beach facing the sea. The top of the outer sea beach is in places fully 15 feet high, and is, like the inner lagoon beach, composed of coral sand at the lower part of the slope, and of coral shingle towards the top. The shingle extends inland in a comparatively gentle slope for quite a distance, and finds its way between the cocoanut and low trees and shrubs forming extensive broad lanes entirely devoid of vegetation. Isolated shrubs often begin to grow on the sea face of the outer beach; they increase somewhat towards the top of the beach, and form usually quite a thick growth at or immediately behind the summit. The vegetation consists of many of the same plants found on the Fiji reefs, and which are as a whole characteristic of all the Pacific coral reef islands.

At the base of the outer beach extends the shore platform (Pls. 8, 11, 12), the underlying bed of which consists of old tertiary coralliferous limestone more or less concealed by stretches of recent beach rock. The shore platform at this part of Rangiroa varies from 75 to 150 feet in width, and is flanked on its very outer edge by a ridge of Nullipores and of Pocillipores rising from two to four feet above the general level of the shore platform, which 
thus forms a shallow sink, the outer Nullipore edge forming as it were the diminutive barrier reef of a shallow and narrow lagoon on the outer part of the shore platform (Pl. 4, fig. 2). The outer wall and outer edge of the platform are cut into by deep gullies, into which the breakers rush with great violence, forcing the sea into the lagoon area of the shore platform, and at contracted spots throwing up huge columns of water in the air. ${ }^{1}$ There is usually a considerable current formed in this platform lagoon, towards the nearest lowest part of the Nullipore ridge.

The shore platform is nearly devoid of growing corals. A few small patches and heads are found here and there in the platform lagoon; towards the outer edge they become somewhat more numerous, and on the sea face or the summit of the Nullipore ridge they often cover quite large areas. The inner part of the platform lagoon is often covered for long reaches with masses of recent beach rock, or masses torn off from the Nullipore ridge which finally have become isolated and undercut by the encroachment of the deep gullies into the shore platform. These deposits often completely conceal the underlying old tertiary reef platform. The islet about $2 \frac{1}{2}$ miles south of Mohican Islet shows this well; there huge masses of modern reef rock and beach rock have been forced by the waves of the lagoon over the old reef rock and into the spaces between the ridges of this rock which constitute the substratum of the islet.

Mohican Islet (Pl. 7, fig. 2) is also composed of old reef rock which has gradually been decomposed and eroded to the level of the lagoon, in which it forms a flat of considerable size ; on Brander Island there is considerable building up going on from the washing up of the ledge sand into bars and islets and from the formation of recent beach rock on the underlying plateau of old reef rock, thus preventing the further disintegration and erosion of the island. On the lagoon slopes of both these islands corals are growing in from one to five fathoms or more, but they diminish rapidly after six fathoms.

In the channel to the west of Brander Island corals grow as far as nine to ten fathoms; they are mainly Madrepores, Porites, and Astræans.

Following the shore line of the lagoon from Avatoru to Tiputa Pass, we 1 See the figures of the blow-holes of Tongatíbu (Pls. 117, 118). 
found the bottom clear of corals in from nine to ten fathoms. It was only between four to six fathoms that they began to appear in patches. They were mainly rather small heads of two species of Astræans.

At Rangiroa I saw for the first time a feature which turned out to be very characteristic of the structure of the Paumotus as well as of the Society Islands, and explained in a very clear way the mode of formation of the outer land rim islands upon the sea face of the platform of the barrier reefs surrounding the volcanic islands of the Society Islands, or forming the rims of the Paumotu atolls. I had noticed, as we first steamed along the outer face of the Rangiroa atoll from the eastward of Tiputa to Avatoru Pass, that the high outer beach was here and there greatly depressed, and in some instances the depression was sufficient to open out a view into the interior of the lagoon across a shallow passage, through which in some cases water was flowing from one face of the island to the other, in others the shallow channel reached but a short distance into the island either from the sea face or the lagoon side. These depressions (Pls. 9, 10; 13, fig. 1) were usually indicated on the sea face by stretches of boulders extending on both sides; and as these were disintegrated they gradually disappeared both to the north and south of the openings, having gone to build up the coral sand and shingle beaches of the sea face of the outer island. There were no less than five such cuts in the island between Avatoru and Tiputa Pass, dividing the island into parts connected at low tide only, and separated at high water by narrow channels, from 75 to 100 feet in width and with one to three feet of water (Pls. 8-11). The first cut to the east of Avatoru Pass was Y-shaped, the main branch extending across from the lagoon to the reef platform nearly in a straight line, the other branch forming a cul-de-sac extending about two thirds of the way across the island from the lagoon face. A high steep coral sandbeach forms a sort of dam across the opening of the cut on the lagoon side (like that of Pl. 13, fig. 2). The greater part of its channel has been cut through beach rock and low masses of coral fragments and a conglomerate composed of pieces of recent corals and of corals and smaller fragments washed out from the old ledge platform, which is exposed at several points at the bottom of the main cut. 
A low coral sand beach is thrown up across the lagoon side of the second channel; this only stops access of the water at half tide, and forms a series of shallow pools which run across the depression for a distance of perhaps 1000 feet from the lagoon side towards the sea face (as in Pl. 9, fig. 1). The pools open into the lagoon through narrow channels. The central part of the depression also exposes, as in the case of the first cut, the old reef rock ledge, and it is topped with recent beach rock and conglomerate and worn fragments of recent corals and of pieces of the old ledge. The sea face of the cut is quite narrow, passing between the extremities of a steep coral sand and shingle beach which will shortly connect across this narrow channel and completely block access of the sea into the cut. The same thing will in its turn take place across the lagoon end of the cut (Pl. 9, fig. 2), so that when access of the sea is completely shut off both on the lagoon and sea face there will remain in the cut near the centre of the island only a shallow pond, which will in its turn be gradually filled with sand blowing over the high beaches from the inner and outer faces, and eventually form a part of the island, to be little by little covered by the vegetation usually found on reef islets. In this manner many of the sinks of the Paumotus have been formed. At the second cut the reef flat platform, viz., the old ledge platform, is fully 250 feet wide, and has been planed off, as it were, having a slight rise towards the base of the sandbeach. The rollers lose much of their force coming in over the outer edge of this platform, which is slightly raised and falls off rapidly into deep water.

The third cut was partially closed both on the lagoon and sea faces, leaving but little access to the water except towards high tide. The shingle across the passage was as high as the shingle on either side of the passage.

The fifth cut is shut off on both faces, on the lagoon side, by a coral shingle bank of about four feet in height, with a brackish pond near the lagoon side of the island. In the cut parts of the old ledge were exposed, and like the others it was cut through a superstructure of recent beach rock and conglomerate and masses of recent corals and fragments of old ledge. The passage was about 30 to 40 yards wide. On the sea face the 
opening of the cut was filled with fragments of beach rock and an agglomeration of fragments of large rocks and masses thrown up from the reef platform.

At the third cut there is a high dam, composed of coarse coral fragments and sand, from five to six feet high, placed directly across the lagoon opening, with a narrow channel leading into the lagoon from a large pool behind the dam, about 60 feet wide and not more than six inches in depth. The channel is partly dry in the middle, and covered with fragments of coral, as are the sides. On the sea face and on the lagoon side the old ledge rock is cut through, and a conglomerate composed of old and recent corals is exposed on the flanks of the cut. Across the centre of the cut, on the sea face, a bank has been thrown up, similar to the beach to the east and to the west of the cut, leaving a channel on each side and not quite closing the sea entrance. The channel is deeper on the west side of the central beach. The old ledge is exposed about 150 feet to the south of the sea beach, and is topped here and there with a conglomerate composed of recent and old reef rock. The mixture of this old and recent material makes the determination of the composition and age of any particular stretch of reef rock somewhat complicated.

Across the lagoon side of the fourth cut extends a dam directly across the channel. This was a shallow depression perhaps 50 feet wide, filled with fine sand to about 100 yards of the outer beach, where the old reef rock ledge cropped out. The sea face channel was open. The sea platform was cut by the sea into numerous tide pools; the rocks and boulders above the reach of the breakers were pitted and honeycombed in all the cuts which were wholly or partly shut off, showing that for a considerable time no currents had passed over them. The sides of the cut indicated that it was made up, as are the other cuts, of a conglomerate of broken masses of both recent and ancient corals, and fragments of modern beach and old-ledge rock.

The sea face of Rangiroa consists of a steep, coarse coral sand beach made up near the summit of coral shingle, the fragments of which are from two to three inches, with finer material at the base of the beach. This beach is flanked for a distance of 75 to 100 feet by a mass of fragments of old reef 
rock thrown upon the shore platform, many of them of great size (Pl. 11). Two masses were measured, one 18 feet long by 5 wide, and varying in height from 6 to 7 feet; another nearly cubical mass measuring 9 feet. These masses are detached during storms or by high seas from the sea face of the old reef ledge and hurled towards the shore, where they are gradually broken up into smaller masses (Pls. 8; 12, fig. 2), and eventually ground into the high coral shingle (Pls. 5; 12, fig. 1) and sand beaches of the sea face ; or are outliers of the old ledge platform.

The old reef rock ledge exposed in the cuts (Pl. 9, fig. 1) can be traced all the way across the land rim till it merges into the old ledge of the sea face that (Pl. 8, fig. 2), and with its extension on the lagoon side, which can be traced reaching into two to three fathoms. On the lagoon side similar masses, but smaller (Pl. 9, fig. 2), have also been thrown up after being detached from the outer edge of the lagoon platform, or they are left as on the sea face standing as remnants still connected with the ledge of the old reef rock of tertiary coralliferous limestone. Some of these ancient masses projected in the bushes beyond the line of vegetation. It was of course not always possible to determine whether they were parts of the old ledge or loose boulders more or less covered by the surrounding fragments of loose corals. When below low-water mark their connection with the old ledge was concealed by the mass of beach rock and fragments of conglomerate surrounding the lower parts.

Nui Nui Island, off the lagoon entrance of Tiputa Pass, is, like Mohican Island, composed of ancient reef rock; the extremities are being gradually cut up into masses and smaller boulders, and finally spread out into the coarse sand flat. The destruction of the islands and islets off the lagoon side of Tiputa and Avatoru Passes (Pls. 7; 12, fig. 1) shows plainly how much material has been removed from the inner ledges of the lagoon, gradually reducing them to the water's edge, and finally, by the action of the waves and currents, as well as the solvent action of the sea, gouging out the inequalities of the lagoon, deepening it little by little, — agencies which have been at work steadily since the last period of elevation of the tertiary coralliferous limestones, when the area of the exposed limestones was not only far greater than it is at the present time, but when the land probably 
rose to a somewhat greater height than that of the highest tertiary limestones found in the Paumotus.

Wherever we examined the bottom of the lagoon we found it generally quite barren of animal life, and covered with a hard Nullipore bottom and coralline Algæ. Fish were quite abundant in the lagoon, and on the flats; in two to three fathoms, corals and other invertebrates flourished. The patches of corals were generally most abundant on the slopes of the ledges and flats in from three to five fathoms.

The land rim surrounding Rangiroa is quite narrow; the islands of the land belt are not more than 1000 feet wide, and in many places less than 500 , and they are limited to the northern and western sides. The islets of the northern side are wooded. On the southern side (Pl. 204) the land belt is reduced to a few wooded islets (Pls. 13, fig. $1 ; 14$ ), the long reaches between them being composed of a wall of old reef rock from 10 to 14 feet in height. It forms the culminating point of the windward sea face platform of the old ledge, which varies in width from 250 to 500 feet, and of its lagoon extension, which can be traced for a mile to a mile and a half as it slopes gradually into eight to ten fathoms of water; the lagoon slope is covered with patches of coral.

The little islet of Paoi, on the way to the south shore, is an elevated old reef ledge with many fossil corals (Pls. 18, fig. 2; 19). It is about 12 feet high, and it, as well as Tiarari to the southward, and the few ledges we found scattered through the lagoon, are the remnants of irregular peaks or ridges, or spurs of the land once covering the area of Rangiroa, which have been planed down and eroded at the same time as the higher parts of the belt of land comprising the northern and southern ridges of the atoll.

On Plate $204 \mathrm{I}$ have given the line of soundings run across the lagoon of Rangiroa by Lieutenant Rodman. It will be noticed that the deepest part of the lagoon is near the northern land rim of the atoll, and that the floor of the lagoon has a very uniform depth ranging from 10 to 16 fathoms, the central part of the lagoon varying from 14 to 16 . The slope of the lagoon flat extending north from the southern land rim is much flatter than the lagoon slope off the northern land rim, where it runs rapidly into ten fathoms; while the lagoon reef flat of the south shore extends more than 
two miles before we obtain a depth of over five fathoms. The lagoon slope of the old ledge as it extends eastward from the southern land belt is quite shallow (Pls. 15, fig. $2 ; 16$ ). About two miles from the south shore the lagoon is not more than two to four fathoms deep, and the surface is covered with huge patches of corals, mainly Porites and Astræans, as well as Madrepores and Pocillipores, at a depth corresponding to that where flourish the corals on the north side of the lagoon, both to the west and east of Avatoru Pass. We landed on the south side of Funuarua Island, the largest of the islands on the windward face of the lagoon (Pl. 16, fig. 1). This island we found, like those on the land belt of the north side, to be in reality a chain of islands and islets, separated, like them, by cuts, only the cuts were much more marked, and the process of formation of the islands of the land belt was much more apparent than on the north side. At our landing-place we found a cut fully 200 feet wide running directly across the island (Pls. 15, fig. $1 ; 16$, fig. 2) from the lagoon side to the great wall of ancient elevated reef rock which shuts it off completely from the southern or windward side. This wall was fully 12 feet high (Pls. 15, fig. 2; 17, fig. 2; 18, fig. 1), and is the remnant of the ancient coralliferous limestone ridge which flanked the southern side of Rangiroa, and which Dana ${ }^{1}$ described (vicariously) while coasting along the southern face of Rangiroa in the "Peacock."

This old ledge is deeply pitted and honeycombed and eroded into all kinds of fantastic spires and pinnacles (Pls. 15, $17 ; 18$, fig. 1) and walls (Pl. 14 , figs. 1,2 ) cut through by crevasses extending from low-water mark to the summit, which is more or less covered by the high sand beach accumulated behind it on the lagoon side. This beach completely conceals the extension of the old ledge (Pl. 16, fig. 2) under the island; it has been formed from the disintegration on the lagoon side of the extension of the ledge (Pl. 15, fig. 1), and has been piled up to a height of from 10 to 15 or even 18 feet against the great sea wall of old reef rock which extends almost unbroken from the northern point of Rangiroa to its southwestern end.

The island we examined (Funuarua), as well as the islands and islets to the westward, are all built up at right angles to the trend of the coast.

\footnotetext{
1 Dana, loc. cit. pp. 203, 369.
} 
Funuarua is perhaps 1000 to 1200 feet wide; the smaller islands near it gradually become narrower as we pass to the westward, forming shorter and shorter dams separated by channels varying greatly in width and in depth (from one to two feet).

The larger and higher islets, covered with bushes, low trees, and cocoanuts, gradually pass into smaller and lower islets with less and less vegetation, until we find, as buttresses to the sea wall which separates all these cuts from the sea face, mere sand bars extending into the lagoon (PI. 14). To the northward are a fer islands and islets, centres of such sand accumulations, where the great sea wall and its extension into the lagoon is hidden by the butt of the sand bars accumulated against it. The great sea wall is more or less cut into fragments, and open here and there to the passage . of breakers which roll in upon the wide ledge flat which skirts the whole southern face of the atoll, - a flat fully two to two and one half miles wide from the sea face to the two-fathom line on the lagoon side. A short distance from the wall on the lagoon side one can see the white line of breakers rising above it and dosing itself through the openings on the reef flat, or appearing in the cuts between the islands as a white line on the top of the dark wall of the cul-de-sac. From the last island which we could see to the westward (Taeroere) there is also a long stretch of this bare wall with here and there a sand bar buttress on the lagoon reef flat.

In the large cut we examined we could trace the extension of the old reef rock toward the lagoon as a more or less distinct slope of the great wall until it became lost in the centre of the cut; then only occasional rocks jutted out here and there above the water line to disappear and pass into the slope of the lagoon ledge (Pl. 16).

On the sea face of the wall extends a reef flat platform fully 450 feet wide in places, the surface of which is deeply pitted and honeycombed and planed off to a general level (Pl. 17, fig. 1). On the outer edge, which is somewhat higher than the depressed edge near the base of the great wall, Pocillipores grow in abundance, and the whole of the platform is more or less protected by a growth of encrusting Nullipores of a pink or brown color. The Nullipores appear to thrive best on the raised outer edge of the reef platform. With the incoming tide the water rushes into the secondary 
platform lagoon through the deep cuts which indent the outer edge of the reef platform, and creates a current of considerable strength parallel with the shore line. A few large masses of reef rock were scattered upon the face of the outer reef platform. There was little animal life in the pools on the reef flat.

The base of the outer slope of the great wall varies in width from 100 to 200 feet; the top, the height of which ranges from 10 to 14 feet, is perhaps 50 feet wide, and the buttresses are well marked for 100 to 150 feet. These buttresses of old reef rock could also be traced across the base of the islands (Pl. 14).

Steaming to the westward of Avatoru Pass, we kept close to the land rim; this retained the general characters it possessed to the eastward, a succession of sand beaches and ledges and a wide shore platform. The land rim consists of a long narrow island, which finally tapers off into a series of islands placed upon a narrow outer reef, the horn of which is quite sharp at the northwest point, and forms on the western extremity a long reef flat covered with low islands and islets. The corrected sketch of the western part of the island, given in Pl. 204, is very different from that outlined by Wilkes. After rounding the northeast corner of Rangiroa, we came upon a series of gaps in the island very much wider than those we had seen between Avatoru and Tiputa Pass. The old ledge was exposed here and there in the gaps between the islands and islets, as well as on the sea face of the islands. The gaps were of varying width and depth. In some cases the beach rock had been piled up in, irregular low heaps so as to leave no access into the lagoon except to high seas. In others there were shallow irregular channels allowing a more or less free access to the sea, while in other cases the gaps were shallow channels with a depth of from one to three feet at low tide, allowing the water to flow across the outer lagoon flat.

After we passed the northeast point of the atoll the outer islands became smaller and separated by wider gaps, exposing to view the whole width of the shore platform and of its extension into the lagoon flat. The islands thus far were for the most part covered with shrubs and cocoanut trees, but we now began to strike low sand bars and islets quite bare of vegetation. These bars extended at right angles to the shore line across the 
lagoon flat, the highest point usually being on the lagoon side of the flat.

The formation of sand bars and islets at right angles to the trend of the outer reef flats is a most characteristic feature not only of the Paumotus but of other atolls in the Pacific. These bars or islets are mainly the results of two causes: the rushing of the water into the lagoon, and the wash of the trades along the lagoon face of the land rims. The accumulations of coral shingle and boulders derived from the decomposition of old ledge and modern reef conglomerate act as jetties across the face of the reef flats. The material worn from the flats, both on the sea face and on the lagoon side, is thus deposited on the flanks and extremities of the jetties. The sand bars and islets thus formed often jut as long spits far into the lagoon, and the beaches flanking the spits form a series of loops connected at the base or leaving gaps for the passage of the sea in and out of the lagoon. The material for these sand bars and islets is evidently derived from the disintegration of the lagoon reef flat and is thrown up by the waves as sand to form these bars and islets; they gradually increase in size and become at first covered with scanty shrubs and finally with cocoanut trees. That seems to me to have been the history of the formation of the land belt on the lee side of Rangiroa. Local conditions of winds and tides and currents, as well as position in the outer belt of the atoll, all tend to make certain points centres of accumulation and of rapid building up of islands and islets, while at other places there is maintained a fair equilibrium between denudation and erosion and building up, and at other points all possible combinations of these two states. These conditions have, of course, commenced to act on each atoll at somewhat different times, and have resulted in modifications which will be noted in the description of the various atolls. The changes all date back to the time when the original land flat, or low ridge of elevated tertiary coralliferous limestone, which occupied the area of the atoll began to be cut down to the level of the sea, and formed finally on the sea face of the atoll the great shore platform which characterizes the Paumotu atolls. The cutting down of the summits of the ridges of the land rim, and of the islands or islets or bars in the lagoon to the same level, supplied material for filling up in part the adjoining depths of the 
lagoon, or the materials were piled up as islets on the outer flat, or carried away across it, or washed out in solution; the disintegration of the land rim by the waves and the solvent action of the sea all tending to deepen the lagoon and to elear it of islands and bars and ledges. In the larger atolls especially they are cut to a general level from which only here and there islets and bars rise to attest the former existence of larger areas of land within the atoll, as will be shown in the description of atolls like Tahanea, Anaa, Marokau, and Ravahere, and of atolls in the topography of which islands, islets, and flats play an important part.

To the southeast of the northwest point of Rangiroa, the great wall of elevated ancient coralliferous rock begins, extending towards Taeroere Island, which we had seen, with the wall extending towards it, from the island of Funuarua. On the south side the reef flat is of great width, varying from one to two miles and more. The wall rises from the shore platform itself, from 300 to 400 feet wide, to a height varying from 8 to 15 feet. ${ }^{1}$ At various distances behind the wall, and in the rear of the larger islands and islets which are more or less covered with regetation, and which abut against the wall, are bars and islets of sand forming on the inner edge of the lagoon reef flat and extending towards the wall, until they finally form a buttress or a narrow island behind the wall, which closes more or less the gaps intervening between the lines of bars and islets and islands built up on the outer land belt of the south shore near the northwest point. Some of the bars have very-scanty vegetation; as they grow larger, this increases; a few cocoanut trees occur, and the larger islands, occupying the whole width of the land belt, are well covered with vegetation and cocoanut trees. On the southwest side the gaps between the islands become of great width; some of them are several miles across. The great wall is the most prominent feature, and runs apparently without a break, not only across the gaps but also across the butts of the islands. In some places the sand beach which has accumulated behind the wall encroaches gradually upon the sea face of the wall itself and conceals it so that spurs of the wall only crop out here and there on the face of the beach. The contrast between the brilliant white sand bars standing out against the green water of the shallow edge of the lagoon and the sand

1 Dana has described what I take to be similar tertiary limestone from Honden and Manihi. 
islands piled up behind the wall on the lagoon flat is very striking; the dark ragged points, the spires, the columns, the buttresses and walls standing out prominently from the light background. Thundering upon the outer shore platform fall the huge rollers, which break at the base of the wall and spend themselves on the platform, or at high tide throw the water far over the top, or force it through the openings between the undercut and honeycombed columns and spires of which the wall is made up.

There is a strong current making towards the lagoon through the gaps where the rollers force their way in, and also in the gaps between the islets wherever there is a passage for the sea, which is driven by the trades against the weather side of the atoll. Where there is no pass we found upon the shore platform, which is furrowed into a diminutive barrier reef and its lagoon, a similar current flowing westward in the direction of the prevailing winds. The decomposition and disintegration of the great wall supplies a certain amount of coarse sand which is thrown up on the top of the great wall and tends to conceal it; in addition sand is supplied from the lagoon side flat, to form the high sand beaches which extend behind the sea wall and form the ridges of the higher islands or islets, which rise to a height of perhaps 18 feet, or else form the high and steep sand beaches of the islands to the east of Funuarua; on the face of these project here and there buttresses of the wall, at the foot of which are piled up masses of old reef rock torn from the outer raised edge of the shore platform and thrown up at the base of the sand beach.

To the eastward of the nucleus of islands and islets of which Funuarua is the centre, we could see, as we steamed aray; extending to the easternmost point of the island, islands and islets similar apparently in all respects to those we had examined.

In comparing the description given by Dana of the great wall occupying the southern face of Rangiroa with what we saw, it is impossible to make them agree. Dana speaks of the absence of islands on this face. It does not seem probable that there should have taken place in sixty years such extensive changes as are suggested by the description of Dana. The natives whom I questioned assert that the condition of things which we found was practically what it has been with very minor changes. It is probable that 
at the distance at which the "Peacock" sailed, she might have seen only the bare part of the southwestern part of the atoll. But as Dana's description is not based upon his own observation, too much reliance should not be placed upon what he states on the authority of others.

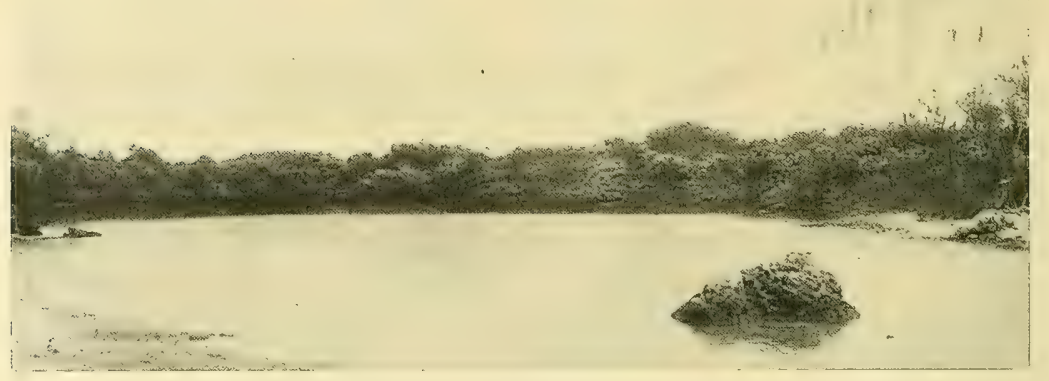

Old Ledge Dam and Spur, Lagoon Side of West Coast of Rangiroa.

\section{Tikahau.}

Plates 20, figs. 2-4; 201, 202; 204, fig. 4 .

On approaching the west side of Tikahau, we found it much like the west coast of Rangiroa, broken up into islands and islets (Pl. 20, fig. 2) separated by gaps, some of them of considerable width, with here and there reaches of the old ledge cropping out in them, and in one place a part of the ledge was standing in the gap as a honeycombed, pitted, and undercut mass of columns of irregular shape, similar to the great sea wall ledge on the south shore of Rangiroa. We could see several islets covered with trees in the interior of the lagoon, as well as rocky ledges similar to the ancient wall ledge on the outer land belt mentioned above (Pl. 20, fig. 3).

The entrance to Tikahau is in a gap on the western side, between low islands covered with cocoanut trees. The entrance is, like that of the passes into Rangiroa, flanked with ledges and islets. The structure of this atoll is in every way identical to that of Rangiroa, the sea faces of the island belt being high sand beaches alternating with exposed ledges. Thie 
height of the cocoanut trees seems to show that the elevation of the island belt, like that of Rangiroa, varies but little. Its islands and islets are covered with similar vegretation. They are separated by gaps and open passages, like those at Rangiroa, where the old reef ledge is exposed.

The island belt must have been formed, like that of Rangiroa, by the throwing up of the sand as dunes or bars and sand islets, upon the inner face of the lagoon flat behind the sea wall of the old ledge. From the smaller size of the lagoon and the proportionally greater mass of available material as sand, the islands and islets formed a more solid land belt concealing the greater part of the old ledge wall or leaving only a few patches of it exposed. The building up of the land belt from the lagoon side in all directions is quite marked in Tikahau. It is still more marked in Matahiva, and culminates, as we shall see, in the filling up of some lagoons in the smaller atolls, as Whitsunday for instance. On the west side of Tikahau there are only a few points where the ancient reef rock ledge is exposed; it has either been cut away or the inland buttresses are buried in the lagoon sand formed upon the lagoon flat, so that it crops out only occasionally, usually in the gaps, and rarely across the face of an island. The outer shore platform is from 150 to 300 feet in width, and the inner lagoon reef ledge from 600 to 1000 feet or perhaps even more.

Tikahau is elliptical in outline, nearly fifteen miles long and ten miles wide. The position of the southwestern part of the atoll is about three miles more to the westward (Pls. 201; 204, fig. 4) than is indicated by Wilkes's sketch in H. O. Chart 85 .

The southwestern and western face of the land rim is also, as we saw it, far narrower than is indicated on Wilkes's sketch, consisting of a narrow reef flat, bare at low water (Pl. 20, figs. 2, 4), with only five small, widely separated islets on the submerged rim. The western part, as we observed it (Pl. 204, fig. 4), differed greatly from the drawing given by the U. S. Exploring Expedition. On the west side of the atoll the sea had access to the lagoon through many wide and shallow openings separating the islets forming the land rim.

It will be. noted that the entrances to Tikahau and to Matahiva are on the western face of these islands, while the entrances to Rangiroa 
are on the north side. This may be due to the fact that the land belts of the former atolls are rapidly building up from the lagoon side, the tendency of the prevailing winds being to keep an opening clear on the western faces.

\section{Matahiva.}

Plates 20, fig. 1 ; 201, 202; 204, fig. 4 .

Matahiva, as seen about four miles off from the southeast, appears well wooded, with cocoanut patches and an outer belt of vegetation of the usual type characteristic of the Paumotu atolls. We could see traces of the old ledge cropping out here and there, separated by sand reaches which seem to have overwhelmed the ledge. There appear to be very few large breaks on the eastern face of the island. I was informed by the gendarme at Rangiroa, and by Mr. Edward Bonnefin, a former resident of Matahiva, and now of Makatea, that the lagoon of this atoll is very shallow, full of ledges and islets, and that one can get about in the lagoon only in a flat boat. From what we could see steaming around the island it is evident that the passes and cuts once separating the islands and islets, similar to the single opening now left, through which boats enter the lagoon (Pl. 20, fig. 1), have been, as in other atolls of the group, gradually closed by the sand blown along the inner shore of the lagoon derived from the breaking up of the ledges of the interior; the sand blowing on the lagoon side of the outer edge of what is left of the ledge, and gradually overwhelming it, the rapidity of this work depending upon the amount of ledge rock exposed to the action of the wind and sea inside of the lagoon.

As we steamed around Matahiva, the outer reef platform seemed to be much wider than we had seen it either at Rangiroa or Tikahau; it varied from 200 to 300 feet in places, judging from the position of the breakers relatively to the shore coral sand beach.

Between the more or less continuous ridges of the old ledge, running diagonally or at right angles to the beach, wide patches and reaches of sand extend. From the greater width of the shore platform of this the westernmost island of the group more material is supplied on the sea face, and thus 
a higher coral sand beach is thrown up, and rapidly closes the cuts and passes leading from the sea face to the lagoon as we had traced it on Rangiroa.

Great care should be taken to call a lagoon closed only when, as in the case of Niau, the outer ring of land surrounding the lagoon is entirely solid. Many atolls are called closed which, while having no boat entrance, yet have many very shallow cuts and passes between the islands and islets of the outer land rim, through which at nearly all stages of the tide a large amount of water passes, and is forced in from certain directions by the prevailing winds.

On the beach of the northeastern shore a table-topped rock of old ledge deeply undercut was a prominent object. Part of the shore ledge undoubtedly consists of beach rock and modern conglomerate piled up or formed between portions of the old ledge left standing, as on the north face of Rangiroa, but the bulk of the ledge is made up of old elevated reef rock ledge.

Matahiva is densely wooded, and much coral sand has been blown in between the trees from the outer beaches. At the boat entrance into Matahiva the old reef rock is well exposed on both sides, and through the narrow pass we could see two wooded islets in the rear of the gap fringed in part by the old reef rock ledge.

The coral sand beaches of Matahiva were from six to eight feet high, and the remnants of the old ledges forming the summit of the land and more or less overwhelmed by sand were from ten to twelve feet. The sea was breaking heavily on the wide platform of the southwest point.

The condition of Matahiva as well as of Tikahau seems to indicate atolls which are gradually filling from the sand blown into them, both from the decomposition of the ledge of the outer beach and outer reef platform, and from the sand of the lagoon side derived from the disintegration of the islets and ledge flats, as well as from the material derived from the lagoon shore platform.

The sketch of Matahiva given by Wilkes on $\mathrm{H}$. O. Chart 85 is not correct. The atoll is triangular in shape (Pl. 204, fig. 4), about seven miles in length, and its position is nearly six miles more to the westward than is indicated on the Hydrographic Chart. 


\section{Makatea.}

Plates 21-32; 201, 202; 205, fig. 1; and Figs. 7, 8.

Makatea is perhaps the most interesting of the Paumotu Islands, as its structure gives us, in connection with Niau and Rangiroa and other atolls of the Paumotus, the key to the structure of the whole group. It is an elevated coralliferous limestone island, the highest point of which is about 230 feet, flanked on the northeast and eastern sides by perpendicular cliffs (Pls. 24, 25, 27) which are especially prominent on the northern and northeastern point of the island as well as on the easternmost point. The southern face of the island slopes quite gradually, and shows the lines of the terraces (Pl. 29) which once characterized the island before the extensive disintegration and denudation which has reduced it to its present dimensions took place: The terraces disappear on the western face of Makatea (Pls. 22, 23), where they run into the steep wooded slope which characterizes that side of the island. Makatea was visited by Dana, and he has given a sketch of its appearance as seen from the sea facing the west coast, ${ }^{1}$ as well as a description of its principal features. The island is four and a half miles long, and its greatest width a little over a mile and a half ${ }^{2}$ (Pl. 205, fig. 1).

The island of Makatea is irregular in outline (Pl. 205, fig. 1). The southern part of the island is more or less rectangular; the northwestern angle extends into an elongated point tapering somewhat towards the northern extremity of the island; the northeastern face is concave; its western face runs nearly north and south; the southern face is convex, and the eastern face, the shortest, runs, like the western face, north and south. Its greatest width extends from the southeast point to the east face.

The southern and eastern faces are flanked by a sand beach, and on the western face two coral sand beaches, separated by low vertical bluffs belonging to the first terrace, occupy the greater part of

1 Dana, J. D., Geology of U. S. Exploring Expedition, p. 67; Corals and Coral Islands, p. 193.

2 H. O. Chart 83 gives a good sketch of Makatea, though on a small scale. 
the west coast (Pls. 23, 24; 26, fig. 2), running along the base of the steep western slope of Makatea. The western extremity of the south coast is also flanked by low limestone bluffs, and a narrow reef platform extends from the southeastern point along the western face to the northern point of the island, perhaps 400 feet at its widest point, and gradually disappears as it passes around the northern point into the face of the cliffs of the east side of the island.

Makatea, as seen coming from the west, rises abruptly (Pl. 21, figs. 1, 2) from the sea. The northern part of the western face consists of vertical cliffs composed of elevated tertiary coralliferous limestone (Pl. 22), deeply cut by vertical fissures, some of them of considerable depth, extending nearly the whole height of the cliffs (PI. 25); these are from 120 to 150 and even 200 feet in height. At the northern end of the island they are capped with a rounded summit probably 30 or 50 feet higher than the crest of the highest cliffs (Pl. 22, fig. 1). The rounded summit falls off equally on both sides, to rise to a low, slightly pointed hill which stands on the northern edge (PI. 21, fig. 3) of what looks from the sea like a marked depression or sink, the southern extremity of which is marked by a low conical hill (Pl. 21, fig. 2) rising slightly above the line of vertical cliffs which occupy the northern half of the southern part of the island. This line of cliffs, covered in great part by vegetation, is considerably lower than those of the northern extremity (Pls. 23; 26, fig. 2), and they are separated by a more or less abrupt slope formed by the crumbling of the limestone cliffs of that part of the island, mainly from the falling in of the first terrace. From the southern summit the island slopes south very gradually, and along the face of this long slope two terraces are plainly indicated. The base of the second terrace can be traced far towards the middle of the island (Pl. 23). From the southern point northward the island is flanked by a steep coral sand beach running up in places close to the line of the cliffs or to the line of vegetation (Pls. 23, 24, 25; 26, fig. 2); and both it and the narrow shore platform of the west face, which is bare at low water, disappear near the northern point.

The first terrace is from 20 to 25 feet high and the second about 30 feet. Along the face of the vertical cliffs lines of caverns and deep 
recesses extend at certain levels, indicating probably the position of the former terraces, which can be traced somewhat indistinctly on the eastern face of the island ( $\mathrm{Pls}_{\mathrm{s}}$ 22, fig. 2; 23, 25). On the northwest side these lines of caverns would indicate no less than five terraces or periods of elevation (Pls, 27, 28); the caverns of the higher levels having in their time probably held the same relation to the sea which those at the base of the cliff (Pls. 22; 26, fig. 1; 28, fig. 2) hold to the present sea-level. On the northwest face the vertical furrows and great bands of stalactites and lines of caverns (Pls. 23, 27, 28) and of former levels of shore under-cutting are most plainly to be seen along the central and northern part of the northwest side of the island. At the northern point, where the shore platform disappears, the base of the cliffs is deeply undercut (Pls. 22; 26, fig. 1).

Steaming around the north point, the line of high vertical cliffs is continued along the east face; they are deeply undercut at the base, with vertical fissures and lines of caverns, only far more prominently marked than those on the northwest side. As we rounded the northern point, we could trace on the east side, as on the west, the extension southward of the slope of the rounded summit towards the northern edge of the sink occupying the central part of the island. The cliffs on the east side are not only higher, but also more uniform in height than on the northwestern face (Pls. 27, 28). The village on the east side ( $\mathrm{Pl} .21$, fig. 1 ) is at the base of a slope 'formed by the crumbling of the first and second terraces, and at the point where the vertical cliffs are somewhat lower than those to the north and south of the village. At this part of the island there is again a narrow shore platform, which however does not extend far to either side of the village, and disappears again. On the face of the vertical cliffs of the east side the lines of four terraces are clearly indicated, and along the slopes of the rounded summit the fifth and perhaps the sixth terrace can be traced.

The coral sand beach of the west face of the island (Pls. 23-25; 26, fig. 2) is about twelve feet high, and the shore platform varies from 200 to 400 feet in width, is slightly raised at the outer rim, with deep channels at right angles to the face, extending sometimes from 10 to 30 feet towards the beach, or forming the merest indentations of the raised outer edge of the shore platform. 
The landing-places at Makatea and at Tikeï show beautifully the little inlets, finger-like cul-de-sacs, which the sea has cut or which have grown out seaward from the edge of the reef platform. Into some of these larger inlets boats can be run and a landing effected. Niue has perhaps the best examples of these corrugations of the edge of the reef platform, affording an excellent landing on the inner part of the reef platform.

The reef flat is covered with incrusting Nullipores, and these constitute the greater mass of the rim. The width of the small channels cutting at right angles into the reef platform varies greatly; their sides are frequently perpendicular, the depth from a few feet to two or three fathoms; or the sides may arch over, nearly bridging the channels in places; the sea rushes with considerable force into these gullies, which, according to their position and size, form blow-holes where the sea or spray is thrown up with considerable force.

From the outer edge of the reef platform the slope to six or seven fathoms was quite gradual, and beyond that somewhat steeper. Pocillipores and scattered corals were common on the exposed rim of the shore platform, crowded with Nullipores in the intervening spaces. Corals, mainly small heads of Madrepores, Pavonia, and Porites, grew in great abundance on the slope to eight fathoms; there the corals began to decrease, both in size and number, and although they extended often to 20 or even 22 fathoms, the patches were separated by wider and wider lanes and patches of coral sand.

The reef flat or shore platform (Pls. 24, 25; 26, fig. 2) is a part of the base of the first terrace, which has been planed down to below low-water mark, and is deeply pitted and honeycombed. On the west face we collected, from the first and second terraces, fossils similar in every respect to those from Fiji, which have been determined by Mr. Dall and myself as tertiary. We also collected many fossils on our way across the island, principally in the deep cuts and caverns of the vertical cliffs on both faces of the island.

To the south of the village, on the east side (Pl. 21, fig. 1), there are four distinct lines of undercutting, and huge stalactites running from cavern to cavern on the vertical faces of the cliffs. The lines of the caverns of the second and third terraces are best marked in the cliffs to the north of the 
southeast point ( $\mathrm{Pl} .27$ ), and at the southeast point these lines become broad belts (Pl. 28), deeply sunken, while to the south of it the cliffs, which now are becoming less in height (Pl. 29, fig. 2), are undercut mainly at the first terrace, and the face of the cliffs is cut into prominent buttresses (Pl. 28, fig. 1). These gradually pass into the face of the second terrace of the south point, where they crop out only here and there through the dense vegetation (Pl. 29, figs. 2, 3) and at the base of the first terrace run across the slope of the steep coral sand beach which separates them in the shape of wide wedges (Pl. 29, figs. 1-3); the base of these buttresses has to a great extent been eaten away, or ground into coral sand.

That the lines of caverns indicate the former lines of terraces is easily seen in the passage of the vertical cliffs of the east coast, where the terraces are only indicated by lines of caverns, into the terraces themselves (Pls. 27-29). This is well shown at the southern point, where the line of the second and third terraces gradually recedes from the face of the vertical cliffs and passes into the walls of the terraces behind the talus indicating their base. The mode of formation of the talus is also well seen along the south point, where the first terrace is gradually eaten away and its material ground into a steep coral sand beach. The sea, by breaking into the face of the cliffs of the first terrace, forms a series of buttresses at right angles to the reef platform, between which run short sand beaches. As we approach the south point, the buttresses become smaller and smaller, and the sand beaches longer, till the first terrace only consists of a series of apparently independent buttresses separated by sand beaches.

The path back of the beach which leads from the centre of the west side of Makatea across to the east face of the island runs in a great crevasse at right angles to the trend of the bluffs. It finds its way up between high walls rising on each side from 20 to 30 feet ( $\mathrm{Pl} .30$ ), until it reaches the top of the bluff, where it enters a small cañon with walls about 12 feet high, running level for a distance perhaps of an eighth of a mile, then a gentle descent begins into the sink occupying the central part of the island. The sink falls away from the foot of the slope of the highest point at the northern end of the island towards the south, where the lowest part of the sink is fully 50 to 75 feet lower than the surrounding rim of the cliffs. The 
lowest part of the sink along the path leading across the island from west to east is probably from 30 to 50 feet lower than the rim, the deepest part being nearest the eastern face. The path winds its way between huge masses of limestone (Pls. 31, 32), forming needles and spires, and on each side are found deep crevasses or potholes or small sinks. Some of the pinnacles are fully 20 feet high (Pl. 32, fig. 1), and some of the narrow crevasses equal them in depth.

The surface of the exposed rock is everywhere pitted and honeycombed and weathered, much as we found it at Ngele Levu and other points in Fiji. The intervening spaces are covered with thick vegetation. The same sort of scenery runs across the island from west to east, patches of vegetation alternating with spires and pinnacles, or huge masses forming indistinct cyclopean walls, alternating with deep crevasses, small caverns, pot-holes, or diminutive caverns running in all directions. On striking the summit of the

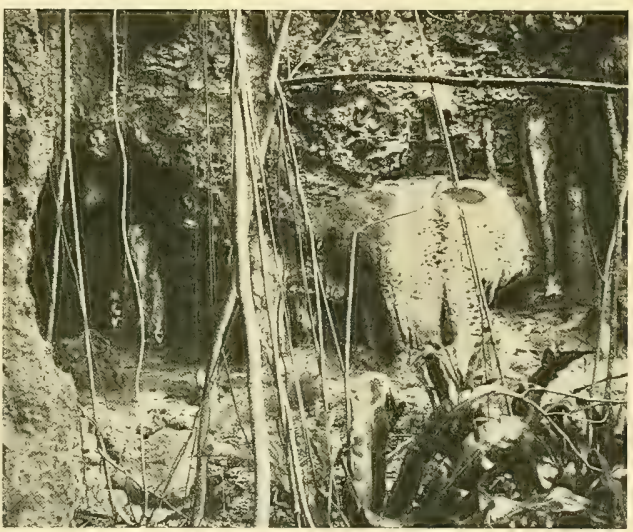

Entrance to Cavern, East Face of Makatea.

cliffs of the eastern face of Makatea, the path leading down the slope to the village runs between walls from 30 to 40 feet high, and on each side the cliffs are honeycombed with caverns and crevasses even to a greater extent than on the west face.

Near the foot of the cliffs on the east side, at the base of the second terrace, a large cavern is found, which is said to run towards the northern point and come out on the shore cliffs at a distance of more than a mile and a half. Other caverns honeycomb the eastern part of the island, as can be seen from the sea from the number of those which crop out on the cliffs of the eastern face of the island. On the east face, in the bight where the 
village is situated, extends a narrow reef platform eut out of the cliffs of the first terrace, similar in every respect to that off the west coast, but perhaps a little wider, with a higher rim and deeper fissured edge. There is no great high sand beach back of the reef platform on the east shore as on the west side; it abuts against the remnants of the slope of the first terrace.

On the east face, to the south of the village, the reef platform disappears; its occasional presence is only indicated here and there by a few small sand beaches at the foot of the line of caverns.

On the face of a vertical cliff immediately south of the village four periods of elevation are most clearly indicated. The edges of the caverns were thickly covered with lines of stalactites running along the face of the cliffs, and giving them the appearance of gray basaltic rocks.

It is evident that the sea has not had access into the interior of the sink, if it ever had any, after the elevation of the second terrace. It is most difficult to decide whether such sinks as those of Makatea and Niau are the remnants of sounds or of atolls, or merely sinks representing huge "banana holes," as they are called in the Bahamas, or "sounds," as they are termed in the Bermudas. 'The great sink at Nassau ${ }^{1}$ has nothing in common with a lagoon, though if the sea were to cut into it we should have a sound having all the appearance of a lagoon, as have the sounds of the Bermudas, yet each owes its origin and present condition to very different causes. The crevasses, pot-holes, spires, pinnacles, and the pitting and honeycombing of the sink of Makatea clearly indicate an enormous amount of erosion and of denudation; and the existence of the endless caverns in the body of the island ${ }^{2}$ also shows how long this disintegration has been going on, to honeycomb as it were the whole of Makatea on so large a scale. Furthermore, this disintegration and erosion has gone on so long that if the sink is the remnant of an ancient lagoon existing in Makatea before the second terrace was elevated, it has been subsequently so modified by atmospheric agencies as to completely obliterate all that characterizes an atoll of modern times, formed in the existing period. The comparatively flat floor, the gentle slopes

1 Bull. M. C. Z., XXVI. No 1, Pl. 10, fig. 3.

2 Similar caverns are known in nearly all the limestone islands of. Fiji, Tonga, the Cook group, Guam, Niue, Ocean and Pleasant Islands in the Pacific, as well as in the Atlantic, at the Bermudas, Bahamas, Cuba, and other limestone islands. 
of the lagoon platforms, the ledges and islets of the inner lagoon, the existence of beach rock ledges, of conglomerate ledges, - all these characteristics of the modern atoll are nowhere to be traced in the sink of such an island as Makatea. In fact, we can explain far more readily its existence through atmospheric agencies and other factors which we know to act upon limestones, after the island had been elevated, or during the course of its elevation.

Dana ${ }^{1}$ has well described the appearance of Makatea while crossing the inland basin. He also states ${ }^{2}$ that the rock of the elevated portion of the island of Makatea "appears to correspond to the interior of the original lagoon of the island, and exemplifies the kind of rock-making which is going on in most of the coral island lagoons." This does not seem probable to me. The material composing the pinnacles, spires, or ledges of the central sink does not differ from that found on the fossiliferous cliff faces of any of the elevated coralliferous limestone islands of the Paumotus and others which have no lagoon, such as Guam, Niue, the Tonga Islands, and Fiji. The material of the bottom of the lagoon generally contains comparatively few corals and other invertebrates, and consists mainly of sand or ooze made up of fragments of Nullipores and corallines.

It seems to me as if $\mathrm{Dana}^{3}$ had laid too much stress upon the absence of fossils in interior basins, as when he characterized these basins as eminently the places for making non-fossiliferous limestones. While it is true that on the lagoon beaches shells and other invertebrates are ground into fine material, yet at a very moderate deptl the calcareous mud of the bottom of the lagoons is often filled with shells, Echini, Crustacea, and other invertebrates, and if fossilified would form anything but a limestone barren of fossils. In many shallow lagoons which are in an eminently marshy condition (as stated by Dana ${ }^{4}$ ), and have become so small and shallow that corals and large shells have all disappeared, the bottom is covered by the finest kind of calcareous mud. But this mud is not necessarily devoid of fossils; on the contrary, we should infer very much the opposite, from the mass of small marine shells found on the shores of the lagoon of Niau and of San

\footnotetext{
1 Loc. cit, p. 193.

2 Loc, cit, p. 386.

8 Loc. cit., p. 389.

4 Ibid.
} 
Salvador, and on the lagoon shores of Maraki, all of which would supply a mass of small shells as fossils in fine calcareous mud, as characteristic of the interior of lagoon deposits, with here and there corals, or, finally, a mass of corals in the larger lagoons to which the sea has full access.

As I have already suggested, I am inclined to look upon the basin of Makatea not as the remnant of the lagoon of an elevated atoll, but as a sink produced by atmospheric agencies acting for a long period upon a comparatively flat plateau of elevated coralliferous limestone. The deepest part of the sink may have been formed as a sound when the third terrace was broken through and the sea cut across towards the north end, leaving that remnant to attest the elevation taking place at the time of formation of the third terrace. Similarly the limestone islands at Fiji are often eaten away at the lowest terrace, leaving fragments of higher terraces untouched, which can be seen in some of the higher islands of many lagoons.

The elevation of the Makatea plateau has taken place too rapidly to allow a connection to be formed between the central sink of disintegration and the deep cuts made by the sea on the flanks of the island, - cuts like those which form the diminutive valleys and crevasses which extend towards the centre of Niue at right angles to the beach line. The elevated plateaus of such islands as Tongatábu, Vavau, Eua, Nine, and Makatea, which are furrowed by valleys, or sinks, or areas of drainage, are in marked contrast to such atolls as Fulanga, Ongea, Yangasá, and others in Fiji, - atolls which must at one time have been similar elevated plateaus into which the sea has eaten channels which, communicating with the central sink, very soon eroded the central part of the mass to form sounds or lagoons.

\section{Niau.}

Plates 33-36, 201, 202.

The island of Niau is the only one of the larger atolls of the Paumotus in which there is no entrance into the lagoon, which is merely a shallow salt-water pond. The atoll is nearly circular, about four miles in diameter; its land rim is well wooded. 
Coming upon Niau from the westward, two low terraces are plainly marked at the northeastern point of the island (PI. 33). As we approached Niau, we could see along the beach spurs or buttresses of the old ledge projecting out from the sand beach, extending at right angles across the shore edge of the reef flat. The lagoon is absolutely closed to the access of the sea, except as it percolates through caverns and fissures of the land rim. It is about three and a half miles across, and it is from 12 to 18 feet deep. The slope from the edge of the lagoon is very gradual. There are large mullet living in it, and the shores of the lagoon are covered with the dead shells of small marine bivalves and gasteropods, which, as was the case in the lagoon of San Salvador, were diminutive examples of larger marine species occurring on the reef flat. The land rim separating the sea from the lagoon (or sink) is fully 25 feet high, and perhaps half a mile wide. The inner slope of the land rim dips slightly towards the sink. It is composed of the same old ledge rock which crops out all around the island, and can be seen forming the outer wall composed of rounded buttresses, more or less widely separated (Pl. 33) by reaches of coral sand, forming small beaches composed of material varying from fine coral sand to coarse coral shingle. The beach of the sea face is quite wide, fully 40 to 50 yards. It rises steeply from the inner edge of the reef flat, which has been dug out and planed off to low-water mark from the first terrace of the old ledge (Pls. $33 ; 34$, fig. 2). The sea rim of the reef platform is slightly raised, Nullipores and Pocillipores growing luxuriantly on it, with deep fissures extending far into the platform from one to twenty feet in width and from a few inches to three fathoms in depth (Pl. 34, fig. 2). Many of these fissures form small inlets for boats and canoes, which the natives are quick to make use of in landing and reaching the diminutive lagoon flat inside of the fringing reef rim of the reef platform.

Pocillipores, Porites, Astræans, Millepores, Madrepores, and Pavonia grow in abundance from the edge of the reef platform, taking their greatest development in from three to seven fathoms. None of the corals are large, the heads are small; and at 20 fathoms, about 100 yards from the outer rim of the platform, there are no living corals; nothing but coral sand is found, with here and there a patch of corals in slightly shallower water. 
The reef flat on the west side is from 100 to 150 yards wide; its foundation consists of coralliferous limestone of the old ledge rock; but along the higher parts of the beach the old ledge rock is often topped with a bed of conglomerate made up of beach rock, fragments of pieces of broken coral, and of old ledge rock ( $\mathrm{Pl} .33$ ), the whole cemented together. This material hides the higher parts of the underlying. ledge rock; ${ }^{1}$ it can, however, be seen cropping out again wherever the upper part of the old ledge buttresses has not been obliterated, and on the top of the land rim back of the beach (PI. 34, fig. 1). All the way across the land rim from the beach to the lagoon the old ledge crops out in the vegetation and rises in small blocks and pinnacles. On the lagoon side the old ledge is fully as well exposed as on the sea face of the atoll (P1. 35). There are no corals in the lagoon, and sea water probably percolates through the porous rock of the land rim. It is rarely washed over the high land rim of the atoll except in a hurricane, as in the cyclone of 1878 , when the lagoon was to a certain extent filled with sand and cornl fragments washed in by the sea. The density of the water in the lagoon is 1.0216 at $28^{\circ} \mathrm{C}$. The water is very salt.

Wherever the old ledge cropped out, either on the sea face of the atoll, the summit of the land rim, or on the lagoon side, it was pitted and honeycombed and covered with diminutive spires and points, as is all the old ledge rock of Makatea; in fact, it was like it in all respects, full of tertiary fossils, and was not composed in any way of recent material except in those places where the conglomerate mentioned above had been formed and deposited on the surface of the old ledge rock or between its buttresses.

At Niau, as is the case at Rangiroa, we find the beach sand is gradually encroaching upon the old ledge, covering it in places, until finally it will obliterate it along the sea face, and eventually the sand will completely hide the old ledge both on the land rim and lagoon side. With the decomposition and disintegration of the reef platform, the undercutting of the old ledge, and the grinding up of the fragments and blocks of dead coral, more material is constantly supplied to build up a higher and higher coral sand

1 This conglomerate or beach rock has also comparatively recently been elevated to a height of from six to eight feet above high-water mark. 
beach, which will encroach on the land rim, and finally advance as dunes do, and little by little fill the lagoon.

It is difficult to say whether the lagoon ever has been the lagoon of an atoll or has been formed as a sink. Both explanations are plausible. The land rim, while solid and unbroken at present, may at one time have consisted of several small islets surrounding a shallow sound, separated by low gaps which have gradually been filled from the coral sand material supplied from both the sea face and the lagoon side of the atoll, as we have seen it to take place in other atolls in the Paumotus, or it may have been a flat patch of elevated limestone the central part of which has been gradually eroded or dissolved out into a sink by atmospheric agencies assisted by the solvent action of the sea percolating through the land rim. That the sea has had access to it, and that it has been shut off for a long period of time, would seem to be proved by the presence of the diminutive race of marine shells living in the lagoon, and the presence of Lagena-like Foraminifera in the lagoon sand. The mud of the bottom of the lagoon is very fine ooze, consisting of decomposed ledge rock sand. Algre are growing in great abundance on the shore flat of the lagoon. Disintegrated corals from the old ledge and fragments of it are found along the lagoon beach.

The shore platform forming the reef flat of Niau shows most plainly (Pl. 33) the manner in which the old land rim has been planed away by submarine erosion, from the outer edge of the reef flat to its present position, leaving on the edge of the land rim buttresses of the old ledge running at right angles across the coral sand beach and lower outliers of the same upon the reef platform, the space between some of these buttresses and outliers being filled with modern reef rock. The same process can be observed on the west shore, the southern extremity of Makatea, the south shore of Rangiroa, and many other atolls in the Pacific, but the changes which have taken place are specially evident at Niau.

On the southern shore of Niau (Pl. 34, fig. 3) the land rim faces upon deep water, and there the low cliffs have merely been undercut, as no platform could be cut on that face of the island. 


\section{Apataki.}

Plates 3\%, $39 ; 40$, fig. 1; 201, 202.

The southern part of Apataki is the only one which has been carefully surveyed; the chart shows the reef flat extending between Motu ruvahine to Pakaka Passage, ${ }^{1}$ with an island on the southeastern point of the atoll connecting by a narrow reef flat, more or less bare at low water, with the islet of the southwestern point, where the reef flat becomes wider and is surmounted by reaches of a high sand beach forming the bank between Seignelay Point and Pakaka Pass. This sand beach passes into the low land rim forming the southern boundary of Pakaka Channel. On the lagoon face of the passage are situated two islets similar to those found across the entrance in other lagoons of the Paumotus, such as Avatoru Pass, Tiputa Entrance, and many others.

The island of Apataki is rectangular in outline, with a somewhat pointed southern face. It is about seventeen miles long, and extends from north to south. On the lee side there are a number of entrances which are available only for small schooners. We examined the lagoon of Apataki in the vicinity of Pakaka Entrance, and steamed along its western and northern faces. The land rim of the southwest face of Apataki is broken into numerous islands and islets separated by gaps and cuts of varying width and depth, in many of which the old ledge is exposed (Pl. 37, figs. 1 and 2). The lagoon sides of the islands and islets are flanked by sand reaches and shingle beaches, while near the sea face they pass into lines of small boulders or larger blocks. There are many ledges exposed in the lagoon. Those we examined near Pakaka Entrance are more or less covered on the weather side with sand or shingle beaches. On some of the sandy islets a few cocoanut trees have obtained a footing.

On the north side of Pakaka Pass a high coarse coral shingle beach has been thrown up, while on the south a low point marks the entrance (Pl. 38, fig. 3). To the north of the passage the land rim is broken by

1 Dépôt des cartes et plans de la marine, 3577. 
numerous gaps, with shallow cuts giving more or less free communication between the waters of the lagoon and the sea (Pl. 38, fig. 2).

We ran at a slight angle to the northern face of the land rim of Apataki; it possessed the same general character as the land on the west side. The stretches of unbroken land rim were, however, longer, the low reaches connecting them much less numerous, and there were comparatively few outcrops of old ledge.

The north face of Apataki, as far as we could see steaming along, is fairly well closed up by a series of low islets and islands similar in every respect to those we had seen thus far, the beaches made up of coral sand with old ledge boulders and occasional old ledge outcrops.

One of the islands of the land rim to the north of Apataki Entrance has all the characteristics of the land rim of Rangiroa near Avatoru Pass. It is marked by a steep white coral sand sea beach, passing into coarse coral shingle ( $\mathrm{Pl} .38$, fig. 1) in its most exposed places, with beach rock boulders cropping out at the base of the steep beach, or conglomerate boulders covering a part of the old ledge reef platform; this has a raised rim of Nullipores and Pocillipores, and a diminutive reef platform lagoon channel. The top of the high beach runs in loops into the bush vegetation, which at first is very meagre, but becomes quite thick beyond the summit rim of the beach, where cocoanut palms cover the land rim.

The shore platform of the lagoon is marked by two slight but distinct steps; these would seem to indicate a very recent elevation of 12 to 18 inches on the lagoon side. The long stretches of sand flats in the gaps and cuts which separate the lagoon from the sea (Pl. 37, fig. 2) are only decomposed ledge flats like the flats on the lagoon side of the land rim (Pl. 39). On some of these are still left the boulders or scattered rocks and corals which once formed part of the old reef ledge (Pl. 37, fig. 2).

The bottom of Pakaka Pass ( $\mathrm{Pl} .38$, figs. 1, 3) is covered by very fine masses of corals, heads of Astræans, Porites, and the like, extending down to 17 fathoms. On the island to the north of the pass, near the entrance point, back of the high shingle beach facing the pass, is found a small sink of brackish water. On the opposite island the shingle beach at the face of the pass is from seven to eight feet high, and the outer 
beach of that island is a steep sand beach topped with small coral shingle (Pl. 38, figs. 1, 3). To the south of the island a wide gap forming a shallow passage towards the sea is covered with fine coral sand silt, and shut off from the sea by a wide sand bar. An islet and a couple of sand banks flank the side of the flat, which opens out broadly into ledge flats extending far into the lagoon.

On the lagoon side the beach rock consists of a conglomerate of recent beach rock and corals, as well as fragments of the old ledge and its component corals.

The old ledge crops out in the lagoon about three quarters of a mile from the wharf in Pakaka Entrance (Pl. 34, fig. 3), its disintegration supplying the materials for the beach on the lagoon face, and for the low dunes three to four feet high, blown up occasionally on the lagoon side of the land rim (Pl. 39, fig. 1). The lagoon is less well closed than that of Rangiroa, where there are high white sand as well as gray shingle beaches on the sea face of the islands and islets of the land rim. The reef flat on the sea face is quite narrow, not more than 75 to 100 feet wide, and negroheads of old ledge are scattered along the platform at the foot of the beach (Pl. 37, figs. 1, 2).

On the lagoon face of Apataki the sand beach is low, not more than one to three feet in height. It is made up of fragments of recent corals and of broken shells. The highest islands of the land rim near the pass are not more than seven to eight feet. The beach on the sea face is steep (PI. 39); old ledge corals as well as recent corals are thrown up together, and form, as at Rangiroa, a more or less coarse shingle.

Dr. Moore collected on the Apataki reef flats Pocillipora, Millepora, Porites, and Madrepores. An islet on the flats to the north runs nearly across the entrance of Pakaka; it is about three feet above high-water mark, and made up of disintegrated old ledge rocks. Inside of the lagoon here and there a long narrow ledge of old reef rock crops out, similar in all respects to that seen in Pakaka Pass (Pl. 38, fig. 3). Similar ledges also occur on the lagoon side of the low reef flats, with occasionally a large negro-head (Pl. 39, figs. 1, 2). The land rim is an alternation of islets and low sand flats, with beach rock ledges on the narrow reef flats comnecting the islets. 
At one point we saw a great accumulation of large old ledge rocks with a regular pavement of smaller boulders piled up on the reef flat in front of them; this line of old ledge boulders extended fully one and a half to two miles. These large boulders are evidently a part of the old ledge still in place which crops out on the sea face of the island.

The island at the north end of the atoll shows the same features characteristic of the islands we had seen thus far near Pakaka Pass, and others on the weather rim; being somewhat more exposed to the action of the sea, the shingle beach is fully from eight to ten feet in height; occasionally a large head of old ledge crops out at the foot of the beach, and its remnants are the scattered boulders occurring on the flats, extending towards the lagoon beach of the land rim. A second islet not more than twelve inches high is made up of beach rock consisting of fragments of recent corals and of fragments of the old ledge, as well as boulders of the same material; it extends to the edge of the flat sloping into the deeper part of the lagoon.

Tihere Entrance is a short pass through a narrow part of the reef flat, presenting no special feature.

\section{Tikøï.}

Plates 40, fig. 2-4; 41-44, 201, 203.

Tikeï was discovered by Kotzebue in 1815. It is circular, about ten miles in circumference, and is an elevated coralliferous limestone island. The central part of the island is occupied by an indistinct sink, which represents a stage of denudation and of erosion somewhat more advanced than that of Niau (Pl. 44). The island is so well covered with vegetation and with decomposed coralliferous limestone material (Pl. 43) that it is difficult to trace the outcrops of the old ledge. These, however, we came upon in the small outlier rising from the pool (Pl. 44) which occupied the lowest part of the shallow sink of Tikeï. There is no lagoon proper, and the denudation of the old ledge has taken place to such an extent that the sea finds access to this shallow sink, which differs from that of Niau only in depth and in the height of the bank, which in the case of Niau prevents inroads of the sea, while at Tikeï it has access to the central sink through the shallow 
passages crossing the northern beach and which reach far in towards the centre of the island (Pls. 41-43).

The reef platform of the island is from 50 to 150 feet wide (Pl. 43, fig. 4); it consists of old ledge planed off on the northwestern fuce, while on the other side the platform is covered by a mass of boulders all consisting of old ledge rocks thrown up in part from the edge of the reef flat after being torn off, or in part from the disintegrated old ledge itself (Pl. 40, fig. 2). This extends inland to the termination of the bight or shallow wide gap (Pl. 41, fig. 1) leading to the sink of the central part of the island (Pl. 44); channels lead from the bight to the innermost parts of the sink, thus connecting it with the sea face of Tikeï (Pls. 42, 43).

The sea face beach of Tikei is high (Pl. 40, figs. 3, 4), from 10 to 12 feet. It consists, as at Niau and Rangiroa, of coral rubble or shingle on each side of the part of the reef flat covered with old ledge boulders. The bight or low gap is crossed by the mass of boulders mentioned above; they extend from the sea face of the platform a short distance inland in the gap. Behind the boulders, on the inner face, has been thrown up a low rubble beach (Pl. 41, fig. 1) composed of smaller fragments of recent corals and old ledge, almost closing the mouth of the gap, which is about 500 feet wide and extends fully 1200 feet inland, forming a cul-de-sac (Pl. 42), from the extremity of which lead the shallow channels (Pls. 41, fig. 2; 43), connecting at highest water with the sink which occupies the position of a lagoon in this island (Pl. 44).

The central part of the island is low, full of shallow sinks (Pls. 43, 44), connected evidently with one another in the rainy season; all leading into the main sink, an irregularly shaped depression about a third of a mile in greatest width, with a pool of brackish water in its deepest part from 40 to 50 feet long and about 25 feet wide (PI. 44). In the centre of the pool there was an outcrop of the old ledge (Pl. 44). The floor of these swampy sinks and channels was covered with Alga (PI. 43); at high-water stages the main sink must have been fully half a mile in length and from 500 to 600 feet wide. The lichens covering the flat resemble those found on the marshy flats of the Florida reefs.

Here and there we came upon patches of recent conglomerate beach 
rock which had been deposited on the underlying old ledge between its outcrops; but the greater part of the beach rock conglomerate had been disintegrated and reduced to isolated fragments, which in their turn had become worn and weathered to fine sand ( $\mathrm{Pl}$. 42).

In the central pool, as well as in the smaller pools of other sinks, we found mullet, probably the same species as that living in the lagoon (or greater sink) of $\mathrm{Niau}$, the former being not more at any time than four to five feet in depth, the latter at least 12 to 15 . The Tikeï sink communicates more freely with the sea than the Niau lagoon, separated as it is from it by a wall of nearly half a mile in width and fully 25 feet high.

The shore platform is full of potholes of all sizes, containing the pebbles of harder corals which formed them. The edge of the reef platform is deeply indented and scalloped by channels varying in width from a few inches to several feet, and some of them large enough to be used as boat passages for landing. The points between these channels rise considerably above the general level of the reef flat. They, as well as the reef platform, are covered with Nullipores and other calcareous Algæ, which appear to thrive best in the full force of the breakers. They rise sometimes as knolls fully four feet higher than the general level of the shore platform. The depth of the channels varies from a few inches to two or three fathoms, frequently the projecting irregularities of adjacent sides become soldered together, forming bridges under which the surf is forced, and is projected behind these connecting bars in columus of spray or water varying in height according to the size of the opening left. These bridges frequently form a continuous floor for a considerable distance. When the force of the surf is too great, they are broken off, as well as the higher knolls or projections which have been built too far out into the breakers and are thrown up on the reef flat as boulders, often of great size, at the base of the sand or shingle beach, to be ground into sand.

As seen looking down upon them from the ship, these indentations look like so many huge fingers extending into the edge of the mass of the reef platform; and in certain lights they look like light or dark blue passes or cuts, standing out in marked contrast to the orange-red masses of Nullipores and Pocillipores into which they have eaten. 


\section{Kauehi.}

Plates 45, 201, 203.

Kauehi was discovered by Captain Fitzroy in the "Beagle" in 1835. It is nearly circular, about twelve miles long from north to south and nine miles at its greatest width. The sketch given by Wilkes ${ }^{1}$ is somewhat different from the outline of Kauehi given by the French Hydrographic charts, ${ }^{2}$ which are somewhat more accurate. There is no entrance on the windward side, as is marked by Wilkes, and the lee face land rim is covered by a far larger number of islands than are indicated by him. We did not enter the lagoon, merely skirting the lee face of the island.

Kauehi is marked for the extent of the weather land rim, covered by islands and islets. With the exception of a short stretch on the southeastern land rim, it is more or less protected from the trades by the atoll of Raraka lying to the southeast; the southeastern face of Raraka, as sketched by Wilkes, ${ }^{3}$ plainly shows the effect of the prevailing winds on the character of the land rim', which is a wide reef flat in great part submerged and devoid of islands.

Along a part of the north shore of Kauehi we came upon a stretch of about a mile which was simply a mass of large boulders of old ledge rock (Pl. 45, fig. 3) spread at the base of the low beach line forming the land rim of this atoll, which is very narrow, so that steaming along we could look far into the lagoon over the low land rim (Pl. 45, fig. 1), and could see in the interior a number of ledges. Along the northwestern side we came upon a cluster of large boulders of the old reef rock scattered along the lagoon face of the reef flats. In the gaps and opposite them the old ledge is pretty well disintegrated (Pl. 45, fig. 2), forming here and there small islets on the reef flats and beyond, the lagoon reef flats being often very wide (Pl. 45, fig. 1), and the bare flats exposed to the action of the sea from both sides. Sand bars also occur on the

1 H. O. Chart 280.

2 Dépôt des cartes et des plans de la marine, 1716.

\& H. O. Chart 280. 
wider flats where sufficient material is supplied from the flats on the lagoon side.

We steamed by the large boulders of old ledge rock figured by Dana, which he considers as boulders thrown up from the outer edge. I am inclined to consider these huge undercut masses, many still attached to the reef platform, as outliers, or as part of the old ledge rock forming that platform; the more so, as a little farther on the same beach we find outcroppings of the old ledge running from the edge of the land rim across the greater part of the beach, - outcroppings which could not be a part of the outer edge of the reef platform.

The old ledge again crops out on the island to the north of the entrance to Kauehi. This island is perhaps ten to twelve feet high, and the old ledge puts out diagonally across the face of the beach from its highest point a series of spurs separated by short reaches of sand.

On the west side of Kauehi there are a great many low gaps between the islands and islets of the land rim opening freely into the lagoon, into which the sea washes. According to the position of the islands, the presence of old ledge or of boulders, either of recent corals or of old ledge, or of recent conglomerate formed of both, the beaches of the sea face are made up of coral sand of various degrees of fineness, or of coral shingle of varying size. The edge of the land rim is, as usual, flanked by a narrow belt of shrubs, which protects the land rim against the prevailing winds.

The entrance to Kauehi is very similar to the entrances into other lagoons, - an opening with deep water between two low headlands, flanked on the lagoon side by reef flats and islets or sand bars. Kauehi is said to have on the east side a secondary lagoon similar to those which we shall describe for Marokau and Ravahere, as well as to the secondary lagoons of Tahanea and Anaa. 


\section{Fakarava.}

Plates 46-50; 51, fig. 2; 58, fig. 1; 201, 203; 204, figs. 1, \%.

We spent some time in the lagroon of Fakirava. This atoll and Makemo, Hao, and Rangiroa are the four largest atolls of the group, Rangiroa being somewhat the larger. Fakarava is abont thirty-two miles long, ten miles wide, and rectangular in form. It runs from southeast to northwest; there are two ship passages, one on the northern face and the other on the southern face of the atoll. The northern passage and the northern part of Fakarava have been surveyed by the French, ${ }^{1}$ and the officers of the "Albatross" made a running survey of the western face from Ngarue Pass to the southernmost point of the atoll. On the lee side the atoll is fringed by large wellwooded islands, while on the weather side there is a wide reef flat on which small islands are found on the inner edge of the reef flat; on the northern face to the westward of Ngarue Pass a series of larger islands also forms the land rim. What is very characteristic of this lagoon is the large area which is studded with islands and islets, showing that probably a great part of the atoll of Fakarava was once a wide flat, ${ }^{2}$ composed of coralliferous limestone, which has little by little been denuded, dissolved, and cut down to the existing level. With the prevailing southeasterly trades a considerable sea runs on the lagoon side of the west coast of the atoll, which is raked diagonally by the trades from one end of the lagoon to the other. The same is the case with nearly all the larger lagoons which trend in a northwesterly direction, like Hao, Makemo, and Rangiroa, as well as with lagoons of somewhat less dimensions like Apataki, Arutua, Kaukura, and Tahanea, as well as others of smaller dimensions, all of which are swept by the prevailing trades.

The. width of the western reef platform is not much greater than that of the land rim on the lee side, showing plainly that the existing conditions are such as to favor the piling up of material on the lee side, while it is carried off on the weather side. It is evident, from the position of the islands on the lee face of Fakarava, that where the trend of the land rim is

1 Pl. 204, fig. 7.

2 Probably similar to the great lats of the lagoons of Anaa and Tahanea. 
such that additional islands are formed on the inner face of the lagoon from the deposition of drifting material, we should have (supposing that the reef flat has been gonged out to a moderate depth by the action of the sea) a secondary lagoon, comparatively narrow, formed between the lagoon face of the flat and the interior line of islands thrown up more or less parallel to the inner lagoon face of the land rim.

When off the north end of Fakarava it appears like a long continuous island with the usual fringe of low bushes and shrubs sheltering the cocoanut palms. On the western side of the lagoon there are many islets, but few rocks and ledges are exposed at low-water mark on the eastern side of the north passage, and the same condition continues southward along the eastern lagoon face.

On the north side of the entrance of Fakarava - Ngarue Pass (Pl. 46, fig. 2), which is half a mile wide - the old ledge crops out in places, and there is a long bare point on the south side of the entrance. In the pass there is from 5 to 7 fathoms of water, and once inside the lagoon the slope drops rapidly into 17 to 19 fathoms (Pl. 204, fig. 1). On the way to the anchorage off Rotoava we passed several outcrops of the old ledge ( $\mathrm{Pl} .47$, fig. 2), indicated as shoals on the charts. Two are three and even five feet above high-water mark (Pl. 58, fig. 1). Several flats make out as spits from the land rim on the lagoon side, showing the former lagoonward extension of the land. The shore line of this atoll has gradually been shifted and changed by erosion and disintegration and solution into the lagoon flats and shoals. All of these are generally composed of old ledge rock planed down from various causes to their present level.

The old ledge crops out on the sea face at several points, and is seen to run out from the top of the beach in wide buttresses upon the reef platform at right angles to the general trend of the surf. At other points the surf has cut down the old ledge to the level of the reef platform, or the sand and shingle forming the sea beach have overwhelmed the remaining low buttresses and concealed their presence (Pl. 51, fig. 2).

In the lagoon the sea breaks with considerable force, and the outcrops of the old ledge are separated by sand reaches, or even by short stretches of recent beach rock (Pl. 49). There are in the lagoon a great many ledges, 
shoals, islands and islets, most of which are outcroppings of the old ledge or are underlaid by the old ledge (Pl.47, figs. 2-4), which has been partially covered by beach rock or recent conglomerate or blocks of dead corals. Some of these ledges and shoals rise to nearly the same height - five to seven feet above high-water mark - as the islands found in the lagoon (Pl. 47, fig. 1).

The island forming the land rim at Rotoava varies in width from 900 to 1200 feet; it rises very gradually from the lagoon shore, where the beach is from four to five feet at high water, towards the top of the beach on the sea face. Its highest point is from 250 to 300 feet from the outer edge of the ledge platform, which is itself quite narrow, only from 50 to 75 feet wide; then comes the steep beach face of coral sand or of shingle of broken coral, next a slight depression, an outside beach of a lower level - a sort of breakwater, as it were - followed by a gradual rise to the highest point of the outer beach (Pl. 51, fig. 2). From the edge of the outer depression commences the fringe of the characteristic Paumotu atoll vegetation which acts as a shelter for the cocoanut trees (Pl. 50).

On the lagoon side the shore platform is in great part made up of beach rock and recent conglomerate, which has covered the old ledge and its shore outcroppings at most places (Pls. 46, fig. 3 ; 49). The lagoon platform is from 60 to 100 feet in width, but often juts far out into the lagoon in isolated patches (Pl. 58, fig. 1). The platform slopes gradually into six or seven fathoms of water, the slope and flats being full of coral patches, some of which extend as far as our anchorage.

Modern beach rock (Pl. 51, fig. 2) and conglomerate are also deposited on the sea face at the base of the steep beach on the top of the old ledge. Here and there the old ledge crops out from the beach rock at some point high upon the sea face of the beach, beyond the reach of the point where recent conglomerate is formed. The narrow sea-face platform is exposed to the full force of the breakers, which pound with their whole swing upon the raised outer edge of Nullipore knolls (Pl. 51, fig. 2). These are constantly broken off and forced up towards the base of the sea beach along the shore platform, and go to add to the mass of coral rubble which is constantly being rolled and ground into shingle or sand (Pl. 50). Together with the 
Nullipore knolls are found masses of Pocillipores, which here, as elsewhere in the Tropical Pacific, seem to flourish remarkably well in such an exposed habitat as the outermost edge of the reef platform.

On the lagoon side in many places a low sand beach, at the outside three to four feet in height, has been thrown up, inside of which runs a long trench or depression, the bottom of which is at about the level of the water in the lagoon at half tide, and is more or less full of brackish or fresh water according to the season of the year (Pl.48). Similar trenches or sinks filled with water are found in many of the Paumotus; they vary greatly in shape according to their position. If occurring along the lagoon face of a narrow island, they are mere trenches, but may become sinks or pools or even small ponds of considerable size, if they have been formed by the isolation of a wider tract of low land, such as at the extremity of an island near a pass, where the land usually widens out. Such pools have been described at Rangiroa (Pl. 204), on the south of Avatoru Pass, and are known in many other atolls in the Paumotus, in the Ellice and Marshall Islands, which are described as having ponds or sinks filled with more or less brackish water. ${ }^{1}$ Dana has described them as occurring at (Manihi) Waterlandt, so named from the presence of a number of such trenches and pools or sinks. One of the sinks to the south of the village of Rotoava must be fully four feet deep and at least 200 feet long by 30 wide. $^{2}$ These sinks, when of considerable length and width or depth, have been described as secondary or subsidiary lagoons. I shall have occasion to describe their formation in other atolls where their structure is more easily seen than in Fakarava, as in the lagoons of Likieb and Jaluit.

The effect which the violent surf has in modifying the mode of growth of corals is very striking, and it would often be difficult to recognize in the spreading mass found on the outer reef flat the delicately branching species characteristic of the lagoon. Everything living on the sea face

I The long sinks more or less parallel to the shore of the island are formed by the throwing up of a low beach sand dam, behind which water collects. At one of the points we really have an atoll within an atoll, formed by the ring of islets and sand bars cutting across the shallow reef flats of the point. This we shall find developed on a larger scale in other atolls not only of the Paumotus, but also in the Gilbert and Marshall Islands.

${ }^{2}$ Dana (p. 324) mentions a sink in Aratika 50 feet in diameter. 
platform seems to adapt itself to its conditions. Holothurians are found only in deep pools worn out of the flat or protected by masses of boulders. Every boulder is full of boring annelids, mollusks, crustacea, and sponges, which one would seek in vain on the exposed face of the reef flat, but which are abundant in the quieter waters of the lagoon. Echini, Ophiurans and Holothurians, which are buried in deep holes on the sea reef, live quietly exposed to full view on the lagoon side. Of Echini, those with massive spines like Heterocentrotus seem to be able to withstand the force of the surf; and they as well as the peculiarly protected Colobocentrotus, the spines of which are merely a close pavement covering the test and strong enough to withstand the full shock of the largest rollers breaking on the edge of the reef flat, seem to prefer the sea face of the atoll to the lagoon side, where in fact they do not occur. ${ }^{1}$

The outer edge (the sea face) of the reef platform is from one to two feet higher than the general level of the platform itself, and in some places even three feet (Pl. 51, fig. 2). This forms a wide channel between the outer Nullipore edge and the foot of the beach, and in this rudimentary lagoon a strong current is formed by the surf driving the water on to the platform through the channels and gaps left between the Nullipore knolls. On a wide reef platform a regular barrier reef with a diminutive lagoon would be formed, as at Anu-Anurunga and Hereheretue. This reef lagoon may be compared to the long narrow sinks formed on the lagoon side of the land rim by the throwing up of sand beaches in a line parallel to the land rim.

We examined about five miles of the lee side of the lagoon to the south of the village, and found it identical in structure with that westward of the village, patches of beach rock cropping out at short intervals for a couple of hundred yards, and again separated by coral sand beaches rising to a height of not more than three or four feet. Here and there we came upon in outcrop of old ledge running at right angles to the beach, encroaching more or less diagonally upon the face of the beach, or upon some outlier of the old ledge, part of the outer platform of the lagoon.

The underlying old ledge is generally concealed by beach rock or by

${ }^{1}$ I was greatly surprised to find Echinoneus alive on the outer reef platform, buried in cavities of the rock. 
recent conglomerate on the sund beaches and flats. Along the lagoon side there are wide platforms of beach rock dipping slightly towards the lagoon, extending out from the shore in points or flats from 600 to 700 feet in width. A number of shallow patches of the same are found in from six to seven fathoms, rising nearly to the surface, the sides overgrown with corals and Nullipores, the corals being mainly Madrepores, Pocillipores, and a few small heads of Porites. The Nullipores and coralline Algæ are of all colors, from white to yellow, pink, or orange.

We made a series of soundings at right angles to the lagoon shelf, passing very gradually into 17 fathoms at a distance of about 2500 feet. At 200 feet from the shore we were in 5 fathoms, obtaining 8 fathoms at 500, 12 fathoms at 1000 , and 16 fathoms at 2000 feet. The bottom of the lagoon was sandy, consisting of decomposed beach rock and of old ledge rock, with patches of Nullipores. We collected large pearl oysters on which were growing two species of Madrepores, one seven inches long, the other four; the shells were said by the natives to be about five years old.

A line of soundings running in a northeasterly direction across the lagoon of Fakarava, about half-way from the eastern edge to the islands inside, developed from 22 to 24 fathoms. Fakarava is marked for the great number of islands in the northern part of the lagoon ( $\mathrm{Pl}$. 204). Those we visited are situated about half-way across the lagoon, rather nearer the reef in a northerly and westerly direction, varying from one to five miles from the edge of the reef (Pl. 47, fig. 1). The island group consists of a cluster of ledges, of shoals, of sand banks, of islets and islands, more than forty in number (Pl. 46, fig. 1), all of which were visible from the point of the island where we landed (Pl. 47, figs. 3, 4). The islets just described extend close to the north coast (Pl. 204, fig. 1). They are scattered in an elliptical area of from four to five miles in diameter. On some of the higher sand bars a little vegetation is found, and as these islets and shoals increase in size they are better covered with shrubs, and an occasional cocoanut tree is found on the larger islets. ${ }^{1}$

\footnotetext{
1 On the isolated islets having cocoanut trees, the nuts must have drifted there and found a foothold, for we can trace all the stages from a single small young tree to a cluster of eight or ten, on islets well isolated from the larger ones on which cocoanut trees have long been planted. 
On the northwestern land rim there are a number of small islets connected by sand bars on the lagoon side, and running somewhat diagonally towards the reef flat edge, the edges of these bars are separated by negro-heads or bands of beach rock at right angles to the coast line.

On a nearer view of the cluster of islets inside the lagoon, we could see that many of them were separated by comparatively deep water from the outer reef flat, which is fully half a mile wide. We could see the old ledge outcrops on many islands (Pl. 47, figs. 1, 3), as well as those of beach rock and of recent conglomerate, flanking many of the sand bars and sandy islets or keys. The lower part of it near the foot of the beaches is covered with a recent very coarse conglomerate of shells and corals (Pl. 47, fig. 2). On one of the islets the old ledge projects prominently at the eastern extremity, the inner extension being covered with sand. On many of the islands the ledges are composed of beach rock and conglomerate which has concealed the old ledge rock cropping out at many of the other islands. The conglomerate has also extended over the shallow parts of many of the flats adjacent to the islands. As we steamed south, the old ledge was again observed on the western face of many of the islets, standing like a raised wall, more or less broken, presenting on a small scale the elevated wall we had seen at Rangiroa (PI. 46, fig. 1). After leaving the cluster of islets, which became gradually more widely separated as we steamed south, we found only a wide reef flat, on the edge of which are large boulders of beach rock or of old ledge.

The few soundings we made indicate quite deep water between the cluster of islands and the outer reef. The islets are covered with vegetation just as are the islands of the land rim flat (Pl. 47, figs. 3, 4).

This group of islands, ledges, and shoals is a part of a wide ridge more or less parallel with the basin of the lagoon, of which the higher parts alone remain as islands and bars which have not been eroded or carried off in solution. The reef flat on the sea face of the eastern land rim is full of pot-holes more or less filled with gravel; these pot-holes are some of them circular, others elliptical or run together as long and deep furrows. The action of the current inside the Nullipore knolls is to scour out a channel along the outer face of the reef platform. This 
is one of the richest collecting grounds we have met, though many reef flats in other islands of the group similarly situated are comparatively poor in animal life. The finger-like scalloping of the onter edge of the reef platform is also well indicated at Fakarava.

The bottom samples of the lagoon, wherever collected, indicate the presence of coral sand made up of Nullipores, of corallines, and of fragments of corals reduced to minute pieces by boring sponges and Algæ, of broken parts of echinoderms and mollusks as well as Foraminifera.

On the lagoon side of Fakarava near the village of Rotoava, in from two to three fathoms of water, are numerous fine patches of corals composed of Astræans, Porites, Goniastræans, and Madrepores. In somewhat deeper water these patches become larger and run out into 8 to 10 fathoms. The same condition exists on the slopes of the shoals, sand bars, and islets, the corals appearing to be most flourishing in from 5 to 9 or 10 fathoms. As we passed out of the Ngarue Pass, we could see in the pass and on the outer slope, down to 17 or 18 fathoms, a fine growth of large masses of corals, which rapidly became separated by wider and wider patches of fine white sand, till the coral patches disappeared completely in from 20 to 22 fathoms.

Skirting along the north shore of Fakarava, the land rim islands are flanked by long stretches of sand beaches. Long reaches of coral rag shingle extend along the eastern face of the island. These sometimes form high beaches, and between them low channels have been cut, such as we found back of the village of Rotoava.

The west side has not been built up as much as the other, and the material washed over the western flat has formed the wide reef flat of the weather side. The sand bars and sand islets are always on the lagoon side of the flat where islands are ultimately developed; lines of beach rock or of coral boulders or fragments of the old ledge run across the flat, generally at right angles to the outer edge, with larger boulders or negroheads of old ledge or beach rock or recent conglomerate on the outer edge of the sea face of the reef flat, across which here and there wide gaps, somewhat deeper than the rest of the reef flat, allow the water freer access to the lingoon than elsewhere. 
On the southwestern point of Fakarava we passed a fine old ledge reef platform covered with Pocillipores, considerably higher than the inner flat, and higher again on the lagoon side, with raised sand bars full of small gulleys running at right angles to the sea line. About two miles north of the southwestern point, the old ledge is standing as a sort of broken wall about two feet high; it is more or less cut into by the sea, and large boulders have been broken off from it on the sea face and thrown up on the reef flat of the western face behind the raised edge, rising fully five to seven feet, as in Rangiroa.

On the south side the land rim is formed by large islands near the south pass and a low reef extending to the islets on the east side. In the middle of the lagoon, about due north of the south pass and near it, there is a wellwooded islet.

\section{Anaa.}

Plates 51, fig. 1; 52, 53, 201, 203.

Anaa is about twenty miles long and six miles wide; it is elliptical; its general trend is from the southeast to the northwest. It receives its name, Chain Island, from the very regular dimensions of the islands forming its land rim, so that a plot of it resembles a long bracelet with links of nearly uniform size. The islands are well covered with cocoanut groves, and, although there are many gaps between the islands and islets, there exists only one very indifferent passage for boats into the lagoon.

On the northwest shore of Anaa are fine outerops of the old ledge running at an angle to the shore line and separated by sandy beaches. On the north side exists an inner line of islands (Pl. 51, fig. 1) dividing the lagoon into two very distinct parts.

At the northwest point of Anaa there is a comparatively deep lagoon, a secondary channel extends parallel with the shore line, from the base of the outcropping old ledge to the Nullipore and Pocillipore edge of the reef flat. This canal runs for quite a distance parallel with the coast line, and expands into a large bay forming the pass or cut between two adjoining islands (Pl. 52, figs. 2, 3). The reef flat then becomes quite wide, -500 to 600 feet. All the way from the west shore to the landing bight there are 
fine outcrops of the old ledge, buttresses reaching nearly to the water's edge across the sand beaches, and separated by coral sand beaches or by coral rag shingle beaches (Pls. 52, fig. $1 ; 53$, fig. 1).

'To the south of the inner line of islands extends an immense flat covered only with a few feet of water (Pls. 52, fig. 2 ; 53, fig. 3), the whole flat shining brightly in the sun as a light green sheet, in contrast to the darker greenish blue band of deeper water extending towards the south. This flat covers so great a proportion of the lagoon that its greenish light, reflected against the clouds, can often be seen long before the atoll itself looms in sight. Other shallow lagoons are also detected in this manner. The greater part of the lagoon is quite shallow, not more than from one to two fathoms in depth. A great many sand bars are found all through the lagoon.

This atoll is intermediate in structure between such an atoll as Fakarava, which has a comparatively deep lagoon full of islands, and a solid island or an island with an insignificant lagoon or sink, such as Tikeï.

The northwestern part of Anaa will soon be filled with islets; in that part of the lagoon sand is constantly piling up inside on the lagoon side, and on the sea face reef coral shingle beaches are thrown up (Pl. 53, fig. 2). At a distance the bight where the boat pass is situated looks like an inlet to the lagoon between the islands, but the lagoon is shut off by a wide flat, the extension of the reef flat to the east of the secondary lagoon.

On the east, as well as on the west side of the atoll, are alternating low and high gaps. On the east face the old ledge crops out in a series of high spurs running diagonally across the face of the beach.

\section{Tahanea.}

Plates 54, 55, 201, 203.

Tahanea Island is about twenty-five miles long, it is irregularly elliptical, and perhaps ten miles at its greatest width. On the north side within a distance of about two miles there are three entrances for small vessels into the lagoon. The land rim on the north side is well wooded, while on the southern face the islands are generally bare. 
We struck the central part of the western face of Tahanea, and found the interior of the lagoon dotted all over with islands or ledges, the islands flanked with spurs of old ledge outcrops, and the ledges running diagonally across the middle and southern part of the lagoon. Parallel with the south face runs a remarkable secondary lagoon, about one mile wide at its widest part, formed on the sea face by the broad reef platform, fully 1000 feet wide, and on the other side by a series of islands rising from an inner reef flat as wide, if not wider, than the outer flat, and separated by a deep channel, in places from two to three fathoms in depth (Pls. 54, figs. 2, 3; 55, figs. 2-4). The depth of the channel greatly varies; it shallows both at the eastern and western ends, where the secondary lagoon narrows, and eventually, at the northern end, terminates in an island (Pl. 54, fig. 1), which blocks the cul-de-sac of that part of the lagoon where the outer reef flat is not more than from 50 to 100 feet wide. The islands to the east of the secondary lagoon are generally well wooded (Pls. 54, fig. 3; 55, figs. 1, 2, 4). From the topsail yards no extensive clear space could be seen in the lagoon, the islets and islands occurring apparently throughout the whole lagoon. The old ledge seems to be exposed all along the south face, and is flanked by a comparatively narrow reef platform, edged by Pocillipore and Nullipore knolls (Pls. 54, fig. 3 ; 55, figs. 3, 4).

The secondary lagoon is cut up by ledges in all sorts of ways; these same ledges send spurs into the main lagoon, where there are innumerable single rocks and ledges and islands and islets making irregular divisions of the lagoon, more or less shut off from one another (Pls. 54, 55). Numerous sand bars form low islets and islands on the inner side of the reef platform. The outer reef flat is from 800 to 1000 feet wide (Pls. 54, fig. 3; 55, figs. 2-4). At the southwestern horn, where the secondary lagoon ends, islands and sand bars again appear on the lagoon side of the outer edge of the reef platform of the atoll. These islets are from eight to nine feet high, with coral sand beaches on the inner or lagoon side (Pl. 55, fig. 3). A few boulders are thrown up on the reef flat, of which the outer edge is well gouged out in the finger-like channels and scollops running at right angles to the sea face of the reef 
platform. On the west face we could see that the islets of the reef flat were placed on the inner lagoon edge, at an angle with the shore line; we could also readily trace the sand beaches of the lagoon end of the islands, as they gradually pass into the shingle beach characterizing their sea face extremity (Pls. 54, fig. 1; 55, figs. 2, 4). These islets and islands, thrown up either from the outside face or from the inside face, alternate with one another, but all have shingle beaches on the sea face extremities and coral sand beaches on the lagoon side ends. The shingle beaches are gradually forced towards the lagoon side, where they meet the sand bars pushed seaward by agencies from the lagoon side, or vice versa (Pl. 55, fig. 2). The currents, both running in and running out, gradually accumulate more and more sand, cover the beach rock boulders and shingle, and spread over the reef flat, and finally form a bar extending quite across it. If the depth of water between the outer and inner edges of the reef flat is too great, two separate islands are formed which will become joined when the channel between them has been filled or bridged over in part, when the whole of the exposed flat, either on the lagoon side or the sea face, has been completely covered by shingle or sand and has formed a continuous island from the lagoon edge of the reef flat to its sea face (Pls. 54, fig. 3 ; 55, figs. 2, 4).

All along the south shore the reef flat or the land rim is so low that at the least sea, water must be driven through the gaps separating the reef flat islands (Pls. 54, 55). In the lagoon the old ledge has been planed off to about high-water level, so that but little material is now supplied from the disintegration of the numerous shoals and ledge flats left in the lagoon; the greater part of the material is derived from the lagoon edge of the outer reef flats or from some of the higher ledges left in the lagoon.

Young cocoanut trees grow on some of the smallest and lowest sand islets when not more than one to two feet high, while on larger and higher islets they are more numerous, and by the time the islands extend across the outer reef platform they are well covered with the characteristic coral reef vegetation, as well as with cocoanut trees (Pls. 54, fig. 2 ; 55 , figs. 1,2 ). 
On the northwestern face of Tahanea we find here and there a stretch of a secondary lagoon similar to the one described on the south shore, but not more than 20 to 25 feet in width. At the horn of the northwestern point are fine patches of beach rock covering the old ledge, and coral shingle, and black shingle thrown up on beach faces from six to seven feet high (Pl. 54, fig. 1).

After passing the northeastern point, going southeast, we saw a beautiful effect of the blending colors of the line of breakers, of the dark masses of rocks and boulders, and of the sky line without any special line of demarcation. We could see the flash of the columns of white breakers, like the explosion of a torpedo, thrown high up in the air against the gray sky, bringing out on the horizon a sharp line of dark spots which were the boulders and rocks covering the reef flats. Along this part of the atoll the reef flat is from 200 to 250 feet in width, the lagoon edge being formed by an irregular belt of sand burs or of beach rock shingle; the central parts of the flat are covered with endless shingle bars at right angles to the trend of the sea face.

The north face of Tahanea is low, narrow, with here and there a broader island, say 800 to 1000 feet, running diagonally across the narrow land rim of the north side, and connecting more or less, on the lagoon side, the numerous ledges in the channel which separate the outer reef flat from the wide inner reef flat, on which these broad islands have been thrown up.

Outcrops of the old ledge are not uncommon close to the narrow outer reef flat of the north shore.

Towards the northern point of Tahanea the atoll is edged with a somewhat narrow reef flat awash, not more than from fifty to one hundred feet in width; for six to seven miles the north shore land rim is low and narrow, with only here and there an islet or ledge within the lagoon. On the face on which are the entrances into the lagoon somewhat higher islands have been formed, with rather more vegetation than is usual in the Paumotus; these islands are all faced by extensive coral sand beaches on the lagoon side. More or less parallel with them on the interior of the lagoon are scattered numerous sand bars and sand patches, many of them rising into 
islands north of the western entrance, with a wide lagoon flat and many rocky ledges extending from a mile to a mile and a half into the lagoon.

The formation of all these islands, more or less at right angles to the line of the outer reef flat, is probably due to the currents which run parallel to the lagoon face of the flats, caused by the hauling of the prevailing winds along the coast lines of the atolls. These currents carry more or less sand, and meeting an obstacle, this acts. like a jetty, some of the sand is deposited, and thus a diminutive sand spit is formed which, little by little, forms a series of sand points projecting into the lagoon. The spits increase from either side, from whichever direction the wind may draw, and thus the reef flats are in the first place widened, and in the second place partially covered with sand, leaving the sea free access to the lagoon only through the gaps between the spits and over the sea face of the reef flat, wherever the beach rock or recent conglomerate or coral shingle spread over the old ledge has not been covered with sand. These sand buttresses thus form the beginnings of small low sand islands on the lagoon face of the atoll; as they increase in size, they gradually join similar accumulations of beach rock or coral shingle, thrown up in a similar but in a much more active way, on the sea face of the reef platform.

This phenomenon is well illustrated on the islands and islets to the south of the north point of Tahanea, where not only their growth can be distinctly traced, as has been described, but where also the manner in which they become clothed with vegetation can be equally well followed. The ledges and the shoals in the lagoon supply the material for the inner sand spits. On the line of reef flats and on the sea face, the breakers grind the material on its edge and supply the coarser material for the shingle beaches, which may be thrown up to a height of from two to three feet.

As far as we could see to the eastward, the conditions of the eastern shore did not seem to differ from those of the northern and southern parts of the atoll which we examined. 


\section{The Raveskoi Islands.}

The Raveskoi Islands consist of three small atolls - Tuanake, Hiti, and Tepoto - discovered by Bellingshausen in 1820 .

\section{Tepoto.}

Tepoto ${ }^{1}$ appears, as seen facing the southeast, edged with high coral sand beaches with a few boulders scattered at their base. According to Wilkes's sketch this small atoll is about two miles in diameter, nearly circular, with a land rim on the northern part of the atoll, and a bare reef flat flanking the southern face of the atoll.

\section{Tuanake.}

Plates 201, 203.

Tuanake appears to have a very narrow land rim, - narrower perhaps than in any atoll of the Paumotus we have seen thus far. On the south side the atoll consists of an extensive flat filling that angle of the lagoon and extending far into it as a huge spit. There are three very prominent islands on the flat connected by beach rock ledges. On the sea face the shores of the islands of the land rim are edged with rocky ledges, alternating with short comal sand beaches, while on the lagoon side they are bordered by coral sand benches only. Tuanake ${ }^{2}$ is, according to Wilkes, rectangular in shape, with the land rim on the eastern, northern, and western faces. The atoll is nearly four miles across.

Owing to thick weather suddenly coming on, we were unable to examine Hiti. Wilkes describes it as also rectangular, and it differs from Tuanake only in size. The atoll is about two and one-fourth miles across. 


\section{Takume.}

Plates 56, 57; 58, fig. 2; 201, 203, 205.

Takume is marked for the great number of the islands and islets which form the land rim on the lee side, from forty-five to fifty, a far greater number for that length of face than we have seen anywhere in the Paumotus. On atolls, which, like Takume, ${ }^{1}$ run from the southwest to the northeast the land rim is mainly on the lee side and only partly on the weather side; on atolls which run in the opposite direction the land rim is usually best developed on the northern and eastern faces, which may be considered the lee side, the southwestern extremity being usually bounded by low bare reef flats with but few islands and islets. This atoll is about twelve miles long, quite narrow, not more than two and a half to three miles at its greatest width. A large island occupies the greater part of the northern point of the atoll; its weather face is one long line of low reef flats hardly bare at low water. This atoll has always been described as a splendid example of a closed atoll without an entrance. If it is intended by that to denote that boats cannot enter the lagoon, such is really the case; but the amount of water which pours in over the weather side of this atoll is something enormous, and numberless passages on the lee side allow free exit to the water, which is driven into the lagoon over the weather reef flat. We steamed around this atoll, and from its elongated and narrow shape were able to take excellent views of the two sides of the islands and islets both on the lee and weather face of the atoll.

The southwestern point of Takume is formed by a reef flat extending east from the southernmost island. It varies in width from 100 to more than 300 feet. The island terminates in a high steep beach covered by coral shingle, at the base of which crops out the old ledge. On the other side of the southwestern horn the inner limits of the reef flat are indicated by a line of sand bars, and adjoining islands of the western face are separated by gaps more or less wide, similar to those we described at Rangiroa, in which the old ledge crops out. The surf washes freely into the lagoon over the east

1 H. O. Chart 83 , sketch by Wilkes. 
face, where there are but three small islands with sand bars on the shallow submerged reef (Pl. 57, figs. 1, 4).

On the central part of the west shore there is a wide reef flat partially covered with beach rock scattered over the surface of the old ledge in innumerable boulders, especially near the sea face. Gaps of varying width follow one after another in quick succession as the separate islands make their appearance along the western face of the atoll. Many of the gaps are not more than 30 or 40 feet wide. The sea face of the islands is usually flanked by coral shingle beaches, while the lagoon beaches consist of coral sand (Pls. 56, figs. 2, 3; 57, fig. 2). Bars of sand seem to be forming both on the lagoon side and in the cuts, the sand piling up on the lagoon edge of the flats (Pl. 56, fig. 2). The island at the southwest point has a high shingle beach (at least six to seven feet), the other islands to the north have low shingle beaches (Pls. 57, fig. 2; 58, fig. 2), not higher perhaps than three to four feet.

A wide reef flat extends on the lagoon side of the islands, more than a third of a mile in width (Pl. 57, fig. 4), and at the northern extremity of the atoll, this flat is covered by a large island occupying its horn, and fully 1000 feet wide (Pl. 56, fig. 1).

At the base of the shingle beaches of the islands, on the western rim of the atoll, are accumulated masses of large boulders (Pls. 56, figs. 1, 2; 57 , fig. 3 ; 58, fig. 2), many of them beach rock or recent conglomerate; other boulders are outcrops of the old ledge which forms the underlying base of the atoll, and which have not been concealed by the mass of recent material thrown up on the surface of the outer platform.

The whole of the shore of the north point is thickly covered with large boulders, many of them undercut on one side, forming so-called horseheads, - parts of the old ledge still attached to old ledge reef platforms. The tinted Nullipores and red or pink and blue Pocillipores color the knolls forming the outer raised edge of the reef platform. On the northern part of the east face the reef flat is wide, fully 1500 feet from the base of the shingle beach flanking the northern island, and slightly dished (Pl. 56, fig. 1), it is full of sinks and pot-holes. At the base of the shingle beach run stretches of beach rock, recent conglomerate, and outcrops of old ledge. 
On the west side the reef flat shows but little tendency to dishing; it has a more uniform slope from the base of the shingle beach to the outer raised edge of the reef platform.

At some points the old ledge must be at some distance below the sea level, judging from the size of the beach rock and recent conglomerate boulders which have been thrown upon the outer reef flat.

On the east face there are but three wooded islands, and a number of rocky islets and sand bars (Pl. 57, figs. 1, 4), all placed on the lagoon side of the outer flat, which is fully 2000 feet wide, and is more or less dished and gouged out into long canals and pot-holes. Numerous boulders consisting of beach rock and recent conglomerate, as well as old ledge, crop out in all directions upon this flat; they are weathered into all possible shapes and sizes, from a large boulder to the smaller fragments which supply the material for the shingle beaches and bars. On the more open part of the east face the reef flat becomes narrow, especially near the central part of the island, where it is not more than 200 to 300 feet.

On the island and islets of the east side of the atoll cocoanut trees, often single, are growing at all points where land is making. Young cocoanut trees have here, as elsewhere in other lagoons, evidently been transported by the sea on the smaller sand islets; they have not been planted.

On the outer edge of the reef flat there is the same raised edge of knolls of Nullipores growing at the extremity and between the narrow and deep cuts which encroach upon the outer edge of the reef flats. Many of these large knobs seem ready to be torn off by the next high sea, to be then thrown among the rocks and boulders and horse-heads studding the outer reef flat.

Many of the islands and islets are, as at Anaa, quite a distance from the outer edge of the reef flat, well on the inner lagoon face of the flat.

The lagoon is comparatively shallow, not more, on the average, than from five to six fathoms.

As we left Takume, this shallow lagoon also showed us the same reflection in the clouds which we had noticed on approaching Anaa, and other large atolls with shallow lagoons and with wide reef flats.

On the reef flat of the east face the old ledge forms the underlying 
base; it is honeycombed and pitted where exposed to the action of the sea and weather, and where the modern beach and conglomerate boulders have been swept off or eroded from its surface. The east face, south of the islets, is a reef flat bare at low water, with a great many shallow gaps through which water flows into the lagoon even at the lowest tides.

Takume is, like other atolls of the group, a narrow pear-shaped ridge, widest opposite Raroia, its lagoon gouged out in part by the action of the sea, or in part shut off from the sea by sand banks and shingle beaches formed in the lagoon on the reef platform.

At dusk, when laying to off the south point of Takume, we could see the whole atoll stretching to the northward as plainly as if it had been charted out. The line of numerous wooded islands and islets flanking the western face of the atoll extends about fourteen miles in a northeasterly direction in a large arc somewhat convex to the west, while on the east face parallel with these runs the low bare reef flat with its three small islets separated by the shallow and narrow lagoon of the atoll. The reef flat is widest near the northeast horn; the southern coast forms a curve which gives to the atoll a slightly pear-shaped outline.

Looking across the narrow lagoon from off the east face, the wide bare reef flat separated by the shallow water from the islands and islets of the western face presented all the appearance of a narrow secondary lagoon, only somewhat wider, such as we have described for Anaa and other atolls of the group.

\section{Raroia.}

Plates 201, 203.

Raroia Island, like Tahanea, was discovered by Bellingshausen. It is very lightly wooded on the east side, but the west and north sides, along which we skirted, are well covered with vegetation. This atoll and Takume to the north of it have a southwesterly to northeasterly trend (Pls. 201, 203), a direction opposite to that of all the islands of the Paumotus we have thus far examined.

Raroia is about twenty miles long; it is a narrow, elliptical, somewhat pear-shaped atoll, not more than six miles at its greatest width, in the 
northern part of the atoll. It and Takume are remarkable for the number of islands which are found on their western face. The larger islands of the land rim of Raroia form the northern and southern horns of the atoll.

Along the west coast of Raroia there are very large boulders scattered all along the shore, seemingly larger than any we had seen before. As we approached the beaches towards the northwest point, the shore ledges became more apparent. There is but little sand above them, and everywhere large boulders were scattered about.

The islets on the opposite face of the lagoon, as seen across the lagoon, have their sandy beaches on the lagoon side, and those on the west face have similar sand beaches on the lagoon side, passing gradually into the coral shingle beaches facing the sea and with a narrow reef platform bordered by long reaches of old ledge rocks. Across the low gaps in the islands we could see also the light green strips of the narrow lagoon platform. The islands and islets on the west side all appear to be placed more or less at an angle across the outer rim flat. At the west point there is a long line of small sand bars on the inner edge of the lagoon flat, some of them islets high enough above tide lines to be covered with a scanty vegetation. The reef flat extending around the northwest point of the atoll is wide, and its sea face is flanked by a low bank of coral shingle. On the lagoon side of the flat rise a series of islets and islands more or less at right angles to the general trend of the shore.

The old ledge crops out at the base of the coarse shingle beaches, and runs out in low buttresses more or less covered by sand or coral shingle. On the reef flat many boulders of old ledge are scattered.

The east face of the atoll, as far as we could see it, is quite bare of islands, the bare or partly submerged ledge, according to our pilot, resembling in every respect that of Takume. The outer islands gradually diminish in number from the north side towards the east and south, while on the north end they are quite closely crowded. The islands, as is usual, are placed at right angles, or nearly so, to the general trend of the shore line. This structure is of course ultimately lost sight of where adjacent islets have united into a larger island. In some cases the process of consolidation has been repeated often enough to make an island several miles in length but 
only a couple of hundred yards wide at the outside. We find on the islets the usual coral shingle on the sea face beaches and coral sand on the lagoon side. The shore platform is from 100 to 200 feet in width, and is edged by high Nullipore knolls; it slopes quite sharply from the base of the shingle beach to the sea face. The boulders and ledges at the base of the shingle beach are made up of beach rock and recent conglomerate which at one time must also have covered the greater part of the old ledge reef flat. But the material which covered the sea face of the old ledge has all been washed away and has been deposited either as boulders at the foot of the beach where the beach rock still crops out, or has been ground into the coral shingle forming the shingle beaches, or has together with the smaller rolled coral fragments supplied the material for building up the sea side of the islands of the outer rim of the lagoon.

A similar condition of things has been described at Fakarava and on the north side of Rangiroa.

On the west face the gaps separating the islands are often quite wide, and from the color of the water passing through them a large quantity of water must pass in and ont at every tide; or else the gaps may be closed either on the lagoon side or on the sea face by shingle banks or sand bars, forming thus diminutive bays opening, as the case may be, towards the sea or communicating freely with the lagoon.

About three or four miles north of the West Pass there is a long line of huge boulders of beach rock, some of them of colossal size; one of them must have been eighteen by twelve feet and nearly as high (twelve feet). They formed a striking dark mass at the base of a narrow beach, with a narrow reef platform of yellowish rock edged with a brilliant band of pinkish and orange Nullipore and Pocillipore knolls slightly raised above the level of the edge of the reef platform. Where the boulders were still a component part of the stratum of rock overlying the old ledge, close to the base of the beach, they are more or less undercut.

All the islands on the east end show fine coral sand beaches on the lagoon side and beach rock boulders and coral shingle on the sea face. Occasionally we come across a stretch of beach or coral shingle from five to six feet high. 
We find the same digitating channels worn into the sea face of the reef platform, cutting the outer edge into knolls which are gradually undermined at the sea face of the reef platform, and finally are broken off in large masses; these are thrown up on the ledge flat and broken up little by little, according to their size and their more or less exposed position on the platform, and also according to their composition of hard old ledge or of more easily disintegrated beach rock or recent conglomerate.

The entrance on the west side of Raroia is fully 1200 feet wide, a strong tide rip running diagonally across the mouth of the passage according to the stage of the tide. The passage is flanked by a high and steep shingle beach on one side, while on the other there is a low, long coral sand spit. The west side is raked by the wind, the sea following the shore; while the east side is butted by the wind and sea, which clear the reef flat of all loose material; as the platform passes into the lagoon and comes under the influence of the lagoon wind and sea following the shore, it is again covered by islets and bars. Opposite the gap forming the entrance we could see on the other side of the lagoon a few islands both to the north and south.

South of the entrance the land rim is more continuous, less cut into islands, with long stretches of shingle beaches, and with small boulders of beach rock at the base of the beaches, with here and there larger masses. The shingle beaches are steep, from six to seven feet high. A section, from the outer sea face of the reef platform to the top of the sand or shingle beach, shows a reef platform of old ledge from seventy to one hundred feet wide, edged with a growth of Nullipores rising from one to three feet above the outer level of the flat and running out in a digitate form. At the base of the beach crops out a ledge of beach rock, which at one time must have covered the greater part of the old ledge flat, but which has been washed away, and supplied as elsewhere the material for the beaches and the building up of the seaward part of the land rim islands.

The stretch from the southwest point to the southeast point forms a great bight, similar in all respects to the stretches to the north on the west face of the atoll; the whole seems one long continuous stretch of land rim without gaps, with a high beach of coral shingle, and a beach rock ledge at the foot of the beaches. 


\section{Taenga.}

Plates 201, 203.

Taenga is triangular in shape, about ten miles long and five at its greatest width. ${ }^{1}$ The land rim is situated mainly on the faces of the northern extremity of the atoll. The whole eastern end of the northeastern and southern faces consists of low reef flats, bare at low water. There is a narrow passage for small vessels on the southwest side of the atoll.

As we steamed westward along the greater part of the northeast shore of Taenga, we skirted along the face of a large island which occupied the northwestern horn of the atoll. At the eastern and southern extremities the islands are separated by wide gaps, and their shores flanked by high coral sand beaches, with many reaches of huge boulders.

The shore of Taenga to the east of the northwestern point is low and lined with huge boulders of beach rock. There is no coral shingle at this point, and on the islands of that part of the land rim the old ledge is hidden by modern beach rock. The reef platform where the old ledge is exposed is quite narrow, and is covered with red Pocillipores and pink and orange Nullipores. As far as we could see into the lagoon there are no islets to the south, but on the western face there are a few.

At the southwest end of the lagoon the land rim is very low and narrow, and at the southwest point passes into a rocky promontory, with masses of large boulders piled upon the inner edge of the platform. On the west face of the lagoon the island forming the northwest point is unusually wide, fully 1200 to 1500 feet, as shown by the long gap cut across the island; this cut must be quite deep, judging from the color of the water, and must be an excellent boat passage. It is edged on the sea face for quite a distance in towards the lagoon by a high coral shingle beach.

The boulders of the beach rock ledge are more or less loosely cemented together, and some of them near the base of the beach are still connected with the underlying beach rock ledge.

On a part of the west face of the atoll an extensive sand bar runs behind the low shingle and boulder bars of the reef flat. The islands and islets on

${ }_{1}$ Dépôt des cartes et plans de la marine, 1716. 
the reef flat of the west face extend nearly to the southwest point. North of the southwest point and to the eastward, shallow gaps cut across the land rim, and water passes freely through the gaps between the bars into the lagoon across the southern face, and the eastern part of the northeast face of the atoll. The whole face of the atoll from the eastern to the southwest horn is open to the full force of the prevailing trades.

\section{Makemo.}

Plates 59-65; 75, fig. 4; 201, 203, 204.

The atoll of Makemo is about forty miles in length, its greatest width not more than six or seven miles. We entered the lagoon through the channel on the northeastern side of the island, near the eastern extremity. The whole south face of this atoll is nothing but a series of rocky bars exposed at low water, with here and there an isolated island thrown up on the reef flat. The reef flat of the land rim of the southwest face of Makemo forms a great are ending in a sharp horn at the southeast point of the atoll. The western part of the north face is convex; it then becomes concave, the land rim trending to the southeast as far as the northeast pass, when the face of the land rim makes, a sharp angle and runs nearly due east to the southeastern point.

On our way to Takume we passed the northwest point of Makemo; it has a wide outer reef flat. The sea edge is higher than the platform flat, with a depression running along the Nullipore edge, forming a narrow platform lagoon. At the northwest point there is a high coral shingle beach; the land rim is narrow, with many low gaps over which one can see into the lagoon. The islands on the west face of the atoll are thrown up from the sea face.

The northwest pass is wide, flanked on the east side by a well-wooded spit with a steep coral shingle beach, and on the west by a low sand spit, partly covered with large boulders of beach rock and edged by a line of smaller boulders of recent conglomerate.

On our return from Takume we struck Makemo about twelve miles north of the northeast pass, where it presents the usual appearance of other 
Paumotu islands. Sand beaches are thrown up on the inner lagoon side of the narrow low islands; these vary greatly in length, and the gaps separating them vary also much in width. The gaps are frequently walled off on the sea face by coral shingle beaches, or only partially so, allowing the sea access to the lagoon through very shallow passages dotted with shingle and rocks and sand bars, forming most irregular canals likely to be closed at any time (Pl. 61, fig. 2). Or the gaps may be similarly closed on the lagoon side by the formation of sand bars and beaches across the openings (Pl. 61, fig. 2), as we have described them at Rangiroa, between Avatoru and Tiputa Pass.

On such steep faces as the sea faces of the Paumotu atolls, the corals living on the outer slope are limited to a very narrow belt, which expands at the passes and spreads into a luxuriant mass over their bottom. In some atolls, judging from the amount of coral shingle derived from the old ledge, they supply but a comparatively small amount of the material which goes to build up the islands and islets and sand bars of the outer rim. In many of the lagoons the corals form very extensive patches, and together with the disintegration of the shoals and ledge flats of the interior, supply, when dead and ground to pieces on the beaches of the lagoon, a large amount of material for the building up of the land rim from the lagoon side. Of course this proposition is not of universal application, as the luxuriant growth of corals on the sea face depends upon a number of local conditions and combinations of conditions which must be taken into account at each atoll. It is not always on the weather side that corals flourish best, but on the lee face of a reef, as, for instance, at Tahiti, where the corals take their greatest development on the lee shore of the island; and that, on the whole, is usually the case in most of the districts I have examined, the lee sea face presenting the healthiest development of corals. Yet from the constant destruction of these going on on the sea face of the weather side, they supply a far larger amount of material for the making of the land rim than the corals which are growing undisturbed on the lee face. As far as accessions are due to Nullipores and corallines, their action is very different from that of the corals; inside of the lagoon their tendency is to coat every fragment of loose coral, and cover it with a harder coating, to prevent 
its further decay and disintegration; at the same time soldering adjoining pieces into a compact paving which eventually forms the great shore reef flats and shoals of the lagroon of an atoll. Or the corallines grow in huge masses on the bottom of the lagoon, and when dead and disintegrating cover the floor of the lagoon with a viscid calcareous mass which, mixed with fragments of shells and other invertebrates or pieces of dead coral, makes a recent fossiliferous mass resembling more or less coarse chalk.

On the northeast face the islands are narrow (Pl. 60, figs. 1, 2); the land rim is generally not more than 500 to 600 feet in width; the beaches are steep (Pl. 59). All along the sea face shores of the Paumotu, where we find high coral sand beaches the boulders and shingle have been completely ground to pieces, and the old ledge is well cleaned and left exposed on the reef flat platform (Pls. 62, fig. 2; 65, fig. 1); where shingle predominates there are usually lines of boulders at the foot of the shingle beach, covering the reef flat in part (Pl. 59, fig. 2); and where there are masses of large boulders the land rim is low, the material for elevating it to the height of the rest of the land rim, either as a coral sand or a shingle beach, remaining piled up in masses of boulders along the low line of reef flat or upon the old ledge reef flat (Pl. 62).

On the northeast face of Makemo the outer platform is narrow. The outer edge is protected by masses of highly colored Nullipores and Pocillipores (Pls. 59, fig. 1; 60, fig. 2; 62, 63). The northeast shore is protected by narrow shingle beaches (Pl. 62) and small masses of beach rock. There are long reaches of this, forming a sort of hedge of beach rock and of recent conglomerate boulders (Pl. 63, fig. 2) in the rear of the narrow reef flat of the old ledge, of which an outcrop runs here and there across the beach and is lost in the mass of the outer belt of vegetation (Pl.64). For a long distance the land rim consists of long narrow islands edged by a coral shingle beach from five to six feet high (Pls. 59, fig. 2; 62); and as we pursued our course the outer shingle beach gradually increased in height to seven or eight feet, and in some places to nearly ten feet. There is no lee on the northeast side of Makemo; the whole shore is raked by the trades.

The high shingle beach stretch is followed by a low coast protected by a ledge wall and masses of boulders. Here and there a small island covered 
with low vegetation, and followed by numerous islets, connects the separate reaches of masses of boulders. None of the boulders on the northeast face are large. To the south of Makemo Pass the islands continue small and low, and are covered with low shrubs. The northeast pass of Makemo has on one side a steep shingle beach (Pl. 59), and on the other a long low sand spit, which on the sea face passes gradually into a high shingle beach fully 13 feet in height. The land rim to the east of the pass is well wooded (Pl. 75, fig. 4) for a short distance, but soon it becomes low, and consists of a series of small, low islands, connected by the reef ledge of beach rock or by a few small boulders. Across the lagoon the horizon was clear, and only a single island could be seen in the distance on the south face.

While at anchor in 13 fathoms we brought up in the dredge two species of Madrepores and masses of broken fragments of corals, mainly Madrepores, cemented together by Nullipores, worm tubes, and alga, and filled with mollusks and worms and other boring invertebrates. Deep water runs close to the shore in the lagoon where we were at anchor, and everywhere are patches of corals to be seen, - no less than ten in our immediate vicinity. To the north of our anchorage the lagoon platform is very narrow, while near the pass it runs out into the lagoon in wide flats and long spits covered with patches of beach rock.

In the passage there were fine masses of coral visible everywhere along our course as we entered the lagoon. The bottom was covered with huge patches of algæ and of coralline algæ.

On shore near our anchorage we found in one of the gaps a fine exposure of beach rock, and of recent conglomerate made up of fragments of beach rock, recent corals, and of fragments of old ledge (Pl. 61, fig. 2). This section was taken near the base of the sea face beach, in a small cañon, as it were, forming the channel through which at high tide the sea is washed into the gap and passes into the lagoon. It exposes admirably the old ledge forming the base of the reef flat platform overlaid in part by the beach rock conglomerate. The old ledge has been planed off and covered by a thick bed of recent conglomerate, which has been washed away from 'the greater part of the surface, leaving only here and there an outcrop of the old ledge, or a horsehead, the upper part of which is beach rock conglom- 
erate, resting upon a pedestal of old ledge rising above the general level of the outer platform (Pl. 65, fig. 1). The conglomerate ledge at the foot of the beach only exposes here and there the old ledge rock at its base, or it is seen occasionally cropping out as an outlier in the midst of the conglomerate bed covering its inner face.

The reef flat near Makemo Pass is not very wide (Pl. 59, fig. 2), and pitches quite steeply towards the high many-colored Nullipore edge, which in many places must be fully three feet higher than the reef flat (Pls. 60, fig. $2 ; 62 ; 63$, fig. 1). For a distance of nearly twelve miles the reef flat cannot be more than 50 to 70 feet in width, and there is, as at the northwest point, parallel to the shore line, a deep sink ditch, between the outer raised edge of the reef flat and the line of old ledge outcroppings which run out at right angles to the beach (Pl. 62, fig. 2). There is a high coral shingle beach at the back of the beach rock conglomerate, made up of recent coral heads and fragments of old ledge, which extends at the foot of the shingle beach in more or less broken stretches, separated by outcrops of the old ledge rising above this recent conglomerate. Innumerable pools are left at low tide along the slope of the reef flat (Pls. 59, 60, 62, 63), filled with Holothurians, sea urchins (Hipponoë), covered with fragments of dead Nullipores, or corallines, with others crowded with Echinometræ; black Diadematidæ and Echinothrix are sheltered under projections of the ledge or in pools protected by boulders. It is difficult to see how these black Echinoderms have derived any advantage from living on this outer reef flat, where they stand in nearly as strong a contrast on the light yellow rock flat, as they do in the interior of the lagoon, against the white Nullipore and coral sand upon which they equally congregate.

Fragments of broken corals, ground or worn into the shape of flat or rounded pebbles of all sizes, are thrown in the cracks and between the boulders of the conglomerate or old ledge rock, and gradually become cemented together, forming a coarse puddingstone, composed of all the various sorts of materials which go to make up the sea face of a coral reef $(\mathrm{Pl} .65$, fig. 2).

The beach near the entrance to Makemo on the northeast side is a high coral shingle beach, fully 14 feet in height. Much of the shingle is thrown 
over the highest point of the beach and rolls inland (Pl. 59, fig. 1). At the base of the beach the shingle has been ground to fine coral sand. From the base of this extends the rather narrow reef flat from 50 to 75 feet wide; this is somewhat dished, forming an irregular ditch flanked on the sea face by a wall of Nullipore and Pocillipore knolls in places fully four feet higher than the reef flat sink (Pl. 60, fig. 3). The large island on the north side of Makemo Pass is from 1000 to 1200 feet in width.

A line of soundings was made in the lagoon by one of the officers (Mr. Kempff). He brought back a number of samples of the bottom; they are most uniform in character, consisting of coral sand, coral fragments, broken shells, plates and spines of sea urchins, fraginents of Nullipores, corallines, Orbitolites, and other Foraminifera. The greatest depth thus far found while surveying in the lagoon is 16 fathoms. A great many islets, shoals, bars, and ledges are to be seen cropping out in all directions. ${ }^{1}$

We went in the steam launch across the lagoon towards the nearest point of. the south side; we made a few soundings, going over, in from eight to ten fathoms; we usually found hard bottom, with Nullipore and coralline patches or corals, extending from the slopes of the numerous shoals we found on the way. On shoals having from two to three feet of water at low tide we found the top covered with dead coral heads more or less overgrown with Nullipores, while on the edges of the slopes began to grow Madrepores and Millepores, with heads of Pocillipores extending into deep water. The top of one of the largest shoals we found, fully a mile in length, was covered with dead corals encrusted by Nullipores and overgrown with algæ and corallines, with scattered patches of thriving corals dotted over the surface and extending over the slopes towards the bottom of the lagoon.

The approach to the lagoon edge of the south shore reef flat is very gradual from the ten-fathom line, which is at a distance of from 1000 to 1500

1 An Echinoneus of a pinkish color, varying to light chestnut, was collected on the outer reef; the sinallest specimen, measuring one fourth of an inch, was pinkish. The pedicellarixe and tentacles are of a dark violet. The pigmented rows of suckers stand out prominently from the rest of the test as dark violet lines. The covering of the glassy tubercles is only a continuation of the epithelial surface, similar to that on the base of the spines, only without pigment spots. The tentacles near the apical system have a rudimentary sucker, which is more developed on the actinal face. The genital openings are protected by small spines. The plates of the anal system are somewhat imbricated; those of the mouth very much so. 
feet from the point where the so-called reef may be said to begin, where there is from one to three feet of water at low tide. This gentle slope is full of great patches of Nullipores and coralline algæe separated by lanes of coral sand and of broken shells, with here and there a coral patch of greater or less extent. The sea face of this reef flat is lined with a belt of great masses of boulders, probably outliers of the old ledge, standing up inside of the breakers at this stage of the tide (nearly low tide). It was impossible to judge of their composition, as there were none accessible on the lagoon face of the reef flat.

The lagoon face of this wide reef flat was here and there edged with sand bars, the heginnings of small islands and islets. Here also, as in so many other atolls of the group, there were occasional bars of coral shingle and smaller rolled material derived from the disintegration of the large masses edging the sea face of the rim flat. A line of soundings run into the lagoon showed a very gradual slope, from 8 fathoms in the middle of a mass of shoals about 500 to 1000 feet from along the lagoon edge of the outer reef flat, towards the deepest part of the lagoon, in about 21 fathoms, rather more than half-way across. From this point we strike 19 fathoms at a distance of six miles from the ship, and eight miles off it was 15 fathoms, the depth we found off the opening where we were at anchor.

We passed not less than twenty-four shoals in a distance of not more than five miles from the lagoon edge of the flats, the slopes of all of which were occupied by corals extending to a depth of 16 fathoms or so into the lagoon. Bars are formed here and there. Algæwere also seen growing on the bottom, and large Nullipore patches. There were more than thirty shoals along the line of soundings we ran across the lagoon. Here and there a few heads of old ledge rock showed above the water line, and where deeper the tops were seen to be discolored with masses of Nullipores and patches of growing corals extending along the slopes.

With the aid of the water glass we were able to see that the bottom of the lagoon was everywhere covered with patches of Nullipores and coralline algæ and of corals, mainly Madrepores, in all but the deepest parts of the lagoon down to sixteen fathoms or so. 
The surface hauls made inside the lagoon proved comparatively poor: a few Copepods, larvæ of Macrurans and Brachiurans, young fishes, a few Appendiculariæ and Sagittæ, and a small Geryonia, - a mixture of pelagic surface life and of littoral pelagic larvæ.

We examined the rocky shoals to the northward of the ship, - one about two, the other four miles from the anchorage; we found them both to be fragments of the old ledge. At the first ledge there is, at a distance of from 70 to 80 feet from the flat edge of the ledge, a depth of 12 fathoms, which thus slopes very rapidly on all sides. Fragments of the ledge have broken off and rolled down, forming a talus; and on the slopes thus formed corals of all kinds have established themselves. On the second ledge quite a small island of old ledge is left standing about five feet in height, irregular in shape, with a diameter of ten to twelve feet. The flat part of both these ledges is a shoal of some length, covered with fragments of the old ledge and overgrown with Nullipores covering also masses of dead shells and fragments of corals which fill the interstices of the larger masses, so that the whole surface of the shoal presents a highly colored appearance, varying from yellowish to pink and red, or dark violet, much as the wide reef flat of the south shore was colored by its covering of Nullipores, corallines, and corals.

On the slopes of these ledges grow masses of corals, of Madrepores, Pocillipores, Goniastræas, of heads of several species of Porites, with differently colored Astræans, and masses of algæ and corallines growing between the heads, and Nullipores encrusting the smaller fragments and cementing the parts into a solid mass. On the lee side of both these ledges, the boulders and loose material formed a regular talus on the face of which but few corals were growing. The corals extended to about ten fathoms, when they were in great part replaced by Nullipores and corallines, and finally coral and coralline sand and fragments of broken corals occupied the bottom of the lagoon from sixteen fathoms down.

In eight fathoms, about three fourths of a mile from shore, Alveopora is very common, growing upon old fragments of corals covered by algæ and corallines. On the greater part of the shoals, in rather shallow water, Millepores grow in great abundance. In $2 \frac{1}{2}$ fathoms we found fragments of beach rock and of old ledge covered by Nullipores and running inshore to connect 
with ledges of similar material making out as points, or being isolated boulders torn off the lagoon face and rolled into deeper water.

Two additional gaps which we examined presented no distinctive features from others we had seen, the cut through the beach rock leaving low walls undercut at intervals, with sand bars across the gaps forming a more or less wide opening from the lagoon side, till it butts against a mass of beach rock boulders at the sea face of the gap. This mass of boulders is scattered over a length of nearly a mile in a belt fully 400 to 450 feet wide, until it reaches the base of the shingle beach. This shingle is often driven into the shore belt of vegetation (Pl. 64), and thus becomes scattered and thrown across the narrow land rim, and in heavy gales is rolled all the way into the lagoon.

At one point the shingle beach was perhaps not more than three feet high ; the slope of the wide sea face on which the masses of boulders rested extended to within five feet of the outer edge of the reef flat; the old ledge was exposed for a width of from 50 to 100 feet inside of the raised Nullipore edge. The sand beaches of the lagoon side often extend into the gaps and form a series of parallel dams across the gaps where they are open to the lagoon side.

The face of the island of the land rim, opposite our anchorage, presents a fine example of islands as buttresses at right angles to the trend of the coast, for many of the gaps, not more than 50 to 100 feet apart, are only separated by strips of low sand land from three to five feet high, ending at the sea face, either into coral shingle beaches or into the wall of boulders mentioned above. The reef flat is composed of old ledge, which also crops out in the cuts below the beach rock stratum.

The recent beach rock conglomerate is made up of masses of recent coral fragments of all sizes (Pl. 65, fig. 2), from whole colonies to the merest chips, and from similar fragments derived from the disintegration of the old ledge rock, huge masses of which crop out through the beach rock conglomerate, so that it is often difficult to determine whether a particular onterop of old ledge is a boulder, or a horse, still connected with the underlying old ledge.

On going south the gaps of the land rim become less frequent. The sand driven from the lagoon has only left low depressions between the 
islets, to show where the gaps existed, and finally is overwhelming the beach rock conglomerate, which only juts out in strips or points separated by reaches of sand of greater or less extent.

Some of our photographs of coral shingle and coral boulders driven inland between shrubs and trees show that they penetrate a considerable distance over the summit of the land rim (Pl. 64). They also show how coral fragments, from the size of one's head to the merest chips, collect and become cemented together to form a conglomerate or breccia merely from the action of the wind and rain, and not under the influence of the sea, thus gradually covering the old ledge, whatever might be its composition, if it should constitute the foundation of an island.

Our examination also shows how all the low land of the rim of an atoll is absolutely at the mercy of waves of great height, or even of a common storm, and how the material from the outer beach, and all kinds of coral shingle fragments, are pushed across between the shrubbery and large trees, killing some of those nearest the shore, and how the sea may cut gullies into the low land, either on the sea face, or through it, or down the lagoon slope.

There is a fine sink on the southern point of the entrance to Makemo, behind the great shingle beach dam which has shut off from the sea the extensive flat area of that end of the island.

Many blow-holes occur on the outer edge of the reef platform; this is cut up by numerous shallow digitations, many of which are bridged to form the blow-holes.

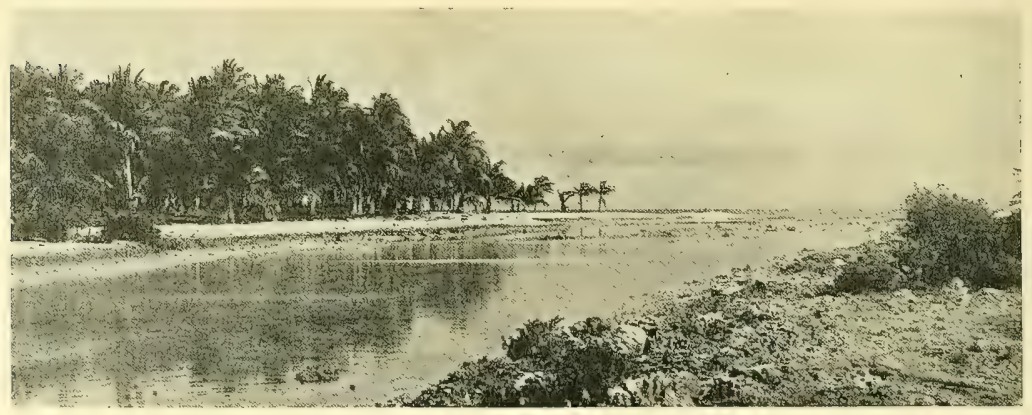

Gap across the Land Rim of Makemo. 
The lagoon side of the land south of the nurtheast passage shows the same features as the land north of the pass. As we passed out and steamed along the eastern face of the north shore, we could see that the south end of the atoll presented the same alternating features of coral sand beach, shingle, low rim land, and islets and islands, characteristic of the land rim which we examined to the north of the pass.

\section{Tekokota.}

Plates 66, 201, 203.

On the southern face of Tekokota, near the northwest horn of the atoll (Pl. 66, fig. 2), where the shallow reef flat forms a wide rounded point of light green water edging the darker blue green of the small lagoon, there are fine examples of bars of shingle and of beach rock running transversely across the reef flats, headed by a shingle beach (Pl. 66, figs. 3, 4) with a tail terminating on the lagoon side in a low sand bar or sand islet. On an island covered by tall Fetau trees (Pl. 66, fig. 4), which shelter a regular rookery of boobies, there is a very fine outcrop of the old ledge tapering off to the south in a line of negro-heads on the outer rim of the sea face platform.

There is no land rim on the eastern end of the atoll (Pl. 66, fig. 1). A long island on the eastern face, four islands on the opposite face, and one on the north side compose the whole atoll land. There is a superb line of breakers all round the atoll following the shore line (Pl, 66, figs. 1, 2). Judging from the color of the water in the lagoon, it must be of very moderate depth, but there is a deep hole of dark blue near the northeast horn of the atoll, as well as a band of darker green.

Large boulders are scattered all along the rim of the reef flat, which is quite narrow in places, the heavy swell and rollers rushing over the flat and pouring into the lagoon over the east face.

This is also called a closed lagoon, yet water is forced into it over seven eighths of the rim flat on the faces exposed to the trades (Pl. 66). 
The atoll of Tekokota is elliptical, somewhat more than a mile in greatest diameter. On the western face off the wooded island the reef flat slopes seaward for a considerable distance, and is well covered with corals.

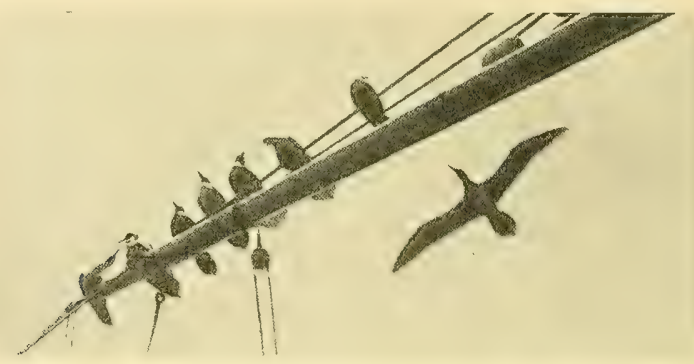

Boobies in Riging.

\section{Hikueru.}

Plates 201, 203.

This is a small atoll running almost east and west, irregularly elliptical, with a comparatively deep lagoon for its size. Its greatest length is about six miles, and three miles in width. The land rim is situated on the north side of the atoll. The southern face is merely a reef flat over which the sea enters into the lagoon, and is forced out again over the northern face of the island.

Hikueru, seen at a distance from the north side, appears like a series of low disconnected rectangular blocks with rounded edges; in fact, that is much the appearance of any atoll seen at from six to ten miles off, according to the height of the cocoanuts or of the vegetation growing upon it. The islands are separated by wide open flats. Nautilus are said to live in the lagoon, creeping along the bottom in the sand, and coming to the surface in calm days.

Near the northwestern point are some large boulders of beach rock conglomerate and of old ledge, the latter undercut and still connected with the old ledge platform forming the outer reef flat. 
The eastern part of the atoll is a wide reef flat, partly covered with beach rock boulders and shingle on the sea face, and edged in part with low sand bars on the lagoon side of the reef flat. All the islands of the atoll, as well as the islets on the outer reef flat, are faced with coral sand beaches on the lagoon side. The lagoon is from 12 to 18 , and, in places, 22 fathoms deep; though it is said to have deep spots of 30 fathoms, the average depth is 15 fathoms.

The old ledge is, as in other atolls, generally planed off to the level of the onter reef flat, and overlaid by recent conglomerate and beach rock, which supplies the material to check the erosion of the old ledge, and to build up the sand bars, islets, and islands heaped up on the rim of the atoll, according to its position with reference to the gaps and the prevailing winds.

Hikueru is, like Makemo, full of shoals. Corals seem to thrive remarkably well in this lagoon. There are great masses of them on the slopes of the shoals and flats, and they supply a large amount of the material which has built up the islands from the lagoon side. It is said that there are in this lagoon, as well as in Hao, deep holes of very limited area, somewhat like the ocean holes of the Bahamas, ${ }^{1}$ but I was unable to obtain any definite information regarding them.

On the wide flat of the southwest point, which must be 1200 to 1500 feet in width, there are long concentric lines of boulders and of shingle and of beach rock and heads of old ledge.

\section{Marokau and Ravahero.}

\section{Plates 70, figs. 1, 2; 201, 203; 204, fig. 5.}

The Two Groups, as the islands of Marokau and Ravahere are called, are interesting; they probably represent the denuded summit of a ridge with a valley of a depth of not more than 270 fathoms separating these two summit ridges. The islands are both triangular, the northern island (Marokau) being somewhat the larger; the second or southern island (Ravahere) is elongated, and is characterized by its secondary lagoon, which extends nearly

1 See A. Agassiz, Bull. M. C. Z., Vol. XXVI. p. 42. 
the length of the island. The two islands are somewhat more than twenty miles in length. The greatest width of Marokau across the northern face is about eight miles, while Ravahere is nowhere more than three to four miles wide. The lagoons of both these islands are closed, there are no ship passages or boat passages, but the sea has the fullest access to the lagoons over certain parts of the reef flats.

At the northwest end of Marokau beach rock and recent conglomerate cover the old ledge, which crops out here and there on the wide reef flat (Pl. 70, fig. 1) of the western face, extending towards the southern point of the island. Boulders also are scattered all along the outer reef flat of the western face, numerous bars of shingle extend across it, with sand bars on the lagoon face, and with gaps of green water forming the communication between the sea face and the interior of the lagoon. The reef flat is at least from 700 to 1000 feet in width, as far as the southern point (Pl. 70, fig. 1). The sea face beaches of the islands are high shingle beaches with small boulders, principally of beach rock, scattered along the outer edge of the reef flat (PI. 70, fig. 1). The southern part of the lagoon is much the shallowest, the flat on the lagoon face being fringed with a broad belt of light green water. The lagoon edge of the western side is faced with sand bars, one of which is specially noteworthy for its length; it must be over a mile in length, and separated from the adjoining reef flat. Two islets could be seen on the eastern face of the atoll which seemed to extend well into the lagoon. In a narrow channel there are some very large masses of beach rock and recent conglomerate on the reef flats similar to those of other lagoons.

At the southwest horn of Marokau there is a wide reef flat, the continuation of the western reef flat ( $\mathrm{Pl} .70$, fig. 1), wider than any we have as yet seen in the Paumotus, with a line of large boulders running about parallel to the raised edge of colored Nullipores and Pocillipores. The large island at the southern extremity of the atoll is flanked by a high shingle beach.

The two atolls of Marokau and Ravahere appear like a single atoll as seen coming from the north, the islands of the one and of the other separated seemingly by a somewhat wider gap than is usual, or by a wide passage opening into a lagoon. Passing through the strait between the atolls, 
we could see the southeast face of Ravahere to be one string of islands (Pl. 70, fig. 2) as far as the eye could distinguish. In addition to the secondary lagoon parallel to the west shore the lagoon at the south end is divided by a flat into two lagoons, a little more to the northward than is marked on Wilkes's chart. Such a division is not uncommon in some of the Paumotu atolls. We have found such a division by reef flats into secondary lagoons in Anaa and Tahanea. At the north end of Ravahere a wide flat runs from the west coast far into the lagoon, on the inner edge of which rises an island with high shingle beaches, as on the islands on the east face of the northern horn. The outer reef flat on the south shore is covered with coral rubble, and on the sea face of the west flat large boulders line the outer edge of the reef flat. Ravahere at the northern extremity is very narrow, and only a thin line of dark blue water indicates the small extent of deeper water in the lagoon, which is said to be very unequal in depth, and full of deep holes.

\section{Hao.}

Plates 67, 201, 203; 205, fig. 2.

Hao was discovered by Bougainville. It is thirty miles long and about five miles wide. ${ }^{1}$ It is shaped somewhat like a boomerang; the southern part of the atoll turning off to the eastward at an angle from the general trend, as is the case with Tahanea, Rangiroa, and Makemo. Two sinks are indicated on the sketch of the entrance to Hao. ${ }^{2}$ They have probably been formed in the same manner as those near the passes of Rangiroa, Makemo, and the like. It is well wooded on the weather side, the islands and islets of the lee side are generally bare, and the sea pours over into the lagoon through the gaps between the islands. The entrance of this lagoon is on the northern side, the tide running in and out with such velocity as to make numerous overfalls. The depth of the lagoon of Hao, especially at the northern extremity, is as great as 30 fathoms in places, although the average depth is about 15 to 20 fathoms. The northern part, but specially the southern and eastern parts of the lagoon are studded with coral knolls and coral patches, which make navigation extremely dangerous.
1 A. Chart 1111.
2 Ibid. 
Immediately to the westward of the entrance to Hao a ledge of beach rock is exposed, overtopping a part of the old ledge reef flat. Both to the west and to the east of the passage there are many shallow gaps, giving free access to the sea to the interior of the lagoon. One, however, is very deep, not more than 50 to 60 feet wide, across a narrow part of the land rim, exposing the beach rock and the recent conglomerate covering the old ledge, which here and there crops out as small buttresses, about four feet in height, at the base of the shingle beach, and runs out on the broad reef platform of the western face. On the north side the sea face of the land rim is composed of alternating reaches of coral sand and buttresses of old ledge.

The northwest horn of Hao (Pl. 67, fig. 3) is formed by two islands, one on the north face, the other on the western, separated by a wide flat nearly planed down to the level of the sea, and cut through but still connecting the two sides of the horn, and covered over with a mass of beach rock and old ledge boulders, with here and there a sand bar.

Beyond the northwest point we came upon many cuts forming short headlands flanked by shingle beaches and lines of beach rock or coral boulders. The reef flat and the land rim (Pl. 67, figs. 1, 2,4) vary greatly in aspect as we steam along the west face. In the interior of the lagoon as seen from the west side we could distinguish a great many shoals and ledges looming up in all directions (Pl. 67).

At one point of the western face the islands run at a sharp angle across the wide reef flat, with water gaps, of considerable depth between them. The sea end of the islands was tipped with beach rock boulders or coral shingle, while along the sides of the islands, on the lagoon side, extended fine coral sand.

At another point the islands were replaced by bars of coral shingle running diagonally across the reef flat, separated by shallow gaps and abutting on the lagoon side on small sand islets and sand bars. Nowhere perhaps have we seen better examples of the transition between a small high bare sand bar, or one a little larger with one or two stunted bushes, passing into a still larger one with a thriving belt of bushes, next a somewhat larger one with a few cocoanut palms, and finally a large island such as are characteristic of the atoll rim with its full quota of coral reef vegetation (Pl.67). 
We then came upon a stretch with eleven islands, ${ }^{1}$ nearly all equidistant, separated by shingle bars abutting on the lagoon face, upon sand bars or sand islets, running like the islands diagonally across the reef flat. After passing this stretch of comparatively small islands, many of the islands on the reef flat became larger ( $\mathrm{Pl} .67$, fig. 4), the land rim consisting of a series of islands of various sizes, alternating with sand bars for short distances. Here and there the ledge of beach rock and of recent conglomerate was continuous on the sea face of the reef flat, forming a wall effectively shutting out the sea from the interior of the lagoon (Pl. 67, figs. 3, 4).

On the sea face of many of the islands on the western face of Hao the old ledge cropped out here and there, like low buttresses, through the mass of beach rock and recent conglomerate which covered the underlying ledge near the base of the shingle beach, or through the coral rubble on the inner part of the reef platform. Some of the shingle beaches must have been from ten to twelve feet high (Pl. 67, fig. 4). The islands on the eastern face of the atoll, as seen from the western face, were all edged by a coral sand beach on the lagoon face.

The east face of Hao, with the exception of a stretch covered with islets and sand bars to the south of the central part of the land rim, consists of a few long islands. If we compare this with the condition of the west face of Hao, we find that those reaches of the land rim which are raked by the prevailing winds are composed of longer and more continuous islands than the faces of the atoll against which the trades butt, where the land rim is broken up into islets and sand bars extending across the broad reef flat. The position of these islets is more or less unstable; they migrate much like sand dunes until they become fixed by vegetation, while the' larger islands raked by the trades are more stationary, the beaches of their faces receiving accessions from the breaking up of the material thrown up on the flanks of the land rim, - material which is in its turn carried seaward or lagoonward in a direction in general parallel to the trend of the land rim, while on the exposed face the tendency of the action of the sea is to widen the reef flat, the material being driven towards the interior of the lagoon.

1 On the chart of Hao the difference between bare sand bars and islets covered with vegetation is not indicated. 
From the southern point of the island to the eastward extends for about five miles a wide reef flat, full of patches and bars of beach rock, incipient shingle beaches, and piles of coral shingle, with sand bars and sand islets on the lagoon face of the reef flat, with many wide rather shallow gaps giving access to large bodies of water to the interior of the lagoon. At the south end there is a large island marked for its superb vegetation.

The Nullipore and Pocillipore knolls ${ }^{1}$ of the outer edge of the reef platform were remarkably brilliant in their coloring, and with the sun shining on the edge of the reef flat the contrast between the different shades of blue to green and the metallic colors of the tongues of water breaking upon these brilliantly colored coral knolls was most striking; blue, red, green, yellow, orange, all contrasting to the white surf dashing across the flat; and as seen from the ship, with the dark blue foreground of the deeper water. The yellow belt of beach rock or conglomerate, inside the brilliantly colored outer edge, formed a striking contrast to the high gray shingle beach or the brilliantly illuminated dead white or cream-colored coral sand beach running in between the masses of the dark green belt of shrub vegetation growing back of the top of the beach shingle and topped with rows of high cocoanut trees, - all this combined with the light blue sky dotted with the low lines of trade wind clouds, formed a kaleidoscope of colors very different from that of an ordinary sea beach.

\section{Aki-Aki.}

Plates 68, 69, 201, 203.

Aki-Aki is a circular island, three quarters of a mile in diameter, formed of elevated coralliferous limestone. It is well wooded. There is no lagoon, a very insignificant sink occupying the western portion of the island. The * beach of Aki-Aki is highest at the south end (Pl. 68, fig. 1), where there is a shingle beach fully twelve to fifteen feet; it is not more than from four to five feet high at the north end, with an occasional short stretch of coral

1 These are developed to such an extent that they are sketched as islets on the edge of the reef flat in the survey of the entrance to Hao by H. M. S. "Blossom." 
sand. The island slopes slightly from the south end towards the north side, where the shingle is coarser, and coarsest at the northeast point. According to Mr. Townsend, the island is slightly dished towards the centre, occupied in part by a small sink of fresh water a little way in from the beach. The central part of this so-called lagoon is covered by low brush (Pl. 69, fig. 1), and surrounded by large trees on the outer edge close to the beach ridge, a short distance inland.

The reef platform is from 75 to 100 feet wide, very flat, with a comparatively low outer edge. On the southeast side there is a continuous beach rock ledge with a wider reef flat platform than on the north side; it is from 150 to 200 feet wide.

The inner part of the island is about two feet lower than the outer edge. A part of it is bare or is covered with fragments of broken coral gradually passing into a rich black soil covered with grass, and large hard-wood trees (Pl. 69) as well as Pandanus, together with bushes similar to those edging the outer rim of the island. Part of the island is also covered with small coral-boulders thrown into the interior while the island was building up.

Recent beach rock and conglomerate as well as parts of the old ledge crop out in the interior, where the natives have dug water holes. A shallow sink exists (Pl. 69, fig. 2), formed undoubtedly, as in all limestone areas, by solution, which has carried off more or less of the material cemented together as beach rock. The island undoubtedly owes its shape to the throwing up of the beaches from different directions upon the original plateau underlying the island, as the soil of the interior is made up of vegetable matter and decomposed coral fragments or boulders, among which can be recognized Madrepores, large masses of Porites, Pocillipores, and Astræans. In the middle of the island are found the largest trees and the best soil. As is shown by the structure of this island, the existence of alternate layers of beach rock and of recent conglomerate or of coral rubble does not by any means indicate a talus; it merely indicates a reef flat over which the sea has either been building up beaches, or cutting down ledges, or adding masses of coral sand or shingle. This may explain much of the character of the successive layers of rock met with by boring through the upper strata at Funafuti, said to have been due to subsidence. 


\section{Nukutavake.}

Plates 70, figs. 3, 4; 71, 201, 203.

Nukutavake is another interesting island from the fact that it also has no lagroon. It is about five miles long and not more than one and a half miles wide. As seen approached from the north, it appears highest at the north point, where there is a high shingle beach with a wide reef flat. The beach extends half-way towards the other extremity of the island, and is in many places edged with beach rock ledges extending along the foot of the coral sand or shingle beach. The island is a very narrow ridge which has been formed by beaches thrown up on opposite sea faces thus gradually building up the outer rim of the island, leaving the interior somewhat depressed, or rather lower than the outer beaches. One of the beaches is fully twenty feet high, and from its crown the land falls off very rapidly.

The reef flat platform is about 150 feet wide, with an occasional outcrop of old ledge along the face of the high coral sand beach facing the village.

A section across Nukutavake from the west shows a very steep outer beach, either shingle or sand, sloping very gradually inland, the inland slope covered at first with coarse coral shingle, passing gradually into finer material and then into fine soil in the central part of the island, occupied by three or four depressions or sinks, many of them full of water, running in general parallel to the trend of the island. We come then upon the inland slope of the beach of the opposite side, which is very much steeper, rising rapidly to a considerable height and sloping abruptly to the sea face. In the depressions we could see beach rock and recent conglomerate cropping out, and fragments of coral and coral boulders more or less cemented together.

Where we examined the island it was about half a mile wide. The whole of the south side of Nukutavake is faced by a line of dunes more or less overgrown with grass or low vegetation. Pandanus are exceedingly numerous on this side of the island. The dunes have killed a large tract of Pandanus, and through their slopes project dead bushes and stumps of all sizes of Pandanus, cocoanuts and other trees. On the east side the sand dunes are bare. The sand dunes which are characteristic of the south face of this island rise in places to fully 30 feet above the top of the beach, as 
high as the highest trees, and show well how in this island the depression or sink, or the so-called lagoon, is produced by the enclosing of an area within the space of coral sand or shingle beaches thrown up from opposite sides. The highest sand dune we saw was fully 35 feet from the high-water mark, and had greatly encroached upon the adjoining vegetation of the outer rim of the island. Stumps of bushes and of trees could be seen protruding from the sides and summit, and long stretches of trees near the coast line were killed, the lower part of the trunk having been buried in the sand (Pl. 70, fig. 4).

The old ledge rock crops out on both sides of the island, but much of the old ledge, however, is concealed by the overlying beach rock, which extends across the island, together with decomposed coral boulders and coral shingle; this, mixed with algæ and dead leaves and bushes, forms an excellent light soil on which is found growing in the interior fine Poukas, Pandanus, and other characteristic coral reef vegetation (Pl. 71).

Following the line of the horn of the western extremity, there is a welldefined secondary lagoon parallel to the outer edge of the reef platform (Pl. 70, fig. 3).

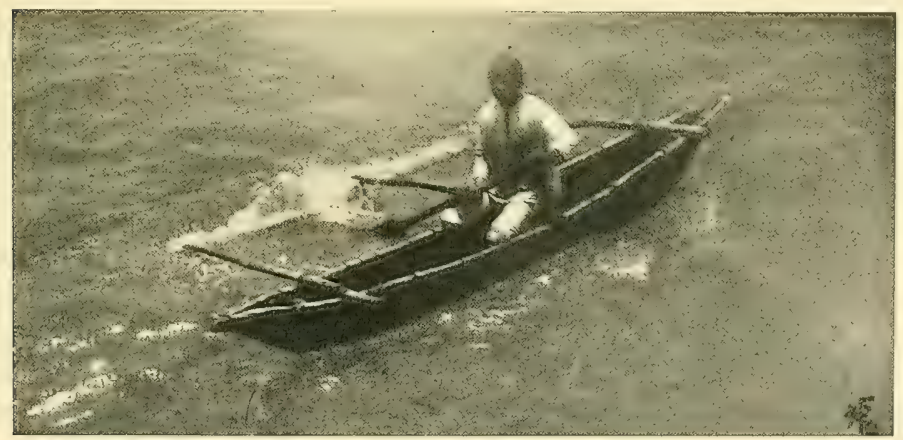

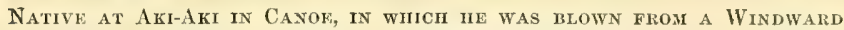
Island a Couple of Hundred Miles. 


\section{Pinaki.}

Plates 79-75, 201, 203; 206, fig. 3; 236.

Pinaki is historically a most interesting atoll. It was discovered by Captain Wallis in 1767. It encloses a shallow lagoon, and is about one and a half miles in diameter; the greatest height of the land rim is from six to nine feet. It is surrounded by a wide reef platform which follows the outline of the island. There is on the southern side a narrow entrance into the lagoon, but it is too shallow for boats to enter even in a smooth sea (Pl. 206, fig. 3). The vegetation of the land rim consists principally of bananas and cocoanuts, which have displaced the Poukas and Pandanus.

Pinaki, as seen coming from Nukutavake, appears like a high unbroken sand beach ( $\mathrm{Pl}, 73)$. On nearer examination we found the sand beach topped with coral shingle, and that a ledge of beach rock cropped out occasionally at the foot of the beach, encroaching somewhat upon its face. The beach rock covers in part the old ledge which crops out on the wide reef flats and in the gap leading into the lagoon (Pls. 72 ; 206, fig. 3). To the west of the entrance gap the beach consists of alternating reaches of fine coral sand or coral shingle rising to a height of six to seven feet (Pl. 72, figs. 1, 2). The land rim is well wooded, and inside of the outer belt of bushes grow numerous Pandanus and tall Pouka trees, with here and there groves of bananas and cocoanuts (Pl. 73).

The wide reef platform is deeply indented with large gullies and edged with Nullipore knolls (P1. 73, fig. 1). The reef flat slopes very gradually from the base of the beach, the top of which is covered with verdure, with a narrow belt of gray coral shingle between it and the creamcolored coral sand beach. On the east face the beach or land rim is in great part formed of high sand dunes, similar to those we saw at Nukutavake, killing the Pandanus and the vegetation of that face of the lagoon by encroaching gradually upon the land rim (Pls. 73, fig. 3; 206, fig. 3). On a part of the atoll on the west side the high shingle beach abuts upon a wide reef flat where an incipient barrier reef is formed on the outer edge of the reef platform (Pl. 72, fig. 1) by a ledge of beach rock covering in part the old ledge. 
The gap which is the only opening into the lagoon of Pinaki is about 500 yards wide, and the land rim at the opening is nearly 1200 feet wide (Pl. 72, figs. 2, 3). No water can come into the lagoon except during the last part of the rising tide. The lagoon is filled with numerous islets (Pls. 74, fig. 1; 75, fig. $1 ; 206$, fig. 3) which rise on the lagoon edge of the inner reef flat, which in places is fully 600 feet wide (Pl. 74, fig. 1). Mr. Alexander counted no less than 116 of these islets; they are all topped with dead Tridacna shells, and there are great windrows of these on the edge of the lagoon flat, close to the lagoon beach of the land rim (Pls. 75, fig. 3 ; 206, fig. 3). The Tridacna islets are all small, ten by twelve feet about, not more than three feet high, and their slopes are covered with Madrepores. Many of the islets are connected by shallow flats. The living Tridacnas are found in great number in the deeper parts of the lagoon towards the northern end of the atoll, where they occur packed much as oysters in an oyster bed. Besides the Tridacnas, the bottom of the lagoon and stretches of the lagoon flat are covered with a species of Arca, the dead shells of which are thrown up in immense masses on the shallow parts of the lagoon and on the inner beaches. On the west end of the island there is in the lagoon a huge bed of these Arcas. The lagoon in some places is from three to four fathoms deep below the inlet. The water is abnormally warm, - much above the temperature of the outer sea water. The lagoon contained many fishes.

The old ledge crops out here and there on the sea face. To the west of the entrance there is a good exposure of it (Pls. 72, figs. 1, 2; 206, fig. 3), as well as in the middle of the entrance to the lagoon (Pls. 72, fig. $3 ; 74$, fig. $2 ; 75$, fig. 2 ), where an outcrop forming an elongated ledge divides the channel into two passages (Pl. 75, fig. 2), while on the sides of the passages of the channel the old ledge is covered by beach rock, recent conglomerate, coral boulders, and shingle, - a condition of things very similar to that which we have observed in the gaps of so many of the Paumotu atolls (Pls. 72, fig. 1; 74, fig. 2; 75, fig. 3). The beach rock cropped out here and there in the interior of the lagoon. The sand which is blown into the lagoon over the land rim is cemented into fine mud when mixed with the mass of decaying Arcas and Tridacnas. The bottom of the 
lagoon consisted of coral sand, broken shells, Nullipores, corallines, and Foraminifera.

A sand bar is forming directly across the opening of the passage on the lagoon edge of the inner flat of the atoll. The lagoon flat is narrower on the two sides of the passage, but widens out towards the eastern and western beaches of the lagoon, and the widest part of the flat opposite the entrance is separated from the opening by the deepest part of the lagoon.

This atoll is well known from a somewhat diagrammatic sketch given by Beechey; this figure has been reproduced in many text-books, so that it has come to be regarded as the typical atoll. But while it undoubtedly represents an interesting phase in the history of atolls, its constant reproduction has given it a celebrity out of proportion to its importance, and has gone far to disseminate a very erroneous impression of what an atoll is (Pl. 72, figs. 1, 2).

The atoll can be taken in at a glance from the bridge of a vessel. Its comparatively small size and regular nearly circular outline, its shallow and narrow opening (Pl: 72, figs. 1, 2), in addition to its comparatively isolated position rising from an area of great depth, all tend to emphasize the somewhat exceptional features which characterize it. With Pinaki as a typical atoll, not only was the great irregularity of the many differently shaped atolls lost sight of, but the composition of the land rim built up of numerous islands, the existence of great stretches of submerged reef, the great depth of many of the atolls, their existence in comparatively shallow areas or position upon great submarine plateaus of very moderate depth, - all these characters were looked upon as constituting essential exceptions to "the atoll"; "the fairie ring," as typified by Pinakı. On the contrary, it is Pinaki which is an exceptional atoll, and the existence of special conditions readily explains its structure.

The presence of ligh dunes on the south face of Nukutavake (Pl. 70, fig. 4) and on the east side of Pinaki (Pl. 72, fig. 3) suggests the possibility of the eventual filling up not only of this lagoon, but also of such islands as AkiAki, 'Tikeï, and Nukutavake. Where the central part is more or less dished, as is Aki-Aki and Tikeї, and where, as in Nukutavake especially, the sea face is covered with masses of coral shingle and sand, we have all the 
materials necessary for such a change. The existence of such high dunes (35 feet) at Nukutavake and at Pinaki introduces an element which had not been taken into account as a factor in the building up of coral islands. Elsewhere also, as in the Marshall Islands, the changes produced by the movement of great masses of sand are perhaps more marked and more important in shaping the outline and extent of the land rim as well as the extent and area of the lagoon flats. The encroachment of the sand dunes on the land rim and the killing of bushes and Pandanus and trees by sand dunes take place at Pinaki as at Nukutavake, but not on such an extensive scale.

We can suppose the old ledge mass of Pinaki, after being elevated to a moderate height, to have little by little been cut down to the level of the sea, this cutting down to have been partly mechanical and partly chemical. The former action produced a mass of material, moving backwards and forwards, which must have formed the earliest shingle beaches on the periphery of the atoll or on one side or face of it, additions being made to this mass from the death and decay and decomposition of the corals which had found a favorable place for growth on the slopes of the old ledge mass.

Thus we can readily imagine Pinaki to have grown; the beaches thrown up on the circumference finally enclosed a comparatively shallow lagoon, constantly becoming shallower by accretions both from the outside and inside; accretions from the inside by the decay of the corals and shells, and from the outside by the mass of coral shingle and boulders thrown into the lagoon at the beginning of the building of the atoll, and also of the sand blown in by the gradual advance and rising of the dunes.

At first there may have been more than one opening into the lagoon; the land rim may, as in other atolls, have consisted of small islets separated by gaps, which with the diminution in size and depth of the lagoon were no longer kept open by the in and out flow of water over the half-submerged gaps. Indications of two such gaps can be seen in the stretch of low vegetation indicated in Pl. 72, fig. 1, and in the low gap covered with coarse shingle shown in Pl. 73, fig. 2. The outer beach of the land rim in the former has become as high as the adjacent coral sand beaches, while the 
last gap is still at a considerably lower level than the high beaches on each side of it. These became gradually closed, and finally there came about the conditions existing to-day, with a single gap allowing the sea access to the interior of the lagoon only at certain stages of the tide.

When the sand blown in, and the material derived from the death and decay of corals and shells, has so shut off the water of the lagoon that its access to the sea is cut off, then the last gap will be closed. We may expect then the lagoon to become a mere brackish sink, growing shallower each year, till nothing is left to indicate the former existence of a lagoon, once in full communication with the sea, except the shallow dishing of the central part of the atoll, more or less marshy, or perhaps consisting of as solid land as any other part of the land rim. In fact, Pinaki may be regarded as a stage antecedent to that of Aki-Aki, of Tikeï, and of Niau. It differs from Niau, however, in not having a sink lagoon, the lagoon of Pinaki being still connected with the sea and constituting what might be called a sound lagoon.

At Pinaki there is a good-sized water hole, a small sink in which the natives keep turtles, occupying the central part of the land rim where there is but little vegetation, where the land rim is from 400 to 500 yards wide. In the water hole of Aki-Aki turtles are also kept by the natives. At Nukutavake there are also sinks, eight to ten feet long, where water collects. These sinks are the result of the banking of material around depressions. In other islands these depressions are sometimes found in the central part of the islands of an atoll, where water collects in moderate quantities. Their origin is due to the same causes; they are littoral sinks dating back to a time when the island was probably of very much smaller size.

The soil of the crest of the land rim of Pinaki is quite fertile, being made up of decomposed leaves and stems and rolled fragments of coral shingle; while on the steep white sand slope it is quite barren, as well as on the sand beach back of the shingle on the lagoon face. The same conditions are found at Nukutavake and at Aki-Aki, where the humus is a little better. This appears to be the character of the soil of all similar islands wherever we landed in the Paumotus. 
On the sea slope of the reef flat corals were not abundant, and on the reef flat none were seen.

The notes for the description of the lagoon of Pinaki were made by Messrs. Townsend and Alexander, who examined it while we steamed about the island.

\section{The Duke of Gloucester Islands.}

\section{Nukutipipi.}

Plates 76, 77, 201, 203; 206, fig. 4.

Nukutipipi Island is the easternmost of the Duke of Gloucester Islands, a small helmet-shaped lagoon about two miles in circumference, which is well wooded on the northern and eastern faces, with a wide bare reef on the southwest face. The vegetation consists almost entirely of Pandanus, with a few cocoanut trees on the centre of the western face and on the northeast face of the atoll (Pl. 206, fig. 4).

Seen about three fourths of a mile distant coming up from the southeast, the high wide coral sand beach of the larger eastern island of Nukutipipi stands out prominently (Pl. 76, fig. 2), with the few patches of beach rock of the westernmost end of the beach and a similar line of beach rock ledge extending into the open half-submerged reef flat which forms the southern land rim of the atoll. The reef flat extends far into the lagoon on the southern side; the deeper part, indicated by its darker blue water, occupies but a comparatively small area towards the northern part of the lagoon (Pls. 76, fig. 1; 206, fig. 4). The regetation here as well as in the greater part of the southeastern atolls of the Paumotns is marked by the predominance of native plants, especially Pandanus, Pisonia, and Scaevola. But few cocoanuts have been planted here as yet.

On the lagoon side the two islands of the land rim are faced with fine coral sand beaches (Pl. 77, fig. 2). On the southwest side a wide reef flat extends far out (Pls. 76, fig. 3; 77; 206, fig. 4) to form the western and southeastern point of the atoll; over this an enormous mass of water must at each tide find its way into the lagoon, as the greater part of the western reef flat is submerged, the flow of water being only broken by a narrow 
line of coral shingle and by a mass of coral boulders and of beach rock (Pl. 77, figs. 1-3). The old ledge which forms the substratum of the reef platform crops out occasionally, coming up through the movable material covering it in part (Pl. 77, fig. 2). On the reef flat rim also numerous bars of shingle and of beach rock form the lagoon edge of the flat (Pl. 76, fig. 1); an islet, covered with the same vegetation as that of the two principal islands, built up of sand derived from the interior of the lagoon, extends across the whole width of the reef flat. Two bare sand bars have also been thrown up on the lagoon side of the reef flat. This islet and the two sand bars are the first indications of future islands to be built up on the land rim and to reduce gradually the great open gap of the submerged reef flat which now occupies the southwestern face of the atoll (Pl. 77, figs. 2, 3).

Nowhere were we so much struck with the beantiful coloring of the waters of the atolls as in these southern groups, and it baffles description to give an idea of the contrast of colors between the green line of vegetation, the yellow or gray shingle, the cream-colored sand beach, with its wide yellowish brown reef flat banded or dotted at low tide with dark brown masses of beach rock, edged with its many-colored knolls of Nullipores or Pocillipores. We then pass through all the shades of light green water to darker green, greenish blue, or dark blue, which a long line of white breakers separates from the darker blue of the deep water on the sea slope. If one were placed high enough to look into the lagoon and take in the whole at a glance, one would see the most wonderful gradations of coloring, passing from the dark blue of the deeper parts of the lagoon to the shallower parts of a lighter hue, next to the greenish blue of the outer edge of the lagoon flat, and finally to the greenish, the greenish yellow, or the lightest imaginable emerald of the shore flats, with here and there a dark blue patch with metallic reflections skirting a projecting sandy point, where all the imaginable variations of green and blue seem to have blended in the brilliant sunlight reflected from the placid, hardly ruffled water of the lagoon, or sparkle on the broken sea and swell of the adjoining ocean. In some of the shallower gaps, the water after a heavy blow sometimes becomes somewhat muddy and slaty-colored from the amount of silt held in suspension, and the sea 
for quite a distance is discolored and in marked contrast to the usual dark blue color of the ocean.

There is a wide gap between the two main islands of the lagoon on the northwestern side of the atoll (Pls. 77, fig. 2; 206, fig. 4). The small island occupies a part of the northwestern face of the atoll, while the larger island flanks the lagoon on the north and northeast (Pl. 77, figs. 2, 4). This and the other atolls of the Duke of Gloucester Islands may indeed be called pocket editions of characteristic Paumotu atolls. In the cut awash the beach rock is in part overlying the old ledge, huge boulders of which are left cropping out from the underlying foundation ( $\mathrm{Pl}$. 77, fig. 2), and crops out again on the inner face of the atoll. Vegetation covered in part the top of the sea beach as well as that of the lagoon face, and ran partly in between the shrubs and trees, showing that but little sand is as yet blown across the beach into the lagoon.

The larger island, forming the northerly and easterly side of the atoll, varies greatly in width, from 150 to 300 yards. At the southwest point of the smaller island the coral shingle beach must be fully fifteen feet in height in places, as a general rule at least twelve. On both islands the vegetation comes down below the summit of the inner and outer beaches, which are also well protected by grass extending on the lagoon face of the beach towards the interior of the land rim. The varying width and the narrow points of the land rim indicate probably the position of former gaps, which have gradually closed and connected the separate sand bars, islets, and islands once undoubtedly occupying the area now covered by the large island.

The reef flat is from 200 to 300 feet wide, and sand bars and incipient islets are forming on the lagoon edge of the reef flat of the land rim. The extent of the reef flat extension into the lagoon is indicated by the light green water (Pl. 206, fig. 4).

If the extension of the dunes were not kept in check by vegetation, comparatively small lagoons like those of the Duke of Gloucester Islands, would become filled and closed very rapidly. At present some of them are in equilibrium, new material is added by the corals on the south face where it is now building up sand bars and islets on the reef flat, while before the 
existing stage, the building up of the larger island must have taken place in great part from the lagoon side, judging from the comparatively small amount of material derived from rolled and dead corals thrown up on the northern and eastern faces of the atoll.

On the east face of the atoll we could see the blue water marking the shape of the deep indentations of the edge of the reef flat, where the Nullipore knolls and Pocillipore patches were unusually high, many of them ready to be torn off at the next high sea and thrown upon the reef flat (Pl. 77, figs. 1, 3). The Nullipore and Pocillipore knolls form the outside wall of an unusually wide and deep platform lagoon, running parallel with the western face of Nukutipipi (Pls. 76, figs. $2-4 ; 77$, fig. 3), which passes into the lagoon at the wide gaps of the reef platform $(\mathrm{Pl} .76$, fig. 4).

The soundings indicate that the sea slope of this island is very steep ; it rises rapidly from a depth of more than 2300 fathoms at a distance of five miles from the shore (Figs. 11, 12).

\section{Anu-Anurunga.}

Plates 78, 202, 203; 206, fig. 1.

Anu-Anurunga is about one and a half miles in diameter; it is slightly elliptical, and neither in this nor in the other islands of the Gloucester group are there any boat entrances to the lagoons; they all come within the term of closed atolls (Pl. 206). There are, however, a number of gaps between the islands, or wide reaches of bare half-submerged reef flats, allowing free passage to the sea at certain stages of the tide.

The eastern land rim consists of two large islands, the one extending from the southern point of the atoll to about the middle of the eastern face, it is separated from the other large island by an islet and a wide gap awash (Pl. 78, fig. 1). The second island extends round the atoll to the northwest side, and is separated from the western island by a stretch of reef awash (Pl. 78, fig. 2). The western island occupies only about a quarter of the western face. The southern half of the western land rim is a reef 
awash terminating in a small islet separated by a wide gap from the western point of the southeastern island.

Coming up from the eastward, the long stretches of gray shingle beach, dotted at the base by short reaches of beach rock ledge, formed the characteristic features of the sea face of this atoll. There are but few cocoanuts to be seen on any of the islands of Anu-Anurunga, the characteristic vegetation being made of the plants common to the group (Pl. 78, fig. 3).

On the east face of the western island the open half-submerged reef flat is very wide, while outside of the coarse shingle beaches the flat is very narrow, with many small boulders along the base of the beach. On the western reef flat there are several extensive patches of large boulders. The deepest part of the lagoon is near the eastern face. On the western side a wide reef flat, the extent of which is plainly indicated by the light green color of the water, extends northward from the western island far into the interior of the lagoon. The gaps between the islands are shallow, yet deep enough to allow a considerable amount of water to enter across them into the lagoon (Pl. 78, figs. 1, 2). Along the east and southwest faces of the reef flat extends a well-defined narrow platform barrier reef, with remarkably high Nullipore knolls on the outer edge of the reef flat, as well as patches of Pocillipores (Pl. 78, fig. 3). The outer edge is also deeply serrated with fan-shaped indentations.

Looking into the lagoon we can see that it is quite shallow, shallower than that of Nukutipipi, there being no really blue water visible in any part of the lagoon; it all is somewhat muddy in color, or of a light green tint, though there is a little darker water to be traced when looking into the lagoon over the western face.

On the wide western reef flat occur also sand bars and lines of shingle, as well as the characteristic shingle and rubble bars running at right angles across the reef flat, abutting on the lagoon side upon incipient sand bars or sand islets (Pls. 78, figs. 1, 2). On the lagoon side the islands are edged with coral sand beaches, while they are in part lined with bands of ledges on the outer sea face of the islands. Some of the smaller sand islets are prominent landmarks on the western reef flat. There is specially a small sand islet, set well back of the reef flat, with two cocoanut trees to distinguish it. A 
sandy islet on the northwest side lies also at an angle to the reef flat; it is protected on the sea face by a shingle ledge. Between the islands of the northwest side are gaps over which water passes into the lagoon even at low tide; these islands have steeper beaches than those more to the westward.

\section{Anu-Anuraro.}

Plates 201, 203; 206. fig. 2.

Anu-Anuraro is more angular in outline than the other islands of the Gloucester group. Its greatest length is about two and a half miles. It is fairly wooded on the eastern face, while its southwestern and northwestern faces are bare, being merely a wide reef flat. There are three small wooded islands on the atoll, one of which forms the westernmost point of AnuAnuraro (PI. 206, fig. 2).

The sea face of the islands of Anu-Anuraro is characterized by its steep high coral shingle beaches bordered at the base at intervals by long lines of ledge rock. There is also a great development of sand dunes on parts of the shingle beaches, where the shingle is completely covered by the inroads of the sand blown over them from the base of the shingle beaches. On the east face these sand beaches are often covered with grass and vegetation, which reach far down towards the sea along the face of the beach.

Along the outer edge of the reef flat at the southwest horn of the atoll Nullipore knolls take a great development. The reef flat is in places more than three quarters of a mile wide, extending far into the lagoon, and being half submerged in many places at all stages of the tide, allows large masses of water to flow into the lagoon. The flat is covered by lines and bands of boulders following in a general way the trend of the outer edge of the reef flat as well as the beach.

The vegetation of this atoll is low, rather scanty; the Pandanus trees, as well as the bushes of Scaevola, are small.

On the western face of the atoll the old ledge crops out on the inner side of the platform barrier reef channel, which is separated from the sea by a wide reef flat, with sand bars and shingle bars and coral rubble bands 
running more or less at right angles to the outer edge of the reef flat, where the Nullipore knolls form an almost unbroken abrupt vertical wall.

Some of the sand dunes have been driven into the lagoon, killing the Pandanus and other vegetation, while other dunes are stationary, being overgrown with grass and scrub vegetation; the beach forms a grass-topped bank which extends into the vegetation of the interior of the land rim. Coral rubble and shingle is also blown and washed in places partly across the islands. The base of the islands is mainly composed of beacli rock resting upon the old ledge, which crops out on the reef flats. In the Gloucester group, where the rubble or beach rock has been washed away, the old ledge forms the floor of the reef flats wherever we have examined them.

\section{Hereheretue.}

Plates 79-83, 201, 203.

Hereheretue encloses a lagoon about three miles in diameter, without a boat entrance. The western half of the land rim consists of a wide reef flat, bare at low water, in the central part of which is placed a small island with a few cocoanut trees. On the southwestern face of the land rim a few sand bars have been thrown up.

On the east face of this atoll are a great many. dead trees and bushes which have been killed by the inroad of the beach sand blown inland (Pl. 81), and along the sea face of Hereheretue, where it is not covered with grass (Pl. 80), blown sand is seen to extend under the trees and shrubs. On the north end of the east face of the atoll there is a good exposure of stratified beach rock running along the base of the high sand beach, which must be from eighteen to twenty feet in height (Pl. 81). At the northwest horn sand and shingle bars extend across the wide gap separating two of the islands; a high dune has also been formed there, the greater part of which is overgrown with vegetation.

The seven islands to the south are almost connected, the gaps between them allowing but little water to flow across into the lagoon except at bigh tide. The islands are all edged with sand beaches on the lagoon side. The 
lagoon flat being quite wide (Pls. 82, fig. 1 ; 83), there is considerable sweep for the sea in this lagoon.

An extensive ledge of beach rock and of recent conglomerate runs along the inner face of the southwestern edge of the lagoon reef platform ( $\mathrm{Pl}$. 82, fig. 2). The reef flat on the sea face of the principal islands of the atoll is narrow (Pls. 79, 80).

The beaches on the south side are formed by a series of low dunes alternating with masses of coral rubble, or shingle beaches with ledges of beach rock at the base $(\mathrm{Pls} .80,81)$. On the reef flat there are sand bars and islets with shingle bars or coral rubble dams. These are especially well developed on the southwest reef, where a well-marked islet is thrown up well back on the bank of the reef flat (Pl. 83, fig. 1).

We landed on the west side of the atoll of Hereheretue, on the outer edge of a reef flat nearly three quarters of a mile wide (Pl. 82, fig. 3). The boat was run up on the reef flat in one of the many indentations gouged out between the Nullipore knolls. The reef flat consisted of old ledge, planed down to about low-water mark, full of pot-holes of all sizes and shapes (Pl. 82, fig. 2). Between the outer edge of the flat and a sand bar perhaps two feet high, separating the reef flat into two parts, there were numerous pools left from two to three feet in depth, some of them quite extensive, where many Holothurians and other Echinoderms, mollusks, and corals were found congregated. Some of the corals, mainly Millepores, Pocillipores, and Porites, were well-developed isolated heads of considerable size. Here and there knolls of beach rock cropped out above the old ledge reef flat, and an occasional horse or wall of old ledge. Close to the shore we came upon a great undercut ledge of recent beach rock and conglomerate lying above the old ledge flat.

Where the reef flat of the atoll is comparatively narrow there is a welldeveloped platform lagoon running parallel with the base of the beach. At the horns of the atoll this lagoon often expands into one of considerable width (Pl. 79).

The island where we landed has been thrown up diagonally across the extensive reef flat of the west side of the atoll, and, like other similar islands, is edged on the lagoon side of the flat (Pls. 82, fig. 1; 83) with coral sand 
beaches and broken shell fragments. Here and there on the lagoon side a beach dam of small Arcas and sand was thrown up, and a few hillocks of dead Arca shells cropped out upon the lagoon side of the flat.

On the sea face of the atoll we could trace the corals down to twenty-two fathoms. They are, however, all small masses of Millepores, Pocillipores, Porites, and Madrepores, not to be compared in size with those growing in the pools of the reef flat or in shallow water.

On the reef flat the surface of the old ledge and the coral fragments were all covered with patches of many-colored Nullipores, protecting the reef flat from further denudation and disintegration. On the outer platform slope, at the foot of the steep and high beaches, were thrown up masses of coral fragments. On the outer sea face much of the dead material is not cast upon the beaches, but is thrown back on the outer slope; driven back and forth, it is ground into fine sand and shingle supplying the material for the beaches. The reef flats encroach extensively into the lagoon, forming extensive spits indicated by the green color of the water.

The reef flats of Hereheretue represent the condition of the flats of the atolls of the Gloncester group. There is always more or less coral rubble and shingle and little of the old ledge exposed, except where the outer part of the flat is cleared of beach rock and shingle or boulders. Beach rock and recent conglomerate take a great development on the inner parts of the reef flat close to the base of the beaches of the islands, where it has been originally deposited either upon the old ledge, so as to conceal the greater part of it, or between its outcrops upon different parts of the rim of the atoll either as buttresses or walls or horses.

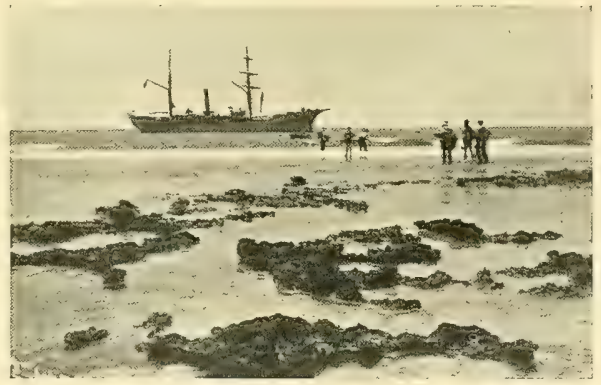

Landing on Reef Platform, Hereheretue.

The four atolls of Hereheretue, Ant-Anurunga, Anu-Anuraro, and Nukutipipi are most interesting. Nukutipipi is the smallest atoll of its kind we 
have seen in the Paumotus. One can take in at a glance the varying conditions which exist in such an atoll, and the different processes which go to make up a typical atoll. Anu-Anurunga resembles Nukutipipi, only it is somewhat larger, and from that we pass to Anu-Anuraro and Hereheretue, which represent each on a larger scale conditions which take their greatest development in such huge atolls as those of Hao, Fakarava, and Rangiroa. On the larger islands it is somewhat difficult to trace the changes which have taken place; but on such atolls as Nukutipipi, which we could take in as a whole, we readily recognized structural features which were somewhat vague from their extensive development in the larger atolls, or from their modification by special conditions.

Having formed our general conception of the group before reaching the more or less isolated atolls of the eastern Paumotus, we could recognize at once in these smaller atolls the distinctive features of the group, well concentrated and sharply developed from being seen on a small scale. 


\section{THE SOCIETY ISLANDS.}

Plates 84-105, 201, 202, 208-210.

$W_{E}$ examined the eastern coast of Tahiti, and the western coast from Papieté as far as Port Phaeton, at Taravoa Isthmus. We examined, in a general way, the Ieeward Society Islands: Murea, Huaheine, Raiatea, Taha, Bora Bora, Motu Iti, and Maupiti. There are excellent charts of the Society Islands, ${ }^{1}$ so that it was comparatively simple to study the typical points of the group and to gain an idea of their structure as far as it relates to coral reefs. The different islands present only modifications of one and the same structure, so that the more careful examination which we made of Tahiti and of Bora Bora undoubtedly gave us the key to the structure of those islands we examined only in a more cursory way. We saw enough of all of them to satisfy ourselves that there were no points of special interest which were not well represented on the islands which we examined.

The description we have given of the modifications of the fringing and barrier reefs of Tahiti applies to all the other islands of the Society group; it varies only according to the shape of the island, the manner in which the mountain ridges have been denuded, and according to its exposure to the prevailing winds. The Society Islands are all volcanic, edged with shore platforms, some of great width, upon which the barrier or the fringing reefs of the islands have grown. The structure of the reefs of the Society Islands is very similar to that of the reefs round the volcanic islands of Fiji. A comparison, for instance, of the charts of Kandavu, Viti Levu, Mbengha, Nairai, and of other volcanic islands of Fiji, with those of the Society group, will at once show the identity of their structure. Huge platforms of submarine denudation and erosion characterize both, with fringing and barrier reefs determined by local conditions; perhaps it is easier to follow the changes which have taken place in the Society Islands. Such islands as Tahaa and Bora Bora, where we anchored, as well as Maupiti, are admirable examples and epitomes of the structure and mode of formation of the coral reefs of that group.

1 A. Charts $1060,1248,1382$, and other charts of details. 
Mehetia has no reef flats; Tetiaroa and Motu Iti are composed of low coral sand islands thrown up on a wide barrier reef flat. In Motu Iti and Tetiaroa the volcanic peaks have disappeared, leaving nothing but a shallow platform, upon the outer edges of which sandy coral islets have been thrown up.

There is, however, one point in which the barrier reefs of the Society Islands differ from those of Fiji. The barrier reefs in Fiji are generally indicated merely by reef flats, upon which the sea breaks, and an occasional rocky islet or negro-head; only rarely do we find sand keys upon the barrier reefs of the islands of Fiji. In the Society Islands, on the contrary, we usually find the line of the barrier reefs well indicated by long lines of narrow islets thrown up on the reef platforms, exactly as they are in the Paumotus. These islands and islets are generally well wooded, and thus give a very peculiar aspect to the barrier reef. In the case of Bora Bora, Maupiti, and Aitutaki, we have a central volcanic peak of considerable height surrounded by a wide lagoon, the sea edge of which is formed by a fringe of wooded islets and islands forming a more than half-closed ring around the central island, which, in Bora Bora and Maupiti, rise in slopes and nearly vertical walls, the former to a height of nearly 2400 feet, the other to about 800 feet.

Tahiti, Huaheine, Bora Bora, Maupiti, and Motu Iti form a series of islands in which we can follow the steps which characterize the successive stages of denudation and of marine erosion they represent.

The Society Islands are divided into the Eastern and the Western groups, called the Windward and the Leeward Islands; Tahiti, Murea, Mehetia, Tetiaroa and Tubuai Manu ${ }^{1}$ forming the Eastern or Windward Islands. The Leeward group consist of Huaheine, Raiatea, Bora Bora, Maupiti, and Motu Iti.

Huaheine, the easternmost of the Leeward group, is about twenty miles in circumference and, like Raiatea, divided into two islands by a deep cut similar to those of Murea, of Maupiti, and of Bora Bora, only in this case the cut extends across the island, leaving but a narrow isthmus covered at high water, to connect the northern and southern parts of the island. Huaheine,

\footnotetext{
1 We did not visit Tubuai Manu.
} 
although surrounded by more or less indistinct barrier reefs, is deeply indented and shows perhaps as well as any of the other islands, the manner in which the wide platform of erosion has little by little been formed by the action of the sea. The wide barrier reef flats on the east, north, and west faces of the island are separated by a comparatively shallow and narrow lagoon from the main island. On the northern part the wide barrier reef flat is covered with islands more or less connected, and covered with trees; so that the slopes of the northern and eastern part of Huaheine appear flanked by a wide, low, wooded platform, identical in every respect with the narrow rim of wooded islands flanking some parts of the east face of Tahiti and differing from them only in width and extent. We can readily imagine that the time may come when all these islands and islets, extending from the easternmost point of Huaheine to the northern face, will in their turn become changed into such a narrow barrier reef as that characterizing Tahiti. This has to a certain extent occurred on the east face of Raiatea (Pl. 210, fig. 2), where the outer reef platform is not well indicated, but is merely outlined by a mass of patches of corals, growing at various depths; these crop out here and there, indicating the existence of a wide reef on the east face, similar to that found on the west as well as on the southeast face of Huaheine.

The peninsula of Taiarapu (Tahiti), not as yet separated from Tahiti, represents a stage of denudation analogous to that of Tahaa and Raiatea, separated by a wide and comparatively shallow passage reaching between Tahaa and Teavarua. Similarly Huaheine Nui and Huaheine Iti are still connected at low water by a narrow pass, a high knoll rising across Maroe Bay in the centre of the channel which divides Huaheine into two parts.

The isthmus of Taravoa (Tahiti) is low, and the channel separating the peninsula of Taiarapu from Tahiti is formed by Port Phaeton, which cuts nearly across it, leaving but a narrow strip of low land uniting the peninsula with Tahiti.

It will be noted that on all the leeward islands the reef flats of the northern and eastern faces are much narrower than those of the lee and southern sides, the circulation over and around the reef flats of the lee side being far less active than on the weather side. On the weather faces also 
coral sand islands and islets have been thrown up on the outer faces of the reef flats.

The fringing and barrier reefs which surround a large island like 'Tahiti, having a diameter of over thirty miles, and summits reaching a height of more than 7300 feet, appear narrow and unimportant when compared successively to the barrier reefs and reef flats fringing much smaller islands, as Murea, Raiatea, Huaheine, Bora Bora, and Maupiti, which respectively attain heights of about $4000,3400,2300,2200$, and 800 feet.

It is but a step from such an island as Maupiti, where the central island is reduced to a height of 800 feet to islands like Motu Iti and Tetiaroa, where the central volcanic nucleus has entirely disappeared, and is represented by the flat of volcanic rocks which probably underies the platform upon which the coral sand islands and islets of these groups have been

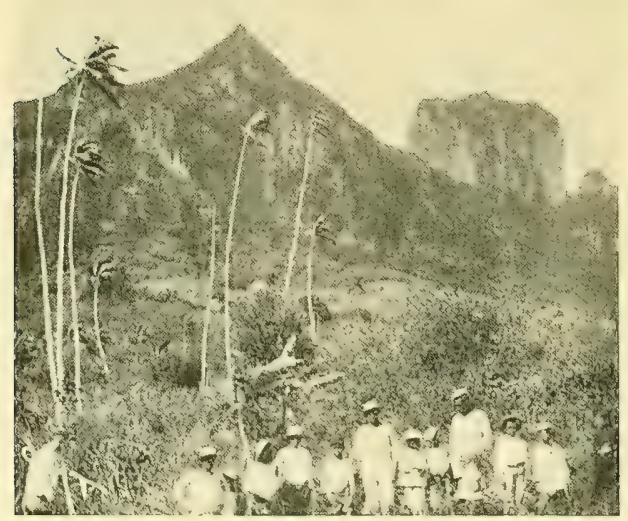

Summis of Bora Bora. thrown up. It is interesting to note that in Maupiti the southern and western reef flats are covered with masses of volcanic rocks, the outliers of former volcanic islets and islands once occupying the outer rim of Maupiti.

In the Atlas of the "Voyage de la Coquille" we find an excellent view of the peaks of Bora Bora (Pl. 16) taken from the lagoon at about the place where we anchored off Vaitape. On

Plate 17 is given a panorumic view of the islets on the reef flats of the northern face of the island, with Raiatea in the distance. This view is taken from the summit of Pahia which Lesson ascended; it has been copied by Darwin on p. 3 of the "Structure and Distribution of Coral Reefs." On Plate 18 an excellent view of Maupiti from inside the lagoon is given. 
Lesson's views of the relationship existing between the outer coral reefs and the central nucleus of volcanic islands seem to have escaped the attention of naturalists. He says, ${ }^{1}$ speaking of the central mass of Bora Bora: "Or à ce noyeau primitif et central s'adjoint une lisière plus ou moins large, très plate, peu élevée au dessus de l'ean, qui repose sur une base de corail.

"Les isles basses, ou Motous, qui paraissent quelquefois à une distance assez notable de l'île principale, ont été élevées indubitablement sur l'irradiation de quelques chaines du noyeau volcanique central. Jamais en effet les bancs de coraux ne s'étendent au large, et toujours ils sont la dépendance de l'île qu'ils entourent."

From what precedes it is natural that Lesson should consider, as he does, the passes leading into the lagoons as primordial volcanic valleys. Lesson ${ }^{2}$

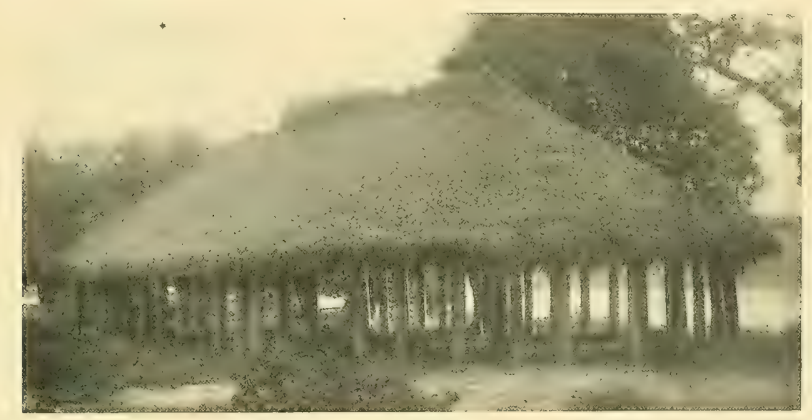

Assembly House, Teavanur Village, Bora Bora.

imagines that when the submarine volcanoes do not reach the surface, corals will grow on the submerged edge of the craters, the interior presenting an immense lagoon.

We may compare the reefs of Tahiti with those of Mauritius and the island of Mehetia with Bourbon, both of which, having no platform of submarine erosion, though in an area where corals grow in great abundance, yet are not surrounded either with fringing or barrier reefs.

1 Voyage autour du Monde sur la Corvette la Coquille, Vol. I., par P. Lesson, Paris, 1839.

2 Hoc. cit., p. 476. 
The vegetation of the Society Islands is already far more luxuriant than that of the Paumotus more to the eastward. This we might expect from the greater size of the islands, the more varied climatic conditions, and the greater fertility of the soil. Even on the coral sand islets on the outer edge of the barrier reef flats, the vegetation is far more varied and luxuriant than on the similar islands and islets of the land rim of the Paumotus. Lesson gives a list of a large number of genera which do not occur east of Tahiti, but which are still better represented as we pass to the westward, to Samoa, to the Tongas, the Fijis, and the Carolines.

\section{Mehetia.}

Plates 90, fig. 2; 95, fig. 1 ; 202.

Mehetia, the easternmost of the Society Islands (Pl. 202), is an isolated volcanic peak nearly 1600 feet in height, with a couple of rocky islets and rocks off the southern point. On the eastern and southern faces the slopes of the island have been abruptly cut off, and terminate in vertical cliffs and columnar masses of basalt at the base of the slope, on the northenstern face of the island. A few corals have been thrown up on the small beaches of the island along the east face and near the northeast point.

On the western face considerable coral sand has been thrown up on the western point of the island, derived from the few coral patches which are formed on the flat, the seaward extension of the western point ( $\mathrm{Pl}$ : 95, fig. 1).

On the summit of the island a well-marked crater exists. It is best seen when facing the island from the north (Pl. 90, fig. 2). It is interesting to find a volcanic island like Mehetia, situated in the belt of the trades, on which corals have taken no such development as they have on the other volcanic islands of the group. As I have stated, there are no coral reefs around the island, only a few coral patches, and the only difference we notice in the structure of Mehetia and of the Marquesas is the absence of a shore platform on which either fringing or barrier reefs can develop.

The absence of a shore platform on Mehetia and the Marquesas is probably due to the steepness of the slopes, which, when cut into, do not form 
the wide level platform characteristic of other Society Islands, the eroded material probably accumulating only as a talus in deep water on the steep declivity of the sea face. It is evident that local conditions, such as occur on a small scale at Mehetia and on a larger scale at the Marquesas and Galapagos, must account for the absence of coral reefs in a region where they generally exist in great abundance, either on platforms underlaid by volcanic rocks - as in the other Society Islands - or on platforms eroded from elevated coralliferous limestone, as in the Paumotus and Cook Islands.

\section{Tahiti.}

Plates 84-89, 202, 208-210.

Tahiti, by far the largest and most important of the Society Islands, is about thirty-three miles in length from its northwesterly point to the southeastern extremity. It consists of a principal land mass (Pl. 202) separated by a narrow isthmus of about one and a half miles, connecting it with the eastern peninsula of Taiarapu (Pl. 208, fig. 1). The main part of the island is circular, slightly angular, and is flanked on the east by a line of narrow barrier reefs which extend as far as Artémise Bank, where it becomes broken into a series of disconnected reef patches extending as far as Point Venus (Pls. 202; 208, fig. 2; 209). At one or tivo points on the east side, from Boudeuse Pass and Faone Pass, the barrier reef becomes more or less connected by secondary patches with a fringing reef, which skirts irregularly the whole eastern coast; ${ }^{1}$ except in the reaches where the shore line is covered by volcanic sand beaches or coral sand beaches, or a mixture of the two. On the northwestern face from Point Venus (Pl. 209) to the northwestern point of the island (Pl. 208, fig. 5) (Tataa Point), beginning to the west of Matavai Bay, the coast is flanked by a wide reef flat forming a barrier reef separated from the shore by a narrow channel, which connects Matavai Bay with Taunon Pass and Papieté Pass, and with the harbor of Papieté (Pls. 202, fig. 2; 209). To the westward a continuation of the same lagoon comes out at Taapuna Pass (Pl. 208, fig. 5). 
Beyond that, the barrier reef flat becomes changed into a wide fringing reef flat, which extends almost unbroken as far as Paea $^{1}$ (Pl. 208, fig. 4). While the reef flat is practically a fringing reef, its outer edge is usually somewhat higher thin the adjoining slightly dished flat, so that here and there, between the outer edge and the shore, are short stretches of water from one quarter to half a foot in depth, the beginning of the lagoon which will eventually be formed parallel to the shore line, as it exists in a more or less disconnected channel to the south of Paea (Pl. 208, fig. 4). From that point the reef flat is separated from the shore by a narrow shallow lagoon opening into Maraa Pass; the south part of the fringing reef extending from Paea to Maraa shows traces of an incipient lagoon channel, formed by the cutting back by the tidal currents running parallel to the shore, along the inner edge of the fringing reef; this channel will eventually unite the lagoon at Paea with the Maraa Pass Channel. At the northern end the lagoon is very shallow and narrow, while to the eastward of Maraa as far as West Ava iti the lagoon becomes quite wide and deep, and is navigable almost to its extremity, which is closed by a regular fringing reef to the east of Apomaoro (Pl. 208, fig. 4). This lagoon connects through two somewhat indistinct passes with the sea. At the extremity of the fringing reef to the east of Apomaoro, a small bay, Popote Bay (Pl. 208, figs. 3, 4), has been gouged out, forming an insignificant reef harbor; from the inmer edge of the adjoining fringing reef flats the tidal currents are cutting back or carrying off in solution the rotten coral on the flats, forming incipient lagoons which will change the fringing reef flats into a barrier reef, separated from a narrow fringing reef by a shallow lagoon, as we noticed it to the north of Maraa Pass. To the west of Popote (Pl. 208, fig. 3), the reef flat becomes wider, the lagoon itself is deeper, and we have a condition of things very similar to those which exist to the east and west of Papieté, - a series of passes separating wide reef flats bare at low tide, flanked by a deep lagoon, with depths of twelve or fourteen fathoms, studded with islands, islets, and reef patches, which indicate the former extension of the mainland, from which the reef flats have been denuded. The islands of Mapeti and Pururu in the barrier reef of the southern part of Tahiti, indicate 
the position of the former extension of spurs of the mainland, of which they are the only outliers left (Pl. 208, fig. 3).

At Taunoa the reef flat again becomes a fringing reef flat; the entrance to Phaeton Harbor is flanked on the two sides by gigantic reef flats (Pl. 208, fig. 1), the northern one of which is a fringing reef flat, while the southern is a wide flat separated from the mainland by a lagoon from ten to fifteen fathoms deep. The lagoon extends along the western and the southwestern shores of Taiarapu Peninsula, as far as Tutataroa Pass (Pl. 208, fig. 1), with here and there a pass connecting it with the sea. Beyond Fareara Point the extension of this reef flat, as it skirts the southeastern extremity of the peninsula, becomes a submerged flat (Pl. 208, fig. 1), covered with from two to eleven fathoms of water. The reef flat has been eroded and forms only an indistinct bar across the face of a broad lagoon, extending from Tutataron Pass to Tomotai Pass (Pl. 208, fig. 1). The eastern and northern face of Taiarapu Peninsula is flanked by disconnected reaches of narrow barrier reefs separated by deep passes. From Tiitau to Papeivi Pass across Taravoa Bay the narrow barrier reef has been greatly eroded, and only here and there an isolated rocky islet is left. Some of the patches and stretches between the narrow barrier reefs of the enstern side of Tahiti have also been planed off by submarine erosion into submerged reefs (Pl. 208, fig. 2), similar to those off Fareara Point.

A very striking feature of Tahiti is the number of watercourses which flow from the centre of the island towards the shore (Pl. 202, fig. 1). The high steep slopes and bluffs which fringe the island are cut by innumerable deep valleys penetrating almost to the centre (Pls. 86, fig. 2; 88, fig. 1 ; 89, fig. 1). The only locality where a gradual slope extends toward the sea is between Paea and Punaavia (Pl. 85), ${ }^{1}$ where the slopes rise gradually to the summit of Mount Taiti to a height of over 4500 feet. The valleys radiating from the central part of the island all bring down to the coast an immense amount of fresh water. On the eastern face numerous waterfalls are seen, many of them falling from great heights. The amount of water which has thus found its way into the lagoons accounts in great part for the exceedingly rotten condition of the coral mass which forms the 
reef flats, especially near the shore. It also gives us a simple explanation of the mode of origin of the lagoon, formed by the scouring of the tides running parallel with the shore, and by the solvent action of the sea, reinforced by submarine erosion. This has gradually changed the wide reef flits, forming at first fringing reefs of great breadth on the northern and southern faces of the island, into such bays as those of Papieté and its eastern and western extensions, and into the lagoons extending from Teavaraa Pass to Phaeton Harbor, and on the southwest side of Taiarapu Peninsula. The amount of silt which the numerous rivers of Tahiti bring down into the lagoon of the barrier reefs is very considerable; we find the bottom of the lagoons covered in great part with volcanic mud and silt, in the central part of the lagoon and in the neighborhood of the shore, but it is mixed more or less with coral sand as we go toward the outer face of the reef flat near the barrier reef.

On the northern and southern side of the island, as well as the western face where the trades do not strike with any great violence, the reef flats are broad (Pls. 202; 208, fig. 3). But on the eastern side, and also off the southeastern point, where the action of the trades is incessant, the reef flats have been greatly eroded, leaving a wide, deep lagoon, separating the barrier reefs from the main shore. Finally, on the northeastern side, between Artémise Bank and Point Venus, the barrier reef has become broken into isolated and disconnected reef patches, all pointing to the existence of a former wide reef platform (Pls. 208, fig. 2 ; 209). The outer edge of the platform is only indicated now by bars like those off the southern point of the peninsula, covered with from two to four fathoms of water and here and there passes, with from four to twelve fathoms, indicating the position of former breaks in the fringing reefs, similar to those still found south of Boudeuse Pass, and as far as the southeastern extremity of the Taiarapu Peninsula. The barrier reefs of the east side are well charted on the B. A. Chart 1382 .

The shore platform of the east face of Tahiti consists mainly of volcanic heads and ledges, outliers standing at a certain distance off shore (Pls. 86 ; 208, fig. 2), on which comparatively little coral grows, judging from the nature of the sand to be found on the beaches of the main island, inside 
of the barrier reef line. On some portions of the beach this sand is for the greater part purely volcanic; on others it is mixed with a little coral sand, where the platform is wider and there are islets left on it. From the amount of coral sand thrown up on the beach, it is evident that corals flourish on these wide flats, not only on the sea face of the shore platform, but also as extensive patches inside the barrier reef and as fringing reefs. The volcanic ledges and rocks of the outer barrier are in part covered by coral boulders thrown up from the sea face as well as from the ledges between them and the shore; on the slopes of the ledges and in the channels the characteristic corals of the Society Islands flourish.

The meagre development of the corals on the east face may be due in part to the great amount of detritus brought down the eastern face of the island by the numerous rivers and streams which have furrowed the whole island of Tahiti and cut extensive gorges penetrating to the very centre of the island. Numerous waterfalls can be seen on the eastern slopes of the mountains beginning the work of cutting back into the island. The photographs of Plates $85,86,88,89 ; 202$, fig. 1, will give some idea of the extent of the denudation and erosion which have taken place at Tahiti, not only on the east side, but on all the faces of the island, according to their exposure to the prevailing winds and rains.

An examination of the chart of Tahiti ${ }^{1}$ shows conclusively the effect of fresh water streams, with the accompanying silt they bring down in the rainy season, in influencing the growth of corals. The passes in the barrier reef are without exception opposite or near the mouth of a river or of a torrent (Pl. 208, figs. 1-5). Aiurua River is opposite Aiurua Pass, Vaitoto River and Vaionifa Pass, Vaitia River and Cook Anchorage, Haavini Valley and Toharoa Pass, Mapuaura River and Faone Pass, Mataea River and Boudeuse Pass, are all rivers opposite passes on the neighboring barrier reefs; all these gaps are on the weather side of the island. The wide fringing reef flats of the lee side are along reaches of coast without streams or small rivers; where wide lagoons separate the barrier reef flats from the shore, they are watered by more abundant streams, and the passes 
through the barrier reefs form the outlets of the waters which accumulate behind the barrier reef flats.

On the fringing reef platform beyond the Utuofai valley and to the north of it, there are only few corals; the beach is made up of volcanic sand, occasionally changed to light brown color by a little admixture of coral sand. We then come upon a long, narrow barrier reef flat extending quite unbroken to Boudeuse Pass; on this flat are scattered numerous negro-heads.

The first and second islets thrown up on the edge of the barrier reef flat north of Boudeuse Pass are made up of coral sand and coral shingle on the top of the beach (Pl. 86, fig. 1); inside of the reef extend a number of ledges which are overgrown with coral. The vegetation of these islands is made up of the usual outer belt of shrubs and bushes with an occasional cocoanut tree. Nansouty, the last island on the onter horn of the reef flat, is much larger; it is covered in part by large trees, similir to those of the main island. Both to the north and south many coral boulders and negro-heads are thrown up on the inner side of the barrier flat. On the wide stretch of the coast south of Artémise Bank there are, again, but few corals; the beaches are composed alternately of volcanic sand and volcanic sand mixed with coral sand, or of coral sand or coral shingle.

To the east of Point Venus there is no well-defined barrier reef on the outer edge of the shore platforms, the slopes of the mountains are steeper, and adjoining valleys are separated by knife-edge ridges, which broaden out somewhat fan-shaped as they reach out towards the shore or shore plain, as far south as Mahaena Pass and Nansouty Island.

Brander's Island is of volcanic structure (Pl. 209), and the beach of the bay east of Point Venus is made up of volcanic sand, showing that the wide platform carrying the fringing and barrier reefs of the west side of Tahiti has been formed by submarine erosion. Motu Tehiri and other islands towards Taapuna Pass, enclosed in the fringing reef flat west of Papieté, are volcanic, and the remnants of the volcanic flat platform. We can see the planing down of the cliffs of the coast, at the base of Arue, Haapape and of Tahara promontories, and their extension into the flat of Matavai Bay upon which a few Nullipores and detached masses of corals 
are growing. The beaches of the bay are composed alternately of volcanic or of coral sand derived partly from the cliffs and partly from the coral patches.

Although the prevailing trade is from the southeast, the wind during the fall and the beginning of winter is more from the eastward, and in the early winter it varies between northeast and northwest; the condition of the reef flats along the shores of Tahiti shows how dependent the topography of the reefs is upon the prevalence of winds from certain directions. The swell which comes from the northeast and east has eroded the wide barrier reef lagoon between Mahaena Pass and Point Venus; the northeasterly and westerly winds have eroded the platform of Matavai Bay, and have to a great extent directed the currents which have formed the harbor of Papieté and the extension of its lagoon to the east and to the west.

The prevailing trades rake the east coast of the peninsula and of the main island, and have reduced the outer edge of the reef platform to a narrow barrier reef. On the southwest and the west faces, which are protected from the prevailing winds and from the variable winds, we have wide barrier reef platforms still fairly extant, joined with the shore by innumerable coral reef patches. From the expansion of these patches the barrier reef platform passes more into what we may call fringing reefs or fringing reef flats of considerable width; the fringing reef flat off Hapaa (Pl. 208, fig. 5) being more than a mile wide, and the outer edge of the barrier reef platform off the northwest point of Tahiti being fully one and a half miles from shore. To the east of Papara the reef flat, both barrier and fringing, is, in some points, nearly one and three-quarters miles wide. The reef flats south of Port Phaeton are also marked for their great width. Off the north face of Tahiti the reef flat which once existed between Artémise Bank and Point Venus must also have been of great width, judging from the outliers of its outer edge which are still left standing. Tidal currents of considerable velocity flow ont through all the narrow reef passes of the northwest, southwest, and south coast of Tahiti. These currents are also reinforced by the mass of water which pours down the hillside during the rainy season. On the east coast the passes are of considerable width and much greater depth, and there is no such concentrated flow as is noticed on the west 
side. It is probable that these passes have, to a certain extent, been formed by the action of the silt, which is brought down by the fresh water flowing into the lagoon and which has killed the corals lying in their path. The strength of the currents is also due, in great part, to the amount of water which is forced over the sea face of the reef flats by the incessant roll of the breakers. Even on the faces of the island where the sea does not strike directly on the land, as on the west side, during the prevalence of the southeast trade, there is a constant swell running in, either from the north or south or west, which pours volumes of water over the outer edge of the reef flat. The strength of the currents which sweep out through the passes depends entirely upon the direction of the wind, the prevalence of the swell, and the season of the year. The coast shelf varies greatly in width, being indistinct, as we have stated, to the north of Paea and comparatively narrow from Paea to Papara, where the steep cliffs rise more than two thousand feet and slope directly to the shore; the shore flats widen out again to the east of Popote Bay, and form deep indentations on the south and west coasts of Taiarapu Peninsula. The eastern and northern coasts of the peninsula are flanked by steep bluffs rising almost vertically from the sea, to a height varying between twelve and fifteen hundred feet, with deep valleys reaching far into the interior of the peninsula. The Isthmus of Taravao itself forms a broad, low gap sloping towards the interior of the main island and the peninsula. From north of the isthmus the scenery of the island is, perhaps, finer than in any part of Tahiti (Pl. 86, fig. 2). Numerous waterfalls fall from great heights, into the deep gorges, which have been cut towards the centre of the island; endless furrows forming sharp spurs and ridges divide this slope into narrow valleys, opening on the coast of the main island. On the northern face of the island the slopes are more gentle, and off Point Venus one can look far into the interior of the island up the broader valleys of that part of the coast.

The extent of the erosion and denudation of Tahiti is well shown by the many directions from which "Le Diadème" can be seen from the sea, as off Point Venus on the north coast, off Tuaura Valley and off the east coast, off Artémise Bank, positions which are almost at right angles to one another. 
Mount Diadème rises to the height of nearly forty-four hundred feet, well towards the central part of Tahiti; it seems to cut off abruptly the extremity of Fautaua Valley (Pls. 88, fig. 1; 89, fig. 1).

The head waters of the Papenu rise from the great central amphitheatre formed by the peaks of Marau, Tetufera, and Orohena; from its southern and eastern slopes arise the rivers and torrents of the corresponding faces of Tahiti; from the western faces of Marau, Diadème, Aorai, Orohena, Taiti, Mahutaa, and Ivirairai rise the rivers which find their way to the sea on the western and northwestern faces of Tahiti. The silt brought down by these rivers has formed the wide flats which extend to the west of Papieté, and form the northern coast shelf towards Faa.

A similar shelf has been formed at Tautira Point, on the north shore of the Taiarapu Peninsula. It is a low tongue of land which extends to the northward for nearly a mile from the foot of the mountain, and has been formed by the deposits brought down by the Vaitia River (Pl. 208, fig. 1). It is the only remnant left of the reef platform, which once existed on the north coast of the Taiarapu Peninsula, on each side of Tautira. The great depth of some parts of the lagoon off the eastern and northern faces of the peninsula, is undoubtedly due to original orogenic conditions. The channel to Cook anchorage, off Tautira Point, was probably a deep valley, which directed the river Vitia in its northerly course (PI. 208, fig. 1). Although the northeast trades have eroded a wide platform on the east side of Tahiti, leaving here and there only a narrow belt of barrier reef on the outer edge of the reef platform, yet the growth of corals on the outer reef face is sufficiently luxuriant to build up, from the dead material thrown up on this reef flat, an occasional island or islet (Pl. 86, fig. 1). These islets are a characteristic feature of the reefs of the east face of Tahiti; they resemble, only on a more limited scale, the coral islets we observed in other islands of the Society group, such as Bora Bora, Raiatea, and others, where the outer edge of the reef platform is flanked by an almost continuous line of islands and islets composed of coral sand. The islands have been thrown up on a sub-basis of volcanic rock, and here and there an outlier of the volcanic rock can still be traced, giving us a clue to the nature of the underlying platform, and plainly showing that it is only the extension of spurs of the mainland 
which have been eroded and washed out to sea, leaving the thin outer line of reefs we have described.

Venus Point is, like Tautira Point, a mass of volcanic sand and mud which has been deposited by the Tuaura River, and the jetty built up from the opposing surf of the western and eastern sides, has gradually been built out so as to unite with the outer edge of a former barrier reef flat (Pl. 209). A wide peninsula flanked with islands and islets has thus been made, forming a harbor to the east of the Brander Plantation, and forming on the west the pocket of the eastern end of Matavai Bay. The islands to the east of Point Venus are composed of volcanic sand, while the islets on the east face of Tahiti, north of Boudense Pass, are mainly composed of coral sand, which has been thrown up on the outer reef face upon a base of volcanic rocks.

On several occasions I examined the north side of the Papieté barrier reef, ${ }^{1}$ the same portion which was surveyed by the "Challenger," " for about two miles north of the entrance towards the Taunoa entrance. We found on the outer face of the reef slope living corals to within the range of the breakers, up to the very crest of the rim of the reef flat; these corals extend, however, only to four or six fathoms, or slightly deeper occasionally, the lower part of the slope being covered with broken fragments of dead corals, or dead corals down to a depth of eighteen fathoms. Here and there small patches of living corals extended below the thriving belt to nine or ten fathoms. The principal genera were Pocillipores, Madrepores, Porites, Pavonia, some of them brilliantly colored, but none very large; the majority of the specimens being small, those of larger dimensions being quite uncommon. At about fifteen to sixteen fathoms the masses of dead corals were separated by wide bare lanes of sand, with here and there larger masses, from two to four feet, on the face of the slope.

We were also greatly struck here, as later in the Paumotus, with the absence of Gorgonians and of other Alcyonaria. On the sea face of the edge of the narrow and comparatively bare reef flat Pocillipores were growing abundantly, and fragments and masses were constantly broken off from the outer edge to form a sort of shingle on the outer reef slope, greatly to

1 Dana, Coral Reefs, p. 149.

${ }^{2}$ Challenger Narrative of Voyage, Vol. I. Part II. p. 777. 
the detriment of the growing corals. These dead fragments, as well as those on the bare reef flats, were covered and cemented with masses of Nullipores.

The lagoon slope of the reef flat is much less steep than the sea face (PI. 209), and on this slope are stretches of large masses and patches of living corals, extending also on the steep slopes of the shoals or islets along the lagoon. The larger masses are usually species of Astræans and Porites; towards the inner part of the lagoon and the harbor, the bottom is covered with fine inud, this becomes gradually composed of larger quantities of coral sand towards the entrance and in the passages across the barrier reef.

I cannot well reconcile the condition of the outer reef of Papieté, as we saw it, with the account given in the Narrative ${ }^{1}$ of the "Challenger," which describes the face of the reef as full of growing corals; or with the statement of the presence of very large blocks on the slope, and of the presence of growing corals to a depth of thirty-five fathoms.

A great part of the reef flat is bare at low water, and exposed to the heat of the sun during a considerable portion of the day. This evidently affects the growing corals, and may account for the unusual number of large masses which are washed down from the flats both on the sea face and lagoon side of the reef. Owing to the exceptionally clear days and smooth sea on which we examined the reef, we could see the condition of the slope of the sea face with the naked eye down to nearly sixteen fathoms, and with the water glass the most minute details could be traced to eighteen fathoms; down to twenty-two we could see indistinctly that the dead corals were replaced almost entirely by coral sand, only here and there a spur of coral shingle extending into the sandy region. There were comparatively few gullies and cuts along the face of the reef, the slope being unusually uniform and unbroken by crevasses or caverns or fissures. Nine to ten fathoms represented the average depth to which thriving corals extended; beyond that they were habitually small, and grew only in limited areas between the greater stretches of fragments of dead corals.

On the crest of the narrow barrier reef flat Algæ and coralline Algæe, as well as the cementing Nullipores, grow in great abundance; the last are specially developed on the lagoon slope, covering the whole slope with a

i Challenger Narrative of Voyage, Vol. I. Part II. p. 777. 
pinkish yellow coating. Several species of Pocillipores grow on the outer rim of the reef flat, rising to a considerable height, and forming its elevated rim. On the lagoon slope, scattered Pocillipores and Madrepores are found, as well as larger masses of Madrepores, Porites, and Astræans of several species growing in from two to six fathoms. Millepores grow abundantly in shallower parts of the slopes, and Fungia are found on the reef flat and slopes. Echinometræ are abundant in the small cavities and pot-holes of the rim and reef flats, while Echinaster, Echinothrix, Linckia, and Diadema, as well as Heterocentrotus, are the most common Echinoderms of the outer reef flat, spreading in the direction of the inner channel of the barrier reef.

On the deeper lagoon slopes of the barrier and of the fringing reef and the fringing reef flats, are found the same corals and Echinoderms which occur on the shallower flats; the corals, however, grow more abundantly on the deeper slopes than on the flats, while the Echinoderms are more abundant on the flats.

Papieté Harbor and the adjoining reefs are interesting, as they have been examined by nearly all the principal writers on coral reefs (Pls. 84; 85, fig. 2 ; 89 , fig. 2 ; 209). The outer reef was visited by Darwin ; it was surveyed by the U. S. Exploring Expedition under Wilkes, and subsequently re-surveyed by the "Challenger," a number of lines of soundings being run by the "Challenger" normal to the face of the reef north of the entrance of Papieté to a depth of from 140 to 180 fathoms. Papieté Harbor is elliptical in shape, about one and a fourth miles in length, three fourths of a mile in width (Pl. 209). On the northern half a number of flats and islets occupy a great part of the harbor. The outer reef flat, which extends to the eastward from the entrance into Papieté Harbor, is about one eighth of a mile in width, crowned at the sea face by a narrow ledge of coral shingle extending towards Taunoa Pass, where it expands into a club-shaped flat nearly half a mile in width. A channel leads from the northeastern extremity of Papieté Harbor to Taunoa Pass; this channel is subdivided into irregular basins by spurs of the wide reef flat, running out from the fringing reef which extends in an easterly direction from the Arsenal towards Taunoa Village. Taunoa Pass opens into a small bay a little over half a mile in length; it is fringed on the east by a wide barrier reef flat, similar to that 
on the western side of Taunoa Pass. The eastern barrier reef flat extends eastward to the western extremity of Matavai Bay, which is connected with Taunoa Harbor by an irregularly shaped navigable lagoon. To the south of this reef flat is the harbor of Papawa; it is much like Papieté Bay. Its central part is covered by a wide reef flat dividing a northern and a southern channel, leading east into Matavai Bay, and west into Taunoa harbor.

Matavai Bay extends from Papawa Harbor to Point Venus. It is remarkable for the absence of corals along its shores. At Pipine Point, at Arue, and Tahara Point we find a diminutive fringing reef; the remaining shores of Matavai Bay are covered with fine volcanic sand which has been washed down from the adjoining hills (Pl. S7, fig. 2). From Haapape to Point Venus a wide flat composed of volcanic sand has covered the extension of the volcanic rocks. The extremity of Point Venus is flanked with a crescentshaped reef flat, nearly half a mile in its greatest width and about one mile long; on its outer face and in the sheltered cuts patches of corals occur. The greater part of the corals on the reef flat have been killed by Nullipores; it will, little by little, become covered with the volcanic sand which is constantly creeping out towards the reef and will finally overwhelm it, filling up the narrow lagoon channel which still separates it from the shore, and connects Brander's Bay, Port Motu Au, with the eastern entrance into the lagoon on the north side of Matavai Bay (Pl. 209).

Reef patches, the remnants of a former barrier reef, extend westward from Venus Point parallel with the shore of Matavai Bay, forming the chain of Toa Tea Reefs, but they are merely patches of Nullipores with here and there diminutive coral heads which have taken no part in the building up of these reefs. The slope from the shore of Matavai Bay out into deep water indicates a somewhat more rapid fall from the fifteen- or twenty-fathom line (Pl. 209), just as it is indicated on the onter face of the barrier reef to the east of Papieté, with the exception that in the range between the eastern extremity of the barrier reef of Papawa and the western face of Point Venus, the reef has a depth varying from ten to sixteen or seventeen, five, four, three, two, and six fathoms, showing the existence of a former barrier reef flat, which has been denuded by the action of the sea constantly pounding upon it, and by the immense rollers which run in from the northwest 
into Matakai Bay. Dolphin Bank (Pl. 209) is the only remnant of that ridge; but its higher points consist entirely, as I have mentioned before, of small heads of corals covered with Nullipores. To the west of the entrance of Papieté, the barrier reef flat is much wider than the eastern flat and covered with negro-heads; it extends in a westerly direction about four miles (Pl. 209). The reef flat is over half a mile in width, having only a narrow lagoon channel widening out towards Torea Point (Pl. 208, fig. 5). There the barrier reef turns a sharp angle and runs parallel with the western shore in a southerly direction; it is separated by a narrow lagoon from the fringing reef flat, which is a mass of dead corals cemented by Nullipores; the lagoon cuts through the barrier reef and forms the pass of Taapuna. The reef flat to the south of the pass gradually becomes a fringing reef which extends beyond Atiue as far as Acua. The shore beaches are composed mainly of volcanic sand with a small admixture of coral sand.

The island of Tehiri is an outlier of one of the volcanic spurs off Torea, at the northwest angle of Tahiti; it is in the very centre of the fringing reef flat which extends from Nututere Point, south of Papieté as far as Torea. Its position, as well as that of Tataa Point, indicates the manner in which the fringing reef flat has gradually been formed, from the erosion of the spurs extending out from the main mass of the island towards the sea ( $\mathrm{Pl}$. 208, fig. 5). The islands in the northeastern part of Papieté Harbor, Motu-uta, Fareute Point, and the isolated flats and bars found in the lagoon channel between the barrier reef flat and the fringing reef flat, as well as other points extending out towards the sea between Papieté and Point Venus, are the remnants of eroded volcanic spurs and ridges which once formed the continuation of the main slope of Tahiti (Pls. 84; 87, fig. 2; 209).

We visited Point Venus to examine the level marks of Wilkes and of Messrs. Le Clere, Lieutenant de Vaisseau, and de Bénazé, naval engineer, relating to Dolphin Bank. ' Wilkes' levels were taken on September 22, 1839, and those of Le Clerc and de Bénazé in September, 1869. ${ }^{2}$ The level of Dolphin Bank, according to Wilkes, was 7.80 ; according to the French engineers it was 7.25 ; making a difference of .55 metres in thirty years.

1 We found the stones and marks as deseribed.

2 Report published in Paris, June 29, 1870 
We were of course very anxious to make careful measurements, and to ascertain if possible the rate of growth of corals on that bank, as it would give a growth of sixty years. While Captain Moser was engaged in placing his instruments in position on the monument established by Wilkes, I reconnoitred in the steam launch the shoal, which is about half a mile from the shore, and sounded across it in all directions, and carefully examined its surface with a water glass. I was greatly surprised to find that the Dolphin Bank was really not a coral bank. Only a few diminutive coral heads (Porites and Pavonia) could be found on it; none larger than my fist. The surface of the bank was covered with fragments of bro-

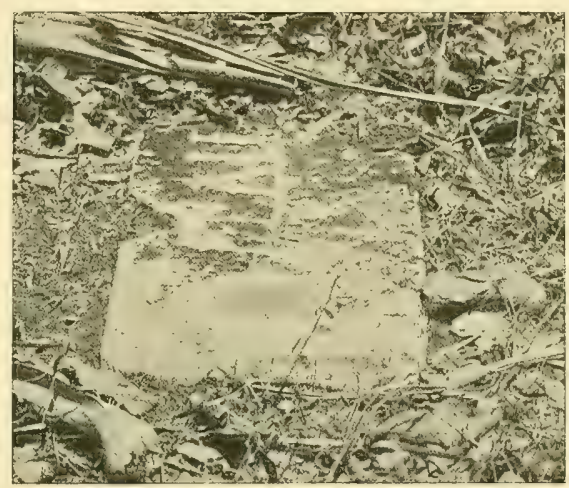

Wilkes' Monument, Point Venus, Tahiti.

ken coral coated with Nullipores, and no corals were growing on the slopes as they passed into deeper water. It was very evident that unless the conditions have been radically changed in the past sixty years, no one had carefully examined the surface of the Dolphin Bank, as nothing was said either by Wilkes ${ }^{1}$ or Dana or the French naval officers of the condition of the corals on the banks. In fact, this part of the shore of Tahiti, as well as the whole of Matavai Bay (Pl. 209), is, with the exception of a small reef flat stretch at the extremity of Point Venus, covered with volcanic sand. A more unfortunate selection could not have been made.

A very heavy swell is always rolling over the bank, and even in moderate weather is nearly on the point of breaking, so that it is difficult to remain any length of time on the shallowest point of the bank, after it has been found. Our soundings agreed with those of the charts within eighteen inches; as there is a considerable range of tide, it would always be difficult to reduce them to the same plane without prolonged observations. 
Narrow shore platforms cut into the volcanic rocks of the points and headlands along the shore of Matavai Bay. The volcanic sands extend to the east of Point Venus to Brander's Bay; the flats formed from the disintegration of the land are all composed of it, as well as the islands and islets to the east of Brander's Bay (Port Motu Au, Pl. 209).

It seems to have escaped Dana as well as Wilkes and Messrs. Le Clerc and de Bénazé, that Captain Beechey in 1836 also attempted to obtain some data regarding the rate of growth of corals on Dolphin Bank. ${ }^{1}$ He says that "from the reports of the natives the coral bordering the volcanic islands does not increase very fast, as we never heard of any channel being filled up. The only direct evidence which I could obtain of this fact was that of the Dolphin Bank off Point Venus in Otaheite. This reef, when first examined by Captain Wallis in 1769, had two fathoms of water upon it. Cook sounded upon it a few years afterwards, and gave its depth fifteen feet. In our visit to this place we found upon the shallowest part of it thirteen feet and a half. These measurements, though at variance from the irregularity of the surface of the reef, are sufficiently exact to warrant the conclusion that it has undergone no material alteration during an interval of fifty-six years." Beechey also noticed that the Dolphin Bank was in a bay into which several rivers flowed, which would materially influence its growth.

\section{Murea.}

\section{Plates 90, fig. $1 ; 91 ; 208$, fig. 6 .}

The island of Murea, distant from Tahiti about nine miles, is more broken in outline than Tahiti its sharp peaks assume most fantastic outlines (Pl. 91, fig. 1). Seen from the north, two wide valleys, separated by Tea Promontory (Pl. 208, fig. 6), form deep harbors extending for more than a quarter of the depth of the island towards the interior. They open out into the wide amphitheatre from which run the spurs and ridges which extend to the eastern and western sides of the island (Pl. 91, fig. 1). The island is triangular in shape, each side being abont nine miles in width, and is

\footnotetext{
1 Beechey, loc, cit., Vol. II. p. 190.
} 
surrounded, as Tahiti is on its eastern face, by a narrow barrier reef with a number of passages between it and the enclosed lagoon. At the eastern point, the southern point, and off the northwest point, as well as the greater part of the north coast, the narrow barrier reef is changed into a more or less prominent fringing reef flat, partly submerged, studded with endless outliers flanked with shallow patches of water, and here and there a deep lagoon basin (Pl. 90, fig. 1), the parts of which are connected on the east face, disconnected on the north, and indistinctly marked on the west coast (Pl. 208, fig. 6). A number of small reef harbors are cut into the wide barrier reef flat. Lakes Temae and Motuiti (PIs. 90, fig. 1; 208, fig. 6) are evidently former lagoons which have been shut off from the sea by the outlying barrier reef flats of the northeastern face of Murea (Pl. 91, fig. 2). Murea Island presents no features which have not been observed in Tahiti; as in Tahiti, there are but few islands and islets on the barrier reef flats; in Murea they flank its northwestern point, as do the islands off the east face of Tahiti, and are composed of volcanic rocks, as is the underlying reef tlat.

The erosion of Murea has been even more extensive than that of Tahiti, and nowhere do we find, except perhaps at Bora Bora, finer examples of erosion than in the needle-like ridge and peaks, characteristic of Murea. An examination of the chart ${ }^{1}$ will indicate to what extent the mass of Murea has been sculptured to reach its present condition. Like Tahiti, it is well watered; numerous streams flow in all directions 'along the slopes of the central mountains, and pour masses of silt into the lagoons of its coast.

\section{Huaheine.}

Plates $92 ; 94$, fig. 4; 202; 210, fig. 1.

Huaheine is about twenty miles in circumference, the northern part of the island being called Huaheine Nui, and the southern part Huaheine Iti; they are separated by a cañon extending two thirds of the way across from the eastern face, forming Farerea Pass, and Maroe Bay. It connects with 
the bay on the western side to the east of Vaiorea Island (Pl. 210, fig. 1). There are a number of deep harbors extending into narrow valleys between spurs of the main ridge, cutting deep indentations into the island (Pl. 92, fig. 1). From Fare Harbor a deep lagoon channel extends along the west face to within about one mile of Tiva Point, the southern extremity of the island. The lagoon is flanked by a wide barrier reef flat. In proportion to its size the interior navigation of Huaheine is comparatively extensive as contrasted with Tahiti, but does not compare with that of Raiatea and Tahaa, where a large vessel can enter the east pass of Teava Moa and sail nearly around the east coast of Raiatea, the east const of Tahaa, and its northern and western faces as far south as Rautoanui Pass, or south of Teava Moa Pass along the southern face of Raiatea, through a deep and wide lagoon forming an almost continuous passage round the island from its southernmost point, only a small part of the island being inaccessible by this great inland passage.

Huaheine is characterized by the great development of the islands on the wide barrier reef flat of the eastern and northern faces. The islands are comparatively narrow south of Farerea Pass, and are separated from the shore of Huaheine Iti by a deep lagoon. To the north of the pass the barrier reef islands are wider, and at the northeast and northwest points they occupy the whole width of the barrier reef flat (Pl. 94, fig. 4), being separated from the land by a very narrow lagoon. The lagoon forms an impounded lake off the northern face of Huaheine Nui (Pl. 210, fig. 1), similar to those on the northeast face of Murea.

Huaheine might be compared in a general way with Bora Bora; it is, however, larger than the latter, the lagoon of the western side of the atoll is smaller, and the reef flat of the eastern face of Bora Bora is separated from the central island by a wider lagoon channel. The islands of the eastern face of the barrier reef are likewise narrower, and only on the northwest face do they compare in width with those of Huaheine Nui. The islands on the edge of the barrier reef flat are all composed of coral sand, Vaiorea Island and Tiva Point alone being spurs and an outlier of the volcanic slope, which has been eroded and denuded, and upon which the barrier reef flats have been formed. 
Motu Araara off the southern extremity of Huaheine is the only island on the outer edge of the barrier reef which has remained to indicate the distance to which the volcanic slopes on the southeastern face of the island at one time extended (Pl. 210, fig. 1).

\section{Raiatea and Tahaa.}

Plates 93; 94, figs. 1-3; 96, fig. 2; 210, fig. 2.

We followed the east coast of Raiatea from Teavarua Pass round to Païpaï Pass on the west coast of Taha. There are a number of volcanic islands on the outer reef of Raiatea and Tahaa, indicating the extent of the submarine platform of erosion which surrounds these islands. This platform varies in width from three quarters of a mile to nearly two miles (Pl. 210, fig. 2). The lagoon is in many places over a mile wide, with deep indentations or harbors, reaching into the valleys formed by the spurs running east and west from the main ridge of Raiatea. Some of these harbors are nearly three miles in depth, cutting well inland towards the centre of Tahaa and Raiatea (Pl. 210, fig. 2), as Hamene, Teoneroa haaoa, and Pari Bays in Tahaa. Faroa Bay reaches more than one third across the width of Raiatea, and a number of indentations extend far up into the broad valleys which stretch from its central ridge towards the east and west shores of the southern part of Raiatea.

The northern reef flat of Tahar is studded with numerous islands and islets (Pls. 93, fig. 2 ; 96, fig. 2 ; 194, figs. 1-3), running at right angles to the outer edge of the barrier reef flats (Pl. 210, fig. 2), much as we have seen the great sand islands and islets thrown up on the outer faces of the Paumotus and of the Marshall Islands. This indicates that during the prevalence of northeasterly and northwesterly winds on these shores a large mass of dead material is derived from the outer edge of the northern face of the reef flat, and goes to build up the islands bordering the outer edge of the barrier reef. The islands are from one to one and a half miles distant from the shore, and are a very characteristic feature of the northern extremity of Tahaa (Pls. 94, figs. 1-3; 96, fig. 2). Nowhere in the Society 
Islands is this feature so greatly developed as it is on Bora Bora, where more than two thirds of the outer reef flat is composed of long islands and islets thickly wooded, forming a green belt on the barrier reef from one to two miles distant from the base of the steep mountain slopes which rise in the central part of the lagoon (Pl. 210, fig. 3).

Raiatea is separated from Tahaa by a passage about two and a half miles in width (Pl. 93, fig. 1), with a greatest depth of twenty-four fathoms. The barrier reef which surrounds the islands of Tahaa and of Raiatea extends directly across the faces of this inlet (Pl. 210, fig. 2). Both on the east and west of the passage, and in the centre (Pl. 93, fig. 1), several islands and flats indicate the position of former ridges or spurs, which once connected Tahaa with Raiatea, and which have been eroded by the same causes which have cut the submarine plateau extending around the islands, on the outer edge of which the encircling barrier reef is situated.

It is only around the northern part of Tahaa that the outer edge of the barrier reef flat is covered with islands (Pls. 93, fig. 2; 94, figs. 1-3; 96, fig. $2 ; 210$, fig. 2). To the south of that belt, both on the east and west, the reef is generally awash (Pl. 93, fig. 1), or with gaps of from eight to ten feet in depth, separated by patches of coral, the color of the water indicating their presence. In the vicinity of all the ship passes leading into the lagoon, either on the east or the west shore, numerous islands and islets still remain (Pl. 93, fig. 3), outliers, indicating the position of the ridges or spurs of the volcanic slopes which have been eroded, and which once extended to the outer edge of the reef flat (Pl. 210, fig. 2), as Mahea and Toahotu Islands at Toahotu Pass on the east side of Tahaa; we follow these islands along the east shore of Raiatea, as Tetaro and Taoro Islands at Te Avapiti Pass, the islands of Tipaemau and Iriru at Iriru Pass, and similar islands at Teava Moa Pass, at Nao Nao Pass. On the west coast they occur at Toamaro Pass, at Tiano Pass, at Rautoaniu, and at Païpaï. Both on the east and west coasts the islands occur only at the passes, and the reef flat is indicated by the coral reef patches which we have mentioned.

The vegetation of the low islands fringing the lagoon is much like that of the Paumotus (Pls. 93, figs. 2, 3; 96, fig. 2). Between the islands the sea is pouring into the lagoon, or rushing ont according to the stage of the 
tide and direction of the wind. There is a marked contrast in the character of the barrier reefs of the Society Islands and those of the Fiji Islands. While the barrier reefs have taken a great development off the larger islands of Vanua Levu and Viti Levu, we do not find at the smaller volcanic islands in Fiji such wide barrier reef flats upon the surface of which incessant movement of material takes place as in the Society Islands. There are no islands where the barrier reefs have taken such an extraordinary development as they have in the Society Islands. Along the northern extremity of Taha huge flat pieces of reef rock or beach rock are found scattered on the barrier reef flat. The material on this part of the reef platform apparently moves in and out according to the supply on the flats, or according to the supply driven out from the inner part of the lagoon. Some of the islets appear to be wasting away, while others in close proximity are increasing in size.

South of Iriru Pass the east shore of Raiatea is flanked with numerous volcanic islets. South of Faatemu Bay lies Haaio Island, a volcanic islet of considerable size placed in the centre of the lagoon; off the west coast between Punaeroa Pass and Tiano Pass numerous volcanic islets are enclosed within the shore fringing reef or rise from the deeper parts of the lagoon. South of the Tiano Pass the lagoon of the western coast is broken up into separate basins by the extension seaward of the fringing reef and patches in lagoons towards the barrier reef flats. The highest point of Raiatea is about 3400 feet, while Tahaa is not more than 2000 feet high.

\section{Bora Bora.}

Plates 96, fig. 3; 97-103, 202; 210, fig. 3; 235.

The most striking of the Leeward Islands of the Society Islands is undoubtedly Bora Bora. The wide barrier reef flat which surrounds the central islands is edged with islands and islets. Many of them are of considerable size. The reef flat is widest on the sonth and west coasts, its greatest width is about one and a quarter miles (Pl. 210, fig. 3) on the northwest flat. The low island of Teveiroa is covered with a scanty vegetation, and extends across the whole width of the barrier 
reef flat. To the north of Teveiroa, on the west coast, a number of long narrow islands, running at right angles to the outer line of the barrier reef flat, indicate the manner in which the barrier reef flat has little by little been covered by the material thrown up during the prevalence of the westerly and northwesterly winds (Pls. 96, fig. 3; 97-99). The gaps between the islands being gradually reduced by dams formed either on the lee or the weather side (Pls. 96, fig. 3; 97, fig. 2; 99, fig. $3)$, exactly as we have described the formation of the land rim for many of the atolls in the Pacific.

Teveiroa consists of a series of smaller islands which have been united, while the islands immediately north of it are still disconnected (Pl. 210, fig. 3). On the northeast and east coasts we find long islands with here and there a gap indicating the manner in which the land rim of those sides of Bora Bora has been thrown up, and has little by little formed a continuous island on the northeast face, and a continuous island on the southern part of the east face (Pl. 98, fig. 1); the long narrow islands are separated by a cluster of small islands which are gradually extending lagoonward over the wide barrier reef flat. Parts of the longer islands are here and there almost separated by indistinct gaps, as is seen on the chart (Pl. 210, fig. 3). On the south face of Bora Bora and on the west face (Pl. 97, fig. 3) the wide barrier reef flat, over a mile in width, is in part bare or awash or covered with coral patches, separated by pools or lanes of water varying in depth from eight to ten feet. The lagoon which separates the main island of Bora Bora from the barrier reef flat forms on the eastern face a series of basins nearly distinct, separated by the spurs which have run out in points from the main ridge of the island; some of these points have been cut, leaving here and there small islets, like Pitu u Uta and Pitu u Tai, outliers completely surrounded by the barrier reef flat, or narrow rocky spurs like Pau Point, Tahio and Tahihi Points. Matira Point is formed by a series of islets and of rocks running half-way across the wide southern barrier reef flat, showing perhaps more plainly than at any other point in Bora Bora the former extension of the slopes of the island, to the outer edge of the barrier reef flat (Pl. 210, fig. 3).

The island of Pitu u Tai is the most distinct outlier of one of these vol- 
canic islands, being neariy three quarters of a mile from the southern point of Bora Bora (Pl. 210, fig. 3). On the west coast of Bora Bora the islands of Tupua, Tupua Iti, indicate the position of the former ridge, which once extended parallel to the main ridge of the island, and through which the entrance to the main harbor of Bora Bora has been eroded (Pls. $102 ; 210$, fig. 3 ). This ridge forms the western face of the main harbor (Pl. 102, fig. 1), and also forms the eastern flank of a spur of the main lagoon which extends around Bora Bora (Pls. 101, fig. 2; 102, fig. 1), but which is interrupted between Matira Point and the southern point of Tupua Iti by the wide barrier reef flat which separates it from the sea. The principal island of Bora Bora is distinguished by a remarkable double peak, Pahia and Temanu, nearly 2400 feet above the level of the sea, two of the most remarkable peaks of erosion found in the Society Islands (Pls. 97; 99, fig. $4 ; 100,101,103)$. Its southern face (Pl. 103) rises vertically, and on the northern side slopes towards the northern ridge of Bora Bora (Pl. 97), which is separated from Pahia by a deep valley (Pls. 97, fig. 2; 99, fig. 4 ; 103), running across the central island from Anau to Fanui Bays. The eastern face of the cliff is also vertical and forms the northern point of the southern ridge of the eastern face of Bora Bora.

The peaks are most striking summits, as seen approaching Bora Bora from the east (Pl. 97, fig. 1). The sketch which Lesson made from the top of the central peak of Bora Bora, showing the fringe of wooded islands thrown up on the barrier reef flat surrounding it, has often been copied.

On the sea face of Bora Bora from Motu Tofari to Motu Mute the beach slope is steep, and reaches of beach rock or coral rock crop out everywhere. These are separated by coral sand or coral shingle beaches. Wherever we examined the sea face of the barrier reef we found the growing coral edge digitate and deeply scalloped and cut into diminutive boat harbors, as in so many of the Paumotus. Both the main island Bora Bora and Tupua are edged with a narrow fringing reef.

The vegetation of the barrier reef islands and islets is much more luxuriant than that of the Paumotus. A line of dark green vegetation stands out above a white sand beach, forming a broad belt of verdure, at a distance from the steep slopes of the central island; it is especially striking when seen 
looking over one of the islets of the barrier reef flat, or across one of the gaps between the islets north of Teveiroa into the broad lagoon (Pls. 97, fig. 2; 99, fig. 3) of the northern extremity of Bora Bora, the distant edge of which is marked by the great curve of the narrow land rim of Motu Ome, while to the right tower the central summits of Pahia and Temanu.

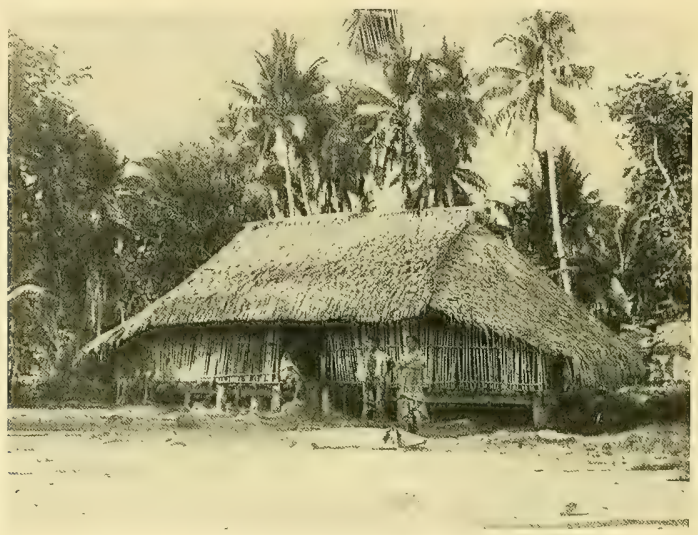

Native Hut, Bora Bora.

\section{Maupiti.}

Plates 104, figs. 3, 4; 105, 202; 210, fig. 4.

The island of Maupiti is not more than six miles in circumference (Pl. 210, fig. 4). The highest point of the central island is about 800 feet above the sea (Pls. 104, figs. 3, 4; 105). An irregularly shaped lagoon, forming a series of intricate passages on the lagoon side of the barrier reef flat, separates Maupiti from the wide barrier reef encircling the island. The barrier reef flat in the southern part of the island is more than two miles wide, and through this a narrow channel flanked by two islands, one on the east and one on the west, connects the labyrinth of the lagoon with the sea (Pl. 210, fig. 4). The central island is flanked by a wide fringing reef; at certain points this runs across the lagoon and becomes connected with the barrier 
reef flat. On the northeastern and on the northwestern extremity of the reef flat two long, low wooded islets, with two islets in the gap separating them, occupy the outer edge of the reef (Pls. 104, fig. 4; 105, fig. 1; 210, fig. 4), similar in all respects in structure to that of the islands which characterize the east and northwest shore of Bora Bora. On the east face of the barrier reef flat south of Tuanaé Island numerous outliers of volcanic rocks are scattered (Pl. 105, fig. 2), indicating the position and structure of the foundation upon which corals have grown. Similar outliers occur in great number on the southern and western barrier reef flats. The main peak of Maupiti is a remarkable perpendicular rocky bluff resembling the ruins of a gigantic castle (Pls. 104, fig. 3; 105). Maupiti resembles in every respect Bora Bora, though its barrier reef flat has a proportionately greater development.

\section{Motu Iti.}

Plates 104, figs. 1, 2; 202.

Motu Iti ${ }^{1}$ consists of two low islands: one of these is L-shaped and constitutes the land rim of the northern part of the northwestern and eastern faces and of. a wide reef flat; the other is V-shaped, forming the land rim of the southwestern part of the reef flat (Pls. 104, figs. 1, 2; 202). These two islands are similar to those of Tetiaroa. They have been thrown up on the wide triangular barrier reef flat, nearly eight miles in length and four miles at the base. The V-shaped island forms the south flank of the lagoon, into which there are two narrow and shallow passes. The lagoon appears to be shallow (Pl. 104, fig. 1). Of course the nature of the foundation base of this atoll is problematical. Judging by the character of the other islands in the vicinity, the underlying rocks of the reef flats are probably volcanic. They represent a stage of denudation somewhat more advanced than that of Maupiti; as if the whole central mass of that peak had been denuded to the level of the sea. At Motu Iti I could not see any volcanic outliers, such as are so common at Maupiti, Bora Bora, and on the barrier reef flats of other islands of the Leeward Society Islands. 


\section{Tetiaroa.}

Plates 95, figs. 2, 3; 96, fig. 1 ; 202.

Tetiaroa consists of a number of coral sand islets thrown up on a somewhat pentagonal horseshoe-shaped reef flat, about six miles in length; they are, judging from the character of the reef platform of Maupiti, probably underlaid by a platform of volcanic rocks. Beach rock crops out at the base of the beaches of most of the islets, and between the wooded islands crop up negro-heads of the same or of modern reef rock (Pl. 95, fig. 3). There appears to be a somewhat deeper part of the lagoon on the western side. The southern extremity is deeply indented (Pl. 96, fig. 1), with a barrier reef along the edge of the platform, from which jut at right angles, far into the lagoon, a couple of sandy islands separating the deeper part of the lagoon from its shallow eastern side, clearly indicated by the light green color of the water. On the western side of the atoll are thrown up two islands; the northern side is occupied by a long island separated into smaller parts by wide and shallow cuts, while on the eastern face there are a large island at the southeastern horn of the atoll (Pl. 95, fig. 2), and two smaller islets. The islands are all connected by negro-heads of beach rock, and long ledges of beach rock project from the points of several of the islands. The northeast and the southwest reef flats are well dotted with large beach rock negro-heads.

The conditions under which these islands and islets have been thrown up on the reef flats seem to be identical with those of the Paumotus, only the nature of the substratum is undoubtedly different. The gaps between the islands are being filled up in the same way as in the Paumotus; the material for the formation of the islands has in this case been derived from the decomposition and disintegration of the beach rock and of the modern coral conglomerate, formed by the fragments of the corals growing upon the reef flats and slopes, thrown upon the volcanic substratum. In fact, Tetiaroa is the last stage of a series in which Bora Bora stands at one end, Maupiti coming next, then Motu Iti, and finally Tetiaroa. ${ }^{1}$ In the case of Bora Bora 
the mountain constituting the nucleus from which has been eroded the submarine platform upon the outer rim of which a circle of islands has been thrown up, rises to a height of over 2400 feet, while in Maupiti it does not rise to more than 800 feet; and in the last the central peaks have been completely eroded, leaving only the volcanic submarine platform, on the outer rim of which the coral sand islets and islands have been thrown up and have enclosed a shallow lagoon.

Disintegration and erosion are quite sufficient to account for the difference of condition of these three island groups without having recourse to special elevation or to individual subsidence.

Motu Iti and Tetiaroa represent, in the Leeward and Windward Society Islands, groups of coral reefs analogous to the low coral islands to the northeast of Nukuhiva; they hold to the high islands of the Society group, such as Tahiti, Murea, Huaheine, Bora Bora, and others, much the same relation which the low islands of the Paumotus, like the Duke of Gloucester Islands, Pinaki, Hikueru, Hao, Takume, and others, hold to Makatea, Niau, and Rangiroa. 


\section{THE COOK ISLANDS.}

\section{Plates 106, fig. 1; 211; 212, figs. 2, 5.}

Is the Cook Islands, as in the Fiji group, we find islands composed of elevated coralliferous limestone, like Atiu, ${ }^{1}$ Mangaia, Mauki ; volcanic islands with comparatively limited fringing reefs and barrier reefs, like Rarotonga ; ${ }^{2}$ and a series of low reefs, like the Hervey and the Palmerston Islands, ${ }^{3}$ from which all traces of the central island have disappeared (Pl. 212, fig. 3); and atolls, like Aitutaki, with high volcanic peaks.

Williams, ${ }^{4}$ who visited the Cook Islands, was an excellent observer, and his account of various islands is most trustworthy. He recognized in a general way the characteristic geological features which distinguish the islands of the same or of different groups, and he classified the Pacific islands, first, into high volcanic islands, secondly, into elevated limestone islands, and finally, into low coral islands.

In Atiu and Mauki are extensive caverns, one of which is described in detail by Williams. At Mauki extensive beds of apatite are also said to exist. Williams speaks of Atiu as made up of elevated coral rock, a solid compact mass of limestone. Gill also speaks of Atiu as made up of uplifted coral perforated in every direction by caverns.

Williams describes at Mangaia a broad ridge (terrace?), said by him to be 300 feet, at a height of 100 feet. Gill also describes it, and figures the terraces of Mangaia; he speaks of the occurrence of dark volcanic rock and red clay in the interior of Mangaia.

Rurutu is said by Williams to be 150 feet in height, while the "Sailing Directions" say the mountains attain a height of 1300 feet. Williams noticed the similarity of the elevated limestone to the streaked basaltic appearance of volcanic rock. Williams also noticed that Savage Island (Niue) was composed of elevated coral reef, and he describes the cuts and caverns found along the shores and inlets.

\footnotetext{
1 A. Chart 1264.

2 Ibid.

8 Ibid. 1176.
}

+ Missionary Enterprises, pp. 18, 23, 28, 30, 292. 
Gill, in his "Life in Southern Seas," writes regarding Mituro that it is about fifty feet above the level of the sea. The entire surface of the island, on the way to the lagoon, is sharp coral rock. The lagoon in the interior is about three miles in extent; the water is very brackish, almost black, with no visible outlet. Gill gives a distant view of the island.

\section{Aitutaki.}

Plates 106, fig. 1; 211; 212, fig. 2.

The volcanic island of Aitutaki is the only one of the Cook group which we examined ; it was surveyed by Captain Rooke in 1892, and represents a condition intermediate between Maupiti and Tetiaroa. The summit of Aitutaki is not more than 300 feet (Pls. 106, fig. 1; 212, fig. 2). As Atiu is composed of elevated limestone, and Rarotonga is volcanic, I hoped we might find Aitutaki to be in part volcanic and in part composed of elevated coralliferous limestone; we found it to be volcanic, an island with the structure of Bora Bora on a smaller scale. The principal island is a little over three miles in length and runs north and south. Its northern extremity forms the northern point of the barrier reef flat which surrounds it (Pls. 106, fig. 1; 212, fig. 2). This is triangular in shape, the greater part of the reef is awash, the eastern face being about seven miles, the southern six miles, the western the same. On the southwestern point of the reef flat a small sand key has been thrown up, and on the eastern face a series of low wooded islands and islets indicate the position of the barrier reef flat; the islands are separated by gaps similar to those we observed between the islands on the barrier reef flats of the Society group (Pl. 212, fig. 2). Between the islands the sea has free access to the lagoon. Most of these islands run at right angles to the general trend of the outer edge of the barrier reef, and have undoubtedly been formed, as we could judge from the indications of former gaps, exactly in the same way as those on the northern coast of Tahaa, of Bora Bora, and Maupiti. With the exception of Maina Island and the two islets near the southeast horn, there are no islands on the western and southern barrier reef flats; they are comparatively 
narrow and enclose a shallow lagoon, nowhere more than four fathoms in depth, and thickly studded with coral knolls. There is an indistinct boat passage leading across the barrier reef flat on the western side of the atoll (Pl. 212, fig. 2). To the west of the central part of the island of Aitutaki the barrier reef becomes a fringing reef, the inner part of which is more or less awash, forming an indistinct lagoon.

The principal island is also connected at its northern extremity with one of the low islands of the belt of islands on the eastern barrier reef flat, at the point where it becomes for a short distance a fringing reef. The island is well wooded, with the exception of the small conical peak on the northern side, which stands out boldly and slopes gradually to the south.

The plan of Aitutaki (Pl. 212, fig. 2) resembles in many ways that of Oeno ${ }^{1}$ in Fiji, only in the former the principal island is an elevated volcanic island, while in the latter the principal island is low, but both are attached to the outer barrier reef flat and extend far towards the centre of the lagoon. In both, the lagoon is enclosed by a narrow barrier reef flat more or less irregular in outline, somewhat triangular.

In the southeast corner of the southern barrier reef flat three or four sand keys have been thrown up on an inner extension of the barrier reef flat. The sand islets, like those on the outer belt of the barrier reef flat, will eventually be covered with vegetation. On the beaches of the west face of the principal island mainly volcanic sand is found, and very little coral sand has been thrown up. The islands on the outer barrier reef are in every respect similar to those on the edge of the barrier reef flat of many of the Society Islands. There are a number of volcanic negro-heads on the flats. This group is an excellent example of a volcanic rock flat upon which corals are growing. The formation of the underlying base can be traced, as volcanic outliers crop out at many points on the barrier reef. Aitutaki shows, perhaps as plainly as any other volcanic island we have visited, the manner in which the lagoon and barrier reef flats have been formed from the denudation and erosion of the volcanic mass which once occupied the area indicated by the outer edge of the barrier reef.

1 A. Chart 1176. 


\section{NIUE.}

Plates 106, figs. 2, 3; 107-110; 211; 212, fig. 1;213.

THE island of Nine ${ }^{1}$ is about thirty miles in circumference (PI. 212, fig. 1). It is surrounded only here and there by a steep fringing reef, forming a narrow shelf on the western and southern sides of the island. The cliffs on the eastern side run nearly vertically into the sea. The highest point of the island is from 200 to 230 feet above the level of the sea, forming a plateau that slopes gradually from the eastern side towards the western shore. The terraces are clearly indicated near the landingplace off Alofi, the village on the central part of the west shore ( $\mathrm{Pl} .107$, fig. 1), and on the cliffs themselves, from the position of the lines of caverns indicating the former lines of sea level on the west face (Pls. 109, 110). In many places they disappear completely, the limestone cliffs rising vertically from the sea, and cutting into the second or even the third terrace. Deep cuts or incipient cañons are formed all along the east and west shore of Niue (Pls. 106, fig. 3; 108, 109), but are especially numerous on the west shore, forming deep, narrow valleys or gorges, penetrating often a considerable distance inland.

The outline of Niue is irregularly octagonal (Pl. 212, fig. 1), its greatest length from north to south being about thirteen miles, and its greatest width about ten, from east to west across the southern end. As seen from the sea approaching from the eastward, the east shore appears like a narrow slope leading to a level top slightly sloping westward.

The two terraces above the undercut part of the cliffs consist probably of several lines of rest; they stand out boldly and are plainly visible two miles off (Pls. 106, fig. 3; 107, fig. 1). The slope between them is thickly covered with trees, and the island is well wooded (Pl. 106, fig. 2). A heavy surf pounds against the walls of the lower terrace, which at many points has been changed into vertical cliffs cut back so as to include the second and sometimes the third terrace, which is frequently gouged out into deep

1 Nive (A. Chart 1176) is an isolated peak of coralliferous limestone, about 250 miles east of Vavau in the Tonga Islands, rising from deep water ; soundings of nearly 2900 fathoms separate it from Aitutaki, and of over 3000 fathoms from the northern part of the Tonga Islands. 
furrows; the exposed surfaces of all the terraces are honeycombed and .pitted and covered with small spires and pinnacles (Pl. 103, fig. 3). At the southwest point the face of the pitted and honeycombed cliffs shows four deep cuts (PI. 106, fig. 3), the first trace of the inroads made by the sea in their steep faces, which will eventually become small, narrow cañons, separating wide buttresses similar to those shown on Pl. 108.

The lowest terrace forming a shelf round the base of the island at the sea level has the appearance of an old beach rock bank (Pls. 106, figs. 2, 3; 107, fig. 1). It is composed of a yellowish rock, very much decomposed. The outer rim of the lowest terrace is remarkably high, and is built up by Nullipores, which grow upon its face as far as the surf reaches (Pls. 106, figs. 2,$3 ; 107$, fig. 1). These masses of Nullipore are usually of a marked yellow color. The lowest terrace is deeply undercut and full of blowholes; its narrow platform is gouged out and then bridged over by corals so as to leave passages through which the water is thrown up in spray by nearly every swell (Pls. 106, fig. 3; 107, fig. 1). These blow-holes extend nearly the whole length of the island. Where the two lowest terraces have been undercut, the cliffs rise to a height varying from twenty to fifty feet (Pls. 108, 109, 110). From the slope of the third terrace innumerable little waterfalls drop from sixty to ninety feet vertically into the'sea, forming the deep ravines which are so characteristic of the west coast of Nine. At one of the points which is deeply undercut, and cut back to the third terrace, rise innumerable sinall pinnacles which cover the whole face of the third terrace (Pl. 106, fig. 3). Where this undercutting has been going on extensively, small sand beaches are often formed at the base of the ravines (Pls. 107, fig. 2; 108, 109), as, for instance, the beach at Avatele immediately around the southwest point. A similar and smaller beach is also found at the principal landing off Alofi, where we anchored (Pls. 107, fig. $2 ; 108,109)$. Between Avatele village and the point north of it, are innumerable caverns and holes cut into the face of the second terrace extending to the upper slope of the third terrace. The lowest terrace varies in height from five to six feet. The second terrace varies in height from thirty to fifty feet, and the slope of the base of the third terrace is about fifty feet; the top of the third terrace appears to be from seventy-five to one 
hundred feet above high-water mark. The terraces are numbered as they appear above the undercut cliffs.

The second terrace is composed entirely of reef rock, the third terrace consists of a mass of rubble at the bottom; at the top a great many fossils were found. ${ }^{1}$ The flat of the third terrace is quite extensive, nearly half a mile wide in places. A good road runs on the level of this terrace around the island. The fourth terrace is seen at intervals on the face of the island as a hill about 200 feet above low-water mark. The ascent to the crest behind Alofi, which was about one eighth of a mile inland, is steep to a point of about 200 feet in height. The path then slopes steadily downward with occasional swales for about two and a half miles. The interior of the island is evidently lower than the outer rims, from thirty to sixty feet perhaps than the crest immediately behind Alofi itself. The surface of this interior sink was not honeycombed or pitted by erosion to the extent observed in Makatea or in Ngele Levu, although there were a few deep pits seen; the others were nearly all small.

A very fertile, apparently shallow, reddish-colored soil, the residuum of the disintegration of a large mass of limestone, shows, as at the Bahamas, the amount of decomposition which has taken place. It exists everywhere in the interior of the island. This soil supports a dense growth of ferns, bushes, and trees, and here and there we found patches of larger forest trees, from forty to sixty feet in height. Bananas, breadfruit, and mangos are common. There are only a few cocoanut trees in the interior; they seem to be limited to the second and third terraces on the sea face.

To the south of Alofi the cliffs resemble in every respect the limestone cliffs of Kambara, and photographs of the two can hardly be distinguished one from the other (Pls. 107, fig. $2 ; 108-110$ ). Seen at a slight angle looking north or south along the west shore, the heads of the deep ravines which have been worn into the face of the limestone terrace by undercutting and cutting back, appear like so many buttresses running at right angles to the island (Pls. 107, fig. 2; 108), extending ont more or less according to the extent of disintegration by atmospheric and marine agencies to which the limestone rock has been subjected.

1 A number of tertiary fossils were given to me by the Rev, F. E. Lawes, collected probably back of the third terrace, consisting of gasteropods, bivalves, and corals. 
Some of the diminutive cañons have been cut back to a height of 180 feet, sloping very gradually inland from the base of the first terrace. One can readily see how the formation of these cañons if extended sufficiently far into the interior would soon enable the sea to cut up the limestone mass of such an island as Niue into a number of columnar islands, surrounding a sound or forming a pseudo lagoon in the interior of the limestone mass. This incipient erosion is the first stage of disintegration of a limestone platean, the ultimate condition of which would be represented by such a labyrinth of undercut islets and islands as we find in Fulanga or at Ngillangillah or Yangasa in Fiji or at Vavau, plainly showing that the so-called lagoons of these atolls are not lagoons, but are sounds which owe their formation to mechanical causes very different from those which have formed a lagoon surrounded by low coral sand islets. There is an abundant growth of coral on the fringing reef platform, usually of Pocillipores with large blocks or Porites, and Millepores extending on the sea face slope down to about twenty fathoms. Lanes of sand between the coral patches begin already at ten fathoms and often extend upward to the top of the reef platform. The edge of the reef flat is gonged by deep indentations with from three to five or six fathoms in depth. We anchored off Alofi, two fifths of a mile from the shore, in twenty-four fathoms, where an extensive flat of white coral sand makes out from the shore reef platform. From the outer edge of this, the slope drops off rapidly. Moss figures a coast scene of Niue, showing the elevated reef rock of the west coast. ${ }^{1}$

1 Frederick J. Moss, Through Atolls and Islands in the Great Snuth Sea, London, 1889, p. 46. In Commodore Goodenough's Journal (p. 188) we also find an excellent account of the geology of Niue. 


\section{THE TONGA ARCHIPELAGO.}

Plates 111-125, 213-219.

The Tonga Islands we found a most interesting group. The elevated tertiary coralliferous limestones take here their greatest development, and are on a scale far beyond that of their development in Guam, the Lau group of the Fijis, or the Paumotus. The first island of the Tongas we visited, Eua, is perhaps the most interesting of the islands composed mainly of tertiary elevated coralliferous limestone I have visited. The four plateaus of Tongatábu, Nomuka, Haapai, and Vavau (Pls. 214-219), which constitute the Tonga Ridge, rise abruptly from the 100 -fathom line; they are separated by deep valleys connecting the eastern and western flanks of the ridge. The extremity of the sonthern one is occupied by Tongatábu Island. The land behind the cliffs of its southern coast rises to a height of over 270 feet, and slopes northward very gradually to form the low land which occupies the northern const of the island, where it is, except at Mount Zion and Cook's Hill, not more than from five to twenty feet above the level of the sea. At Cook Point and along the southern coast three terraces are indicated. The northern coast is deeply indented by shallow bays, full of islands, reef flats, and reef patches, on which corals grow in great profusion. For a distance of nearly ten miles northward of Nukualofa the plateau is nowhere more than fifteen fathoms deep; it then runs as a long tongue northward, gradually deepening into twenty to fifty fathoins to the 100-fathom line.

The Tongatábu Plateau is separated from the Nomuka Plateau by a funnel-shaped channel with a depth passing rapidly into 300 fathoms from the 100 -fathom line. The Nomuka Plateau is rectangular (Pl. 216); its principal island is Nomuka. We found the island to be composed of tertiary elevated coralliferons limestone, with a shallow sink, filled with brackish water, occupying the southeastern part of the island. The sink is separated from the sea by a high sand beach, about 200 yards wide. 
Nomuka Iki, the island next to Nomuka, we found to consist, at its southern extremity, of stratified volcanic material, resembling somewhat the socalled soap-stone of Fiji. I was informed that other islands in this group, near Tonumeia, in the centre of the Nomuka Plateau, were volcanic. Mango, as we could see it from our anchorage, appeared to be volcanic. So that this part of the Tongas is, as has been indicated by Lister, like the Lau group in Fiji, made up of islands in part volcanic and in part composed of elevated coralliferous limestone or wholly volcanic and wholly limestone. In Fiji the trend of the large volcanic islands and of the Lau group forms an angle, in the Tonga Archipelago, the line of volcanoes and the axis of the Tonga Plateaus are parallel. The eastern edge of the Nomuka Plateau (which we did not visit) is edged with small low islands. We merely steaned by the western islands of the Haapai group, but close enough to see that Tongua, Kotu, ${ }^{1}$ and Fotuhaa, which vary in height from 120 to 200 feet, are composed of elevated limestone. The eastern flank of the Haapai Plateau is edged with long, low islands, with extensive coral reefs along the western reef flats of these islands.

The Haapai Plateau is triangular (Pls. 217, 218), with isolated islands rising on the northwestern side from the deep water separating it from the Vavau Plateau. It is separated from the Nomuka Plateau by a narrow channel with over 300 fathoms of water.

The northemmost plateau of the broad ridge of the Tonga Islands is the Vavau Plateau (Pl. 219). This is elliptical, with a long tongue extending on the eastern face of the ridge toward the northern point of the Haapai Plateau, ending in isolated banks (the Disney Reef and Falcon Bank), lying to the northward of the broad channel, with over 400 fathoms separating it from the Haapai group. The Vavau group is by far the most picturesque of the Tonga Islands. It consists of the principal island of Vavau, extending across the northern part of the Vavau Plateau. Several parts of the island of Vavau, as at the southwestern extremity, at the entrance to the harbor of Neiafu, and at Neiafu, are finely terraced f four terraces are indicated there, and other flat-topped smaller islands show traces of two or

1 Lister considers that the raised rocks which form the edge of the sink of the island of Kotu must lave surrounded a lagoon, when they stood at the level of the sea. 
three terraces. The northern edge of Vavau Island rises to a height of more than 500 feet, and slopes in a general way southward and inland. The southern shore is deeply indented by bays and sounds, and flanked by innumerable islands and islets, some of considerable height (150 to 250 feet), they gradually become smaller and smaller toward the southward and eastward. These islands have been formed by the denudation and erosion of the greater Vavau; they form tongues of land and sea and sounds of all shapes and sizes, showing the traces of the former land connections of the islands and islets, and their disintegration to the eastward and southward by the action of the sea. The islands and islets to the southward of the main island rise from more or less extensive reef flats which stud the whole plateau, and on which corals grow in great profusion (mainly Millepora, Porites, Pavonia, Pocillipora, Fungia, and Astrea), and to a depth of five to six fathoms in the sounds. In the Nomuka group they extend in the more open waters to fourteen and sixteen fathoms.

It is evident that in the Tonga group, which is a very extensive area of elevation, recent corals have played no part in the formation of the masses of land and of the platem of the Tonga Ridge, and that here, as in the Society, the Cook and Fiji Islands, also in areas of elevation, they are a mere thin living shell or crust, growing at their characteristic depths, upon platforms which are either volcanic or calcareous, the formation of which has been independent of their growth.

It appears probable to Lister that the atoll-shaped islands of the southern part of the Tonga group have grown on a bank of volcanic material laid ont in shallow water, and that there is no necessity to call on the hypothesis of subsidence to account for their formation. The distribution of the land masses of the Tonga Archipelago is quite different in the four plateaus. In Vavau the main land mass occupies the northern edge of the plateau; in Tongatábu it flanks the southern edge, while in the Haapai group the narrow eastern rim-is edged by a row of broad islands, and in Nomuka the Otu Tolu group on the east face and Nomuka Island on the northern face constitute the elevated area of that plateau.

To the westward of the Tongas, from Honga Hapai to Fanua lai, a line of volcanic islands extends for nearly 200 miles; some of them have been active 
very recently (Pl. 214). Falcon Island, ${ }^{1}$ thrown up in 1885, disappeared in 1898, and Late is still active. This line of volcanoes runs at a distance of from fifteen to twenty miles parallel with the trend of the four irregularly shaped plateaus upon which rise the Tonga Islands. They are the summits of a great ridge, over 200 miles in length, sloping very gradually to the westward into deep water, and being somewhat steeper on the eastern faces of the smaller platforms from which rise the volcanic peaks of the group.

Falcon Island has had a very varied existence. It was thrown up in 1885 to a height of about twenty feet, and in July, 1898, was destroyed by a submarine explosion. It was first surveyed in 1889, and again in August, 1895; when the island was last surveyed it was about 800 by 700 yards, nearly circular, the highest part of the island being forty feet above highwater mark; its site is now marked by a shoal of nearly 100 yards in extent, over which the sea is breaking with great violence. ${ }^{2}$ To the south of Falcon Island are Honga Hapai and Honga Tonga; Lister considers them to be the fragments of an old crater. To the north of Falcon rises the island of Tofua to a height of nearly 1900 feet; it is an active volcano, about fifteen miles to the west of the Haapai group. It has a crater which is about 140 feet above the sea level, filled with water. Numerous small craters form a close rim around this lake. We could easily imagine this volcano as well as Niuafó ${ }^{3}$ to be denuded to the level of the sea, leaving nothing but a narrow volcanic rim on which corals would grow and form a circular atoll with a comparatively deep lagoon. Kao, the volcano to the north of Tofua, is over 3000 feet in height and a much sharper peak. Half-way to Late, Metis shoal rises to the surface. The next peak to the north, Late, is an active volcano, rising to a height of over 1700 feet. The crater is deeply indented with fissures running down on the eastern side. Near the east coast there is a second inactive crater; its inner sides rise perpendicularly from a small flat ledge surrounding a lake. Still farther to the north, about twenty-five miles from the northern

1 An excellent account of Falcon Island, by Lister, will be found in the Proceedings of the Royal Geographical Society of London, for March, 1890, p. 157. Lister visited the island in October, 1889; he states that the height of the island was then $153 \frac{1}{2}$ feet; he gives three excellent views of the island.

2 A. Chart 1385 ,

${ }^{3}$ Ibid., 1176. 
extremity of Vavau, rises the island of Toku, and nearly ten miles farther the voleanic island of Fanua lai, at the extremity of a line of volcanic islands separated from the Tonga Ridge by a channel less than 1000 fathoms. Falcon rises from a depth of about 1000 fathoms, Tofua and Kao and Late from less than 500 fathoms. The islands on the northern extension of the Vavau Plateau rise from somewhat greater depth. The volcanic islands, as far as Late, are on the edge of a bank, parallel with the Vavau Plateau, separated from it by a channel about 900 fathoms deep.

At the Tongas the volcanic outbursts are mainly indicated by the summits of a volcanic ridge running parallel to the greater Tonga Plateau, with the exception of the few outbursts through the limestone area which have been traced in the Nomuka group.

Of course, until all the islands have been carefully examined, it is impossible to say that other points may not show volcanic outbursts, as those observed in Nomuka. ${ }^{1}$ But it is very evident that the distinction, which was first made by Lister, of islands partly volcanic and partly of coralliferons limestone, or wholly volcanic or limestone, is one of a very general character. We find scattered over the Pacific volcanic islands in the Cook, the Society, the Hawaiian, the Samoan, and the Fiji Island groups, or we find coralliferous limestone islands, in the Paumotus, the Fijis, the Tongas, and the Cook Islands. Or we find a combination of the two in the various groups we have mentioned.

The existence of such a gigantic plateau of elevated limestone, like that of the Tongas, which extends for nearly 200 miles in length and with an average width of over twenty miles, indicates that the formation of these huge masses of limestone must have taken place over extensive areas of the sea during Tertiary times. In the case of the Tongas, the limestone was probably deposited at a depth not much greater than 1000 fathoms, and has been raised to form the gigantic ridge known as the Tonga or the Friendly Islands.

Of course this thick mass of coralliferous limestone could only have been formed during a period of subsidence; but it was only after its elevation,

1 Mango, Tanoa, Nomuka iki, Tonumeia, and Kelefesia are stated by Lister, to be formed of volcanic tuff. 
which continued until the present epoch, that denudation and erosion took place on the gigantic scale on which they have acted upon the land of this elevated limestone plateau and it assumed existing conditions. In the Tonga group we find all the conditions which characterize the so-called elevated atolls, or plateaus of limestone, or high elevated limestone islands, like Eua. The terraces of this, the southernmost of the Tonga Islands, and of the Haapai and Vavau Plateaus, clearly indicate a sort of synchronism, marking the periods of rest which have taken place during the elevation of this gigantic ridge of limestone.

The sounding at Station 182 shows that the Aldrich deep, which culminates off the Kermadec Islands in 5155 fathoms, extends much farther north than has been indicated heretofore by the soundings. The greater cold of the bottom also indicates the existence of a ridge separating the Moser Deep from the eastern extension of this tongue of deep water of the Southern Pacific. It was immediately off the entrance to Vavau, at Station 187 , that sounding in 682 fathoms we brought up remarkable colored crystalline calcite and other crystals, some reddish in color, others gray, which look like the weathered and washed sand coming from the old coralliferous limestone ledges. It is probable that much of this sort of bottom has been called volcanic sand on the charts, and has given rise to the statements that the underlying rocks of Vavau are probably volcanic in their structure. While it is true that to the westward of Vavau true volcanic sand exists near the line of volcanoes which stretches north and south a distance of nearly 200 miles parallel with the Tonga Plateau, yet this voleanic sand is, when closely examined, very different in its appearance and can readily be distinguished from the colored calcite crystals.

\section{Eua Island.}

Plates 111-114; 120, fig. 8; 212, fig. 4; 213, 214.

Eua Island (Pl. 212, fig: 4 ) is at least ten and a half miles in length, and three miles broad; it lies southeast of Tongatábu, about ten miles distant, and is separated from it by a comparatively shallow channel, with not more than 120 fathoms in the shallowest part of the channel. The soundings on the 
flanks of Eua indicate that the island and the plateau from which it rises are a part of the great Tonga Plateau. In fact, it is not separated from Tongatábu by as deep channels as those which divide the Nomuka, the Haapai, or the Vavau plateaus one from the other. The soundings to the south of Tongatábu, in the direction of Pylstaart ${ }^{1}$ Island, indicate a southern extension of the Tonga Ridge, of nearly ninety miles, with irregular depths (PI. 214).

Eua was the first of the Tonga Islands we examined. It was surveyed by Captain Aldrich in the "Egeria" in 1888. From the description given by Dana, which was obtained at second-hand, I imagined that this island would be simply a volcanic ridge, surrounded in places by a very narrow fringing reef. On approaching it from the east, and striking the northern point, we were much surprised to find it composed of elevated coralliferous limestone, rising at points to nearly 1100 feet. 'The crest of the eastem ridge, which runs parallel to the eastern coast, is not much more than three fourths of a mile from the shore. Its highest points are towards the south, where the successive terraces, indicating periods of inaction during the elevation of the island, are clearly seen, - terraces which run from the southern point to the northern extremity, interrupted by high vertical cliffs, the whole extent of the eastern face (Pls. 111, figs. 2, 3; 112, 113). The eastern ridge forms the northern extremity of the island (Pl. 111, fig. 3); the steep vertical cliffs extend but a short way around the western coast of Eua.

The highest point of the ridge on the western face, towards the southern extremity of the island, is not more than 560 feet; it is cut by a small river coming out at the English Roads (PI. 212, fig. 4), and draining the central valley of Eua, formed by the two ridges which run, the one parallel to the east coast (Pl. 114), and the other parallel to the west coast (Pl. 111, fig. 1). On the west coast, however, the slope from the highest summit towards the shore is quite gradual, as is also the western slope of the eastern ridge towards the sink or drainage valley, which occupies the central part of the island.

The southern slope of the western ridge is somewhat steeper than that of the eastern ridge; its summit forms a platean varying from one fourth 
to half a mile in width, giving the western ridge the appearance of being flat-topped (Pl. 111, fig. 1), while the eastern ridge is only here and there flat-topped (Pl. 114). As we steamed around the southern point, we could look up into the divide of the central basin between the slopes of the parallel ranges, and look into the drainage basin which occupies the central part of the island (Pl. 212, fig. 4).

It is quite probable that the central part of this basin was once occupied by a lake, or a pool, or finally a morass, such as still exists immediately back of the gap, opposite English Roads, where the river has cut a deep cañon into the western ridge, perhaps as far as the third terrace. We can readily imagine erosion and denudation to have gone on at such a rate that the ridge flanking the central part of the basin may have been cut down, at some period during its elevation, so that the opening should lead from the English Roads into this basin, and change it into a huge sound. Thus might have been formed an interior lagoon of comparatively small size as compared with the rest of the island, similar to that of Nomuka, having. nothing to do with elevation or subsidence, and yet resembling in every respect what is called a raised atoll, similar to some of those we have described.

While this was taking place, the range on the east side would probably still be continuous, and its highest points rise to perhaps 400 or 500 feet, while on the west the various gaps to be seen between the flat-topped summits would have widened out into huge openings, and the western slopes changed into a reef flat, varying in width from half a mile to one and a half miles, the highest point of the western ridge rising perhaps to 200 or 250 feet on the western face. On the southern face a deep indentation, which might or might not have been connected with the central basin, would occupy the place now taken by the more gentle slopes of the two ridges flanking the central basin on the southern side of the island.

At the south point there are four very distinct terraces, and the fifth and sixth, which rise to a height of 1036 feet, can be traced somewhat indistinctly. Vertical cliffs extend north in continuation of the fourth terrace, along the eastern face; those rising from the shore are cut back generally to the top of the third terrace. At the northern point the island 
is a little over 640 feet in height, the highest point forming a part of the fourth terrace (Pl. 111, fig. 3). Along the central part of the eastern face of Eua, the terraces are somewhat indistinct ( $\mathrm{Pl}$. 113). A large number of caverns are found in the third terrace near the northern point, indicating former lines of elevation between the third and fourth terraces (Pls. 111, fig. $3 ; 112$ ). An extensive sand beach has been formed near the northeast point, by the disintegration of large blocks of limestone once a part of the third terrace. A narrow shore platform, the first terrace consisting of Nullipores, edges the reef platform near the north point (Pls. 111-113). In the face of that terrace are seen caverns which are cutting out and indicate the present sea level, just as those of the higher terraces indicate former sea levels during the periodic elevation of Eua. Huge stalactites have dropped across the month of most of these caverns. On the west side the terraces are somewhat indistinct (PI. 111, fig. 1). The rounded denuded tops of the lower terrace show in some cases very prominent honeycombing, their surface being covered with small spires and crossed by crevasses in all directions. Very few cocoanut trees were growing on the island. South of the centre of the island, on the west side, there is a deep gap in the terraces; the slope runs uniformly to the highest point of the island on the east side from the top to the fourth terrace. Here and there are seen remnants of terraces five and six, with patches of the characteristic red coral earth standing out boldly in the centre of the green slopes. Near English Roads there are extensive sand dunes and the remnants of an old beach near the anchorage.

The south point seen from the south shows distinctly all the terraces from the lowest to the sixth; towards the southern end of the eastern ridge there is a small sharp pinnacle at the top of the sixth terrace, which may possibly be the remnant of the seventh terrace. This small pinnacle is a prominent object in the topography of the island, and can be seen from many points along the shore and from the interior. On the western crest of the main drainage valley of the island (Pl. 114, fig. 2), facing the western slope of the eastern ridge, we see that terraces four to six have been eroded, and that there is a uniform slope leading up to the sixth terrace and to the top of the line of hills which forms the east face 
of the island. Towards the south point the lines of terraces pass into gentle slopes, cutting wide gaps between the summits; only here and there could the position of terraces four to six be determined. As far as we could see, the third, fourth, and fifth terraces were of the same height on the two sides of the island.

At the southern extremity of the island huge caverns have cut into the vertical faces of the cliffs, forming here and there natural bridges. Innumerable pinnacles, cones, and spires stand out from the eroded surface, leaving the slope between the third and the base of the fourth terrace covered with red volcanic earth; on this an entirely different type of vegetation grows from that found on the east side of the island. We found here bananas, pisonias, and aloes in great profusion, in marked contrast with the hardwood vegetation of the east and west sides of the island. Lister has described the remarkable chasm which exists at the southern extremity of Eua, formed by the falling in of the roof of adjoining caverns. At the southern point the shore, or first terrace is somewhat higher than in other parts of the island; it is from eight to ten feet high. On rounding the southern point of Eua, its little satellite, Kallau, is passed, where four terraces are distinctly seen (PI. 214). This little island is covered with bananas and cocoanut trees, and on the northern extremity there is a long sand beach fringed with beach rock. After passing the southern point of Eua, there are no gaps cutting across the terraces. The base of the second terrace is distinctly marked, pitted, and honeycombed, and the edges of the first and second terraces are full of blowholes. The tradewinds, of course, are shut out from the west side of the island by the high range of bluffs of the east coast. The terraces of the west coast are more or less indistinct, and we generally find a gentle slope from the top of the third terrace to a height which corresponds to that of the fifth terrace on the east face. The Nullipore platform at the base of the lower terraces forms huge rounded masses, a sort of wall; on the outer edge of the shore shelf, blow-holes exist similar to those described at the southern and northern extremities. As we go north on the west side, sand beaches are formed at the base of the lower terraces; they consist mainly of Nullipores ground up. The beaches become more extensive as we 
go north, and near the outlet of the drainage valley of the island opposite English Roads, sind beaches flank the west coast of the island (PI. 111, fig. 1). Immediately behind the beach, however, we generally find a small ledge rising to a height of perhaps fifteen feet, the remnant of the lowest terrace. This is usually eroded and honeycombed, and conceals the greater part of the second terrace, which only reappears where the sand beach does not exist. On the west side we can also trace, here and there, fragments of cliffs cropping out at different heights, indicating the former existence of various terraces (Pl. 111, fig. 1) to which they belonged. The western slopes are thickly covered with vegetation, and seem, with the exception of the outcrops just mentioned, to run unbroken from the beach or lowest terrace up to the level of the fifth terrace, the terraces on the west side having, as a rule, fallen in and crumbled so as to entirely change the appearance of the topography. The succession of beaches and of patcles of the third and fourth terraces characterizes the topography of the west coast of the island as compared to that of the east.

From our anchorage at English Roads, we could see the slopes of reddish volcanic earth of the west face of the cliffs forming the terraces on the east side of the island, passing down towards the central part of Eua, flanked on the west by the line of hills of its western face. Back of the village of Ohonua, the road rises quite rapidly to a height of about 150 feet, which is probably the level of the fourth terrace. From there, going sonth on the ridge which forms the west face of the island, we rise gradually to a height of 310 feet, then to a height of 370 feet, and drop again to a height of about 350 feet, at a point opposite the highest pinnacle of the ridge on the east side of the island (Pl. 114). Striking out from this point at right angles to the ridge, we go down into a sink, which is merely a sink of denudation, showing no trace of having once been a lagoon or a part of a lagoon (Pl. 114). The valley formed between the hills of the eastern and western sides is probably 150 feet lower at this point than the highest point of the western ridge. It then slopes very gradually both north and south, after rising to the south to a low ridge, which may have been 400 feet in height, and forms the deep valley into which we looked when rounding the southern point. The 
northern line of drainage slopes gradually towards the cañon north of Ohonua village (Pls. 114, fig. 1; 212, fig. 4), and through this the water collected in the valley comes out as a small stream. No outcrops of coralliferous limestone were found in the depression between the two ridges, except on the western face of the eastern line of hills, where, at a height of about 525 feet, a small ledge was found surrounded by earth of volcanic origin. Dr. Mayer ascended to a point a little over 600 feet on the west side of the eastern hill range. As a rule, the soil of the western ridge is of volcanic origin, of a light red brown or yellow color; the highest point of the western ridge was about two and one-half miles from the village of Ohonua. The soil of the bottom of the valley is also of volcanic origin ; it is deep, of a dark red brown, and quite fertile. It was covered with large groves of cocoanut trees, pisonias, and a couple of species of Gardenia, in addition to numerous ferns and grasses; no outcrops were found in the lower parts of the valley. The fourth terrace of the western line of hills was probably 300 feet above high-water mark. We took some photographs from the highest point of the western ridge to show the great extent of the sink of the island ( $\mathrm{Pl}$. 114), and also from other points along the crest; they plainly show that this is merely a valley of erosion, and that the river at English Roads landing has cut its way through the western ridge, and drains the valley as any other drainage valley would do. Other small creeks run east from the slopes through the limestone country of the western range, and disappear in the bottom of the valley at the foot of the eastern range. At a distance of five miles from Ohonua village, the bottom of the valley must be at least 120 feet lower than the highest point of the western crest; it drops gradually to the level of the sea, following the level of the creek which drains the interior valley and comes out at English Roads. A number of fossils were found at a height of 300 feet in the fourth terrace.

Speaking of Eua, Lister ${ }^{1}$ says: "The volcanic formation comes to the surface over a great part of this high ground (the western slope of the highest part of the eastern ridge), and when bare of vegetation it is readily recog-

1 Notes on the Geology of the Tonga Islands, by J. J. Lister, in Q. J. Geol. Soc., London, Vol. 47, 1891, p. 590 . 
nized by its red color; but patches of limestone occur in many places, sometimes in large projecting mass, like that which forms the south summit, sometimes weathered down into groups of isolated pinnacles, standing on a volcanic basis."

The outcrop of the volcanic formation is also well seen on the western face of the east ridge to the north of Ohonua Village.

On Plate XXIII, ${ }^{1}$ Lister has given an approximate sketch map of the position of the patches of volcanic formation of Eua. ${ }^{2}$ The volcanic basis underlying the coralliferous limestones is exposed near the centre of the eastern face, and at the shore there are dykes of intrusive rock, which cut through the volcanic deposits but do not enter the overlying calcareous strata.

The present topography of Eua indicates that at one time it must have been a large flat limestone plateau, originally similar to that of Tongatábu and Vavau, but of greater height and less extent, pushed up by volcanic outbursts on the east coast, which was little by little disintegrated according to the hardness of the various terraces, and finally eroded so as to form the central valley with the comparatively smooth faces of the eastern and western ridges. Only a few outcrops of the coralliferous limestones are seen, here and there, in the valley, - remnants of the harder terraces, such as the fourth terrace, a long line of which is left on the northern part of the west slope of the central valley. On looking back on Eua on our way to Tongatábu one can see, perhaps better than on the island itself, extending for a great part of its length, the deep central valley of erosion, which has given to Eua its characteristic topography, and certainly there is nothing less like a lagoon than this inner valley or sink of erosion of Eua. ${ }^{3}$

1 Loc. cit., Geol, of the Tonga Islands.

2 See Harker, Volcanic Rocks of Eua, Geol. Mag., June, 1891.

${ }^{3}$ Commander Oldham of the H. M. S. "Egeria" has given in "Nature" of May 22, 1890, p. 85, an interesting sketch of Eua, corresponding in the main with Lister's account. In a note to the above Professor Judd speaks of the limestones as made up of Foraminifera and water-worn Nullipores. As regards the volcanic rocks he thinks their composition lends support to the view that all oceanic islands are of volcanic origin. 


\section{TONGATÁBU.}

Plates $115-118,213-215$.

THE southern cluster of the Tonga group ${ }^{1}$ (Pl. 214) consists of the islands of Tongatábu (Pl. 215), and its satellites, with the shoals extending to the north about thirty miles from the harbor of Nukualofa, the soundings on the northern part of the bank varying from 20 to 40 fathoms; two indentations of shallower water run into the plateau, the one from the east, south of Dido Shoal, towards Ava Lahi Pass, and the other, west of Eua iki, forms the main entrance into the harbor of Nukualofa.

The island of Tongatábu is about eighteen and a half miles in greatest length. From Cook Point the southwestern shore, as well as the southeastern extremity, is high. Its terraced cliffs rise to about 270 feet immediately back of Cook Point. Tongatábu is irregularly triangular in shape. Its greatest breadth is formed by the southeastern coast, which is about nine miles long. It tapers at the northwestern extremity to a long curved point, Nui Aunofo Point, not more than half a mile in width, which encloses the flats which once formed the northern extremity of Tongatábu, and are now represented only by the islands and flats of Atatá, Boloa, Hakau Tábu, Alakibeáu, and Tufaka (Pl. 215). From the highest point of the southwest coast the shore falls very gradually towards the north, and the whole northern part of the island is composed of a comparatively low flat, undulating in places (Pl. 116, fig. 1).

To the east of Nukualofa ${ }^{2}$ Tongatábu consists of a labyrinth of low islands and islets (Pl. 215), which occupy the whole of the straits between Nukuleka and Holevai (Pl. 115). The pass between these two points widens out to the south and west into long fingerlike bays, extending the one towards Bea and the other towards Mua, the land between consisting of low swampy ground covered with mangroves; the whole of that part of Tongatíbu forms an irregularly shaped digitate lagoon (Pl. 215), which can be navigated only by canoes (Pl. 115, fig. 2). 
To the northeast of the harbor of Nukualofa, north of the Narrows, immense L-shaped flats extend, on which are a number of low islands (Pl. 115, fig. 3), such as Fafa, Monu afe, Velitoa, Onevai, Motu Tabu, Onevao, Fukave, Nuku, Atà, and Tau. The L-shaped flat encloses a wide bay covered with coral patches, shoals, and islands, the principal of which is the low island of Malinoa, and extends towards the Lahi Passage (Pl. 215). Biha, or the eastern passage, leads as far as Atatá Island into a wide open bay, flanked on the northeast by innumerable coral patches leading to Egeria Pass, which is the principal western entrance of Tongatábu (Pl. 215). To the north of Egeria Channel is an extensive, low, triangular reef flat, which separates it from the Lahi Pass.

To the west of Atata Island, a deep indentation of the reef flat to the east of Niu Aunofo Point, with from seven to ten fathoms of water, is called Maria Bay. It is cut off from free access to the sea by large reef patches, outliers and islands, thrown up on the western face of the plateau of Tongatábu. The principal flats are called, the one Hakau Tábu and the other to the northeast of Egeria Pass, Hakau Mamao (Pl. 215). From that point the Tongatábu bank gradually slopes to the northward, and disappears on the edge of the broad channel which separates it from the Nomuka group. The least depth in this channel is about 270 fathoms. At the western extremity it has a width of about four miles, and at the eastern a breadth of nearly ten miles (Pl. 214).

As we entered the passage leading into Tongatábu, we could distinguish on our left patches of two terraces separated by short reaches of coral sand beaches, the low limestone cliffs of the terraces being deeply undercut and gouged out. Tongatábu as seen coming from the sea is very striking. The numerous islands which once formed part of the main land can be seen stretching to the north as far as the eye can see; and as we approach Tongatábu, the whole of its north shore seems cut into myriads of little hills and sand bars, with but little vegetation. Here and there a larger island rises among the lower ones, showing according to its height (Pl. 115, fig. 3) that it once formed part either of the first or of the second terrace. Low vertical limestone cliffs crop out on nearly all the islands, and these are more or less rounded according to their 
exposure to the prevailing winds; those which are more protected are covered with a slight vegetation which has prevented their erosion and denudation. Nukualofa, the principal harbor of Tongatábu, is merely a channel left between the innumerable islands which must once have formed a connected flat extending far to the north of the town, a flat which has been changed into a very irregularly shaped lagoon, a lagoon of erosion and denudation, covered with islands and full of mangrove swamps (Pl. 215). On landing, it is evident that a great part of the flat on which the town is built consists mainly of æolian rocks which have been formed by the trades blowing along the sand beaches, derived from the disintegration of the corąl reefs and coral reef flats of Nukualofa. In the central parts of the flats, between the islands and islets, corals grow in great abundance, and on the slopes of the reef flat into deeper water they are especially abundant. Numberless starfishes belonging to species found on the Australian and Fiji reefs are seen in all directions, and the reef flats are full of fishes which are left at low tide in large pools, where the natives fish for them with hand nets (PI. 115, fig. 3):

Mount Zion (Pl. 215), near the shore of Nukualofa, is composed of elevated coralliferous limestone full of fossils; it and Cook's Hill are probably outliers of the second or third terraces, showing that the whole of the main island of Tongatábu has been eroded and denuded to its present level, leaving only here and there, as we saw when entering the harbor, traces of the greater elevation at which the land once stood. This elevation is best seen on the south side of Tongatábu, in the rear of Cook Point, where the terraces rise to a height of more than 270 feet, as well as along the Liku or the windward side of the island (Pls. 116, fig. 2; 117, fig. 2); from that shore the land slopes gradually to the height of a few feet south of Nukualofa. Near Cook Point lines of blowholes are developed on the outer edge of the reef flat which surpass in size any of the blowholes we have seen in the Pacific (Pls. 117, fig. 1; 118).

On the island of Atatá, northwest from the village of Nukualofa, a number of fossils have been found similar to those of Mount Zion, and they in their turn are similar to those we found in Eua, and other islands in the Tonga group. Tongatábu, as seen in the distance, is marked for its flat-topped 
summit, and the terraces of the south point; they are clearly visible at a distance of ten miles. The island of Eua iki is also flat-topped, and terraced as seen from the north point of Eua.

There is no outcrop of coralliferous limestone on the great flat south of Nukualofa. On leaving our anchorage at Nukualofa ${ }^{1}$ we passed the island of Boloa, which rises to a height of over sixty feet, and where the undercut ledges probably represent fragments of cliffs belonging to the second terrace. We also passed the island of Alakibeáu, which is somewhat lower than Boloa ; at Atatá, where the second terrace is very distinct, but deeply undercut, the top of the island has been rounded and huge crevasses and

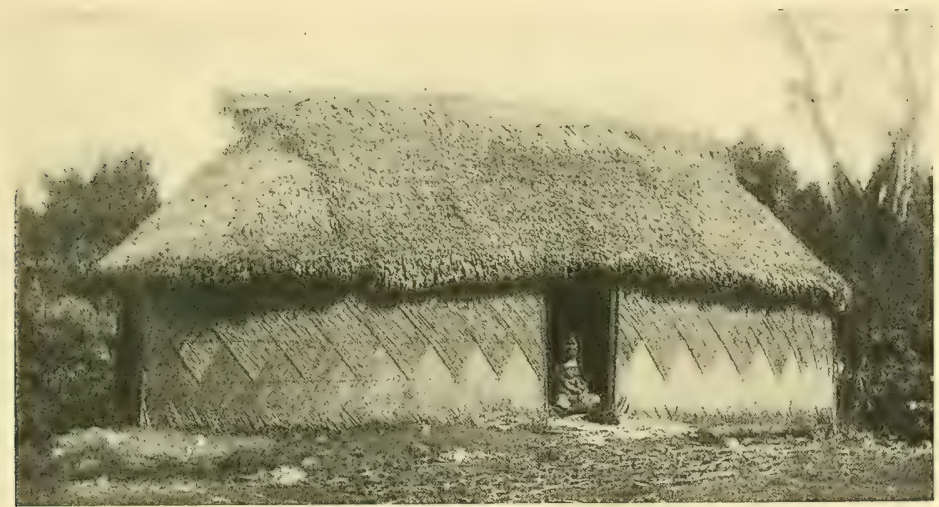

Native Hut near Nukualofa, Tongatábu.

cracks cut into the face of the vertical cliffs. To the north of Egeria Channel extends a long reef flat, the outer edge of which is plainly marked by its line of breakers. A number of islets are also seen between Atatá and the outer edge of the reef flat; this seems to be a series of huge sand banks connecting the south spit of Atata with the eastern edge of the reef flat to the south of Egeria Channel and to the east of Niu Aunofo Point. Another islet south of Egeria Channel is the small narrow island of Tufaka, with its undercut ledge like that of Atatá. After passing out of 
Egeria Channel, we ran a short distance parallel to the line of breakers which extends towards the north from Maria Bay, on the western side of the reef.

\section{The Nomuka Group.}

Plates 119, 214, 216.

The Nomuka group, the second bank to the north of Tongatábu, is rectangular in outline; its eastern and western sides being about thirty miles in length, and its southern and northern sides somewhat longer. The western face of Nomuka Bank is comparatively clear, the bank falling rapidly from 30 or 40 fathoms into more than 200 fathoms, while numerous shoals line its eastern edge. The northern side is covered with islands, islets, and shoals, forming a continuation of the islands and shoals of the eastern face. Toward the central part of the bank several low islands have been thrown up, and numerous patches render navigation of the eastern side of Nonuka exceedingly dangerous, so that we did not examine that side of the Nomuka Bank.

The island of Nomuka is composed of elevated coralliferous limestone. Seen at a distance, it shows distinct traces of a first, a second, and a third terrace. What is left of the third terrace rises as a low conical peak on the summit of the second terrace. Before coming to our anchorage, we passed Nomuka Iki, a low island on which the old ledge crops out at its base, near high-water mark. We also passed by the island of Muifuiva, a patch of old elevated coral reef rising to a height of perhaps nine or ten feet, topped with bushes and a few cocoanut trees (Pl. 216). To the rear of us we could see the flat-topped island of Mango Iki, and also the island of Mango, which has a volcauic peak at the eastern extremity, its western end being composed entirely of elevated coralliferous limestone rocks. The highest point of the island of Nomuka is Mata Maka (166 feet in height), and when seen from the eastern side, it looks as if a part of Koto Maka, the next highest peak, might be a portion of the fourth terrace. In addition to Mango, which is voleanic, I was informed that Fonoifua, as well as Tanoa, are composed of volcanic rocks. Mr. Moore, who went on 
shore at Nomuka Iki (Pl. 216), found the southern peak (147 feet high) made up of volcanic material very similar to the Fiji soapstone, but somewhat darker. An elevated ledge of old coralliferous limestone runs on the south side of the west end, and a high sand beach faces the northern line of the shore. From the southeastern point sand keys extend, forming a flat of considerable extent.

The eastern part of the island of Nomuka is occupied by a large lagoon, which has been separated from the sea by a high sand beach thrown up between the southern extremities of the two limestone ranges forming the western and eastern faces of the island (Pls. 119, 216). The island must formerly have been more or less horseshoe-shinped, its faces enclosing a sound formed by denudation and erosion and the inroads of the sea, much as the sounds in the Bermudas and elsewhere have been formed. The lagoon is not more than four to five feet deep, and occupies the shallow sink enclosed between the two main ridges of Nomuka. Yet such a lagoon if surrounded by a low land rim would be looked upon as an excellent specimen of a subsidence atoll! The slopes from the outer ridges toward the central basin are slopes of denudation; here and there are huge spurs covered with vegetation, running out as buttresses on the flanks of the rim ( $\mathrm{Pl} .119$, fig. 1), a very different structure from that found in any atoll we have examined; this can only be accounted for by the difference in the extent of denudation and erosion, which has taken place in different parts of this basin, according to the density and more or less friable nature of the calcareous limestone of the outer ridges. The buttresses remind us of similar buttresses in the sink of Kambara; they are in marked contrast with the comparatively bare volcanic slopes of Nomuka Iki, and other volcanic islets in the vicinity. A number of salt-water fishes are found in the lagoon.

Koto Maka and the western part of Nomuka were examined by Dr. Mayer, who found it to consist of elevated coralliferous limestone, much of it changed to hard calcite, and containing numerous fossils near its base. I examined, myself, the ridge to the east of the lagoon, as well as the shores of the lagoon itself, and found the highest point of the eastern ridge of the lagoon to consist of calcite, and of elevated coralliferous limestone from 
base to summit. A beautiful mangrove swamp extends along the southern part of the lagoon (Pl. 119, fig. 1). The reef flats surrounding Nomuka are extensive. The reef flat to the south of Nomuka Iki (Pl. 216) is quite bare, covered with Nullipores, forming a thick crust over it, with but few corals. On the east coast Nomuka is flanked by a high coral sand beach fully fifteen feet above low-water mark; the coral sand is of a grayish color, mixed with red earth near the lagoon. The soil is very fertile. There are a few coral and sand patches near our anchorage in fifteen fathoms, and also between the anchorage and the shore, as well as an extensive fringing reef on the southwest face of Nomuka. The corals extending into deep water do not seem to be numerous; they are separated by wide lanes of sand.

Dr. Mayer also collected fossils on the low land forming part of the slope towards the northern extremity of Nomuka, probably a part of the second terrace, from the first terrace, which is about nine feet high, and also from near high-water mark. The soil of the northern slope is deep; it consists of decomposed coral, of a rich brown and red color, and supports a dense growth of cocoanuts, Tahitian chestnuts, Pisonia, Paritium, breadfruit, limes, bananas, etc.

On the slope between Koto Maka and the shore, is a slight sink, or basin of erosion similar to that which formed on the east face, the so-called lagoon of Nomuka (Pl. 216). The old ledge rock crops out at a point immediately above the first terrace, where it is about nine feet high above high-water mark. On the southeast face of Nomuka a huge sand dune has formed on the weather-side, and hides the lower part of the old ledge of elevated rock. Similar dunes can be seen on other islands in the vicinity of Nomuka, where the tradewinds rake the coral sand beach. The sand gradually creeping up on the slopes would eventually hide the outcrops of the ledge, and would soon form a perfectly uniform slope of coral sand, with here and there an outcrop of the old ledge where it had not been covered by the encroaching dune. 


\section{The Haapai Group.}

Plates 217, 218.

As we left our anchorage at Nomuka, we could, going north, see the summit of Mata Maka, sloping to the shore line where limestone bluffs alternate with long reaches of coral sand beaches, fringed with beach rock. To the south rose Koto Maka, similarly flanked with low bluffs of old beach rock alternating with coral sand beaches. Immediately above the cliffs, the slopes were covered by thick vegetation, probably up to the height of the third terrace; above that the higher summits of Nomuka were more or less bare (Pl. 216). We could see in the distance, to the northeast of Nomuka, the flat-topped Oua composed of limestone (140 feet high) covered with scrub vegetation, as well as the more rounded summit of Fonuaika, covered with cocoanut trees. We passed by Kito Island, a low sand beach covered with scrub bushes (Pl. 217). Tongua and Kotu resemble Oua, their limestone cliffs rising to a height of more than 120 feet. Off Kotu there is a sink in the reefs surrounding it, forming an incipient atoll which has not risen to the surface from the surrounding bank, on which is a depth of twenty to thirty fathoms. The island of Fotuhaa is also flanked with old elevated reef rock; its second, third, and fourth terraces are plainly visible when steaming past at a distance of about three miles. The first, a low terrace, flanks the whole of the west coast; in the third terrace a number of caverns indicate a former sea-level, at a height of probably thirty to forty feet above high-water mark. The cliffs of Fotuhaa are deeply undercut to the base of the third terrace, and gouged vertically into incipient valleys at right angles to the shore line, as we saw them at Nuie.

The islands of elevated coralliferous limestone which dot the western part of the southern portion of the Haapai Bank are the outliers of larger islands; their former extent is indicated by the extensive reef flats and patches occupying the greater part of the area of the Haapai Plateau, by the reef flats to the east of Oua, those surrounding Haafeva and Kotu (Pl. 217), Alexander and Wickham reefs, and many others scattered over the surface of the Haapai Plateau. 
In addition Haapai Bank is covered with small low islands, scattered over the bank for a distance of about forty miles (Pls. 217, 218); the bank stretches in a northeast and southwestern direction, and has a greatest width of about twenty-three miles. On the eastern face Haapai Bank is flanked by a continuous angular line of reefs and islands, extending from Haano Island on the north to Lima Island on the south. Some of the islands are separated by narrow passages of considerable depth $;{ }^{1}$ they are low, and some of them broad, and appear to consist, like the lower parts of Tongatábu, of elevated coralliferous limestone, which has gradually been denuded to the level of the sea, while the islands on the western part of the bank rise to a considerable height and are plainly terraced.

The Haapai Bank is triangular (Pls. 217, 218), its depth varies from ten to forty or fifty fathoms; it drops off rapidly from 40 fathoms to 50 and 100 and then to the 500 -fathom line on the west. $\Lambda$ number of the islands, patches, and flats on the western part of the bank rise from comparatively deep water, from water fully as deep as that of any part of the channels which separate the banks, indicating that there are a series of more or less independent summits on that part of the Haapai group.

The larger islands flanking the eastern face of the northern part of the Haapai Bank (Pls. 217, 218) are quite broad; they are low, with low cliffs of elevated coralliferous limestone edging their eastern face, or cropping out on the western; they are, according to Lister, from ten to twenty feet, and slope very gradually towards the west. The broad and extensive reef flats adjoining the islands and forming their continuation on the eastern face of the bank, have either been elevated; or have been denuded from larger limestone lands; they are flanked by a narrow reef platform of about 200 yards in width, edged by a narrow line of fringing reefs which might, from its independence of the reef flat, be called a barrier reef. The reef flat to the westward, the remnant of the former land area, is represented only by irregular patches of coral or flats covered with sand bars and sand ridges.

The larger islands flanking the east side of Haapai Bank, Haano, Foa, Lifuka, and Uoleva occupy the greater part of the surface of the flats which

${ }^{1}$ Over thirty fathoms in Ava Mata Mata Vika, and nearly twenty fathoms south of Uoleva. 
connect them; south of Uiha the reef flats extend as a narrow belt towards Tofanga Island, and to the south of Ava Mata Mata Vika (Pl. 218) the reef flat is merely a narrow line reaching to the southern horn of the bank, on which there is only a single small island, Lima. Remnants of the elevated limestone crop out as outliers on the narrow reef fringe, some of them attaining, according to the charts, a height of a few feet.

On account of the weather we did not venture into the labyrinth of patches to the west of Lifuka, and were mable to examine the peculiar atolls sketched on the chart of the northern part of the Haapai group. ${ }^{1}$ They differ from the greater number of the islands of Hapai and Nomuka, which are surrounded by extensive fringing reef flats, in having an outer somewhat raised edge forming an incipient barrier reef, resembling the raised barrier edge of the fringing reef of the larger islands like Foa, Haano, Lifuka, Uoleva. The transition of an island with its fringing reef to one of these incipient atolls is shown by comparing such islands as Luangahu (Pls. 217, 218), ${ }^{2}$ an islet with an extensive fringing reef, with Lofanga, an elevated coralliferous limestone island (150 feet), or. Moungaone (100 feet in height), which has in part a fringing reef, in part a barrier reef, to such an atoll as Niniva, or Ofolanga, or Hakau Lahi, the remnants only of islets encircled by a narrow barrier reef enclosing a space full of dry coral patches. The earlier stages, Lofanga, Moungaone, Tongua, Kotu, Haafeva, patches or outliers of the great Haapai land (Pls. 217, 218), resemble the condition of the large eastern islands of Uiha, Uoleva, Lifuka, and Haano, which in their turn recall the existing condition of the northern parts of Tongatábu.

\section{Vavau.}

Plates 120-125, 219.

Approaching Vavau from the southwest, we come upon the triangularly shaped island, Hunga, forming the western entrance to the Vavau group (Pls. 121, fig. 1; 219). To the enst two immense white patches appear on

\footnotetext{
1 A. Chart 3099.

2 Ibid, 3099 and 3100.
} 
the vertical limestone cliffs of the southwest face of Vavau (Pl. 120, fig. 2), which has been formed by the sloughing off of large masses of limestone rocks heaped up at the base of the cliffs. The cliffs are all deeply undercut, and the first terrace is nearly everywhere obliterated by the mass of débris which has fallen off from the second and sometimes from the third terrace (Pl. 124, fig. 1). To the north of Muitoulo the second, third, and fourth terraces are plainly visible; to the south and east, looming up over the slopes of Fata and Kapa, rises the island of Pangai. The second, third, and fourth terraces are very distinct along the side of Moungalafa, and form the southern face of the bluffs on the western entrance into the harbor (Pl. 121, fig. 2). The height of Moungalafa is about 600 feet, while the height of the three terraces to the south of it is probably somewhat less; when looking southwest, the cliffs of other islands rise vertically to a height of more than 200 feet (Pl. 120, fig. 1).

Rounding Point Fata, we pass into the main entrance to Neiafu, leaving on the right Nua Papu, Oto, Ava, Kapa, Otungake and Pangai ; in the east we can distinguish the line of islands on the edge of the Vavau Plateau and an interior line flanking the western edge of the eastern part of 'the platean (Pl. 120, fig. 1). All the islands to the south of Vavau, and the spurs making out from the principal island, show the immense amount of denudation, disintegration, and erosion which must have taken place in this limestone land during its elevation (Pls. 120, figs. 1, 3; 122, fig. 2). The cliffs are nearly vertical, deeply undercut, and all traces of the second and third terraces have been obliterated. Some of the islets are almost cut in two, deep cañons having been cut into their faces (Pl. 219). One of the most striking of the canons of the Vavau group is the cut that separates Kitu Island from Nua Papu (PI. 219); it is not more than twenty or twentyfive feet wide. The vertical cliffs are full of caverns. North of the eastern point of Pangai three terraces are plainly seen. On looking to the east and south of Pangai we can see the numerous islands and islets composed of elevated coralliferous limestone, some of which are still terraced, scattered over the whole of that part of the Vavau Plateau (Pl. 219). To the north of Pangai rises Talau (Pl. 121, fig. 3); one of the most characteristic of the elevated points of Vavau; it is a cone of elevated 
coralliferous limestone, ${ }^{1}$ reaching a height of over 400 feet, the terraces of which are distinct on all sides, except where it connects with the mainland immediately to the west of Neiafu, the principal village of the group. The terraces in the hills to the west of Teleki are also remarkably distinct.

At Neiafu the cliffs have been disintegrated so as to leave a mass of débris at the base. This in its turn has generally been changed into short reaches of coral sand beaches, but the sand beaches throughout Vavau are few in number, and small, except in the stretch lying eastward of Neiafu Harbor, in the long arm of the sea which starts at the base of Talau and reaches the eastern face of Pangai (Pl. 219). The cliffs are cut back to the second or third terraces, and their slopes covered with large trees. An immense amount of red earth is found on the levels of nearly all the terraces, and constitutes one of the striking features of the main island of Vavan to the north of Neiafu, all the way to Holonga on the north shore (Pl. 124, fig. 2).

There are no well-marked reef platforms on the sides of the deep channel which winds its way towards Neiafu Harbor through the islands scattered over the Vavau Plateau (Pls. 121, fig. 3; 122, fig. 2; 219). To the south of the village of Neiafu, the first terrace is very distinct; it is undercut and as in this narrow arm the sea is smooth, it slopes gently into deep water (Pls. 121, fig. 3 ; 219). Masses of coral, mainly Millepores, and Porites, are found in large blocks down to a depth of five fathoms. At that depth the heads become smaller, and large lanes of sand encroach between them; beyond that depth everything is coral sand. The cliffs of Vavau are composed of elevated coralliferous limestone; this is readily disintegrated, as is shown by the multiplicity of cañons, cuts, and valleys formed in these cliffs throughout the Vavau group (Pls. 124, fig. 1; 125). When we reach the southern extremity. of the eastern arm of Neiafu harbor, we find a pretty narrow gap (Pls. 123, 219), bare at low tide, separating it from Pangai Motu, forming the communication of this inland arm of the sea with the immense reef flat forming the eastern face of the Vavau group. This gap (Ahanga

${ }^{1}$ Lister considers Talau an atoll similar to Kotu. It seems to me the so-called lagoon of Kotu should be regarded as a sink. 
Passage) is a cañon cut through the limestone rocks, deeply undercut on one side, the sides of which are perhaps 200 feet high (Pls. 123, 219).

The vegetation which comes down to the water's edge on the faces of this deep inlet of Neiafu is very luxuriant (Pl. 123). In every direction are large trees covered with vines, and the vegetation is perhaps as fine as any we have seen in the Southern Pacific. The cañons in Vavau resemble those of Ngillangillah in Fiji, only they are on a much larger scale. The vertical cliffs of the sound to the south of Neiafu, and all the cliffs we have examined, are full of caverns indicating former lines of sea level. The

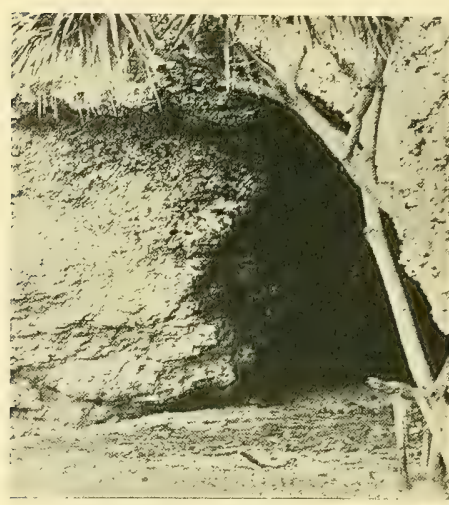

Entrance to Cave, Vavau. caverns near low-water mark are used by the natives as boat-houses. The excellent chart of Vavau, ${ }^{1}$ from the surveys of Captain Field, gives us the means not only of following the changes which have taken place in the topography of the group, but also of tracing the manner in which they have been brought about (Pl. 219). The bars and islands indicate old connections, and are now represented by reef flats. The cuts which have been made across the narrow parts of the land, like the cut at the south end of Neiafu harbor, are due to the gradual wearing away of the original land (Pl. 219).

It is interesting to note the similarity of the results of denudation and erosion of Nomuka and of Vavau. The sinks of Hunga, of Ano (Pl, 219), are similar to the sink of Nomuka. The horseshoe-shape of that island corresponds to the ridges which enclose the sinks of the former island. A similar denudation and erosion, together with the solution and disintegration of the enclosed limestone, only carried on on a larger scale, gives us the explanation of the formation of such basins as those to the south of Tofon, to that of Nua Papu, to the sink separating Pangai and Otungake (Pl. 219), to the bays south of Pangai, the dry sink to the north of Koloa, the 
impounded sink back of Tulie, the sounds on the two sides of Makave Spit, the tongue of Vaipuua, and the extensive sink to the north of Teleki, opposite Talau (Pl. 219). We may thus account for the numberless fiords, cuts, gaps, and inlets which characterize the sonthern part of Vavau (Pl. 219); of course, much of the material has been carried off in solution. We have in the first place brackish lakes, like Ano, which, little by little, have been changed into sounds like that north of Teleki (Pl. 219), opening more and more to the sea, until finally they become mere bights of greater or less depth, according as solution and denudation have been carried for a greater or less length of time.

When denudation and submarine erosion have taken place to a considerable extent, as on the east face of Vavau, we have a complicated series of banks, flats, islands, bars, and islets (Pl. 219). Lalalolomei Bank, and the cluster of Hakaufussi, are remnants of land ridges and summits which have been elevated along the eastern face of the Vavau group, and culminate in the high land forming the island of Vavau (Pl. 219), and its extension south on the high islands of Hunga and Nua Papu. North of Euakafa Island there is a perfect labyrinth of islands and islets, some of which are of considerable size and height.

Vavau occupies the greater part of the northern extremity of the Vavau Bank. We crossed over to the north end of the island of Vavau with Dr. Hansen. Immediately behind Neiafu there is a gradual rise to the top of the third terrace, on which the road runs as far as Feletoa, then rises again to Holanga on the north shore, about eight miles distant. A magnificent vegetation covers this sloping land, which rises gradually from the upper level of the first terrace; the whole of this is nearly denuded, a gentle and uniforın slope extends over the greater part of the first and second terraçes. The soil of this part of Vavau is very fertile; it consists mainly of the red earth so characteristic of the decomposition of coralliferous limestone. On the summit of the bluffs of the north shore (Pl. 124, fig. 2), at Holanga, at a height of 500 feet, we collected a number of fossils. Very few outcrops of limestone are met with on the way.

A number of living corals were collected in the sound of Neiafu, Porites, Pavonia, Madrepores, Goniastrea, Millepores, and a number of Gorgonians. 
We also found living among the corals a number of specimens of Centrostephanus. Dr. Mayer examined Talau to the west of Neiafu Village, and collected a number of fossils at the different points. The summit varied in height from 380 to 425 feet. At the base of the upper cliff the height is about 325 feet. The top of the third terrace is probably 200 feet, the base of the second is about 100, and the summit of the second terrace, immediately to the west of Neiafu, half-way between it and the Talau, is perhaps 40 to 50 feet higher. The rock at the top of Talau is a hard, reddish-colored crystalline limestone, very much altered by weathering, and is not fossiliferous, but fossils were collected on all the other terraces.

On our way out from Vavau, we passed by the village of Teleki, where there is an immense sink of fresh water (Pl. 219), overgrown with all kinds of lacustrine vegetation. The terraces to the west and south of Teleki are very apparent (Pl. 122, fig. 1); the top of the third terrace forms an especially well-marked line on many islands. Some of the islands on the southeastern part of the Vavau Plateau show indications of the second, third, and perhaps the fourth terrace, but the line of the third terrace is the most characteristic of all. Looking eastward between the islands of Kapa and Pangai, we see a number of small islands and islets with vertical faces looming up in the space between them and the eastern edge of the outer reef (Pl. 120, fig. 1).

As we steamed past Hunga (Pl. 219), we could distinctly see the stratification of some of the limestone strata, which suggested an æolian origin for those beds. This æolian limestone probably formed only a belt, blown in between more solid cliffs of limestone, as both to the north and to the south the cliffs resemble, in every respect, those of other parts of the Vavau group. At the base of the æolian cliff we could trace a coral sand beach extending as far as a gap in the uplifted limestone to the south. The vertical cliffs of Hunga are deeply undercut and full of diminutive caverns; the island slopes in an easterly direction. To the south of Hunga, the island of Fofoa also slopes to the eastward. It is flanked on the west by low vertical cliffs of coralliferous limestone, with here and there a low sand beach. Still farther south, the most southwesterly of the islands of Vavau rise in sharp weathered peaks above low vertical cliffs, and form the last 
barrier which separates the Vavau group from the Haapai group to the south (Pl. 219).

It would seem as if the Vavau Plateau attained its greatest elevation on the western face of Vavau; its terraces, as well as those of all the islands, slope decidedly towards the east. On the east face of Vavau extend wide reef flats; on the outer edges, both the eastern and the western, exist high islands, and islets; sand-bars, patches, and foul ground indicate the extent of denudation and erosion which has taken place over the former Vavau land.

The general depth of the northern part of Vavau Bank varies from 20 to 60 fathoms, and falls off steeply into deeper water on the west side, close to the 100 -fathom line. The bank is somewhat shoaler on its eastern face. The soundings are so irregular that it is impossible to state, except in a general way, that the bank is sloping to the west, while the land seems sloping to the eastward. About half-way between Vavau and the Samoan Islands is situated Niuatobutábu, the highest point of which is 350 feet; it is an elevated coralliferous island, connected with the northern part of the Tonga group by a ridge the deepest part of which is about 1100 fathoms; the ridge slopes rapidly to the east into deep water ranging from 2500 to over 4500 fathoms. ${ }^{1}$

1 A. Chart 2935.

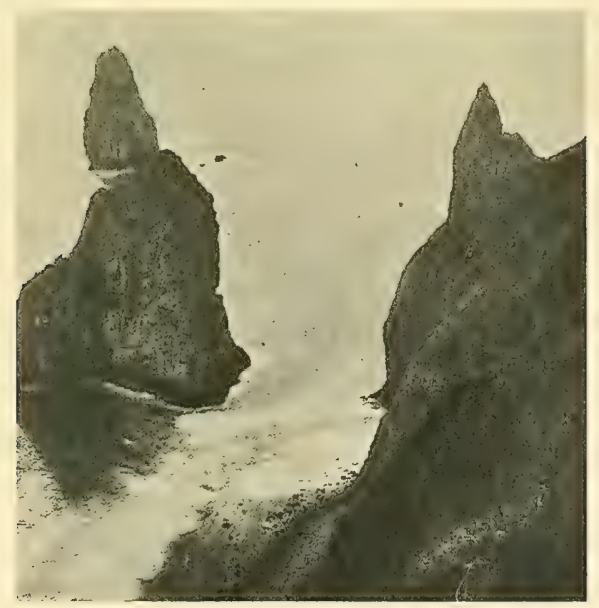

Pylstaart Island. 


\section{THE FIJI ISLANDS.}

Plates 126-128; 220.

THE Fiji Islands ${ }^{1}$ are among the most interesting groups for the study of coral islands and reefs, owing to the great variety in the conditions under which coral reefs occur there, their accessibility, and the admirable charts of the group which have been published by the English Admiralty. The dimensions of Viti Levu and of Vanua Levu, the great height of the two main islands, and their position in the region of the trades, are such as to give us almost continental conditions for the formation of great barrier reefs. The rivers which radiate from the central part of Viti Levu (Pl. 220), the Rewa (Pl. 128, fig. 1), the Singatoke, ${ }^{2}$ the Ba (Pl. 128, fig. 2), bring vast bodies of water to the sea, and are in marked contrast to the rivers of other Pacific islands, even of such islands as Tahiti, where the streams, although constant, are torrents.

The coral reefs of such volcanic groups as Fiji, the Society, the Sandwich, the Samoan, and other islands, are in marked contrast with the coral reefs of such groups as the Paumotus, the Ellice, Gilbert, and Marshall Islands, where the rehandled reef rock material plays the principal part in shaping the physiognomy of the islands.

Reaching the Lau group in Fiji from the windward side, we had a far better opportunity of seeing the terraces of Yangasá, coming from the northeast, than on a former visit ${ }^{3}$ when we examined the group from the west. We also had the advantage of greater experience in detecting traces of terraces, which are indistinct in Fiji compared to their sharp delineation in Niue, the Tongas, and the Paumotus. Yangasá Levu, seen from the passage south of $\mathrm{Na}$ Potu, is hat-shaped; flat-topped, and when seen from the south, three of its terraces are plainly marked. The smaller island of Navutuiloma is also terraced, but less distinctly than Yangasá

1 For an account of older and recent explorations of the Fiji Islands, see J. D. Dana, Corals and Coral Islands, 3d ed.; Dana, Geology of the U. S. Ex. Ex.: Seeman, Flora Vitiensis; Agassiz, Am. Jour. of Science, Vol. V., p. 113 (February, 1898); J. S. Gardiner, Proc. Camb. Phil. Soc., Vol. IX., pt. viii., p. 457 (1898) ; A. Agassiz, Bull. M. C. Z., XXXII. (1899); E. C. Andrews, Bull. M. C. Z., XXXVIII. (1900); Geol. Ser. V., No. 1.

2 Bull. M. C. Z., XXXVIII. Pl. 3s.

3. The Islands and Coral Reefs of Fiji, Alexander Agassiz, Bull. M. C. Z., XXXIII. (1899). 
Levu. To the north the terraces of Karoni could also be seen. Passing Fulanga, we thought we could detect the traces of three terraces, with Quoin Hill rising from the remnant of the third terrace. We passed Marambo, where there are indications of three terraces, and Wangava, where the top of the third terrace forms the long slightly dished top of the island, flanked on all sides by two lower terraces.

While passing through the Fiji Islands we added a number of interesting photographs of Suva and of the main island, which had not been successfully taken during our previous visit; among them a view of the stratified soapstone beds, and a greneral view of the scenery of the soapstone area back of Walu Bay. We also took a number of photographs at the mouth of the Rewa, and a few interesting views in the interior towards the head waters of the Rewa.

After leaving Suva we passed Nuku Mbasanga on the east. Both the northern and eastern sides were flanked with beach rock and by accumulations of coral sand presenting the same appearance as when seen from the west. We passed Ngele Levu and Taulalia near enough to get an excellent view of its peculiar conical erosion. The small cañons of the group represent the inmense amount of erosion and denudation which have taken place over the old land of Ngele Levu. We steamed past this group on a different side from that we had examined before, but found nothing different on the north or on the east from what we had observed on our former visit, when leaving the lagoon through the western pass, or skirting the southern shore.

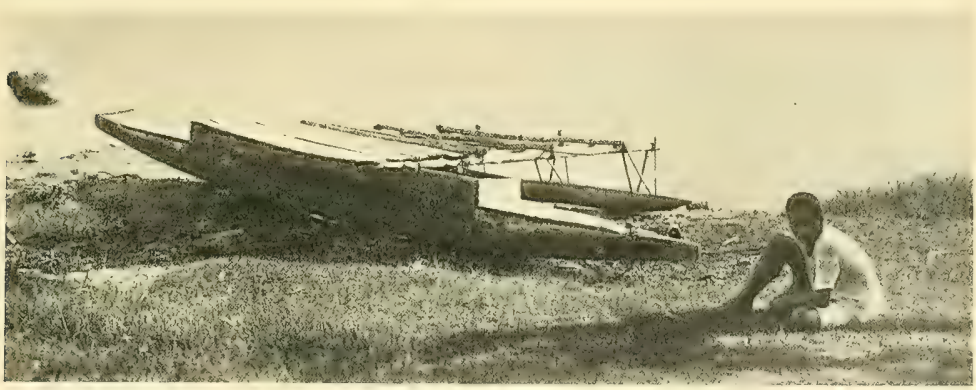

Fiji Canoe, Suva. 


\section{Kambara.}

Plates 126, 127, 220.

On opening the south point of Kambara we could readily trace three terraces; they could also be made out indistinctly on the north point. We visited Kambara ${ }^{1}$ in order to examine again the basin or sink of the island. We ascended the volcanic cone rising to the south of Tokalau Village, to a height of about 470 feet, and which forms the most prominent object of Kambara. The cone has burst through the outer rim of elevated coralliferous limestone (Pls. 126, 127); it rises nearly 150 feet higher than any other part of the rim of the central basin of Kambara. It was very evident that this basin is a basin of erosion, and not the basin of an elevated atoll (Pls. 126, fig. 2; 127, fig. 1). It must have formed like other sounds we have described in Fiji, like those of Fulanga, of Yangasí, of Ongea, of Namuka, Wangava, ${ }^{2}$ and many others. One of the gaps which formerly gave access to the sea to the old sink, or formed an outlet to the sound once occupying the centre of the island, can still be distinguished immediately behind the village of Tokalau (Pl. 127, fig. 2), and others at one or two points on the eastern and on the southwestern rim of the sink of Kambara. In fact, as we have shown in a former report on the Fiji Islands, ${ }^{3} \mathrm{I}$ consider Naiau and Tuvuthá, as well as the islands we have just mentioned, to be merely elevated plateaus, or irregular masses of coralliferous limestone, or plateaus with incipient sounds, which have also been denuded and eroded by atmospheric agencies to form sinks imitating to a certain extent the elevated lagoon of an atoll. It is evident that an elevated lagoon would be far deeper than the sinks

1 A. Chart 441 .

2 The top of Wangava shows a slight depression; as seen from the top of the voleanic cone of Kambara it appears like a hat, the broad brim of which is the reef platform, surrounding the island on all sides (Pl. 127), with a shallow sink formed by the outer edges of the rim. At first sight Wangava appears to be an elevated atoll, yet on comparing the sinks of Kambara and Wangava with the sounds and lagoons, the formation of which has been so carefully traced in many of the Fiji Islands, there is no reason to consider such islands as Wangava, Kambara, Naiau, Tuvuthá, as other than elevated plateaus at different stages in the formation of sounds, the sinks of which have been denuded and eroded after their elevation or during its process.

3 Bull. M. C. Z., XXXIII., 1899, p. 52. 
thus formed; that it would have precipitous sides, leading from the outer rim toward the deepest parts of the basin, and not the gentle slopes characteristic of the basins of Kambara, of Mango, and of other so-called elevated atolls.

The gap to the south of Tokalau shows plainly that the sound (Pl. 127, fig. 2), which existed at the time when it communicated with the sea, was eroded much in the same way as were the sounds of Fulanga, or of Mango, or of Namuka. ${ }^{1}$ The diminutive sound formed on the southern part of Onger opens out into a valley which extends far inland towards the northern extremity of the larger island of the atoll, and thus has been formed an area of denudation in the interior of Ongea, very similar to that of Eua, only on a much smaller scale. Similarly the topography of Thithia, Tuvuthá, of Wangava and other islands, clearly indicates that submarine erosion, as well as solution and denudation, has been the principal factor in shaping their topography, and that the lagoons of the so-called elevated atolls are merely sinks, such as are common in all limestone districts."

The basin of Kambara, as seen from the top of its volcanic cone, is not deep; the greatest difference of level between the bottom of the sink and the top of the volcanic hill is not more than 250 feet. The limestone rim which forms the edge of that basin is of very varying height (Pls. 126; 127, fig. 1); at some points it can hardly be more than fifty feet above the level of the bottom. It is very evident that during its elevation there has been connection between the sink and the sea through the lower parts of the rim, or through some of the gaps which have been cut, probably at a time but little antedating the present, and have given an outlet to the drainage of that basin. The volcanic outburst has carried up on its sides part of the limestone rim, as large masses and fragments of limestone were picked up over the volcanic slopes. At the very top of the hill a calcareons ridge still exists, the remnant of the edge of the limestone basin which has been broken into by the volcanic outburst. The bottom of the basin is perhaps from 75 to 100 feet below the highest point of the calcareous rim; it

1 Bull. M. C. Z, XXXIII., 1899, Pls, 20, 22.

2 Hill, R. T., Geology of Jamaica, Pl. IX. fig. 2, Bull. M. C. Z., XXXIV., 1899. 
has in no way the appearance of the bottom of a lagoon, - at any rate, not of such lagoons as we now find in the atolls of the Paumotus, Ellice, Gilbert, or Marshall groups. Judging from the soundings, if one of these atolls were to be elevated, the bottom would be almost flat, and rise very rapidly towards the outer edge to the rim. This is not the case with the basin forming the elevated sink of Kambara, or of any of the so-called elevated atolls. The slopes from the outer edges to the middle of the sink appear to be gentle slopes of denudation, and here and there are huge spurs running out as buttresses on the flanks of the rim, - a very different structure from that found in any atoll we have examined, and to be accounted for only by the difference in the degree of denudation and erosion of the coralliferous limestone in different parts of the basin (Pl. 126, fig. 1). These buttresses are covered with thick vegetation, and are in marked contrast with the bare slopes of the volcanic cone on the western face of Kambara. The limestone slopes of the outer edge of the rim are both deeply eroded, and the whole surface is covered with pinnacles, with crevasses, with cuts, and honeycombed in every direction, showing that the weathering of that part of the island, as well as the weathering of the limestone fragments left on the slope of the volcanic outburst, has been going on for a long period of time. Even if this sink represented the remnant of an old lagoon, denudation has gone on long enough to alter its shape radically, and to give it its present topography, - a very different one from what it would have were it the bottom of the lagoon of an atoll raised above the level of the sea. The top of the limestone cliffs probably forms the third terrace. The resemblance of the volcanic cone of Kambara to Qnoin Hill at Fulanga is striking; both these hills have undoubtedly been prominent factors in the formation of the characteristic topographical features of Fulanga and of Kambara. They have broken through the original limestone area and have formed, in this way, a more or less incomplete sound, having probably here and there access to the sea. The sea once having gained access to the interior of the limestone area began its work of erosion and of disintegration, a process which was further assisted by the large rainfall, and has helped to carry off, in solution or in suspension, the limestone composing the elevated areas. Thus was left 
a sink of greater or less depth, according to the length of time during which these processes had been going on. The plateau of both Kambara and Fulanga runs very rapidly into deep water. The characteristic outline of hat-shaped islands like Wangava is due to the formation of a wide reef platform by submarine erosion and denudation. 


\section{THE ELLICE ISLANDS.}

Plates 129-137; 212, figs. 6-8; 221, 222; 224, fig. 1.

TrE Ellice Islands ${ }^{1}$ extend in a northwesterly direction for nearly 360 miles (Pl. 221). The group is composed of the large atolls of Funafuti (Pl. 222) ${ }^{2}$ and Nukufetau (Pl. 212, fig. 6), and of seven smaller ones, Nukulailai, Vaitupu, Niu, Niutao, Nanomana, Nanomea, ${ }^{3}$ and the island of Nurakita (Pl. 212, fig. 8), the southernmost of the group; Nanomana, like Niutao (Pl. 212, fig. 7), is a flat island having no lagoon, a shallow brackish sink occupying a part of the islands.

On our way to Funafuti we stopped at Nurakita; we also examined Nukufetau. I was, of course, greatly interested in my visit at Funafuti, where a boring had been made under the direction of a committee of the Royal Society, in charge of Professor David, of Sydney, after the first attempt under Professor Sollas failed. The second boring reached a depth of 1114 feet. This is not the place to discuss the bearing of the work done at Funafuti, as, beyond the fact of the depth reached, we have as yet no final statement by the Committee of the interpretation put upon the detailed examination of the core obtained, and now in the hands of Professor Judd and his assistants.

\section{Nurakita.}

Plates 129, fig. 1; $21 \%$, fig. 8 ; 221.

The first island of the Ellice Group we made was Nurakita; it is a low flat island with a high beach (Pl. 129, fig. 1), somewhat triangular in shape (Pl. 212, fig. 8), about a mile long and one half to three fourths of a mile wide. The high beach is topped by a wide belt of low bushes, beyond which cocoanut trees and other forest trees stand out. The island is surrounded by a broad reef flat forming a fringing reef.
1 A. Charts $766,987,2983$.
2 Ibid., 2983.
3 Ibid., 766, 987. 
The southern face of Nurakita is covered with large blocks of beach rock, alternating with steep coral sand and coral shingle beaches. The beaches have been driven inland, running in as long fingers between the low scrub vegetation which borders the summit of the beach and even extending as far as the trunks of the cocoanut trees which grow on the inner face of the onter belt of bushes. On the southwest side we noticed a few very large boulders of beach rock and one or two blocks resembling old coralliferous limestone, but in general the boulders were composed of beach rock.

The approaches to the island are rather shallow; a mile off we could readily see bottom, and detect extensive patches of corals scattered between stretches of coral sand at a depth of from sixteen to eighteen fathoms. A wide flat extends around the island; the only channels which make land. ing possible occur between masses of beach rock on the outer edge of the beach. A sort of secondary fringing barrier reef is found on the north point where a small platform of shingle has been thrown up on the outer edge of the reef flat, which must be from 150 to 200 feet distant from the beach.

On the south point a similar lagoon has been formed on the reef flat platform, the outer rounded rim of which is edged by masses of Pocillipores and of Nullipores, from two to three feet above low-water mark. The edge of the outer rim is deeply gouged, and forms small channels in which access can be had to the reef platform at low water. Both on the east and on the north side, the beach is steep, is at least eight to nine feet high, covered with coarse coral shingle extending to the edge of the outer belt of bushes. The interior of the island forms a shallow dish surrounded by high steep beaches which have been thrown up on the outer periphery of the island. The island has no lagoon.

We did not visit Nukulailai $;^{1}$ judging from the chart, it presents no characteristics different from those of Nukufetau or Funafuti, both of which we examined. 


\section{Funafuti.}

Plates 129, fig. 4; 130-13\%, 221, 222 ; 224, fig. 1.

Funafuti, ${ }^{1}$ the next island of the Ellice group we visited, is about thirteen and a half miles in a north and south direction, with an extreme breadth of ten miles. As seen from the sea, it looked like one of the large Paumotu atolls ( $\mathrm{Pl}$. 222), the land rim formed by a series of narrow islands of different sizes flanked by a belt of low vegetation, inside of which grow groups of cocoanuts; on the east face of the atoll along which we were steaming ( $\mathrm{Pl} .222$ ), the islands and islets are separated by gaps of variable width. At the southern horn of Funafuti, the reef flat is covered by huge boulders and reaches of beach rock and coral breccia with coarse shingle above them. The land rim of the atoll of Funafuti is even narrower than in most of the atolls of the Paumotus (PI. 222).

The land rim of the island of Funafuti is extremely narrow, with the exception of the slight expansion which takes place back of Fongafale at the east point of the island ( $\mathrm{Pls} .222 ; 224$, fig. 1). The photographs here published (Pls. 129, fig. 4; 130, 131) show in succession the characteristic features of the eastern face of the atoll of Funafuti; first Motungie and Motuloa Island (Pl. 129, fig. 4), at the southern extremity of the atoll, next the sea face between the islands of Telele and Funafara (Pl. 130, fig. 1) showing the wide gap with an islet in the middle. The gap separating these two islands is covered with beach rock and shingle; further in towards the lagoon they are separated by a broad stretch of coral sand which fills the greater part of the shallow lagoon of the southern horn of Funafuti (Pl. 222). The extremities of the two islands extend towards the lagoon nearly at right angles to the outer reef flat (Pl. 222), and from the centre of the gap huge sand bars run towards the lagoon. A similar gap is next shown between the islands of Funafara and Lua motu (Pl. 130, fig. 2); then comes the gap between Lua motu and Mateika (Pl. 130, fig. 3).

North of the extremity of Mateika there is a break of nearly three miles in the continuity of the encircling reef, the island of Falefatu alone 
dividing the two wide ship channels on the eastern face of Funafuti, south of Funamanu (Pls. 130, fig. 4; 222). From that island the encircling reef is again continuous as far as the northern entrance to the atoll of Funafuti. By far the greater extent of that part of the narrow eastern land rim is occupied by the island of Funafuti (PIs. 131, fig. 1; 222), it forms an inverted $\mathrm{L}$, the smaller shank of which occupies the easternmost horn of the atoll (Pls. 222; 224, fig. 1). To the south of Funafuti are Funamana, Funangongo, and Fatato (Pl. 222), all separated by wide shallow gaps, while to the north of Funafuti come Tengako separated from it by a dry gap (Pl. 133, fig. 2), next Amatuku (Pl. 131, fig. 2), and Mulitefala (Pl. 131, fig. 2), the former separated by a wide gap from Tengako. Between Mulitefala and the islets to the east of the northern entrance to Funafuti (Pl. 131, fig. 4) there is a reach of reef nearly three miles in length, not quite bare at low water (Pl. 222). With the exception of Tebuka the islands on the northern and western face of the atoll are few in number and quite insignificant (Pl. 222). There are in the western face several passages (deeper gaps) between parts of the wide encircling reef on the western side of Funafuti. At nearly all the passages the reef flats extend a considerable distance into the lagoon at right angles to the reef face.

At the south point of Funafuti Island there is a gap between it and Fatato, the island to the south of it, over which the sea is breaking. with great violence. Following the eastern face of the atoll along Funafuti and Tengako Island, we come upon short stretches of coral sand beaches separated by steep coarse coral shingle beaches with cocoanuts growing to the very edge of the shingle (Pls. 132, fig. $2 ; 133$ ). The belt of bushes is narrow. Coral breccia crops out at the foot of the beach (Pls. 132, fig. 2 ; 135, fig. 2); this is flanked by the narrow reef platform where the coral breccia is in place (Pl. 136, fig. 1). The coral breccia crops out on the outer edge of the reef platform; it is covered with huge knolls of Nullipores and Pocillipores. Huge boulders of coral breccia and coral shingle in all possible stages of disintegration (Pl. 136, fig. 2) are scattered over the reef platform.

The sea must encroach more or less on the sonthern part of the eastern face of Funamanu, as we found the cocoanuts overhanging the beach, and 
many of them on the edge of the water. Pandanus appear in Funamanu; they seem to be very common to the north on all the islands of the land rim of Funafuti.

Skirting along the east coast of the island, after passing the eastern point of Funafuti Island, we came upon a narrow gap (Pl. 133, fig. 2) which separates Funafuti from Tengako, and is marked on the chart "pile of stones "; the gap is flanked on each side by extensive ridges of coral breccia (Pls. 134, fig. 2; 135, fig. 1; 136, fig. 2). The beach of the east coast of Funafuti is exceedingly steep and covered with large coarse coral rock shingle (Pl. 132, fig. 2), topped by the belt of low bushes so characteristic of the coral islands of the southern Pacific. On the lagoon side of the belt grow cocoanut trees. Pandanus and other typical atoll trees are found in great abundance.

The reef platform is quite narrow (Pls. 132, fig. 2; 135, fig. 2; 136, fig. 1), and the coral breccia which covers it has in a great many instances, been worn and cut so as to form a shallow sink between the outer raised edge of the reef platform and the base of the shingle beach (Pls. 132, fig. 2; 135, fig. 2). The remnants of this breccia, which once rose to a greater height than it does at present, occur as buttresses, running at right angles to the base of the beach, near its foot, to a height of from two to five feet (Pls. 135, fig. 2; 136, fig. 1). The base of the buttresses is separated by ridges of coral shingle (Pl. 132, fig. 2), or in some cases by coarse coral sand. The outer edge of the reef flat rises from two to three feet above the level of the inner part of the flat, and thus forms along the east coast of Funafuti Island a number of extensive pools varying in depth, according to the depth of the gaps of the outer edge through which the sea may have access to them. As we opened out the northeast passage into the atoll of Funafuti (Pl. 131, fig. 4), we could see in the distance the sand bar and island which flank the north side of the passage; from its southern extremity extends a bar of shingle more or less marked.

Turning into the northeast passage, we see in the distance the small islands, islets and sand bars on the northern and northwestern side of the atoll (Pl. 222). Some of these islets are tufted with cocoanut trees, others are bare, and others are thickly covered with a belt of low bushes and tall 
cocoanut trees. The sea faces of these islands are flanked with lines of breccia separated by coral shingle beaches. A long line of breakers indicates the position of the outer edge of the reef platform upon which these islands are all situated. On the lagoon side of the islands the beaches are covered with coral and coralline sand (Pl. 132, fig. 1), and only here and there a small border of coral breccia is seen.

The small sand key of Te Afualiku (Pl. 131, fig. 4) at the northeast entrance of Funafuti atoll has a steep sand beach flanked at the base with breccia and coral shingle; it is topped with five low cocoanut trees. Steaming in slowly through the northeastern entrance, we could see, on the bottom of the passage, the masses of corals separated in the deeper part by wide patches of sand. As we were coming in, we could see in the distance on the west face, the islands of Fualopa and Tebuka, and the sand bars and reef flats to the south (Pl. 222). The lagoon faces of the island, as well as the small sand key ${ }^{1}$ in the northern part of the atoll, are flanked with steep sand beaches. Turning towards the anchorage, we steamed along off the lagoon beach of the island of Funafuti; the lagoon beach consists of a succession of sand beaches alternating with short buttresses of coral breccia, extending as far as the village of Fongafale.

With our pilot as a guide, we examined the position of the second bore hole drilled under the direction of Professor David. It is situated in a sink west of the weather beach in the midst of a coral breccia. At that point the outer rim of the reef platform consists of knolls of Pocillipores and of Nullipores rising to a height of from two to three feet above the general level of the reef flat extending between it and the base of the beach (Pls. 132, fig. $2 ; 135$, fig. $2 ; 136$, fig. 1 ). The reef flat varies from forty to fifty yards in width. The outer edge is deeply gouged with passages cut by the action of the sea, or where the sea has broken through the elevated rim of the platform. The flat between the outer rim and the base of the beach consists of coral breccia, planed down to the level of low-water mark or even below it; it is slightly dished, so as to form a very shallow lagoon at low water, flanked by an incipient barrier reef, as it were, formed by the

1 While there are many shoals and submerged patches in the lagoon of Funafuti, Te akau Tuluaga (Pl, 222) is the only dry patch in the interior of the lagoon. 
constantly growing Nullipores of the outer rim. Towards the base of the coral shingle beach, occasional buttresses of coral breccia rise to a height of two to three feet or more, outliers showing the former height of the elevated reef platform. The beach itself is formed of fragments of coral breccia and of recent corals, thrown up on the steep slope of the beach to a height of eight to ten feet above high-water mark, or left as outliers of the disintegration of a former higher reef platform. This coral shingle forms a dam from twenty to seventy feet in width (Pls. 132, fig. 2; 135, fig. 2), on

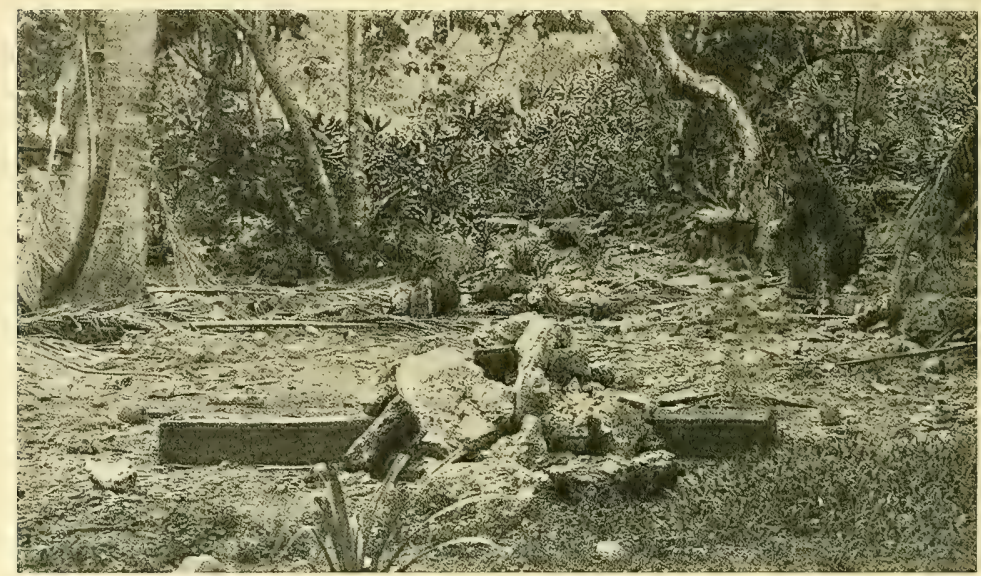

Postition of the Bore, Funafuti.

the top of which grows the narrow belt of low vegetation which flanks the cocoanut trees growing towards the lagoon. The inner slope towards the lagoon is much less steep than the outer slope, it is formed of similar fragments of coral and of breccia, only of a less size, though occasionally huge boulders have been thrown inland by hurricanes over the upper edge of the shingle dam, or are outliers of the older buttresses.

The lagoon beach only rises three to four feet above high-water mark; it consists almost entirely of comminuted coralline foraminiferal sand with little admixture of coral sand which has been laid down on a steep slope towards the lagoon (Pl. 132, fig. 1). The coral breccia seen on the outer 
slope of the sea face seems to extend to a considerable depth, judging from the buttresses exposed on the reef flat. The coral breccia is made up of rolled recent coral shingle, of pieces of coral, of shells, of sand, quite unlike any breccia we have seen before, and partly changed into a hard ringing limestone. Here and there I thought I could detect fragments of the old limestone ledge; of this I am not positive, it being very difficult in some cases to detect the difference between the old ledge and the highly calcified recent breccia, we were unable to find any outcrop of this old coralliferous limestone at any point in Funafuti. The reef flat has been gonged from the coral breccia exactly as has the old reef rock ledge in the Paumotus. It supplies the materials for the building up of the island, of the sand and of the shingle beaches, both on the lagoon and on the sea face.

On the sea face, to the south of the bore, extends a high narrow shingle beach which shuts off a small lagoon to the west (Pls. 222; 224, fig. 1). This lagoon, called Taiisale, forms an isolated pear-shaped pond in which the tide rises and falls (PI. 137). The inner edge is lined by mangroves (Pl. 137, figs. 1, 2); a fine section of the coral breccia, which characterizes the outer sea dam, can be seen on the western face of the lagoon (Pl. 137, fig. 3). The narrow high beach thrown up across the eastern point of Funafuti has shut off this pond from the sea; huge blocks of shingle of beach rock and of coral breccia have been thrown up on the upper part of the outer dam. According to the testimony of the natives, no water passes over this dam; but the dam itself must be of rather hollow construction, and the floor of the sink must be full of cavities to allow the existing free inflow and outflow of the sea. There is a narrow fringe of pisonias growing on the summit of this bank.

The gap between Telele and Funafara Island ${ }^{1}$ (Pl. 222) shows a stage in the formation of such a sink as the lagoon of Taiisale (Pl. 224, fig. 1), previous to the junction of the inner wings of the extremities of the islands, and previous to the throwing up of the coral shingle dam shutting off the bay forming the gap open to the sea. We shall have occasion to describe the shutting off of similar bays on the sea face of some of the Gilbert and Marshall Islands, and their change into closed ponds or sinks. 
The Heliopora reef, described by Sollas as occupying the floor of Taiisale, ${ }^{1}$ exists under conditions very similar to those of extensive Porites and Millepora reefs, which I shall have occasion to refer to in my description of some of the Gilbert and Marshall Islands, more especially when giving an account of the Millepora and Porites reefs of Taritari.

The surface rock of the land rim of Funafuti consists of innumerable small fragments of coral and of coral breccia, more or less decomposed into soil. On the lagoon side, on the north end of the island of Funafuti, nothing but reaches of coral breccia, more or less disintegrated, could be seen, with short stretches of coral sand beaches separating them. South of the monument of Funafuti there is an extensive dry sink in the centre of the island. This is the southern extension of the same sink which one crosses going from the village to the bore.

Dr. Mayer examined the coral breccia, the beach rock, and the conglomerate existing towards the southern point of Funafuti Island, where a line of low coral breccia cliffs and an extensive coral sand beach terminates to the south against steep buttresses, and alternates with ridges of coral breccia. He found on the lagoon side a conglomerate composed of rounded water-worn masses of hard crystalline limestone, cemented together with fragments of shell and of sand. This rock extends only about one foot above high-water level, and to the eastward or inland, back of the beach, one finds a mass of coral heads, and more or less rounded masses of a somewhat crystalline structure. These masses and fragments of coral rock or shingle are not cemented together, but plainly show that they are derived from the disintegration of the adjoining crystalline limestone masses of coral conglomerate, of which only a few outliers are left intact. As at other points of Funafuti, these outliers of beach rock, of coral breccia and conglomerate are, on the lagoon side, separated by long stretches of fine coral sand beaches, while on the sea face of the southern part of the island, as elsewhere in Funafuti, we found but little coral sand, the steep beach being composed almost entirely of broken fragments of crystalline limestone, many of them water-worn and rounded as on the lagoon side, but most of them are large masses of jagged rock, evidently thrown up by unusually powerful

1 Page 510, fig., Proe. R. S., February, 1897. 
waves, or fragments of outliers of old buttresses or of a higher older reef platform. These various kinds of fragments, found either on the lagoon side or on the outer beach, form what is called the coral breccia or conglomerate of the seaward side (Pls. 132, fig. 2 ; 133, fig. 2 ; 134, fig. $2 ; 135$, 136). There its composition can be more easily studied than on the lagoon side, where its extension has been overwhelmed in so many places by the fine sand thrown up on the inner beaches by the waves of the lagoou. On all the islands with rock exposures, we came upon the hammer marks of Messrs. Sollas and David. The low gap to the north of the village of Fongafale is perhaps 60 to 75 feet wide; it has been formed across the lagoon shingle beach; coarse coral sand is found in the middle of the land rim, and breccia and conglomerate boulders are found on the sea face.

We examined the northern end of the island of Amatuku at a point where the cliffs are marked on the chart as "five feet high" (Pl. 133, fig. 1); they consist of elevated conglomerate or breccia dipping towards the lagoon. This gives us the key of the origin of the mass of material which lines the beaches, the lagoon, the sea faces, and the summit of the land rim, all of which has been so much disintegrated and decomposed that where no outcrop is visible it is difficult to understand whence the mass of material which composes the island, the sea faces, the sea beaches, and the land rim itself has been derived (Pls. 134; 135, fig. 1; 136, fig. 2). The shallows and the banks within the lagoon are merely remnants of the great stretch of coral conglomerate or breccia which once must have covered, at a greater elevation, nearly the whole area of the atoll of Funafuti. An extraordinary mass of coarse broken coral shingle conglomerate and breccia forms the northern point of Tengako (Pls. 135, fig. 1; 136, fig. 2); it is flanked by sand bars on the lagoon side, running at right angles to the line of the low land rim.

A section across the southern part of Funafuti does not differ from that across the east point, back of Fongafale, and which is typical for the whole island, only according to the width of the island, the sink between the outer beach and the lagoon beach is more or less wide, and the dam on the lagoon side is often a broad, white flat ridge supporting a luxuriant growth of cocoanut trees and pisonias. The seaward ridge may be wide or narrow; 
it is composed of loose coral shingle or of beach rock or coral breccia or conglomerate, the surface of which has been weathered and pitted and honeycombed. In addition huge boulders are scattered upon its face, and a mass of finer coral shingle, more or less disintegrated, has been deposited on the inland slope between the base of the cocoanut trees. The sink between the lagoon and outer ridges is evidently flooded during the rainy season, and is left bare during the dry season. The bottom of the sink is covered with loose blocks and small pieces of coral rock similar to those of the sea beach, while in other places it is composed of coralliferous mud, which has evidently been washed down from the side dams during the rainy season.

On the eastern sea face of the island of Funafuti, we saw everywhere evidences of an elevation varying from eighteen inches to three or four feet, judging from the position of the buttresses of beach rock and conglomerate which characterized that side of the island.

Elevated coral breccia or conglomerate, such as is found at Funafuti, also occurs in many of the Paumotus, where it has been elevated simultaneously with the old tertiary coralliferous reef rock. At other points the old reef rock is not visible, having been overwhelmed with the mass of beach rock or coral breccia and conglomerate which has been formed between the outliers of the old tertiary reef rock. On the east face of Amatuku (Pl. 134) the elevated conglomerate and breccia rock is well seen; it extends as a flat on the sea face of the island about two feet above high-water mark; it is pitted and honeycombed and greatly eroded. The lowest point reached by erosion shows no trace of the old ledge, but fragments of it form a part of the conglomerate and coral breccia rock. We have, however, been unable to satisfy ourselves of its origin. Huge beach rock or breccia or conglomerate slabs connect the northerm part of Tengako (Pl. 135, fig. 1) and the island of Amatuku as well as the little sand islet on the lagoon side of the breccia exposures. Making up the conglomerate and breccia, were fragments of worn corals united together in a sort of puddingstone. The spaces between them were filled in with smaller material like amyggdules. Sometimes this puddingstone was exceedingly hard, at others quite soft and friable, or, again, it was calcified and rang to the hammer like fragments of the old 
coralliferous limestone rocks. The northern extension of Tengako ( $\mathrm{Pl}$. 135, fig. 1) is a long sand spit reaching out towards Amatuku.

Some of our photographs show well the method of cutting the elevated beach breccia and conglomerate along the east face of Funafuti into buttresses (Pls. 135, fig. 2; 136, fig. 1) and to the level of the reef platform (Pl. 132, fig. 2), from the time that it was elevated, four to five or perhaps even six feet, above low-water mark (Pls. 135, fig. 2 ; 136, fig. 1).

A similar process has gone on on the lagoon side, but at a very inferior rate, as is shown by the character of the material derived from the disintegration on the sea face of the breccia or beach rock into very coarse shingle or even slabs, and on the lagoon side into coral sand of varying fineness. Over the central part of the land rim more or less fertile land has been formed from the decomposition of the coral rock. Crossing the centre of the island to the east of the village, we came upon a magnificent isolated mass of beach rock conglomerate, showing plainly the extent to which denudation of the former land rim has taken place on Funafuti, after the slight elevation to which it had been subjected. It also showed that the position of the outer beach must at one time have been close to that now occupied by the present lagoon beach at the northern extremity of Funafuti Island (Pl. 133, fig. 2). At several points in Funafuti, north of the village, beyond the end of the sand beach, the island shows traces of once having been covered by a continuous mass of beach rock conglomerate or of its outliers, and of boulders thrown up by the sea which filled the space between the breccia buttresses, as at the point marked on the admiralty chart " Pile of stones."

We had no extremely low tides while at Funafuti, and therefore could obtain only indifferent access to the outer part of the reef platform; while we could see that the coral breccia and conglomerate of the reef platform were cut into spires and buttresses and knolls, and that its outer edge was bordered with knolls of Nullipores and Pocillipores, yet the heavy swell prevailing during our visit prevented us from examining in detail the outer edge of the reef flat or of examining the slope to the seaward on which corals were growing.

Pava and Fualifeke, two islands to the northeast of the northern pass (Pl. 222), are connected by sand bars and by ledges of beach rock con- 
glomerate. They both stand on a comparatively wide platform, with a narrow land rim towards the sea and towards the lagoon a wide flat, sinking in a comparatively steep slope into the general level of the deepest part of the lagoon itself.

On the western face of the atoll, on the island of Tebuka, the beach rock conglomerate ledge is limited to a small part of the northwest side, where it is found on the very summit of the island, and there is no coarse shingle on that side. This is probably due to the fact that Tebuka is situated to the westward of the line of action of the strong trade rollers which beat incessantly on the eastern reef platform of the atoll of Funafuti, and lose much of their force northward as the curve of the atoll gradually trends to the westward.

The channels on the west side of the atoll, like the passages into the Paumotus in similar positions, are narrow and deep, and are cut through the wide western platform on which but few islands or islets are seen. South of Tebuka there is only Tebuka vili vili and Fualopa, north of the western horn of the atoll, and to the south a couple of small islands to the north of the chain of islands forming the western face of the southern horn of Funafuti atoll. Fuafatu is capped with a belt of low bushes protecting a few cocoanut trees growing on the eastern side of the island.

The flats and points on the west side of the atoll indicate the former greater extension of the land rim which has little by little been cut down to its present dimensions by the incessant action of the sea, of the trades, and of the weathering due to atmospheric agencies. On the shoals which extend between our anchorage and the shore, we found magnificent patches of Madrepores, large heads of Porites, patches of Alcyonarians, of Millepores, and of Pocillipores, as well as blocks of Pavonia and masses of Astreans. The same corals we also found on other shoals in the lagoon. Great patches of coral flourish on the slope of the lagoon, as well as on the knolls, shoals and elevated ledges throughout the lagoon of Funafuti (Pl. 222). The corals on the slopes of the knolls flourish especially well when situated near or opposite gaps connecting the lagoons directly with the sea. In the lagoon calcareous Algæ take a great development in eighteen to twenty fathoms, immense masses of them extend from that depth towards the shore into three or four fathoms. 
The bottom of the lagoon at our anchorage in Funafuti consisted of fine coral sand and limestone mud, cementing more or less loosely the larger fragments of corals and of shells, which form a very characteristic plaster over the whole bottom of the lagoon wherever we had the opportunity to examine it.

During our stay at Funafuti we recorded the warmest water we observed during any part of our trip. At noon on the first day of our arrival, the temperature of the water at the bottom of the lagoon, at fifteen fathoms, was $88^{\circ}$ and of the air $92^{\circ}$. The next day the temperature of the water varied between $86^{\circ}$ and $87^{\circ}$, and at 2 P. M. the day after, the temperature of the water in the lagoon was $89^{\circ}$, while the air was $94^{\circ}$. The temperature of the air on the following Sunday had increased to $104^{\circ}$ and that of the water remained at $89^{\circ}$ during the day.

"In $1896^{1}$ Funafuti was selected by a committee of the Royal Society as being a typical atoll in which to make deep borings, for the purpose of throwing light upon the geological formation of atolls in general. Attempts were accordingly made, both on the lagoon side, at about a quarter of a mile to the southwestward of the Mission House, and also on the edge of the beach on the seaward side, at about one mile from the western end of the island; in both cases the borings had to be abandoned, at depths of 100 and 70 feet respectively, on account of the sand and boulders that were met with, and the nature of the formation."

In 1897, however, the attempt was resumed by the New South Wales government, and a depth of 1114 feet was reached (A. Chart 2983, and Pls. 222 ; 224, fig. 1).

A bore was also driven into the bed of the lagoon from the deck of H. M. S. "Porpoise" (Captain Sturdee); it reached a depth of 144 feet in the bed rock of the lagoon, or in all 245 feet below sea level. ${ }^{2}$ It passed throngh an upper layer of sand composed mainly of calcareous organisms. Broken pieces of coral became more common in descending, and at the greatest depth attained progress was stopped by hard coral rock, at a depth but little greater than that of the lagoon of many Pacific atolls. The core was placed for examination in the hands of Professor J. W. Judd.

1 Hydrographic Notice, No. 7, for 1897.

2 T. G. Bonney in "Nature," November 11, 1898. 
Several accounts regarding the structure of Funafuti have been published by Hedley, ${ }^{1}$ Sollas, ${ }^{2}$ Gardiner, ${ }^{3}$ David, ${ }^{4}$ and Bonney, ${ }^{5}$ as well as a popular description of the atoll by Mrs. David. ${ }^{6}$

Professor Sollas and Mr. Hedley called attention to the evidence of a slight elevation in Funafuti from the existence of Porites and of Heliopora at a level where they could only have been reached by high tides. It does not seem to me as if the mangrove swamp originated in the mamner described by Hedley. ${ }^{7}$ I am inclined to refer its formation to the closing of a bay which probably existed east of Fongafale, much as the gap between Telele and Funafana at the southern point of the atoll of Funafuti is closing (Pl. 222). This mode of formation of sinks, by the closing of bays, is quite common throughout the atolls of the Pacific, and many instances will be found described throughout this Report.

I agree with Gardiner that the term "hurricane beach" is not an appropriate one; many of the large coral masses which have all the appearance of having been thrown up by the sea are fragments of elevated reef rock outliers; the successive more or less concentric ridges of sand and shingle which form the land rim are not necessarily due to individual hurricanes; their height and width depend in great part on their distance from the outer edge of the reef flat, and on the amount of sand and shingle available at special points for their gradual formation and increase.

Mr. Hedley gives an excellent account of Funafuti Island and of one of the leeward islands. He considers the lagoon to be filling up; it certainly is receiving material to some extent near the passes and along the lagoon shore of the land rim; but so large a lagoon as that of Funafuti is, as he

${ }^{1}$ General Account of the Atoll of Funafuti, by C. Hedley, Australian Museum, Sidney, Mem. III., 1896.

${ }^{2}$ Report to the Committee of the Royal Society Appointed to investigate the Structure of a Coral Reef by Boring, by J. W. Sollas, Proc. R. S., February, 1897, Also in "Funafuti": The Study of a Coral Atoll, Natural Science, January, 1899.

3 The Coral Reefs of Funafuti, Rotuma, and Fiji, by J. Stanley Gardiner, Proc. Camb. Phil. Soc, IX. Pt. VIII., March, 1898.

4 Summary of Professor Edgeworth David's Preliminary Report on the Results of the Borings in the Atoll of Funafuti, Proc. R. S., December, 1897.

${ }^{5}$ Recent Coral Boring Operations at Funafuti, Nature, November 3, 1898.

${ }^{6}$ Funafuti, by Mrs. Edgeworth David, London, 1899. With a note on the Results of the Borings at Funafuti, Ellice Group, by Professor T. G. Bonney.

? Loc, cit., p. 11. 
says, only very slightly affected by the agencies at work, "which must take long to make a perceptible advance in so huge a task."

Mr. Hedley has called attention to the shallow passages which interrupt the thread of the land rim, but not of the reef rim upon which the islets are placed. These passages I have called "gaps," they are a feature which occurs in all the Pacific atolls, but the gaps vary in depth from dry depressions above high-water mark to flats bare at low water, to cuts through the reef platform with variable depth, forming merely boat passages, or to openings of somewhat greater depths passing into ship passages.

The slope of the bottom on the lagoon face of the passages is stated by Hedley to extend into it fan-shaped. This is not universally the case, the shape of the extension, as I have shown in other atolls, depending upon the width of the shallow passages, their depth, the character of the bottom, and their exposure to the prevailing winds, all of which are essential factors in determining the resultant action.

Mr. Hedley has given a list of the plants of the Ellice group, ${ }^{1}$ with interesting remarks on their uses by the natives. He compares the flora of the western atolls of the Pacific to that of the eastern islands, and finds the number of species repeated from atoll to atoll increases as we go westward.

In the summary of his observations, Mr. Hedley states that Darwin's theory is favored as against Murray's by the fact that the atoll is planted on a cone, that it is girdled by a precipitous submarine cliff, and that the lagoon is filling up; whereas Murray demands its excavation. Similar statements are made by Professor Sollas; they are mere repetitions of former arguments. In spite of the fact that a lagoon may be filling up at a certain stage of its development, that does not prevent solution from being an effective agent in carrying off material from the lagoon of an atoll. Nor is the existence of a precipitous submarine cliff explicable only on the theory of subsidence. There certainly are a sufficient number of such cliffs found in areas of elevation, in no way dependent upon subsidence for their formation.

The reports of Bonney and of David refer to the progress made in the boring at Funafuti. 
Mr. J. Stanley Gardiner has given an excellent account of the general features of Funafuti, somewhat more in detail than Hedley. The brackish pools of Funafuti he compares to the "Barachois" of Diego Garcia, ${ }^{1}$ described by Bourne.. 'They seem to me to be similar in their structure with the "bays" and sinks so frequently met with in the Ellice, Gilbert, Marshall and Maldive Islands, and to owe their origin to the same causes.

Gardiner noticed that some of the slabs thrown up on the slope and reef flat were consolidated to the rock below them. He gives an excellent description and figures ${ }^{3}$ of the outer rim of the reef flat with its fissures and tongue-like indentations, more or less arched over by the growth of Nullipores across the openings, leading to the formation of blow-holes. ${ }^{4}$ Like Sollas, he has noticed that on the lagoon side the beach sand is not composed of coral sand, but that its principal constituents consist of fragments of calcareous Algæ and Foraminifera.

Gardiner lays great stress, and justly, on the existence of great buttresses running at right angles to the land rim, which once formed part of a higher land, the greater part of which has been washed away or dissolved. Gardiner speaks of the great width of the leeward reef of Funafuti (Pl. 222). He states that with the exception of the shoals, which come nearly to the surface and are indicated by the breaking of the sea, there are no shoals now forming by corals which would eventually grow to the surface. Yet the Admiralty Chart of Funafuti ${ }^{5}$ atoll indicates several patches rising to a considerable height above the floor of the lagoon. Among them I may mention that there are more than ten knolls rising to 20 fathoms from the surrounding depth of 23 to 24 fathoms, a number to 19 fathoms, three to 18 , two to 16 , two to 15 , one to 14 , one each to 10 and 11 , one to 7 , four to 4 , two to 3 , and four to $2 \frac{1}{2}$ fathoms. These patches constitute a large percentage of the shoals which have nearly reached the surface and on which the sea breaks.

I have already, on several occasions, called attention to the narrow bathy-

1 A. Chart 920.

2 Proc. R. S., XLIII. p. 440 (1888).

3 Loc. cit., Funafuti, p. 433.

4 Gardiner says he never found boulders torn off from the Nullipore rim on the reef flat. This has not been my experience either in the Gilbert or Marshall Islands.

6 A. Chart 2983. 
metrical range of corals in the interior of lagoons. Gardiner noticed that corals grow in abundance on the slopes and summits of shallow shoals, but were not found on the bottom of the lagoon. It is natural to suppose that the silt from the shores of the lagoon and from the shoals should settle on the bottom of the lagoon of Funafuti, so that corals would not grow there, and that nothing but corallines or Nullipores would flourish in the midst of that waste. He could find no signs that the lagoon was filling up at any appreciable rate. He found, as I did, a hard bottom on the floor at many points in the lagoon. Gardiner insists justly on the prominent part taken by Nullipores and corallines in building up the thickness of a coral reef, or its base, or in extending the rim of the reef seaward.

The difference in the width of the outer reef platform of different atolls may be due to the gradual piling up on the sea face of successive rows of shingle and sand beaches. Where this has taken place regularly, an original wide sea face reef flat may gradually become reduced to a narrow belt. ${ }^{1}$ Well-marked cases of such narrow reef flats are found in the Marshall and in the Gilbert Islands, and the land growth lagoonward from similar causes is also well seen in islands of the same groups. That the outer rim where coral reefs grow expands seaward, is seen on the slope of the fringing reef off Papieté, Tahiti (Pl. 209), as well as along all the sea faces of islands where the slope is not too steep to allow the formation of a talus made up of the dead material which has become loosened from the living part of the coral slopes.

Professor Sollas, in an address before the British Association for the Advancement of Science, delivered at Bristol, gave an account of Funafuti. He does not seem to have been aware that several attempts were made to study coral reefs by boring before the middle of the last century, ${ }^{2}$ by Wilkes, Belcher, and Beechey. Professor Sollas states that an atoll like Funafuti belongs to a family of atolls of unexceptional character, and that the atolls of the Gilbert and Marshall Islands belong to a system all of them excellent atolls. I would refer Professor Sollas to the Hydrographic p. 174.

I See also the notes of Hedley on the broadening of atoll islets, Natural Science, March, 1898,

2 See Bull. MI. C. Z., XXXIII. p. 46 (1899). 
Charts of these groups; they will show more kinds "of excellent atolls" in these groups than he gives them credit for.

Without entering into a discussion of the permanence of the Pacific Ocean, we need only state that the components of the great groups of atolls in the Pacific are generally separated by deep water, and that to bring up the bulk of the coral islands to the surface would be merely increasing slightly the size of the atoll or island as it exists at present, and would in no way present a very considerable tract of land in the very middle of the Pacific Ocean, unless we bring up the bottom of the Pacific with it to a height of more than 2000 fathoms. We may even be justified if, in questions relating to the distribution of land in former ages, we are not carried away by speculations which have no more stable foundation than the ingenious sketching of continents over areas varying in depth

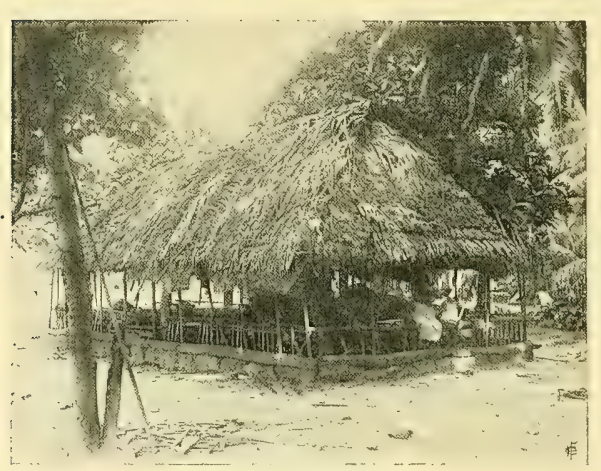

Native Hut, Funafuti. from 2000 to 3000 fathoms.

The statements of Professor Sollas that the "table mountain" of Chamisso which covers the summit of Funafuti, is of a similar nature from base to summit, and that "all this is coral reef," is somewhat premature; its nature and structure will be better understood when we can speculate upon the data supplied by the final examination of the core

now in the hands of Professor J. W. Judd. The results obtained thus far from an examination of the elevated coralliferous limestones of Christmas Island ${ }^{1}$ and of Mango ${ }^{2}$ lead to very different conclusions from those expected by. Professor Sollas.

No one has, to my knowledge, called attention to the fact that the sound-

1 A Monograph of Christmas Island, by Charles W. Andrews, Brit. MIus., 1900.

${ }^{2}$ Notes on the Limestones and General Geology of the Fiji Islands, by E. C. Andrews, Bull. M. C. Z., XXXVIII. No. 1, 1900. 
ings taken off any of the coral reefs do not indicate the existence of terraces. Surely, if there has been a general subsidence at all corresponding to the general elevation which exists in the Paumotus, the Tongas, the Fijis, the Ellice, Niue, the Cook and Ladrone Islands, the successive steps of which are indicated by well-marked terraces, we should find in the so-called great areas of subsidence traces of the subsidence, if it has, like the elevation, taken place intermittently. Even at Funafuti, where the sections off the atoll are more numerous and more detailed than those off any other coral reef, no such terraces have been developed.

\section{Nukufetau.}

Plates 129, figs. 2, 3; 212, fig. 6; 221.

Nukufetau $^{1}$ is somewhat triangular in outline (Pl. 212, fig. 6), and resembles to a certain extent Funafuti. Its main entrance is on the west side, and there are no passages on the other faces of the atoll. Nukufetau is about twenty-seven miles in circuit. The largest island is on the southern point (PI. 129, fig. 2); the east face of the atoll is flanked by numerous islets and sand banks, separated by gaps similar to those we have described before (Pl. 129, fig. 3).

Nukufetau, as seen from the sea, is flanked with heavy masses of beach rock alternating with reaches of sand beaches, usually topped with black coral shingle. The general appearance of the beach, as seen from the sea, reminds one of that of Funafuti, but the ledges are more marked and better characterized as buttresses, and show, as at Funafuti, traces of a slight elevation. As far as we could see while steaming around the island, the beaches, reefs, and land rim of Nukufetau did not differ in any way from those of Funafuti. The vegetation of Nukufetau was, however, richer than that we noticed on any of the islands of Funafuti. In addition to Pisonias and to cocoanut trees, large hardwood trees grew in numbers in the rear of some of the beaches.

In addition to the gaps between the islands of the land rim, the islands were often separated by long ridges of beach rock constituting a more or 
less imperfect division wall between the sea face and the lagoons. The gaps between the buttresses of beach rock gave the sea face of Nukufetau a very characteristic aspect. Immediately behind the belt of beach rock, small islands or islets of sand and sand bars extend at right angles to the general line of the shore, and form walls of sand; these may little by little become connected, and finally close up the gap, as we have seen it take place in the Paumotus, and thus form connecting islands closing that part of the land rim and preventing the sea from having access to the lagoon. Some of the reef platform sand bars extending towards the lagoon at right angles to the outer islands are of considerable length. The reef platform of Nukufetau is very similar to that of Funafuti, growing knolls of Nullipores and Pocillipores forming its outer raised edge.

On the north end of the east face of Nukufetan are indications of former gans now nearly closed; they are apparent from the aspect of the different parts of the outer shingle beach, - it is quite white and fresh towards the gap, while immediately behind it, or rather on its northern side, the shingle is dark and weathered. On the chart only seven gaps are indicated; we noticed nine. I would call attention to the remarkable position of ten of the small islands, which follow in rapid succession, and flank the gaps from the point marked $\mathrm{A}$ on the chart (Pl. 212, fig. 6).

On the lagoon side of Nukufetau the shore is a succession of short sand reaches of fine coral sand, with here and there a low stretch of beach rock. The islands of the land rim all have on their steep sea faces more or less extensive tracts of black shingle above the beach rock; owing to the narrowness of the outer land rim, the shingle often extends inland far enough to connect with the fine sand of the lagoon beaches. The depth of the lagoon of Nukufetau is said to vary between sixteen and twenty fathoms.

From Nukufetau we made for Niutao, ${ }^{1}$ a nearly round island, about one and a fourth miles in diameter, surrounded by a narrow fringing reef. It has a small shallow lagoon, nothing but a brackish water sink. The island of Niutao represents a stage in which an incipient sink has been formed in the central part of the island. The sink of Niutao is probably 
merely a remnant of the open area, now nearly filled up, once existing between the high beaches thrown up on all sides of the original reef platform. Other islands, like Nurakita ${ }^{1}$ and Nanomana, ${ }^{2}$ are merely small coral reef flats on the summits of which reef material has been heaped up, while in the case of Niutao the central space has been left partially undisturbed. Unable to land, owing to bad weather, we continued our way to Arorai.

1 A. Chart 766 .

2 Ibid. 


\section{THE GILBERT ISLANDS.}

Plates 138-160, 223 ; 224, figs. 2-6; 226, figs. 1-3.

ThE Gilbert Islands (Pl. 223) follow much the same trend as the Ellice Islands. They extend from Arorai to Taritari, about three degrees of latitude on both sides of the equator.

Three of the southern islands, Arorai, Tamana, and Nukunau are low flat islands, and have no lagoons. Peru is a long, low flat island (Pl. 226, fig. 3), flanked by a narrow lagoon on the western side. Several of the larger atolls of the group, Onoatoa, Tapeteuea, Maiana, Tarawa, and Taritari, are noted for their open western faces, the western reef flats being more or less submerged. In others, on the contrary, like Maraki and Aranuka, the lagoons are nearly shut off from the sea, while such atolls as Apamama and Apaiang remind us of similar atolls in the Paumotus.

The soundings we took between the various islands of the Gilbert group indicate the absence of a connecting plateau; they are a series of isolated peaks and ridges, separated by deep water, rising from very considerable depths, as will be seen by examining our lines of soundings, Stations 196208 (Pl. 223). ${ }^{1} \quad$ We obtained 2221 fathoms between Apamama and Maiana, 1569 south of Tarawa, 2156 between Apaiang and Maraki, and 2255 fathoms between Maraki and Taritari. The soundings also indicate that Apaiang, Tarawa, and Maiana are the summits of a plateau with a depth of less than 500 fathoms, rising from great depths north and south of it (Pl. 223).

Our observations in the Gilbert and the Ellice Islands indicate that in those districts where it is impossible or difficult to observe the structure of the underlying platform, the coral reef question limits itself to the study of the cutting down of the reef platform and of the land rim, of the movements of the mass of material which rests upon the underlying platform, whatever be its nature, the material being supplied by the growth and decay of the corals, of the Nullipores and animals living upon the reefs, either of the sea face or of the lagoon, and to following the endless combinations resulting from the nature of the outer reef platform, and the 
local phenomena due to the shape of the land, the tides, and winds. In a region where the trades blow with regularity, the rehandling and moving of all this material is due to the action of the prevailing wind; the extent and character of this depend almost entirely upon the position of the land with reference to its direction. Where the northeast trade winds strike the islands at a sharp angle, the effect of the swell will be to follow the coast and haul around the two sides of the atoll. Should the atoll be wide and long, the effect of the prevailing trades will be felt, not only on the weather, but also on the lee side, inside of the lagoon. Considerable material will also be handled and rehandled on the lagoon side of either face, according to the strength of the sea, the direction of the winds, and the length and breadth of the lagoon. If, on the contrary, the trade winds should strike an island nearly at right angles to its weather face, then a very decided lee is formed, even in the case of comparatively small islands. In such a case the material is moved almost entirely on the weather side, and the effect of the sea and wind on the lagoon shores of the outer land rim is reduced to a minimum. During the changes of the trades exactly the opposite will take place; but the winds then prevailing will act only during a short time compared with that during which the long season of the trades is effective.

To the west of the central part of the Gilbert Islands are situated Paanopa and Nauru (Pl. 234), isolated peaks of coralliferous limestone elevated to a height of more than 200 feet. These islands are considered as forming a part of the Gilbert group, though the most distant one, Nauru, is about 300 miles from Nonuti, the nearest island of the Gilbert chain. They are interesting, holding, as elevated islands, to the low Gilbert atolls much the same relation which the elevated islands of Makatea, of Niau, and Rangiron atoll hold to the low eroded Paumotus. They give us, if not the key, at any rate a strong hint as to the probable nature of the beds forming the substratum of the recent reef rocks of the atolls of the Gilbert group.

The sea face of Pleasant Island (Nauru) $\left(\mathrm{Pl} .160^{\mathrm{b}}\right.$ ) is not as regular as that of Ocean Island; its greatest length is three and three-fourths miles, and its width varies from two to two and three-fourths miles. The island 
is surrounded by a wide reef flat platform from 100 to 130 yards in width, cut away from the flanks of the elevated coralliferous limestone slopes of the island. The topography of the island as shown from the figure is quite irregular; there are three main lines of hills, the higher parts of which are about 220 feet high. Above high-water mark is a low platform (the first terrace?), ranging in width from 30 to over 400 yards. On this most

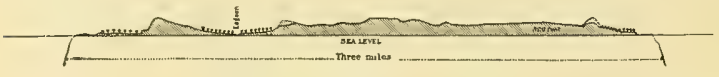

Section across Sink, S. W. to N. E.

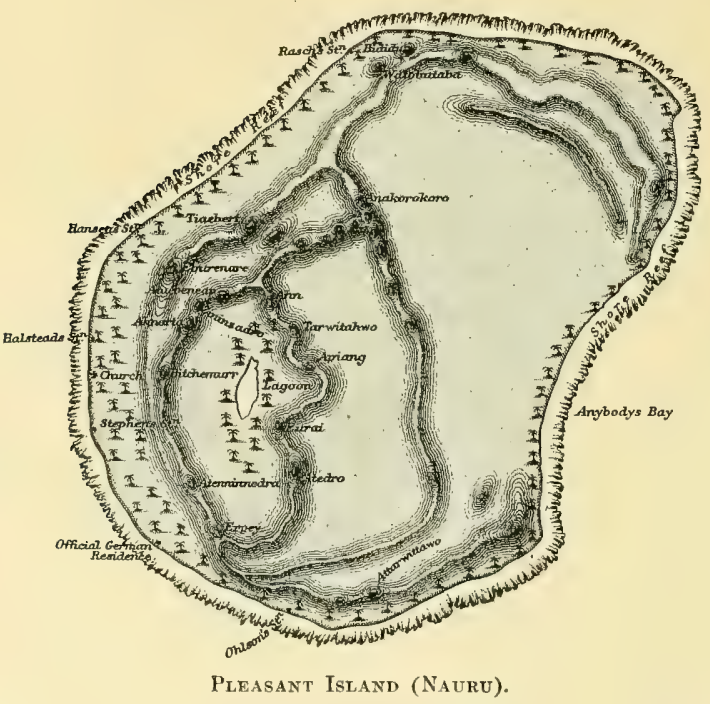

of the natives dwell. Near the southwest end of Pleasant Island is a shallow lagoon, a sink 100 by 200 yards with about 5 feet of water, enclosed by a regular rim; as is seen by the sketch map and section of the adjoining figure, numerous gaps occur between the higher parts of the rim. The above data are taken from a report by Mr. F. D. Powers to the Pacific Islands Company limited.

This island was visited by Krämer,

who gave a short account of it in Globus. ${ }^{1}$ I am indebted to Mr. Hütter for photographs of Nauru showing the massive bluffs of elevated coralliferous limestone a short distance from the shore, and to him as well as to Mr. John Arundel for specimens of the limestone, which is identical with that of similar elevated islands like Niue, Eua, Vavau, and others.

1 Globus, Vol. LXXIV. No. 10, September, 1898. 
Ocean Island (Paanopa) is also an elevated coralliferous limestone island, rectangular in shape, about six miles in circuit; it has the same structure as Pleasant Island; its highest points are from 260 to 270 feet.

Ocean Island ( $\left.\mathrm{Pl} .160^{a}\right)$ is dome-shaped, somewhat flatter from east to west than in a section from north to south, as is shown by the section of the accompanying figure. The slope is somewhat steeper on the weather side; the island is surrounded by a line of elevated coralliferous limestone cliffs, ranging from 12 to 30 feet in height; from these the reef flat platform has been cut away. The platform is about 100 yards wide.

I am indebted to Mr. John Arundel of the Pacific Islands Company for a copy of the Report of Mr. Powers on Ocean (Paanopa) and Pleasant (Nauru) Islands.

Mr. Arundel was also kind enough to allow me to reproduce a number of characteristic photographs of these islands (Pls. $160^{\mathrm{a}}, 160^{\mathrm{b}}$ ).

The sections of Paanopa and Nauru Islands are interesting; they show admirably that the sink of Nauru and its irregular surface are due to denudation and do not represent the lagoon of an elevated atoll. Paanopa has been greatly denuded and eroded on the flanks, near the shore platform,
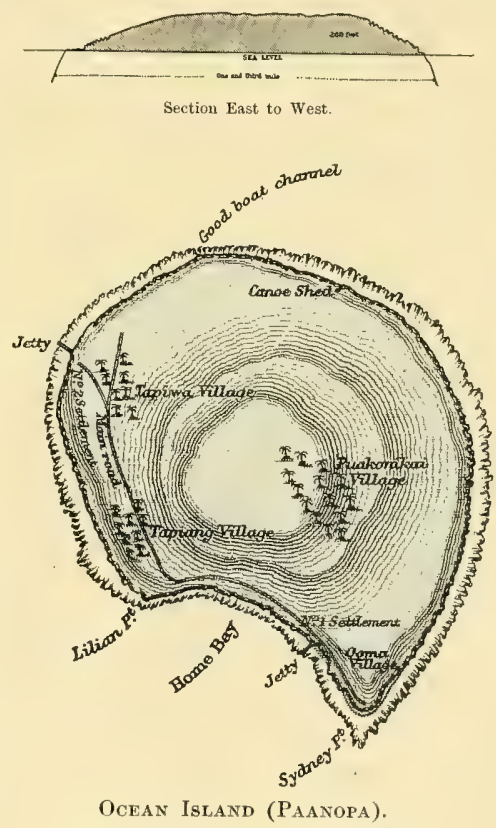
its dome-shaped surface having been but little modified by atmospheric agencies. In both the islands deep cuts similar to those described at Niue extend inland from the beach edge of the shore platform. 


\section{Arorai.}

Plate 223.

Arorai Island, the southernmost of the Gilbert Islands, is about six miles long, and loalf a mile wide, running from southeast to northwest; it is a low island with a high beach and a small brackish lagoon in the southern part of the island. On the sonthwest side the island is flanked by a steep shingle beach, at the base of which cropped ont, here and there, short stretches of conglomerate beach rock. The high and steep white shingle beach shows that the southwestern part of the island must, comparatively lately, have changed its character, as the northern part of the beach is covered with rough, highly weathered and pitted black coral rock shingle. The northwesterly winds, during the change of the trades, blow with considerable force, and this may account for the changes that have occurred in the outline of the western part of the island. At the western spit is a huge pile of stones, evidently built by the natives in former times, of the origin of which the natives of the present day know nothing; so that it is probable that the topographical changes of the western side of Arorai have been comparatively slight, and limited, perhaps, merely to the migration of the shingle on the high beach southward or northward, according to the direction of the prevailing wind. Off the contral part of the island, the reef flat is wider than at the two extremities, and parts of it are covered with flat slabs of beach rock.

\section{Onoatoa.}

Plate 293.

Onoatoa, the next atoll of the group we visited, is about twelve miles long; its lagoon is five miles at its greatest width. We examined the southern part of the atoll, and steamed along a part of the land rim of the eastern face; this forms a large crescent open to the west. The gaps between the islands and islets are so shallow that at low water the narrow land rim of the eastern face of the atoll is continuous. The west side of the lagoon is open, and only protected in the central part by 
a wide triangular reef flat giving the sea free access to the lagoon, both to the north and south of it.

The sea face of the land rim, where we examined it, is flanked by a low beach; the vegetation creeps down almost to high-water mark; little conglomerate beach rock is found at the base of the beach, with here and there ridges of coral shingle, alternating with longer stretches of fine coral sand.

The absence of land rims on the western face of several of the atolls of the Gilbert Islands is a characteristic feature of that group. At Tapetenea and Tarawa, as at Onoatoa, the eastern faces form a nearly continuous land rim, while the western face is only protected by a sunken reef flat, covered with water of variable depth, enclosing very indistinctly marked lagoons. These indistinct lagoons appear to have been formed, at least in the case of Onoatoa and Tapeteuea, from the erosion of wide fringing reef flats once occupying the summit of the shoal areas of the atolls of Onoatoa and Tapeteuea, on the eastern face of which the land rim has been thrown up. The wide fringing reef flats on the lagoon side of Onoatoa may be the remnant of a former more extensive flat. A similar flat has been more carefully examined at Taritari, where I shall describe it in detail.

\section{Tapeteuea.}

Plates 138, figs. 1-3; 220; 206, fig. 1.

Tapeteuea is a triangular-shaped atoll, ${ }^{1}$ its eastern face is nearly thirty miles in length; the southern face is eight miles long, with a shallow passage into the lagoon. Its land rim is limited to a few sand bars. The reef flat of the western face encloses an elongated triangular lagoon; towards the northern extremity of the atoll it passes into the wide fringing reef flat flanking the western face of the northernmost island of Tapetenea. The greatest width of the lagoon is about six miles at the southern face of the atoll. An indentation in the northern part of the atoll forms an indifferent anchorage on the west coast (Peacock anchorage). It is only toward the southern part of the atoll that the lagoon becomes important. On the west face are two passages available for small craft.

${ }^{1}$ H. O. Chart 120. 
The lagoon is said by Wilkes to be about five fathoms deep, and to have many sand and coral shoals dry at low water.

Tapeteuea is undoubtedly the summit of a very extensive ridge, as to the south of the charted part of the atoll an extensive reef has been reported by the U. S. S. "Narragansett."

The northern horn of Tapeteuea ${ }^{3}$ (Pls. 223 ; 226, fig. 1) reminds us of the horns of the atoll of Arhno, in the Marshall Islands, where the land rim is flanked on both faces by a fringing reef platform widest on the lee side. The loose material composing the eastern land rim has, as yet, reached only an initial stage of concentration, consisting wholly of small islands, islets, and sand bars. On the northern and southern extremities alone a part of the land rim of the east face is continuous, and has been consolidated into larger islands (Pl. 138, fig. 3).

We came upon Tapeteuea ${ }^{2}$ near the centre of the eastern face of the atoll, where the land rim consists of numerous islands and islets, flanked by low sand beaches (Pl. 138, fig. 2); many of the islands seem to be connected by sand bars.

On the southern side of Utiroa we saw several artificial mounds, such as we had noticed at the extremity of Arorai. Some of them seemed to be beacons, indicating, perhaps, a canoe passage into the lagoon. But on the western side of the same island occurs a long line of these artificial piles, the object of which is not so apparent, as they merely extend westward into the narrow lagoon on the broad western fringing reef flat. As we steamed along the east side of Tapetenea (Pl. 226, fig. 1), close to the line of breakers, we could see that the various islands and islets to the south of Utiroa are largely sand bars reaching out at right angles to the line of the outer reef platform, the sea face of which is flanked with conglomerate beach rock, while the lagoon end of the islands and islets is covered with fine coral sand thrown up by the waves of the lagoon during the prevailing trades. These sand bars, according to their size and age, are covered at first by a low growth of bushes, subsequently cocoanut trees find a foothold, and eventually cover the greater part of the ridges of the islands. The gaps between the islands and islets appear to be shallow (Pl. 138, 
fig. 2), judging from the color of the water, which is light green, like that on the reef flat on the inside of the lagoon. The character of the east face of Tapeteuea is well indicated on the sketch chart of the atoll made by the United States Exploring Expedition under Wilkes ${ }^{1}$ (Pl. 226, fig. 1).

South of the island of Utiroa, we came upon a low elevated vertical wall, consisting of short reaches from ten to forty or fifty feet in length. It is not more than three to five feet in height, is deeply undercut, and has the appearance of being composed of the tertiary elevated coralliferous limestone. Where the reef platform is wide, the vertical wall passes, little by little, into lines of buttresses running more or less diagonally across the face of the steep coral sand beach. On the beaches is found an immense mass of driftwood and of logs of all kinds, mainly of Pandanus and cocoanut trees, as well as some of the hardwood trees. This we had not seen before; it shows that the east face of the atoll is bathed by a strong current coming from the eastward, bringing a mass of drift material from islands to the eastward. Some of the gaps between the islands illustrate well the characteristic mode of formation of the land rim of an atoll. We could see how a short sand bar had been deposited at right angles to the line of the outer reef flat, where fragments of beach rock or conglomerate have formed a spur towards the inside of the lagoon, and had gradually grown towards the interior of the lagoon, increasing also in width, and finally almost closing up the spaces between it and the adjoining sand bars or islands or islets, leaving, as can be seen, a more or less shallow gap through which the lagoon has an intermittent communication with the sea.

Many of the islands of the land rim are covered with a fine growth of Pandanus and of cocoanut trees. The last island on the northern part of Tapeteuea shows the old ledge cropping out here and there, and extending either as outliers, or as diagonal buttresses across the steep beaches, the intervening spaces being covered with coarse coral shingle. The outer reef platform off the northern point is wide; we also find there traces and outliers of the low old ledge wall existing to the southward. At the northern extremity of Tapeteuea two secondary lagoons are formed. They are due

1 H. O. Chart 120. 
to the junction of sand bars, separated by a low islet, extending diagonally over the face of the inner fringing reef flat of the lagoon; they have surrounded, in this way, a part of the reef flat, and separated it from the rest of the lagoon It is easy to see how a series of chains of such secondary lagoons may thus be formed similar to those we observed in some of the Paumotu Islands ; there their mode of structure is not as evident as it is in this particular instance. The sea face coast of the northernmost island on the eastern side of Tapeteuea consists of a long stretch of fine coral sand, with a few buttresses of the old ledge, with here and there an isolated, short, low coral shingle beach, flanked by wide reef flats (Pl. 138, fig. 3).

\section{Apamama.}

Plates 138, fig. 4; 139, figs. 1-3; 223 ; 226, fig. 2.

The next island of the Gilbert group we visited was Apamama, neither Nonuti, nor Aranuka, nor Kuria seeming from the chart to present specially interesting features.

Apamama is irregular in outline (Pl. 226, fig. 2), ${ }^{1}$ about twelve miles in its greatest length and about seven miles in width at the northwestern extremity. The eastern coast of the atoll is convex, forming a sharp point at the southern extremity. The entrances to Apamama are on the northwest and southwest faces; the lagoon is said to be shallow, varying from two and a half to seven fathoms in depth. We examined a part of the southern and eastern side of the atoll.

The charts of Apamama ${ }^{2}$ are not very accurate. The northwesterly shank of the southern land rim is much longer than represented; there are many bays along the eastern face of Kabañaki, and from Tebaña to Tabonua many gaps and cuts subdivide that part of the land rim as well as its southern face.

From the northern horn of Apamama we skirted the eastern side of the atoll; this is flanked by a wide reef flat; a shallow, reef flat lagoon is formed between the outer edge of the reef platform and the base of the sand beach of the land rim. Along the east shore reef platform lagoons are also

\footnotetext{
1 A. Chart 731.
}

2 Ibid. H. O. Chart 122. 
formed in the gaps on the sea face of the land rim and not on the inner face, as we have described them for Tapetenea. Some of the gaps, instead of being closed on the sea face, are closed on the lagoon face (Pl. 139, fig. 2), forming at first a bay into which the waters pouring over the outer edge of the reef flat platform have free access. Gradually as the currents which once passed into the lagoon have been shut off, sand accumulates on the two sides of the bay, and is forced towards the outer edge of the reef platform. So that a part of the reef platform, once a bay, is now separated from the adjoining district by a spur or spurs from the islands once flanking the gap leading into the lagoon. These spurs, however, do not consist mainly of sand, as they do on the lagoon side, but are made up generally of coral rock shingle, and smaller fragments of coral, with comparatively little sand, though, according to local conditions, these ledges are often covered with fine coral sand. The bottom of the bay flanking the lagoon is almost always a low sandy beach; it has been formed much in the same. manner as the adjoining islets on the outer reef flat, by the throwing out of sandy spurs on their opposite faces.

On some of the spits forming the boundary of the platform lagoons, the reef rock platform has occasionally been elevated at least a couple of feet. Here and there we also find outliers of the old ledge forming low vertical walls from three to five feet in height; they are undercut, and the spaces between them have been filled either with beach rock, or conglomerate, or with coarse shingle or with sand.

Pandanus trees are comparatively rare on the east coast of Apamama, but there are a large number of Pisonias and cocoanut trees, and, in some cases, beautiful hardwood trees. Some of the higher beaches look like dunes covered by vegetation, and in this way long wide beaches have perhaps been formed. We found large masses of driftwood on the eastern side of Apamama.

Towards the southern horn, on the eastern face of the land rim of Apamama, numerous islands and islets are found in the lagoon bays with intricate passes between them. The islands run more or less parallel with the outer reef flat. They indicate the former existence of a number of old gaps now shut out from the sea by the bars of rubble and of sand which 
have formed in the platform lagoons. The bars of rubble on the outside edge of the reef platform are at first covered with a little vegetation, but as they become larger spurs or islets, and extend out into the lagoon, the coating of vegetation increases. Low sand dune reaches, overgrown with vegetation, unite them on the lagoon side, and form a kind of platform lagoon on the outside edge of the reef flat differing from any twe have seen before. The secondary platform lagoons can be looked upon as owing their origin primarily to old gaps, then to dam lagoons, then to lagoon rims filled with islands. On the eastern face a succession of such secondary lagoons exists, showing that the land rim must have been a series of islets like those of Tapeteuea, running perpendicularly to the outer reef flat line. No landing was possible on the east face of Apamama.

Near the south point on the east side, the reef platform becomes narrower as it extends towards the south, and the low wall of old ledge which flanks that part of the atoll is gradually changed into more or less indistinct buttresses; they are situated well above high-water mark, and run diagonally across the steep beach of that part of the land rim. Behind these ledges sand dunes are formed which raise the beaches or the land rim to a greater height than is usual in the Ellice Islands (Pl. 139, fig. 3).

At the southernmost point of Apamama the old ledge reaches well up on the beach and has been elevated at least seven to eight feet. This is not beach rock, but is part of the old elevated coralliferous limestone. Beach rock or coral conglomerate is found on the outer edge of the reef flat, or at the base of the beach. A wide coral sand beach separates the old ledge buttresses from the beach rock, or coral conglomerate, or breccia deposited between its outliers; this, being softer than the old ledge rock, has in great part been washed away. On the south side we found the same formation as on the east face, a series of secondary platform lagoons, gaps, and small bays; here and there beach rock or coral conglomerate ledges are exposed, the higher parts of which must have been elevated at least three feet above high-water mark. One of the gaps is broad, fairly shallow, and leads from the reef flat into the lagoon. Another bay is, perhaps, larger than any we have seen on the east face; it is probably older also, the dam between it and the lagoon side being of considerable width; the two spits flanking it 
on the east and on the west, are formed of the same beach rock conglomerate we noticed on the eastern face. Behind the village the dam (it can hardly be called a dam now) has a width of nearly half a mile, and has increased to such an extent as to form a wide land rim extending as far into the lagoon as any part of the outer land rim. Messrs. Mayer and Moore, who landed in this bay, reported that they saw nothing but modern beach rock or conglomerate on the edges of the bay, some of it slightly elevated. In the centre of the land rim behind the village, an imperfectly cemented beach rock conglomerate was noticed, and masses of coral shingle and small fragments of corals well weathered, but no traces of the old ledge were seen in this part of the island. The beach sand is fine, and the beach rock conglomerate or breccia is not composed of specially large fragments. The reef flat at this point is at least 150 yards wide, and the bay about 200 , while the land belt from the lagoon to the village is about 250 yards in width. Back of the village a number of sinks were observed from 50 to over 100 feet in length. One of them is at least 125 feet long and 40 wide, the depth being about 18 inches. The sinks contain more or less brackish water. Immediately behind the sea face of the beach similar sink holes were observed with a number of pools of brackish water; some of them are fully eight feet deep; they have steep slopes at an angle of even $30^{\circ}$. It is very probable that these sink holes and pools represent parts of the old secondary platform lagoon or of the old lagoon bay when it was filled with islets and islands now connected together to form the main land rim. On the eastern side of the bay there is a sand bar enclosing a remnant of one of these small secondary lagoons, such as we have described from the eastern side of the island. This secondary lagoon is about 200 feet long, 40 feet wide, and, perhaps, three feet deep. We have observed similar sinks or troughs at Nukutavake, Fakarava, and islands in the Gilbert and Marshall groups.

On the lagoon side of the bay the coral sand is rather coarse, while on the bay side was found the finest sand yet seen on the sea face of these atolls. The beaches on the sea face of the bay, and on the spits on each side of it, have been thrown up far above the level of the land immediately behind it. The depth of water on the reef shelf enclosing this bay is only 
from three to four feet at about half tide; inside of the outer line of breakers, for a short distance, a depth of from two to two and a half fathoms is found, with numerous heads of corals reaching to within one foot or eighteen inches of the surface.

At the head of the bight in the larger bay near the village, the beach is steep; it consists of fine sand passing gradually into shingle at each end, this, in its turn, giving place to beach rock or coral breccia towards the seaward part of the shore. The sea face of the bay is composed of comparatively recent beach rock conglomerate, or breccia, extending to the gap on the west side of the bay, about two thirds of the distance to the lagoon. This rock is about two feet above high-water mark; above it rises a beach of shingle and small rolled pieces of coral, having the general character of the breccia which constitutes the beach rock.

None of the outliers of beach rock conglomerate on the sea beach, to the east of the bay, rise to more than two feet above high-water mark; the beach conglomerate is formed of fragments of modern corals and shells, washed inland from the outlying barrier reef, and cemented with coral sand.

To the east of the bay the sea beach between the reaches of beach rock conglomerate is composed of extremely fine coral sand with scattered patches of reddish particles; they are similar to the red earth characteristic of limestone districts. Immediately above the fine sand, and rising sometimes to a height of seven to nine feet above high-water mark, a mass of coral fragments has been thrown up, evidently derived from the outlying reef platform. These fragments become gradually smaller as one travels inland, and at a distance of about 300 feet from the beach they become a fine gray sand composed of the eroded and decomposed coral fragments washed in from the beach. No part of the island behind the beach was more than four feet in height; near the centre of the island the soil was wet and of a putty-like consistency; back of the village it is composed of coral sand, cemented in some places into a soft rock; here and there lie scattered fragments of coral, more or less weather-worn. The natives have dug holes to a depth of two to three feet, and at the bottom of these is found the same material as that which characterizes the surface. Above the high-water mark the lagoon beach is steep, but slopes more gently into 
the lagoon itself. It is composed of coarse white coral sand; the bottom of the lagoon is formed of the same material for a distance of 100 to 200 yards from the shore, where some of the huts of the village are built on piles.

The southern part of Apamama is thickly covered with trees, mainly Pandanus, Pisonias, and cocoanut trees, as well as with the usual belt of low bushes on the outer face of the land rim.

\section{Maiana. •}

Plates 139, fig. 4; 140, fig. 1; 223; 224, fig. 6 .

From Apamama we proceeded to Maiana, ${ }^{1}$ about forty miles to the northwest; it is a quadrilateral land rim, about nine miles long and six miles broad (Pl. 224, fig. 6). The northeastern and southeastern faces form a continuous land rim, while the northrestern and southwestern faces consist of a broad reef flat with only here and there an islet or sand bar to indicate its position. A boat passage leads into the lagoon on the west face at the northern extremity of the island (Pl. 224, fig. 6). Near the southern horn of Maiana a steep, wide, fine coral sand beach extends from the belt of vegetation towards the outer reef flat. It passes first into coral shingle, then into beach rock conglomerate at its base, and slopes towards the outer edge of the reef flat platform, which is edged by knolls of Pocillipores and Nullipores. The comparatively steep slope of the reef platform differs from that observed in other islands. On the sea face of the Pocillipore knolls the slope is steep as it passes into deep water. Nowhere have we seen the line of demarcation of the vegetation on the summit of the beach from the fine sand and shingle of its slope, the beach rock conglomerate at its base, the sloping reef platform, and the outer knoll of Nullipores, so well defined as on the sea face of Maiana (Pl. 139, fig. 4). The yellow color of the beach rock, of the coral and beach rock shingle, is in marked contrast with the glistening white coral sand, and in still more marked contrast with the reddish, the orange, and the violet of the encrusting Nullipores and of the Pocillipore knolls on the outer edge of the reef platform. The pink

1 H. O. Chart 122 ; A. Chart 732 . 
Pocillipores and the gayly colored Nullipores growing on the outer edge of the reef flat platform form, perhaps, the most striking display of colors we have as yet seen, with the yellowish brown beach rock and the light green water of the pools covering portions of the flats, and the dark blue digitate channels penetrating far into the reef flat slope. These small channels, cut out of the edge of the reef flat, form convenient points for landing, and along the shore we could see the canoes of the natives hauled up on the beaches opposite these diminutive landing-places.

Maiana is one of the most interesting of the Gilbert atolls. It is enclosed on the west by a wide reef flat, with only two small gaps through which there is free communication between the lagoon and the outer sea. Undoubtedly in former times other gaps opened into the lagoon, but they have, little by little, been closed by the process we have described as uniting the islands and islets of the land rim in other atolls of the Ellice group.

As we passed the first gap on the southeastern shore, we obtained an excellent view of the inner part of the lagoon of Maiana, and were surprised to find in the atoll a series of inner beaches running parallel to the outer shore, forming huge secondary lagoons, similar to those we observed in other atolls of the Ellice group. These secondary lagoons are formed by incipient sand bars on the broad reef flats, which extend far into the interior of the Maiana lagoon (Pl. 224, fig. 6).

We could see, at some points of the land rim, low dams (Pl. 140, fig. 1), indicating the position of the gaps which once connected the lagoon with the sea, showing that the secondary lagoons of Maiana must have been formed by a process similar to that now shaping the secondary lagoons on the east and southern coast of Apamama. These secondary lagoons are certainly not due to subsidence; they owe their origin to mechanical agencies, such as we have seen at work in the atolls of Tapeteuea and Apamama.

On the northeast face the beach changes its character; it is made up almost entirely of coarse coral shingle, and even of huge boulders of coral thrown up on the steep beach on that face of the atoll (Pl. 140, fig. 1). Here and there, however, a coral sand beach separates the reaches of shingle beach. Outliers of the beach rock conglomerate or coral breccia 
crop out occasionally near the top of the beach, buried in part in the fine sand, and indicating an elevation of a few feet (Pls. 139, fig. 4 ; 140, fig. 1).

The land rim is beautifully wooded (Pls. 139, fig 4; 140, fig. 1), and the little islets thrown upon the bars and dams which form the secondary lagoons are covered with the same trees as those which characterize the main land rim of the atoll. Pandanus grow in great abundance on Maiana, and we find the usual fringe of low shrubs on the top of the wide sand beach (Pl. 139, fig. 4); this is considerably higher than the land immediately behind it.

\section{Tarawa.}

Plates 140, figs. 2-4; 141-144; 145, fig. 4; 223; 224, fig. 5.

The atoll of Tarawa ${ }^{1}$ is triangular in shape (Pl. 224, fig. 5); its southern face runs nearly east and west, and is about fifteen miles long; the eastern face, twenty miles in length, runs from southeast to northwest; the western limit of the lagoon is indicated by a rather narrow barrier reef with from two to ten fathoms of water. The position of the barrier reef is only indefinitely indicated by patches of corals separating the lagoon from the sea (PI. 224, fig. 5). There are several entrances into the lagoon on the west side; many shoals and islets are scattered over its surface.

The lagoon is said to vary in depth from five to eleven fathoms. On the western extremity of the southern face of the atoll a large island extends into the lagoon. The southern extremity of the eastern face forms a rounded horn, while the northern extremity of the atoll forms a sharp point, flanked on the east by a narrow reef flat, and on the west by the extension of the western reef flat of the lagoon (Pl. 224, fig. 5).

We made the south shore of Tarawa, and anchored about one eighth of a mile off the principal islets of the south shore (Pls. 140, fig. 4; 141, fig. 1). There is no reef platform proper on the south side of Tarawa. The bottom slopes very gradually seawards from the indefinite edge of the reef flat; a depth of 95 fathoms is obtained at a distance of about half a mile, and not more than 200 fathoms at nearly a mile and a half from shore, a slope unlike

1. H. O. Chart 123; A. Chart 732. 
that off any other group of coral islands we have examined. ${ }^{1}$ The beaches of the islands on the south face of Tarawa consist of fine coral sand; the islands themselves are extremely narrow; they are covered with cocoanut trees and shrubs. The sand beaches have been formed as low dunes; they are somewhat higher than the islands and islets immediately to the north. Beach rock and conglomerate ledges characterize the southern face of many of these islands; none rise more than a foot or two above high-water mark. We observed, coming through one of the gaps opposite our anchorage, a mass of discolored water, which spread fan-shape a considerable distance out to sea. This material is derived from the immense shallow reef flats to the rear of the gap on the southern face of Tarawa. Similar streams pouring out the muddy water from the shallow bay to the rear of the Florida Keys are seen at Cæsar's Creek. ${ }^{2}$

At the gap opposite our anchorage, are a number of islands, more or less parallel to the coast line, forming a secondary lagoon, similar to those of the southern coast of Tapeteuea (Pls. 140; fig. 4; 141, figs. 2-4). The eastern part of the southern face of Tarawa is flanked by a land rim; its western half is flanked by islets; the western horn is formed by a wide triangular reef flat, gradually increasing in width to about 1000 feet at low tide.

To the eastward of the gap where we anchored, or rather of the long spit which forms the western side of the gap, a series of islets extends at right angles to the line of breakers, separated by shallow flats, which connect the inner lagoon with the sea (Pl. 141, figs. 2-4). The lagoon extremities of some of the islands are connected, thus forming deep bays extending northward from the sea face, and communicating through shallow passages with one another on the lagoon face (Pl. 141, figs. 2-4). Immediately across the lagoon extremities of these islands, a low sand bar extends, flanked with beach rock conglomerate, more or less elevated; this forms the beginning of a secondary lagoon extending behind the spit of the western side of the gap, and shows, perhaps, better than elscwhere the mechanical causes

1 Prel. Report "Albatross" Tropical Pacific Expedition, Mem. Mus. Comp. Zoöl., 1902, XXVI., No. 1, p. 61, Stations 200, 201.

2 Bull. M. C. Z., XXVIII., No. 2, 1896, p. 46, Pl. XIV. 
which have led to the formation of these secondary lagoous (Pl. 141, fig. 2). The inner island is in reality a bar thrown up on the inner or lagoon side of the reef flat at right angles to the outer reef flat, and a dam has been formed connecting the inner and outer islands; these bars or dams are edged with beach rock or shingle (Pl. 141, figs. 2-4). The areas thus shut off, finally become rectangular enclosures, entirely separated from the lagoon (Pl. 141, fig. 2), forming the peculiar secondary lagoons the structure of which has so greatly puzzled many observers. The material for the islets bounding the secondary lagoon is derived from the breaking up of the conglomerate beach rock, or breccia ledge cropping out everywhere on the platform on which the land rim has been thrown up. The inner reef flat is wide (Pls. 141, fig. 2; 142, 143), and extends far into the lagoon. We were unable to ascertain how far north the flats extend.

The coral shingle found above the beach rock conglomerate consists of fragments of the beach rock itself, more or less disintegrated. The flats between the islands and islets are covered with fine sand, almost silt, and on the lagoon side they are covered with masses of broken land shells. The natives use these secondary lagoons, or parts of them, as fish ponds (Pls. 144; 145, fig. 4), the islets acting as barriers, which they connect by artificial dams to enclose limited areas of the lagoons. Immediately behind the principal island, which has formed the dam of the secondary lagoon, are three successive bars on the lagoon side, forming long spits parallel to one another, and coming out as spurs from the main land rim. These, when dammed off at their lagoon extremity, will in their turn form a third and even a fourth line of lagoons in the same way as the secondary lagoon we have just described has been formed.

The wide beach flat slopes most gradually to the Nullipore and Pocillipore edge, which on this flat reef platform apparently indicates merely the lowwater line. There are no great cuts in the outer edge of the Nullipore knolls as in other atolls, except an occasional gully of three to four feet in depth, not more than a few feet in length, flanked by knolls rising from one to two feet above the general level. On the slope of the reef flat scattered over its whole face, fine corals are growing; the principal heads consist of Porites, of pink Madrepores, and of Millepores; the flat is also 
covered with huge masses of Nullipores. The conglomerate beach rock is composed entirely of fragments of modern species of corals, covered with encrusting Nullipores. In some places the conglomerate is changed into a hard ringing limestone, while in others the fragments of corals have merely been agglutinated, and remain soft and crumbling.

Skirting along the east coast of Tarawa, about two miles from the southern point, we came across a number of gaps (Pl. 140, figs. 2, 3) formed by islands and islets, separated by shallow passages, flanked on the east by a reef platform of variable width. Through the gaps we could see the lines of inner islands, immediately in the rear of those of the land rim, towards which spits or dams from the outer islets were gradually reaching, forming more or less distinct secondary lagoons. About the centre of the east face of the atoll we came upon a large secondary lagoon, forming a huge bay, its outer edge flanked by the reef platform on which the sea was pounding. The width of this secondary lagoon was at least 2000 feet, and its inner dam consisted of a series of low beach rock ledge walls, parallel with the land rim separating the secondary lagoon from the main lagoon. Somewhat north of this point the inner or secondary row of islands on the wide outer reef platform became even more prominent, and finally we came upon a part of the lagoon with three and four rows of islands and islets, all more or less parallel with the outer reef platform (Pl. 140, fig. 4); on the lagoon face they form prominent spits extending at right angles to the line of the outer reef flat. The wide reef flat on which the inner rows of islands were thrown up extends far into the lagoon. The islands and islets are flanked on the sea face by beach rock conglomerate.

The outer and older of the islands and islets are covered with vegetation, while the inner islets are generally mere bare ledges of beach rock conglomerate or breccia or sand spits. Somewhat farther north we came upon another secondary lagoon where the distance from the lagoon edge of the outer row of islands to the second row is from 1000 to 1200 feet. Here the inner islands are as well covered with vegetation as the outer ones; they are occasionally connected by low sand spurs and form secondary bays, with passages between the extremities of the island leading in one case into the lagoon, and in the other opening out on the outer reef flat. 
The spurs usually connect the central parts of the islands, showing that the outer islands, at any rate, have increased in size uniformly on the two sides of the original spit.

Still farther north we find a series of three lines of islands; the second and the outer row are sometimes connected by a spit fully as well covered with vegetation as the inner or the outer islands. The prolongation of the three lines of islands is not always well marked; they are somewhat irregularly placed. Taken as a whole they form an enormous secondary lagoon on the inner reef flat; this at some points must be three fifths of a mile in width. Farther north still, an islet of shingle and sand has been formed directly across the gap of the two inner islets on the outer edge of the reef flat and parallel with it.

The extent of the secondary lagoons depends wholly upon the width of the lagoon reef flat. Where it is narrow, the secondary lagoons appear as small bays, facing either the sea or the lagoon, according to the local conditions which have shut off gaps, more or less wide, either from the sea or from the lagoon. Their depth depends upon the differences of level found upon the lagoon reef flats, upon the depth of the gaps and the shallower passes, as well as the distance to which the channels or sinks extend lagoonward across the reef flat. The lagoon faces of an atoll as large as Tarawa are raked by seas of considerable size, so that we often find, especially on the eastern and southern faces, bars and beaches of considerable height thrown up in the interior of the lagoon, forming the boundaries of secondary lagoons (Pls. 143, fig. 2; 144; 145, fig. 4).

The width of the reef flats on the lagoon side of Tarawa is well seen on Pl. 143, fig. 1, and on Pl. 142, fig. 2, where is exposed an extensive flat of coral sand, of silt, and small fragments of corals and broken shells. This flat forms a huge wide spur to the north of the inner line of islets flanking the secondary lagoon. On Pl. 143, fig. 2, is shown an extension to the east of a high sand bar covered with vegetation, forming the northern boundary of a long shallow sink or secondary lagoon. On Pl. 143, fig. 1, we are looking westward along the lagoon face of the land rim. Outliers of reef rock and breccia and conglomerate crop up along the face of the lagoon; they have not as yet been disintegrated and ground into sand as they have 
in other parts of the lagoon platform. The land rim of the east face of Tarawa, as far as we examined it, consists of secondary lagoons such as we have described. The secondary lagoons are not indicated on the charts of Tarawa, of Maiana, Taritari, or the few atolls in the Paumotus where they have been observed.

\section{Apaiang.}

Plates 145, figs. 1-3; 223; 204, fig. 2.

After skirting the eastern face of Tarawa we examined the southern part of Apaiang, ${ }^{1}$ an atoll about sixteen miles in length, and eight miles wide across its northern extremity (Pl. 224, fig. 2). Its outline is formed by a series of large loops, the reef flats running ont into well-marked points on the northern, eastern, and western faces. The principal land rim is on the eastern face of the atoll, while on the wide northern and western reef flats only a few low islands are found, with the exception of the larger island of Nuotaea, which forms the northwestern spit of the atoll (Pl. 224, fig. 2). On the southwest face two well-marked ship passages lead into the lagoon; numerous shoals occur in it.

The beach of the southeastern shore is flanked by beach rock; outliers of coarse conglomerate, separated by stretches of coarse coral sand, line the shore above high-water mark (Pl. 145, fig. 3). On the lagoon side of the island forming the southeast point, the steep beach consists of fine coral sand. Rounding the eastern point (Pl. 145, fig. 2) of the south face of the atoll, south of the boat passage leading into the lagoon, we found, from a depth of twenty fathoms up to two, masses of corals covering the bottom ; they consist mainly of Mrandrinas, Madrepores, Pocillipores, Millepores, and Alcyonarians ; of special interest were a number of large sponges closely allied to species found on the Australian barrier reef. As we came in through the inner boat passage, the coral heads in the narrow part of the channel became more and more luxuriant, especially the Iarge blocks of Porites; as we approached shallow water, they spread horizontally; as the tops neared the surface, many of them were dead and covered with masses of white and of red Nullipores, which form a cement over the whole surface of the reef flat on both 
sides of the boat passage. These Porites reef flats are similar to the Millepore and Porites flats which take such an extraordinary development in Taritari, and are described in detail in the account of that atoll. They show admirably how extensive areas covered with living corals like Porites, Millepores, or Pocillipores, are gradually changed into dead reef flats with a surface cemented by Nullipores, and become the base upon which a land rim of bars or islands or islets is gradually thrown up.

The high coarse sand beach where we landed was at least six to seven feet above low-water mark. It is made up of small disintegrated fragments of coral; the same is the composition of the lagoon beach, which is fully as steep as the sea face, but the material of this beach contained a larger proportion of broken shells. The outer spit to the south of the village, near the outer face of the island, is made up of a steep coarse coral shingle beach; it is of a gray color, weathered, pitted, and honcycombed.

On the east side of Apaiang, as far as we followed it, high coral sand beaches, topped by scrub vegetation, alternate with' low ledges of beach rock conglomerate, forming low vertical walls slightly undercut at the base, flanking the base of the sand beaches. The lagoon reef flat slopes but slightly, and is covered with knolls and heads of Nullipores, Corallines, and Pocilli-. pores, colored red, pink, and yellow, giving a very variegated appearance to the lagoon flat; the heads are separated by large, wide patches of sand. The outer reef flat slope, where it consists of beach rock conglomerate, is a brilliant yellowish brown as at Tarawa.

From Apaiang we steamed to Maraki, one of the most interesting atolls we have as yet examined.

\section{Maraki.}

-Plates 146-150, 223 ; 224, fig.3.

We steamed around the southeastern and western faces of Maraki, an atoll triangular in shape, about five miles in length by three miles wide. A single narrow boat passage leads into the lagoon on the western face (Pl. 146, fig. 1), with this exception, the land forms a continuous rim of considerable height, which has been thrown up on the onter reef flat. On 
the east face a former gap or passage, now closed, is indicated (Pl. 224, fig. 3). This low part of the land rim is quite distinctly seen from the western face of the land rim. The island is an interesting one; it was considered by Dana to be perhaps the most typical of the atolls he visited. At Maraki nothing indicates that the island has ever been subjected to subsidence. On the contrary, the immense amount of material thrown up, both on the east and on the west face, forming the land rim of this atoll, clearly shows the manner in which the land rims of the atolls of the Ellice and Gilbert groups have little by little been accumulated. It is only when we examine such a small atoll as Maraki that we can take in at a glance the changes that have taken place on the underlying platform which has supplied in part the material for the coarse shingle beaches; the dead and decaying corals fringing the outer reef flat, and the material derived from the subsequent disintegration of the beaches of conglomerate and breccia supplying the rest. This is well seen on the west face, north of the boat passage, where huge boulders of conglomerate form a shingle beach (Pl. 147, fig. 2) extending along the greater part of the northern extremity of the west face. On the western side of the lagoon masses of beach rock conglomerate are found cropping out at the surface (Pl. 146, fig. 3); they form the underlying base of the narrow line of islands and islets parallel to the outer land rim, a line defining the inner margin of secondary lagoons (Pls. 149; 150, fig. 2) so characteristic of the Gilbert and Ellice Islands, and so well developed at Taritari and Tarawa.

Near the southeast point of $\operatorname{Maraki}^{1}$ (Pl. 146, fig. 2) the reef flat slopes gradually to the outer edge. This is marked by huge knolls of Nullipores and of Pocillipores, forming an outer barrier to the shallow pool which extends from the outer edge of the reef flat towards the base of the beach of the main land rim (Pl. 146, figs. 2, 3). The beach rock flanking the base of the high and steep beach of Maraki is of a brilliant brownish yellow; its patches extend as large slabs over the reef flat and partly up the slope of the high beach, form a belt of brilliant color, in strong contrast with the white coral sand and the light yellowish mud which covers, in places, the bottom of the platform lagoon enclosed by the outer knolls (Pls. 147, fig. 1; 148; 
149, fig. 1 ; 150, fig. 1). The outer platform lagoon is full of fishes; many of the natives were seen fishing along its edge as we passed. There has probably been a slight elevation at Maraki corresponding to that noticed in other atolls of the Ellice and Gilbert group, as some of the beach rock conglomerate has been elevated far above the line of the highest high-water mark (Pl. 147, fig. 1).

From the southeast horn of Maraki (Pl. 146, fig. 2) we turned westward, skirting as close as practicable to the outer edge of the reef flat. As we passed along the southern coast, we could see in the lagoon, over the belt of low vegetation of the land rim, a secondary line of islands (Pls. 149, fig. 1 ; 150, fig. 1), running parallel with the south shore, as at Tarawa. The brilliant belt of color, extending from the summit of the beach to the outer Nullipore knolls, increases in brilliancy as we proceed westward. The color of the carpet of many-colored corals and Nullipores is reinforced by that of long lines of green and yellow Algæe, which flourish in the shallow pools left by the tide on the flat between the base of the sand beach and the outer edge of the reef. The knolls on the outer edge of the reef were here and there gouged out by deep gullies connecting the pool of the platform lagoon with the sea, but in spite of these openings there was left, even at low water, a nearly continuous platform lagoon between the outer Nullipore edge of the reef flat and the base of the beach (Pls. 146, figs. 2, 3; 148; 149, fig. $1 ;$ 150, fig. 1).

A section across the south shore, as we could see it from the deck of the vessel, showed the outer knoll of Nullipores and Pocillipores gouged at right angles to the trend of the outer reef flat, by gullies varying in width from ten to fifty feet. Immediately behind the knolls, the slope dips sharply to form the bottom of the platform lagoon; it then rises uniformly to the base of the sand beach; the slope is covered with many-colored rocks and fragments of beach rock and conglomerate, separated by patches of yellow and green Algx, and the whole more or less covered with a coating of bright-colored Nullipores. Then comes a steeper slope of white coral sand, flanked at the base by beach rock and beach rock conglomerate, behind which the beach rises rapidly to a height of at least seven or eight feet above high-water mark. The top of the steep beach was covered with 
the usual belt of low bushes behind which rose the larger trees, mainly cocoanut trees. We could trace the brilliant colors of the corals growing on the outer slope of the reef down into twenty fathoms.

Torvards the western point of the southern face of the land rim, the outer edge of the shore platform suddenly joins the beach which flanks the western coast of Maraki (Pl. 147, fig. 2). The western coast of Maraki is flanked almost for its whole length by sand beaches and coarse shingle beaches alternating with one another, much as we saw them in Maiana. The absence of the shore platform on the greater part of the west side is a most striking feature; this may show that Maraki is a later stage than that of some of the atolls of the Ellice and of the Gilbert groups, where no islands exist on the reef flats of the west side, and that where few islands or islets have been formed on the reef platform of the western face. It is easy to see, from the case of Maraki, how these differences have been brought about. On examining its lagoon we are able to trace the successive steps which distinguish Maraki from atolls which have remained more or less open on the west, like Tapeteuea, ${ }^{1}$ Tarawa (Pl. 224, fig. 4), Onoatoa (Pl. 223), or from those like Taritari (Pl. 224, fig. 4), Apaiang (Pl. 224, fig. 2), Nonuti, ${ }^{2}$ with only one or two islets on the western face, until we reach a stage where the local conditions are such that the trade wind and other prevailing winds have thrown up, on the outer faces of the atoll, a high bank, such as exists at Maraki, which has finally closed the lagoon, leaving only an unimportant opening leading into it.

On the west face of Maraki a large number of huge blocks of Nullipores have been thrown up on the shore (Pl. 147, fig. 2). The soundings taken when lying off the village to the north of the boat passage show the absence of a shore platform, and that on the west face the atoll slopes gradually into deep water. ${ }^{3}$

As we passed the gap of the boat passage (Pl. 146, fig. 1), on the west face of Maraki, we could look into the lagoon and see indistinctly the eastern face of the land rim, as well as the secondary lines of islands and

1 H. O. Chart 120.

2 A. Chart 731 .

3 Prel. Report "Albatross" 'Tropical Pacific Ex., Mem. M. C. Z., XXVI., No. 1, 1902, p. 62, Station 205. 
islets and ledges parallel to the southern and to the western coast of Maraki. The two sides of the gap of the boat passage are flanked with coarse black coral shingle, with here and there a patch of coral sand. Huge boulders of Nullipores (Pl. 147, fig. 2), thrown up at the base of the shingle beach, supplied the material which, on further disintegration or grinding by the sea, formed the sand beaches stretching between the beach rock conglomerate and the line of Nullipore boulders.

We landed on the west coast, a little north of the monument, on a sand beach (Pl. 147, fig. 1), flanked on the left with masses of Nullipore boulders (Pl. 147, fig. 2). The underlying platform has evidently been covered with such blocks from the sea face across to the lagoon, so that it seems as if the land rim of the western coast had been built up, by the gradual increment due to the piling up of this coarse material upon the underlying platform, from the lagoon to the sea face. Making a section across the atoll at this point, we find on the west face the gradually sloping platform which once probably extended to the inner line of islands in the lagoon. On that slope has been formed, by the action of the huge rollers sweeping round the northern point of the atoll and following the western coast, the mass of shingle, composed of Nullipore boulders and of coral rock fragments (Pl. 147, fig. 2), which extends inland perhaps as far as the lagoon edge of the land rim. Next comes the reach of the sand beach, as far as the first line of islets running parallel to the west coast along the lagoon side of the atoll (Pl. 150, fig. 2). This slope may even extend a considerable distance into the lagoon, and on it have been thrown up a second or a third row of islets (Pl. 149, fig. 2); they form the secondary lagoon we have seen at different points, parallel to the southern, eastern, and western faces of the island (Pls. 149, fig. 1; 150, fig. 1). From the eastern side of the western land rim we could see that the eastern face of the lagoon rises to about the same height as. that on the west (Pl. 149, fig, 2). The slope of the outer beach on the eastern sea face is very similar to that on the west, only from the southern horn it runs into a wider outer reef platform (Pl. 146, fig. 2), similar to that we followed along the southern shore (Pls. 148; 149, fig. 1; 150, fig. 1), while on the greater part of the western face this platform, as has been stated, has disappeared (Pl. 147, fig. 2). 
Off the west shore, from the anchorage to the landing, we found huge patches of corals separated by wide lanes of sand. The mode of formation of the land rim of this atoll is apparently very different from that of any other atoll we have examined, but, as has been shown it is only the last of the successive stages in such widely different atolls as Tapeteuea and Taritari. Dana mentions Maraki as one of the most characteristic and prettiest of the atolls of the Pacific; it must be remembered that he described its general appearance from a chart, and had no opportunity to examine the interior of the atoll, or to trace the mode of formation of its secondary lagoons.

\section{Taritari.}

Plates 151-160; 223; 224, fig. 4.

Taritari, the northernmost of the Gilbert Islands, has much the same angular outline as other atolls of the Gilbert group, but runs east and west (Pl. 224, fig. 4). It is about twelve miles in length, its western face running northwesterly ten miles. The western part of the northern face is concave and convex towards the eastern point of the atoll; the southern face consists of two concave arcs projecting at the centre of the atoll in a sharp point. The land rim of the southern face consists of two principal islands, with islets and bars in the gaps between them forming indistinct secondary lagoons (Pl. 152, figs. 3, 4). The western face of the island, on which is Butaritari, widens out to nearly three miles; towards the east the land rim tapers into a narrow belt less than a third of a mile in width, and ends in a wider hook-shaped point.

The eastern island is narrow, with here and there a spit running out into the wide reef flat, which flanks the southern face of the lagoon, as well as the eastern and western extremities of the atoll. The lagoon of Taritari is full of shoals, islands, islets, and coral patches, rendering navigation extremely difficult. The western face is flanked by three larger islands, and four or five smaller ones, indicating in a general way the position of the broad reef flat forming the western boundary of the lagoon (Pl. 154, figs. 1, 2).

South of Napuni and the adjoining islands are the broad passages which 
lead into the lagoon (Pl. 224, fig. 4), flanked on the north and south with numerous coral patches and shoals, through which a depth of from ten to twelve fathoms can be carried to the anchorage, immediately to the north of the village of Butaritari (Pl. 151, figs. 1-3).

The northern face consists of a narrow reef flat passing gradually into the shallow waters of the eastern part of the lagoon; a few islands widely separated are situated on the face of the wide eastern reef flat.

The atoll of Taritari has, off its northeastern point, a small satellite, Little Makin Island, distant not quite two miles; it is a coral reef flat surmounted with three or four low islands (Pl. 224, fig, 4).

The reef flat at the eastern extremity of Taritari is of great width (Pl. 224, fig. 4); its outer edge is well marked by huge blocks of beach rock conglomerate and of coral shingle, with low islets running into the lagoon at right angles to the trend of the eastern reef flat. The eastern part of the lagoon, adjoining the wide reef flat, is evidently shallow, judging from the light green color of the water. The existence of the islets along the eastern edge and in the horn forming the eastern point shows that they probably are secondary islets, and that the whole of this part of Taritari will soon become an extensive flat upon which vegetation may arise. The outer edge of the eastern horn is flanked by a steep dam of black coral shingle forming a narrow barrier which may eventually become cut up into islands and islets (see Pl. 158). This mode of formation of a land rim on the very edge of the reef platform, where a shingle beach may reach a height of four to five feet, we have not noticed before. The only other case I have observed is that above the central part of the east coast of Taritari, where a shingle ledge islet has been thrown up directly across a gap or bay on the very outer edge of the reef flat (Pl. 157, fig. 2). In this case it is only a diminutive islet, while in the former case an extensive are is formed by a steep coral shingle beach which extends for a great length on the edge of the reef flat, and protects the lagoon from the encroachments of the sea. The little islands and islets fornd on the horn (Pl. 224, fig. 4) are all more or less parallel to the outer reef dam; they have undonbtedly been formed as spits much as they have been described for so many other atolls of the Gilbert and of the Ellice Islands. 
Where the shingle is low the water passes at half or high tide directly into the lagoon, while in other parts of the eastern horn of this atoll, water can only enter the lagoon at high stages of the tide, and in some parts where the beach is highest, it flows around the two ends of the shingle. On the south face of Taritari the land rim is flanked by a series of steep sand beaches, alternating with beach rock conglomerate ledges and coral shingle beaches from four to six feet in height (Pl. 155, fig. 1). Large blocks of beach rock or of conglomerate are often mixed with the shingle.

The larger forest trees characteristic of the South Pacific atolls grow close to the highest point of the beach; there are neither Pisonias nor the scrub vegetation usually met with on the summit of the outer beaches (Pl. 155).

Judging from the position of the line of the breakers, the outer reef flat is extremely narrow. In the gap between the two principal islands of the southern face (Pl. 224, fig. 4) we found a series of islands and islets on the inner face of the broad reef flat forming spits extending at right angles to the outer edge of the reef platform (Pls. 152, fig. $2 ; 153 ; 156$, fig. $1 ; 157$ ), which at this point is marked by a low, steep, coarse, coral rock shingle beach. The islands and outer islets are flanked on their sea faces by beach rock or conglomerate shingle, while on their lagoon face the spits are composed of fine coral sand. This peculiar combination of islands and of low outer beaches with two inner rows of islands forming a secondary lagoon we have described in Tarawa and elsewhere (Pls. 152, fig. 2; 153; 156, fig. $1 ; 157$ ).

At a point near the middle of the south shore we obtained an excellent view across the outer rim, towards the interior of the lagoon, with the islands and islets beginning to build up secondary lagoons (Pls. 152, 153), the outer edge of the reef flat being edged with a high dam of black coral rock shingle (Pl. 158). This dam extends fully a mile to one and a half miles from the gap.

West of the gap on the south face, the shore of the rim of Taritari consists of alternate sand and shingle beaches (Pls. 152, figs. 3, 4; 155, fig. 1), or reaches of beach rock or conglomerate, and flat-topped ledges.

Here and there on the south shore of Taritari we find a still different 
kind of secondary lagoon, formed by the bulging out of the outer edge of the reef flat, and running parallel to a slight projection of the outer shore line of the land rim. One of the best examples of this is south of Butaritari on the south face of Taritari (Pl. 152, figs. 3, 4).

Going west from Butaritari, towards the southwestern point, at the extremity of the main street, we come upon a series of beach rock and conglomerate ledges topped with steep sand beaches and enclosing shallow lagoons. The outer rims of these are quite well defined by knolls of Nullipores and Pocillipores, so that pools of from 50 to 75 yards in diameter are formed extending from the base of the beach on the lagoon side.

West of Butaritari, on the sea face, near the southwestern point, the outer reef flat is edged by Nullipores; on the flat are two or three islets running parallel with the main beach of the island (Pl. 224, fig. 4). At the west point of Butaritari we found the extension of the Nullipore edge which has formed the extensive flat running from the southwest point northward, and immediately behind it a steep weathered coral shingle beach covered with vegetation. From the beach a spit covered with only scant vegetation cuts directly across the reef flat towards the shore of the island, and forms a secondary lagoon, isolated, or only connected very indefinitely with the main lagoon of Taritari.

On the west side of the southwest point, near the village of Ukiaññañ, we found that the southern extension of this wide reef flat becomes gradually narrower as it reaches the village, and finally becomes a part of the main shore of the island itself (Pl. 154, fig. 4), widening out again to a certain extent towards the southwest point. The Nullipore boulders which have been thrown up on the shore (Pl. 154, fig. 4) consist of large rounded masses; they are mixed with round heads of Porites, Mæandrina, and the like, and are gradually being pounded into coarse black shingle. This, in its turn, is ground still finer, and forms the short sand beaches alternating with beaches of Nullipore boulders. This coarse black shingle beach resembles that of the west face of Maraki.

A part of the southern area of Taritari is similar in structure to that of the western side of Maraki. The secondary lagoons occupying the great expanse of the southwest point of Taritari encroach upon its outer 
reef flat; this is gradually disappearing, as we traced it on the west side of Maraki.

From the western spit of the south shore of Taritari extends a long reach of black coral shingle forming the sea face of the southwestern part of the atoll and the eastern side of the entrance to Taritari (Pl. 154, figs. 2, 4). The extension of the sea face of the spit is formed by a series of low islets connected by ledges and covered with scrub vegetation. The vegetation gradually becomes more scanty, and finally disappears from the northern islets and sand bars. On the north side of the passage a stretch of disconnected islets forms a barrier parallel with the western opening into the lagoon (Pls. 154, figs. 1, 3; 224, fig. 4). To the south of the passage the great expanse of the shallow lagoon is occupied by numerous shoals (Pls. 151, figs. 1, 2; 224, fig. 4).

When about three miles from the western edge of the passage, we turned in towards the anchorage (Pl. 151, figs. 1-3). On our way we passed islets, shoals, flats, and bars, separated by deep lanes of blue water, the bottom between them consisting of white mud formed from the disintegration of the corals or Nullipores growing on the flats. The islands (Pl. 154, fig. 3) and islets to the north of the southern ship passage are better wooded than those to the south; they form only a very imperfect barrier to the sea, which sweeps into the lagoon over the whole of the wide western flat (Pl. 224, fig. 4). Between the shoals most intricate passages connect the lagoon with the sea on the western face of the atoll (Pl. 224, fig. 4). A section across the land rim to the south of Butaritari shows a secondary platform lagoon on the sea face of the outer reef flat edged with Nullipore and Pocillipore knolls, forming a shallow sink; the reef flat is not more than 150 feet in width; it rises gradually towards the base of the beach, this is fringed with beach rock and coral conglomerate and rises to a height of about seven feet. From the summit the slope runs gradually to the edge of the lagoon; a narrow sink exists immediately behind the beach near the sea face. At the foot of the long slope, on the lagoon side, the beach ends in a low steep coral sand beach, and the face of the slope is covered with weathered fragments of broken coral gradually worn into the coarse sand of the beach. The sink on the lagoon face of the slope is in places changed 
into a secondary lagoon of considerable size, showing that it has been formed by the throwing up of the lagoon beach as a dam across a part of the low reef flat, and enclosing it, has formed the secondary lagoon. The bottom of the lagoon is covered with masses of Algæ, and where the bottom has been exposed as on the edges of sinks, or secondary lagoons, it is soft and spongy.

From the shore to the west of Butaritari a wide mangrove flat extends into the lagoon almost to the channel (Pl. 151, figs. 2, 3); it is covered with fine silt, composed of coralline Algæ and extremely fine coral sand, and scattered over it are large patches and masses of dead Porites, but in situ (Pl. 159, fig. 1). On our way to the southwestern spit we also came upon a number of secondary lagoons, formed by the shutting off of parts of the flat of varying depth, either from the seaside beach shelf or from the lagoon side, by spurs from the outer or inner lagoon edge (Pl. 158, fig. 1), or by ridges and dams thrown up in succession at a time when the flat was open to the lagoon and formed a part of its reef flat. One of these secondary lagoons was fully a mile in width (Pls. 159, fig. 2 ; 160, fig. 1). The flats, ridges, and dams are covered with low bushes, grass, and cocoanut trees. Some of the secondary lagoons are hardly to be distinguished from large sinks, surrounded as they are by vegetation (Pl. 160, fig. 2). Everywhere on the land rim we found Taro sinks.

On reaching the village of Ukiañnañ, on the west face of the island, we came upon a steep coral shingle beach, formed by the breaking up of beach rock conglomerate, and masses of Nullipores and Pocillipores, with fragments of huge Tridacnas, as well as other shells (P]. 151, fig. 4). The breakers pounding upon this material have broken it up into coarse coral shingle. The beach is steep on the lagoon side; to the rear the ground slopes very gradually towards the immense flat and secondary lagoons over which we walked for a distance of about five miles, and which forms the western extremity of the island on which is Butaritari village. Some of the coral shingle material has become cemented, and forms a coarse beach rock conglomerate or breccia, composed sometimes of rounded fragments, and sometimes of more or less angular pieces of beach rock.

On our way to examine the eastern part of the atoll of Taritari, we 
landed on the first of the islets of the lagoon; it is entirely made up of fine coral sand and coarse coral shingle, about three feet in height, and perhaps 50 wide, and 100 feet long. Blocks of beach rock conglomerate were scattered in all directions, many of them had been pounded into more or less fine coral sand. From the edge of the beach, extending down into the deeper water of the lagoon, were growing fine coral masses and heads, mainly Madrepores, Pocillipores, and Porites. Very few heads were seen at a depth of sixteen fathoms; there the bottom consisted entirely of wide lanes of coralline or coral sand separating the few coral heads still left.

From this island eastward we made a number of soundings in the lagoon, passing gradually from 17 to 11 to 3 fathoms off the lagoon reef flat extending across the gap (Keuea gap) between the principal islands of the sonth face of Taritari.

At the gap north of the south horn of Taritari a row of islands runs at right angles to the coral shingle beach; they are covered with cocoanut trees and low brush (Pls. 152, figs. 1, 2; 153; 156, fig. 1). The reef flats connecting the main islands on each side of Keuea gap are left bare long enough to be used as a wagon road during certain stages of the tide.

On the lagoon face of the main islands of the land rim extends an immense Millepore flat fully three quarters of a mile in width (Pl. 224, fig. 4), and to the west of Keuea gap the flat juts out to a point nearly half-way across the lagoon. The formation of this flat, covered with dead Millepores, overgrown with Nullipores and coralline Algæ (Pls. 155, fig. 3; 156, fig. 2), is readily explained by what we observed on the patch of Millepore heads which connects the shore of one of the islets in Keuea gap with the outer sea ledge. On going from the sea beach of the islet north of the gap (Pl. 156, fig. 1), towards the outer edge of the reef flat, we come upon a huge dam of large blocks of beach rock and of beach rock conglomerate thrown up on the reef flat (PI. 158, fig. 2), so as to form inside of it, and between it and the eastern beach of the islet, a deep and wide secondary lagoon (Pl. 158, fig. 1), in which Millepores are growing in great profusion. The top of the heads of Millepores, as they arose and became exposed to the air and the action of the sea, were gradually killed, and formed a pave- 
ment of huge square or oblong or irregularly shaped masses of coral, with flat tops, on which were growing Nullipores. Between these blocks was left a labyrinth of passages or of narrow lanes covered with fine coral sand, the depth of which varied from two to three feet of water. At low-water mark one could walk across, on the top of these blocks, from one to the other, and thus reach the sea face of the dam thrown up by the sea on the outer edge of the reef flat, and partly derived from the breaking up of elevated modern reef rock. The secondary lagoon behind the dam (Pl. 158, fig. 1) is about 200 feet in width, and extended from the northern side of Keuea gap as far as the southeast point of the main islind of Taritari (Pl. 224, fig. 4); the outer dam forming a barrier to what might be called a platform barrier reef lagoon, which varied greatly in depth according to the level of the underlying reef flat platform. On the west face of this secondary lagoon the shore beach of the island forming the land rim ( $\mathrm{Pl} .157$, fig. 1) is about eight feet in height, and slopes very gradually towards the lagoon face, where we come upon the continuation of the reef of Millepores, we have just described, which has been covered by this inner dam (Pl. 155, fig. 3). The Millepore reef flat must once have extended out from the east face of the land rim, before the existence of the great dam now forming the breaker to the disintegration of the existing islets of the land rim.

There must have been a time when the Millepores were abundant in the outer secondary barrier reef lagoon, and when those on the wide lagoon reef flat were connected with them, as they are now connected in the gaps between the islands, before a part of the Millepore flat was covered by the material thrown up on the higher parts of this immense flat, both from the lagoon side and from the sea face. As the Millepores cropped up at the surface, the labyrinth of passages between the clusters became gradually filled, as fast as the tops died and were broken off by the action of the sea or from other causes. The Heliopora reef described by Mr. Henley and Professor Sollas at the eastern horn of Funafuti owes its origin to similar canses. There was a time when the different belts of the island itself held to the lagoon the same relation which the outer breakwater now holds to the secondary platform lagoon, formed between it and the outer breakwater; as we walked across the island (Pl. 157, fig. 1), we observed in several direc- 
tions, bands of the same shingle beach and masses of conglomerate rock which characterize the outer beach. As the inner island was not exposed to as violent an action of the sea as is the present outer face of the reef flat, the boulders thrown up to constitute the line of islands forming the land rim of Taritari are much smaller than the huge blocks thrown up by the rollers on the very edge of the outer reef. The fine coral sand beach on the lagoon side of the land rim is formed from the dead tops of Millepores, and from fragments of Nullipores, broken up and ground into fine coral sand by the action of the waves of the lagoon itself. The secondary

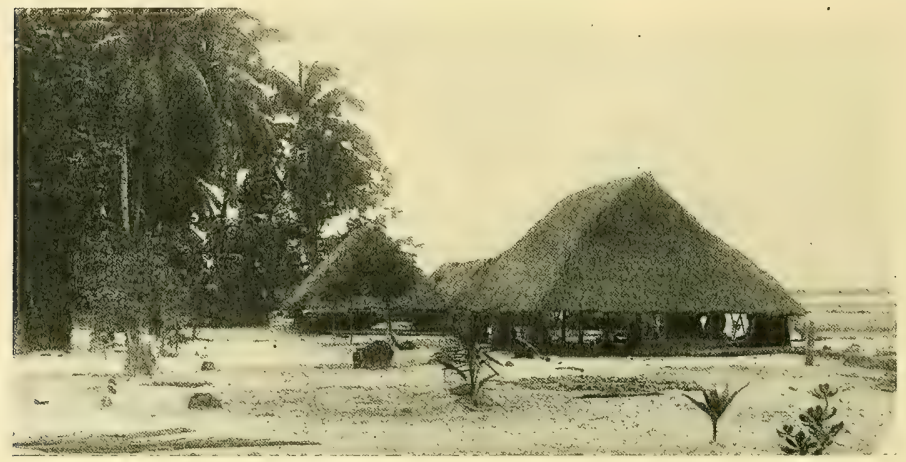

Keuga Village, Taritari.

lagoon flanking the eastern face of the land rim is, in some places, entirely shut off from the main lagoon by dams connecting the islets formed on the outer edge of Taritari (Pls. 157, fig. 2; 158, fig. 1), while at other points extensive gaps still exist, as between this islet and the main island, where the village of Keuea is situated, forming a shallow reef flat upon which numerous islets are thrown up by the waves of the lagoon, forming spits at right angles to the great dam of the outer edge of the reef flat. Between these islands and islets are passes connecting different parts of the main lagoon; elsewhere the outer dam only protects a deep bay, bare at low water, in which numerous islands and islets exist formed by the action of the waves of the lagoon. 
The dam or ledge on the outer sea face (PI. 158, fig. 2) was composed of huge masses of coral beach rock and conglomerate piled up in endless confusion, forming mounds of different heights, more or less connected (Pl. 15ร, fig. 1); on some of these the inner side, or sometimes the upper part of the dam had been weathered and worn and honeycombed and broken into sand sufficiently fine to allow vegetation to obtain a foothold. Here and there we found little tufts of low bushes and shrubs growing on the summit of the outer dam, as they once began on the summit of the inner row of islands (Pl. 157, fig. 2); these have gradually become connected either by the formation of dams from the inside of the lagoon, or by the building up of the main dam on the outer edge of the reef flat; this has changed the gaps between the islands, which once connected the lagoon with the outer sea, into bays opening either on the sea face or on the lagoon face (Pls. 153; 156, fig. 1; 157).

The shores of the sand bars and spits of the islands and islets and the inner shore lines of the gaps or of the bays were generally covered with masses of dead shells. From the number of dead tests of Metalia, Echinonëus, Laganum, and Spatangus mixed with the shells, they must live in great numbers in the shallow and protected waters on the bay side.

The changes going on at certain points of the great outer sea dam show that the material piled upon the outer sea face gradually becomes broken and ground, and forms first a shingle beach, and finally a fine coral sand beach. Nowhere is there a better example than at Taritari of the process by which additions are made to the land rim, and material is thrown up on the flats, both on the sea face and on the lagoon face, and of the formation of secondary lagoons, of huge bays or small gaps, by the gradual cutting off of extensive areas of the reef flats, and their isolation under conditions due to the prevalence of the trades, and to the general direction of the wind, both on the lagoon side and on the sea side.

In Kenea gap the flat is covered with dead Millepores, the interstices between them must have been rapidly filled by sand and ooze, by fragments of dead shells, and Nullipores; the whole became cemented, leaving only here and there an occasional Millepore head cropping up above the general level to indicate the character of the corals which have built up the 
immense reef flat flanking the lagoon side of the southern face of Taritari. The cementing of slab shingle on the top of the Millepore heads killed by Nullipores shows how living and dead corals may alternate and strata be passed through in which some coral is found in its natural attitude, while the rest appears as if it had been transported by the sea a considerable distance. This certainly is not the case on the extensive flats of Taritari, where the old material, or rather the dead material, is still in place occupying the position it had when forming a part of the great living coral reef flat of the lagoon.

On the lagoon flat to the west of the village of Butaritari (Pl. 159, fig. 1), the Porites covering the flat have been killed by a process identical to that which has changed the great thriving Millepore reef of the eastern part of the atoll into a shallow flat, over which are scattered small slabs of Nullipores, and fragments of dead Millepores, the whole covered with coral sand and ooze. On the wide Porites flat forming the extremity of the land rim to the west of Butaritari, certain parts have been cut off along given lines by accumulations of material derived from the dead Porites and have enclosed limited areas constituting secondary lagoons. Scrub vegetation, forest trees, grasses, cocoanut trees have sprung up on the bars thus formed, and from the decay of the vegetation and the killing of the Porites in the enclosed areas by exposure or by the growth of Nullipores, the shallow circumscribed flats have gradually been filled, leaving only indistinct areas, occupied by pools separated by belts covered with vegetation, slightly higher than the general level of the western part of the island west of Butaritari.

The high coral shingle beach on the western face of Butaritari, the great shingle and boulder dam, extending north from the southern point on the very edge of the outer reef flat, and the great sea wall running north from the eastern point of Taritari, all clearly indicate how the wide reef flats of these faces of the atoll have been shut off from free access to the sea, and how an outer barrier has been formed behind which the land rim of Taritari has slowly developed.

The first indication of the formation of an islet on the outer reef flat consists of a line of coral shingle thrown up to a height of not more than four 
or five feet above high-water mark; when this shingle has been pounded into more or less coarse sand, vegetation begins to grow (Pl. 157, fig. 2), and the islands and islets thus formed become connected, until a large island is formed by the union of the smaller ones (Pl. 157, fig. 1). In this way the land rim of Taritari, which on the south shore is composed of two larger islands of no less than eight and six miles in length (Pls. 152, figs. 3, 4; 155, fig. 1), was undoubtedly formed. Here and there indistinct gaps still exist to indicate the nature of the changes which have taken place, and are still going on at the eastern, northern, and part of the southern faces.

Numerous shoals and coral patches exist in every part of the lagoon we examined (Pl. 224, fig. 4). On the slopes of the shoals large heads of the different species of corals mentioned above are seen to a depth varying from ten to sixteen fathoms; here, as elsewhere, the number of species which flourish in the lagoon is comparatively small. We examined no less than six of these little sand islets, on our way to Keuea. According to the chart of Taritari $^{1}$ (Pl. 224, fig. 4), the lagoon to the northward is full of ledges, shoals, and islets; we passed through a number on our way to the anchorage, and while in the atoll could see them rising against the horizon in all directions and again when steaming along the west face of Taritari (Pl. 154, fig. 3).

Passing out of the western channel of Taritari, we had the opportunity of noticing the structure of the land rim of the northwest point of the atoll; we could see that the islets on the outer edge of the reef flat were forming at right angles to its general trend (Pl. 224, fig. 4), as sand spits extending towards the lagoon, flanked on the sea face by ledges and boulders of beach rock or coral conglomerate, while the lagoon end of the spits consisted of fine coral sand. We observed nothing of special interest on the west face of Taritari.

Napuni Island is a long narrow island (Pl. 224, fig. 4), or rather a sand spit with rocky ledges; it extends north and south a distance of nearly two miles on the sea face of the wide outer reef flat. Beach rock coral conglomerate and boulders characterize its sea face, while shingle and coarse sand are thrown up on the lagoon beaches. 
The northwest passage is, like the western passage, formed by a gap in the outer reef flat, flanked on one side by a low islet running at right angles to it, edged with beach rock and terminating in a long sand spit. On the other side of the passage is a similar island edged with beach rock on the sea face; this passes gradually into a low sand spit forming a part of the immense reef flat and system of shoals and islets which edge the northwestern horn of the lagoon of Taritari.

The islands and islets on the west face of Taritari are very scantily wooded. Pandanus begin to grow to the westward of the southern point, and the summit of the beach and the lagoon side of the islands on the outer reef flat are covered with Pisonias, with scrub vegetation, and tall hardwood trees. Nowhere have we seen finer groves of cocoanut trees; they attain a colossal size, grow thickly in an unbroken mass (Pls. 152, figs. 3,4 ; 155, fig. 1 ; 157, fig. 1 ), and both here and at Maraki are perhaps the finest cocoanut groves of the tropical Pacific.

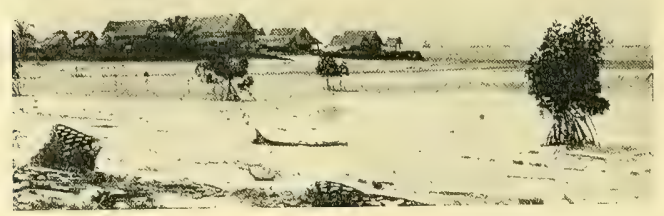

Lagoon Flat, Taritari, 


\section{THE IIARSHALL ISLANDS.}

Plates 161-182, figs. 1, 2; 225; 226, figs. 4-10; 227, 228.

After a few days spent in coaling at Jaluit we passed about three weeks in exploring the Marshall Islands, taking in turn the representative atolls of the Ralick Chain to the north of Jaluit: Ailinglab Lab, Namu, Kwajalong, and Rongelab, and then some of the atolls of the Ratack Chain, Likieb, Wotje, and Arhno. The atolls of the Marshall group are noted for their great size and the comparatively small area of the outer land rims, in some of the atolls they are reduced to a few insignificant islands and islets.

In none of the atolls of the Ellice or Marshall groups, and only in a few of the Gilbert Islands were we able to observe the character of the underlying base forming the foundations of their land areas. In this respect these groups are in striking contrast to the Paumotus, the Society and Cook Islands, Niue, the Tonga, and the Fiji Islands, where the character of the underlying foundations of the land rims is readily ascertained. In a group like the Marshalls, we have as our guide for the character of the base rock only that of the Caroline Islands, which is volcanic, while Nauru ${ }^{1}$ and Paanopa Islands, to the west of the Gilbert and to the southwest of the Marshall Islands indicate a base of tertiary limestone.

The monotony of structure of the Marshall Islands ${ }^{2}$ is very striking. They are all more or less irregular in outline, and generally run from southeast to northwest, with the exception of Ailinglab Lab, Mille, Majuro, and Wotje, which run east and west. But the general direction of the atolls of the two chains is practically the same. They evidently are summits of a line of peaks or of ridges, forming on the one side the Ralick Chain, and on the other the Ratack Chain, with spurs or parallel ridges indicating the line of islands which run north of Wotje to Ailuk, Utirik, Bikar, and Taongi, or the line of the small atolls of Kili, Lib, Lae, Ujae, and of

1 Nauru, von Dr. Augustin Krämer. Globus, Vol. LXXIV., No. 10, September, 1898.

${ }^{2}$ Pläne von den Marshall Inseln; Hydrog. Amt d. Reichs Marine Amts, No. 113, 1890. 
Eniwetok, which is more or less parallel with the Ralick Chain, while another line having the same trend is formed by Ebon and Namorik.

Parallel with the western face of Taongi, an extensive secondary lagoon has been formed, similar to those we have described at Jaluit, and at many atolls in the Gilbert Islands and the Paumotus.

Mille is characterized by a small satellite, elliptical in outline, about five miles in length, and two in its greatest width; its southwestern shore is flanked by large islands, while the northern face of the atoll is indicated by a comparatively bare reef flat. The depth of the lagoon varies from two to three fathoms; there is an opening on the northwestern face for boats. As will be seen from an examination of the charts, in such atolls as Mille, we find the passages, of which there are a large number, well indicated by great sand spits and sand bars extending far into the lagoon, as for instance the Reiher and Burrh Passages. The islands west of Lukunor on the south face, and the islands and islets opposite the passage in the southern face all indicate the part which the trades have taken in depositing these bars and islands and shoals near the openings forming the ship channels. The atolls of Wotje, Mille, and Majuro are similar in outline. The Eniwetok group, on the other hand, is somewhat circular. The islands of its land rim are scattered more profusely on those parts of the reef flat upon which the trades have the greatest influence; its lagoon is from eighteen to twenty-five fathoms in depth.

In all the atolls of the Marshall group the slope from the shore on the lagoon side is comparatively steep; the inner reef flat however varies greatly in width, according to its position near a gap or near a pass, or near the central part of an island of the land rim of greater or less dimensions.

The atolls of Odia (Ailinglab), Rongelab, Wottho, Likieb, and Rongerik are very similar, with the exception that the spits of Rongelab and Odia turn towards the east, while that of Likieb turns towards the west. The atolls of Aurh, Maloelab, Erikub, and Ailuk are also similar in structure; their western faces are open to the sea, as is the case in some of the atolls of the Gilbert Islands, like Tarawa and Tapeteuea. Situated on banks of irregular outline, and but imperfectly known, are the islands of Utirik and Taka, the atoll of Bikar, which might perhaps be classed with Aurh. Mejit, 
Jeno, Lib, Kili, and Jabwat are small islands, the summits of diminutive ridges surrounded by reef flats similar to those of somewhat smaller islands, like Tikei and others in the Paumotus.

I am informed by our pilot that Lib and Mejit both have shallow, diminutive lagoons filled with brackish water, entirely shut off from the sea, with neither corals nor fishes, and only a few diminutive shells living in the lagoon. Jemo has no sink, and is flat. Jabwat and Kili have small sinks in which water collects. Jaluit, Namu, Kwajalong, Ujae, and Wottho are more or less elongated, irregularly shaped atolls. Arhno is the most peculiar atoll of the Marshall group, with characteristics of some of the other atolls extravagantly exaggerated. Finally, Ebon, Namorik, and Lae, three small atolls, six to seven miles in diameter, circular in outline, approach nearer the condition of a theoretical atoll than any of the other islands in the Marshall group. These form the principal types of atolls of the Marshall Islands. The western faces of Namorik and Lae are formed by a narrow reef flat; while in Ebon the western shore slanting slightly towards the south is occupied by islands of considerable size, through which a long and intricate pass leads into the lagoon. The lagoon of Ebon varies from eighteen to twenty-five fathoms in depth. That of Namorik has recently been gradually filled up, as it is impossible for a schooner to pass the western reef flat; when first visited by whites, schooners of considerable size anchored in what is now a closed lagoon as far as navigation is concerned. In Ebon a pass from the westward leads into the lagoon with a depth of from ten to twelve feet. The western face of Ebon is flanked on its lagoon side with innumerable sand spits, sand bars, and coral patches; the passes into the lagoon are completely blocked by numerous shoals which extend through it.

Ujelang, one of the Marshall Islands, nearly 300 miles to the west of Ujae, has the same general direction as the islands of the Ralick Chain. It is eleven miles in length, with a greatest width of about two and a half miles; it is evidently the summit of a long narrow ridge to the west of the Marshall Islands. The depth of its lagoon is said to be eighteen to twenty fathoms, and numerous coral patches and sand bars are scattered through the interior. 
The land rims of all the atolls in the Marshall Islands are really insignificant in comparison with the wide expanse of the lagoons they enclose; their depth as well as that of the passes is also remarkably uniform. The conditions existing over the Marshall group are less varied than they are in any of the other groups of atolls we have examined; there is not even the same diversity which exists among the atolls in the Paumotus. The amount of moisture which falls in the Marshall Islands is not only great, but most constant, and, owing to the varying position of the faces of the atolls with reference to the trades, we find in consequence the vegetation far more luxuriant than on the Paumotus, although the extent of the land rim is much more limited. Dana has made an approximate estimate of the land areas of some of the atolls of the different island groups $;^{1}$ they show remarkably well the conditions which have resulted from the peculiar geographical position of the Paumotus as contrasted with the Marshalls, or the Marshalls as contrasted with the volcanic atolls of the Carolines and of the Society Islands. It is evident that in the case of volcanic islands, like those of the Society Islands, the Fijis, the Carolines, Samoa, and the Cook Islands, the land areas are, in consequence of the greater hardness of the volcanic rocks, far greater in proportion to the extent of the lagoons than in such districts as Lau in Fiji, where the atolls are either elevated coralliferous limestone islands, or where they are partly limestone and partly volcanic; or in the extensive areas of the Paumotus, where they are coralliferous limestone. When we come to groups like the Marshall, Ellice, and some of the Gilbert Islands, there is no such connection between the dimensions of the lagoon and the land rim; the foundation has been eroded and much of the material which forms the land rim is constantly shifting backward and forward during the existence of the trades; it is thrown up in one direction on the narrow land rim in favorable exposures, while it is eaten away from the opposite side during the prevalence of the westerly winds. In the Marshall Islands, where the lagoons present such a long reach to the prevailing trades, we often find on the lagoon face, either on the eastern or western sides of the atoll, an amount of mechanical work performed during the season of the

\footnotetext{
1 Dana, loc. cit., p. 169.
} 
trades, entirely out of proportion to that which takes place in smaller atolls, although they are exposed to the same conditions, but where the sea does not gather the strength it attains in these gigantic atolls.

It will be seen on examination of the charts of the various Marshall atolls that the land rim is especially developed on the side exposed to the raking of the northeast trade. It is somewhat less developed on the faces where the trades strike the shore at a greater angle. The land rim on the southern and western faces is usually bare of islands and islets. This is well seen at Namu, where the bulk of the land rim is on the southern and eastern faces, while the western and northern faces, except at the northern horn are a belt of reef flats awash. In Odia, where the west coast faces almost southwest, the effect of the trades in throwing up the land rim is more apparent. It is somewhat less so on the southeastern face and hardly appreciable on the northwestern face. Similarly we may trace the effect of the trades on the extent of the land rim of the irregularly shaped Menschikov atoll. Wherever the coast line faces the general trend of the trades, the narrow land rim of the Marshall Islands is found; wherever, on the contrary, it runs more or less parallel to it, the land rim is limited to a few insignificant islands and islets; where the outer face of the lagoon is protected during the greater part of the year, the land rim is still more insignificant, or becomes a belt awash. Where any part of the land rim is exposed to the northwest winds a few islands and islets are thrown up on a part of the reef flat which is usually protected from the eastern trades. By carefully examining the charts we may usually determine the causes which have brought about special conditions on short stretches of the outer land rim in such irregularly shaped lagoons as Menschikov, Namu, Arhno, and others.

The amount of water forced by the trades into the lagoons of the Marshall Islands must be very great, the land rim being reduced to a minimum, and a large proportion of the outer rim often covered by a considerable depth of water either on the lee or on the weather side. The islands and islets of the land rim are, except in occasional instances, the merest threads of land; the lagoon is often separated from the sea by a dam not more than six to seven feet in height, and sometimes not more 
than twenty to twenty-five feet in width; the outer reef platforms likewise are often very narrow, in marked contrast with the wide reef flats of some of the Paumotu or Fiji Islands. Again the land rim is often composed of a number of small islets separated by gaps of greater or less depth, nearly as large as the islands they separate, allowing additional circulation into and out of the lagoon. In fact, as has been noticed before, there is no group of atolls where the land rims are reduced to such an insignificant area as in the Marshall Islands, and where what are usually shallow gaps become deep passes with sufficient water to allow the entrance of large ships. In the atolls of the Marshall Islands the number of passes suitable for navigation is in marked contrast with those of other atolls (Pls. 226, 227), especially in the Paumotu and Fiji Islands. It is not uncommon to find passages varying from eight to twenty fathoms, or in fact as deep as the deepest part of the lagoon itself. This would seem to indicate that the material forming the outer rim of the Marshall Islands atolls rested upon a submarine platform of a depth varying from eight to twenty fathoms, and that the mass of material kept in motion and affected, according to the local conditions, by the sea and by the winds, forms the special feature of each atoll in the Marshall Islands.

Although the trades are the principal winds at work shaping the land rims of the Marshall Islands, yet during three months westerly winds prevail during the change of the monsoons. When the length and trend of some of the lagoons is taken into consideration, we may have acting upon the lagoon sides of the land rim, especially on the beaches of the western islands, waves nearly as powerful as those beating on the eastern side of the same islands during the trades. Thus the movement of loose material on the lagoon side is far more extensive on the exposed patches and reef flats of the western slope of the eastern islands of the land rim, than is usually the case in lagoons of a smaller size. The reach which the sea obtains during westerly winds, or during the season of the trades, is often from forty to sixty miles, a distance great enough to act with considerable force on the movable material of the land rim of these atolls.

The level at which some of the dead coral heads still in place are found, 
as, for instance, at Gehh and Tengeli on the west face of Menschikov, and the manner in which they are worn, or undercut, and form walls or isolated tables, as it were, would seem to indicate a slight elevation perhaps of a couple of feet, since the corals flourished on the reef flat.

The amount of sand which floats off from a lagoon and is blown to sea is very considerable; fresh material is constantly added from the beaches, from the spits, and from the gaps along the land rims of such atolls as Likieb and others in the Marshall Islands. The distance to which sand can be carried by the trades is clearly shown by the amount of sand we found in our nets in all the surface hauls in the Marshall Islands when off the lee side of the atolls; sand is floating there in considerable quantities. Off the east coast of the United States, from Cape Hatteras south, shore sand is carried out to sea by the prevailing westerly winds to a very considerable distance.

It is interesting to compare the charts of the great groups of atolls in the tropical Pacific, and to note the extensive differences existing in the outlines of the atolls. Taking the Paumotus, as a whole, the atolls are elliptical; the few of irregular outline have rounded corners, and a number are circular (Pls. 201-206). In Fiji many of the Lau Islands are most irregular in outline; others, on the contrary, are circular or elliptical (Pl. 220).

The principal atolls of the Ellice Islands are of very different shapes (Pls. 221, 222). In the Gilbert group we have atolls varying from triangular to rectangular and elliptical or angular shape; not a single atoll having the so-called typical outline (Pls. 223, 224, 226).

In the Marshalls a few atolls are circular, ${ }^{1}$ but the majority of the large atolls vary even more in shape than those of the groups we have enumerated (Pls. 225, 227, 228).

The Carolines likewise vary greatly in outline (Pls. 229-233), both the voleanic islands as well as the low groups. In fact, by far the great majority of the atolls of the tropical Pacific are irregular in outline, and it would be impossible to detect from the charts their resemblance to the typical atoll.

1 Kubary has given an excellent account of Ebon and a sketch of the main pass into the atoll. Journal d. Mus. Godeffroy, Heft I. p. 33. 
We made a number of soundings from south of Nurakita towards the Marshall group $;^{1}$ these, in addition to those of the "Penguin," clearly show that the Ellice Islands are isolated peaks (Pl. 221) rising from considerable depths (from 1500 to over 2000 fathoms), and that the same is the case with the Gilbert Islands (Pl. 223); Maiana, Tarawa, and Apaiang however being summits of a secondary plateau with greatest depths of 413 fathoms (Pl. 223). The thirty soundings we made between the atolls of the Marshalls (Pl. 225) ${ }^{2}$ indicate that they also rise as independent peaks or ridges, with steep slopes, from 2000 to 2500 fathoms. The atolls are not connected by a great plateau or a broad ridge as would seem to be indicated by the trend of the atolls in tivo parallel lines, forming the two sides of the Marshall Islands group. The parallel chains of atolls of the Marshalls,

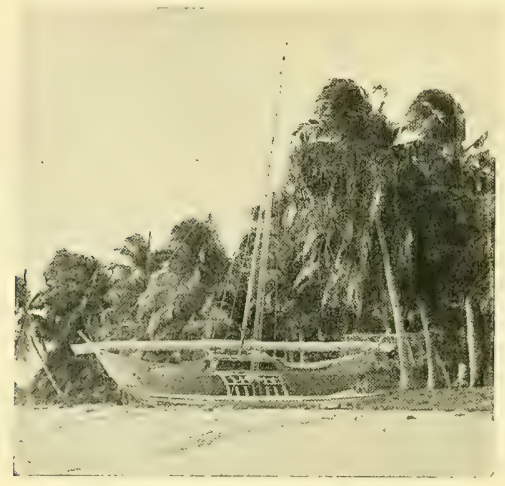

Marsifall Island Canoe,"Wotje. the Ralick, and the Ratack are really only the summits of isolated peaks rising but a few feet above the sea level. The soundings between Elmore and Namu are not as deep as between other atolls of the group; they indicate a connecting ridge with a greatest depth of less than 1100 fathoms (Pl. 225). Between Rongelab and Ailinginae even shallower water is indicated. The Gilbert and the Marshall Islands are separated by great depths, over 2500 fathoms. South of Nurakita towards Fiji no depths greater than 2000 fathoms have as yet been reported (Pl. 221). The Marshall, as well as the Ellice and Gilbert Islands, seem to be somewhat higher than the Paumotus; but this difference is only apparent, and is due to the difference in the height of the tides; it is very small in the Paumotus, while in the former groups it may be five and even seven feet.

After leaving Arhno, our soundings indicated that we had struck the

1 Mem. M. C. Z. XXVI., No. 1, Prel. Rep., p. 61, Stations 194-207, 1902.

2 Loc, cit., Stations 208-237. 
deep basin we encountered between the Gilbert Islands and Jaluit, and its extension in the northern Marshall Islands, a comparatively flat basin varying between 2200 and 2600 fathoms in depth, the spurs of which form the channels between the atolls.

The vegetation of the atolls of the Ellice, ${ }^{1}$ Gilbert, and Marshall Islands ${ }^{2}$ is more luxuriant than that of the Paumotus, probably from the greater rainfall, though the number of species of plants characteristic of the western atolls is not much greater. It is only in the larger western volcanic islands - the Fiji, ${ }^{3}$ Samoan, and Caroline ${ }^{4}$ group - that we note the marked increase in the number of species of forest trees allied to those occurring still farther west, over those on the eastern groups, like the $\mathrm{Cook}^{5}$ and Society Islands.

\section{Jaluit.}

Plates 161-166, 167, fig. 2; 225 ; 226, figs. 4-10 ; 227, figs. 1-3 ; 228, fig. 2.

The atoll of Jaluit is rectangular in shape; the eastern and western faces, however, run to a point towards the north; it is about thirty miles in length and seventeen miles in width (Pl. 226, fig. 6). The land rim to the south of the southeast passage forms the island of Jaluit, a long, extremely narrow strip of land (Pl. 161, fig. 1), in places but a few yards in width. It consists of a high coarse shingle beach (Pl. 165, fig. 1), extending from Jabor to the southern point of Jaluit, where it forms a sharp angle, and extends north about three miles. Across the lagoon angle of the southern horn extends a wide triangular reef. The northeast coast from the eastern cape to the northern point consists of a series of small islands and islets separated by gaps and shoals with a number of deeper passages between them.

1 See C. Hedley, General Account of the Atoll of Funafuti, p. 20, for an account of the flora of the Ellice Islands.

2 There is an excellent account of the plants of the Marshall Islands by Betche, Gartenzeitung 1884 , p. 133.

8 A full account of the flora of Fiji will be found in Seemann, Flora Vitiensis. The Algæ and corallines of Fiji, Tonga, Samoa, have been described by A. Grünow in Jour. d. Mus. Godeffroy, Heft VI. p. 23. The lichens of the Tropical Pacific are enumerated by Dr. A. $\mathbf{v}$. Kampelhuber in the Journal d. Museum Godeffroy, Heft IV. p. 269.

4 Ponapean Trees, Plants, Shrubs, p. 328. The Caroline Islands, by F. W. Christian.

5 A list of the ferns of the Cook Islands has been published by C. Luerssen in Jour. d. Mus. Godeffroy, Heft I. p. 59. 
Some of the islands on the east face, like Medjado, Emidj, and others, near East Cape, are of considerable length, being over three miles, but all are exceedingly narrow, slender threads of land, forming a land rim flanked on the sea face by high shingle beaches, on the lagoon face by sandy beaches and spits which project out on the lagoon flat of the atoll (Pl. 162, fig. 2). Many boat passages exist between the islands and islets, both on the western and on the eastern faces. There are three main ship channels, the southeastern (Pl. 161, fig. 2), the northeastern (Pl. 162, fig. 2), and the southwestern passage (Pl. 163, figs. 1, 2), all in the southern half of the atoll (Pl. 226, fig. 6), and deep enough to allow large ships to enter the lagoon. Over the whole lagoon are scattered numerous flats and coral patches. These, however, are most extensively developed on the flats of the lagoon side in the vicinity of the ship passages which extend from two to three miles out into the lagoon (Pl. 226, fig. 6); the flats are formed by the sand which blows in from the sea face of the ship passages and has gradually extended the land rim as gigantic spits into the lagoon. In fact the flats flanking the ship passages represent, on a large scale, the spits found on the lagoon side of the smaller gaps between the islets and sand bars of land rims not only in the Marshall Islands, but also in the Ellice and Gilbert groups.

It will be noticed that at Jaluit the greatest area of land is on the weather face of the atoll (Pl. 226, fig. 6). The entrance into Jaluit Harbor (Pl. 228, fig. 2) was surveyed by the officers of the "Albatross"; their survey shows clearly the peculiar sand flats and sand bars which have been thrown up by the currents and by the trades on the lagoon face of the northern and the southern side of the entrance into Jaluit. The average depth of the lagoon is from ten to fifteen fathoms, though there are large stretches of the lagoon where the depth varies from twenty to twenty-five fathoms. The southwestern face of Jaluit (Pl. 226, fig. 6), between Pinglapp Island, the western horn of the atoll, and the south point is flanked by a submerged reef flat as far as the southwest pass, and beyond by a narrow land rim with islands and islets (Pl. 163, figs. 1-3), much as is the eastern face.

The islands are flanked by low coral shingle beaches, alternating with 
reaches of large rounded boulders of beach rock or coral conglomerate; the summit of the steep beach is covered with low vegetation; behind it rise a few cocoanut trees, forming a slender line on the narrow land rim of the atoll.

The land rim of the southeastern part of Jaluit is certainly narrower than that of any of the many atolls which we have seen thus far. The outer reef platform itself is also narrow, judging from the position of the line of breakers as we saw it when steaming north along the east coast of Jaluit from the southern point. On the eastern land rim, north of the south point of Jaluit, there are comparatively few cocoanut trees and Pandanus, and here and there only a few large hardwood trees, standing out in the narrow belt of low vegetation which surmounts the summit of the high shingle beach edging the eastern face of Jaluit (Pl. 161, fig. 1). Considerable driftwood is also seen on the beach, consisting of logs of Pandanus, of cocoanut trees, and of different kinds of hardwood.

The coarse shingle beach of the east face becomes gradually higher as we go north. The upper part of the beach resembles a stone wall (Pl. 165, fig. 1); it is steep, and consists entirely of coarse slabs of beach rock. The top of the beach is exceedingly narrow, so much so that it looks like a dam; it also slopes abruptly towards the lagoon side. Steaming along the eastern coast of the atoll, we could see over the eastern land rim and distinguish the shoals and islands and islets, not only in the lagoon, but also across on the western face of the atoll.

As we approach the southeast entrance into Jaluit, the reef flat of the northern extremity of Jaluit Island becomes somewhat wider (Pls. 164; 167, fig. 2), as well as the land rim which is club-shaped (Pl. 228, fig. 2), and forms the southern spit of the entrance into Jaluit. On the northern side of the entrance, which is not more than two cable lengths wide, stretches Enübor, a low island (Pls. 161, fig. 4; 164, fig. 1), flanked like the island of Jaluit with beach rock and conglomerate ledges and shingle beaches; it is covered with a scanty growth of cocoanut trees and with a luxuriant growth of bushes. In the southern extension of Enibor lies a wide spit formed by three low islands, thrown up on the northern side of the entrance to the lagoon (Pls. 161, fig. 4; 228, fig. 2). After passing 
into the lagoon, we turned sharply to the south, and anchored opposite the principal village of Jaluit, near the northern extremity of the island (PI. 228, fig. 2). The high and steep beach flanking the eastern sea face of Jaluit Island is made up of large flat blocks of coral rock, many of which were extremely hard, and masses or fragments of corals and coral beach rock of all sizes, washed up on the outer slope of the island. Near the northern extremity of Jaluit Island the outer sea face slope is steep, while the inner slope from the summit of the outer beach to the edge of the lagoon is very gradual; the lagoon beach is scarcely more than one or two feet above high-water mark. The slope which extends from the base of the shingle beach towards the Nullipore knolls and the masses of Pocillipores (P1. 164, fig. 2), which form the outer edge of the reef platform, is very gradual (Pls. 164, 165). Judging from the many outliers left on the reef flats (PI. 165, fig. 2), an extensive flat of beach rock conglomerate must once have extended from the base of the shingle beach to the outer edge of the reef platform, from two to three feet higher than its present level. This rocky flat, however, is no longer continuous; it has been planed off and gouged into buttresses at right angles to the trend of the outer shingle beach, forming spurs which extend sometimes fifty to sixty feet towards the outer edge of the reef platform (Pls. 164, fig. 2; 165). The space between the extremity of those spurs and the outer edge of the platform has been planed off by the sea, and is covered by needles or mounds and spires of beach rock and coral conglomerate denuded and eroded into all kinds of fantastic shapes (Pl. 167, fig. 2).

The knolls on the outer edge rise from two to three and sometimes four feet above the general level of the outer reef flat (Pl. 164). They are as usual composed of Nullipores and of masses of Pocillipores; the edge is indented and cut into numerous digitiform lobes. The outer beach is about seven feet in vertical height; the boulders and fragments of coral and of beach rock conglomerate on the uppermost part of the slope are generally pitted and honeycombed. On the lagoon side the slope is more gentle; it is covered by a mass of coral fragments thrown over the summit of the shingle beach by the action of the sea; this mass gradually passes into a finer body of coarse coral sand, till we strike the 
beach rock conglomerate cropping out on the lagoon side (Pl. 162, figs. 1, $3,4)$, and is the extension of the beds of beach rock conglomerate forming the spurs we have described on the sea face of the shingle beach (Pls. 164, 165).

On the lagoon side of the beach rock conglomerate a narrow sink has been formed between it and the numerous smaller shingle islets so common in the lagoon of Jaluit (Pl. 162, figs. 1, 3, 4), the outliers of a former extensive coral conglomerate flat; from the islets the slope is gradual to the bottom of the lagoon itself. Immediately east of the village of Jabor the island is widest, and the beach rock conglomerate of the inner land face passes very gradually into the slope of the lagoon (Pl. 162, fig. 4), while further to the south, the belts of inner and outer beach rock conglomerate are separated by a comparatively narrow land rim (Pl. 162, figs. 1, 3), showing that the inner and outer reef ledges of beach rock conglomerate were once continuous, and as they were gradually elevated, have been eaten into on the one side to form the spurs on the sea face (Pl. 165), and on the other side to form the platform edging the lagoon side of the reef flat ( $\mathrm{Pl} .162$, fig. 4). At some subsequent time, the beach rock dam or coarse shingle beach was thrown up to its present height; the material for this dam was derived from the beach rock which once filled the space between the spurs on the outer sea face, and whatever material was planed off on the outer face from the top of the beach rock platform. The beach rock conglomerate nowhere rises to more than about two to three feet above high-water mark.

The narrow parts of the outer land rim to the south of Jabor are bare; the blocks of beach rock conglomerate are not sufficiently disintegrated to allow the growth of any vegetation; but on some of the wider parts we found Pisonias and Pandanus. The condition of the islands on the lagoon side to the south of Kennedy's wharf gives an excellent idea of their mode of formation, and how they have been thrown up on the lagoon side, and on the wide lagoon reef flats of beach rock conglomerate. Secondary lagoons have gradually been formed from the disintegration of the beach rock conglomerate by the waves of the lagoon; the land rim has been gradually widened on the lagoon side as on the outer face, but in a less degree. 
The village of Jabor is on the west side on the widest part of the island of Jaluit (Pl. 228, fig. 2); the wider land rim forming the extremity of the island has been formed by the washing to the westward of material from the outer southern face of the entrance to Jaluit, and thus little by little the flat upon which Jabor is built has expanded. One can see how the western shore line is gradually extending into the lagoon, forming, near the coal wharf, a long spit made up of small shingle and more or less coarse coral sand, gradually moving around the northwest point of the island during the season of the trades. The beach so formed is fully three feet higher than the island itself. Near our anchorage we could see masses of sand blown across the narrow land rim into the lagoon and distributed by the winds and the drift of the tides over the bottom of the lagoon. The flat of the northern extremity of Jaluit Island is barren; the ground is covered with small fragments of corals and beach rock conglomerate, more or less weathered and edged on the lagoon side, to the south of the northern point forming the harbor, by a fine sand beach; this to the south of the settlement passes into the beach rock ledge of the lagoon shore (Pl. 162, fig. 4); the ledge has a steep face, and is eaten and honeycombed and weathered by atmospheric agencies and by the action of the sea fully as much, only on a small scale, as some of the most characteristic of the elevated coral reef rock ledges in other parts of the Pacific.

Immediately back of Jabor are two fresh-water lagoons, or rather brackish lagoons, formed by the throwing up on the lagoon face of low beaches, and thus isolated from the inroads, both of the waters of the lagoon and of the sea (Pl. 166, fig. 2). They rise and fall with the action of the tides, showing how loose or porous the dam of the narrow land rim is. These sinks ${ }^{1}$ supply a large amount of the water used by the natives; immediately around the edges of some of the sinks mangroves are growing.

The reef flat to the south of the wharf is made up of beach conglomerate gradually disintegrating and forming flats covered with larger and smaller fragments, either of dead corals or of beach rock conglomerate (Pl. 162,

1 One of the prettiest sinks that exist in the Marshall Islands is found on the island of Enubor, a photograph of which has been taken by Mrs. Brandeis (Pl: 166, fig. 1). 
fig. 4). Large blocks of Porites and of Mæandrina, some of them fully five feet in height, occur on the flats of the lagoon side; they are the remnants of the mass of beach rock conglomerate which was once elevated above the present level of the summit of the reef rock conglomerate beach. It was interesting to examine the rolled corals on the outer beach and to trace the gradual disappearance of the typical characters of the different species of corals, showing when fresh and first thrown up on the beach all their specific characteristics, losing them as they become gradually worn by the action of the sea, until finally the rolled masses are changed to rounded pebbles, which have lost their coral features and look much like the pebbles of any shingle beach. We made a large collection of the rolled corals to. show the different conditions under which the same species may be found in close proximity, and to assist in determining the fossil corals of some of the elevated coral reef ledgres, where they must have been subjected, before being fossilified, to the same modifying agencies as those of the present day.

The surface of the beach rock conglomerate or breccia on the outer sea-face platform is full of potholes of all shapes and sizes (Pl. 165, fig. 2), many of them still partially filled with the pebbles to which they owe their origin. While the sea is rushing up and down across the face of the outer reef flat, the pebbles are revolved rapidly in the potholes, wearing them deeper and deeper, until finally they reach a depth where the action of the sea becomes less or ceases. Adjoining potholes are often gradually united, according to their shape and position on the outer reef flat, forming deep bowl-shaped recesses, or more or less narrow troughs and intricate channels.

The large blocks found on the sea face of the reef flat (Pl, 165, fig. 2) have either been torn off from the knolls of the outer edge of the reef flat, or else they are a part of the conglomerate beach rock or breccia ledge left, owing to their greater hardness, after the erosion of the conglomerate on the flat. The slope of the outer platform is quite flat (Pls. 164; 165, fig. 2; 167, fig. 2); a comparatively shallow sink extends between the outer knolls and the base of the shingle beach.

Outer reef platforms as they exist in the Pacific and Indian Ocean are only slightly developed in the West Indies. 
Millepores are the most abundant of the corals within the lagoons of the Marshall Islands. In addition to Millepores, Porites, and the other larger corals, which have already been mentioned, we collected Pavonia and Fungia on the reef flats of Jaluit, and also a very peculiar Millepore, different from any we had found elsewhere. The flats of the lagoon, both on the eastern and on the western faces, are covered with Nullipores, wherever coarse coral sand or coral shingle exists. On the lagoon face of the land rim corals are quite abundant, as well as on the slopes of the sand spits, to the north of the entrance to Jaluit. When the coral heads reach the surface of the flat, they are overwhelmed by sand, Nullipores begin to grow upon the dead materials, and little by little they become covered, forming an inner coral reef flat similar to those we have observed both on the inside and outside reef flats in other groups. Following the lagoon slope, the corals disappear gradually towards deep water, and at a depth of from sixteen to twenty fathoms we find only patches of Nullipores and wide lanes of sand separating the few diminutive heads still left.

The average depth of the Jaluit lagoon varies from eighteen to twenty-five fathoms, although here and there a deeper hole occurs. Large stretches of the lagoon are comparatively shallow, having undoubtedly been filled up from the weather side; we can see how a smaller lagoon might readily have been filled from the sand and shingle blown in over the outer land rim during the prevailing trades. This filling up of the lagoon by sand and shingle from the outside is a prominent feature in the Marshall Islands; it modifies to a considerable extent the width of the flats adjoining the land rim.

From our anchorage in nine fathoms came up a block of worn coral, probably blown over the shingle dam into the lagoon from the outer sea face. We found this to be a common feature on many of the islands of the Marshall group, where the sea often breaks over the narrow outer land rim, carrying large blocks of coral, which are deposited in lanes along the lagoon slope of the land rim between the lines of outliers of higher buttresses of harder breccia. This was perhaps better seen in Arhno than in any other island of the group. 
In many of the Marshall Islands coral boulders and dead corals have been thrown up on the low and narrow land or over the reef flat before the formation of islands and islets on the inner lagoon side had taken place. They show the continuity in the formation of the outer land rim and of the inner islands and islets forming spits, as at the eastern point of Arhno. Many of the ditches or sinks we have noticed are formed by the junction of these islands and islets in lines parallel to the outer land rim. The sinks may be eircular, elliptical, or long troughs.

On our way to Imrodj Island (Pl. 226, fig. 6), on the east face of Jaluit, we came upon a mass of shells indicating either the extent to which the lagoon has been filled up, or the extent to which patches of corals once flourishing have gradually been overwhelmed by the sand blowing into the lagoon. The island of Imrodj is on the east side of one of the northeastern passes (Pl. 162, fig. 2); it is flanked by a small sandy islet covered with cocoanut trees; the islet has been blown up on the reef flat during the last seven years. Enormous breadfruit trees flourish on Imrodj and one of the finest groves we have seen covers its central part.

A section across the island of Imrodj is most characteristic; on the lagoon side a reef flat fully 500 feet in width slopes gently from the outer edge to our anchorage into six fathoms. On the way from our anchorage to the shore we passed through magnificent patches of Pocillipores, masses of Porites and Madrepores growing most luxuriantly from about four fathoms to the shore which is flanked by a comparatively steep coral sand beach. From the summit of the sand beach, which is perhaps five or six feet high, the slope extends inland, forming a sink about one mile in length occupying the greater part of the island. The lagoon sand beach is covered with fragments of corals and coral heads from the adjoining reef flat, killed by exposure to the air and overgrown by Nullipores. Similar boulder reef flats are found in many of the Marshall Islands.

As we go towards the sea face of the island at right angles to the lagoon side, we come upon rolled masses of coral gradually increasing in size till we reach the summit of the outer sea beach. There the coral rocks, the coral and beach rock conglomerate boulders consist of huge masses thrown 
by the breakers over the summit of the steep shingle beach, at least eight to ten feet above high-water mark. From the base of the shingle beach extends a wide outer reef flat consisting of beach rock conglomerate, with occasional coral heads, planed down to a gradual slope from the base of the beach to the outer edge of the reef flat.

At the northeastern extremity of the island a shingle bar has been thrown across the outer sea flat. On this an island has been formed, and a secondary lagoon cut of directly across the wide gap which separates Imrodj from the island to the east. The formation of the island and of the secondary lagoon on the outer reef flat, within less than seven years, shows the extent to which modifications may take place in the arrangement of the material constituting the outer land rim of the Marshall Islands. In the course of a few years charts indicating the position of the islands and islets of the land rim may become rapidly obsolete, as well as the soundings on the lagoon face, where sand is blown over the narrow land rim, or where gaps between adjoining islands have been closed, changes which rapidly alter the general appearance of the outer land rim. The condition of the sea face reef flat of Imrodj shows that the island flanking it on the lagoon side is made up of material thrown up on its inner slope, derived from the growing corals on the sea face and of the older beach rock and coral conglomerate material once elevated a few feet above high-water mark.

The efficiency of a wide outer reef flat in protecting from disintegration islands forming a land rim.is well seen at the Marshall Islands. Where the outer reef flat platform is narrow, the huge breakers and rollers strike the beach slope at high tide (Pls. 161, fig. 1; 165, fig. 1), and either carry its material out to sea again or break through the beach and widen the outer reef flat at the expense of the land rim. Where there is a wide outer reef flat platform there are at high tide sometimes five or six successive lines of breakers on the flat (PI. 167, fig. 2), the first of which strikes the outer sea face of the shingle or sand beach with a very moderate force; while over a narrow platform a single line of breakers thunders directly upon the beach and distributes an immense amount of loose material at each high tide. The pools on the lagoon side of wide outer reef flats are 
gradually filling with material derived from the sea face, and islands and islets, similar to those existing on the lagoon side of Imrodj, are eventually formed.

A marked characteristic of the part of the sea face of Jaluit atoll near Imrodj is the number of deep pools which separate the islands and islets, showing that the sea must once have been driven through passes between these islands, when they formed channels across the outer reef flat. These channels have gradually become closed and the sea shut out from the lagoon by the mass of material forming dams thrown across the gaps. At Jabor, where the reef flat is of moderate width, one can see that should hurricanes occur the whole island would be swept by the sea; even during one of the very high tides we experienced at the time of ordinary tradewinds, the moderatesized rollers, pounding upon the outer sea face of Jaluit, washed over the top of the low shingle dam land rim and flooded to a certain extent the interior of the island, filling with sea water the sinks and pools upon which the natives depend for fresh water.

The filling up of the gaps at some of the passes is often quite rapid; when the sand spits on opposite sides reach out well into the deeper water of the lagoon, and sand comes from the two sides of the gap, the building up of the dams is rapid and the spits soon become connected.

On leaving Jaluit we steamed directly across the atoll towards the southwestern passage. As the islands and islets of the west side came into view we saw that they arose from a wide reef flat which, like the flats on the flanks of other passages, extended far into the interior of the lagoon. The lagoon face of the islands and islets was edged with fine coral sand beaches, while on the sea face they were edged with coral beach rock conglomerate. The islands and islets of the western land rim are connected by flats covered with beach rock conglomerate. It is not astonishing that the material on the lagoon face of the islands on the western side of the atoll showed greater mobility than the material on the reef flat off the western face of the eastern islands. ${ }^{2}$ The sweep of the trades across the lagoon is considerable, and

1 The western reef platform is wide, much wider than on the east side. This is natural, as the conditions are exactly reversed. 
the amount of material they pile up and shape into beaches and dams on the lagoon face of the western islands is quite marked as compared with the material moved on the west face of the islands forming the eastern land rim of the atolls.

On the western side, hardwood trees, the "iron wood trees," grow in considerable numbers. The western passage is long, narrow, and winding (Pl. 226, fig. 6); it extends into the lagoon from the western side between lines of reef flats, composed mainly of Millepores and Porites, killed as they approach the surface, much as we found the Millepores and Porites of the Taritari lagoon flats covered by Nullipores. The reef flats formed, in this case, a marked yellow belt on each side of the pass, in striking contrast to the dark blue ribbon of the channel through which we steamed. The reef flats on the lagoon side of the passage form a large spit, cut in two by a narrow passage, and flanked on both sides with beach rock. The southwest passage runs between the islands of $\mathrm{Ai}$ and Medjerrurik. The channels we passed through, as well as the wide bands of blue water indicating moderate depth on the reef flat in that part of the lagoon, once formed, I have no doubt, part of the intricate passages and channels which connected the sea with the lagoon. Land was gradually formed on the reef flat by material thrown up from the outer beach, and the corals growing on the flat were gradually overwhelmed by sand coming in either from the sea face or from the lagoon flats. The beaches on the lagoon side of the land rim were formed in part of beach rock, and in part of fine coral sand separating short stretches of beach rock conglomerate. A strong current was flowing in against the steady trades, through the passage and gaps of adjoining islands, and to a certain extent the reef flats on the two sides of the passage were swept clean during that stage of the tide. On the lagoon edges of the flats the current meeting the waves formed by the trades, the reef flats were more or less covered with sand bars built up by the material bronght on the one side from the sea face of the land rim, and on the other from the lagoon side by the trades blowing across the whole width of the atoll.

The full force of the trades blowing across the lagoon is felt on the lagoon edge of the western reef platform, while the sea face of the western 
land rim of the atoll is only disturbed by the swell of the sea during a comparatively short time, while northwest winds are blowing. The island to the north of $\mathrm{Ai}$ is connected with it by a narrow line of light green water, through which rises, here and there, an occasional sand bank.

The fine coral sand on the eastern face of the western land rim gradually passes, on the beach facing the chamnel, into black shingle, and finally into the beach rock conglomerate, which edges the beach on the western side of the land rim. As we passed out, we noticed a series of spurs extending on the reef flats at right angles to the outer reef line, and deflected in a direction parallel to the outer line of islets, thus forming an inner line of islands similar to those south of the village of Jabor.

The charts of most of the atolls represent usually the sand spits, which are formed near all the passes, as at the southwest and southeast passes of Jaluit (Pls. 226, fig. 6; 228, fig. 2), and are so characteristic a feature of the passes leading into the atolls of the Marshall Islands (Pls. 226, fig. 6; 227 , fig. 1 ; 228, figs. 3, 4).

The sand spits or reef flats are extensive tracts on which Millepores and Porites flourish. Where the corals reach the surface they are killed by constant exposure to the air, Nullipores grow on the fragments of the dead corals, which break off and gradually fill the interstices between the heads and change the living reef flat to a bare flat covered with huge patches of more or less coarse coral sand, with comparatively few living corals. The existence of these sand spits formed on either side of the passages is often indicated by the presence of a ferw small islands and islets running at right angles to the general trend of the outer land rim. On the west side of the atoll, as we steamed past it, we could see, near the centre of the western face, the great wide flat extending far into the inner part of the lagoon (Pl. 226, fig. 6), formed from the disintegration of a few larger islands still to be seen either as islets or as low sand bars, some of them covered with a little vegetation. The islands and islets on the wide lagoon flats and shoals are arranged either in lines parallel to the outer land rim, or else at right angles to its trend.

When steaming along the western face of the atoll past the northern extremity, we could, when looking across the narrow lagoon, note the number 
of islands and islets on the land rim of the northeastern face of the atoll. We could also see across the western land rim, near the northern extremity, the line of breakers indicating the position of shoals and islets, and low sand bars heaped up across the gaps of that part of the atoll, or indicating the position of a former land rim worn down by the action of the trades sweeping across from the eastern face of the lagoon. North of the centre of the western face of Jaluit is a marked secondary lagoon (Pl. 226, fig. 6) formed as have been formed the secondary lagoons of Taritari and of Apaiang. Here, however, the secondary lagoon has been formed by the throwing up of islands and islets and spits on the lagoon face of the land rim, the sea sweeping across the lagoon with sufficient force to build up on the lagoon face of the lee side secondary lagoons such as usually characterize the weather face of other atolls. More to the north a similar secondary lagoon exists at Ngain, where, however, it only forms a small bay.

The sand bars and flats encroaching upon the lagoon of the northwestern horn of Jaluit indicate the method by which the horn of an atoll may gradually be changed into a great sand spit by filling the space between the land rims on the two faces of the atoll. Only a narrow gap, with a shallow entrance into the atoll, exists at the northern end of Jaluit. From the island of Urbett across to the west face of the atoll the lagoon is not more than four miles in width; the two faces of the lagoon extend northward in a nearly parallel line, a distance of about twelve miles, forming at the northern extremity a wide horn between the island of Boggenadick and Bogenaga. The west face of the atoll, with the exception of Pinglapp, which forms the western spit of the atoll, and of the secondary central lagoons, is edged by a narrow reef flat, the greater part of it bare at low water, with a few islands and islets thrown up on its face (Pl. 226, fig. 6).

Immediately south of the island of Boggenadick, as well as east of Pinglapp and at the southern horn of Jaluit, extensive flats have formed on the lagoon face of the reef, where coral patches grow in profusion or sand bars have been thrown up, as also in the central part of the west face of the atoll at a distance of about eight miles north of Pinglapp, where the 
sandy' flat is at least two miles in width and is covered with numerous patches of corals and beach rock.

The strength of the waves on the two sides of the lagoon can easily be measured by the condition of the islands on the opposite land rims. Judging from the mass of material found on the reef flats of the western face of the lagoon, it is evident that this material must be supplied from the wearing of the reef flat on the inner part of the lagoon. There are not enough corals thrown up from the sea face of the western side of the atoll to supply the material even for such a narrow land rim as exists on

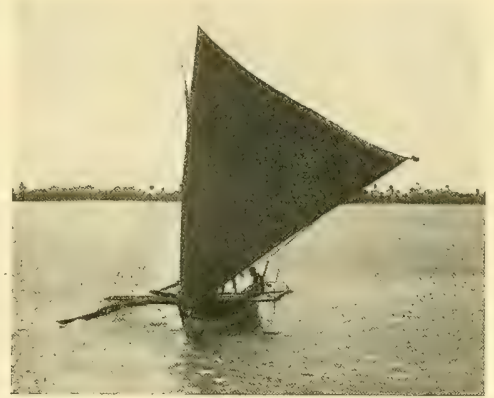

Marshall Island Canoe, Jaluit. that side of Jaluit, yet this is the source to which many writers on coral reefs would look for the material to form the lee land rim.

\section{Ailinglap.}

Plates 168; 171, fig. 1; 225; 226, fig. 5.

Ailinglap (Odia or Elmore) is a triangular atoll (Pl. 226, fig. 5). Its eastern face is twenty-five miles in length, its western about the same, and the northern nearly thirty miles in length. The principal islands are on the land rim of the western face, and on the eastern face, where, however, the land rim is much broken, there being numerous passages for boats of considerable size through the gaps between the islands (PI. 226, fig. 5). On the northern face are a large number of sand bars and islets and two passages for larger vessels. The principal entrance is through the southern passage north of the island of Eniiebing (PIs. 168, fig. 1; 226, fig. 5). On the lagoon side of the passages we could see the same sand bars and spits and flats which characterize the passes of Jaluit. This lagoon is said to be from twenty to twenty-five fathoms in depth; its 
northern part is crowded with shoals, coral patches, sand bars, and sand flats (Pl. 226, fig. 5).

We skirted along the southwest shore of the atoll of Ailinglap. On the sea face the beaches consist alternately of shingle beaches, coral sand beaches, and ledges of beach rock coral conglomerate. There are comparatively few cocoanut trees on the islands, but there is a belt of vigorous scrub vegetation and large hardwood trees close to the shingle beach (Pl. 168, figs. 1, 2, 4). The outer reef platform has a uniform slope from the base of the beach, where the beach conglomerate crops out to the outer Nullipore knolls rising on its outer edge. The beach conglomerate is usually of a yellow color, forming a marked contrast with the black, weather-beaten, pitted and honeycombed shingle, which rises in a steep slope immediately behind the beach conglomerate (Pl. 168). The first gap we passed showed no secondary lagoons; it was barred on the lagoon side by a low island with sandy beaches, on either side of which existed a passage into the lagoon. The shores of the islands forming the entrance to the passes were flanked, as was the outer beach, with yellow beach rock conglomerate, and a steep shingle or coral sand beach rising behind it (Pl. 168, fig. 1). The black shingle beaches are more continuous than the sand beaches. The west coast of Ailinglap is deeply indented by bays (PI. 168, fig. 2), formed by the throwing up of sand from the lagoon side on the outer reef flat, into elongated spits, separated here and there by reaches of yellow beach rock conglomerate and forming a kind of secondary lagoon, differing somewhat from those we have observed in other groups ( $\mathrm{Pl} .168$, fig. 2).

The wide reef flats characteristic of Ailinglap slope gradually to the outer edge; they are covered with numerous ledges and blocks of yellow beach rock (Pl. 168, figs. 2, 3). The prevailing wind blows nearly parallel with the trend of the eastern coast. Pandanus and a belt of scrub trees form the characteristic vegetation of the islands on the land rim of the west side of Ailinglap; only few cocoanut trees are found on the majority of the islands on the western face. The islands on the west coast are well wooded and separated by narrow gaps; they have been formed on a wide reef flat, which, as we could see at the southwest pass, extends far into the lagoon (PI. 226, fig. 5); sand bars and sandy islets separated by intricate 
channels forming secondary lagoons extend on the lagoon side of the western face of Ailinglap.

As we go farther north, the islands and islets form a narrow land rim (Pl. 168, fig. 3), with low passes or gaps; some of them were bare at half tide. The wide reef flat is covered with numerous sand bars and islets (Pl. 171, fig. 1), forming on the lagoon side of the islands, and yet, in spite of the great width of this reef flat, the land rim did not seem to be increasing in width, either on the sea face or on the lagoon face, much of the material on the reef flats evidently being shifted backwards and forwards according to the season of the year and the direction of the prevailing winds. On the inner side of the lagoon, opposite its widest part, the breakers due to the trade winds are high, their sweep is considerable, and they must play an active part in the shaping of the land rim on the west side of the atoll, exactly as do the northeast trades on the sea faces of the eastern and northern part of the atoll. On the northeastern point of Ailinglap the island forming the eastern edge of the horn is covered with a luxuriant vegetation, and is situated on a reef flat somewhat narrower (Pl. 226, fig. 5) than that forming the western horn of the atoll (Pl. 171, fig. 1). From the northern point the islands gradually pass into islets and finally into low sand bars; they indicate in a general way the position of the rim of the wide outer reef of the atoll. Beach rock conglomerate crops out on the sea face of most of the islets and islands of the western horn, and high sand beaches characterize the lagoon side of the land rim. The wide outer reef flat is edged by Nullipore and Pocillipore knolls; the outer edge is deeply indented and cut, forming numerous boat passages on the outer face of the reef. The lagoon is said to be from twenty to twenty-five fathoms deep.

\section{Namu.}

Plates 167, fig. 1 ; 225 ; 2227, fig. 1.

Namu ${ }^{1}$ is a long narrow atoll about thirty-five miles in length and a little over four miles at its widest part. 'The western face of the atoll is

1 Hydrog. Amt d. Reichs Marine-Amts. Pläne d. Marshall Inseln. No. 113. 
like the western face of Jaluit, flanked by a reef more or less exposed at low tide, while the eastern and the southeastern faces of the atoll are flanked by a narrow land rim, differing in no respect from those of Jaluit or of Ailinglap.

We approached Namu on the east face so that we could look up the weather side for a considerable distance. We skirted along a part of the southwest shore of the atoll; there the islands of the land rim are covered with a remarkably fine growth of Pandanus, of Pouka, of Pisonias, of other hardwood trees and low bushes (Pl. 167, fig. 1). On the east face we could see numerous gaps separating the islands and islets, through many of which the sea was breaking with considerable violence. On the southeast shore the shingle beaches are flanked with large boulders, with only here and there a small sand beach. It happened to be high water as we steamed by Namu, but we could see at the passes the outer shingle beach and on the lagoon side the fine coral sand beaches; we also noticed on the reef flat the sand bars and islands and islets thrown up by the sea on the lagoon side. The sand spits and sand bars gradually become covered with vegetation; they often form two or three successive lines of elongated islands and islets barring the gaps. These sand bars and islets eventually become connected by spits with the outer islands, and gradually form islands of greater width than those now existing on the outer land rim

\section{Kwajalong.}

Plates 169, 170, 225 ; 22\%, fig. 2.

It will be noticed from the dimensions given of some of the Marshall Islands that with few exceptions they are among the largest atolls known; they equal and even surpass the largest of the atolls in the Paumotus and Maldives.

Kwajalong, or Menschikov, the next atoll we visited, is more than seventy miles in length. ${ }^{1}$ The centre of the western coast is convex to the east.

1 Menschikor and Suvadiva, one of the Maldives, are the largest atolls known; Kwajalong is no less than seventy-five miles in length, and with the exception of one or two of the Paumotus none of the atolls of the Pacific are to be compared with them in size. 
The northern coast juts out into a point about eighteen miles east of the western point of the atoll; the average width of the atoll is at least fifteen miles. The western point forms, as do the extremities of many of the atolls in the Marshalls, a sharp narrow spit, where two faces of the atoll meet and run together. Similar spits exist at Namu, Mille, Ujae, and specially at Arhno; they are more or less marked in many of the other atolls. The principal land rim of Menschikov atoll is on the southern part of the eastern face of the atoll, and on the eastern face of the northern point; the west coast is irregularly dotted with islands and islets, following one another in rapid succession. Numerous ship passes cut through the west coast, and near these we find the same development of spits, sand bars, and reef flats already described.

To the east of the south pass of Menschikov ${ }^{1}$ atoll extends a long line of sand bars reaching southward to Enübuj Island. Beach rock con. glomerate flanks the base of the steep beaches on that island; large blocks of shingle and of conglomerate are thrown up on the beaches; they consist of fine or coarse sand.

We could see across the southern horn, on the opposite side of the lagoon, the islands on the eastern face. The effect of the raking sea in gigantic atolls like Menschikov, the axis of which is at least seventy-five miles long, in accumulating sand on the lagoon side of the land rim, is well shown on the land rim flat south of the south pass and in the break of the land rim between Enuibuj and Kwajalong Islands. The flats are covered at low water; during the northeast trades the sea breaks over them.

A section of the beach on the south end of Ennuilabegan Island shows a structure characteristic of all the islands on the western land rim of Menschikov atoll. The wide reef flat is covered with beach rock or conglomerate boulders; at the base of the sea face of the beach extend outcrops of beach rock and coral conglomerate topped with yellow rubble, masses of beach rock conglomerate and with smaller shingle forming the summit of the beach. The beach varies from nine to eleven feet in height; from the upper part of the shingle beach tongues of beach rock and conglomerate

1 Darwin has given a figure of Menschikov atoll (PI. II., fig. 3), taken from "Krusenstern's Atlas de l'Ocean Pacifique," which has been copied by Dana. Krusenstern's figure differs greatly from that of later' surveys (Pl. 227, fig. 2). On Krusenstern's chart it is called "Is. du Prince Menchicoff." 
shingle extend far into the belt of hardwood trees which surmounts the high platform of the island. We noticed here, for the first time, a peculiar coloration of the water in the gaps or passages leading into the atoll. On the sea face, but more especially on the atoll side of the gap, in from nine to ten fathoms, the color of the water was usually of a metallic blue, and the various colors reflected, as the depth passed into shallower sand bottoms, represented as many hues as those on the feathers of a peacock; while the main channel itself, sometimes of considerable depth, was of a dark blue, rendered only more intense by the contrast of the line of white breakers rolling on the sandy reef flat.

The wide reef flat slopes gradually from the base of the sand or shingle beach ; it consists of recent beach rock or coral shingle conglomerate planed off by the action of the breakers, and is covered with shingle rubble coated by Nullipore growths of variegated colors. Here and there on the outer face of the land rim low sand dunes exist, or they are blown to a considerable height from the lagoon side, rising sometimes seven to eight feet above the top of the highest part of the shingle beach. This method of encroachment by dunes on the land rim from the lagoon side is different from any we have seen in the Paumotu Islands, or other atolls where dunes exist. Usually the widest beaches are on the side of the outer reef platform; in the case of many of the Marshall Island atolls, coral sand is piled up over extensive flats, on sand bars and sandy islets on the lagoon side. Thus is supplied an immense amount of material blown by the trades sweeping over the lagroon, across to the sea face of the atoll, overwhelming, from the lagoon side, the luxuriant vegetation covering the summit of the narrow land rim. The knolls forming the Nullipore rim of the outer edge of the reef platform are usually highly colored, and in some parts of Kwajalong the outer rim has been deeply indented, forming wide boat passages leading towards the beach slope. In other parts of the reef flat the Nullipore edge forms a wall of considerable height, three to four feet sometimes above high-water mark, as on Ennuilabegan Island. As I have stated, the sea face of all the islands is comparatively high, the slope towards the lagoon is gradual; the green vegetation of the land rim is in striking contrast with the outer black shingle beach, and with the glistening white coral sand reaches. 
We went ashore on Gehh Island (Pl. 169, fig. 1), a small island, in reality only a sand dune blown up from the lagoon side, overwhelming the huge boulders and coral heads of all kinds growing on the outer reef flat. The destruction of the corals on the outer reef flat recalls that of the Millepores and Porites on the lagoon flats of Taritari. At Gehh, however, the heads of corals are much larger; many of them are dead masses thrown up on the outer reef flat; the living corals are more isolated and consist of various species of massive corals characteristic of the Marshall Islands, such as heads of Millepores, Porites, Madrepores, Pavonias, and Mæandrinas. The heads are separated by deep lanes, in which are accumulating dead corals or sand; the top of the heads is often covered with fragments of dying and dead corals, killed by exposure during low tides and covered with a coating of Nullipores. The sea breaks the tops of the dead masses, and with the sand dunes encroaching upon them from the lagoon side we have a reef flat formed of an entirely different character from that of any reef flat we have yet seen. ${ }^{1}$ The reef flat slopes gradually into deep water; from the outer edge of the platform we could trace large masses, and heads of corals of the same species as those found on the reef flat itself, only in full activity, growing most luxuriantly in from six to seven fathoms of water, and gradually becoming more distant and smaller towards the seventeen-fathom line, where the coral boulders have entirely disappeared, and are replaced by fine coral sand washed down from the upper part of the reef flat.

It happened to be an unusually clear day when we examined this outer slope, so that we were able to distinguish remarkably distinctly the corals growing under the lee of this islet; at some points many of the heads seemed to extend even to a depth of twenty or twenty-two fathoms, and certainly grew comparatively luxuriantly as far as fourteen fathoms. From seventeen to twenty-five fathoms large blocks of Algæ and Nullipores were seen. No large masses of dead corals exist at the foot of the extensive reef flat; its slope is very gradual, the distance from the outer edge of the reef flat (lowwater mark) to the twenty-fathom line being about 300 yards. There is not the sudden drop into fifty or one hundred fathoms as on many of the outer

1 A similar condition of things exists at the north end of Illeginni (Pl. 169, figs. 3, 4), where the sand from the lagoon face has been blown over the narrow land rim and encroached upon the outer reef platform. 
reef faces; it is only when an unusually large block of coral forms the outer edge at low-water mark that we may have a drop of four to six feet.

The base of the sand dunes is flanked by a sort of beach rock conglomerate composed of fine and coarse particles, small fragments or blocks of which had been thrown up on the sea face of the dunes.

We found at many other points on the west side of Menschikov sand dunes overwhelming old and much-weathered coral heads near the head of the reef flat, while on the outer part may run a ledge of higher blocks of corals, some of which are still alive and have not been overwhelmed either by sand or cut down by the action of the sea to the level of the reef flats, as have the inner line of blocks. We found a large number of Echinoderms living in the cavities between the corals.

The mode of formation of the extensive flats we described at Taritari, on the weather side of the atoll, is identical with that of the lagoon flats near the openings and passes in the Marshall Islands. These flats are characteristic of all of the atolls; their existence has been more or less correctly indicated and sketched out on the German charts of the group (Pls. 226, figs. $5,6,9,10 ; 227$, fig. 3 ).

Tengeli (Pl. 227, fig. 2), another island on the west face of the land rim of Menschikov, is in a somewhat more advanced stage than Gehh, the island we have just described. Here the mass of sand, coming from the inner part of the lagoon, has overwhelmed the coral heads, and it is only here and there, on the face of the reef flat, that we see an outcrop of the coral heads.

Between Mann and Torrutj Island a good pass exists; on the lagoon side of this gap a number of lines of secondary islands are formed on the reef flat parallel to the outer island. These islands are separated by reaches of blue water, forming two or three entrances into the lagoon from that face of the island.

From what I could ascertain of the depth of the lagoons in the Marshall Islands, some of them are exceedingly shallow, as at Taongi (Pl. 227, fig. 3) and Namorik (Pl. 226, fig. 10); in general they have a depth of from fourteen to seventeen fathoms, though some of the larger lagoons reach a depth of twenty to twenty-five fathoms. 
Many of the gaps on the west face of Menschikov are comparatively shallow, judging from the color of the water, but occasionally a light or even a dark blue streak indicates a deeper passage for boats or small vessels.

North of Ennuigenliggelap (Pls. 169, fig. 2; 227, fig. 2), between it and Boggen Island, stretches an extensive reef flat on which long sand spits have been thrown out on the lagoon side of the shingle beach of those islands. This reef flat is covered with green water, showing that the pass is comparatively shallow. On the lagoon flat two lines of breakers, parallel to the outer reef, indicate the position of sand bars which are in the near future to form a double line of islands and islets. A little north of this we came on a still more instructive reef flat, where there is not only a second, but also a third line of sand bars indicated by breakers on the wide reef flat. On the very edge of the outer reef flat are two small sand islands; the lagoon flat extends eastward from twelve to fifteen hundred feet, then a narrow line of blue water separates the inner edge of this flat from the second and third line of islands and sand bars. Still further in the lagoon a fourth line of breakers shows the piling up of sand in the shallow part of the lagoon. Opposite passages and gaps the breakers usually throw up islands, islets, and bars, wherever a considerable body of water flows across the reef flats. The width of the reef flat of Menschikov atoll varies greatly. Sometimes it is narrow, nothing but a shallow beach line, on the one side of which beat the lagoon breakers, and on the other the rollers on the sea face, the land rim forming only a narrow sand dam separating perhaps the deepest part of the lagoon from the deep water off the sea face. Where the reef flats are wide, they are usually cut into intricate channels and dotted with sand bars, as near Gehh and 'Tengeli.

Similar lagoon reef flats are developed north of Oniimak Island, immediately south of the adjoining pass. At Wotje Pass we strike one of the finest examples of lines of secondary islands and lagoons (Pls. 170, figs. 3, 4; 227, fig. 2), separated by strips of deeper water than is usual on reef flats where sand bars are readily formed. At Wotje Pass we again found high sand dunes, blown over on the outer reef flat from the lagoon side, which have nearly overwhelmed the beach rock on the sea face. Here sand dunes exist not only on the two outer islands flanking the north and south side 
of Wotje Pass, but also on the islands to the north of the pass; they have covered the shingle beach rock conglomerate edging the western face of these islands. On the sea face of the outer land rim coarse shingle crops out at the base of the sand dunes.

North of Eru Pass we have a repetition of the same reef flats and lines of islets. These are, however, mere narrow strips, barely apparent at high water from the line of breakers coming from both the lagoon side and the sea face, which meet from opposite directions and thus form sand bars, as north of Illeginni Island (Pl. 170, fig. 4), the summits of which can be seen cropping out here and there in the line of breakers (see also Pl. 169, figs. 3,4). A similar condition exists at Nanuku, one of the Fiji Islands, where the reef flat of the southern horn forms a submerged ridge, across which the breakers of the prevailing trades roll into the lagoon side of the island. ${ }^{1}$

At Gegibii Island, north of Eru Pass, the second and third lines of bars and breakers must be at least three fourths of a mile from the outer land rim. North of Lubu the reef flat disappears, and only here and there is the presence of comparatively shallow water indicated by an occasional breaker, or where it does not break, by a thin green line between two darker belts of blue, indicating the position of the ridge, in from eight to ten fathoms, in the extension of the wide reef flat of the western face of the atoll which separates the deep lagoon from the outer sea. ${ }^{2}$ The islet of Tabik and the cliain of islands terminating with Ebadon form the narrow western point of Menschikov. But few islets and bars exist on the narrow submerged reef flat which runs from the northern to the western point and forms the northern face of the atoll. Over this face of the atoll, as well as over the northern part of the western face, the sea, driven by the trades, must pour uninterruptedly.

1 Bull. M. C. Z., XXXIII., Pls. 103, 104.

2 According to the German charts there is a similar well-developed, deep channel extending along the whole western face of Taongi (Pl. 227, fig. 3). 


\section{Rongelab.}

Plates 171, figs. 2, 3; 172, 173, 225; 226, fig. 8 .

The atoll of Rongelab (Pl. 225), irregularly triangular in shape, is a little over thirty miles in length, and about fifteen miles across at its southern land rim. The eastern side is occupied by a narrow land rim, forming a great bay; there are numerous passages into the lagoon both on the eastern and southern face. The main land rim is on the southern side and on the eastern face; the western reef flat is narrow, and only here and there a few islands and islets have been thrown up during the prevalence of the westerly winds. The island of Rongelappelap on the southeastern horn is the principal island of the atoll ; it is exposed to the full force of the trades; its south shore (Pl. 226, fig. 8) is flanked by a long sand beach of moderate height; in some places it has been blown in as dunes among the trees and the belt of scrub vegetation (Pls. 171, fig. 2; 172, fig. 1). This is especially well marked at the eastern point of the south passage, where the sand dunes have killed the greater part of the vegetation and have only left the stumps of the trees rising through the sand. Along the sand dunes we found, here and there, boulders of beach rock or coral conglomerate forming a broken line of yellow boulders at the base of the sand beaches. The principal islands on the east face of Rongelab are sandy islands or islets, with few low bushes growing near the line of heavy breakers which indicates the position of the outer edge of the reef flat (Pl. 171, fig. 2). The inner lagoon beaches of Rongelab (Pls. 171, fig. 3; 172, fig. 2) are ledges of beach rock and coral conglomerate, alternating with coral sand beaches and with reaches of black weathered coral shingle. The sand and shingle is also frequently driven in between the trees from the lagoon side. The vegetation consists mainly of Pandanus (Pl. 173), and the few cocoanut trees which have been planted by the natives.

At the pass, off the south side of the island, a low spit runs fully two thirds of a mile westward with two to three fathoms of water; the peculiar metallic color we had observed in some of the gaps of Menschikov is well shown at the gap formed by the spit. 
The outer reef flat slopes gradually on the lagoon face; we found sixteen fathoms more than half a mile from the inner beach. No corals are found on this grentle slope, but Algæ grow in great abundance on the coralline sand. In some places in the lagoon we found a few patches of corals, mainly Madrepores, Porites, Pocillipores, and Millepores, but they are comparatively few in number and moderately developed.

The beach rock cropping up on the lagoon face (Pls. 171, fig. 3; 172, fig. 2) is a coarse conglomerate composed of fragments of recent corals; these when ground have formed the high steep beach of coarse coral sand mixed with small fragments of broken corals. On the lagoon face of the outer beach the slope passes rapidly to the level of the bottom of the sink which extends nearly two thirds across the land rim of the island. At the point where we made the section, the land rim is nearly one third of a mile wide, and the outer shingle beach must be about twelve feet in height. The numerous water holes and sinks are surrounded with Pandanus, Poukas, a few Pisonias and large hardwood trees (Pl. 173), and on the outer beach is the usual belt of broad-leaved bushes and scrub vegetation (PI. 172, fig. 2). The beach conglomerate extends nearly half-way across the land rim; we then come upon masses of heads of corals until we reach the sea beach; its slope is covered with fragments of shingle of all sizes, varying from moderately large heads to sand. This shingle has encroached far into the vegetation of the land $\operatorname{rim}(\mathrm{Pl} .172, \mathrm{fig} .2)$, and here and there we found an isolated tree or a bush standing out from the shingle almost within reach of the ordinary tides. The island of Rongelappelap has been built up both from the sea and from the lagoon face; the sand from the lagoon side and the small shingle being blown eastward, while the disintegration of the beach rock which once covered the outer reef platform has supplied the material for the outer, high steep shingle beach (Pl. 172, fig. 1); some of the material of course has also been derived from the destruction of the masses of coral heads and of Nullipores growing on the outer reef flat. Sand dunes exist in the wide and shallow gaps to the north of Rongelappelap.

To the prevalence of the northeast trades, which in the Marshalls blow with greater strength than the southeast trades do in the Southern Pacific, we must look for the forces which move the great mass of material con- 
stantly shifting in these atolls. It is interesting to note the marked difference there is in the method of handling the material in the large lagoons, due to the reach of a very strong northeast trade or that of the more moderate southeast wind. In fact, the action of the northeast trade on the eastern lagoon face of the west rim of the Marshall Island atolls is nearly as great as that of the southeast trades on the eastern face of the Paumotus or of some of the atolls to the south of the line.

One of the most characteristic corals we found in the Marshall Islands is a long, slender branched Madrepore which grows in smooth water in protected parts of the lagoon. It would be an interesting study to compare the modifications of different species of corals flourishing best in the midst of breakers, or when found in shallow or deep water along protected shores. The variation we have observed in some of the corals is so great that at first glance specimens taken from different parts of the same atoll would hardly seem to belong to the same genus.

One of the best examples of such adaptation, due perhaps to a constant struggle against the action of the heavy breakers to which they are subject, is seen in the peculiar growth of the spines of Heterocentrotus and of Colobocentrotus. The spines in the one case are massive clubs with which the sea urchin braces itself in corners or angles of the reef flats and retains its hold against the action of the sea; while in the other genus the immense development of the suckers on the lower side and the reduction of the spines to a dome-shaped pavement gives to that genus a still greater security. It is comparatively rare to find the tests of these species thrown up on the beach flat or on the shingle beaches. Side by side with them in pools exposed to the full action of the sea are found immense numbers of Holothurians; they seem to have no capacity for protecting themselves against this very action, and yet do not appear to be affected by the action of the breakers.

The section of the beach we examined (Pl. 172, fig. 1) shows a high, steep beach consisting of fine white coral sand of about twelve feet in height, flanked at the base by a small secondary beach of coral shingle covered on the top by large blocks of beach rock conglomerate, thrown by the sea towards the lagoon side. 
The reef flat is about 100 feet wide, and covered mainly by huge blocks of Porites and Millepores separated by lanes of water; the tops of the masses of coral have died and are overgrown with many colored Nullipores. The dead coral heads of the reef flat were evidently once flourishing, but those now alive are limited to the outer heads growing near the knolls of Nullipores on the outer edge of the narrow reef flat we have just described. The Nullipores are of a brilliant red, carmine or yellow color. The coral heads have become united by the breaking off of the upper branches and cemented with fragments of Nullipores. This reef flat is very similar to the one we described at Gehh on the west coast of Menschikov atoll.

The lagoon side of the south face of Rongelab is exposed to the full action of the trades sweeping across the atoll; they have a reach of about thirtyfive miles. The strength of the trades is shown by the high breakers seen in the gap, to the eastward of the beach where we anchored. We found a few coral heads in the lagoon, on the way to our anchorage.

When lifting anchor we brought up a huge mass of white, dead coralline Algæ and coral mud formed from the agglomeration of fragments of dead corals, shells, and beach rock fragments, but consisting principally of coralline Algæ and Nullipores, forming a sticky mortar covering the bottom of the lagoon wherever we had an opportunity to examine it. This conglomerate is formed in an inner sea, as it were; it differs strikingly from the conglomerate formed on the beaches, both on the sea face and the lagoon face, a conglomerate made up of larger angular or worn fragments of broken coral and of beach rock.

On the east of Rongelab are a number of sandy islets and sand points flanked by high steep beaches, edged with beach rock and topped with low vegetation. The island to the west of the pass resembles the main island; its south shore extends in a long sand spit at the west end, and the small sand islet to the north as well as the beach are both flanked by beach rock conglomerate. 


\section{Likieb.}

Plates 174-17\%; 225; 228, fig. 3.

The island of Likieb has been fairly sketched by Captain Melander in 1885; he made a running survey from the lagoon side; as we steamed along the western shore of the atoll, we were able to correct, to a certain extent, the position of the outline of the western face.

The islands and islets on the eastern face, as will be seen from the sketch chart (Pl. 228, fig. 2), are nearly all at right angles to the general trend of the reef flat; on the western and southern faces the islands are narrow and insignificant in size, the gaps being far apart, leaving wide areas of reef flat awash, with only here and there a sand bar upon them. We entered Likieb through the south pass. The lagoon is covered with numerous coral patches scattered in every direction. On the western face are several passes south of the island forming the northwestern horn of the atoll. The atoll is said to be from fifteen to twenty-five fathoms in depth. The islands of this atoll are considered as among the most fertile of the Marsball Islands. They are subject to the trades; but in the northern part of the group they do not blow with the same violence as south of Ebon Island and north as far as Jaluit and Arhno.

We arrived under the lee of Likieb much later than we expected, the distance from Rongelab as indicated on the charts being far from correct, as is the position of many of the islands on the charts of the Paumotu, Ellice, Gilbert, and Marshall Islands.

Likieb is a triangular atoll (Pl. 228, fig. 3), nearly thirty miles in length and fifteen across the southern face. The northwest point of Likieb, seen from the west side, is occupied by Mat Island, on which grow a few coconnut trees; the rest of the island is covered with low scrub and tall hardwood trees. The point is flanked by a steep coral sand beach, edged at its base with beach rock conglomerate alternating with shingle reaches. The reef flat extending from the western point is wide and slopes gradually from the foot of the steep and high sand beach (which must be from eight to ten feet in height) towards the outer edge of the reef platform. On the south side of the western horn a gap between Mat and Emegua 
Islands runs across the base of the northwest point to the northern face of the atoll; on the western face a narrow submerged reef flat connects the two islands. The outer edge of the gap is flanked with beach rock, as are the sides of the gap between Mat and Emegua Islands. On the north side, opposite the opening of the gap, which is shallow, an island has been thrown up by the surf, from the lagoon side, upon the wide reef flat of the base of the northwestern horn of Likieb.

The northwest point of Likieb has been formed by large sandy islets thrown directly across the extremity of the reef flat forming the horn of the atoll, the material being derived both from the lee and from the weather side. In proportion as the islands of the land rim of the faces of the lagoon diverge on the lee and on the weather side, a channel is formed at the extremity of Likieb ${ }^{1}$ separating the western island from the series of islands and islets and sand bars which run directly across the end of the lagoon, more or less parallel with the base of the outer island. A wide, shallow gap is thus formed between them and the island to the west; on the weather side the land rim extends toward the east in a long series of islands, islets, and sand bars; on the lee side an island, more or less triangular in shape, originally also made up of separate islets, is connected with those of the weather side by shallow flats covered at high water. The sea face of these islands is flanked with beach rock, while the lagoon side is formed by high steep fine coral sand beaches. The second eastern set of islands will undoubtedly, in time, become united and form a second belt to the south of the northern one, and in time that will again be united with the preceding belt, forming, as in the case of Arhno, a solid spit with spurs flanking the two sides of the lagoon. This shows very simply how the shallower parts of a lagoon are gradually filled up by the action of the trade winds. The pass between the islands of Mat and Emegua must be shallow, judging from the color of the belt of light green water separating them. The pass opens out into the shallow flat of the lagoon itself; on the lee side it is indicated by a line of breakers, and a slight discoloration of the water between the south point of the second island and the island to the south of it.

1 H. O. Chart 996. 
The island of Rongerik to the south of Emegua consists of large masses of flat beach rock, thrown up like a shingle beach, and partly overwhelmed by sand dunes blown over from the flats on the lagoon side. Usually the islands of Rongelab are covered with sand at the two extremities, and it is only in the centre that beach rock slabs and coral conglomerate crop out. The small islands on the west face of Likieb are narrow, and have a scanty capping of low scrub. The little island of Bokelan has a few trees on it; at its extremities are high sand beaches; beach rock conglomerate crops out only over the central part of the western face, having been overwhelmed at the extremities of the island by the sand blown over from the lagoon side.

The northwest face of Kapenor (Pl. 174, fig. 1) is flanked by a steep sand beach, from twelve to fourteen feet in height, capped by a rich belt of low vegetation. An occasional boulder of beach rock conglomerate crops out on the base of the beach at the level of about three-quarters tide. Sand from the lagoon side has overwhelmed, to a certain extent, the reef platform. From the west point of Kapenor extends a high black shingle beach; it crops out again on the flat of the lagoon side; the beach rock conglomerate also crops out on the reef flat. The two extremities of the island of Kapenor and the islands and islets to the north are covered with sand, blown over from the lagoon flats; the central part of Kapenor, immediately above the base of the beach, is covered in part by shingle, in part by sand, the beach rock cropping out only irregularly. The little islands of Rongerik, Rongelab, and Bokelan all have high sand beaches; sand tongues have been driven, from the beaches of the lagoon face, into the belt of vegetation directly across the island. Scattered among the stretches of beach rock conglomerate are masses of coral thrown up from the reef flat. On the east side of Kapenor a bight has been formed on the miniature horn of the northern flat of the island. This bight is separated from the lagoon and the sea exactly as is the northwestern horn of Likieb; it is gradually filling by the formation of bars on the reef flat connecting the weather and the lee sides. In this case the flat only extends from the weather side of the lagoon to the lee face of the western rim, but the process is the same. From Kapenor a reef flat extends to the 
deep pass north of Maten Island; there the lagoon sand has overwhelmed the beach rock conglomerate, only a short stretch of shingle appearing on the face of the central part of the beach. We could readily trace the sand coming from the lagoon side, and gradually forcing its way over to the sea face. The pass north of Maten has two lines of shoals blocking the opening. Across the narrow submerged reef flat we could see many bars extending far into the lagoon to the south of Maten Island, separated by light green water, and here and there sand bars forming the beginning of an islet, or reaches of beach rock conglomerate flanking the western side of an incipient bar on the half-submerged reef flat.

Takahave, on the western face of Likieb, is densely wooded; it is covered with tall hardwood trees; cocoanut trees are not found on the island. The lagoon side is flanked by a sand beach, fully fifteen feet in height. The beach rock conglomerate ledge crops out on the sea face in the centre of the island; it has been overwhelmed by lagoon sand at the two ends. Coming from the north one can see on the extremity of Takahave the lagoon sand piled up on the eastern side of the coral shingle beach, and partly blown over its highest parts.

The south face of Likieb is convex to the north, flanked at the western end by Lukunor; and at the eastern by Likieb Island. The western extremity of Lukunor Island is extremely narrow; the land rim is a mere thread edged by a reef platform, formed by the destruction of the large coral heads once growing upon it, and forming the pavement upon which, on the lagoon side, the sand bars are formed. The reef flat will gradually be changed into a bare solid flat, covered with Nullipores, so that it will be difficult to distinguish the separate blocks forming the gigantic pavement of flourishing coral heads on the lee face of the land rim. The coral heads extend on the shelving shore into deep water; they gradually disappear at a depth of from twelve to sixteen fathoms. At the point where we examined it in detail we could trace the extension of the boulder reef flat both on the sea face and on the lagoon side.

In the centre of the south face the south pass of Likieb opens between the island of Eotile on the west (Pl. 174, fig. 3) and the island of Agony on the east (Pl. 174, fig. 4), both flanked on the sea face by beach rock con- 
glomerate; a long sand spit extends towards the west from Agony Island. On the lagoon side of the pass are two islands thrown up on the lagoon reef flat, and dividing the passage into two channels. One of the islands is a mere sand bar, and the other a low wooded islet flanked with beach rock. In the distance loom up the islands and islets and sand bars flanked with coral sand beaches which form the weather side of Likieb atoll.

We entered the south pass of Likieb, passing Agony Island (Pl. 174, fig. 4), flanked on the lagoon side with beach rock shingle; the island is covered with brush and hardwood trees. Here and there a low sand spit reaches into the lagoon from the half-submerged reef flat on the south face. Between Agony and Likieb Islands a number of small wooded islets occur on the narrow reef flat to the west of Likieb (Pl. 228, fig. 3). Both Likieb and Lado are comparatively broader islands than usually form part of the land rim in the Marshall atolls. They are both on a very wide reef flat, nearly three miles wide at places; the flat forms the southeastern horn of the atoll, and has probably been formed by sand blowing into the angle of the eastern and southern faces of the reef platform, and covering the coral heads which probably once flourished there. The reef flat becomes gradually narrower to the westward of Lado; it is narrowest about half-way toward the northwestern point. The lagoon side of the island of Likieb (Pl. 175, fig. 2) is formed by low coral sand beaches.

A coarse grass grows on the low beach of the lagoon side to the very edge of the shingle flat or of the beach rock conglomerate. On the lagoon side the shingle beaches are composed of small fragments of corals and of beach rock conglomerate consisting almost entirely of fragments of recent corals. The steep sea face beach of Likieb is at least fourteen feet high (Pl. 175, fig. 1). From the base of the shingle beach extends a reef flat about 250 feet wide, planed off out of the beach rock conglomerate, and sloping gradually towards the outer edge of Nullipore and Pocillipore knolls rising to a height of three to four feet above low-water mark. On the outer face the reef flat is gouged out into narrow and deep boat passages. Masses of dead coral boulders in place form portions of the outer reef flat (Pl. 175, fig. 1); they must have grown in the spaces between the ledges of beach rock conglomerate which form the reef 
flat. The top of the shingle beach consists of large boulders of dead coral thrown up during strong gales; the smaller fragments have been blown over the top of the beach, down the slope of the island towards the lagoon side (Pl. 176). The coral boulders on the lagoon face of the beach are generally black, pitted, and honeycombed, and much worn and weathered. On the lagoon side of Likieb Island a low coralline and coral sand beach not more than three to four feet in height (Pl. 175, fig. 2) slopes gradually into ten or fifteen fathoms; on this slope Nullipores and a few corals occur. Comparatively few corals are found on the sandy part of the lagoon of Likieb except on the very edge of the flats and of the coral knolls. Corals are found scattered over the lagoon on the flats, on the shoals, and on their steep side. They are the usual species we have found in other Marshall Islands, though there are a larger number of Hydrocorallida than are usually found in other atolls of the group. The bottom at ten fathoms, where we anchored, consists of fine coral sand silt and Nullipore mud; this extends over the lagoon wherever we examined it.

Pools exist on the outer reef flat between the Nullipore knolls and the base of the land rim. On the sea face the island has increased in height from material thrown up on the top of the shingle beach. The reef platform of beach rock conglomerate, which crops out on the lagoon side, is only the extension of the outer sea reef platform.

Most interesting are the so-called stranded islets of Likieb. They are islets formed parallel to the shore on the lagoon side and have become united by beach dams thrown up from the lagoon face as well as from the sea face through the gaps (Pl. 177). When these stranded islets have become united, they form hummocks, as it were. That the hummocks were once islands and islets which have become united, in the manner we have stated, is evident from the existence of old channels, still showing the former isolation of these islets. Mr. José DeBrunn tells me that on the island of Lado similar hillocks occur.

At the gap north of Likieb Island is a wide reef flat, where the heavy breakers have thrown up, as shingle, masses and fragments of corals derived from the outer edge and wide sea flat which separates Likieb 
from Lado to the north. Much of this shingle, as well as the shingle on the outer beaches of the islands on the northern face of Likieb, is ground into sand. Within the atoll of Likieb, as at Jaluit, sand spits extend from near the sea face of the gaps well into the lagoon. A large amount of sand is blown in towards the lagoon from the sea face of the numerous islands and islets of the western land rim, and finds its way through the gaps separating them, extending into the lagoon in gigantic spurs. These are eventually united from the two sides of the gap, and form a solid bar directly across the gap on the lagoon side of the islands, leaving a flasklike bay to indicate the position of the former gap. This bay, in its turn, may also be closed by the gradual filling in by the sand blown in from the sea beaches, or by the formation of a dam directly across the sea face of the bight. Thus sinks are formed, separated by islands and islets, which, if they had been connected with the shore of a large island, would present the appearance of the stranded islets we have just described. To the north of Lado this condition of the lagoon face is well seen, and one can follow far to the north spits running out from the gaps on the lagoon side of the reef flat.

The sand is mainly derived from the pounding up into sand of the coral shingle on the weather side, where masses of beach rock, of coral conglomerate are constantly thrown up on the outer beaches, as well as of the fragments of the dead corals thrown up on the outer reef flat from the sea slope of the atoll. As the breakers force their way at high tide over the reef flat into the gap, this material is little by little carried further into the lagoon and deposited, until it forms a dam to the very breakers which have built it. As the trades blow incessantly for nine months of the year, we can see how, with the torrential rains occurring in the Marshall Islands, this mass of material is readily decomposed into shingle, then into sand, and finally into silt.

In the gap between Likieb and Lado we can trace the formation of the sand flat from the consolidation of the sand spits extending far into the lagoon; a line of gigantic breakers indicates the position of the outer reef flat connecting the two islands. On this wide reef flat numerous sand bars are thrown up; they will eventually fill up the wide and shallow bay now 
existing between these two islands, a bay once perhaps a wide and deep gap connecting the sea with the lagoon. The widening of the lagoon flats of the Marshall Islands by the transportation of the mass of material exposed to the action of the trades differs somewhat from that due to the action of the trades in closing the gaps between islands on the land rim of atolls, either in the Paumotus or in the Fiji Islands.

'The line of islands and islets on the east face of the atoll are well plotted on the chart (Pl. 228, fig. 3) ; they form a succession of islets and islands and sand bars, separated by gaps, sending out spits across the reef flats on the lagoon side. The spits gradually project across the gaps, as we have described it, forming first tongues of sand at right angles to the shore line, then bays open to the sea or to the lagoon, and finally sinks, closed up by high shingle beaches on the sea face.

The rise of the tides in the Marshall Islands is from three to seven feet; as there are no hurricanes, the conditions under which the mass of material deposited on the reef flats is moved is not subject to the cyclonic conditions which occur in Fiji, or further east in the Paumotus. In the Marshall Islands, as at Jaluit, where the beach is not more than five feet above high-water mark, high seas have only occasionally forced their way across the island.

The southeastern part of the lagoon, and as far as one can see, is full of shoal patches and coral knolls. The deepest part is said to be from twenty-five to thirty fathoms, though as a whole the average depth of the lagoon varies from fifteen to twenty fathoms. We have not, in any lagoon, found such a mass of floating sand as at Likieb. It was impossible to make a haul of the tow nets anywhere without bringing up with them a large amount of sand.

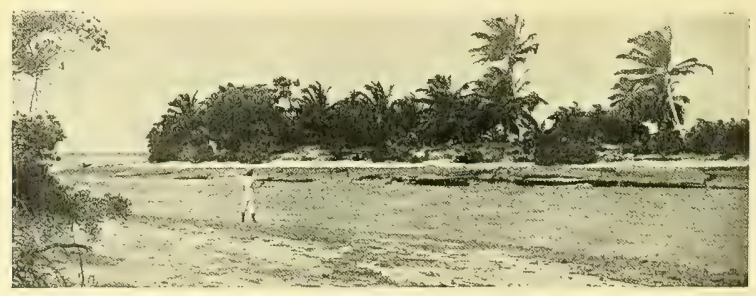

Gap across Land him, Likieb. 


\section{Wotje.}

Plates 178-180, figs. 1, 2; 225; 227, fig. 4; 228, fig. 1.

At the time we steamed past the western horn of the lagoon there was hardly any sea to show the line of demarcation of the submerged reef flat rising between the lagoon and the deep blue water (Pl. 228, fig. 1). The light green color of the shallow water on the submerged reef formed a striking contrast with the deep blue and iridescent colors on the two sides of Rurick Pass. We entered Wotje by the Rurick Pass and anchored about a mile inside of the lagoon in twenty-two fathoms. We could see in the distance Christmas Harbor, formed by the low islands and islets of the northern face of Wotje. As far back as 1817 Wotje was surveyed by Kotzebue. The "Rurick" entered the atoll through Rurick Pass, near the western extremity of the south face, explored the north face of the lagoon from Goat Island eastward and passed out again through Schischmarev Strait. This is one of the earliest and best charts of an atoll. The soundings indicated (Pl. 228, fig. 1) were all taken by the "Rurick." According to the Russian chart a great part of the lagoon of Wotje has a depth varying from twenty-five to twenty-eight fathoms. Little notice has been taken of this atoll by writers on coral reefs, in spite of the accurate information given by Lieutenant Schischmarev. ${ }^{1}$

Rurick Pass leads to Christmas Harbor; no obstructions exist at that end of the lagoon (Pl. 228, fig. 1). The gaps between the islands on the weather side appear, judging from the color of the water, to be quite deep. The weather side of the lagoon is in marked contrast to the lee side, where the land rim consists of only a few isolated islands thrown up on the narrow reef flat which forms that side of the atoll.

As we passed out of Rurick Pass on the following morning, the contrast we had noticed the evening before in the color of the water on the two sides of the passage was perhaps even more marked. On one side spread the dark blue of the lagoon, on the other the still darker blue of the deep water off the lee side, with the bright green belt indicating, on the two 
sides of the passage, the position of the submerged reef, the dark blue gradually passing into a lighter blue, finally into a bluish green, a yellowish or even light green; the edges of the passage being covered with patches of the peculiar iridescent and metallic coloring we have mentioned before. This band of highly colored water seen in the morning and evening sun seems to be characteristic of the Marshall Islands; we did not observe it, or saw it only on a very limited scale, in any of the other atolls we visited.

Passing out of Rurick Pass, we followed the narrow submerged reef line of the lee face of Wotje atoll marked by its light green color, interrupted here and there by an occasional islet or breaker. The tide at the Marshall Islands rises from five to seven feet, so that the amount of water which is daily poured over the reef flat into the lagoon must be enormous. In addition this mass of water is driven by the trades, so that a very different condition exists from that of the Paumotus, where although there is a powerful swell, yet the tides are comparatively insignificant, the southeast trades are more or less interrupted, and the passes are few in number and usually narrow. The amount of water entering into the atolls of the Paumotus bears no comparison to the rush of water entering into many of the other atolls of the Pacific.

The first island to the eastward of Rurick Pass was well wooded, although but a narrow thread of land. It was edged on the sea face with beach rock conglomerate, the two extremities of the island forming sand spits, the sand having been driven from the lagoon beach and overwhelming little by little the beach rock conglomerate which crops out upon the reef flat (Pl. 228, fig. 1). This island is crowded with terns and forms a gigantic rookery. To the eastward another islet is thrown up on the half-submerged reef flat. To the south of these crop out occasional stretches of coral sand raised slightly above the level of the reef flat. There is considerable swell on the southern face of the atoll, and a long line of breakers indicates the position of the outer half-submerged reef flat. Many of the islands and islets near Schischmarev Pass (Pl. 180, fig. 2) are only reaches of beach rock conglomerate pounded by the breakers. At the angle of the southern face of the atoll leading to Schischmarev Pass a large island has been formed; 
it is flanked by a high black shingle beach fully fourteen feet above highwater mark. Sand spits extend from the extremities of this island on the wide reef flat, covered by huge coral boulders, the tops of which have died, and have been more or less cemented, as in other coral boulder reef flats we have described.

Sand spits and sand bars extend northward on the inner part of the lagoon, and a number of islands, islets, and sand bars are indicated by lines of breakers parallel with the outer line of islands. Schischmarev Pass is near the western extremity of the deep curved bay of the south face of the atoll (PI. 228, fig. 1). Abont four miles to the enst of Schischmarev Pass opens Lagediak Pass, another strait leading into Wotje. These two passes are, only on a larger scale, as we have observed in other atolls of the Marshall Islands, blocked on the lagoon side by one or two rows of islands parallel in a general way to the outer islands flanking the opening of the passes (Pl. 180, fig. 2). The islands and islets on the reef flat of the southern face of Wotje are generally connected by sand bars; some of them are wooded, covered with hardwood trees, Pandanus, and a few cocoanut trees. At Schischmarev Pass the outer islands have been thrown up on the edge of the wide beach rock conglomerate flat. They are separated by deep gullies forming passes more or less clear, lanes of dark blue water separating the outer and inner rows of islands which block the pass to the north. On the south side of Schischmarev Pass the islands of the land rim are partly connected by low sand bars, sometimes entirely closing the gaps between them ( $\mathrm{Pl}$. 228, fig. 1), though there are a number of indistinct gaps separating the islets of the land rim. On the eastern part of the south side of the lagoon, the islands thrown up on the reef flat are flanked on the sea face with sand spits; these reach out towards the outer edge, making huge loops or shallow bays opening out to the sea.

On Wotje Island but little beach rock conglomerate is exposed on the lagoon side, the coral sand beaches are high, and a few boulders are scattered on the flat between it and the next islet. The islands to the north of Wotje are similar in structure; they show but little beach rock conglomerate outcrop; the lagoon face is flanked by fine coral sand beaches (Pl. 179). The gap between Wotje and the island to the north of it (PIs. 
$179 ; 180$, fig. 1 ) is flanked by two sand spits. The beach on the lagoon side is about seven feet high (PI. 179, fig. 2), while on the sea side it is at least twelve to thirteen feet. The shore of the gaps towards the lagoon are flanked on the outer edge with beach rock conglomerate; this is gradually changed into fine coral sand as we reach the edge of the lagoon (Pl. 179). A line of breakers extends directly across the gap; the light green color of the water shows there is only a shallow passage between the lagoon and the sea face (Pl. 180).

We anchored in twelve fathoms, about three quarters of a mile off Wotje Island. Corals grow in large patches between our anchorage and the shore, mainly blocks of Porites, patches of Pocillipores, of Millepores, and of Madrepores; wide patches of Algæe and Nullipores, separated by lanes of sand, extend to seven or eight fathoms in depth. Along the slope of the beaches both the corals and the Algæ diminish in number with increasing depth, to twelve or fifteen fathoms, and more rapidly to twenty fathoms. The island of Wotje (Pl. 227, fig. 4) is fully three quarters of a mile wide; it

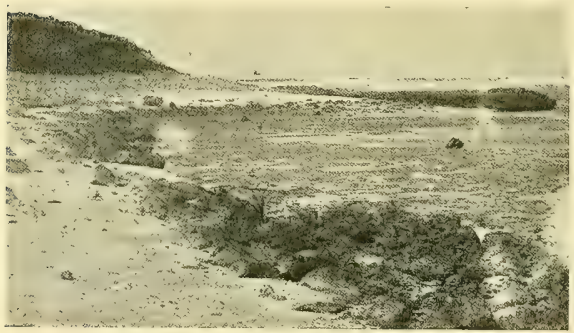

SFa Face of WOTJE IsLand. is formed by a succession of low ridges, - four where we crossed it, - forming sinks, in which the natives have dug water-holes. The ridges are covered with magnificent Pandanus, breadfruit, and Pouka trees. The belt of vegetation is much finer (Pl. 178) than on any other atoll we have visited. Rolled beach corals are met with across the whole island; on the sea face the island is flanked by a wide reef flat, edged with Nullipore and Pocillipore knolls. The reef flat is about 150 yards in width; it slopes gently; large numbers of coral heads have been thrown upon its surface. The sea beach is at least fourteen feet high, composed in part of shingle, in part of sand. . At the base of the beach extend masses of beach rock conglomerate, made up of large blocks of coral heads, and of smaller fragments of beach rock and corals. On the lagoon side the beach rock 
conglomerate is finer, containing many amygdules, and made up of small fragments of corals. The large coral masses on the sea face of the reef flat, the outliers of beach rock conglomerate, and the fragments of corals thrown over the sea- beach inland are honeycombed and pitted, and much weathered.

As we left our anchorage, we could trace on the northern extension of the west face of the eastern land rim the successive sand spits projecting out from the lagoon side of the land rim, and forming a series of bays on the inner side of the atoll, far larger and more distinct than those we have described as existing on the outer sea face of the south shore. Both, however, are formed by the same agencies. On the east face the sand from the sea beaches is blown by the trades into the lagoon between the sides of the gaps, and the gap may be closed by the extension of the shingle beaches on the sea face of the islands on the two sides of the gap (Pl. 179, fig. 2); on the south side of the lagoon the sand forming the spits extending to the sea face on the outer reef flat comes from the lagoon sand beach. The sand beach or dam thrown up across the lagoon face of the bay is due to the reach of the trades in the lagoon itself (PI. 179); but the result is the same. In each case the gaps of the land rim are closed by sand blown in from the outer or inner beaches of the land rim.

It is probable that the line of sinks we have described on Wotje are evidences of gullies and gaps once separating islets on the lagoon face of the land rim, gaps which have gradually been closed by a process similar to that which has connected the independent islands and islets forming the outer land rim of Wotje. If we imagine the result, of the consolidation of the double or treble row of islands blocking such a gap as Schischmarev Pass (Pl. 180, fig. 2), we see that the resultant would form a line of sinks and reaches and of gaps similar to those we observed while crossing Wotje from the lagoon side to the sea face.

To account for the existence of islands increasing in size at both extremities, such as form the land rim of the Marshall Island atolls, we assume that the base upon which the loose material of which they are built is moved must be either stationary or have been elevated. There is not sufficient new material supplied from the growth of corals to build up 
such a land rim while the atoll is subsiding. The evidence we have shows a certain amount of elevation, indicated by the position of outliers and outcrops of the underlying base or fundament upon which the loose material has accumulated. If the land had been subsiding, this material must in the end have been washed off from its surface and deposited either on one side or the other of the face of the atoll.

According to the chart, many shoals and flats exist or are forming in the lagoon of Wotje, especially in the northern part along the whole length of the land rim (Pl. 228, fig. 1). Where we steamed past shoals and flats their position was marked by long lines of breakers, separated by greenish bands of shallow water, indicating the intervening sandy flats. The amount of sand continually in motion on these flats is considerable, and shows how fast the coarser materials, the boulders and the blocks thrown up on the beaches, are pounded and ground into sand. In an enormous lagoon like Wotje (thirty miles by fifteen), the northern side of the lee face is, of course, subject to the influence of the northeast trades. The very outlines of the islands of the land rim on the weather side of the atoll indicate how regular the action of the trades must have been in throwing up this mass of material upon that face of the atoll. As seen from the south, across the lagoon, the islands appear like rectangular blocks of nearly uniform size, 'with rounded corners, separated by gaps. The islands are all edged on the lagoon side with glistening white coral sand beaches. They are from five to six feet high. As we steamed out of Schischmarev Pass, we observed on the second island to the west a huge boulder, a mass of Porites, thrown high up on the reef platform, similar to those found on the reef flat of the sea face. Several hauls made by the Krämer machine to limited depths outside of the atoll brought less pelagic material than in the lagoon. This may be due to the great disturbance of the surface outside of the lagoon, where the trades drive the pelagic material to a considerable depth, while in the lagoon the pelagic material lives in comparatively smooth water; a large proportion of the surface of the atoll is sheltered at all times during the prevalence of the northeast trades, or in calm weather, or during the short time that westerly winds prevail. 


\section{Arhno.}

Plates 180, figs. 3, 4; 181; 182, figs. 1,2; 225; 228, fig. 4.

Arhno, the last atoll we visited in the Marshall Islands, is rectangular in outline (Pl. 228, fig. 4), the southeastern and northwestern faces being about seven miles in length, the southwestern about thirteen, and the northeastern about ten. From the northern extremity of the northeastern face of the atoll extends a long spit, about six miles in length, and off the northeastern point of the atoll a similar spit, fully ten miles long; the northeast face of the atoll is a gigantic arc, running in a northeasterly and northerly direction, forming, as it were, two handles to the rectangular lagoon of Arhno (Pl. 228, fig. 4). The charts of Arhno are somewhat misleading; it was not until we had steamed around the northern point of the island, and obtained a general idea of its topography as seen from the sea, that we understood its peculiar shape.

We examined the northeastern, the northwestern, and eastern face of the atoll, as well as part of the southwestern coast. The depth of the lagoon varies from ten to twenty-five fathoms; a large number of shoals and patches are scattered over it. The slope from the land rim towards the bottom of the lagoon is quite steep; at our anchorage in Arhno we found a very rapid drop from the shore to fifteen or seventeen fathoms, the remainder of the Iagoon being comparatively flat, as in the Paumotus.

We entered Arhno through Dodo Pass (Pl. 228, fig. 4), and anchored off the east face, immediately at the base of one of the long spits which give it its peculiar outline (Pl. 181, fig. 3). We could look up the narrow lagoon between the two sides of the northeastern spit formed by a western line of islands and on the east by Terranova (Pl. 228, fig. 4). The western part of the horn of the lagoon is separated from its northeastern extension by an elbow of Terranova Island running directly across the reef flat from one side of the spit to the other. A similar formation occurs at the north point of Likieb. At Arhno, however, the spit is much longer; the eastern extremity is flanked on one side by the northern extension of Terranova, and on the other by an open reef flat enclosing an auxiliary lagoon, with an opening about an eighth of a mile in width, suitable for 
the navigation of small boats. The eastern extension of Terranova is partly flanked on the lagoon side by a high sand beach, and a heavy shingle beach on the sea face rising from a narrow reef flat. On the lagoon side of the land rim a large part of the shore is divided into a series of bays, separated by points and spits of beach rock conglomerate and rolled coral boulders which have been thrown over the island, or rather thrown over the reef flat forming the eastern spit, before the

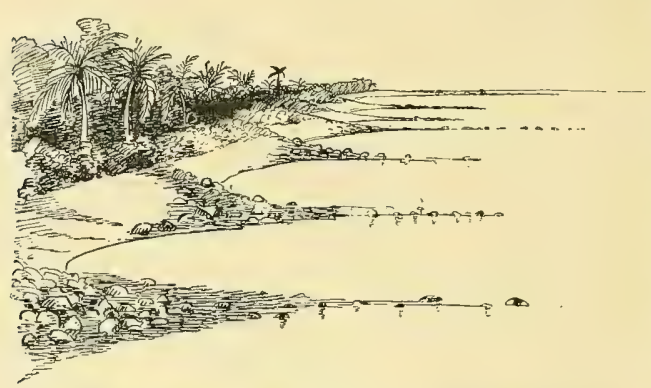

Boulder Cusps, lagoon Face of Northeast SPIT, Armo. island was built up to its present height. The greatest width of the secondary lagoon is one and a quarter miles, and its length about three miles. The islands and islets on the western face of the northeast horn of the lagoon (PI. 181, figs. 3, 4) are flanked by coarse shingle beaches on the sea face, and by sand beaches on the lagoon side. They are well wooded and, as a general rule, have been built up at right angles to the trend of the horn of the lagoon. The gaps between the component islands and islets have, little by little, been closed from the outside or the inside, according to the prevalence of the trades. The formation of the secondary lagoon of the northeastern spit is easily explained by the accumulation of loose material thrown up on the reef flat, derived either from the eastern or the western face of the horn bounded by the line of islands on the west and Terranova on the east of the lagoon. This has separated the horn of the lagoon from the principal lagoon exactly as the secondary lagoon of the northeast point has been separated from the northeast horn of the main lagoon.

The northeast horn of the lagoon is undoubtedly gradually filling up; a number of coral patches, sand bars, and spits will little by little encroach upon the lagoon, the depth of which is at present very considerable, 
and change parts of it next to the land rim into a reef flat, continually becoming broader.

The bay of the northeastern extension of the lagoon is more than a mile wide. The islands on its northern face (Pl. 181, figs. 3, 4; 228, fig. 4) are separated from the islands to the east of Dodo Pass by a long stretch of reef nearly awash at low water; on its outer edge a line of heavy breakers is pounding and constantly throwing material across the flat into the inner part of the lagoon.

The sea face of Terranova, the principal island on the eastern side of the atoll, is nearly fourteen feet high ; it consists of coral boulders derived from the outer narrow reef platform thrown up to form a steep beach. The summit of the beach is fully fifty feet in width; large masses of coral have been rolled inland across the whole width of the island to form the spits in the northeastern lagoun. It is evident from the position of the masses of coral boulders that the island forming the eastern face of the northeast branch of the lagoon has been built up by material derived from the outer eastern face, as has been formed the high steep bank of the east shore of Terranova. The spits on the western face of Terranova, once lines of boulders extending across a wide reef flat, have been excluded from the sea by an outer dain; this has obliterated all traces of the gaps existing between the islands once forming the east face of Arhno. The lines of rocky ledges on the lagoon side remain to indicate the gaps, closed by the formation of a shingle dam as the nucleus of the land rim of the east face of Arhno. The eastern face of the northeastern extension of the lagoon is occupied by Terranova, a narrow and slightly hook-shaped island. The lagoon beach is composed of fine, slightly reddish coral sand, with here and there a stretch of beach rock made up of a conglomerate of broken corals cemented with fine coral sand. Near the southern extremity of the island on the lagoon side is a spit composed of broken angular masses of dead coral. This mass is underlaid by beach rock, and at this point the lagoon beach is from six to eight feet above low-water mark. About fifty feet inland, back of the lagoon beach, the lowest land of the island is found that is, there exists immediately behind the lagoon beach a long trough-like depression running parallel with the lagoon beach nearly half the length of the island. There 
are no sinks or ponds in this depressed region. The bottom is sandy and covered with scattered broken or beach-worn corals washed in from the sea face of the island.

The island is not more than 200 yards in width; back of the eastern face of the trough the land rises gradually to the summit of the sea beach. This is flanked by a reef flat varying from 100 to 300 feet; upon it are scattered loose heads of corals of large size; many of them have been driven together on the beach, forming a continuous wall of about ten to fourteen feet in height. This wall of beach-worn coral is underlaid by beach rock conglomerate and the whole island is covered with masses and fragments of coral washed in from the reef on the sea face. At a distance of about two thirds the length of the island towards the southern extremity we could trace these masses of corals thrown completely across the island, where they have formed the coral boulder spits of the inner face of the lagoon, underlaid by the beach rock conglumerate, as I have described them on the sea face of the beach.

The soil of Arhno is fairly productive. Its larger islands are covered with grass, fine groves of cocoanut trees, with magnificent breadfruit, Pandanus, and Pisonias, and the usual belt of low vegetation growing upon the summit of the beach.

The long island of Ine occupies the southern part of the atoll; it does not differ from that which flanks the eastern face. There are said to be several boat passages on the southwest face of the lagoon (Pl. 228, fig. 4).

We steamed out of the atoll through Dodo Pass, and skirted the eastern face of Arhno on our way round the northern point of the atoll. On the northern point a $Y$-shaped land rim is thrown up on a wide flat (Pl. 228, fig. 4); at its southern base the islands have united in a single crescentshaped island, extending from one side of the spit to the other. The shanks are formed by lines of islands on the opposite faces of the northern point; they are separated by wide gaps and enclose a secondary lagoon in the centre of the northern reef flat. Where the larger island cuts directly across the secondary lagoon of the northern point a shallow wide bay forms a closed area; its western face is formed by the islands thrown up on that face of the wide flat of the northern point. The northern extension 
of the islands forms the sweep of the eastern and western face of the horn of the northwest point (Pl. 182, figs. 1, 2). To the south of the first transverse island a second row of islands cuts across the southern part of the wide reef flat of the northwest point, flanked in its turn by islands and islets with a steep sea face and high shingle or sand beaches. They form the western land rim; this passes gradually into a more or less indistinct reef, the position of which is barely indicated by the color of the water. On the north face is a continuous line of islands covered with luxuriant vegetation, with steep shingle beaches extending east from the base of the northwest point (Pl. 180, fig. 3), flanked at the base with high shingle and beach rock, extending as far as Dodo Pass (Pl. 180, fig. 4), and from Dodo Pass to the base of the northeast point.

At the base of the northern spit the land rim extends on one side towards the southeast, north of Dodo Pass, and on the other towards the westernmost point of the atoll. On the broad reef flat of the western face, which is bare at its northern extremity, are a number of islands and islets near its western point; this is occupied by an island of somewhat greater size. Skirting along the western coast we could see the lagoon side of the many islands and islets extending northward from Dodo Pass to the base of the northern spit (Pl. 180, fig. 4).

When off the eastern face of the northwest point of Arhno, we were able to examine the secondary lagoon formed on that spit (Pl. 182); it differs but little from the secondary lagoons of the spits or extensions of many of the atolls in the Marshall Islands. In the case of Arhno, the northern extremity of the flat of the spit is exposed to the action of the sea from all directions; the secondary lagoon is open to the north (Pl. 228, fig. 4), the northern reef flat being too deep to allow material to accumulate, either on its weather or on its lee face. The reef flat of the northern point, south of the secondary lagoon, is more than a mile wide. Two rows of islands and islets flank the eastern and western face; from the extremities of the islands extend lines and bars of sand and shingle at right angles to the general line of the land rim, with here and there gaps opening on the extensive inner reef flat. We could see from the east side the sand beaches on the lagoon face of the islands 
of the west side, with their sand spits and bars, forming the southern edge of the secondary lagoon of the northern point (PI. 182, fig. 2). The secondary lagoon must be of considerable depth, judging by the dark blue color of the water. The northern extension of the two sides of the secondary lagoon is indicated by a mere thread of breakers and of discolored water, showing the extension of the reef flat as it passes into the deeper bank off the northern point of Arhno (Pl. 228, fig. 4).

The islands of the west face extend about five miles south of the base of the secondary lagoon of the northern spit; they are on the very edge of the wide reef flat. On the lagoon side of the flat exists here and there a huge sand bar connected with the outer shingle beach forming the west face of the land rim. The islands and islets are separated by wide gaps, edged by shingle beaches, the sand spits running towards the lagoon forming wide, exceedingly shallow bays. We skirted for a considerable distance along the west face of the narrow outer reef flat of the islands. The position of the wide reef flat which forms the northern part of the western side of the atoll is indicated by the reach of greenish or light green water extending eastward into the lagoon.

Along the northeast face of Arhno, from the northwest point to Dodo Pass, bars run at an angle across the wide reef flat, with a number of islands and islets and spits, connected at half-tide by beach rock conglomerate and shingle. The outer reef flat is comparatively narrow, but on the west side the lagoon flat is wide, and there are from two to three lines of islands and sand bars and sandy islets on the lagoon reef flat immediately north of Dodo Pass (Pl. 180, fig. 4).

The islands are flanked on the lagoon side by beach rock conglomerate surmounted with coral shingle on the outer face of the reef platform, and with fine coral sand on the inner side of the reef flat. These islands and islets become gradually connected, forming a series of irregular parallelograms enclosing shallow basins; these finally become filled up, forming a wide island extending more or less diagonally across the reef flat. When this process has taken place on the flat of a point, as, for instance, the northwest point of Likieb, the point will gradually be filled up, and thus a secondary lagoon be formed. Should this take place on the northeastern 
point of Arhno, for instance, the secondary lagoon will be formed by a land rim on one side, leaving the face exposed to the action of the sea more or less open. The islets in the vicinity of Dodo Pass are interesting (Pls. 180, figs. 1, 2; 181, fig. 1); the inner line of islets, banks, and flats and spits gives us an excellent example of the manner in which a wide reef flat becomes gradually covered with islands and islets, and finally may become changed into a wide land rim by the movement of the material carried backwards and forwards by the breakers, material which has been supplied from the disintegration of the outer beach rock conglomerate, from the corals thrown up on the sea face, or from the corals growing on the slopes of the interior of the lagoon. The coarse shingle of the beaches consists of rolled fragments of corals near the summit and at the base of boulders which are scattered over the reef flat of the atoll; this is fully three quarters of a mile wide at low water at some parts of the land rim. On the two sides of Dodo Pass the breakers sweep across the gaps between the islands and islets (Pl. 180, fig. 4) exposed to the action of the prevailing wind, throwing a large amount of material into the gaps. Many of the islands on the sea face between the northwest point and Dodo Pass are covered by dunes blown westward over the rolled corals and coral heads of the lagoon flat. Immediately east of Dodo Pass a large wooded island has been formed on the inner side of the reef flat. The islands to the east of Dodo are larger than those immediately to the west, and are separated by wide gaps generally bare at three-quarter tide (Pl. 228, fig. 4). On the lagoon face of the islands are numerous bars of shingle or of sand at right angles to them, running far into the flats; these, little by little, become covered with sand and vegetation. Dodo Pass is flanked on the western face by a series of flats, shoals, islands, and bars; on the northern side they extend nearly three miles into the lagoon parallel to the northeastern and eastern coast. The ridge which forms the northern point extends a considerable distance northward as a bank, with from three and a half to six fathoms of water for a distance of over two miles north of the reef flat. It is probable that the northern and northeastern points of Arhno are spurs of the main ridge or summit upon which, after its denudation, the atoll of Arhno has been built up. To the eastward of 
Dodo Pass the reef flat was, as on the north, covered with a number of islands and islets, extending to Tagelib Pass and beyond to East Pass (Pl. 228, fig. 4). From Tagelib the reef flat is bare, the sea breaking heavily upon it; it remains bare as far as the base of the small lagoon which extends like a huge horn in a northeasterly direction from the northeast corner of Arhno.

On the west side of Arhno, near the south point, we encountered high shingle dams, forming exceedingly narrow land rims, the outer sea face and the lagoon being separated by a mass of rubble thrown up on the sea face and washed, in part, towards the interior of the lagoon.

A striking feature of Arhno is that the sea face of the islands on the land rim of the northeastern part of the atoll is flanked by heavy shingle (Pl. 181, fig. 1), similar to that which has been thrown upon the eastern face of the atoll.

In many places the high shingle beaches form isolated dams of considerable length; as, for instance, the immense dams of rubble on the sea face of the secondary lagoons of Taritari, where the rubble has been thrown to a height of at least nine feet. With the decomposition of this rubble and broken fragments into sand, islands covered with vegetation have been built on the line of the dam. At the northeast point of Arhno, spits of rubble, similar to the sand spits so common in the gaps of the atolls of the Marshall Islands, have been thrown out from the lagoon face of the immense dam forming its eastern land rim.

The small islets of the Marshall group which are not atolls or possess no sinks, or where only slight depressions exist, must have been thrown up on isolated peaks or ridges, as have secondary lagoons on extensions of the faces of spits of such atolls as Likieb, Arhno, and Rongelab. That is, beaches are thrown up on a shoal to a height of from twelve to fourteen feet enclosing a circular sink, or an elliptical depression, or a longitudinal trough, the existence of which has nothing to do with either elevation or subsidence; it is merely an open space left between a series of encircling beaches. The sink is gradually filled with material thrown over the beaches from all directions. Thus a low island is formed with a slight depression or with a shallow lagoon, the land rim of which may become 
covered with vegetation, and seem to be an atoll raised from the depth of the sea, or the remnant of a peak which has gradually sunk, according to the theory of subsidence. Yet a large number of such atolls have been formed merely by the transporting of dead material from the outer face of the shoal, and its deposition on the inner parts of the flat.

\section{Namorik.}

Plates 225; 226, fig. 10.

During our passage from Jaluit to Namorik, we were unable to do any work on account of the heavy trades, so gave up all idea of stopping at that atoll and kept on to Kusaie. Namorik is open to the west, nearly circular, and about six miles in diameter. Namorik atoll, from the description given by Hernnsheim, is undoubtedly gradually filling up. On the western face is an enormous reef flat flanking a diminutive lagoon (Pl. 226, fig. 10), with passages only for small boats, though forty years ago, according to sketches I have seen, schooners of considerable size entered the lagoon and crossed the reef flat. This does not necessarily mean that to the growth of corals is due this difference in the depth over the flats. The material which has covered them is probably material blown in over the reef flat from the sea face. The main reef flat is, according to some sketches, covered with many large coral boulders, one of which is said to be of the size of a native house. The depth over the reef flat has, on that side, been diminished by the disintegration of the beach rock conglomerate, and of the boulders mentioned above. 


\section{THE CAROLINE ISLANDS.}

Plates 182, figs. 3, 4; 183-193, 225, 229-232; 233, figs. 1-3.

We visited among the Carolines the islands and atolls of Kusaie, Pingelap, Ponapi, Andema, Losap, Nama, the Royalist group, Truk, and Namonuito, obtaining thus an excellent survey of the high volcanic islands of the group from our examination of Kusaie, Ponapi, and of Truk, while the others represent the structure of the low atolls; some of them have probably a volcanic basis, and others a tertiary limestone foundation, but neither were observed at any of the low islands we visited.

Of the eastern Carolines, Kusaie and Ponapi are volcanic islands, and of the western, Yap and the Pelew group are also volcanic. The reefs of the Pelew group have been well described by Professor Semper. ${ }^{1}$

The barrier reefs of the volcanic islands of the Carolines are similar in character to those of the Society Islands, though some features, such as the great width of the platforms of submarine erosion of Truk, Ponapi, and of Kusaie, and the development of a border of mangrove islands at the base of the volcanic islands, are not found in the Society Islands.

The Truk Archipelago is perhaps the most interesting of the island groups of the Carolines; it is the only group of volcanic islands surrounded by an encircling reef $I$ have thus far seen in the Pacific which at first glance seems to lend any support to the theory of the formation by subsidence of such island groups as Truk. I can well imagine that an investigator, seeing for the first time coral reefs in this group, would describe the islands as the summits, nearly denuded, of a great island that had gradually sunk. But a closer examination readily shows, I think, that Truk is not an exception to the general rule thus far obtaining in all the island groups of the Pacific we visited during this trip; that we must look to submarine erosion and to a multitude of local mechanical causes for our explanation of the formation of atolls, of barrier and encircling reefs, and

\footnotetext{
1 Die Natürlichen Existenzbedingungen d. Thiere, v. Karl Semper, Leipzig, 1880, Bd. II., p. 39.
} 
that subsidence has played no part in bringing about existing conditions in the atolls of the South and Central Pacific. This group was not visited by either Darwin or Dana.

Nowhere have we seen better than at Truk how important is the part played by a submarine platform in the growth of coral reefs. The encircling reef protects the many islands of the group against a too rapid erosion, so that they are edged by narrow fringing reefs, and nowhere do we find the wide platform so essential to the formation of barrier reefs. The effect of the northeast trades blowing so constantly in one direction for the greater part of the year is of course very great; the disintegration and erosion of islands within its influence is incessant, and their action undoubtedly one of the essential factors in shaping the land rims of the different atolls, not only according to their local position, but also according to the geographical position of the groups. Thus far I do not think any observer has given sufficient weight to the importance of the action of the trades in modifying the islands within the limits of the trades; nor has it been noticed that the coral reef areas are, with few exceptions, situated within the limits of the trades, both north and south of the equator.

We did not visit a number of the eastern and central Carolines, but, judging from the Admiralty Charts, they present no features of special interest. The small land rims of some of the low atolls are very striking; for instance, at the Mortlock Islands, ${ }^{1}$ the land rim of Sotoan, its principal atoll, nearly twenty miles in length and six in width, is indicated only by a few islands and islets; the greater part of the atoll is marked merely by a reef flat with extensive, coral patches on its western and northern face. Lukunor, another atoll of the Mortlock Islands, has been surveyed by Captain Liitké. It is slightly pyriform in outline; its lagoon has a depth varying from twenty to thirty fathoms, with an average depth of about twenty. The land rim of the southern and of the southern part of the east face of the atoll consists of a large number of islands and islets; the narrow northern and western reef flats are awash.

The Hall Islands resemble the Mortlock group, as do the Lamotrek and the Uluthi Islands, all of which have been surveyed by Captain Lütké. 
There are also among the Carolines a number of isolated islands and islets; they appear, from the Russian surveys, similar to some of the above-named islands or to such islands as Pingelap.

Wolea Island ' has also been surveyed by Captain Lütké. It consists of two open arcs of flats on which low islands have been thrown up, the lagoons in the two arcs varying in depth - the eastern from five to twenty fathoms, and the western to twenty-five. The eastern lagoon is entered by a passage of about three quarters of a mile in width, while the western lagoon is partly closed by two indistinct patches; the ridge separating the lagoon from the sea rises to a depth of four or five fathoms.

We may note that the islands of the western part of the Carolines run from southwest to northeast, having the same general trend as the southern group of the Ladrones. The line of elevation of the central and eastern Carolines from Kusaie to Truk runs in a general way from south of east in a westerly or slightly northwesterly direction; a number of parallel lines of elevation pass through the low atolls of the eastern and central part of the central Carolines.

The soundings made by the "Albatross" from Jaluit to Namonuito" indicate that there is no great plateau from which the Carolines rise, but that the various groups are, as is the case with the neighboring groups of the Marshalls and Gilberts, isolated peaks with steep slopes rising from a depth of over 2000 fathoms. The line we ran from the northern end of Namonuito to Guam developed the eastern extension of a deep trough running south of the Ladrones. The existence of this trough had been indicated by a sounding of 4475 fathoms made by the "Challenger" ${ }^{3}$ to the southwest of Guam. We obtained, about 100 miles southeast of Guam, a depth of 4813 fathoms, a depth surpassed only, if I am not in error, by three soundings made by the "Penguin" in the deep trough extending from Tonga to the Kermadecs, ${ }^{4}$ and by two still deeper made by the

1 A. Chart 772.

2 Mem. M. C. Z., Vol. XXVI., No, 1, 1902, Prelim. Report, p. 63. Stations 238-244.

3.A. Chart 2935, Oceanic Soundings, Sheet 3. Named "Challenger Deep" in the Summary of Results, Chart 1c, of the Voyage of the "Challenger."

${ }^{4}$ Ibid. 
U. S. S. "Nero" 1 to the eastward of Guam, probably in continuation of the same "Deep" called the "Caroline Deep" by Professor Supan. ${ }^{2}$

\section{Kusaie.}

Plates 182, fig. 3 ; 184-18\%, 225, 229.

The easternmost island of the Carolines, Kusaie, is about seven and threequarters miles long from north to south, and nearly nine miles from east to west. It is a volcanic island; the central part, Mount Crozer, rises to over 2100 feet in height; the northern summit, Mount Buache, rises to nearly 2000 feet (Pl. 229).

Kusaie is the first of a series of islands differing from any we had seen since leaving the volcanic regions of the Society, Cook, and Fiji Islands. High peaks with needles of all possible shapes show the extent of erosion and denudation which has taken place in the volcanic summits of the Carolines (Pls. 184, fig. 2; 185, fig. 2). Kusaie, as seen coming from the east, at a distance of from three to four miles, steaming towards Chabrol Harbor, shows perhaps as well as any other island of the group the extent to which its volcanic rocks have been subjected to erosion and denudation. It is cut into a number of deep valleys centering towards the middle of the island, with here and there a marked point or pinnacle of harder material left to indicate the former height of the range.

Between the northern and central part of the island runs a deep valley connecting Chabrol Harbor on the east to Coquille Harbor on the west (Pl. 229). Kusaie is somewhat irregular in outline; a deep indentation on the east side forms Chabrol Harbor, flanked on the north by Lélé Island. The southern shore forms a deep bight; in the centre of which is the reef harbor Port Lottin. Coquille Harbor is a similar reef harbor on the west side.

The principal ridge of the island runs east to west from Point Duperrey

1 The deep soundings of the "Nero" have been marked "Nero Deep" on H. O. Chart 529, published June, 1900, but it does not give the deep sounding of the "Challenger" to the westward (4475 fathoms), which was the first indication of the probable existence of a deep trough south of Guam. The deepest sounding made by the "Nero" attained the enormous depth of 5269 fathoms.

2 Petermann's Mitteil., 1899, Vol. 45, VIII., p. 180. 
to Cape Vauvilliers (Pl. 229), with a series of peaks varying between 1500 and 2100 feet, and deep valleys running south and north from the ridge. A spur extends from the eastern end of this ridge towards the south to Cape Tupinier, from which valleys run east, west, and south. Kusaie is flanked by an extensive reef platform forming either a fringing reef or a barrier reef with deep reef harbors, like Coquille, Chabrol, and Lottin (Pl. 229). Chabrol Harbor is a deep valley between two chains of voleanic rocks; on its sea face a platform has been worn away to the north of the entrance to the harbor, forming a comparatively narrow reef flat covered with low vegetation, with a similar reef flat off the east face of the chain forming the southern point of the entrance to Chabrol Harbor. Owing to the heavy sea running across the entrance, we did not enter the harbor; turning south we skirted the outer reef platform; it increases in

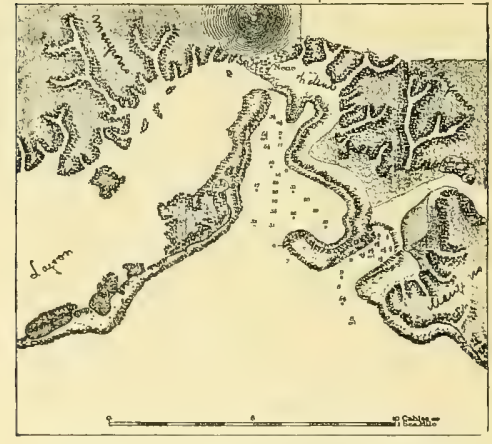

Port Lottin and Adjoining Mangrove ISLANDS. width towards the south and is covered with low islands and islets.

The greater part of the base of the shore slope of Kusaie is fringed by a belt of mangrove islands; between Port Lottin and Cape Tupinier it forms a most intricate system of lanes and bars (Pls. 184, fig. 2; 185, fig. 3 ; 186, 229). Between these points there is an outer line of mangrove islands and islets (Pls. 184; 185, figs. 1,2 ), with a passage of considerable width and depth (Pl. 186), connecting with the eastern part of Port Lottin and the barrier reef of the lagoon, which extends from Port Lottin to about one and one-half miles south of Point Duperrey (Pl. 229), affording thus, with the passage in the lagoon to the west of Port Lottin, an almost continuous boat track around Kusaie with the exception of the short stretches where the reef flat becomes a fringing reef. Between Port Lottin and Cape Vauvilliers the lagoon is broader and wider than on the east or north face. The mangrove belt on the outer edge of the reef flat is formed by a 
series of small islands at right angles with the outer beach. This mangrove belt is a most characteristic feature of the barrier reef of Kusaie. The mangroves grow upon a labyrinth of low islands ( $\mathrm{Pl} .229$ ), formed of material washed down from the hills immediately behind the shore line; this material is mixed with coral rock material thrown up by the waves on the outer broad reef flat which we were skirting. The beaches of the outer mangrove islands are composed either of coral shingle or shingle composed in part of beach rock conglomerate and in part of volcanic rock.

As we approached Cape Tupinier, the southern point of the east face of Kusaie, we could see the rounded bluffs forming the termination of the spurs extending towards the southern reef flat of the island, with deep valleys running towards the interior separating them. From the base of the spurs beach rock and volcanic boulders extended over the reef flat in huge spits (Pl. 229); on these grow the mangroves which form so characteristic a fringe to that part of Kusaie (Pls. 184, figs. 1, 2; 185, figs. 1, 2). They recall the belts of vegetation we have observed in some of the Society Islands, especially at Bora Bora, where the vegetation, instead of consisting of mangroves, was principally made up of cocoanuts and the usual reef bushes. At Kusaie the vegetation at the base of the volcanic slopes consists of magnificent forest trees (Pl. 186); they also extend over the mangrove islands and islets and give to the belt a different aspect from that which characterizes the belt of vegetation on the outer reef flat of the Society and Fiji Islands.

A similar belt of mangroves skirts the greater part of the northwestern coast; from Cape Halgan, the northern point of the island, it extends both west and south, and thus forms a nearly continuous belt around Kusaie, interrupted only at some point where the barrier reef flat is rather narrow, or where the barrier reef becomes a fringing reef (Pl. 229). The greatest width of the reef flat is about a mile; a number of basins are formed by projections of the spurs from the volcanic slopes to the outer edge of the reef flat, especially between Port Lottin and Cape Vauvilliers (Pl. 229). The islands of Lélé and Yenas are the remnants of the spur which once ran from Mount Buache to Point D'Urville (Pl. 229).

It is evident, from the position of the volcanic rock outliers and from 
the composition of the shingle of the outer barrier reef flat at points where the barrier reef is narrow and impinges upon the volcanic slope, that the barrier reef flat has been formed by submarine erosion, that on its surface have grown the reefs which supply the material for the sand and for the sand beaches on the lagoon face of the reef and of the islands, while here and there in the basins of the lagoon and in the channels a few coral patches rise. Even on the outer sea face of the reef flat, the shingle is partly mixed with volcanic rock showing that the outliers and outcrops of the lava masses are only covered by a thin sheet of limestone. South of Chabrol Harbor the beach rock conglomerate contains a number of volcanic pebbles.

The greater part of the corals on the flats themselves have been killed by the volcanic silt washed down the deep valleys of Kusaie, and by the vegetable matter derived from the decay of the mangroves; this when held in suspension in sea water kills the corals in the immediate vicinity on the mangrove belt. ${ }^{1}$

We entered the little reef harbor of Lottin through a passage which reminds one of the lagoon openings of the barrier reefs of some of the Society Islands (Pl, 229). At the head of the harbor, the reef flats become almost fringing reefs; they are narrower than on the south side of Kusaie, where the platform off the base of the gentle southern slope of Kusaie is far wider than that of any barrier reef we have visited thus far (Pl. 229). The entrance to Lottin Harbor is on the south side of Kusaie; it is flanked on one side by two low islands, thrown up on the outer reef flat, on the other by a ledge of coral boulders on the spit forming the eastern entrance to Port Lottin (Pl. 182, fig. 3). The outer edge of the reef flat of the southern coast, from Cape Tupinier to Port Lottin, consists of a series of reaches of beach rock and of large coral boulders. Numerous deep passages, similar to the one leading into Chabrol Harbor, eut through the outer edge of the reef platform, and form a series of tortuous channels leading into the great expanse of the shallow lagoon which separates the outer reef flat from the shore belt

1 Corals are killed by overtlows from the swamps of the Everglades along the southern extremity of the coast of Florida. 
of mangroves (Pl. 229). At the southern extremity of Kusaie, near Cape Tupinier, large angular boulders of coral reef conglomerate were thrown up on the spits, supplying the material for the coral shingle beach which characterizes the sea face of the belt of mangrove islands separating the inner lagoon from the outer lagoon. The flats and islands of the inner lagoon have been formed by the accumulation of volcanic sand, washed down from the adjoining slopes, and forming patches upon which the mangroves have taken root. The patches are often separated by deep lanes of water, in which corals may grow; where corals have been overwhelmed by the volcanic sand they form disconnected patches. Thus has been built up the inland labyrinth of mangrove islands which reaches from Port Lottin not only round the south shore of Kusaie, but also on the eastern, as well as the western and northwestern faces of the island (Pl. 229).

The reef flat to the eastward of our anchorage is covered with large patches of beach rock conglomerate; on their slopes corals were growing in profusion, and mangroves had, here and there, taken possession of islands or islets disconnected, as yet, from the labyrinth of islands forming the inner belt of the reef flat. We examined the chamel leading among the inner belt of mangrove islets, on the east side of the harbor. The channel runs at least five miles parallel to the shore line, is from three to six feet deep, meandering in all possible directions, and sending off branches at right angles, forming an anastomosing belt of channels as far as Cape Tupinier. There are an endless number of water lanes, with ample depth for their canoes, which the natives use in passing from one part of the island to the other, inside the barrier reef. The mangrove trees take here an enormous size, many of them being between forty and fifty feet in height, and their branches, together with those of the Fetaus, the Poukas, the passion flower trees, and other hardwood trees, form an immense arch which sometimes covers the channels so completely as to make a tunnel through which the canoes or boats may pass (PI. 186). The main channel of the lagoon runs along the base of the volcanic slopes of Kusaie; it is separated from them by numerous small mangrove islets, covered with volcanic mud, which finds its way 
between the roots of the trees growing upon the islets. Between this inner channel and the outer face of the mangrove belt innumerable islands and islets are forming, reaching as far as the outer beach. As we come upon the southeast corner of the island, where the outer reef flat approaches, and even encroaches upon the mangrove belts, the roar of the surf can be distinctly heard. From Cape Tupinier these intricate channels open out into more or less wide bays, separated from the sea only by the high dam of beach rock conglomerate, or of coral rock thrown up as a long shingle beach, and extending north as far as Chabrol Harbor (Pl. 229). From Cape Tupinier the lagoon channel extends nearly to Point Duperrey. The outer belt of mangroves is quite narrow, while the inner belt is far less important than off the southern coast. The western shore of Chabrol Harbor is again edged by mangrove islands.

The island to the west of the channel leading into Port Lottin consists of coral rock and shingle thrown up at least six feet above high-water mark. A similar process took place upon the whole of the volcanic reef flat; as it was cut away, the masses of limestone which form the various patches upon which corals are now growing were thrown upon it from the then existing sea face $\left(\mathrm{Pl} \cdot{ }^{\cdot 187}\right)$. Here and there volcanic rocks jut out, and piles of volcanic stones are to be seen cropping out in all directions. This shows that below the patches of corals volcanic rocks exist, the outliers of which indicate the process of planing off the great reef flat which has taken place on the eastern, southern, and western faces of Kusaie (Pl. 229).

The islands off the entrance of Chabrol, and off other parts of the coast of Kusaie, show how the barrier reef platform has been formed by denudation and submarine erosion of the longer slopes and bluffs. From the former have been cut the wider reef platform, as on the south coast, and from the latter the narrow reef flats where there is barely room, sometimes, for a canoe to pass between the volcanic slopes and the coral shingle dam forming the barrier reef. Where the barrier reef platform is reduced to a minimum, owing to the steepness of the slope of the island, we pass at once from the narrow reef shelf to the volcanic rocks, as on the eastern slope; where the pitch of the volcanic rocks is less steep, a wider and extensive reef flat has been eroded. On this shelf, however, 
the outliers and outcrops of volcanic rock still indicate the mode of origin of the wide reef platform.

On the outer sea face, especially on the eastern face, a number of cocoanut trees and hardwood logs have been thrown up on the shingle beaches. To the east of Port Lottin a small fresh-water river flows through the volcanic shingle, so that a considerable amount of volcanic silt has been carried out by the river to the outer edge of the inner harbor. The corals flanking the harbor are partly killed by this volcanic silt. We found heads of Porites, of Mrandrina, of Pocillipores, of Madrepores, and of Millepores growing luxuriantly on all the flats and shoals and ledges of the lagoon to the west of Port Lottin. In the lagoon to the west of Port Lottin an outcrop of volcanic rock occurs in the very midst of the mangrove islands. On the western side of Kusaie the reef flat gradually becomes narrower, until at Point Vauvilliers the outer edge of the reef flat is only separated from the western slope of Kusaie by a narrow lagoon.

The lagoon channel to the south of Chabrol Harbor is undoubtedly kept clear by the streams running down the slopes of the eastern coast.

As we steamed out of Port Lottin and followed the outer belt of land rim towards Point Vauvilliers, we found the outer beach to consist of voleanic sand mixed with fine coralline sand. At our anchorage, in twenty-one fathoms, volcanic sand or silt composed the greater part of the material we brought up, although at a comparatively small distance on both sides of us were extensive reef flats on which corals were growing. On examining the wide lagoon to the east of the anchorage, we found, as we approached the shore, the bottom to consist of fine volcanic silt, brought down by the rains from the hill slopes, and carried to the very edge of the reef flat. The patches of corals and coral heads were as frequently killed by volcanic sand as by coral sand, formed by the disintegration of the coral heads overwhelmed by the sand coming from the outer sea face. About three quarters of a mile from Port Lottin is the western lagoon; its onter sea beach is formed of heavy shingle and of coral boulders thrown up to a height of seven to nine feet. On the top of the shingle beach an extensive belt of mangroves was growing, 
in continuation of the line of mangrove islands edging the reef flat to the west of Port Lottin. The outer rim of mangrove islands extends continuously from Point Lesson to Point Vauvilliers, where volcanic heads crop out. On the northern extension of the reef flat coral boulders form a gigantic spit, shutting off the inner lagoon from the wide reef flat to the north (Pl. 229). On this wide reef flat flanking the northwest face of Kusaie (PI. 229) the islands of Hesi, Bérard, and Gabert rise to a slightly greater height than the numberless outcrops of volcanic rocks which dotted, in all directions, the western barrier reef flat of Kusaie from Point Vauvilliers to Coquille Harbor. As far as we could see, the inner belt of mangroves which characterized the southwestern and southern part of the west coast extends in a northerly direction, to join the labyrinth of mangrove islands coming from the east, to the north of Coquille Harbor.

\section{Pingelap.}

Plates 183, figs. 2-4; $225 ; 227$, fig. 5.

Pingelap, ${ }^{1}$ the next group we visited, is an irregularly rectangular atoll, with sides of about two and one-half miles in length (Pl. 227, fig. 5).

Pingelap is undoubtedly an atoll built upon a volcanic platform, the lagoon of which is enclosed on the east by Pingelap Island, and on the northern horn by Tugulu and Takaï Islands, two low islands well covered with cocoanut trees. On the sea face the islands are flanked by heavy shingle beaches (Pl. 183, figs. 2-4); on the southernmost part of Pingelap the lagoon face is flanked by a steep coral sand beach; this gradually passes into the wide reef flat which connects all the islands (Pl. 227, fig. 5). The reef flat encloses a shallow lagoon; in the gap between the two larger islands a shingle beach separates the lagoon from the outer sea face. The western reef flat itself is even at low tide covered with sufficient water to be navigable for canoes and small boats. It is covered with large boulders and masses of smaller coral blocks. The deepest part of the lagoon, said to be fifteen fathoms, seems to be in 
the northeastern part, towards the gap which separates Pingelap from Tugulu Island. The islands, as far as we could see, were formed by high beaches thrown up on the two faces, forming a central sink, running parallel with the shore lines. High breakers are seen directly across the eastern gap, as the sea during the season of the trades runs high on the windward side. No island in the Carolines has probably so large a population in proportion to the extent of land as this atoll. No less than 1000 inhabitants are said to live on the southern island (Pingelap), and certainly, as we approached it, the number of natives crowding the beach, with the many canoes drawn up near high-water mark (Pl. 183, fig. 4), would indicate a large population, depending for its food on the products of the sea, and on the supply of cocoanuts growing upon the islands. The intercourse of the natives of Pingelap with the outside world is most limited; when we passed the natives had not seen a ship manned by whites for more than eight months.

We did not observe the base underlying the loose material of this atoll; judging from the structure of the adjoining islands, this base probably consists of volcanic rocks. The low atolls in the Carolines hold to the volcanic islands of the group the same relation which the atoll of Tetiaroa holds to the volcanic islands in the Society group, although in the region adjoining both the Carolines and the Society Islands atolls exist which are undoubtedly built upon platforms of a limestone origin, and some of the Carolines are composed of elevated coralliferous limestones.

The atoll of Mokil $^{1}$ resembles Pingelap in every respect. Namoluk and Ifalik have the same general features. Feys or Tromelin Island, according to the description in the "Sailing Directions" and the Admiralty Chart, ${ }^{2}$ is an elevated coralliferous limestone platean of about two ando one-half miles in circumference, steep to and rising to a height of thirty feet. This and the Oraluk or Bordelaise group are the only elevated coral reefs of the group; the latter is about half-way between Ponapi and Truk. We did not visit Oraluk; the "Sailing Directions" state that on the northwestern extremity of the group an elevated coral reef 
rock island is found (San Augustin) which rises to a height of 107 feet; on the southeastern end of the atoll a small limestone island. Baxo Trista, is fifty feet high.

\section{The Seniavina Islands.}

We next visited the Seniavina Islands; they consist of the high volcanic island Ponapi and the low atolls Pakin and Andema; the last are separated from Ponapi by deep water. Ponapi rises to a height of nearly 2900 feet, while the atolls of Andema and Pakin have been thrown up on a volcanic platform, denuded to about the level of the sea, or upon a summit elevated to the depth at which corals grow.

\section{Ponapi.}

Plates 188-190, figs. 1-3; 225, 230.

The island of Ponapi is about twelve miles long north and south and perhaps thirteen miles from east to west. It is surrounded by a wide reef flat; at some points this is nearly three and one-half miles in width (Pl. 230). Within the barrier reef surrounding the main island a number of smaller volcanic islands are formed, satellites as it were of the principal island; on the outer edge of the reef flat a number of low coral sand islands have been thrown up.

Ponapi is distinguished from Kusaie by the number of the volcanic islands enclosed within the barrier reef; their position shows even better than at Kusaie how a wide and broad reef flat has been eroded from the central mass and has left as outliers such islands as Jekoits, Parum, Langa, Mantapeti, Tababac, Tacahu, Mutokaloj, Tauche, Mutok, Tulatik, Tahuak, and other islands, all in the extension of spurs from the main ridge (Pls. 188; 189, figs. 1-3; 190, figs. 1, 2); in some cases they are on the very outer edge of the barrier reef (Pl. 230).

The base of the volcanic slopes of Ponapi is, like Kusaie, fringed 
with a shore belt of mangrove islands and islets, but it does not attain the great width of the mangrove belt on the southeastern coast of Kusaie, as will be seen by a comparison of the charts (Pls. 229; 230). The outer edge of the barrier reef flat surrounding Ponapi carries but few insignificant islands and islets, covered with an exceedingly scanty vegetation (Pls. 188; 189, figs. 1-3), in striking contrast to the vegetation which thrives on the islands thrown up on the outer barrier reef of Kusaie.

Near the eastern and western side of Kiti Harbor one can see how the volcanic sand brought down from the hill slopes is gradually filling the great barrier reef lagoon flat, and how mangrove islets extend out towards the barrier reef and may finally bring about a condition of things very similar to that existing on the south shore of Kusaie, both to the west and to the east of Lottin Harbor. The reef harbors are more numerous in Ponapi than in Kusaie (compare Pl. 230 to 229), but they are small and can hardly shelter vessels of any size. During the prevalence of the trades it is somewhat dangerous to enter such narrow harbors as that of Métalanion (Pl. 188, fig. 2), or of Jamestown (Jekoits), mere openings in the reef less than one fourth of a mile in width. A heavy swell breaks across the openings leading into inner channels generally obstructed by bars and shoals and flats, the position of which it is difficult to ascertain except under favorable conditions of tide and light.

We made Ponapi ${ }^{1}$ at a point a little to the south of Métalanim Harbor, with Narpoli Island rising to the north on the wide reef flat flanking the southern entrance of that harbor. The sugar loaf Mount Takain, on the northern side of Métalanim, is one of the best examples of the extent of the erosion to which the volcanic rocks of Ponapi have been subjected. ${ }^{2}$ The island of Narpoli is volcanic, as well as other islands on the wide reef flat to the south of the entrance of Métalanim Harbor. The sea face of some of these islands is covered with fine coral sand beaches and few coral boulders. The islands and islets near Métalanim are well wooded. On the wide reef flat to the north of the entrance

1 H. O. Chart 425 ; A. Chart 981.

2 Basalt v. der Insel Ponapi, A. Wichman, Jour. d. Mus. Godeffroy, Heft VIII., p. 123. 
to Métalanim only a single island occurs (Pl. 188, fig. 1). To the south of Métalanim, north of Port Lod, an immense tongue of mangrove islands runs out to the very edge of the outer barrier reef flat (Pl. 188, fig. 3). We happened to pass this point at moderately high tide, when the barrier reef flat, edged by the breakers, formed an immense shallow bay, indicated by the green water, though a strip or tongue of somewhat deeper water runs from the reef flat towards Métalanim Harbor. As we approached Port Lod the tongue of mangrove islands gradually recedes from the edge of the barrier reef flat, and approaches the foot of the slope of the island (PI. 188, fig. 4). To the east of Point Nantiaiti extends a shore belt of mangrove islands, similar to that south of Métalanim and similar to the mangrove shore belt so characteristic of Kusaie. Immediately below Point Nantiaiti are two small volcanic cones (Likintakai Island); they show how far the outliers of the ridges and spurs of Ponapi may. reach into the main barrier reef flat. This outlier also indicates the amount of denudation which has taken place from the southeast point of Ponapi in a westerly direction, and formed the immense barrier reef platforms so characteristic of Ponapi and of Kusaie. On the outer edge of this reef platform, to the south of Mutok Island, but few low islands exist (Pl. 190, fig. 1); they are either patches of volcanic rock, disintegrated and covered by low vegetation, or negro-heads; these may be fragments of a volcanic mass, or a patch of coral rocks thrown up on the outer edge of the barrier reef lagoon. To the west and east of Mutok Island the shore of Ponapi is flanked by a narrow fringe of mangrove islets running round the base of the slopes of the ridges and spurs (Pls. 189, fig. $4 ; 230$ ).

Immediately to the east of Mutok Island a deep indentation (Port Mutok) is formed in the outer edge of the barrier reef, opening into a deep channel running across the reef flat, and leading into a bay immediately behind Mutok Island. On the southern barrier reef flats, between Mutok and Kiti Harbor, numerous bars of beach rock have been thrown up, separated by bands of greenish or bluish water, according to its depth; the bands of deeper water probably indicate the southern extension of the valleys on this face of Ponapi. The spurs and ridges 
separating them have gradually been eroded, and nothing is left to indicate that they formerly extended almost to the very outer edge of the barrier reef flat. West of Mutok Harbor along the southern face of the barrier reef flat of Ponapi are a number of deep gaps cutting into the onter edge of the barrier reef flat, forming either reef harbors or entrances into the barrier reef lagoon. The gaps are connected by pools and a labyrinth of lanes formed around the coral shoals which occupy so great a part of the barrier reef lagoon flat of the southern face of Ponapi. The reef harbors of Ponapi, as well as those of Kusaie, are deep and narrow; they are usually in the extension of the numerous water courses which run down the slopes of these islands in all directions, as at Kiti, Métalanim, Port Lod and Jamestown (Jekoits).

Cocoanut trees grow on the sandy islands of the outer edge of the barrier reef (Pls. 189, figs. 1, 2; 190, fig. 3); the outer islands when flanked by shingle are usually bare. It is only when we strike the base of the main volcanic slopes of Ponapi that we come upon the magnificent vegetation already characteristic of the Marshalls to the east, and especially developed in the Carolines and as we go westward.

We followed the south shore of Ponapi as far as Kiti Harbor, where we anchored much in the same position taken by the "Coquille," nearly seventy years ago. Near Kiti Harbor the mangrove islets extend out much farther from the coast than they are marked on the chart. The chart is very definite as regards the position and extent of the islands existing at the mouth of Kiti Harbor. Their present dimensions indicate a considerable change, as natives informed us that the outer islands have been greatly modified within the last seven years (PI. 190, fig. 3); they certainly do not agree the view given by Captain Duperrey in the Atlas of the Voyage of the "Coquille."

A section across Ponapi beginning at the outer reef of Kiti Harbor shows that on the edge of the barrier reef numerous coral boulders have been thrown up; mangroves grow here and there (Pl. 189, fig. 3), especially on the small sand bars or sand islets of the outer reef. The outer slope of the reef is quite abrupt; the sea face is covered with gigantic masses of Porites, Millepores, Mrandrina, Goniastrea, Madrepores, 
Alcyonarians, and Actinarians, growing in great profusion upon it. The coral belt of the outer slope is in marked contrast with the corals of the shallower water dividing the lanes and pools of the lagoon flat, where the coral belt is comparatively shallow, although the species are the same as those which grow on the outer face. ${ }^{1}$ The lagoon flat between the outer edge of the barrier reef and the edge of the mangrove belt is, as has been described, covered with pools and lanes of more or less deep water, alternating and separating the patches of corals which have grown up from the bottom of the lagoon, the greater part of which have been killed by silt. On the edge of the outer mangrove belt (Pl. 189, fig. 4), which is probably not more than 100 to 150 yards wide, a few small coral masses are thrown up, and the whole slope facing the lagoon is covered with deep, dark blue, finely ground mud. In the inner Kiti Harbor a volcanic ridge runs down close to the shore. It is very narrow and flanked with a band of mangroves.

Looking up the west coast from our anchorage in the outer Kiti Harbor, the great extent and width of the barrier reef flat to the west is very striking (Pl. 190, fig. 2); near the entrance to Kiti Harbor a series of low islands and islets and sand bars encloses a pool of about one and one-half to two miles wide. The islets on the west side of the entrance of Kiti Harbor are well wooded; the islands on the eastern side have, according to the statement of the pilot, been washed away, and nothing remains to indicate their former extent except a few isolated coral rock boulders on the edge of the outer reef flat. The water of the lagoon on the south and west shore of Ponapi is exceedingly muddy from the silt brought down by the rivers emptying into Kiti Harbor and discharged through the 'long belt of mangrove islands. Something analogous occurs along the Florida keys, when the water dammed up in the Everglades is forced between them in times of floods. Only at Ponapi the land is high, the slopes are broad, and the silt is scattered more uniformly, and not concentrated at a few channels, as is the case along the Florida reefs.

1 Ueber die Korallen d. Insel Ponapi, v. Dr. F. Brüggeman, Jour. d. Mus. Godeffroy, Heft XIV., 
The navigation of the lagoon, which varies greatly in width, is somewhat intricate, though it is said by the pilots that the Missionary Steamer "Morning Herald " can navigate from the west side of Kiti Harbor as far as Port Métalanim. To the west of the onter Kiti Harbor the flats and pools form an intricate network of channels, with from three to ten fathoms of water, which can be navigated from the mast-head of small schooners without difficulty. At any rate, canoes find but little trouble in circumnavigating the island by running out from one reef harbor into the adjoining one, where the lagoon channels are too narrow for them to pass. Kiti Harbor cannot be entered from the lagoon to the west. From the outer entrance to Kiti a tortuous passage leads into the inner harbor (Pl. 230).

To the east of the outer Kiti anchorage a similar condition exists. ${ }^{1}$ As far as we could see endless patches of coral separate lanes, or leave deep pools between them; the corals on some of the patches grow with great luxuriance. At other places nearer the shore, towards the edge of the mangrove islets, they become overwhelmed with volcanic sand, and are gradually dying, forming shoals and bars upon which mangroves begin to grow and finally become a part of the existing belt of mangrove islands off the shore. The formation of these coral patches and their ultimate connection with the belt of mangrove islets indicates the gradual mode of formation of the belt of mangrove islands along the south and west coast

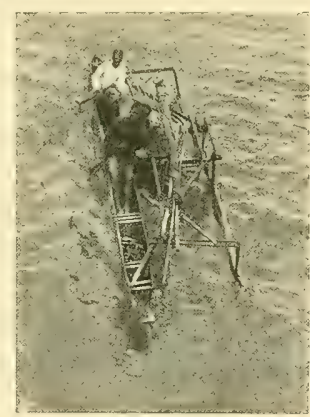

Ponapi Canoe. of Ponapi from the shoals of the barrier reef flat itself. These coral patches have grown up wherever the conditions were favorable, and increased in size, laterally and vertically; when they reach the surface they are either killed by exposure to the sun or are overwhelmed by volcanic silt. The dead corals are then in their turn cemented by Nullipores; living corals flourish only down to a comparatively moderate depth; as the silt settles in

1 See the view of the great reef flat east of the anchorage in Kiti Harbor, given in the Atlas of the "Voyage de la Coquille," Plates 49 and 60, giving a general view of Ponapi, as seen from the same anchorage. 
deeper water, corals no longer find propitious conditions for growth, and even on the lee side of the patches corals are killed by the silt. Corals growing on the slope of the patches extend generally down to fifteen or eighteen fathoms.

The corals on the flats have all disappeared at a depth of twenty fathoms, where nothing but silt and a mud bottom are found. According to the proximity of the coral patches to the belt of mangroves, the depth to which they reach varies from ten to fifteen or twenty fathoms. We found growing among the corals Alcyonarians, sponges, and large Actinians. The corals were mainly huge heads of Millepores, Madrepores, Goniastreas, Porites, Pavonias, and also Fungia. Nowhere in the Pacific have we found more magnificent corals than in the Carolines, reminding us of those which flourish on the Great Barrier Reef of Australia, where the sponges, Alcyonarian and Actinarian masses play such an important part in the physiognomy of the coral reefs. A few Mæandrinas also occur, the first we have seen for a long time; between the heads grow large masses of Sabella. The coloring of the corals is also much more brilliant than that of the coral reefs to the eastward. The corals I have mentioned form huge masses of pink, purple, yellow, and brown; they alternate with green sponges, with the many variegated, banded, and striped Alcyonarians, and with the large masses of purple Actinians which grow to an enormous size among the coral heads over the more exposed parts of the flats. $\Lambda$ coating of Nullipores has gradually spread over the dead corals. It is mainly on the slopes of openings and channels leading into the barrier reef lagoon that corals are most flourishing, sheltered as they are to a certain extent from the encroaching silt. The Porites heads growing near the inner edge of the mangrove flats are the first to be killed. Near the outer edge of the reef flat the tops of the coral patches are killed by the loose material thrown in by the action of the sea, and this loose material is in its turn cemented by a coating of Nullipores. As we approach the inner mangrove belt of the muddy reef flat, the bottom becomes covered by volcanic silt, the water becomes dirtier and dirtier, the corals have all been killed, excepting those which live on the upper slopes of knolls or are attached to the sides of large heads. 
According to the tradition of the natives, the prevailing winds affect the position of the islands on the outer edge of the barrier reef. They seem to be eaten away on the east side, and during the last eighty or one hundred years to have been building up on the western face.

The amount of water which comes down the slopes of Ponapi during the rainy season is enormous; the extent of denudation and disintegration it effects is considerable, as can be seen from the formation of the deep trough-like river valleys of that face of Ponapi. The channel of the river which empties into Kiti Harbor is filled with bars of pebbles and of gravel. The volcanic rock of which Kusaie and Ponapi are composed is readily disintegrated and decomposed into a fertile soil, or washed away as silt and deposited immediately off shore and in the deeper parts of the eastem and western barrier reef lagoon flanking the island of Ponapi.

The fauna of Ponapi is quite different from that of the islands more to the east. Fruit bats are found here, as well as paroquets, pigeons, babblers, flycatchers, swifts, king-fishers, three species of lizards, and two of bats. The vegetation is also different from that of the low coral islands of the Marshall, Gilbert, and Ellice groups, although the vegetation of the former is already in striking contrast to that of such islands as the Paumotus, where the rainy season is not so continuous as it is further to the westward. The vegetation of the Carolines, as far east as at Kusaie, is almost continental, resembling somewhat that of the Malayan district to the west. The variety of forest trees found on the slopes of Ponapi is very striking; they run down to the inner channel in the mangrove belt, along the shore of Ponapi. It is interesting to compare the list of the magnificent forest trees occurring on the Carolines, as given by Christian, ${ }^{1}$ with the list of the scanty vegetation characteristic of the Paumotus found in Dana's "Coral Islands," ${ }^{2}$ or the more recent list of the similar flora of Caroline Island given by Professor Trelease in his Report on the Botany of the American "Eclipse" Expedition to Caroline Island."

1 The Caroline Islands, by F. W. Christian, 1899, p. 328.

2 Corals and Coral Islands, 3d ed., 1890, p. 326.

a Mem. National Acad. Science, 1884, Vol. II., p. 88. 


\section{Andema Islands.}

Plates 18\%, fig. 4; 183, fig. 1 ; 225, 230.

Andema ${ }^{1}$ atoll is irregularly triangular in shape, with sides of about seven miles in length. It is about eight miles to the west of Ponapi (Pl. 230). The islands composing the atoll of Andema are all low (Pl. 182, fig. 4), flanked by coarse shingle beaches, with but few coral blocks on the outer edge of the narrow reef flat. A ship passage from sixteen to twenty fathoms deep opens into Andema lagoon. The gap between the island of Kahalape and Pachiai has been formed by the same process as have the gaps of the Marshall Islands. Coming from the southeast, we see that the northern island on the east face (PI. 183, fig. 1), and those on the southern face of the atoll, are flanked by low shingle beaches; the land rim is limited to the southeastern and eastern faces. On the northern and western sides the reef flat is bare, with a few narrow ledges, and comparatively few heads of coral are exposed at high water (Pl, 230).

The islands of the land rim of Andema, like those of Pingelap, have been thrown up on an underlying base, probably a volcanic summit planed down, as were probably a number of the other low atolls of the Carolines. On Panemur, the westernmost island of the group (PI. 230), large coral boulders form the outer edge of the reef flat, with here and there a few fragments of volcanic rocks, showing that the land rim of Andema must at one time have consisted, in part, of volcanic rocks. It is difficult to explain the formation of such islands as Andema and Pingelap and similar low atolls in the Carolines as dne to subsidence. We can trace in Pingelap, Truk, Kusaie, and in Ponapi four successive stages of disintegration, due to denudation and erosion, of which Ponapi is the highest, Kusaie the next, and Truk still lower, until we reach such submarine platforms as those of Andema and of Pingelap. If we ascribe their formation to subsidence, we must admit 
that it has taken place over an extensive area extending from the Pelews to the Pomotus, the greater part of the tropical Pacific, ${ }^{1}$ where we find depths varying from 2000 to 2500 fathoms separating the islands and atolls of the Caroline, Ellice, Gilbert, Marshall, and Paumotu Islands. Such an explanation involves, in addition, the sinking not only of these islands from a comparatively great height, but also the uniform subsidence of the entire belt of deep water indicated by the soundings. Some of these depths reach over 3000 fathoms.

Pakin $^{2}$ is about fifteen miles to the westward of Ponapi. It is somewhat crescent-shaped, about five miles long; the reef flat is less than a mile in width. At Pakin the islands of the land rim are scattered irregularly on the northeastern and eastern reef flat; they enclose a very indistinct lagoon on the western face.

\section{Losap.}

Plates 232 ; 233, fig. 3.

We passed Losap $^{3}$ at a distance of about five miles. According to the "Sailing Directions," the atoll has a lagoon of a depth of about sixteen fathoms, with a number of passages leading into it. It consists of a series of low islands, covered with tall trees, rising to a height of from sixty to eighty feet. There is a small secondary lagoon at the northeast end of the atoll.

\section{Nama.}

\section{Plate 23?.}

The island of Nama (D'Urville) consists of a low flat-topped island covered with tall trees; it has no lagoon. It is somewhat higher than the low atolls of the Carolines and may be a summit of elevated coralliferous limestone.

1 A. Agassiz, Mem. M. C. Z., Vol. XXVI., No. 1, 1902. List of Stations, p. 29.

${ }^{2}$ A. Chart 981.

${ }^{3}$ A. Chart 772. 


\section{The Royalist Islands.}

\section{Plates 190, fig. 4; 231, 232.}

The Royalist Islands ${ }^{1}$ are an elongated atoll, a satellite of Truk (Pl. 231), of an irregularly rectangular shape, about eleven miles in length and five across the southern face. The northern extremity is not more than a mile and a half from the southern point of the barrier reef of Truk, and separated from it by a deep channel. Two passages lead into the lagoon, one at the southern, the other at the northern extremity. The northern passage is flanked on the east by Givry Island. Hacq Island is in the central part of the eastern barrier reef flat, South Island (Pl. 190, fig. 4) is at the southernmost point of the atoll, to the west of the southern passage. The south side of Fanek Island, on the north side of the southern passage, is composed of a long line of yellow coral boulders and covered with low vegetation, the beach rock extending on the outer end of the reef flat, with here and there a larger coral boulder thrown up by the sea. In the Royalist Islands the vegetation everywhere reaches close to the coral boulders scattered on the wide reef flat. A narrow belt of deep water extends along the western face of the northern land rim of the atoll. ${ }^{2}$ The wide reef flat forming the southern part of the lagoon is full of patches, reaches, and bands of shallow water, with here and there a cluster of large coral blocks, especially near the northern and western extremities. The reef flat is from two thirds to three fourths of a mile in width. Far beyond the northern horn of the Royalist lagoon we could see to the north the high peaks of Truk, and to the west the high islands in the western part of its lagoon. On reaching the northern end of Royalist atoll, we found the western edge of the reef flat flanked with an extraordinary line of huge coral boulders, honeycombed and undercut, forming ledges of the most fantastic outline, extending to the extremity of the western horn of the atoll.

1 H. O. Chart 425.

${ }^{2}$ A. Chart 982. 


\section{Truk.}

Plates 191-193, 231, 232.

Truk $^{1}$ is the largest atoll in the Carolines. The circumference of the lagoon enclosed by the outer barrier reef is not less than 125 miles (Pl. 231). In our approach to Truk we followed much the track of the "Astrolabe and Zélée," though we entered the lagoon of Truk through Aualap Pass, east of Faleú, and steamed towards the northwest between Eiol and Udot Islands, after being abreast Tsis Island. We could follow, as we passed, the intricate passages formed between the spurs of the islands and the coral reef flats which reach out from their sides. We anchored off the island of Uola, the largest island in the eastern part of the atoll.

As one enters the lagoon from the south, the appearance of this atoll is most striking; when once in the central part of the lagoon, after losing sight of the barrier reef flat, facing the eastern cluster of islands (Pl. 191, figs. 3, 4), with the western cluster to the rear (Pl. 193, figs. 1, 2), the numerous peaks, rising, as it were, directly out of the sea (Pls. 191, figs. 3,4 ; 193, figs. 1-3), appear like summits of islands gradually sinking. Had this atoll been among the first visited by us, it would have been natural to explain its present condition as one due to subsidence. Yet whenever the line of the barrier reef with its belt of islands and islets thrown up on the outer reef flat again became well defined, the atoll at once found its place among other similar but smaller atolls, the structure of which we have explained by the mechanical action of the trades, of atmospheric agencies, and of submarine erosion.

The reef flats forming the great encircling barrier reef of Truk are generally wide ( $\mathrm{Pl} .231$ ); they are broadest on the northern and northeastern faces, gradually becoming narrower towards the southern part of the eastern face, and quite narrow in parts of the southern face. On the northern and eastern faces the barrier reef flat is covered with a large number of low islands (Pl. 191, figs. 1, 2); between the disconnected portions of the encircling reef flat a number of deep passages 
exist by which the lagoon can be entered, not only on the north side, but also on the east, as well as the southeast side (Pl. 231), the principal passes being on the north face to the west of Pis Island (Pl. 193, fig. 4) and on the east coast opposite Gregoire Island (Pl. 193, fig. 3). On the southeast face are also numerous passages, as well as along the southern face of the lagoon, where the barrier reef flat is narrow, with only here and there a low island thrown up on the face. Between the disconnected reef patches on the southern face there are no less than seventeen passes, all of considerable depth. The western point of the reef flat forming the western extremity of the atoll is broad; on it are four low islands (Pl. 231). The greater part of the lagoon varies from fifteen to twenty-five fathoms in depth; a few soundings indicate depths of thirty-five to thirtysix fathoms. The northwestern part of the lagoon is nowhere more than thirty fathoms, the deepest part being towards the southern face of the atoll.

The islands on the outer margin of the immense atoll of Truk are very irregular in size; they have been washed up on the outer barrier reef flat, both from the sea and from the lagoon face. Numerous sand keys, more or less covered with vegetation, have also been thrown up on the barrier reef flats (Pl. 231). Truk is helmet-shaped and not less than thirty-five miles in diameter; as we approached the atoll, we could see gradually rising from the central parts of the lagoon the mountains of Umol, of Toloas, of Ruk, and of other islands, the character of their slopes clearly indicating their volcanic origin (PIs. 191, figs. 3, 4 ; 193, figs. 1, 2). The islands were flanked at the base by sand and coral shingle beaches, derived from the fringing reefs which encircle them $(\mathrm{Pl}$. 231). The fringing reefs have grown upon the disintegrated spits of the islands and their shores, and have formed extensive reef flats. The outer barrier reef rim of the atoll differs in no wise from the rim of encircling reefs such as we found in the Society and Fiji Islands, where the central land mass of the lagoon, or the land mass of the rim, was made up of volcanic rocks.

Enclosed by the encircling barrier reef are a number of high volcanic islands, at a distance of from two to fifteen miles from it; twelve of 
these rise to a considerable height. Uola is over 1300 feet, Toloas rises to 1200 , Ruk to nearly 1000 , Umol to over 800 , Udot to about 1000, and the large island of Tol has several peaks, the highest of which is more than 1200 feet (Pl. 231). In addition to the large volcanic islands, a number of smaller islands are scattered through the atoll, such as Eiol, Periadik, Tarik, Ulalu, Fala, and others, rising from twenty to 300 feet above the level of the sea. The names given to the islands in the lagoon of Truk and on the Royalist atoll - such as Quoy, Gaimard, Brongniart, Gaudichaud, Bouquet, Givry, Hacq, Lauvergne, Bertrand - are many of them names associated with the "Astrolabe and Zélée " expedition in the early part of the past century; a survey of Truk was made in 1838, by Dumont D'Urville, who spent considerable time in this atoll.

Uola, the largest island on the eastern half of the lagoon, is triangular, a little over four miles in length and about three and one-half miles wide on its western face. The principal ridge of the island extends parallel to the southeastern face (Pl. 192, fig. 2); it is separated by a deep valley, cut, down almost to the level of the sea, from Mount Ton Azan, the summit of which forms the northern extremity of the island (Pl. 191, fig. 3). Uola is surrounded by a fringing reef, as are all the other volcanic islands in the group we have examined; here and there the disconnected fringing reef flats are separated by short stretches of coral sand beaches. The smaller islets in the eastern half of the lagoon from Eo north are similarly edged with a fringing reef (Pl. 231).

A steep beach of fine yellow coral sand extends on the west coast of Uola from the village to the northern extremity of the island. About 100 feet back of the water line the beach reaches its greatest height; it is covered in many places with loose masses of broken coral of small size, mainly Madrepores and Porites. A beach of the same character extends along the greater part of the west face of the island towards the southern point. Back of this, fine coral sand mingled with voleanic particles, washed down from the adjoining slopes, extends to the foot of the mountain slopes. This platform of coral and volcanic sand is somewhat lower near the foot of the mountain slope than it is near the 
shore, so that inland one finds stagnant pools of water, in which a dense growth of mangroves flourishes (Pl. 192, fig. 1). A sluggish stream of brackish water winds through the flat between Mount Ton Azan and the main range. This stream appears on the western side of the island, about one and one-half miles north of Mission Station. It has numerous small tributaries and is from three to three and one-half feet deep and about twelve feet wide; its channel is scoured by the tide, as well as by the fresh water flowing from the hills. The edge of this stream is covered with black volcanic mud containing coral fragments and coral sand; a dense wall of mangrove bushes follows its course. Neither beach rock nor coral reef rock was found in place or on any part of the shore flat to the south of the village; but here and there one finds small loose blocks of eroded coral. These extend inland to the foot of the mountain slope; they are nowhere more than five feet above high-water mark. Several small islands of beach rock conglomerate lie off the beach line of the western coast of Uola; they are raised only about eight inches above high-water mark and support a fine growth of mangroves (Pl. 192, fig. 1). They are probably covered by high spring tides; there is little evidence to show that they are elevated reef rock.

Ruk, the next island in size in the eastern half of the lagoon, is four miles in length, with a greatest width of about one and one-fourth miles (PI. 193, fig. 1).

Toloas Island is irregularly circular, about two miles in diameter (Pl. 193, fig. 1), with a long spur extending off the eastern coast nearly a mile, and parallel to it a low voleanic ridge, forming the island of Erin; Toloas and Erin are included within the same fringing reef flat.

To the south of Toloas rise a couple of low volcanic islands. To the southeast of Ruk lies Umol (Pl. 193, fig. 1); it is irregularly triangular in shape, a little over two miles long, with an extensive spit running south similar to that of Toloas. At the base of the spit the low island of Atokin has been thrown up; it indicates the position of a former ridge like that of Kutua Point on Toloas. Between these four larger islands and the barrier reef flat, distant from five to eight miles, extends a line of low volcanic islets: Herit, Fanamu, Onna, Onnaram, Fananan, and 
Fanan (Pl. 231). These islands are remnants of a volcanic ridge once probably extending in the centre of the eastern part of the lagoon, more or less parallel to the outer barrier reef flat; they are separated by depths varying from seventeen to twenty-four fathoms. To the eastward of Ruk are four other volcanic islands, each about a mile in length. Tsis Island runs in a northwestern direction, while Eiol, Periadik, and Tarik (Pl. 191, fig. 1) run in an easterly direction nearly parallel with the iprincipal range of Uola. To the west of the central line which divides the lagoon of Truk into two almost equal parts is another group of islands; the largest, Tol (Pl. 193, fig. 2), is nearly seven miles in length, running from southeast to northwest. A deep bight extends almost one third the length of the island on the northeastern side, bounded by a low peninsula rising not over 300 feet; it is connected by a narrow isthmus to the principal island. To the east of Tol is the triangular island of Fala-beguets, about one and one-half miles in length; to the north of Fala-beguets, the islands of Ulalu and Kuli; they are about three fourths of a mile long and run east and west. In an easterly direction from Tol, near the central part of the atoll, lies the island of Udot (Pl. 193, fig. 2); it is Y-shaped, with one ridge running north and south, and the other running in a southeasterly direction. To the westward of Tol are two volcanic islands, Pata and Polle, the former about one and three-fourths miles in length, and the latter nearly two and one-half miles long.

In the northern half of the atoll, about half-way between Udot and the island of Pis, are two islands, the largest of which is Brongniart Island, a low sand island, over a mile in length, thrown up on an extensive reef flat (Pl. 231). Several of the islands and islets near the eastern and southern faces of the atoll are low sand islets thrown up on some of the numerous coral reef shoals scattered over the southern half of the lagoon of Truk. The southern part of the lagoon has been fairly well surveyed and a number of lines of soundings extend across to the northern part of the atoll. The islands thrown up on the outer barrier reef flat on the eastern and northern coast are all noted for the high shingle benches facing the sea, and the steep fine coral sand beaches 
on the lagoon side. Nearly all the islands of the outer reef flat are well covered with cocoanut trees and with the usual belt of low bushes characteristic of the outer barrier reef flat islands.

The summits of Truk vary from 100 to 1200 feet in height. The outline of some of the islands clearly shows the extent of denudation to which they have been subjected. Patches of beach rock conglomerate flank some of the islands; small narrow belts of mangroves also line the shores, as in Kusaie and Ponapi, only on a very small scale. We see in this atoll, perhaps better than in any other we have visited, that its present configuration is mainly due to orogenic conditions; the great depths of parts of the lagoon represent valleys formed at the time of upheaval of the original mass of Truk, the spurs separating them having been planed off to form the great platform of Truk.

We must look upon the deep parts of some lagoons as due to the submarine erosion and denudation of the outer slopes of the spurs of the original land masses. Volcanic slopes often extend far across the barrier reef platforms; when denuded and eroded they become islands and islets and bars, shaved down to the level of the sea and covered with coral sand, or with large coral boulders thrown up between them on the outer barrier reef flat. Here and there an islet may be the remnant or the outlier of one of the volcanic spurs, once extending close to the outer edge of the reef.

The points of the islands we passed on the way to Uola are covered with short reaches of coral. At the northern extremity of Tsis Island a long line of voleanic boulders extends far out into the lagoon, and is the remnant of a spur of the central ridge of the island.

Between the islands the lagoon is full of patches, some of which are volcanic ledges broken into all kinds of fantastic shapes, while others are coral reef flats which have grown up on the volcanic ledges after they have been eroded to below the level of the sea. A long line of such ledges extends between Periadik towards the northern point of Ruk.

The shore of Uola is edged by a fringing reef belt, varying in width from 500 to 800 feet, extending out in a gradual slope into the lagoon to a depth of from five to six fathoms. Where coral heads growing to the surface have 
been partly killed and covered with Nullipores the belt forms the extension of the shore line. In somewhat deeper water, the corals form huge clumps separated by lanes of sand; the corals do not reach a greater depth than five to eight fathoms, when they disappear, having gradually become separated by wider and wider lanes of coralline sand as they extend into deeper water. In depths of less than seven to eight fathoms, huge patches of black coralline Algæ, alternating with large masses of Millepores and Madrepores, are found scattered over the bottom of the fringing reef belt. Large pieces of coral rock have been thrown up on the beach; they are derived from adjoining elevated masses of undercut coral beach rock; this would indicate near the landing of Uola an elevation of some three to four feet. The fringing reef impinges on a steep sand beach about five feet in height, and in some parts has formed a flat of at least 1000 feet in width, over which large coral boulders are scattered. This flat has been formed on the top of the extension of the adjoining volcanic slope or flat, and abuts against the volcanic sides of the hill. The honeycombed and weathered coral masses, occurring as outliers on the volcanic slopes, indicate the height to which this flat must once have been elevated.

When volcanic outbursts have thrown up limestone masses, the action of solution, disintegration, denudation, and erosion upon such rocks is very rapid; se'a-water also carries off in solution and suspension a large amount of material, leaving fewer spits and outliers than is the case when volcanic rocks are subject to the same agencies.

On this limestone plateau cocoanut trees are growing in great profusion. On the volcanic hillsides the vegetation consists of breadfruit trees, sago and ivory nut palms and Pouka trees (PI. 192, fig. 2). The shore of Uola is flanked by a narrow fringe of mangroves, growing close to the sand beaches, or of mangrove islets formed mainly of volcanic sand mixed with coral sand (Pl. 192, fig. 1). Off Uola the water of the lagoon is exceedingly muddy; a mass of volcanic silt being carried out as far as our anchorage, fully half a mile from shore.

On the south side of Uola the same conditions exist; points of sand make out from the fringing reef, and masses of corals are thrown up on the beach; reaches or patches of black as well as green coralline Algre occur on the 
fringing reef, while scattered over the extensive shallow flat were growing masses of Pocillipores, three or four species of Madrepores, and huge masses of Porites elevated from three to four feet, killed in the centre, but still living at the base. These formed huge agglomerations extending into deeper water, where are found many massive species of Madrepores, with Mycedium, Allopora, Pavonia, and masses of sponges, Gorgonians, and Alcyonarians.

To the south of Uola rises Tolomen, a conical peak on Toloas, nearly 1200 feet in height, and still further south the cone of Umol, about 850 feet in height. From the anchorage we could trace on the volcanic flats extending towards Tol numerous coral ledges, the remnants of the spurs which once extended from the base of the many islands of Truk towards the interior of the lagoon. We could also see the islands occupying the southwest corner of Truk, the highest point of which (at Tol) reaches a height of about 1200 feet.

We left Truk by the northern passage. Steaming by the northern end of Uola, we looked across the valley which separates the southern ridge from Mount Ton Azan on the northern extremity of the island (Pl. 231). The neck connecting the two parts of Uola is a low reef flat, the remnant of the elevated reef flat which once surrounded the greater part of this island. To the north of Uola lies Gregoire Island; to the westward, well on the way to the north passage, lies Brongniart Island. Still further to the north and east, on the outer edge of the barrier reef rim of Truk, we see Gaudichaud, Quoy, Guinard, and a number of low well-wooded islands on the flats to the east of Pis Island. The islands on the barrier reef flats are connected by sand banks and sand bars, or by ridges and stretches of beach rock conglomerate. Some of the barrier reef flats of the eastern and northern part of the atoll have a width of nearly three miles. The outer low islands are covered with magnificent vegetation.

On the northwest face of the rim of the atoll there are only two islands. On the northern face, running east to west, Pis Island, flanked by sand bars and sand spits, occupies the whole length of the flat thrown up between two passages leading out of the lagoon; the principal passage is to the west of Pis (Pl. 193, fig. 4). Another smaller pass exists to the eastward of the sinaller islets on the northeast face of the reef, but it is so tortuous that it 
cannot be used by vessels of any size. Pis Island is flanked on the sea face by a high coarse shingle beach, while on the lagoon side it is edged with a magnificent beach of fine coral sand of considerable height, on which the natives draw up their canoes. The islands on the northern face have been thrown up by the combined action of the trades, the sea and swell from the lagoon side. The spits at the extremity of the islands on the north face of the atoll of Truk are generally covered with masses of boulders; deep water separates some of the smaller islands on the inner side of the barrier reef flats of the lagoon, showing that this part of the lagoon was at one time a reef flat similar to that to the west and to the east, merely flanking the inner coral patches which have now become more or less connected with the outer land rim, forming as it were small secondary lagoons similar to those we have described elsewhere.

The island of $\mathrm{Pis}$ is covered with magnificent vegetation and is one of the most thickly populated of the islands in the Carolines; the natives living there have but little contact with the settlements at Uola and the southern part of Truk.

On the larger volcanic islands the vegetation reminds one more of the vegetation of the eastern continental islands; it is even more luxuriant than that of Kusaie or of Ponapi. Judging from the little that is known of the larger forest trees, it is evident that the flora has felt the influence of its greater proximity to that of the East. We are constantly reminded of the similarity between the flora of the Malay Archipelago and the flora of the Carolines, a similarity gradually becoming less marked as we go east to Ponapi, to Kusaie, and to the Marshall Islands. This relationship appears still more striking when we take a more southerly course and pass east through Fiji, Samoa, and the Couk Archipelago to the Society Islands, where it is difficult to recognize that part of the flora which owes its origin to a migration from the west to the east.

On examining a chart of the Carolines, we notice that the central part of the Carolines occupies an area where denudation and erosion have been far more active than it has been at the eastern and at the western extremities of the group. On the east the islands of Ponapi and of Kusaie rise to the height of nearly 3000 feet, and on the west such islands as Yap and the 
Pelew Islands rise to 2000 feet, a greater height than that of the islands of the Truk lagoon. Within a radius of one hundred and fifty miles of Truk are a number of low islands and atolls eroded to the very level of the sea, such as Namonuito, the Hall, the Mortlock Islands (Pl. 232), and the numerous islands and islets lying between Namonuito and Wolea, none of which rise far above the level of the sea. Of course there is no proof that the base of the low atolls to the east and to the west of Truk is composed of volcanic rocks; it is only by analogy that we can

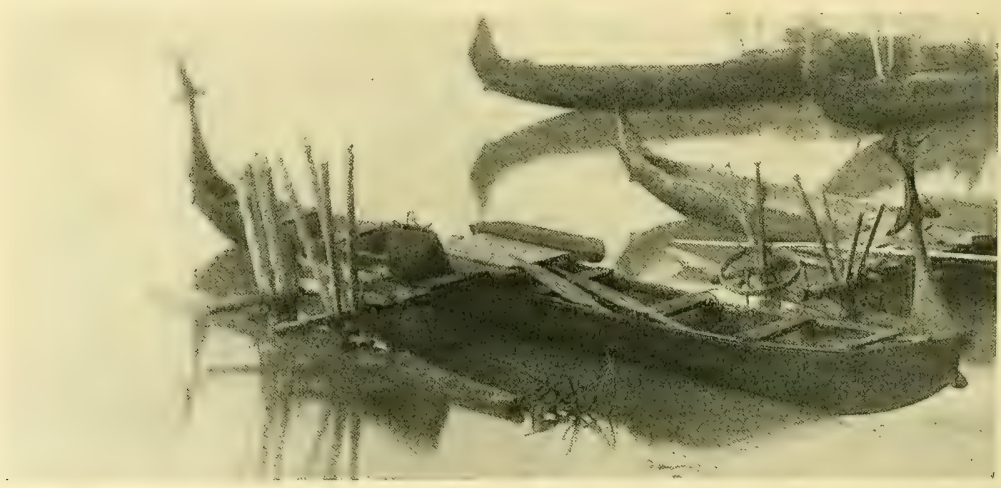

Native Canoes, Mokn, Truk, Carolines.

venture to say that some of the low islands of the Carolines are underlaid by a volcanic base.

On the other hand, the existence of islands composed of elevated coralliferous limestone, such as Nama, of San Augustin in the Oraluk group, said to be 110 feet high, of Feys (Pl. 233, fig. 2), as well as the presence of elevated reefs of tertiary age in the southern Pelew Islands, ${ }^{2}$ makes it probable that some of the low coral atells of the Carolines may rest upon a foundation of tertiary limestones, as is the case in the Paumotus, the Fiji and Tonga groups, and other isolated islands in the Pacific.

1 A. Chart 982.

2 Semper, C., Die Palau Inseln, pp. 17, 155, 277, 285; Zeits. f. Wiss. Zool., 1868, XIII., p. 555 ; Die Natïlichen Existenzbedingungen d. Thiere, 1880, II., p. 39. A. Wichman, Zur Geolog. Kenntniss l. Palau Inseln, Jour. d. Mus. Godeffroy, Heft VIJI., p. 123. 
Judging from the structure of Kusaie, of Ponapi, of Truk, of Yap, and of the Pelews, we may infer that some of the low islands represent only a state of greater denudation and submarine erosion than the groups I have just mentioned. Truk is perhaps the best evidence we have that such extensive denudation has taken place, for it requires but little imagination to picture its islands reduced to the level of the sea, when Truk would be an atoll similar in all respects to the larger low atolls like Namonuito, the Mortlocks, and others, differing from them only in having numerous coral flats upon which low islands like Gregoire, Brongniart, and many others in the atoll have been thrown up. These low islands in their turn might eventually be changed into mere coral shoals should the denudation go on a step farther. We noticed that in Truk, as in the low atolls of the Carolines, the principal land rim thrown up on the outer barrier reef is found on the northern and the eastern faces, where the barrier reef flats are exposed to the full action of the trades or of the sea during the change of the trades and the prevalence of northerly winds.

\section{Namonuito.}

\section{Plates 232; 233, fig. 1.}

The only one of the large low atolls of the Carolines we examined is the Namonuito group. It is a triangularly shaped flat (Pl. 233, fig. 1); its apex towards the north, at a distance of about twenty-five miles from the southern face of the reef, which is nearly forty-five miles in length. The lagoon has been fairly surveyed in $1828,{ }^{1}$ by the Russian ship "Seniavina," which crossed and recrossed the lagoon in several directions. The charts do not indicate any features of interest other than those we observed.

The southeastern point of Namonuito projects out as a sharp reef flat covered by shallow water, enclosing a secondary lagoon very similar to those on the northern and the northeastern points of Arhno, but there are no islands on the sides of the secondary lagoon.

On the extremity of the eastern spit rises the island of Pisaras, on which a few cocoanut trees grow; it is flanked by coarse shingle, and a shingle 
beach partly covered by coral sand. Owing to the depth over the barrier reef flat ridge, no breakers were visible on the reef to the north of Uneyeute Island until we came close to Unalik. Here, about the centre of the northeast face, are a number of islands and islets on the edge of an ill-defined plateau, with here and there shoal spots where corals have been washed up. They are separated from the island of Onoupe, lying to the north of them, by a pass with deep water; a continuation of the reef flat can be traced farther north, trending in a northwesterly direction.

The sliore of Onoupe is flanked by a shingle beach; high cocoanut trees grow on the island; two islets are situated on the barrier reef flat, near the northern point of the lagoon. At many points on the east and south faces the presence of the reef flat is merely indicated by the difference in color of the water covering the flat, and the occasional reef patches which rise to the surface. The western horn of the atoll is occupied by the low island of Ulul. The lagoon varies in depth from twenty to twenty-five fathoms. Namonuito, Oraluk, and similar atolls represent the extremes of the minimum development of a land rim, a mere thread of a narrow reef flat encircling the lagoon, with only an occasional islet to indicate its presence. ${ }^{1}$

The atolls of the Mackenzie group are very similar in structure to that of Namonuito, although the shape of the atolls is somewhat different. The same is the case with the Hall Islands, with West Faiu, Lamotrek, Olimarao, Faraulep, Kama, and Ifalik; while Feys (Pl. 233, fig. 2), Pikelot, and East Faiu are the only islands of the Carolines known covering nearly the whole reef flat upon which they have been thrown up, that is, they are diminutive summits similar to the small islets in the Marshall Islands, in the eastern part of the Paumotus, and other groups in the tropical Pacific.

${ }^{1}$ If the sketch of Oraluk on A. Chart 982 is correct the barrier reef flat of the atoll is by far narrower than that of any atoll known to me. Some of the narrow barrier reefs of Tahiti may be compared to Oraluk. 


\section{THE LADRONES.}

Plates 194-199; 232; 233, figs.4, 5.

THe Ladrones form a line of volcanic islands, many of which are active; they extend north from Guam as far as the Farallon de Pajaros; there are no less than twelve active volcanoes in a distance of less than 300 miles. The southern groups of the Ladrones are islands partly volcanic and partly composed of elevated coralliferous limestone. In Guam a volcanic massif forms the southern half of the island; in the northern part Mount Santa Rosa, a volcanic outburst, rises at least 200 feet above the general level of the limestone platean of Guam. At Rota Island we could only trace the existence of a small volcanic outburst, on the northwestern shore of the island.

The islands of the next cluster to the north, Saipan, Tinian, and Aguijan, are partly volcanic and partly limestone; we did not visit them, but their probable geological structure is indicated by the sketches given on the Hydrographic Charts. ${ }^{1}$

The line of the Ladrones beginning at Santa Rosa reef forms a gigantic flat arc; the southern portion runs from the southwest to the northeast, the central portion runs nearly due north, and the northern group extends in a somewhat northwesterly direction. Between the Ladrones and Japan a line of volcanic islands extends somewhat to the west of the line of the Ladrones; its principal groups are the Volcano, the Bonin Islands, Lot's Wife, Aoga-sima, and the volcanic islands and islets which run south of Oosima. These form a line of active volcanoes running for more than $20^{\circ}$ of latitude, from the southern part of the Ladrones to the south coast of Japan. The line of soundings of the "Nero" ${ }^{2}$ indicates the remarkably uneven character of the bottom along that line of volcanic islands.

The irregularity of the bottom along that line is in marked contrast to the line of soundings at right angles to it, extending from Guam to Midway Island; the latter indicates a fairly uniform level bottom of an average 
depth of about 2700 fathoms. Across the south of Guam extend "Caroline and Nero Deeps"; they are probably the eastern extension of "Challenger Deep." This deep valley, with a greatest depth of 5269 fathoms, separates the Ladrones from the Carolines.

\section{Guam.}

Plates 194-198; 232; 233, fig. 4 .

The island of Guam is rectangular, about twenty-two miles in length; its greatest width across the southern part is eight miles, and in the northern six miles, narrowing near the central part of the island at the latitude of Tumun Bay to about three miles in width (Pl. 233, fig. 4): South of the central part of the western shore, between Agaña and Agrate Bay, extends the peninsula of Oroté; it runs out four miles in a northwesterly direction, and forms the southern side of the harbor of San Luis d'Apra; the north side is protected by Cabras Island, about two miles in length; its western extension has been denuded and eroded into a wide barrier reef flat, Luminan Reef and Calalan Bank extending as far as Spanish Rock, the western extremity of the northern strip enclosing the Bay of San Luis d'Apra (Pl. 195, fig. 1). This bay has been eroded out of the elevated coralliferous limestone of which the northern part of the island of Guam consists.

From Port Pago north (Pl. 233, fig. 4), on the east coast, are most distinct coralliferous limestone terraces, marking the position of the former sea level, and indicating the periods of rest during the elevation of Guam; where they are not well defined their position is still indicated by the lines of caverns which crop out in the vertical faces, and give an indication of the position of former lines of sea level. The mode of formation of the vertical cliffs of the eastern side of the island, by the gradual sloughing off of the lower parts of the vertical faces and encroaching upon successive terraces, is well seen north of Anao Point; the parts thus falling off remain as outliers of the older terraces on the narrow shore platform. The vertical cliffs of the northern part of Guam vary in 
height from 300 to 500 feet (Pl. 194, figs. 1, 2). The lower part of their faces is riddled with crevasses and cracks, and at a higher level, probably on the face of the fourth or fifth terrace, numerous caverns crop out.

Wè struck the east coast of Guam near Point Hanoum; the vertical cliffs of the east face consist of elevated coralliferous limestone, rising at the northern extremity of the island to more than 300 feet (Pl. 194, fig. 1). They flank the eastern shore of the island from Point Ritidian, the northernmost point of the island, as far as Port Pago; there the vertical cliffs become indistinct patches and isolated cliffs resting upon the volcanic massif of the southern half of the island. Magnificent terraces can be traced in all directions, indicating the periods of rest during the elevation of Guam (Pl. 194, figs. 1, 2). The vertical cliffs representing the lower terraces are deeply pitted, honeycombed, furrowed, and distorted.

On the east coast, north of Point Anao, some of the coralliferous limestones are stratified, dipping towards the sea; others, nearer the northern extremity, show evidence of great disturbance, probably caused at the time of their elevation, when Sta Rosa Peak burst through the coralliferous limestones in the interior of the northern part of the island (Pl. 198, fig. 3). They resemble in every way those of similar limestone islands, such as Makatea, Niue, Eua, Vavau, and others in Fiji, with which we had become familiar in our explorations. Outside of Viti Levu and Vanua Levu, Guam is the largest

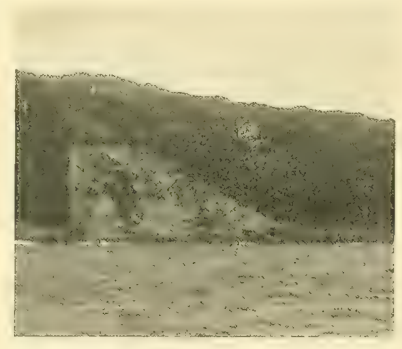

Twisted Strata, East Face of Guam, South of Patay Point. island we visited, composed in part of volcanic rocks and of elevated coralliferous limestone.

At the northern extremity of Guam are five distinct terraces; the first and second are somewhat lower than the third and fourth; the mass of vegetation growing on the slopes sloughed off from the limestone bluffs, has, at many points, obliterated all traces of the terraces. Taragay Bay, at the northern extremity of Guam, is an immense sandy flat, flanked by a comparatively broad reef platform (PI. 233, fig. 4), full of horse-heads 
and of negro-heads; it extends between Point Tagua, past Point Ritidian, as far as Falcona anchorage on the west coast. From that point the vertical cliffs edge the coast until we reach the reef flats of Tumun and Agaña Bays (Pl. 194, fig. 2), which extend as far as Cabras Island. To the south of Oroté Peninsula a narrow reef flat juts out from the west coast at various promontories in the extension of spurs of the volcanic slopes (Pls. 198, figs. 1, 2; 233, fig. 4). At Merizo Bay a broad reef flat forms the southwestern extremity of Guam. Two low islands, Cocoa and Bali, have been thrown up on the southwestern extremity of this wide reef flat; it extends to the eastward as far as Point Ajayan, and is lost as we reach Port Ynarajan. Beyond that point, as far as Port Pago, the coast is edged by a narrow reef flat. The northern part of the east coast of Guam, between Port Pago and Point Patay, consists of steep vertical cliffs, varying in height from 150 to over 500 feet. At Point Hanoum a narrow reef flat again skirts the eastern shore as far as Point Anao.

As we looked back on the northeast point after turning to the west, we could see indistinct traces of the terraces which once ran round it; from constant erosion and disintegration, the lines of terraces lave been changed into a long irregular slope, with here and there a rounded step indicating the position of a former terrace.

The general level character of the northern part of the island to the south of Point Ritidian is very apparent as seen from the sea. The surface slopes slightly to the west towards the central part of the island. The northern face is flanked by a coral sand beach; irregular patches of corals extend from Point Tagua round the west side. The sloughing off of the sea face of the terraces has obliterated their lines of demarcation. Their number is indicated by the position of the rows of caverns seen on the cliff faces. At the northwest point the fifth terrace stands out boldly. The steep slope at the base of the point is probably the remnant of the third and second terraces, while the first terrace slopes more gradually to the sea. Looking south from Point Ritidian we could see the succession of headlands formed by the line of vertical limestone cliffs separating the shallow bays or indentations between the headland 
knolls (Pl. 194, figs. 1,3). The low vertical cliffs on the western shore, rising here and there directly from the sea, are not more than fifty to sixty feet high and are probably remnants of the first and part of the second terrace, while the higher vertical cliffs immediately behind, which gradually become lower and lower as we go south, are parts of the second, third, and fourth terraces. From the latter the land extends nearly horizontally towards the interior of the island (Pl. 194, figs. 1-3).

From the northwest point looking south, we could see at a distance of about twenty miles the volcanic ridge on the southwest side of the island; its peculiar outlines are in marked contrast with those of the limestone bluffs and points we followed from Point Hanoum (Pls. 195, figs. 2, 3 ; 197). The west coast presents no striking differences from the east coast until we come upon Punta de los Amantes, where the caverns plainly indicate the existence of four terraces in the face of the vertical cliffs. To the south of the point an extensive coral sand beach stretches along the base of the cliffs; to the south of Point Fafai a number of broad valleys open out on the west face; they extend inland and have been formed from the disintegration of remnants of limestone, such as still flank, in places, the lower portions of the volcanic mass which has burst through the coralliferous limestone once occupying the southern part of the island (Pls. 194, fig. 3; 195, figs. 1-3; 197, fig. 1; 198, figs. 1, 2).

As we steamed south, parallel with the west coast, the high vertical cliffs become gradually lower, until at Punta de los Amantes we find the lowest. of the vertical cliffs which, to the north, form a series of promontories at right angles to the west coast, separated by deep bights (Pl. 194, fig. 2). The east as well as the west coast presents a deeply scalloped appearance, due to the gradual inroads made by the sea in the vertical cliffs (Pl. 233, fig. 4). The bays forming the small reef ports on the southern part of "the east coast of the island, like Port Pago and Ports Ynarajan and Tarafofo, as well as the larger indentations like Tumun and Agaña on the west coast, and a number of smaller bights, indicate the character of the submarine erosion which has taken place on those shores during the prevalence of the trades or of westerly and northwesterly winds (PI. 233, fig. 4). The extent of the disintegration of the faces of the 
terraces is well seen north of Point Hanoum, where a huge boulderlike mass resting on the lower terrace is all that is left of the terrace immediately above it.

The harbor of San Luis d'Apra is protected on the north by Cabras Island and the adjoining reef on the west, an outlier of the limestone mass which has been broken through by the voleanic outburst (Pls. 195, figs. 1,$2 ; 233$, fig. 4). On the south of the harbor lies Oroté Peninsula (Pls. 195, fig. 3 ; 233, fig. 4), a broad low spit of elevated coralliferous limestone; the western face of its northern base is eaten away and forms the shallow reef flat on the western face of the harbor (Pl. 195, fig. 2). From the anchorage in San Luis d'Apra we could distinctly trace the position and extent of the remaining limestone masses (Pls. 195, fig. 2; 197, fig. 1). The base of the long spit forming Orote Point (PI. 195, fig. 2) extends to the eastern part of the harbor; its structure is indicated by the characteristic vegetation of a limestone area ; it is in inarked contrast to the bare volcanic slopes immediately in the rear.

Cabras Island (Pl. 195, fig. 1) consists of old elevated coralliferous limestone, deeply pitted and honeycombed; the limestone mass is full of crevices, pot-holes, and funnels, covered with stalactites (Pl. 196); numerous fossils are found in it, mainly corals. Traces of a recent elevation of from three and one-half to four feet are seen in the undercutting of the small buttresses of coralliferous limestone jutting out into the beach. This line of elevation follows the shore of Cabras; it is very recent, as is plainly shown by the well-preserved calcified barnacles found on the under side of the shelf where they had been protected from the rain. Cabras Island (Pl. 197, fig. 1) does not rise more than eight to ten feet above high-water mark; the shore is undercut and the island furrowed by numerous gullies; it is full of caverns, crevices, and pits.

In the distance, and running across the eastern flank of the harbor, rises the highiest point of the volcanic massif of the southern part of Guam (Pls. 195, figs. 2, 3; 197, fig. 1; 198, fig. 2). To the north of Cabras Island rise a number of elevated coralliferous islands; they are outliers of a point similar to Oroté Peninsula, on a smaller scale, projecting from the base of the western face of the volcanic mass of Guam (Pl. 233, fig. 4). 
Here and there we could distinguish on the western slope of the volcanic mass the remnant of an ancient elevated coralliferous limestone bluff standing like a wall to indicate the height at which the coralliferous limestone had once existed and the amount of erosion and denudation to which that extremity of the island had been subjected (Pl. 194, fig. 3).

Some of the patches of red earth scattered over the volcanic slopes (Pl. 197, fig. 2) are probably similar to the red earth so characteristic of many atolls in the Paumotus and of other limestone islands; it represents the existence of former huge masses of limestone, the iron having accumulated in sufficient quantities to perceptibly color the slopes on which it has been deposited. Of course, in addition to the iron deposit derived from the - limestone, the greater part of the red earth of Guam owes its origin to the disintegration of reddish volcanic ash which has been changed into silt and swept down the slopes of the hills.

The harbor of San Luis d'Apra has been formed as an angular sound gradually encroaching into the banks and spits which gave it its original outline. Parts of these banks form the intricate passages between the flats covering the eastern extremity of the harbor and the anchorage (Pl. 233, fig. 4). To the north, towards the town of Agaña, a long narrow reef flat stretches at the base of the volcanic slope (Pl. 194, fig. 3). This reef flat is covered by the remnants of elevated coralliferous limestone masses; its eastern outliers are still found on the western voleanic slopes of Guam.

The southern part of Guam consists of a volcanic massif which has burst through the coralliferous limestone (Pls. 195, fig. 2; 197, fig. 1; 198, fig. 2); at Mount Tinkio it has risen to a height of over 1000 feet. This is the highest point of the volcanic ridge; it has burst through the limestone near Agaña and extends parallel to the west coast from Agaña to the southern point of Guam, running at a distance varying from a mile to two miles from the shore (Pl. 233, fig. 4). This ridge slopes rapidly to the west, but towards the east the voleanic slopes pass gradually to the southem part of the east coast of the island (Pl. 233, fig. 4). Outside of the volcanic slopes run a few limestone outliers, such as Cabras Island (Pl. 197, fig. 2), the Oroté Peninsula (Pl. 195, fig. 3), Point Facpi (Pl. 198, fig. 1), and a line of 
islands and islets south of Oroté Peninsula, parallel to the west coast (PI. 198, figs. 1, 2). This volcanic massif has burst through the mass of coralliferous limestone which once covered the whole of Guam, so that its southern part is really volcanic, with the exception of a few limestone outliers (Pl. 198, figs. 1, 2), while its northern extremity is composed of elevated coralliferous limestone.

Considerable denudation has taken place on the volcanic slopes of Guam, as is shown on the west const from the presence of huge isolated masses of limestone and coralliferous rock elevated and left as outliers of the cliffs once forming the second or third terraces. The extent of this denudation is also seen in the interior of Guam, from the existence of the manifold peaks, ridges, and pinnacles, forming a chain parallel to the outer line of cliffs on the east side for about one third of the northern end of the island.

From our first position on the east coast, we could see the gradual change taking place in the topography towards the south, as the terraces of elevated coralliferous limestone gradually died out towards the southern extremity of Guam (Pl. 233). On the western and southern sides of the mass of volcanic rocks which has burst through the southern part of Guain the former limestone masses which once covered the sides of the volcanic ontburst have in great measure disappeared (Pl. 197, fig. 1), owing to the extensive disintegration which has taken place over the whole southern part of the island of Guam. The slopes of the volcanic hills consist of a soft material, are much eroded, and are rapidly washing away; the valleys form diminutive cañons with remarkably steep sides.

To the south of San Luis d'Apra the slopes of the main ridge have been greatly denuded and eroded. They are covered with patches of volcanic red earth and with nodules of the same material. Towards the south the shore reef has been elevated, although until we reach Facpi there has been no volcanic outburst close to the coast.

The peninsula of Oroté is, like Cabras, composed of elevated coralliferous limestone. It contains well-preserved fossils; they show no signs of metamorphism, as do those collected in the vicinity of Mount Makana, east of Agaña. The fossils, however, are highly calcified, and their hardness and 
the crystallization of the rocks would seem to indicate that they were of considerable age.

Near the town of Agate, on the west coast, the outcrop of coral rocks becomes more or less covered with volcanic soil washed down from the mountains immediately to the east. About half a mile to the south of Agate is a remnant of a spur (Pl. 233, fig. 4), similar to that of Oroté and of Cabras; it has all the characteristics of the elevated coralliferous limestone of Oroté. To the south of San Luis d'Apra the outlying islands and islets of the west coast, as far as Point Facpi, consist of elevated coralliferous limestone rock much undercut and eroded (Pl. 233). The Peladgi Islands, Alutung and Anaya, are about fifteen feet in height and deeply undercut. The small island off Point Facpi is at least thirty feet high and is exceedingly jagged and honeycombed. (Pl. 198, fig. 1). The coast in the region of Facpi and immediately to the north is quite abrupt; the volcanic rocks form a bluff at least seventy-five feet in height (Pl. 198, fig. 1). A number of volcanic negro-heads lie at the foot of the bluff, extending fully fifty yards out into the sea, while at a distance of 100 to 120 yards lie the high coral islands just mentioned with a few coral negro-heads at their base.

Immediately to the north of Point Facpi is an elevated coral reef about two and one-half feet above high-water mark. The corals here are recent and appear to be in place; while they are hard and to a certain extent calcified, they differ materially in structure and appearance from the elevated crystalline coralliferous limestone masses of the islets to the north and of Oroté Point, as well as from the coral boulders derived from the outlying islands.

Looking south from Point Facpi we could see that the islands of that part of the west coast are also composed of elevated coralliferous limestone and are about the same height as Alutung and Anaya. The shore line is volcanic for a considerable distance to the south of Point Facpi; we then strike again the elevated coralliferous limestone with its characteristic high bluffs.

Apurguan Point forms the northern promontory of the harbor of Agaña. Immediately to the east of Agaña we could see outliers of elevated coral- 
liferous limestone. The character of its magnificent vegetation shows its extent and position, and is in marked contrast to the bare and barren volcanic slopes covered with reddish earth (Pl. 197, fig. 2).

At the base of the volcanic slope forming the eastern side of San Luis d'Apra Harbor is a wide limestone flat varying greatly in width, from a few feet to at least 1000 ; it has been formed by the washing down of hill slope material, which has become mixed with the disintegrating coralliferous rock. Upon this flat, and its northern and southern extension, cocoanut trees grow in great profusion.

The road leading to Agaña runs north from the landing. It skirts the west shore, crossing successive spurs of elevated limestone rock. At a distance of about two miles we strike the first volcanic ridge; it extends towards the beach, the road passing round the foot of the volcanic bluff. This ridge is composed of greatly decomposed gray volcanic rock containing much hornblende. We next come upon a spur of hard ringing limestone full of corals and of other fossils and of red earth. This and other spurs of coralliferous limestone are all that is left of the former mass of limestone elevated by a volcanic outburst (Pl. 194, fig. 3). The slopes of the volcanic hills to the east of the road are covered with red volcanic earth and decomposed volcanic tufa.

As we go north the limestone spurs increase in height and gradually pass into the limestone mesa of the northern part of Guam (Pl. 194, figs. 2, 3). From the hill east of Agaña (Pl. 197, fig. 2) we could see Sta Rosa Peak, a volcanic mass rising from 150 to 200 feet above the general level of the limestone (Pl. 198, fig. 3). The surface of the northern part of the island, while generally level (Pl. 198, fig. 3), is crossed with crevices and full of pot-holes and sinks and funnel-shaped cavities, the whole pitted and honeycombed and covered with spires and pinnacles - much as we have found the surface of islands composed of old coralliferous limestone in other parts of the Pacific. Northward the island gradually rises to a height of 350 to 500 feet.

South of Agaña, at the junction of the volcanic outburst with the elevated coralliferous limestone (Pl. 194, fig. 3), we can trace the successive terraces existing between the shore of Gapan Island and the 
highest point of Mount Makana, about 600 feet above the town. Some of the terraces are clearly indicated on the island of Cabras as well as at the extremity of Point Oroté (Pls. 195, fig. 3; 196): and on the western face of the peninsula, where they gradually disappear, owing to denudation.

Mount Makana is about 600 feet in height; its summit consists of various kinds of volcanic rocks; it has protruded through the coralliferous limestones, a spur of which extends to fully 400 feet along the side of the mountain towards Agaña.

Near the sea coast, and to within a few hundred yards of the point of protrusion of the volcanic material, the elevated coralliferous limestone is of moderate hardness, containing many well-preserved fossils. Near the point of junction between the volcanic mass and coralliferous lime-

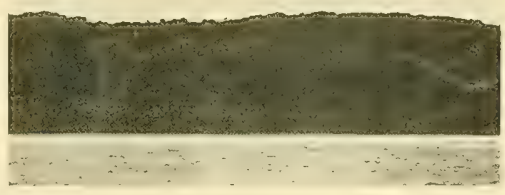

JUNCTION OF Volcanic OUtBuRst AND LimeSTONE, WEst COAST OF GUAM.

stone, however, it suddenly becomes highly crystallized, very hard, and the fossils disappear. The coralliferous strata are much tilted at this point, plainly showing that the volcanic mass has burst through the coralliferous limestone. From the anchorage we could trace this bed of limestone broken into cliffs and lifted into masses with precipitous sides by the volcanic outburst, the limestone belt being clearly indicated by its characteristic vegetation.

Volcanic agencies have been at work at Guam in very recent times. Unata was destroyed by an earthquake in 1849 ; this is not remarkable, as Guam is at the extremity of a long line of active volcanoes extending sonth from Japan; it may be that the volcanic outbursts which have pushed through the limestones, or have elevated parts of the islands of the Ladrones, are of comparatively recent date. ${ }^{1}$

We can imagine a large island like Guam, partly composed of coralliferous limestones, to be gradually eroded to the level of the sea, by a

1 The marine barracks and other buildings at Agaña were destroyed by earthquakes on the 25th of September last. 
process identical with that forming such atolls as Fulanga, Vanua Mbalavu, or Mbengha, in Fiji. The result would be a gigantic atoll, shaped somewhat like Wotje in the Marshall Islands; it would pass through a series of stages, each one of which is represented in some atoll at Fiji. A huge sink may first have formed in the northern extremity of Guam; the bays edging the coast may have been extended inland until they reached the sink. The sea would then rapidly open a sound or a series of sounds in the interior of Guam; these sounds might be separated by ridges or lines of islands, and while these changes were going on, the outer edge would gradually be rednced to a low limestone belt enclosing the sounds or cut into a series of islands, with a huge volcanic nucleus at the southern extremity. Finally, a gigantic atoll would be made by these successive changes, but one in the formation of which subsidence played no part.

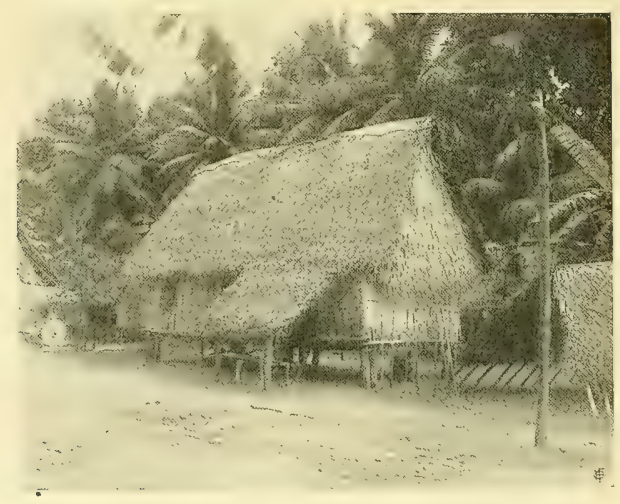

Native Hut, Guam.

\section{Rota.}

Plates 199; 232; 233, fig. 5.

To the northeast of Guam lies the island of Rota (Pl. 232); it is about twelve miles in length, and has a greatest width of perhaps five miles; it rises to about 800 feet, and runs nearly east to west. I was not surprised 
after examining the charts of the Ladrones to find that Rota, as well as Guam, consisted of elevated coralliferous limestone. The western extremity of Rota is formed by a long rectangular peninsula; its terraces are most distinctly marked and five periods of elevation are clearly to be distinguished (Pl. 199, fig. 2). The western peninsula is connected by a narrow neck with the main island (Pl. 233, fig. 5), a huge mass of coralliferous limestone sloping equally in all directions, but most distinctly terraced (Pl. 199). In Sosanjaya Bay and off the northwestern shore of Rota the island is flanked by a narrow reef flat (Pl. 233, fig. 5). The outliers and horse-heads on the western shore (Pl. 233, fig. 5) indicate the amount of erosion to which this island has been subjected.

On Rota the termaces marking the successive elevations of the southern Ladrones are admirably preserved. At a distance of three miles off shore five terraces conld be distinguished. The summit of the island is almost level (Pls. 199, fig. 2; 233, fig. 5). Coming from the south we could see no indication of any volcanic outbursts. The spit forming the sonthwestern extremity of Rota, separating Sosanlagh and Sosanjaya Bays, also shows remarkably well-defined terraces (Pl. 199, figs. 1, 2). There are four of these on the southernmost spit, and, when facing the main island, at least seven terraces are plainly indicated. The face of the southern spit is riddled with caves (Pl. 199, fig. 2). The lower terrace is deeply undercut, showing traces of two stages of elevation, one not more than three or four feet, identical in height with the low terrace described at Cabras Island. Looking across the low land separating the southern promontory of Rota from the main island, we could see numerous caverns in the vertical face of the cliffs of the main mass of Rota. As we steamed north we observed that the slope of the northwestern point, as well as the character of the vegetation, indicated a volcanic outburst at that extremity of the island (Pls. 199, fig. 1 ; 233 , fig. 5 ).

It is probable that others of the southern islands of the Ladrones we did not examine are, like Rota and Guam, elevated coralliferous masses forming the summit of an extensive limestone plateau through which more recent volcanic rocks have burst at different points. After volcanic outbursts the elevated coralliferons limestone beds have often been denuded and eroded 
to the line of the slope of the volcanic mass, and have disappeared. The sketch of the island of Saipan and others to the south, as shown on the Hydrographic Charts, ${ }^{1}$ would indicate the existence of a number of terraced islands. On leaving Rota we entered the field of the "Challenger's" soundings, and, stopping all work, shaped our course for Yokohama.

1 H. O. Chart 1748. 


\title{
LIST OF THE STATIONS
}

\author{
OCCUPIED BY THE U. S. F. C. S. “ALBATROSS," DURING HER \\ CRUISE IN THE TROPICAL PACIFIC,
}

August, 1899-March, 1900.

SAN FRANCISCO, CALIFORNIA, TO NUKUHIVA, MARQUESAS ISLANDS.

\begin{tabular}{|c|c|c|c|c|c|c|c|c|}
\hline \multirow{2}{*}{ 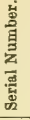 } & \multirow{2}{*}{$\begin{array}{l}\text { Date. } \\
1899 .\end{array}$} & \multicolumn{2}{|c|}{ Position. } & \multicolumn{2}{|c|}{$\begin{array}{l}\text { Temper- } \\
\text { atures. }\end{array}$} & \multirow{2}{*}{ 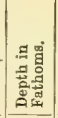 } & \multirow{2}{*}{$\begin{array}{l}\text { Nature } \\
\text { of } \\
\text { Bottom. }\end{array}$} & \multirow{2}{*}{ Remarks. } \\
\hline & & $\begin{array}{l}\text { Latitude } \\
\text { North. }\end{array}$ & $\begin{array}{c}\text { Longitude } \\
\text { West. }\end{array}$ & $\begin{array}{l}\text { Sur- } \\
\text { face. }\end{array}$ & $\begin{array}{l}\text { Bot- } \\
\text { tom. }\end{array}$ & & & \\
\hline 1 & Ang. 26 & 3i 10 & $\begin{array}{cc}\circ & \prime \\
125 & 00\end{array}$ & $\begin{array}{c}\circ \\
63\end{array}$ & $\stackrel{\circ}{.}$ & 1955 & $\cdots \cdots$ & Lost thermometer and detacher; 320 \\
\hline 2 & Aug. 27 & 2823 & 12657 & 66 & 34.6 & 2368 & $\begin{array}{l}\text { Red clay. Light } \\
\text { brown ooze. }\end{array}$ & $\begin{array}{l}450 \text { miles from Guadalupe Island, } 500 \\
\text { miles from Point Couception. Large } \\
\text { haul of manganese nodules, sharks' } \\
\text { teeth, and cetacean bones. }\end{array}$ \\
\hline 3 & Aug. 28 & 2618 & 12854 & 68 & $\therefore$ & $\therefore$ & $\therefore \cdots \cdots$ & $\therefore \ldots \ldots \ldots$ \\
\hline 4 & Aug. 29 & 2445 & 13016 & 69 & 34.6 & 2628 & $\begin{array}{l}\text { Light brown ooze, } \\
\text { same as at St. } 2 . \\
\text { Red clay. }\end{array}$ & $\ldots \ldots \ldots \ldots$ \\
\hline 5 & Aug. 30 & 2242 & 13154 & 70 & 34.6 & 2740 & $\begin{array}{l}\text { Light brown ooze, } \\
\text { same as at St. } 2 . \\
\text { Red clay. }\end{array}$ & $\begin{array}{l}\text { Too rough to trawl; distant from } \\
\text { Guadalupe Island } 800 \text { miles, from } \\
\text { Point Conception } 960 \text { miles. }\end{array}$ \\
\hline 6 & Aug. 31 & 2026 & 13328 & 75 & . & 2810 & $\begin{array}{cc}\text { Dark brown mud } \\
\text { ooze. Red clay. }\end{array}$ & $\begin{array}{l}\text { Distant from Guadalupe Island } 960 \\
\text { miles, from Sebastian Viscaino } 1060 \\
\text { miles. }\end{array}$ \\
\hline 7 & Sept. 1 & 1819 & 13457 & 76 & . & 2881 & $\begin{array}{l}\text { Red clay. Dark brown } \\
\text { ooze. Very sticky. }\end{array}$ & $\cdots \cdots \cdots \cdots$ \\
\hline 8 & Sept. $\quad 2$ & 1713 & $136 \cdot 09$ & 78 & . & $\begin{array}{l}2766 \\
3003\end{array}$ & $\ldots \cdots$ & $\ldots \ldots \ldots$ \\
\hline 10 & 6 & $\begin{array}{ll}16 & 52 \\
16 & 38\end{array}$ & $\mid \begin{array}{ll}136 & 12 \\
136 & 14\end{array}$ & $\begin{array}{l}76 \\
78\end{array}$ & $\because$ & $\begin{array}{l}3003 \\
3085\end{array}$ & $\begin{array}{lll}\cdots & \cdots & \cdots \\
\cdots & \cdots & \cdots\end{array}$ & Deepest part of Moser Basin. \\
\hline 11 & Sept. 3 & 1438 & 13644 & 79 & . & 2646 & Red clay. & $\begin{array}{l}\text { Passing out of deepest part of Moser } \\
\text { Basin. }\end{array}$ \\
\hline 12 & Sept. 4 & 1207 & 13719 & 81 & . & 2883 & Red clay, radiol. & $\ldots \ldots \ldots \ldots$ \\
\hline 13 & Sept. 5 & 957 & 13747 & 82 & - & 2690 & $\begin{array}{l}\text { Red clay. Light } \\
\text { brown ooze, coarse } \\
\text { mineral particles. } \\
\text { Radiolarian ooze. }\end{array}$ & $\begin{array}{l}\text { Large balls of manganese nodules, ce- } \\
\text { tacean bones, sharks' teeth. }\end{array}$ \\
\hline 14 & Sept. 7 & 641 & 13700 & 82 & . & 2776 & $\begin{array}{l}\text { Gray ooze glob. } \\
\text { Foram. no radiola- } \\
\text { rians. Not sticky. }\end{array}$ & $\ldots \ldots \ldots$ \\
\hline 15 & Sept. 8 & 435 & $136 \quad 54$ & 79 & $\cdot \cdot$ & 2583 & $\begin{array}{l}\text { Fine gray ooze. Ra- } \\
\text { diolarians. }\end{array}$ & $\ldots \ldots \ldots \ldots$ \\
\hline 16 & Sept. 9 & 238 & & 79 & 35.2 & 2440 & $\begin{array}{l}\text { Light yellow gray } \\
\text { glob. ooze. }\end{array}$ & $\begin{array}{l}\text { To Hawailan Islands } 1500 \text { miles, to } \\
\text { Marquesas } 660 \text { miles. }\end{array}$ \\
\hline 17 & Sept. 10 & 050 & 13754 & 79 & . & 2463 & $\begin{array}{l}\text { Light yellow gray } \\
\text { glob. ooze. }\end{array}$ & $\begin{array}{l}\text { Sea too heary to sound after this till } \\
\text { Sept. } 13 \text {. }\end{array}$ \\
\hline
\end{tabular}




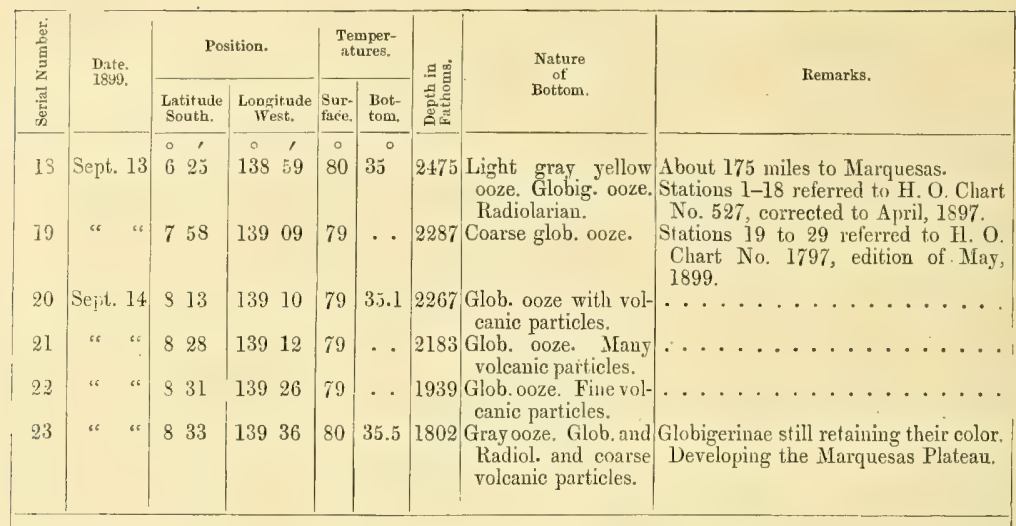

\section{MARQUESAS ISLANDS TO TAHITI, SOCIETY ISLANDS, VIA NORTHWESTERN - PAUMOTUS.}

Stations in Vicinity of the Marquesas Islands.

\begin{tabular}{|c|c|c|c|c|c|c|c|c|}
\hline & & 1 & & ○ & $\circ$ & & & \\
\hline 24 & Sept. 14 & 841 & 13946 & 80 & 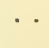 & 1040 & $\begin{array}{l}\text { Coarse glob. ooze. } \\
\text { Volcanic particles. }\end{array}$ & $15 \frac{1}{2}$ miles N. $43^{\circ} \mathrm{W}$., same as below. \\
\hline $2 j$ & " & 849 & 13948 & 80 & 38 & 830 & $\begin{array}{l}\text { Globig. and volcanic } \\
\text { mud and fragments. }\end{array}$ & $\begin{array}{l}13 \text { miles N. } 73^{\circ} \mathrm{W} \text {. of Haunanu Point, } \\
\text { Ua Huka Island. }\end{array}$ \\
\hline 23 & & 852 & 13952 & 80 & & 1173 & $\begin{array}{l}\text { Glob. ooze. Ptero- } \\
\text { pods and volcanic } \\
\text { particles. }\end{array}$ & $\begin{array}{l}17 \text { miles west of Mt. Uranupe, Nuku- } \\
\text { hiva Island (Taï-o-haé). }\end{array}$ \\
\hline 27 & Sept. I5 & 901 & & 79 & . . & 687 & Glob. ooze. Volcanic & 6 miles S. $20^{\circ}$ E. of Anna Maria Bay. \\
\hline & Sept. 17 & 905 & 14013 & 80 & . . & 1284 & $\begin{array}{l}\text { Rocky. Volcanic } \\
\text { fragments. }\end{array}$ & $\begin{array}{l}\text { About } 18 \text { miles } \mathrm{S} .13^{\circ} \mathrm{W} \text {. of Chicka- } \\
\text { koff Point. }\end{array}$ \\
\hline
\end{tabular}

Stations from the Marquesas to Rangiroa.

\begin{tabular}{|c|c|c|c|c|c|c|c|c|c|c|}
\hline & & 0 & , & & , & & & & & \\
\hline 29 & Sept. 17 & 9 & 16 & 140 & 25 & 80 & 34.9 & 1932 & $\begin{array}{l}\text { Light yellow gray } \\
\text { glob. ooze. Coarse } \\
\text { yoleanic particles. }\end{array}$ & $\begin{array}{l}25 \text { miles from Cape Chickakoff, Nuku- } \\
\text { hiva, } 20 \text { miles from Ua pu Island. }\end{array}$ \\
\hline 30 & Sept. 18 & 10 & 29 & 141 & 52 & 81 & 35 & 2456 & $\begin{array}{l}\text { Light gray glob. Few } \\
\text { Radiol. Volcanic }\end{array}$ & $\begin{array}{l}\text { Stations } 30,31 \text { referred to H. O. Chart } \\
\text { No. } 824^{3} \text {, Oct. } 1888 .\end{array}$ \\
\hline 31 & Sept. 19 & 12 & 20 & 144 & 15 & 80 & 35 & 2700 & Red clay. & Deepest part of Chamnel separating the \\
\hline 32 & Sept. 20 & 13 & 37 . & 145 & 42 & 80 & 35 & 2451 & Red clay with Foram. & Stations $32-35$ referred to H. O. Chart \\
\hline 33 & «) & 14 & 10 & 146 & 10 & 81 & 35.1 & 2527 & Red clay. & 22 miles N. $28^{\circ} \mathrm{E}$. of entrance to Ahii. \\
\hline 31 & & 14 & 26 & 146 & 25 & 81 & . & 1208 & Very light col. glob. & About $2 \frac{1}{2}$ miles northwest of entrance \\
\hline 35 & Sept. 21 & 14 & 42 & 147 & 03 & 80 & . & 1462 & Fine coral sand glob. & $\begin{array}{l}\text { Position according to } H . \text { O. Chart } \\
\text { No. } 77 \text {. }\end{array}$ \\
\hline
\end{tabular}




\begin{tabular}{|c|c|c|c|c|c|c|c|c|}
\hline \multirow{2}{*}{ 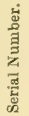 } & \multirow{2}{*}{$\begin{array}{l}\text { Date. } \\
1899 .\end{array}$} & \multicolumn{2}{|c|}{ Position. } & \multicolumn{2}{|c|}{$\begin{array}{l}\text { Temper- } \\
\text { atures. }\end{array}$} & \multirow{2}{*}{ 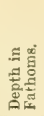 } & \multirow{2}{*}{$\begin{array}{l}\text { Nature } \\
\text { of } \\
\text { Bottom. }\end{array}$} & \multirow{2}{*}{ Remarks. } \\
\hline & & $\begin{array}{l}\text { Latitude } \\
\text { South. }\end{array}$ & $\begin{array}{l}\text { Longitude } \\
\text { West. }\end{array}$ & $\begin{array}{l}\text { Sur- } \\
\text { face. }\end{array}$ & $\begin{array}{l}\text { Bot- } \\
\text { tom. }\end{array}$ & & & \\
\hline
\end{tabular}

Ranglroa to Tikahau and to Matafiva.

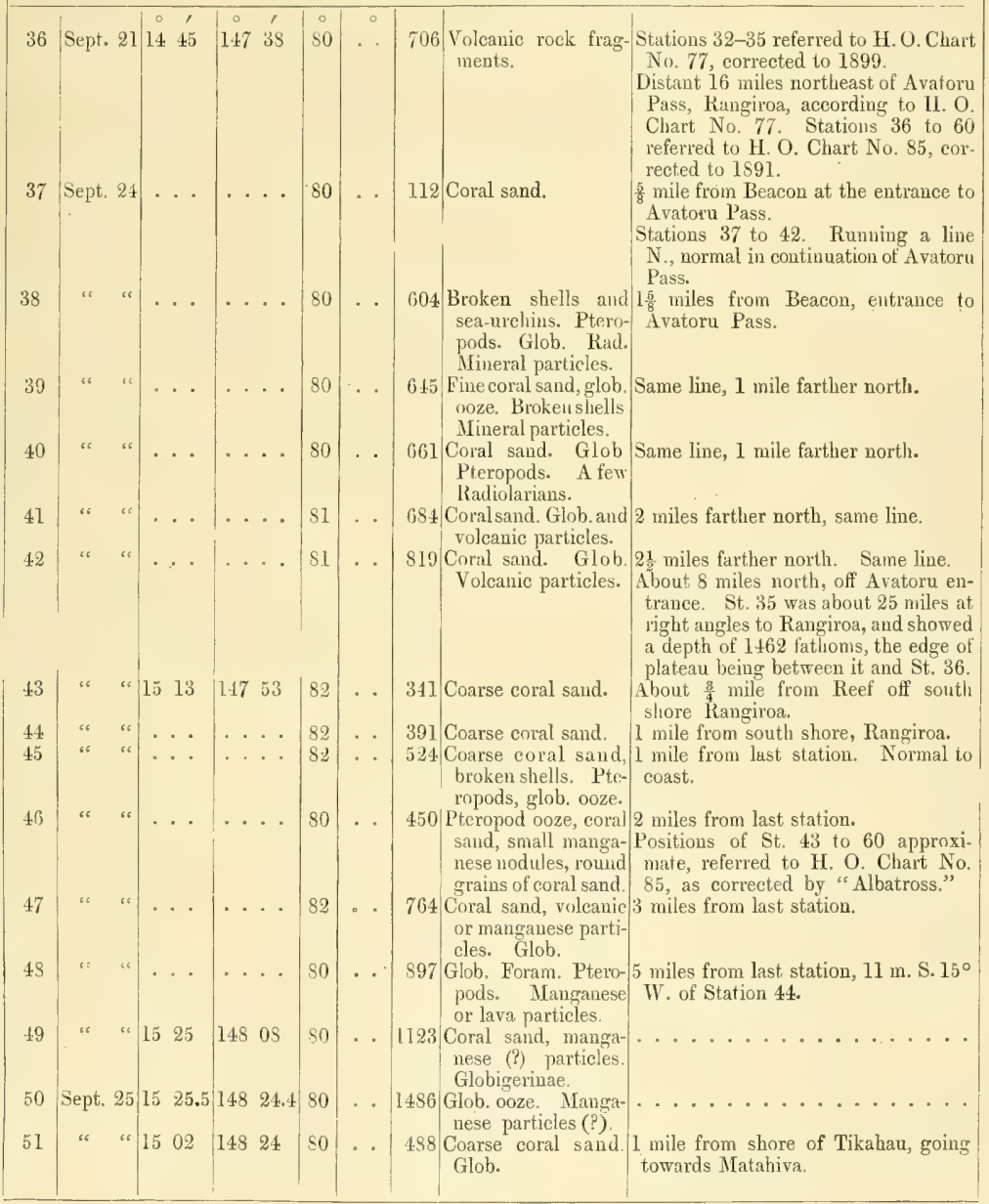




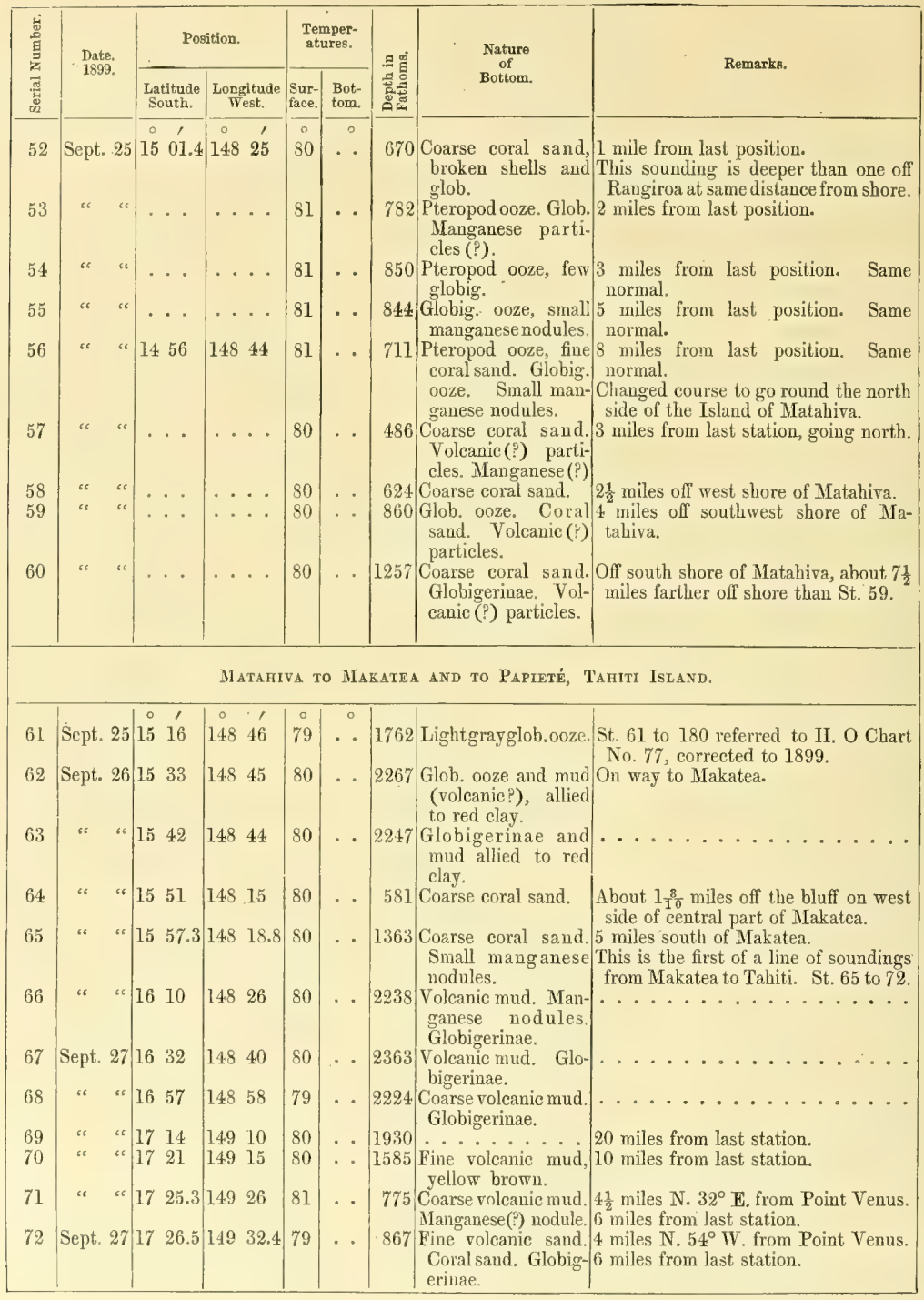




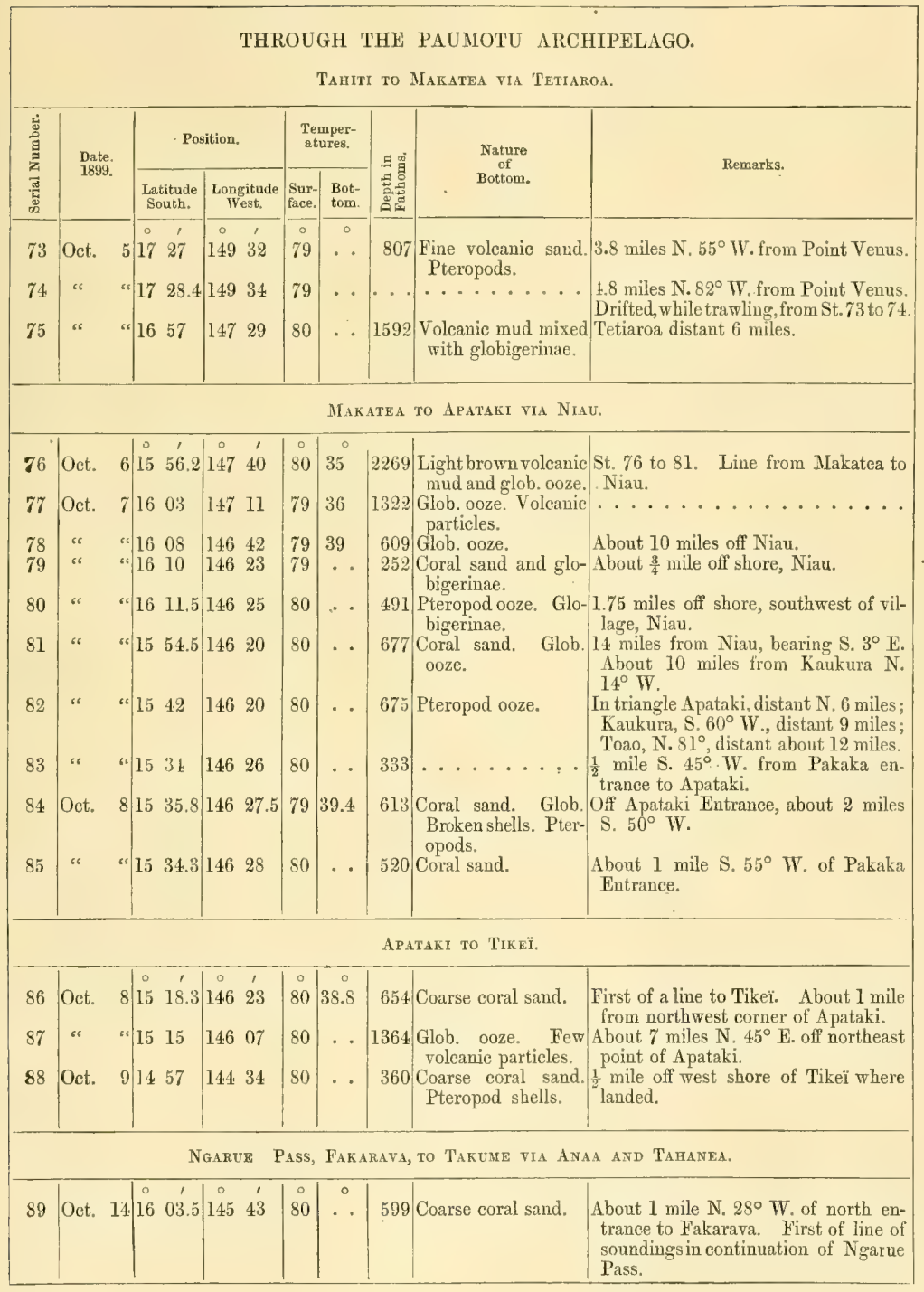




\begin{tabular}{|c|c|c|c|c|c|c|c|c|c|}
\hline \multirow{2}{*}{ 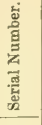 } & \multirow{2}{*}{\multicolumn{2}{|c|}{$\begin{array}{l}\text { Date, } \\
\text { 1899. }\end{array}$}} & \multicolumn{2}{|c|}{ Position. } & \multicolumn{2}{|c|}{$\begin{array}{l}\text { Temper- } \\
\text { atures. }\end{array}$} & \multirow{2}{*}{ 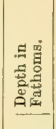 } & \multirow{2}{*}{$\begin{array}{l}\text { Nature } \\
\text { of } \\
\text { Bottom. }\end{array}$} & \multirow{2}{*}{ Remarks. } \\
\hline & & & $\begin{array}{l}\text { Latitude } \\
\text { South. }\end{array}$ & $\begin{array}{c}\text { Longitude } \\
\text { West. }\end{array}$ & $\begin{array}{l}\text { Sur- } \\
\text { face. }\end{array}$ & $\begin{array}{l}\text { Bot- } \\
\text { tom. }\end{array}$ & & & \\
\hline 90 & Oct. & 14 & 160 & 145 $\quad \begin{array}{c}0 \\
\mathbf{1} 3.5\end{array}$ & 80 & $\stackrel{\circ}{\circ}$ & 666 & $\begin{array}{l}\text { Coarse coral sand. } \\
\text { Pteropods. }\end{array}$ & $\begin{array}{l}\text { About } 3 \text { miles farther north than last } \\
\text { station, } 3 \frac{1}{2} \text { miles } \mathrm{N} .35^{\circ} \mathrm{W} \text {. from } \\
\text { Ngarue Pass. }\end{array}$ \\
\hline 91 & "6 & “ & 1638 & 14531 & 80 & . & 602 & $\begin{array}{l}\text { Coarse coral sand. } \\
\text { Pteropod ooze. }\end{array}$ & $\begin{array}{l}\text { About } 2 \text { miles due S.W. from soutl- } \\
\text { west Point of Fakarava. }\end{array}$ \\
\hline 92 & s6 & " & 1644 & 14535 & 80 & .. & 839 & $\begin{array}{l}\text { Coral coated with } \\
\text { manganese. }\end{array}$ & $\frac{5}{6}$ mile farther than Station 91 \\
\hline 93 & “6 & - sc & 1651 & $145 \quad 42$ & 80 & 35.7 & 1300 & Glob. ooze. & $\begin{array}{l}10 \text { miles farther than } 92 . \text { Line to } \\
\text { Anaa at first } 40 \text { miles to S.W., then } \\
30 \text { miles to morth side of Anaa. }\end{array}$ \\
\hline 94 & 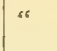 & “ & 1657 & $145 \quad 49$ & 79 & . & 1531 & $\begin{array}{l}\text { Fine volcanic mud } \\
\text { and globigerinae. }\end{array}$ & 10 miles from Station 93 \\
\hline 95 & Oct. & 15 & 1709 & 14600 & 78 & 36.10 & 1079 & Glob. ooze. & $\begin{array}{l}\text { Changed course towards Anaa at this } \\
\text { station. }\end{array}$ \\
\hline 96 & " & “ & 1714.5 & $145 \quad 49$ & 77 & 39.7 & 527 & $\begin{array}{c}\text { Coral frgts. covered } \\
\text { with manganese. }\end{array}$ & $\cdots \cdots \cdots \cdots$ \\
\hline 97 & "c & " & 1717 & $145 \quad 45.5$ & 79 & . & 804 & $\begin{array}{l}\text { Globig. ooze and } \\
\text { many very small } \\
\text { manganese nodules. }\end{array}$ & 6 miles from Station 96 \\
\hline 98 & 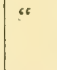 & $\because$ & 1721 & $145 \quad 41$ & 79 & . & 642 & $\begin{array}{l}\text { Pteropod ooze. Man- } \\
\text { ganese nodules on } \\
\text { coral sand. }\end{array}$ & Off Anaa, 6 miles from Station 97. \\
\hline 99. & $" 6$ & " & 1722 & $145 \quad 37$ & 79 & 39 & 568 & $\begin{array}{l}\text { Manganese nodules. } \\
\text { Coarse coral sand. }\end{array}$ & $\begin{array}{l}\text { About } 1 \frac{8}{10} \text { miles off northwest face of } \\
\text { Anaa. }\end{array}$ \\
\hline 100 & "6 & " & 1720 & 14531 & 80 & . & 225 & Coral sand. & $\begin{array}{l}\text { About } 1 \text { mile to edge of reef off vil- } \\
\text { lage at entrance to lagoon of Anaa. }\end{array}$ \\
\hline 101 & " & “ & 1716 & $145 \quad 27$ & 80 & 36 & 1110 & $\begin{array}{l}\text { Pteropod ooze. Fine } \\
\text { coral sand. Man- } \\
\text { ganese nodules. }\end{array}$ & $\begin{array}{l}\text { About } 5 \text { miles N. } 50^{\circ} \mathbf{E} \text {. off Anaa Lin- } \\
\text { trance, This is first of a line of } \\
\text { soundings across to Taluanea. St. } \\
101 \text { to } 106 \text {. }\end{array}$ \\
\hline 102 & " & “ & 1710 & $145 \quad 19$ & 82 & 36 & 1679 & $\begin{array}{l}\text { Light yellowish brom } \\
\text { globig. ooze. }\end{array}$ & $\cdots \cdots \cdots \cdots \cdots$ \\
\hline 103 & " & " & 1703 & $145 \quad 08.5$ & 82 & 35.1 & 1733 & White glob. ooze. & 15 miles from Station 102. \\
\hline 104 & " & “ & 1655 & $145 \quad 03$ & 81 & . & 966 & $\begin{array}{l}\text { White glob. ooze. } \\
\text { Few manganese } \\
\text { nod. grains. }\end{array}$ & $\begin{array}{l}\text { About } 10 \text { miles from Station } 103,4 \\
\text { miles W.S.W. from southwest point of } \\
\text { T'ahanea. }\end{array}$ \\
\hline 105 & “ & “ & 1653 & 14500 & 80 & 38.6 & 654 & $\begin{array}{l}\text { Very small manganese } \\
\text { nodules. Coral sand. }\end{array}$ & $\begin{array}{l}\text { Abont } 2 \text { miles } W \text {. of southwest point } \\
\text { of Tahanea. }\end{array}$ \\
\hline 106 & Oet. & 16 & 1655 & 14456 & 80 & . & 269 & Coarse coral sand. & $\begin{array}{l}\text { About } \frac{1}{2} \text { mile off sonth shore of Taha- } \\
\text { nea and about } 3 \text { miles S. } 45^{\circ} \mathrm{W} \text {. of } \\
\text { southwest point of Tahanea. }\end{array}$ \\
\hline 107 & “ & “ & 1624 & 14359 & 80 & . & 467 & White coral sand. & $\begin{array}{l}1 \text { mile N.W. of northwest Pass of } \\
\text { Makemo on angular line to Raroia. }\end{array}$ \\
\hline 108 & “ & “ & 1620 & 14355 & 80 & . & 856 & $\begin{array}{l}\text { Pteropod ooze. Fine } \\
\text { coral sand. Light } \\
\text { yellow gray glob. } \\
\text { Few volcanic par- } \\
\text { ticles (?). }\end{array}$ & $\begin{array}{l}4 \text { miles } \mathrm{N} \text {. of nortluwest end of } \mathrm{Ma} \text { - } \\
\text { kemo. }\end{array}$ \\
\hline 109 & s" & & 1613 & $143 \quad 48$ & 80 & . & 987 & $\begin{array}{l}\text { Pteropod ooze. Glob. } \\
\text { Volcanic particles(?). }\end{array}$ & 10 miles north of Station 108. \\
\hline 110 & " & $"$ & 1603 & $143 \quad 32.5$ & 80 & 36.3 & 1084 & Light jellow gray & 15 miles north of Station 109. \\
\hline 111 & Oct. & 17 & 1553 & 14326 & 80 & 35 & 1805 & $\begin{array}{l}\text { Light yellow gray } \\
\text { glob. ooze. }\end{array}$ & $\begin{array}{l}\text { At next station on line to Raroia } \\
\text { changed direction at Station } 111 \text {. }\end{array}$ \\
\hline 112 & ss & “ & $15 \quad 54$ & 14306 & 80 & 35.4 & 1568 & $\begin{array}{l}\text { Glob. ooze. Light } \\
\text { yellow. Manganese. }\end{array}$ & 20 miles from St. 111. \\
\hline
\end{tabular}




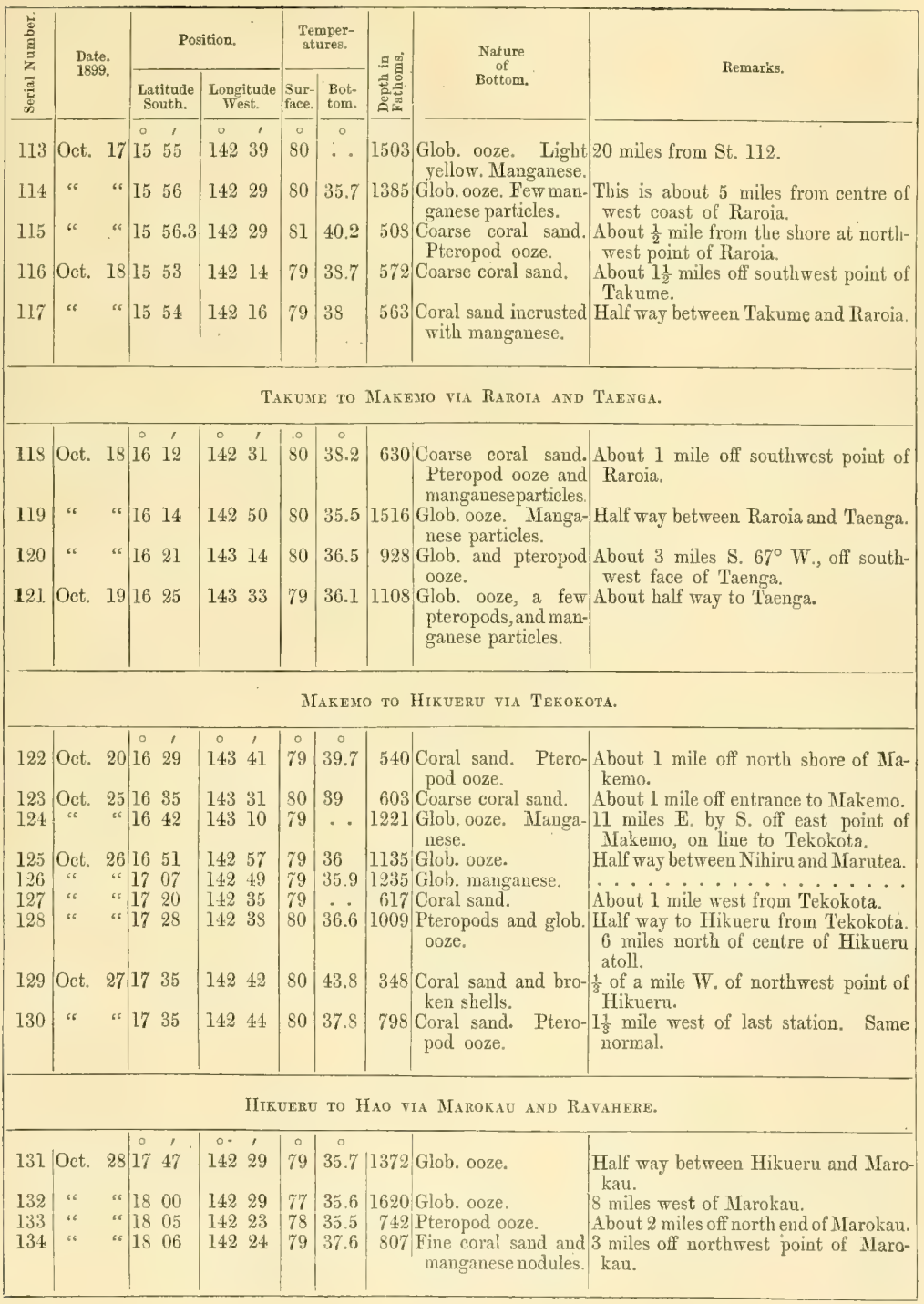




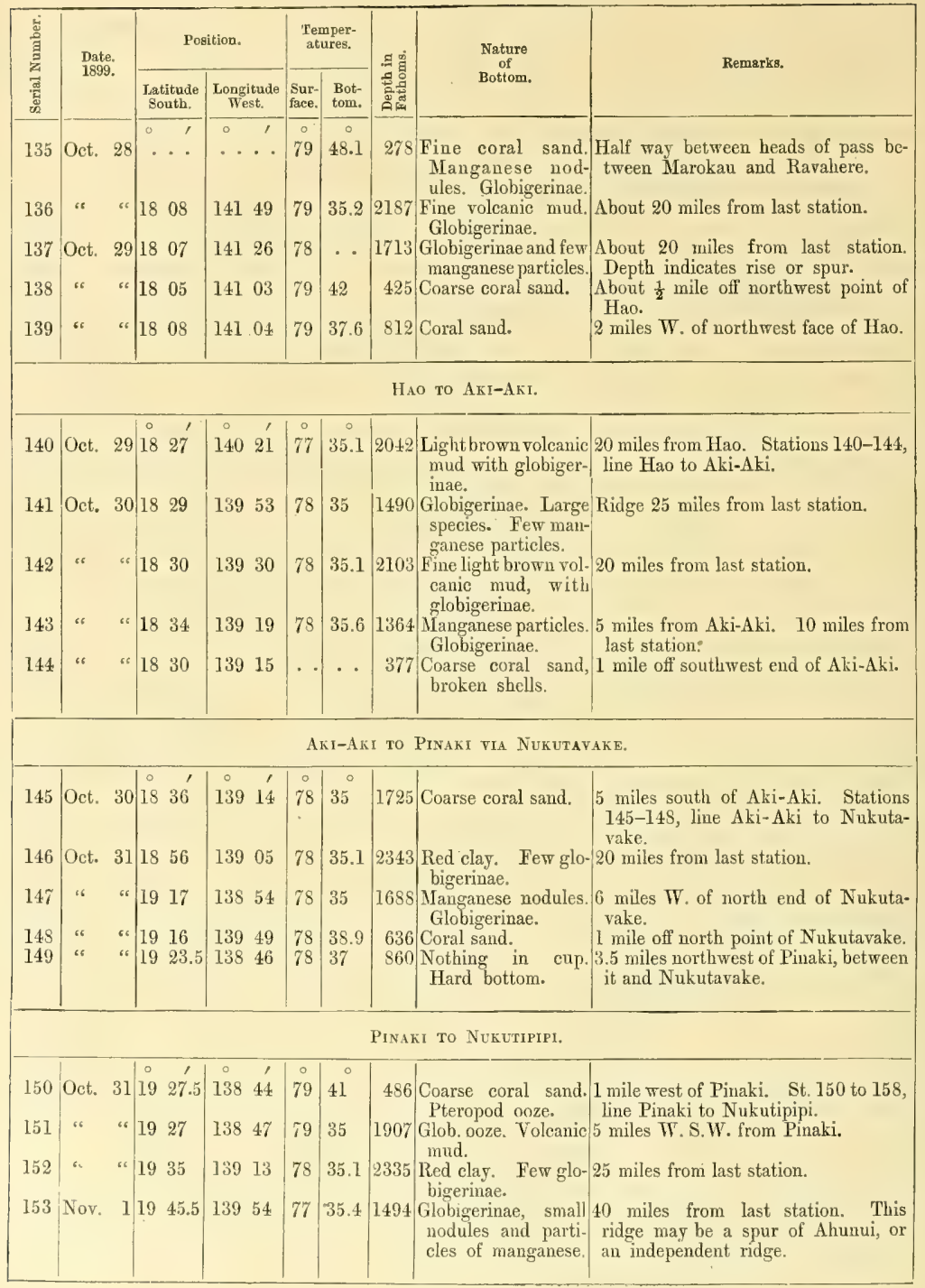




\begin{tabular}{|c|c|c|c|c|c|c|c|c|c|}
\hline \multirow{2}{*}{ 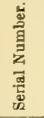 } & \multirow{2}{*}{$\begin{array}{l}\text { Date, } \\
\text { 1899. }\end{array}$} & \multicolumn{3}{|c|}{ Position. } & \multicolumn{2}{|c|}{$\begin{array}{l}\text { Temper- } \\
\text { atures. }\end{array}$} & \multirow{2}{*}{ 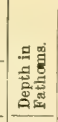 } & \multirow{2}{*}{$\begin{array}{l}\text { Nature } \\
\text { of } \\
\text { Bottom. }\end{array}$} & \multirow{2}{*}{ Remarks. } \\
\hline & & \multicolumn{2}{|r|}{$\begin{array}{l}\text { Latitude } \\
\text { South, }\end{array}$} & $\begin{array}{c}\text { Longitude } \\
\text { West. }\end{array}$ & $\begin{array}{l}\text { Sur- } \\
\text { face. }\end{array}$ & $\begin{array}{c}\text { Bot- } \\
\text { tom. }\end{array}$ & & & \\
\hline & & & $\circ$ & 1 & 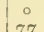 & 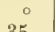 & & & \\
\hline $\begin{array}{l}154 \\
155\end{array}$ & Nov. & $\frac{1}{4}$ & $\begin{array}{ll}9 & 52 \\
0 & 07\end{array}$ & $\begin{array}{ll}140 & 16 \\
141 & 00\end{array}$ & $\begin{array}{l}77 \\
78\end{array}$ & $\begin{array}{l}35 \\
35\end{array}$ & $\begin{array}{l}2284 \\
2391\end{array}$ & $\begin{array}{l}\text { Red clay. } \\
\text { Manganese particles. }\end{array}$ & $\begin{array}{l}20 \text { miles from last station. } \\
40 \text { miles from last station. }\end{array}$ \\
\hline 756 & $\mathrm{Nat}$ & & & & 77 & 35 & & Red clay. & 60 \\
\hline 100 & lvov. & 220 & 031 & $1 \pm 200$ & 17 & ग5 & 2108 & $\begin{array}{l}\text { fed clay. No or- } \\
\text { gauic remains. }\end{array}$ & b0 miles from last station. \\
\hline 157 & "6 & & 046.5 & 14251 & 78 & 35 & 2315 & Red clay and num- & About 5 miles southeast from Nuku- \\
\hline 158 & ‘6 & " 20 & 043 & $143 \quad 0.5$ & 77 & 39 & 649 & $\begin{array}{l}\text { Coral sand. Broken } \\
\text { shells, Pteropods. }\end{array}$ & About 1 mile southeast of Nukutipipi. \\
\hline \multicolumn{5}{|c|}{ NUKUTIPIPI To } & \multicolumn{3}{|c|}{ HERERERETUE } & via ANu-ANur & AND ANU-ANURARO. \\
\hline & & & & & $\circ$ & $\circ$ & & & \multirow{4}{*}{$\begin{array}{l}1 \text { mile W.N.W. on course of Nuku- } \\
\text { s, tipipi to Anu-Anurunga. } \\
\text { s. } \\
\text { walf way to Anu-Anurunga. Sound- } \\
\text { - Hing indicates a low ridge connecting } \\
\text { the islands of the Gloucester group. } \\
\text { d I mile off east side of Anu-Anurunga. } \\
\text { d- }\end{array}$} \\
\hline 159 & Nov. & 220 & 2042 & 14303 & 77 & . & 736 & $\begin{array}{l}\text { Coral sand, ptero- } \\
\text { pods, broken shells, } \\
\text { manganese particles. }\end{array}$ & \\
\hline 160 & “ & & 2040 & 14309 & 78 & 35.5 & 1609 & $\begin{array}{l}\text { Coral sand. Few } \\
\text { globigerinae. Man- } \\
\text { ganese narticles. }\end{array}$ & \\
\hline 161 & ‘s & $" 20$ & 2037 & 14315 & 78 & 39 & 574 & $\begin{array}{l}\text { Pteropod ooze. } \\
\text { Coarse coral sand } \\
\text { and manganese par- } \\
\text { ticles. }\end{array}$ & \\
\hline 162 & "6 & & 037 & 14318 & is & 38.5 & 659 & $\begin{array}{l}\text { Coral sand, ptero- } \\
\text { pods, and broken } \\
\text { shells. }\end{array}$ & $\begin{array}{l}\text { One mile northwest of Anu-Anurunga, } \\
\text { on line to Anu-Anuraro. }\end{array}$ \\
\hline 163 & " & $" 20$ & & 14323 & 78 & 35.2 & 1890 & $\begin{array}{l}\text { Light gray glob. } \\
\text { ooze. Small and } \\
\text { large globigerinae. }\end{array}$ & $\begin{array}{l}\text { Half way to Anu-Anuraro from Anu } \\
\text { Anurunga. }\end{array}$ \\
\hline 164 & " & & 0029 & $143 \cdot 29$ & 78 & 40.7 & 438 & Coral sand. & $\frac{8}{4}$ of mile from shore off southeast side \\
\hline 165 & "6 & $" 20$ & 027 & 14332 & 77 & 42.5 & 406 & $\begin{array}{l}\text { Coral sand. Ptero- } \\
\text { pods. Small man- } \\
\text { ganese nodules. }\end{array}$ & $\begin{array}{l}\frac{1}{2} \text { mile northwest of Anu-Anuraro } \\
\text { St. } 165 \text { to } 168 \text {, line Anu-Anuraro to } \\
\text { Hereheretue. }\end{array}$ \\
\hline 160 & "6 & & 2015 & 14400 & 77 & 34.8 & 2265 & $\begin{array}{l}\text { Red clay. Globig- } \\
\text { erinae. Manganese. }\end{array}$ & 26 miles from last station. \\
\hline 167 & Nov. & 320 & 2002 & 14428 & 78 & 34.9 & 2524 & $\begin{array}{l}\text { Very soft red clay. } \\
\text { Few globigerinae. }\end{array}$ & $\begin{array}{l}3 \text { miles from last station. Continue to } \\
\text { find manganese particles and small } \\
\text { nodules at nearly every sounding. }\end{array}$ \\
\hline 168 & "6 & "19 & 954 & 14449 & 77 & 35 & 1719 & Globigerina ooze. & 6 miles from last station. East of \\
\hline 169 & " & " 19 & 954 & 14453 & 78 & 39.5 & 594 & Coarse coral sand. & 1 mile off the east coast of Hereheretue. \\
\hline \multicolumn{10}{|c|}{ Hereheretue to Tahiti via Mehetia. } \\
\hline 170 & Nov. & $3 \mid 19$ & 954 & 144. 59 & 78 & $\begin{array}{c}\circ \\
62.1\end{array}$ & 189 & $\begin{array}{l}\text { Coral sand. Manga- } \\
\text { nese particles. }\end{array}$ & $\begin{array}{l}\frac{8}{10} \text { mile from edge of reef on west side } \\
\text { of Hereheretue. St. } 170 \text { to } 176 \text {, lime } \\
\text { Hereheretue to Mehetia. }\end{array}$ \\
\hline 171 & " & & 950 & 14503 & 78 & 35.3 & 1688 & $\begin{array}{l}\text { Light gray glob. } \\
\text { ooze. Manganese } \\
\text { particles. }\end{array}$ & 5.3 miles northwest of Hereheretue. \\
\hline 172 & “ & 19 & 922 & $145 \quad 47$ & 77 & 35 & 2322 & $\begin{array}{l}\text { Red elay with glo- } \\
\text { bigerinae. }\end{array}$ & 50 miles from last station. \\
\hline
\end{tabular}




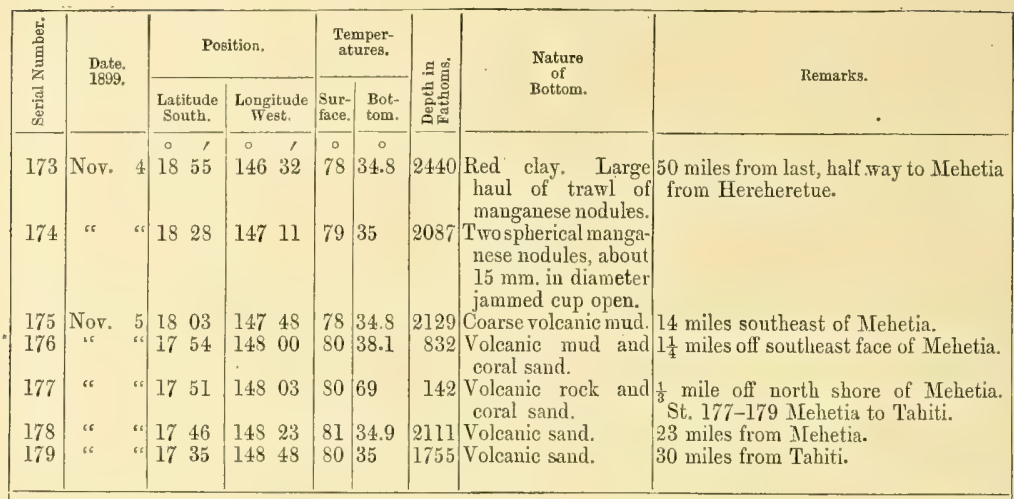

SOCIETY ISLANDS TO TONGATÁBU, TONGA ARCHIPELAGO, VIA LEEWARD SOCIETY ISLANDS, THE COOK GROUP, AND NIUE ISLAND,

From Tahiti to Leetrard Soctety Islands.

\begin{tabular}{l|l|cc|cc|c|c|c|c|c}
\hline 180 & Nov. 15 & 17 & 30 & 149 & 41 & 79 & 36.7 & 981 & $\begin{array}{c}\text { Volcanic sand. Pter- } \\
\text { opod ooze. }\end{array}$ & $\begin{array}{l}\text { About half way to Murea from Papieté. } \\
5 \text { miles from the northeast point of } \\
\text { Yurea. }\end{array}$ \\
\hline
\end{tabular}

From Aitutaki to Nive.

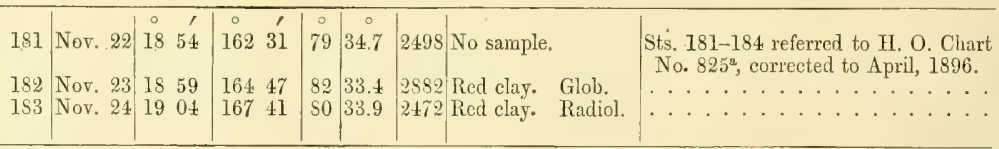

From Nive to Eua (Tonga).

\begin{tabular}{|c|c|c|c|c|c|c|c|c|}
\hline & & 7 & & 0 & 。 & & & \\
\hline 181 & Nov. 26 & 2015 & 17200 & So & 34 & 3141 & Red clay. & \\
\hline 85 & Nov. 27 & 2118 & 17331 & . & $\cdots$ & 4173 & $\begin{array}{l}\text { Light brown volcanic } \\
\text { mud. Radiol. }\end{array}$ & $\begin{array}{l}\text { Near } 4762 \text { fms. hole, siliceous sponges } \\
\text { in trawl, Deepest haul of trawl yet } \\
\text { made. Lost thermo. }\end{array}$ \\
\hline 6 & & 2118 & 17351 & 77 & 34.15 & 4540 & $\begin{array}{l}\text { Light brown volcanic } \\
\text { mud. Radiol. }\end{array}$ & $\ldots \ldots \ldots$ \\
\hline
\end{tabular}

\section{VAVAU TO FIJI.}

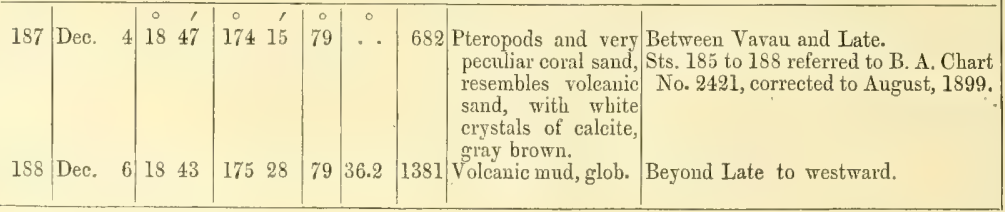




\begin{tabular}{|c|c|c|c|c|c|c|c|c|}
\hline \multirow{2}{*}{ 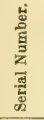 } & \multirow{2}{*}{$\begin{array}{c}\text { Date, } \\
\text { 1899-1900. }\end{array}$} & \multicolumn{2}{|c|}{ Position. } & \multicolumn{2}{|c|}{$\begin{array}{l}\text { Temper- } \\
\text { a.tures. }\end{array}$} & \multirow{2}{*}{ 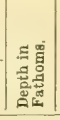 } & \multirow{2}{*}{$\begin{array}{l}\text { Nature } \\
\text { of } \\
\text { Bottom. }\end{array}$} & \multirow{2}{*}{ Remarks. } \\
\hline & & $\begin{array}{c}\text { Latitude } \\
\text { South. }\end{array}$ & $\begin{array}{c}\text { Longitude } \\
\text { West. }\end{array}$ & $\begin{array}{l}\text { Sur- } \\
\text { face. }\end{array} \mid$ & $\begin{array}{l}\text { Bot- } \\
\text { tom. }\end{array}$ & & & \\
\hline \multicolumn{9}{|c|}{ IN FiJi ARCHIPELAgo. } \\
\hline 189 & Dec. 7 & $\begin{array}{cc}\circ & 1 \\
18 & 50\end{array}$ & $\mid \begin{array}{cc}\circ & 1 \\
178 & 28\end{array}$ & $\begin{array}{c}\circ \\
79\end{array}$ & $\left|\begin{array}{c}\circ \\
42.9\end{array}\right|$ & 453 & $\begin{array}{l}\text { Fine coral sand. Pter- } \\
\text { opod ooze. Few } \\
\text { glob. }\end{array}$ & $\begin{array}{l}\text { About in centre of passage between } \\
\text { Yangasá-MIothe. Southernextension } \\
\text { of eastern Fiji plateau. }\end{array}$ \\
\hline 190 & "c & 1854 & $178 \quad 35$ & 79 & 47 & 324 & $\begin{array}{l}\text { Coral sand Colored } \\
\text { in part by manga- } \\
\text { nese. }\end{array}$ & $\begin{array}{l}\text { Between Nanuka and Yangasá. } \\
\text { Sts. 189-193 referred to B. A. Chart } \\
\text { No. 2691, correctèd to Dec., } 1897 \text {. }\end{array}$ \\
\hline 191 & 66 & 1856 & $178 \quad 43$ & 79 & 39.3 & 600 & $\begin{array}{l}\text { Pteropodooze. Frag- } \\
\text { ments of pumice. } \\
\text { Fine coral sand, } \\
\text { glob. }\end{array}$ & $\begin{array}{l}6 \text { miles S. } 23^{\circ} \text { W. from west end of } \\
\text { Namuka. Between Namuka and } \\
\text { Marambo. }\end{array}$ \\
\hline 192 & « & 1856 & 17850 & 79 & 42.4 & 450 & $\begin{array}{l}\text { Coral sand. Ptero- } \\
\text { pods. Mangamese, } \\
\text { glob. }\end{array}$ & $\begin{array}{l}2.7 \text { miles } \mathrm{N} .19^{\circ} \mathrm{W} \text {. from Marambo. } \\
\mathrm{Iu}_{\mathrm{u}} \text { centre of triangle Marambo, } \\
\text { Kambara, Wangava, about } 5 \text { miles } \\
\text { distant. }\end{array}$ \\
\hline 193 & Dec. 9 & $18 \quad 56.5$ & 17916 & 80 & 37 & 990 & $\begin{array}{l}\text { Very fine light yellow } \\
\text { brown coral ooze. }\end{array}$ & $\begin{array}{l}\text { About } 15 \text { miles west of Kambara, on } \\
\text { way to Totoya. }\end{array}$ \\
\hline \multicolumn{8}{|c|}{$\begin{array}{l}\text { FIJI THROUGH ELLICE AND GILBERT ISLANDS } \\
\text { ARCHIPELAGO. }\end{array}$} & S TO JAI \\
\hline 194 & Dec. 21 & $\begin{array}{cc}0 & 1 \\
12 & 43\end{array}$ & \begin{tabular}{cc|}
$\circ$ & $\prime$ \\
179 & 50 \\
Longitude \\
East.
\end{tabular} & $\stackrel{\circ}{85}$ & $\left|\begin{array}{c}\circ \\
35.6\end{array}\right|$ & 1445 & $\begin{array}{l}\text { Light yellow brown } \\
\text { glob. ooze. }\end{array}$ & H. O. Chart No. 825 , cor. April, 1895. \\
\hline 195 & $\begin{array}{c}\text { Dec. } 22 \\
1900 .\end{array}$ & 1047 & 17930 & . & . & 245 & Coral sand, rocky. & $\begin{array}{l}\text { Tanner machine. } \frac{1}{2} \text { mile south, off } \\
\text { Nurakita. B. A. Chart No. 1830, } \\
\text { corr. March, 1898. }\end{array}$ \\
\hline 196 & Jan, 1 & $\begin{array}{c}018 \\
\text { Latitude } \\
\text { North. }\end{array}$ & 17354 & . . & . . & 170 & Hard bottom. & $\begin{array}{l}\text { mile south of village off south side of } \\
\text { Apamana. Sts. 196-207 H. O. Chart } \\
\text { No. 119, corr. May, 1999. }\end{array}$ \\
\hline 197 & Jan. 2 & 030 & 17335 & 83 & 35 & 2221 & $\begin{array}{l}\text { Light yellowgrayglob. } \\
\text { ooze. Struck glo- } \\
\text { bigerinae of Equat. } \\
\text { Current (obtained } \\
\text { before in Paumotus) }\end{array}$ & $\begin{array}{l}\text { On way Apamama-Maiaua. About } 16 \\
\text { miles from northwest end of Apa- } \\
\text { mama. }\end{array}$ \\
\hline 198 & & 046 & 17309 & 84 & 35.6 & 1365 & $\begin{array}{l}\text { Yellow gray glob. } \\
\text { ooze. Very coarse } \\
\text { large species. }\end{array}$ & About 9 miles southeast of Maiana. \\
\hline 199 & & 112 & 17305 & 84 & 43.5 & 413 & $\begin{array}{l}\text { Same coarse large } \\
\text { glob. ooze as before. }\end{array}$ & $\begin{array}{l}\text { Halfway to Tarawa from Maiana. Un- } \\
\text { known summit. }\end{array}$ \\
\hline 200 & & $1-20$ & 17303 & - & . & 95 & $\begin{array}{l}\text { Broken shells. Coral } \\
\text { sand. }\end{array}$ & $\begin{array}{l}\text { About } \frac{1}{2} \text { mile from centre of south } \\
\text { shore of Tarawa. Tanner sounding } \\
\text { machine. }\end{array}$ \\
\hline 201 & $" 6$ & 120 & 17304 & . & . & 200 & $\cdots \cdots \cdots$ & $\begin{array}{l}\text { About } 1 \text { mile E. of last station, off south } \\
\text { shore of Tarawa. Tamer sounding } \\
\text { machine. }\end{array}$ \\
\hline 202 & Jan. 3 & 117 & 17309 & 84 & 35.3 & 1569 & $\begin{array}{l}\text { Coarse large globig- } \\
\text { erinae. Same as } \\
\text { before. }\end{array}$ & $\begin{array}{l}\text { About } 5 \text { miles S. } 12^{\circ} \text { E. of southeast } \\
\text { point of Tarawa. Shoal said to ex- } \\
\text { tend there. Evidently no plateau; } \\
\text { may be a ridge, connecting the islands } \\
\text { Maiana, Tarawa, and Apaiang. }\end{array}$ \\
\hline
\end{tabular}




\begin{tabular}{|c|c|c|c|c|c|c|c|c|c|}
\hline \multirow{2}{*}{ 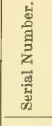 } & \multirow{2}{*}{\multicolumn{2}{|c|}{$\begin{array}{l}\text { Date. } \\
1900 .\end{array}$}} & \multicolumn{2}{|c|}{ Position. } & \multicolumn{2}{|c|}{$\begin{array}{l}\text { Temper- } \\
\text { atures. }\end{array}$} & \multirow{2}{*}{ 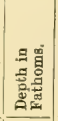 } & \multirow{2}{*}{$\begin{array}{c}\text { Nature } \\
\text { of } \\
\text { Bottom. }\end{array}$} & \multirow{2}{*}{ Remarks. } \\
\hline & & & $\begin{array}{l}\text { Latitude } \\
\text { North. }\end{array}$ & $\begin{array}{c}\text { Longitude } \\
\text { East. }\end{array}$ & & \begin{tabular}{|l} 
Bot- \\
tom.
\end{tabular} & & & \\
\hline 203 & Jan. & 4 & 140.5 & 17259.5 & 政 & . & 170 & $\cdots \ldots \ldots$ & \multirow{4}{*}{$\begin{array}{l}\text { About } 2 \text { miles from southeast point of } \\
\text { Apaiang, between Apaiaug and north } \\
\text { point of Tarawa. Tanner sounding } \\
\text { machine. } \\
15 \text { miles from Apaiang, on way to } \\
\text { southeast point of Maraki, about } \\
\text { half way. } \\
\text { About } \frac{1}{2} \text { mile off shore off west coast } \\
\text { of Maraki, N.W.-by-W. from monu- } \\
\text { ment. } \\
\text { About } 26 \text { miles N.W.-by-N. of Maraki. } \\
\text { About } 16 \text { miles scutheast from centre } \\
\text { of south shore of Taritari. }\end{array}$} \\
\hline 204 & Jan. & 4 & 152 & 17315 & 84 & 34.9 & 2156 & $\begin{array}{l}\text { Light gray glob. } \\
\text { ooze. Sumall spe- } \\
\text { cies. }\end{array}$ & \\
\hline 205 & \multirow{2}{*}{\multicolumn{2}{|c|}{ " }} & 204 & 17316 & \multicolumn{2}{|l|}{86} & \multirow{2}{*}{\begin{tabular}{|c|c|}
431 \\
\\
2255 \\
3 & 1461 \\
\end{tabular}} & $\begin{array}{l}\text { Coral sand and glo. } \\
\text { bigerinae. }\end{array}$ & \\
\hline $\begin{array}{l}206 \\
207\end{array}$ & & & $\begin{array}{ll}2 & 27 \\
2 & 49\end{array}$ & $\begin{array}{ll}173 & 09 \\
173 & 01\end{array}$ & $\begin{array}{l}80 \\
83\end{array}$ & $\begin{array}{l}34.8 \\
35.3\end{array}$ & & $\begin{array}{l}\text { Glob. ooze. } \\
\text { Glob. ooze. Large } \\
\text { species. }\end{array}$ & \\
\hline \multicolumn{10}{|c|}{ From Taritari to Jaluit. } \\
\hline \multirow[t]{2}{*}{208} & \multirow{2}{*}{\multicolumn{2}{|c|}{ Jan. 7}} & \multirow[t]{2}{*}{$\begin{array}{ll}0 & 1 \\
3 & 57\end{array}$} & \multirow[t]{2}{*}{17000} & \multirow{2}{*}{\multicolumn{2}{|c|}{\begin{tabular}{l|l}
$\circ$ & \\
S3 & 34
\end{tabular}}} & & Light yellow glob. & - About 60 miles nor \\
\hline & & & & & & & & $\begin{array}{l}\text { ooze, coarse and } \\
\text { fine. }\end{array}$ & $\begin{array}{l}\text { tari. St. 208-239.B. A. Chart No. } \\
983 \text {, April, 1891. }\end{array}$ \\
\hline 209 & Jan. & 8 & 425 & 17113 & 83 & 34.7 & 2505 & Lightgrayglob. ooze, & A bout 130 miles northwest from Tari- \\
\hline 210 & " & & 454 & 17021 & 83 & 34.7 & & Light gray glob. ooze, & About 60 miles southeast from Jaluit. \\
\hline 211 & Jan. & 9 & 520 & 16943 & 83 & 34.8 & 2411 & $\begin{array}{l}\text { size. } \\
\text { Light yellow drab } \\
\text { glob. ooze. }\end{array}$ & About 30 miles $\mathrm{fr}$ \\
\hline 212 & " & & 544 & 16945 & 82 & 35 & 1937 & $\begin{array}{l}\text { Light gray glob. } \\
\text { ooze. }\end{array}$ & $\begin{array}{l}\text { About } 5 \text { miles } \mathrm{S} . \frac{1}{4} \mathrm{~W} \text {. from the south } \\
\text { point of Jaluit. }\end{array}$ \\
\hline & & & & $\mathrm{T}$ & & &  & & \\
\hline & & & 01 & & 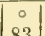 & & & & \\
\hline $\begin{array}{ll}213 \\
214\end{array}$ & $\begin{array}{l}\text { Jan. } \\
\text { Jan. }\end{array}$ & 14 & $\begin{array}{ll}6 & 34 \\
7 & 00\end{array}$ & $\mid \begin{array}{ll}169 & 13 \\
169 & 01\end{array}$ & $\begin{array}{l}83 \\
82\end{array} \mid$ & $\begin{array}{l}35 \\
35\end{array}$ & 2613 & & About \\
\hline 215 & & & 708 & 16856 & 82 & 35.9 & 1283 & $\mathrm{Co}$ & E. of southeast \\
\hline 216 & “ & & 729 & 16832 & 82 & 36.5 & 1068 & Coral sand. & 6 miles northwest of west point Ai- \\
\hline 217 & “ & & 737 & $168 \quad 27$ & 82 & $\sigma_{0}$ & 906 & & Half way to $\mathrm{Na}$ \\
\hline 218 & & & & & 83 & 39.7 & 631 & & $\begin{array}{l}\text { About } 2 \text { miles south of south point of } \\
\text { Namu. }\end{array}$ \\
\hline 219 & Jan. & 1) & 802 & 16743 & 82 & 35 & 2179 & & rest of centre of Namu. \\
\hline & & & & 16737 & 82 & 35 & $|1897|$ & & $\begin{array}{l}\text { About } 12 \text { miles southwest of west } \\
\text { point of } \mathrm{K} \text { wajalong Island. }\end{array}$ \\
\hline 221 & Jan. & $18[1]$ & 1109 & 16646 & 80 & 43.4 & 400 & $\mathrm{Co}$ & $\frac{1}{2}$ mile south of Southeast pass of \\
\hline 222 & “ & $" 1$ & 1107.5 & 16646 & 80 & 39 & 827 & Coral sand. & $1 \frac{1}{2}$ miles south of Southeast pass of \\
\hline 223 & “ & +1 & 1049 & 16715 & 80 & 35 & & $\begin{array}{l}\text { Glob. and light brown } \\
\text { voleanic mud. Red } \\
\text { clav (?) }\end{array}$ & $\begin{array}{l}\text { About } 35 \text { miles southeast from South- } \\
\text { east pass of Rongelab. }\end{array}$ \\
\hline 224 & Jan. & 19 & 1030 & 16742 & $80 \mid$ & 35 & 2586 & $\begin{array}{l}\text { Globigerinae and } \\
\text { light brown voleanic } \\
\text { mud. Red clay (?) }\end{array}$ & $\begin{array}{l}\text { About } 35 \text { miles from last station } \\
\text { towards Likieb. }\end{array}$ \\
\hline
\end{tabular}




\begin{tabular}{|c|c|c|c|c|c|c|c|c|}
\hline \multirow{2}{*}{ 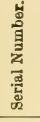 } & \multirow{2}{*}{$\begin{array}{l}\text { Date. } \\
1900 .\end{array}$} & \multicolumn{2}{|c|}{ Position. } & \multicolumn{2}{|c|}{$\begin{array}{l}\text { Temper- } \\
\text { atures. }\end{array}$} & \multirow{2}{*}{ 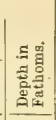 } & \multirow{2}{*}{$\begin{array}{l}\text { Nature } \\
\text { of } \\
\text { Bottom. }\end{array}$} & \multirow{2}{*}{ Remarks. } \\
\hline & & $\begin{array}{l}\text { Latitude } \\
\text { North. }\end{array}$ & $\begin{array}{l}\text { Longitude } \\
\text { East. }\end{array}$ & $\begin{array}{l}\text { Sur- } \\
\text { face. }\end{array}$ & $\begin{array}{l}\text { Bot- } \\
\text { tom. }\end{array}$ & & & \\
\hline 225 & Jan. 19 & $10 \quad 15$ & $168 \quad 0^{\prime}$ & $\stackrel{\circ}{81}$ & $\stackrel{\circ}{34.9}$ & 2609 & $\begin{array}{l}\text { Globigerinae and } \\
\text { light brown volcanic } \\
\text { mud. Red clay (?) }\end{array}$ & $\begin{array}{l}\text { About } 35 \text { miles from last station, on } \\
\text { way to Likieb. }\end{array}$ \\
\hline 226 & Jan. 20 & 955 & 16856 & 80 & 34.9 & 2231 & Glob. mud. & $\begin{array}{l}\text { About } 8 \text { miles W. S.W. of Kapenor } \\
\text { Island. West of north point of Li- } \\
\text { kieb. }\end{array}$ \\
\hline 227 & Jan, 2] & 948 & 16914 & 81 & 42.6 & 468 & Coarse coral sand. & $\frac{1}{2}$ mile south of South pass of Likieb. \\
\hline 228 & & 947 & 16914 & 81 & 36.9 & 934 & Coarse coral saud. & 11 mile south of South pass of Likieb. \\
\hline 229 & "6 & 940 & 16932 & 81 & 35.5 & 1583 & $\begin{array}{l}\text { Globigerinae. Very } \\
\text { fine species. }\end{array}$ & About half way Likieb to Worje. \\
\hline 230 & Jan. 23 & 919 & 17010 & 81 & 41.7 & 482 & Coral saud. & 1 mile south of Selischmarev Pass. \\
\hline 231 & & 917 & 17011 & 81 & 36.1 & 1187 & $\begin{array}{l}\text { Coarse coral sand. } \\
\text { Trace of manganese. }\end{array}$ & 2 miles south of last station. \\
\hline 232 & "s & 850 & 17026 & 81 & 34.9 & 2221 & $\begin{array}{l}\text { Wh. and gray glob. } \\
\text { ooze. }\end{array}$ & $\begin{array}{l}\text { About } 40 \text { miles south of last station, } \\
\text { hall way between south end of Erikub } \\
\text { and Maloelab. }\end{array}$ \\
\hline 233 & Jan. 24 & 754 & 17056 & 80 & 36.5 & 1009 & Coarse globigerinae. & $\because \cdots \cdots$ \\
\hline 234 & & 721 & 17135 & 81 & 36 & 1326 & Coarse globigerinae. & $\begin{array}{l}\text { About } 7 \text { miles } \mathrm{N}, 50^{\circ} \mathrm{W} \text {. from north- } \\
\text { west point of Arhno. }\end{array}$ \\
\hline 235 & Jan, 28 & 657 & 17134 & 82 & 36 & 1253 & $\begin{array}{l}\text { Cream colored coarse } \\
\text { globigerinae. }\end{array}$ & $\begin{array}{l}\text { About } 6 \text { miles southwest of south point } \\
\text { of Arhno. }\end{array}$ \\
\hline 236 & " & 634 & 17059 & 81 & 34.9 & 2482 & Globigerinae. & About 40 miles from last station. \\
\hline 237 & “ 29 & 611 & 17025 & 81 & 34.7 & 2486 & Fine glob. mud. & $\begin{array}{l}\text { About } 40 \text { miles from last station. } \\
\text { The same deep water we found on } \\
\text { coming north from the Gilberts, and } \\
\text { also all through the Marshalls and } \\
\text { between the islands both of the Ralick } \\
\text { and Ratack chain. }\end{array}$ \\
\hline
\end{tabular}

MARSHALL ISLANDS THROUGH THE CAROLINES TO GUAM, LADRONES ISLANDS, AND TO YOKOHAMA, JAPAN.

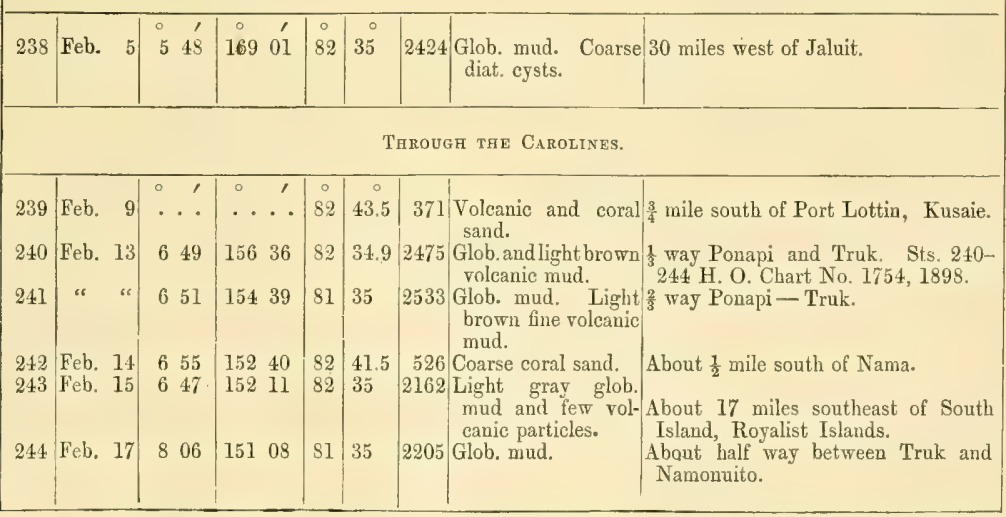




\begin{tabular}{|c|c|c|c|c|c|c|c|c|}
\hline \multirow{2}{*}{ 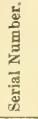 } & \multirow{2}{*}{$\begin{array}{l}\text { Date, } \\
1900 .\end{array}$} & \multicolumn{2}{|c|}{ Position. } & \multicolumn{2}{|c|}{$\begin{array}{l}\text { Temper- } \\
\text { atures. }\end{array}$} & \multirow{2}{*}{ 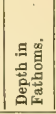 } & \multirow{2}{*}{$\begin{array}{l}\text { Nature } \\
\text { of } \\
\text { Bottom. }\end{array}$} & \multirow{2}{*}{ Remaxks. } \\
\hline & & $\begin{array}{l}\text { Latitude } \\
\text { North. }\end{array}$ & $\begin{array}{l}\text { Longitude } \\
\text { East. }\end{array}$ & $\begin{array}{c}\text { Sur- } \\
\text { face. }\end{array}$ & $\begin{array}{l}\text { Bot- } \\
\text { tom. }\end{array}$ & & & \\
\hline \multicolumn{9}{|c|}{ Namonuito to Guam. } \\
\hline & & $\begin{array}{l}0 \\
0\end{array}$ & $0 \quad 1$ & $\circ$ & 0 & & & \\
\hline 245 & Feb. 18 & $\begin{array}{rr}9 & 31\end{array}$ & $149 \quad 36$ & 81 & 35 & 2735 & Red clay. & 50 miles northwest from Magur islet. \\
\hline 246 & Feb. 19 & 1034 & $148 \quad 25$ & 81 & 35 & 2993 & $\begin{array}{l}\text { Red clay and small } \\
\text { particles of manga- } \\
\text { nese nodules. }\end{array}$ & $\begin{array}{l}200 \text { miles further towards Guam. Sts. } \\
245-249 \mathrm{H} \text {. O. Chart No. 529, corr. } \\
\text { June, } 1896 .\end{array}$ \\
\hline 247 & Feb. 20 & 1135 & 14715 & 80 & 35 & 3213 & $\begin{array}{l}\text { Manganese nodules. } \\
\text { Pumice. Red clay. }\end{array}$ & $\begin{array}{l}100 \text { miles furtler, same course, towards } \\
\text { Guam. }\end{array}$ \\
\hline 248 & "6 6 & 1251 & $145 \quad 46$ & 81 & 35.8 & 4813 & $\begin{array}{l}\text { Manganese. Pumice. } \\
\text { Volcanic particles. } \\
\text { disks of diatoms(?). }\end{array}$ & $\begin{array}{l}\text { Our deepest sounding. } 100 \text { miles fur- } \\
\text { ther, same course, towards Guam. } \\
\text { Thermometer could not have regis- } \\
\text { tered correctly. }\end{array}$ \\
\hline 249 & Feb. 21 & 1308 & $145 \quad 25$ & 80 & 35 & 2337 & Fine volcanic sand. & $\begin{array}{l}\text { About } 25 \text { miles further, same course, } \\
\text { distant } 45 \mathrm{~m} \text {. from north end of Guam. }\end{array}$ \\
\hline
\end{tabular}




\section{N D EX.}

Adam and Eve Point, 1

Agaña, 374

Agate, 373

Agate on sea wall of Rangiroa, 10

Agony Island, 310

Ahanga Passage, 199

Ai, 290

Ailinglap, 293

Bays of, 294

Entrance into, 293

Northeastern point of, 295

Shape of, 293

Slope of outer platform of, 294

Southwest shore of, 294

Trades at, 294

Vegetation of, 294

Wide reef flats of, 294

Aitutaki, 169

Barrier reef flats of, 169

Denudation and erosion of, 170

Islauds of barrier reef at, 170

Sand keys at, 170

Shape of, 169

Aiurua Pass, 145

Aiurua River, 145

Aki-Aki, 116

Beach rock at, 117

Boulders at, 117

Coralliferous limestone at, 116

Dimension of, 116

Vegetation of, 117

Width of reef tlat at, 117

Alakibeáu, 188

Aldrich Deep, 180, 332

Alexander Reef, 195

Alofi, 171

Alutung, 373

Alveopora, 106

Amatuku, 213

Anaa, 84

Buttresses of old ledge at, 85

Depth of lagoon of, 84

Lagoon flat of, 85

Lagoon of, filled by islets at, 85

Outcrops of old ledge at, 84,85
Anaa-Continued

Reflection from lagoon flat at, 85

Size of, 84

Anaho Bay, 4

Anau Bay, 163

Anaya, 373

Andema Islands, 350

Compared to volcanic islands, 350

Disintegration of, 350

Land rim of́, 350

Subsidence at, 350

Underlying base of, 350

Volcanic outliers at, 350

Andrews, C. W., 228

Andrews, E. C., 228

Anu-Anuraro, 130

Dimension of, 130

High coral shingle beach at, 130

Nullipore knolls at, 130

Old ledge at, 130

Sand dunes at, 131

Vegetation of, 130

Anu-Anurunga, 128

Depth of lagoon of, 129

Dimensions of, 128

Gaps of land rim of, 129

Submerged reef tlat of, 129

Aoga-sima, 365

Aorai, 149

Apaiang, 252

Boat passage into, 252

Color of Nullipores at, 253

Dimensions of, 252

Nullipore cement at, 252

Porites flats at, 253

Range of corals in, 252

Southeast face of, 252

A pamama, 240

Bays of, " 40

Coral shingle at, 241

Coral soil at, 244

Depth on reef shelf of, 243

Elevated limestones at, 242

Elevation of, 241

Gaps at, 240 
Apamama - Continued

Height of beaches at, 244

Mayer, Dr., on, 243

Moore, Dr., on, 243

Old gaps at, 241

Outliers of beach rock at, 244

Outline of, 240

Passes into, 240

Platform lagoons at, 240

Reef platforms of, 242

Sand dunes at, 242

Secondary lagoon at, 243

Vegetation of, 241

Apataki, 68

Corals at, 69, 70

Islands of land rim at, 69

Lagoon of, 70

Land rim of, 68

Nullipore knolls at, 69

Old ledge at, 69

Old ledge boulders at, 71

Platform lagoon at, 69

Shape of, 68

Shore platform of, 69

Apurguan Point, 373

Arhno, 321

Beach rock conglomerate of, 326

Boulder cusps at, 322

Charts of, 321

Dodo Pass at, 321

East face of, 325

Filling up of horns of, 322

High shingle beaches at, 328

Horns of lagoon of, 322

Islets on north face of, 327

Northeast spit of, 326

North face of, 325

North spit of, 325

Secondary lagoon of, 322

Vegetation of, 324

West side of, 328

Arorai, 236

Artémise Bank, 141, 144

Arue, 146

Arundel, John, 234

"Astrolabe and Zélée" Ex., 355

Atà, 189

Atatá, 188, 190

Atiu, 168

Elevated limestone of, 169

Gill on, 168

Williams on, 168

Atokin, 356

Aualap Pass, 353

Australian Reefs, 190

Ava, 198
Ava Lahi Pass, 188

Ava Mata Mata Vika, 197

Avatele, 172

Bali Island, 368

Baxo Trista, 342

Elevated limestone of, 342

Height of, 342

Beechey, Capt., 7

On absence of lagoons, 8

On bottom of lagoons, 9

On coral islands, 8

On Henderson IsIand, 8

On Paumotus, ?

On Pinaki, 9

On plants of Paumotus, 7

On sinks at IIac, 8

Survey of Gambier, 7

Belcher, Capt., boring at Hao, 10

Bellingshausen, 94

Bérard, 340

Bertrand Island, 355

Betche, 279

Bogenaga, 292

Boggen Island, 301

Boggenadick, 292

Bokelan, 309

Boloa, 188

Bonnefin, E., 54

Bonney, T. G., 224

Bora Bora, 161

Assembly house at, 139

Barrier reef flat of, 162

Double peaks of, 163

Fringe of islands of, 163

Islets on flats at, 162

Lesson on peaks of, 138, 163

Native hut at, 164

Vegetation of reef at, 163

West coast of, 163

Bordelaise Group, 341

Boudeuse Pass, 141, 145

Bougainville, 113

Bouquet Island, 355

Bourbon, corals at, 6

Brandeis, Mrs., 284

Brander Island, 34, 146

Channel off, 40

Brander's Bay, 153

Plantation, 150

Brongniart Island, 355

Brüggeman, F., 346

On corals of Ponapi, 346

Burrh Passage, 272

Butaritari, 258 
Cabras Island, 370

Calalan Bank, 366

Cape Halgan, 335

Cape Martin, 1

Cape Tupinier, 334

Cape Vauvilliers, 334

Caroline Deep, 333

Caroline Islands, 330

Admiralty Charts of, 331

Central area of denudation of, 361

Eastern, 330

Low islands of, 361

Semper on, 330

Soundiugs at, 332

Submarine platform of, 331

Trend of the, 332

Western, 330

Chabrol Harbor, 333

Challenger Deep, 332

Chickakoff Point, 1

Christian, F. W., 279, 349

Vegetation of the Carolines, 349

Christmas Harbor, 315

Christmas Island, 228

Cocoa Island, 368

Colobocentrotus, 80

Comptroller Bay, 1

Cook Anchorage, 145, 149

Cook Islands, 168, 279

Gill on the, 168

Vegetation of, 279

Williams on the, 168

Cook Point, 175, 188

Cook's Hill, 190

Coquille Harbor, 333

Dana, James D.,

On absence of corals at Marquesas, 5

On absence of fossils in lagoon basins, 63

On area of Marshall Islands, 274

On Dolphin Bank, 156

On Fiji Islands, 204

On lagoons shut off from sea, 23

On Makatea, 18, 63

On sinks at Manihi, 79

On tertiary limestones of Honden, 50

On tertiary limestones of Manihi, 50

On vegetation of Paumotus, 32, 349

Darwin,

On absence of corals at Galapagos, 5

On absence of corals at Marquesas, 5

On the Gambier Islands, 7

On Kwajalong, 297

David, Mrs. T. E., 224

David, Prof. T. E., 210, 224

Dido Shoal, 188
Dodo Pass, 321

Dolphin Bank, 154

Beechey, Capt., on, 156

Cook, Capt., on, 156

Dana on, 155

Leclere and Bénazé on, 154

Moser on, 155

Nullipores on, 155

Wallis on, 156

Wilkes on, 154

Duke of Gloucester Islands, 125

D'Urville, Dumont, 355

East Faiu, 364

Ebadon, 302

Ebon, 273

Echinonëus, 104

Egeria Pass, 189

Eiol, 353, 355

Ellice Islands, 210

Atolls of, 210

Emegua, 309

Emidj, 280

English Roads, 186

Eniwetok Group, 272

Ennülabegan Island, 297

Eo Island, 355

Eotile Island, 310

Eru Pass, 302

Eua, 180

Caverns at, 184

Central basin of, 182

Central valley of, 185

Channel north of, 180

Drainage valley of, 186

Eastern range of, 182

Eastern ridge of, 181

Elevated limestone at, 181

Fossils at, 186

Gaps in terraces at, 183

Honeycombed rocks at, 185

Mayer, Dr., on, 186

Nullipore platform, 184

Nullipore terrace at, 183

Shore platform of, 183

Sixth terrace at, 183

South point of, 182

Southern slope of, 181

Surveyed by Capt. Aldrich, 181

Terraces of, 181, 182

Topography of, 187

Vegetation of, 184, 186

Volcanic earth at, 184

Voleanic outcrop at, 187

West face of, 185

Western ridge of, 181 
Eua iki, 191

Euakafa Island, 201

Faaroa Bay, 159

Faatemu Bay, 161

Fafa, 189

Fakarava, 76

Depth of Ngarue Pass at, 77

Echinonëus at, 80

Lagoon sand beach at, 79

Lee side of lagoon of, 80

Modern beach rock at, 78

North pass at, 76

Nullipore knolls at, 78

Old ledge covered by beach rock, 80

Old ledge outcrops at, 77,78

Platform lagoon at, 80

Rotoava anchorage at, 77

Sea breaks in lagoon of, 77

Secondary lagoon at, 77

Shore platform of, 78

Sinks at, 79

Trend of land rim at, 76

Width of western reef flat, 76

Fala, 355

Falcon Island, 178

Lister on, 178

Falefatu, 212

Faleú, 353

Fanek Island, 352

Fanua lai, 179

Fanui Bay, 163

Faone Pass, 141, 145

Farallon de Pajaros, 365

Faraulep, 364

Fare Harbor, 158

Farerea Pass, 157

Fareute Point, 154

Fata, 198

Fatato, 213

Fautaua Valley, 149

Feletoa, 201

Feys, 341, 362, 364

Fiji, 204

Charts of, 204

Coral reefs of, 204

Erosion of, 205

Explorations of, 204

Lau group, 204

Reefs of, 190

Rivers of, 204

Soapstone at, 205

Terraces of, 204

Vegetation of, 279

Fitzroy, Capt., 74

Foa, 196
Fofoa, 202

Fongafale, 219

Fonuaika, 195

Fotuhaa, 195

Fualifeke, 221

Fualopa, 215

Fukave, 189

Funafara, 212

Funafuti, 212

Alcyonarians at, 222

Beach rock slabs at, 220

Bottom of passes into, 225

Boulders on flats of, 212

Buttresses at, 214, 226

Charts of, 226

Conglomerate outliers at, 221

Corals at, 222

Crystalline limestone at, 218

David, Prof., on, 215

Denudation at, 221

Depth of bore at, 223

Dimensions of, 212

Eastern face of, 212, 220

Elevated breccia at, 220

Expansion of reef, 227

Filling of lagoon of, 224

First bore at, 223

Former land rim of, 222

Gaps at, 225

Gardiner, J. S., on, 224, 226

Hedley, C., on, 224

Height of, 219

Heliopora reef at, 218

Mayer, Dr., on, 218

Nullipore boulders at, 226

Old ledge at, 217

Pools at, 214

Position of bore at, 216

Range of corals at, 227

Reef flat platform of, 221

Royal Society borings at, 223.

Second bore at, 215

Secondary lagoon at, 217

Section across, 219

Shoals and banks at, 219, 226

Sollas, J. WV., on, 224

Southern horn of, 212

Sturdee, Capt., on, 223

Submarine cliffs off, 225

Temperatures at, 223

Vegetation of, 214, 225

Western face of, 222

Funamanu, 213

Funangongo, 213

Funuarua Island, 46 
Gabert, 340

Gaimard Is]and, 355

Galapagos, absence of corals at, 4

Gardiner, J. S., on Fiji, 204, 224

On Funafuti, 224, 226

Gaudichaud Island, 355

Gegibü Island, 302

Gehh Island, 299

Corals killed at, 299

Sand dume at, 299

Slope of reef flat at, 299

Gilbert Islands, 232

Northeast trades at, 233

Soundings in, 232

Underlying platform of, 232

Gregoire Island, 354

Griinow, 279

Guam, 366

Caverns of cliffs at, 368

Denudation of, 372

Dimensions of, 366

Disintegration of, 369

East coast of, 366

Elevated coralliferous limestone of, 372

Elevated coral reef at, 373

Erosion of, 368, 375

Fossils of, 372

Junction of volcanic outburst aud elevated limestone, 374 .

Limestone outliers at, 373

Mesa of northern part of, 369

Northwest point of, 369

No subsidence at, 376

Red earth at, 371

Ridges and pinnacles of, 372

Road to Agaña in, 374

Sloughing of sea face of, 368

Southern part of, 371

Southern volcanic massif of, 370

Terraces of, 366,367

Twisted strata at, 367

Vegetation of, 373

Vertical limestone cliffs of, 366

Volcanic agencies in recent times at, 375

Volcanic bluffs at, 373

Volcanic earth at, 371

Volcanic negro-heads at, 373

Volcanic rocks of, 367

Volcanic slopes of, $3 \pi_{2}$

Volcanic soil of, 373

West coast of, 369

\section{Haafeva, 197}

Haaio Island, 161

Haano Island, 196
Haapai Bank, 196

Depth of, 196

Islands of, 196

Haapai Group, 195

Elerated islands of, 195

Haapai Plateau, 175, 195

Haapape Promontory, 146

Haavini Valley, 145

Haeq Island, 352, 355

Hakahe, 3

Hakaufussi, 201

Hakau Lahi, 197

Hakau Mamao, 189

Hakau Tábu, 188

Hall Islands, 331

Hamene Bay, 159

Hanaiapa, 4

Hansen, Dr., 201

Hao, 113

Buttresses at, 115

Color of reef flat at, 116

Coral shingle bars at, 114

Depth of lagoon of, 113

East face of, 115

Gaps at, 114

Islands on reef flat, 114

Nullipore knol]s at, 116

Old ledge at, 115

Hat-shaped Islands, 209

Hatutu, 1

Hedley, C., 224

On Funafuti, 224

Vegetation of Ellice group, 279

Henderson Island, 8

Hereheretue, 131

Dimension of, 131

Echinoderms at, 132

Island across land rim at, 132

Landing at, 132

Nullipore knolls at, 132

Old ledge flat at, 132, 133

Platform lagoon at, 132

Range of corals at, 133

Reef tlats at, 133

Vegetation killed by sand at, 131

Hernnsheim, 329

Hesi, 340

Heterocentrotus, 80

Hikueru, 110

Deep hules at, 11

Deptli of lagoon, 111

Nautilus at, 110

Old ledge at, 111

Shoals in, 111

Trend of, 110

Hiva Oa, 4 
Holanga, 201

Fossils at, 201

Holevai, 188

Honga Hapai, 178

Honga Tonga, 178

Huaheine, 157

Compared to Bora Bora, 158

Dimensions of, 157

Islands on barrier reef of, 158

Huaheine Iti, 157

Huaheine Nui, 157

Hunga, 197

Eolian limestone of, 202

Limestoue strata of, 202

Vertical cliffs of, 202

\section{Ifalik, 341, 364}

Illeginni, 302

Imrodj, 287

Beach, height of, at, 287

Boulder reef flats of, 287

Breadfruit trees at, 287

Section across, 287

Shingle bar of, 288

Ine, 324

Iriru Pass, 161

( Jaluit, 279

Beach rock conglomerate at, 283

Buttresses at, 282

Conglomerate beach at, 282

Continuity of land rim of, 286

Corals of lagoon of, 286

Currents in lagoon of, 290

Depth of lagoon of, 280,286

Dimension of, 279

Driftwood at, 281

Filling of gaps at, 289

Filling of lagoon of, 286

Flat outer platform at, 285

Flats of lagoon face of, 292

Fresh-water lagoons at, 284

Gentle slope reef platform at, 282

Lagoon face of islands of, 289

Lagoon shore extension at, 284

Land rim swept by sea at, 289

Large blocks of corals at, 285

Long islands of rim of, 280

Millepore flats of, 291

Narrow laud rim of, 279

Northeast face of lagoon of, 292

Northern horn of, 292

Nullipore knolls at, 282

Pools on lagoon face of, 288

Porites flats of, 291

Porous land rim of, 284
Jaluit - Continued

Potholes at, 285

Range of corals at, 286

Rolled coral blocks at, 285

Sand bars encroaching on lagoon of, 292

Sand blown into lagoon of, 280

Sand spits of, 291

Sinks at, 283

Secondary lagoons at, 283, 292

Ship channels at, 280

Shoals in lagoon of, 280

Slab beaches at, 281

Slope of lagoon face. of $f_{1} 282$

Southeast passage into, 281 .

Southern horn of, 279

Southwest passage of, 289

Steep sea face of, 282

Sweep of trades across lagoon of, 289

Vegetation of, 281

Western passage of, 290

Wide outer reef flats of, 288

Johnson, Lieut,

Boring on Aratika, 10

Judd, J. W., 223, 228

Kahalape, 350

Kallau, 184

Kama, 364

Kambara, 206

Bottom of basin of, 207

Buttresses at, 208

Central basin of, 206, 207

Gaps at, 206

Height of, 206

Slope of denudation of, 208

Terraces at, 208

Tokalau Gap at, 207

Volcanic cone of, 206

Volcanic outburst at, 206, 207

Kapa, 198, 202

Kapenor, 309

Karoni, 205

Kauehi, 74

Daua on huge boulders at, 75

Effect of prevailing winds at, 74

Entrance to, 75

Low gaps at, 75

Old ledge boulders at, 74

Sand bars at, 74

Secondary lagoon at, 75

Weather land rim of, 74

\section{Kaukura,}

Outliers of old reef rock at, 38

Keuea Gap, 264

Kiti Harbor, 343

Kito, 195 
Kitu Island, 198

Koto Maka, 193

Kotu, 195

Kotzebue on Tikeï, 71

On Wotje, 315

Krämer, Dr. A., 234

Krusenstern, Capt., 297

Kuli Island, 357

Kusaie, 333

Belt of mangrove islands of, 334,337

Coral patches at, 337

Corals killed by silt at, 336

Driftwood on, 3.39

Erosion and denudation of, 333,338

Fringing reefs at, 336

Height of, 333

Lagoon basins at, 335

Lagoon passages at, 334

Main lagoon channel of, 337

Main ridge of, 333

Outcrops of rolcanic rocks of, 338

Outline of, 33.3

Passes through reef platform of, 336

Submarine erosion at, 338

Vegetation of, 335

Volcanic boulders at, 335

Volcanic rock outhiers at, 335

Volcanic sand beach at, 339

Water lanes at, 337

Wide bays of, 338

Wide reef fiat platform of, 338

Kutua Point, 356

Kwajalong, 296

Chart of, by lírusenstern, 297

1)unes at, 298, 300

Gaps on west face of, 301

Great size of, 296

High sea face of, 298

Lagoon reef flats wide at, 302

Nullipore knolls of, 298

Sand bars in lagoon of, 301

Secondary islands at, 301

Section of beach of, 297

Sonthern horn of, 297

South Pass of, 297

Trades at, 302

Western point of, 297

Lado, 311

José DeBrunn on, 312

Ladrones, The, 365

Caroline Deep off, 366

Challenger Deep off, 366

Coralliferous limestone islands of, 365

Deepest sounding off, 366
Ladrones, The - Continued

Irregular soundings along, 365

Nero Deep off, 366

Soundings of "Nero" in, 365

Southern islands of, 377

Volcauic islands of, 365

Lagediak Pass 317

Lahi Passage, 189

Lalalolomei Bank, 201

Lamotrek, 331

Langa, 342

Late, 178

Lau Group, 204

Lauvergne Island, 355

Lélé Island, 335

Lifuka, 196

Likieb, 307

Bays at, 313

Coral patches in lagoon of, 307

Corals on lagoon flats of, 312

Dead corals in situ at, 311

East face of, 307

Floating sand at, 314

Gap at, 313

Grass on, 311

Hydrocorallidæ at, 312

Incorrect position of, 307

Islands on east face of, 314

Lagoon sand overwhelming outer platform of, 309

Maten Pass at, 310

Melander, Capt, survey of, 307

North point of, 308

Sand spits of, 313

Sinks at, 313

South Pass of, 311

Stranded islets of, 312

Width of island of, 311

Likintakai Island, 344

Lima Island, 196

Lister, 179

On Eua, 186

On Haapai Bank, 196

On Kelefesia, 179

On Mango, 179

On Nomuka iki, 179

On Tanoa, 179

On Tonumeia, 179

On volcauic and limestone islands, 179

Little Makin Island, 259

Lofanga, 197

Losap, 351

Lot's Wife, 365

Lua motu, 212

Lubu, 302

Luerssen, 279 
Lukunor, 310

Luminan Reef, 366

Lütké, Capt., 331, 33 z

Mackenzie Group, 364

Madagascar,

Corals at, 6

Mahaena Pass, 147

Mahea Island, 160

Maiana, 245

Boat passage at, 245

Color of beach rock at, 245

Coloring of Nullipores at, -246

Coral shingle at, 246

Dimensions of, 245

Secondary lagoons of, 246

Slope of platform of, 245

Vegetation at, 245, 247

Maina Island, 169

Makatea, 56

Absence of ref platform at, 62

An elevated limestone island, 56

Areas of drainage of, 64

Bottom of sink, 62

Buttresses of old ledge at, 60

Caverns at, 61

Central sink of, 58,60

Crevasses in sink of, 61

1)all on fossils of, 59

I) aua's visit to, 56

Kastern face of, 56

Erosion at, 62

Fossils of, 18, 59

Incrusting Nullipores at, 59

Landing places at, 59

Lines of caverns of, 58

Lines of undercutting, 59

Northern point of, 58

Outline of, 56

Path across, 60

Sea slope of, 59

Slope of southern face of, 56

Sonthern face of, 56

Terraces of, 56,57

Vertical cliffs of, 57

West face of, 58

Makemo, 99

Accession to reef by corallines at, 100

Beach rock conglomerate at, 107

IBlow holes at, 108

Bottom of lagoon of, 104

Conglomerate ledge at, 103

Corals in pass of, 102

Corals on shoals of lagoon at, 106

Echinoderms on reef flat of, 103

Gaps of land rim of, 100, 107, 108
Makemo-Continucel

Islands as buttresses at, 107

Land rim of, 102

Masses of boulders at, 105

Northeast face of, 101

Old ledge outcrops at, 101, 102, 106

Pass into, 102

P'udding-stone at, 103

Range of corals at, 100, 104, 105

Sand driven from lagoon at, 107

Shingle beach of, 101

Shingle driven into vegetation of, 108

Shoals in lagoon of, 105

Sink of, 108

Slope of lagoon at, 104

Surface hauls at, 106

Mangaia, 168

Terraces at, 168

Williams on, 168

Mango, 192, 228

Mango Iki, 192

Mann, 300

Mantapeti, 342

Mapuaura River, 145

Maraa Pass, 142

Maraki, 253

Abseuce of shore platform at, 256

Beach rock of, 254

Blocks of Nullipores at, 256

Bottom of lagoon at, 254

Closiug of land rim of, 256

Color of Nullipores at, 255

1)ana on, 254

Elevation of, 255

Increase of land rim of, 257

Monument on, 257

Nullipore knolls at, 254

Secondary lagoons of, 254

Secondary line of islands at, 256

Section across, 255

Size of, 253

Slope of, 254, 257

Underlying platform of, 254

West face of, 256

Marambo, 205

Marau, 149

Maria Bay, 189

Maroe Bay, 157

Marokau, 111

Dimension of, 112

Sea face of, $11 \%$

Wide reef flat at, 112

Marquesas Archipelago, 1

Absence of reefs from, 3

Native lut at, 6

Soundiugs at, 5 
Marshall Islands, 271

Areas of, 274

Atolls with small lagoons in, 273

Canoe of, 293

Deep basiu south of, 279

Depths of lagoons of, 273,300

Elevation at, 277

Extent of lagoons of, 274

Great moisture at, 274

Insignificant land rims of, 274

Monotonous structure of, 271

Movement of loose material in, 276

Passes iuto atolls of, 276

Ralick Chain at, 271

Ratack Chain at, 271

Reach of trades at, 274

Rise of tides in, 314

Shape of atolls of, 272,277

Slope of lagoons of, 27 ?

Small islets of, 328

Small islets of rim in, 276

Soundings in, 278

Trades at, 275

Trend of atolls of, 271

Underlying base of, 271

Vegetation of, 279

Water driven into lagoons by trades, 275

Weather side land rim of, 275

Mataea River, 145

Matahiva, 54

Bonnefin on lagoon of, 54

Filling of lagoon of, 55

Gaps of, closiug of, 54

Ridges of old ledge at, 54

Vegetation of, 55

Mata Maka, 192

Matavai Bay, 146, 153, 155

Mateika, 212

Maten Island, 310

Matira Point, 162

Mauki, 168

A patite beds at, 168

Maupiti, 138, 164

Bluffs of, 165

Central island of, 164

Jimension of, 164

Height of, 164

Shape of, 164

Mauritius,

Corals at, 6

Mayer, Dr.,

On Eua, 186

On Nomuka, 193

On 'Talau, 202

Medjado, 280

Medjerrurik, 290
Mehetia, 140

Absence of shore platform at, $\mathbf{1 4 0}$

Corals at, 4, 140, 141

Crater of, 140

Melander, Capt., 307

Merizo Bay, 368

Métalanim, 344

Metis Shoal, 178

Mituro, 169 Gill on, 169

Mohican Island, 34 Old ledge of, 40

Mokil Island, 341

Monu afe, 189

Moore, 70 On Nomuka Iki, 192

Mortlock Islands, 331

Moser Deep, 180

Motuloa, 212

Motungie, 212

Motu Araara, 159

Motu Iti, 165

Islands of, 165

I ake, 157

Underlying rocks of, 165

Motu Mute, 163

Motu Tabu, 189

Motu Teheri, 146

Motu Tofari, 163

Motu-uta, 154

Moungalafa, 198

Moungaone, 197

Mount Buache, 333

Mount Crozer, 333

Mount Diadème, 148

Mount Makana, 372

Mount Santa Rosa, 365, 374

Mount Tinkio, 371

Mount Ton Azan, 360

Mount Zion, 190

Mua, 188

Muifuiva, 192

Muitoulo, 198

Murea, 156

Erosion of, 157

Outlines of, 156

Murray, Sir John, 225

Mutok Island, 344

Mutokaloj, 342

Naiau, 206

Nama, 351

Coralliferous limestone at, 35I, 362

Namoluk, 341 
Namonuito, 363

Lastern spit of, 363

Low atoll of, 363

Russian survey of, 363

Western horn of, 364

Namorik, 329

Namu, 295

Vegetation of, 296

Nao Nao Pass, 160

$\mathrm{Na}$ Potu, 204

Napuni Island, 258, 269

Narpoli Island, 343

Nauru, 233

Navutuiloma, 204

Neiafu, 176

Cliffs at, 199

Corals at, 201

Entrauce to, 198

Range of corals at, 199

Reef platforms of, 199

Third terrace at, 202

Vegetation at, 200

Nero Deep, 333

Ngarue Pass, 76

Ngele Levu, 205

Niau, 64

Beach of sea face of, 65

Corals on reef flat at, 65

Density of water in lagoon of, 66

Diminutive marine shells at, 67

Lagoon of closed, 65

Lagoon or sink of, 67

Lagoon shut off from sea, 23

Nullipores at, 65

Old ledge at, 66

Pocillipores at, 65

Range of corals at, 65

Sand encroaching on old lelge at, 66

Shape of, 64

Slope of land rim of, 65

Sonth shore of, 67

Submarine erosion at, 67

Terraces of, 65

Width of recf flat of, 60

Wooded land rim of, $6+$

Niniva, 197

Niuafóu, 178

Niuatobutábu, 203

Connection with Tonga, 203

Niue, 171

Blow holes at, 172

Cañous at, 174

Cliffs of, 171

Erosion at, 174

Moss on, 174

Nullipore masses at, 172
Niue - Continued

Soil of, 173

Terraces, height of, at, 171

'Terraces of, $171,172,173$

Williams on, 168

Niutao, 230

Nomuka, 192

Buttresses at, 193

Coralliferous limestone of, 192

Deptl of Iagoon at, 193

Fertile soil of, 194

Fishes in lagoon of, 193

Height of beaches at, 194

Highest point of, 192

Island of, 192

Lagoon of, 193

Mangrove swamp of, 194

Mayer on, 193

Old ledge outcrop at, 192

Sand dune at, 194

Slopes of denudation at, 193

Vegetation of, 19

Nomuka Group, 192

Bank of, 192

Nomuka Iki, 176, 192

Nomuka Plateau, 175

Nua Papu, 198

Nui Aunofo Point, 188

Nui Nui, 33, 44

Nuku, 189

Nukualofa, 190

Nukufetau, 229

Black shingle at, 230

Depth of lagoon of, 230

Dimension of, 229

Gaps at, 230

Islands on rim of, 230

Lagoon sand beach at, 230

Vegetation of, 229

Nukuhiva, 1

Nukuleka, 188

Nuku Mbasanga, 205

Nukutavake, 118

Sand dunes at, 118

Native canoe at, 119

No lagoon at, 118

Old ledge at, 119

Secondary lagroon at, 119

Section across, 118

Nukutipipi, 125

Color of water at, 126

Dimension of, 127

Extension of dunes at, 127

Formation of islands at, 126

Lagoon of, filling, 127

Nullipore knolls of, 128 
Nukutipipi - Continued Platform lagoon at, 128 Steep sea face slope of, 128 Vegetation of, 125

Nurakita, 210

Approaches to, 211

Dimensions of, 210

Secondary fringing reef of, 211

Sink of, 211

Soundings off, 278

\section{Ofolanga, 197}

Ohonua, 185

Olimarao, 364

Onevai, 189

Onevao, 189

Onoatoa, 236

Absence of western rim of, 237

Onoupe Island, 364

Onümak Island, 301

Oosima, 365

Oraluk, 364

Elevated limestone at, 342

Narrowest land rim of, 364

Orohena, 149

Oroté Peninsula, 370

Oto, 198

Otungake, 198

Oua, 195

Outline of,

Carolines, 277

Ellice Islands, 277

Fiji, 277

Gilbert Islands, 277

Marshall Islands, 277

Paumotu Islands, 277

\section{Paanopa, 233}

Pachiai, 350

Paea, 142

Pahia, 163

Paipaî Pass, 159

Pakaka Entrance, 68 Bottom of, 69

Pakin, 351

Panemur, 350

Pangai, 198

Paoi, 45

Papara reef flats, 147

Papawa Harbor, 153

Papenu River, 149

Papieté, 150, 152

Algx at, 151

Barrier reef at, 150, 151

"Challenger" at, 150
Papieté - Continuco

Corallines at, 151

Corals at, 151

Echinoderms at, 152

Lagoon slope at, 152

Range of corals at, 151

Slope of reef flat at, 151

Pari Bay, 159

Paumotu Archipelago, 7

Absence of Alcyonarians in, 29

Area of elevation of, 29

Atolls rising from moderate depths in, 28

Birds of, 31

Canoe and mative of, 119

Character of corals of,' 29

Crustacea of, 31

Deepest sounding in, 28

Depth of lagoons of, 23

Development of Nullipores at, 30

Dished islands of, 24

Echinoderms of, 30

Elevated coralliferous limestone islands of, 20

Elevation of western islands of, is

Flat-topped islands of, 24

Formation of land rim of, 21

French Hydrografhic Charts of, 11

Islands of accretion in, 17

Lagoons shat off from sea in, 23

Land rims of, 15, 21

Lines of upheaval of, 27

Pancity of marine animals in, 31

Pearl oysters, age of, at, 30

Pearl oysters, reproduction of, in, 30

Reef flat pudding-stone in, 21

Secondary lagoons of, 22

Shells in mud of lagoons of, 63

Shoals, ledges, and islands in lagoons of, 22

Small atolls of, 19, 23

Small size of 'Tridacnas of, 30

Surface hauls in, 31

Surveys of, 12

Transportation of cocoanuts in, 32

Trend of islands of , 27

Vegetation of, 7,31

IVestern islauds of, 18

Western platean of, 19

Wind follows trend of islands in; 22

Paumotu Plateau, 25

Soundings on, 25

Pau Point, 162

Pava, 221

Peacock Anchorage, 237

Periadik, 355

Permanence of Pacific Ocean, 228

Phaeton Harbor, 144, 147

Pikelot, 364 
Pinaki, 120

Alexander on, 121

Arca beds at, 121

Bottom of lagoon at, 122

Coral shingle at, 120

Depth of lagoon of, 121

Islets in lagoon of, 121

Old gaps at, 120, 123

Sand bars at, 122

Sand beach at, 120,123

Sand blown in at, 124

Sand dures of, 120, 122

Townsend on, 125

Tridacna at, 121

Vegetation of, 23, 120

Water hole at, 124

Width of reef platform of, 120

Pingelap, 340

Population of, $3+1$

Shallow lagoou of, 340

Volcanic platform of, 341

Pinglapp, 292

Pis Island, 357

Pisaras Island, 363

Piti u Tai Island, 162

Piti u Uta Island, 162

Point Ajayan, 368

Point D'Urville, 335

Point Facpi, 371

Point Fafai, 369

Point Fata, 198

Point Hanoum, 367

Point Lesson, 340

Point Nantiaiti, 344

Point Patay, 368

Point Ritidian, 367

Ponapi, 342

Alcyonariaus of, $34 \hat{6}, 348$

Bands of deep water at, 344

Bars of pebbles in Kiti Rirer at, $3 \mathbf{4 9}$

Bottom of lagoon of, 346

Brüggeman on corals of, 346

Changes of reef flat islands of, 345

Channel across reef flat of, 344

"Coquille," The, at, 347

Corals killed by exposure at, 348

Dimensions of, 342

Effect of trades at, 349

Forest trees at, 349

Mangrove islands, belt of, 343

Masses of corals at, 345

Muddy water of lagoon of, 346

Navigation of lagoon in, 347

Nullipore coating on corals at, 348

Outliers of spurs of volcanic ridges at, 344

Range of corals at, 348
Ponapi-Continued

Reef harbors of, 343

Section across, 345

South shore of, 345

T'ongue of mangrove islands at, 344

Vegetation of, 346

Volcanic islands in barrier reef at, 342

Volcanic rocks of, 349

Volcanic silt on bottom of lagoon at, 348

Water coming down slopes of, 349

Wichman on, 343

Popote Bay, 142

Port Lod, 344

Port Lottin, 333

Port Motu Au, 153

Port Pago, 368

Port Tarafofo, 369

Port Ynarajan, 368

Powers, F. D., 234

Punaavia, 143

Punaeroa Pass, 161

Punta de los Amantes, 369

Quiros, 7

Quoin Hill, 205

Quoy Island, 355

\section{Raiatea, 159}

Barrier reef of, 160

Channel separating Tahaa from, 160

Height of, 161

Vegetation of, 160

Ralick Chain, 271

Rangiroa, 32

Appearance of, seen from sea; 35

Avatoru Pass, 34

Bare sand bars of, 48

Beach concealing old ledgre wall of, 46

Bottom of lagoon of, 45

Buttresses of old ledge of, 48

Coral shingle of, 38

Corals on reef plateau of, 37

Corrected sketch of, 48

Currents in, 34

Current through gaps of great wall at, 51

Dana on great wall of, 46,51

Jenudation of, 16

Deposits covering old ledge of, 40

Destruction of islands in lagoon of, 44

Disintegration of great wall of, 51

Erosion of 36

Exposure of old ledge in gaps at, 43

Formation of cuts in land rim of, 42

Formation of land rim of, 35

Formation of sand bars at, 49

Formation of sinks of, 42 
Rangiroa - Continued

Gaps in land rim of, 41

Great wall cut into fragments at, 47

Great wall of elevated limestone at, 46

Height of beach of, 39

Lagoon beach of, 38

Lagoon of, bottom of, 36

Lagoon sink of, 39

Lagoon slope of, 46

Lee land of, 37,49

Narrow land rim of, 45

Northern land rim of, 33

Nullipores on outer platform of, 47

Range of corals in lagoon of, 47

Sea face of, 43

Sea face of the great wall at, 47

Section across, 37,38

Shore platform of, 40

Size of, 14,35

Soundings in lagoon of, 36,45

Spur of old ledge dam of, 52

Tiputa entrance at, 33

Vegetation of, $33,36,39$

Water flowing over reef flats of, 14

\section{Raroia, 94}

Bays at, 96

Boulders of beach rock at, 96

East face of, 9.5

Entrance to, 97

Gaps at, 96

Large boulders at, 95

Length of, 94

Low gaps at, 95

Nullipore knolls at, 96

Old ledge at, 95

Pocillipore knolls at, 96

Sand beaches at, 95

Shingle beaches at, 95

West side of, 97

Width of shore platform of, 96

Rarotonga, 169

Ratack Chain, 271

Rautoanui Pass, 158

Ravahere, 111

Large boulders at, 112

Secondary lagoon of, 111

Width of, 112

Raveskoi Islands, 90

Reiher Passage, 272

Resolution Bay, 2

Rewa River, 205

Rodriguez,

Corals at, 6

Rongelab, 303

Adaptation of Echinoderms at, 305

Beach rock at, 304
Rongelab - Continued

Bottom of lagoon of, 306

Corals in lagoon, 304

East face of, 303

Lagoon side of, 306

Iand rim of, 303

Northeast trades at, 304

Sand dunes of, 303

Section of beach at, 305

Siuks at, 304

South pass into, 303

Variation of corals at, 305

Rongelappelab, 303

Rongerik, 309

Rota, 376

Caves at, 377

Elevated coralliferous limestone of, 377

Northwestern print of, 377

Southern spit of, 377

Terraces of, 377

Volcanic ontburst at, 377

Western peuinsula of, 377

Royalist Islands, 352

A satellite of Truk, 352

Line of boulders at, 352

Northern passage of, 352

Vegetation of, 352

Royal Society, 210, 224

Committee on boring in a coral reef, 210, 224

Ruk, 354, 356

Rurick Pass, 315

Rurutu, 168

IVilliams on, 168

Saipan, 378

San Augustin, 342

Elevated limestone of, 342

Height of, 342

San Luis d'Apra, 370

Savage Island, 163

IVilliams on, I 68

Schischmarev, Lieut., 315

Schischmarev Pass, 316

Seeman, 204, 279

Flora Vitiensis, 204

Semper, C., 362

On geology of Pelew Islands, 362

Seniavina Islands, 342

Seychelles,

Corals at, 6

Sinks and Sounds of,

Ano, 200

Hunga, 200

Koloa, 200

Makave Spit, 201 
Sinks and Sounds of - Continued

Nux Papu, 200

Pangai and Otungake, 200

'T'eleki, 201

T'ofoa, 200

'T'ulie, 20 !

Vaipuua, 201

Society Islands, 135

Barrier reefs at, 136,137

Denudation at, 135, 137

Eastern, 136

Fringing reefs at, 138

Heights of, 138

Islets on barrier reef ait, 136

Lesson on vegetation of, 35

Modifications of, 135

Shore platforms at, 135

Submariıe denndation, 135

Vegetation of, 140

Western, 136

Wooded islets at, 136

Sollas, Prof. J. W., 210, 224

Unexceptional atolls, 227

Sosanjaya Bay, 377

Sosanlagh Bay, 377

Soundings,

Across Rangiron lagoon, 45

Aki-Aki to Nukutavake, 27

Among Ellice Islands, 278

A mong the Ladrones, 365

At Eakarava, 81

At Makemo, 104, 105

At Niue, 171

Between islands in lagnon of Fakarava, 82

Between the Gilbert Islands, 232

Between the Marshall Islands, 278

By " Nero," 333, 365

Deepest, 333, 366

Fast of Tonga, 180

From Namonuito to Jalnit, 332

Guam to Japan, 365

Guam to Midway Island, 365

Hao to $\mathrm{Aki}-\mathrm{Aki}, 27$

Hikneru to Marokau, 27

In lagoon of Taritari, 264

Makatea to Tahiti, 26

Matahiva to Makatea, 26

Nian to A pataki, 26

Nukutipipi to Mehetia, 27

Off Avatoru Pass, 2:5

Off Nurakitn, 278

I'inaki to Nukutipipi, 27

Rangiroa to Tikahan, 26

South of 'longa, 181

Tikahau to Matahiva, 26

Submarine terraces, 229
Taapuna Pass, 146

Tababac, 342

Tabik, 302

Tabonua, 240

Tacahu, 342

Taenga, 98

Large boulders at, 98

Low land rim of, 98

Sand bars, west face of, 98

Shape of, 98

Taeroere, 47

Tagua Point, 368

Tahaa, 159

Beack rock at, 161

Height of, 161

Reef flat at, 159

Tahanea, 85

Boulders on reef flat of, 86

1)epth of secondary lagoon of, 86

Digitate channels of, 86

Formation of islands of land rim of, 89

Formation of spits at, 89

Islets of reef flat of, 87

Lagoon sand bars of, 88

Length of, 85

Low land rim at, 87

Northern point of, 88

North face of, 88

Sand beaches at, 87

Sand buttresses at, 89

Secondary lagoon of, 86,88

Shingle beaches at, 87

Spreading of cocoanut trees at, 87

Wacer driven over land rim at, 87

Tahara Promontory, 146

Tahihi Point, 162

Tahio Point, 162

Tahiti, 141

Absence of Alcyonarians at, 150

Artémise Bank at, 141

Barrier reef flat at, 142

I3arrier reef lagoon at, 142

Barrier reefs of, 141

Corals of east face of, 145

Dimensions of, 141

Eastern coast shelf of, 149

Erosion and denudation at, 148

Islets on barrier reef of, 146

Mapeti Island at, 142

Matavai Bay at, 141

Origin of lagoons at, 144

Point Venus'at, 141

P'urum Island at, 142

Rotten coral on flats at, 143

Shore platforms of, 144

Silt of streams at, 145 
Tahiti - Continued

Southeast trades at, 147

Taunoa reef flat at, 143

Tidal currents at, 147

Watercourses at, 143

IVaterfalls at, 145

Tahuak, 342

Taiarapu Peninsula, 137, 144, 149

Taiisale, 217

Tai oa Bay, 2

Tai-o-hae Bay, 2

Taiti, 149

Takahave, 310

Takaï Island, 340

Takume, 91

Colored Nullipore knolls of, 92

Depth of lagoon of, 93

Gaps of laud rim of, 92

Islands of east face of, 93

Islands on lee land rim of, 91

Lagoon flats wide at, 92

Lagoon of, not closed, 91

Large boulders at, 92

Length of, 91

Outerops of old ledge at, 92

Recent conglomerate at, 92

Sand beaches at, 92

Secondary lagoon at, 94

Shingle beaches at, 92

Surf wash into lagoon, 91

Trend of, 91

Wide reef flat at, 92

Young cocoanuts at, 93

Talau, 198

Fossils at, 202

Height of, 202

Lister on, 199

Mayer on, 202

Terraces of, 202

Upper cliffs of, 202

Tanoa, 192

Taongi, 272, 302

Secondary lagoon of, 272

Taoro Island, 160

Tapeteuea, 237

Artificial mounds at, 238

Dimension of, 237

Driftwoor at, 239

Gaps at, 238

Islands of land rim: of, 238 .

Northern horn of, 238

Old ledge at, 240

Secondary lagoons at, 239

S. S. "Narragansett" survey of, 238

Vegetation of, 239

Taragay Bay, 367
Taravoa Isthmus, 137, 148

Tarawa, 247

Cuts in onter edge of, 249

Depth of lagoon of, 247

Dimensions of, 247

Discolored water at, 248

Dunes at, 248

East coast of, 250

Fish ponds at, 249

Islands on platform of, 248

Lagoon face of, 251

Lines of islands in lagoon of, 251

Position of barrier reef at, 247

Secondary lagoon at, 248

Slope of atoll of, 247

Slope of Hats, 249

South side of, 247

Wide lagoon reef flats of, 250

Width of secondary lagoon of, 250

Vegetation of, 250

Tarik, 355

Taritari, 258

Angular outline of, 258

Broad passages into, 258

Connecting passages of lagoon to sea at, 262

Corals in lagoon of, 264

Coral shingle at, 268

Dam of huge blacks at, $26+267$

Echinoderms in lagoon of, 267

Forest trees at, 260

Gap of south face of, 260

Islets in lagoon of, 264

Kenea village at, 266

Lagoon flat at, 270

Land rim of, 258

Land rim on eđgè of platform of, 259

Low outer beaches at, 260

Mangrove flat at, 263

Millepore flat of, 264

Narrow reef flat of, 260

Northern face of, 259

Nullipore boulders at, 261

Passes connecting lagoon of, 266

Pavement of coral blocks, 265

Platform lagoon at, 262

Porites flat of, 268

Secondary lagoon at, 261

Shoals and patches in lagoon of, 269

Sink at, 262

Soundings in lagoon of, 264

Tridacnas at, 263

Vegetation of, 270

Western channel of, 269

Western spit of, 262

West face of, 263

Wide reef flats at, 261 


\section{Taritari-Continued}

Width of east face of, 259

Tataa Point, 141

Tau, 189

Tauche, 342

Taulalia, 205

Taunoa, 143

Taunoa Pass, 152

Tautira Point, 149

Te Afualiku, 215

Te akau Tuluaga, 215

Te Avapiti Pass, 160

Tea Promontory, 156

Teava Moa, 158

Teava Moa Pass, 158

Teavarua Pass, 144, 159

Tebuka, 213

Tehiri Island, 154

Tekokota, 109 Depth of lagoon of, 109 Rookery at, 109

Teleki, 199

Telele, 212

Temae Lake, 157

Temanu, 163

Tengako, 213

Tengeli, 300

Teoneroa haaoa Bay, 159

Tepoto, 90

Terranova, 321

Lagoon beach of, 323

Sea face of, 323

Tetaro Island, 160

Tetiaroa, 166

Disintegration and erosion at, 167

Formation of, 166

Negro-heads at, 166

Underlying stratum of, 166

Sand islets of, 166

Teveiroa Island, 162

Thithia, 207

Tihere Entrance, 71

Tikahau, 52

Entrance to, 52

Dimension of, 53

Dunes at, 53

Filling of lagoon of, 55

Land belt of, 53

Old ledge of 53

Outline of, 53

Tikeï, 71

Bridges over digitating channels at, 73

Central pool of, 73

Central sink of, 71, 72

Conglomerate beaches at, 72
Tikeï-Continued

Depth of channels of reef platform at, 73

Digitate channels at, i3

High sea face beach at, 72

Old ledge outcrops at, 71

Potholes at, 73

Sinks covered by Algæ at, 72

Wide reef flat platform at, 72

Tiva Point, 158

Toahotu Island, 160

Toa Tea Reefs, 153

Tofanga, 197

Tofua, 178

Toharoa Pass, 145

Toku, 179

Tol, 357

Toloas, 354, 355, 356, 360

Tolomen Peak, 360

Tomotai Pass, 143

Tonga Archipelago, 175

Corals of, 177

Elevated plateau of, 179

Lister on, 177

Terraces of the, 180

Volcanic islands of, 177

Volcanic outbursts at, 179

Volcanic sand off, 180

Tongatábu, 188

Blow holes at, 190

Egeria Channel at, 191

Flats of, 188

Fossils at, 190

Lagoon of, 188

Limestone outcrops at, 191

Native hut at, 191

Nukualofa, 188, 190

Slope of, 190

Star-fishes of, 190

Tongatábu Plateau, 175

Trend of, 176

Tongua, 195, 197

Tonumeia, 176

Torea Point, 154

Torrutj Pass, 300

Trelease, Prof., 349

Botany of Caroline Island, 349

Tromelin Island, 341

Truk Archipelago, 330, 353

"Astrolabe and Zélée" at, 353

Coral boulders in, 361

Coralline Algæ in, 359

Corals on flats of, 360

Deep passages into, 353

Depth of lagoon of, 354

Eastern pass into, 360 
Truk Archipelago - Continued

Elevatiou of, 359

Fringing reef belts of, 358

Great encircling reef of, 353

Height of islands of, 355

Islanils on outer margin of, 354

Largest Caroline atoll, 353

Mangroves in, 356

Mount Ton Azan at, 355

Muddy water in, 359

Native canoes of, 362

Northeru pass of, 360

Nortluwest face of, 360

Original land masses of, 358

Rauge of corals in, 359

Shoals and patches in lagoon of, 358

Submarine erosion of, 358

Summits of, 358

Vegetation of, 359,361

Volcanic islands of, 354

Volcanic islets of, 356

Volcanic mud in, 356

Tsis Island, 353, 357

Tuanaé Island, 165

Tuanake, 90

Tuaura Valley, 148

Tufaka, 188, 191

Tugulu Island, 341

Tulatik, 342

Tupua Island, 163

Tupua Iti, 163

Tutataroa Pass, 143

Tuvuthá, 206

Two Groups, 111

Ua Huka, 3

Ua pu, 3

Udot, 353, 355, 357

Uiha, 197

Ujelang, 273

Ulalu, 355

Ulul Island, 364

Uluthi Islands, 331

Umol, 354, 356

Unalik Island, 364

Uneyeute, 364

Uola Island, 355

Beaches of, 355

Corals at, 355

Height of, 355

Uoleva, 196

Utiroa, 238

Utuofai Valley, 146

Vaeio Bay, 3
Vaionifa Pass, 145

Vaiorea Island, 158

Vaitia River, 145

Vaitoto River, 145

Vavau, 197

Cañons at, 200

Capt. Field on, 200

Cares at, 200

Chart of, 200

Denudation of, 198, 200, 201

Depth of bank of, 203

Fertile soil of, 201

Fossils at, 202

Height of, 201

High land of, 201

Slope of plateau of, 203

Terraces of, 198

Vegetation of, 201

Vertical cliffs of, 198

Vavau Plateau, 175

Denudation and erosion of, 177

Velitoa, 189

Venus, Point, 144, 146, 150, 153.

Barrier reef at, 144

Leclerc and Bénazé on, 154

Marks of Wilkes at, 154, 155

Volcanic sand beach at, 146

Walu Bay, 205

Wangava, 205, 206

West Ava iti, 142

West Faiu, 364

West Indian Group,

Absence of platforms in, 6

Wichman, A., 362

On geology of Pelew Islands, 362

On Ponapi basalt, 343

Wickham Reef, 195

Wilkes, Capt., 9

On coral reefs, 9

On elevated limestones, 10

On Kauehi, 74

On Makatea, 10

On method of surveying atolls, 10

On Paumotus, II

On sea wall of Rangiroa, 10

Sketch of Matahiva, 10, 55

Sketch of Rangiroa, 13

Sketch of Tikahau, 13

Sounding in Raraka, 9

Soundings off Clermont-tonnerre, 9

Wolea Island, 332

Wotje, 315

Color of waterin, 315

Corals in lagoon of, 318 
INDEX.

Wotje - Continued

Extension of west face of, 3I9

Increase in size of, 319

Islands of land rim of, 319

Lagoou sand spits in, 316,319

Lee face of, 316,318

Lieut. Schischmarev on, 315

Movement of sand at, 320

Rookery at, 316

Shoals in lagoon of, 320

Sinks of, 319
Wotje - Continued

South face of, 317

Surface and deep hauls in, 320

Survey by Kotzebue, 315

Vegetation of, 318

Wooded island of, 316

Wotje Island, 317

Wotje Pass, 301

Yangasá Levu, 204

Yenas Island, 335 



\section{PUBLICATIIONS}

OF THE

\section{MIUSEUM OF COMPARATIVE ZOÖLOGY}

AT HARVARD COLLEGE.

There have been published of the Bullierin, Vols. I. to XXXVII.; of the Memorrs, Vols. I. to XXIV., and Vol. XXVIII.

Vols. XXXVIII., XXXIX., XL., and XLI. of the Bulletin, and Vols. XXV., XXVI., XXVII., and XXIX. of the Menorrs, are now in course of publication.

A price-list of the publications of the Museum will be sent on application to the Librarian of the Museum of Comparative Zoölogy, Cambridge, Mass. 





